\title{
FACTORS THAT INFLUENCE ENTREPRENEURIAL INTENTIONS AMONG UNDERGRADUATES OF SOUTH- SOUTH AND SOUTHEAST NIGERIA
}

\author{
Ita Joseph JOHN
}

Thesis submitted in partial fulfilment of the requirements of Oxford Brookes University for the degree of Doctor of Philosophy

(Word count: 98,923) 


\begin{abstract}
Research shows intentions as the best predictor of behaviour or action, more so if the behaviour requires some unknown time lags to get it realised. This mixed methods research is conducted to explain what factors encourage or discourage entrepreneurship among undergraduates in Southsouth and Southeast Nigeria and to know whether the factors are the same across the two regions. It surveys 1,129 indigenous final-year undergraduates from 11 states, in 15 universities across 12 faculties and 68 departments in the two regions studied plus four focus groups of 42 participants. It uses a partial least squares structural equation modelling technique (PLS-SEM) to analyse the survey data. It finds the personal attitude construct as the strongest influence on the entrepreneurial intentions variable, followed by the perceived behavioural control construct. The next influence is the perceived barriers construct; it acts as a discouraging factor. The focus group interview results find that the undergraduates explained the factors that influence them as being transformational, affective, push, personal fulfilment motives and personality traits. Moreover, the results indicate that the undergraduates would more likely embrace entrepreneurship if courses were taught in a more practical or application-oriented approach than theory-oriented. Also, if relevant internships were introduced in their courses, entrepreneurship lecturers were experienced entrepreneurs, and universities had a strong collaboration with relevant industries too. The partial least squares multi-group analysis detected no significant differences in any of the 18 relationships hypothesised, based on the model paths. This result suggests that, conceptually or theoretically, the factors modelled as influencing the South-south and Southeast students toward entrepreneurship are fundamentally the same. Nevertheless, in practice as well as in the wider society, the pattern between the two regions might somewhat differ. The reason is that the participants in the focus group interviews consistently demonstrated that they observe and, therefore, perceive the people of Southeast Nigeria as exhibiting a more peculiar flair for entrepreneurial activities in practice. The participants offered various explanations for their position to include: apprenticeship, serial mentorship, crave for independence, early childhood introduction to business by family, and profit motives as the factors that they believe, are more likely to distinguish the Southeast people from their South-south counterparts in entrepreneurship pursuits. They believe, also, that graduates from the two regions would probably follow the same observed patterns of entrepreneurial behaviours. Thus, a major implication would be that in undertaking undergraduate entrepreneurship research, accommodating multi-logical approaches that also encourage views of the students could offer more useful solutions for policy on what students perceive would attract them toward entrepreneurship.
\end{abstract}


TABLE OF CONTENTS

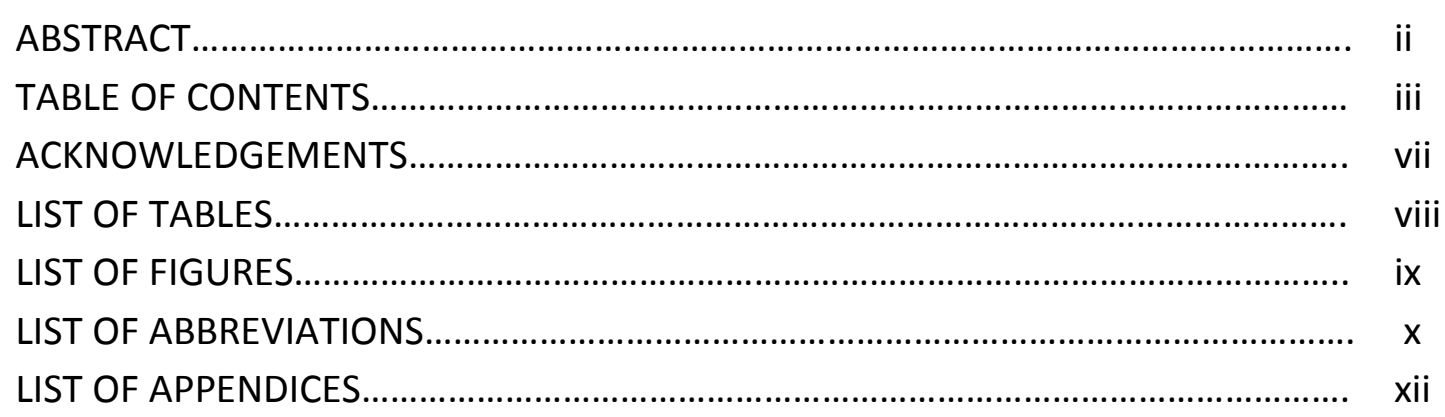

$\begin{array}{ll}\text { CHAPTER ONE: INTRODUCTION } & 1\end{array}$

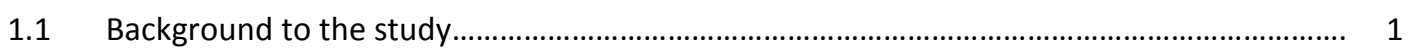

$1.2 \quad$ Aim and objectives...................................................................................................... $\quad 7$

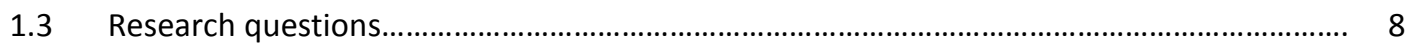

1.4 Organisation of the study............................................................................................. 8

1.5 Definition of some key concepts................................................................................. 9

CHAPTER TWO: THE HISTORICAL CONTEXTS OF ENTREPRENEURSHIP DEVELOPMENT IN NIGERIA AND THE ROLE OF INSTITUTIONS 11

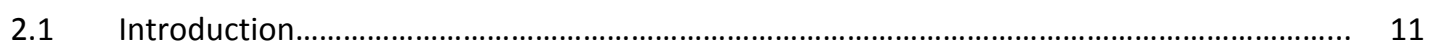

2.2 Some entrepreneurship development efforts in Nigeria: A brief history.......................... 11

2.3 The kind and pattern of entrepreneurship activities in Nigeria............................................ 14

2.4 Institutional factors and entrepreneurship development................................................... 27

2.4.1 Institutions, incentives and entrepreneurship development............................................. 28

2.4.2 The key institutions for entrepreneurship: "Property rights" and "the size of the state". 29

$2.5 \quad$ Problems faced by Nigerian entrepreneurs......................................................................... 32

$\begin{array}{ll}\text { CHAPTER THREE: THE CONTEXT OF ENTREPRENEURSHIP EDUCATION } & 37\end{array}$

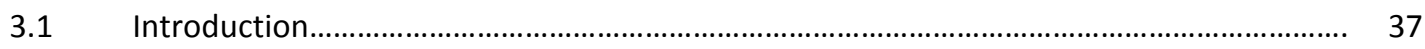

3.2 Higher education institutions (HEIs) and entrepreneurship education (EE).................... 38

3.2.1 The influence of "right" university-based entrepreneurship education in producing more entrepreneurs........................................................................................................ $\quad 39$

3.3 The "individual" motivating factors to starting one's businesses...................................... 52

3.4 Cultural and social barriers to entrepreneurship intentions............................................ 56

3.5 Raising capital to start entrepreneurial activities....................................................... 60

3.6 Reasons for selecting the undergraduates of Southeast and South-south Nigeria

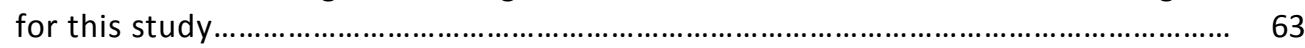

$\begin{array}{ll}\text { CHAPTER FOUR: REVIEW OF RELATED LITERATURE } & 68\end{array}$

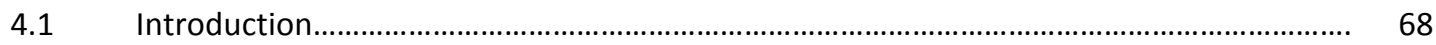

4.2 Theoretical perspectives on entrepreneurial intentions and its influencing factors......... 68

4.2.1 Shapero's (1984) "model of the entrepreneurial event" .................................................... 68

4.2.2 Bird's (1988) "model of implementing entrepreneurial ideas" .......................................... 70 
4.2.3 Robinson's et al (1991) "entrepreneurial attitude orientation model"............................. 72

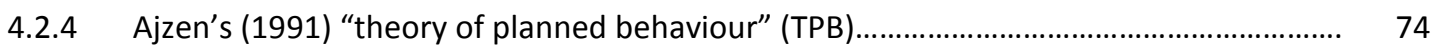

4.2.5 Krueger and Carsrud's (1993) "intentional basic model" ..................................................... 77

4.2.6 Krueger and Brazeal's (1994) "entrepreneurial potential" model..................................... 78

4.2.7 Boyd and Vozikis' (1994) intention model......................................................................... 80

4.2.8 Davidsson's (1995) "economic-psychological model” of entrepreneurial intentions....... 81

4.2.9 Douglas and Shepherd's (2002) "maximization of expected utility" model...................... 83

4.2.10 Elfving, Brännback and Carsrud's (2009) contextual model of entrepreneurial

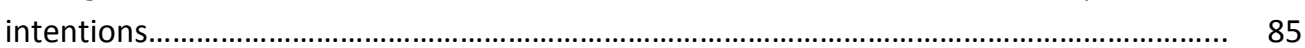

4.3 Conceptual framework on the factors that influence entrepreneurial intentions............ 88

4.3.1 Justification of the conceptual framework and hypothesis formulation............................. 95

4.4 Review of related empirical literature on factors that influence entrepreneurial intentions

4.4.1 "Personal attitudes" (PA), "subjective norms" (SN), "perceived behavioural control" (PBC) and entrepreneurial intentions.....

P.4.2 Personality traits and entrepreneurial intentions........................................................... 107

4.4.3 Entrepreneurial capabilities and entrepreneurial intentions............................................. 110

4.4.4 Contextual factors and entrepreneurial intentions.......................................................... 111

S.5 Summary of the literature review.............................................................................. 113

$\begin{array}{lr}\text { CHAPTER FIVE: RESEARCH METHODOLOGY } & 115\end{array}$

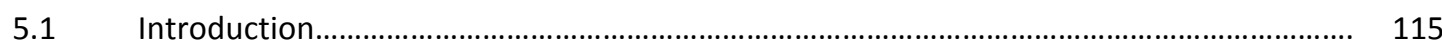

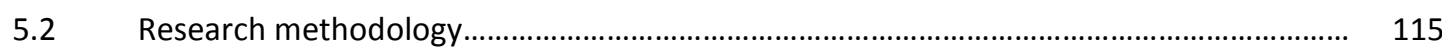

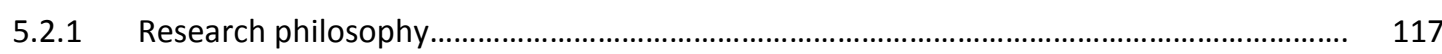

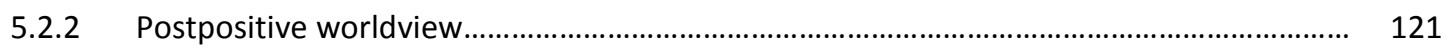

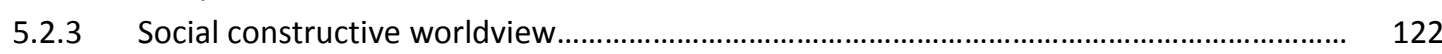

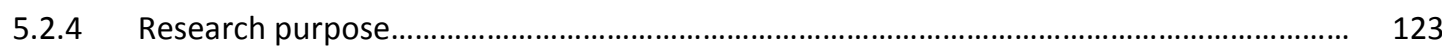

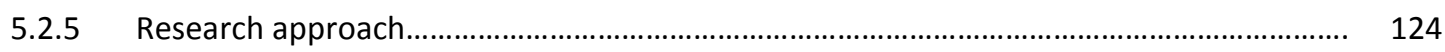

5.2.6 Research design or strategy (quantitative phase)............................................................. 126

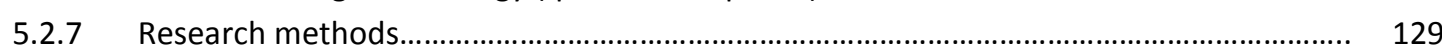

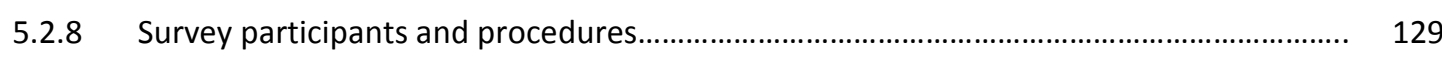

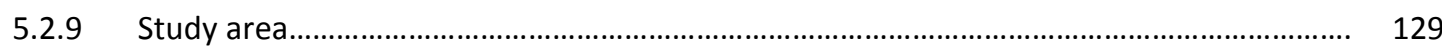

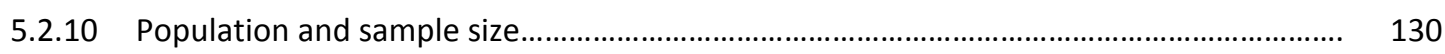

5.2.11 Sampling procedure and sampling frame.................................................................... 130

5.2.12 Survey data collection procedure ............................................................................ 138

$5.3 \quad$ Data analysis techniques.......................................................................................... 138

5.3.1 Analysis techniques and preparation of quantitative data for analysis ........................... 138

5.3.2 The structural equation modelling (SEM) technique ......................................................... 139

S.4 Survey questionnaire design............................................................................................... 140

5.4.1 Test for reliability of the questionnaire using the pilot study conducted in Nigeria......... 141

5.4.2 Qualitative focus group interviews: protocol for interview development........................ 149

5.4.3 Focus group interview participants and procedures........................................................ 149

5.4.4 Qualitative data analysis techniques for the focus groups interview transcripts............. 150

5.5 Integrating quantitative and qualitative findings for interpretation and discussion.......... 152

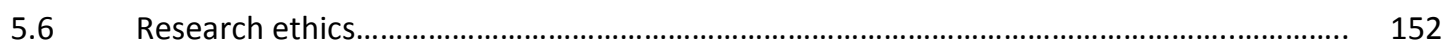

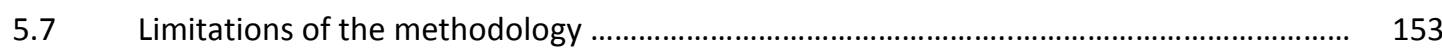

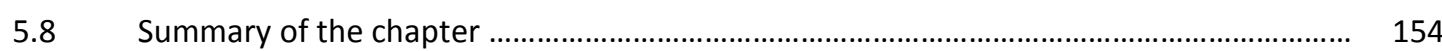




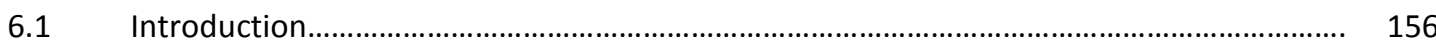

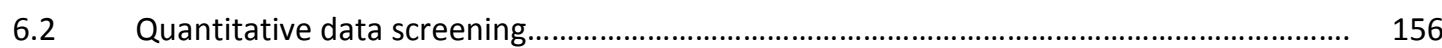

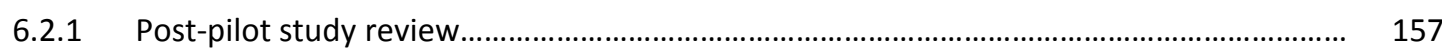

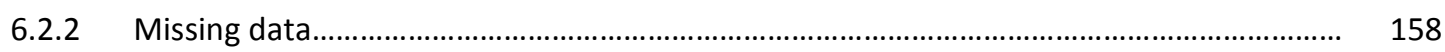

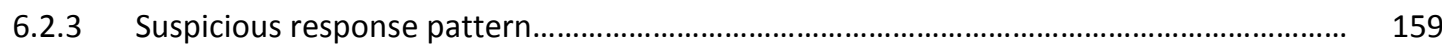

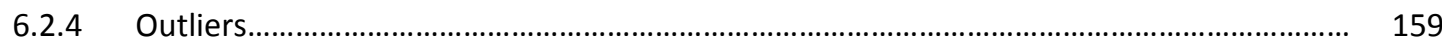

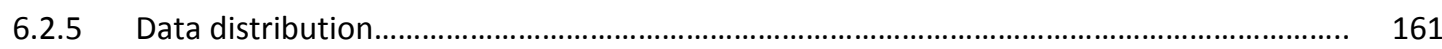

6.2.6 Test of normality..................................................................................................... 162

6.2.7 Frequency distribution of the respondents and descriptive statistics for the

6.2.8 Descriptive statistics for each construct....................................................................... 170

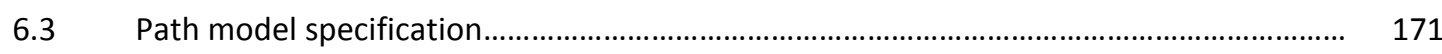

6.3.1 The structural model specification................................................................................... 171

6.3.2 Specification of the measurement model.......................................................................... 174

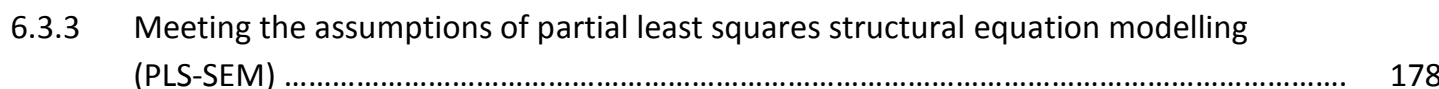

6.4 PLS-SEM measurement model validation......................................................................... 179

6.5 Partial least squares multi-group analysis (PLS-MGA): observed heterogeneity test....... 184

6.6 Structural paths' model estimation results...................................................................... 184

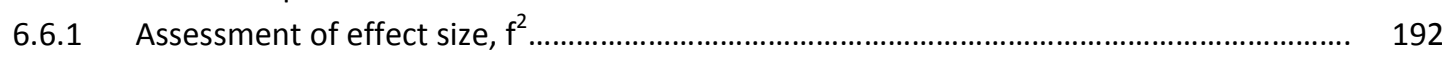

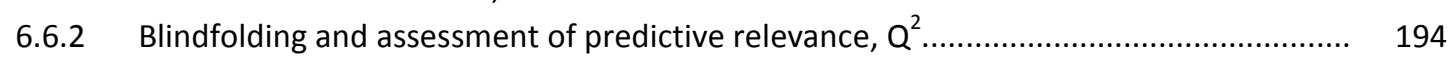

6.7 Results of the qualitative study................................................................................... 196

6.7.1 Results of qualitative study on the factors that influence entrepreneurial intentions.... 197

6.7.2 Results of qualitative study on whether there are regional differences or not................ 211

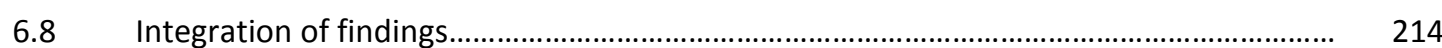

6.9 Credibility and trustworthiness of the results................................................................. 215

Summary of the chapter................................................................................................ 215

CHAPTER SEVEN: DISCUSSION OF THE FACTORS THAT INFLUENCE ENTREPRENEURIAL INTENTIONS AMONG UNDERGRADUATES OF SOUTH-SOUTH AND SOUTHEAST

NIGERIA 217

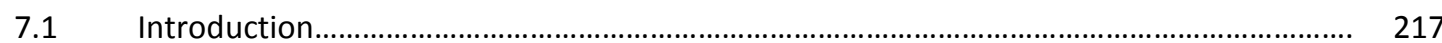

7.2 Discussion of the empirically-researched findings........................................................... 218

7.2.1 Discussion of the factors that influence undergraduates' intentions in the two regions. 221

7.2.2 Discussion of the extent of similarities or differences regarding the factors that influence undergraduates' entrepreneurial intentions in the two regions........................ 228

7.2.3 Discussion of students' "meaning making", explanation, and thinking on what influences entrepreneurship intents............................................................................. 231

CHAPTER EIGHT: SUMMARY, CONCLUSIONS AND RECOMMENDATIONS 235

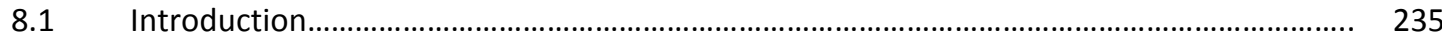

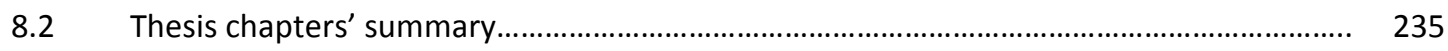

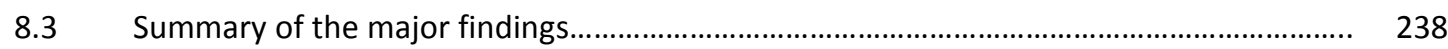

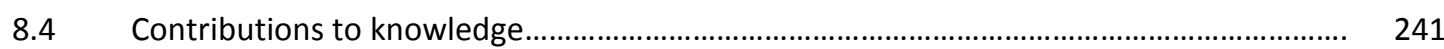

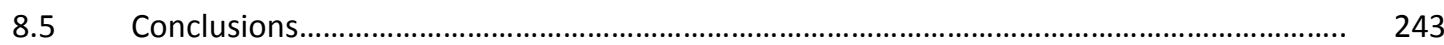


8.6 Limitations of the study...

8.7 Summary of implications and recommendations.............................................................. 246

8.8 Recommendations for further research............................................................................. 255

8.9 Final reflections regarding the doctoral programme experience....................................... 257

REFERENCES................................................................................ 259

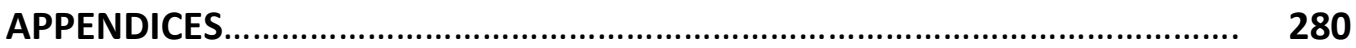




\section{ACKNOWLEDGEMENTS}

I wish to thank my supervisors deeply; first, Professor Pritam Singh, my Director of Studies for his immense support and guidance. On the feedback that I receive, your research experience and pedigree are always an asset I found very useful. There were always some things to learn from as a new researcher and a junior academic. Second, Dr Sola Adesola, you have been of great support especially in offering your research experience having worked in the students' entrepreneurship field in the Nigerian universities. Third, Dr Richard Beresford, you joined the team last year to offer your support and experience from your teaching of entrepreneurship and enterprise development in the faculty of business. I deeply thank you all.

A special thank you also goes to Dr David Bowen, Director of Doctoral Programme. Your suggestions right at the registration stage and at the transfer stage were very useful. Thank you for also offering me the opportunities to present my work at the faculty's 20-20 seminar sessions for colleagues' feedback. In addition, a big thank you also goes to Chris Spurgeon and lan Holgate at the research programme administrative office as well as Jason Joliffe, Peter Clift, Emma Polley, and Laura Bartholomew in the facilities unit. You were always willing to help.

I also thank the final-year students in the selected universities in Nigeria who participated in this study. Without your assistance, the field work would never have been successful. Appreciation also goes to the Deputy Vice-Chancellors, Deans of Faculties, and Heads of Departments in the universities who assisted, permitted me to administer the questionnaires, and provided venues for the focus group interviews.

This section will be incomplete if I fail to give a loud "shout out" to my dear wife, Esther, and our son Jamie. You endured with me during this "lonely" time of the doctoral journey. Many times it was hard, but you still endured. I deeply appreciate you.

Lastly and very importantly, my most sincere gratitude goes to the external examiner, Professor Catherine Wang of Royal Holloway University of London, and the internal examiner Dr Karen Handley for reviewing my work.

Ita Joseph JOHN

Oxford Brookes University

September 2015 


\section{LIST OF TABLES}

Table 2.1

Major indigenous oil service and production companies in Nigeria.

Table 2.2

Indigenous Airline Companies

Table 2.3

Major Nigerian indigenous shipping companies.

21

Table 3.1

Culture indicators.

Summary of selected studies on entrepreneurial intentions among students

showing percentage of variance explained and significant factors.

Table 5.1

Comparison of elements of dialectical and pragmatic paradigms

Table 5.2

Elements of postpositivist and constructivist worldviews and implications for practice.

Table 5.3 (a)

List of the South-south universities.

Table 5.3 (b)

Distribution of sampled South-south universities.

Distribution of faculties/schools/colleges/institutes and departments: Southsouth.....

Table 5.4 (a)

List of the Southeast universities.

Distribution of faculties/schools/colleges/institutes and departments: Southeast...

Table 5.5 Questionnaire statements and factors that influence entrepreneurial intentions....

Reliability test of achievement orientation (ACHIEVE), risk-propensity (RISK), locus of control (LOC), and perceived support (PSUPP)..

Table 6.2

Results of outlier statistics.

Aggregated scores of cases identified as outliers and their Mahalonabis Distance...

Table 6.3 (b)

Descriptive Statistics.

Table 6.4

Kolmogorov-Smirnov test of normality...

160

Table 6.5

Frequencies output.

Table 6.6

SPSS output of descriptive statistics for each construct.

162

Table 6.6

Results of measurement model constructs and PLS algorithm overview.

Table 6.7

PLS algorithm's cross-loadings

170

Table 6.8

Results of Fornell-Larcker criterion of discriminant validity...

180

Table 6.9

Table 6.10

Table6.11 (a)

Results of PLS multi-group analysis.

Assessment of collinearity diagnostics 


\section{LIST OF FIGURES}

Figure 3.1 Framework for creating business ideas from core course....................................... 44

Figure 3.2 Map of Nigeria showing the six South-south and five Southeast states............... 67

Figure 4.1 Shapero's model of the "entrepreneurial event ".................................................. 69

Figure 4.2 (a) The contexts of intentionality............................................................................. 70

Figure 4.2 (b) Intention-direction process................................................................................ 71

Figure 4.3 (a) Ajzen's theory of planned behaviour....................................................................... 75

Figure 4.3 (b) Factors that influence the predictive power of Ajzen's theory of planned behaviour..................................................................................................... 77

Figure 4.4 The basic intentions-based process model............................................................. 77

Figure 4.5 Model of entrepreneurial potential (simplified) ....................................................... 79

Figure 4.6 Intention model of Boyd and Vozikis................................................................... 81

Figure 4.7 An economic-psychological model of determinants of entrepreneurial intentions..................................................................................................... 82

Figure $4.8 \quad$ The context-specific entrepreneurial intention model............................................ 86

Figure 4.9 Conceptual framework on the factors that influence entrepreneurial intentions 91

Figure 4.10 Framework for identifying enterprise competency................................................. 93

Figure 5.1 Research methodological framework adopted.............................. 116

Figure 5.2 Phase, procedure, and product in this explanatory sequential mixed.................. 127

Figure $6.1 \quad$ Distribution of respondents by size........................................................................ 168

Figure 6.2 Structural model of the factors that influence entrepreneurial intentions........... 173

Figure 6.3 (a) Measurement model of the factors that influence entrepreneurial intentions (in SmartPLS window) ................................................................................... 175

Figure 6.3 (b) Reflective-formative type of second-order component model............................. 177

Figure 6.4 Algorithm results in PLS window.......................................................................... 189

Figure $6.5 \quad$ Classification of the themes................................................................................. 298

Figure $8.1 \quad$ Revised integrated conceptual model................................................................. 249 


\section{LIST OF ABBREVIATIONS}

\begin{tabular}{|c|c|}
\hline ACHIEV & Achievement orientation \\
\hline $\mathrm{AO}$ & Achievement orientation \\
\hline AVE & Average variance extracted \\
\hline BB & Behavioural beliefs \\
\hline BBC & British Broadcasting Corporation \\
\hline CAPA & Capabilities \\
\hline $\mathrm{CB}$ & Control beliefs \\
\hline CV-R & Cross-validated redundancy \\
\hline EAO & Entrepreneurial attitude orientation \\
\hline $\mathrm{EE}$ & Entrepreneurship education \\
\hline EFCs & Entrepreneurial Framework Conditions \\
\hline EI & Entrepreneurial intentions \\
\hline EINTEN & Entrepreneurial intentions \\
\hline ELS & English and Literary Studies \\
\hline ESDP & Entrepreneurial Skills Development Programmes \\
\hline EUFB & EU Flash Barometer \\
\hline FG & Focus groups \\
\hline GEDI & Global Entrepreneurship Development Institute Index \\
\hline GEM & Global Entrepreneurship Monitor \\
\hline HBS & Harvard Business School \\
\hline HEls & Higher education institutions \\
\hline ICF & Integrated conceptual framework \\
\hline ICM & Information and Communication Technology \\
\hline ICT & Integrated conceptual model \\
\hline IDO & Improvement-driven opportunity \\
\hline IMF & International Monetary Fund \\
\hline INNOVA & Innovation orientation \\
\hline 10 & Innovation orientation \\
\hline IPOs & Initial public offers \\
\hline LOC & Locus of control \\
\hline MAHA. DIST. & Mahalonabis distance \\
\hline MBA & Master's in Business Administration \\
\hline MIT & Massachusetts Institute of Technology \\
\hline MMR & Mixed methods research \\
\hline NB & Normative beliefs \\
\hline NUC & National Universities Commission \\
\hline OECD & Organisation of Economic Co-operation and Development \\
\hline PA & Personal attitude \\
\hline PATB & Personal attitude toward target behaviour \\
\hline PBARR & Perceived barriers \\
\hline PBC & Perceived behavioural control \\
\hline PERSON & Personality traits \\
\hline PEST & Political, economic, social, and technological factors \\
\hline
\end{tabular}


PESTLE Political, economic, social, technological, legal, and environmental factors

PLS-SEM Partial least squares structural equation modelling

PSED Panel Study of Entrepreneurship Dynamics

PSN Perceived subjective norms

PSUPP Perceived support

QUAL Qualitative

QUAN Quantitative

R \& D Research and Development

RISK Risk-propensity

S.W.O.T Strength, weakness, opportunity and threat

SAP Structural Adjustment Programme

SEE Shapero's entrepreneurial event

SN Subjective norms

SME Small and medium-scale enterprise

SSE Sum of squared error

SSO Sum of squared observation

TEA Total entrepreneurial activity

TPB Theory of planned behaviour

U.S. United States

VIF Variance inflation factor

WVS World Value Survey 


\section{LIST OF APPENDICES}

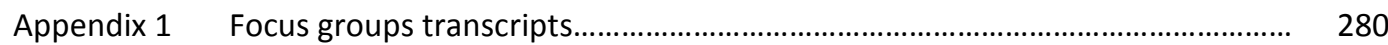

Appendix $2 \quad$ Sample- access letter request.............................................................................. 296

Appendix 3 Participant information sheet- Focus groups interview..................................... 297

Appendix $4 \quad$ Consent form............................................................................................... 299

Appendix $5 \quad$ Focus groups interview questions (protocol).................................................. 300

Appendix $6 \quad$ Participant information sheet: self-administered survey questionnaire.......... 301

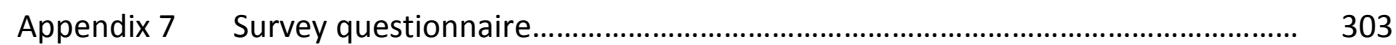




\section{CHAPTER ONE}

\section{INTRODUCTION}

\subsection{Background to the study}

Higher Education Institutions (HEls) and governments are consciously trying to encourage undergraduates to embrace entrepreneurship. It is a common belief that entrepreneurship can exert a positive influence on job creation and reduction in graduate unemployment, increase in economic growth, poverty alleviation, productivity, innovation, and transformation of the informal sector (Ăcs, Szerb and Autio, 2014). This perceived usefulness and outcomes, however, are hardly investigated empirically and more so for Nigeria (Ăcs et al., 2014).

In Nigeria, the National Universities Commission (NUC) mandated all universities, in 2006, to introduce a compulsory two-semester undergraduate level course on entrepreneurship. The goal was to reinforce an entrepreneurial mindset among Nigerian undergraduates and to inculcate the necessary enterprise knowledge and skills. The course is offered under the "Entrepreneurial Skills Development Programmes (ESDP)" as a general subject for all students, irrespective of one's core discipline. Despite these efforts, there is still an observably-poor use of entrepreneurship education among Nigerian graduates, including the indigenous graduates of South-south and Southeast regions of Nigeria (Siyanbola et al., 2009).

Regions or countries that develop more entrepreneurs than the others get many benefits. Here entrepreneurs are defined as persons who strive to add value, through the creation or growing of economic activities by recognising and exploiting new products, methods or markets (Ahmed and Hoffmann, 2012). An interesting addition to the Ahmed and Hoffmann's definition is the acknowledgement by Blundel and Lockett $(2011$, p.6) that entrepreneurs should also be "for meeting outstanding social and environmental needs." It is normal in the entrepreneurship circles to believe that where there is a high birth of businesses, such a region, or country stands to gain more. They would have employment generation capacity, contribute to production output expansion, use local natural and human resources, and stimulate and transform indigenous technology. They would also diversify economic activity, create and distribute wealth, reduce poverty, and contribute to government revenue. Also, they would create capital, mobilize savings, and provide a platform for backward, forward, and inter-industry linkages (Duke, 2006). Thus, the levels of entrepreneurial activities among different societies and nations might not always be the same considering the differences in their politico-economic contexts. 
In the socio-political context of Nigeria, there is a common belief that youths from the Southeast region are more likely to go into entrepreneurial activities than their South-south counterparts (Siyanbola et al., 2009). The South-south region consists of people who are mostly from the Efik, Ibibio, Oron, Annang, ljaw, Itsekiri, Urhobo and Bini tribes. The Southeast consists of the Igbospeaking tribes who are one of the majority ethnic groups apart from the Yoruba-speaking (Southwest) and the Hausa-Fulani-speaking groups (the North).

While there is a high drop-out rate from school in the Southeast, youths from the area are more likely engaged in some form of entrepreneurial activity (Siyanbola et al., 2009). However, students who drop out from the South-south region at roughly the same rate are less likely involved in entrepreneurial ventures. Even after graduation from formal tertiary educational institutions, this pattern of behaviour might not be grossly different. People from the two regions have many things in common such as geographical boundaries, religious beliefs and inter-marriage and, therefore, may be expected to be entrepreneurially similar. The people of Ibo ethnicity, however, are believed to be more prevalent in and more likely successful when it comes to entrepreneurial activities. There is, however, insufficient empirical verification. Therefore, researchers need to gain a clear understanding of the underlying factors. This apparent behavioural distinctiveness between people of these two regions of Nigeria brings the question of what set of factors is more influential in forming intentions of setting up one's own business among the younger generation. However, in the entrepreneurship research circles, the definition of entrepreneurship has less uniformity among scholars.

Van Gelderen and Masurel (2012, p. 2), for example, states that "various possible meanings of entrepreneurship exist" such as starting a business, running a business, growth, innovation, opportunity discovery and exploitation. They also noted that the "first two are the most frequently used" definitions in the literature. Therefore, most definitions of entrepreneurship boil down to founding and running of business, the outcomes of the behaviour (Fayolle and Gailly, 2015; Ahmed and Hoffmann, 2012; Peng, Lu and Kang, 2012; Lüthje and Franke, 2003). It is common knowledge also that the business created can be for-profit or not-for-profit; that is, it can have monetary, non-monetary or social entrepreneurship goals. For ease of analysis and focus, this research adopts a narrow sense of entrepreneurship as business creation (and running), business ownership and self-employment rates. The core idea is that the business must add something new; it must add value (Onu, 2013). The new thing can be: the creation of new products or services, penetration of new markets, discovery of new systems, opportunities, processes, methods, new institutions, social change (Ahmed and Hoffmann, 2012; Sarasvathy and Venkataraman, 2011). 
This study, however, also acknowledges that entrepreneurship can occur in other wider contexts. These contexts include corporate entrepreneurship, entrepreneurship within the professions and disciplines, public sector entrepreneurship, international entrepreneurship, cultural entrepreneurship, academic entrepreneurship, and rapid growth ventures. For a detailed description of these contexts of entrepreneurship, the works of Van Gelderen and Masurel (2012), Westhead, Wright and Mcelwee (2011), and Boettke and Coyne (2009) are relevant references. The present research, therefore, argues that student entrepreneurship studies, first, centre on the individuals' intentions toward business start-ups. Consequently, studies on what best influences these start-up intentions among undergraduates, whether at the individual or contextual levels, remain a continuous subject of debate in entrepreneurship circles.

Several studies have examined the factors that influence individuals to engage in entrepreneurial activities. There seem to be four main positions in the literature from the way this researcher understands the debates. Past studies have examined these factors in terms of the personal background factors (demographics) and personality traits; attitude studies; external context factors; and entrepreneurial capabilities or competencies (Peng et al., 2012). The general belief is that individuals who measure higher in psychological traits tests, entrepreneurial attitudes, entrepreneurial capabilities or skills, or have favourable contextual factors will be more likely inclined toward entrepreneurship.

Specifically, personal background demographics includes sex, age, marital status, birth order, race, educational level and socioeconomic status. Others look at the individual's personality traits such as the need for achievement, the need for control, the risk-bearing propensity, self-confidence, the tolerance for ambiguity and innovativeness (; Okhomina, 2010; Krasniqi, 2009; Siyanbola et al., 2009; Taormina and Lao, 2007; Gurol and Atsan, 2006; Louw et al., 2003). According to Robinson et al. (1991), the criticism against the demographic and personality characteristics approaches is that it is unable to predict who will more likely be or not be an entrepreneur. Another criticism is that these factors are too rigid: they are static and cannot fully capture the complex nature of entrepreneurship. The critics also say that researchers often use these variables inappropriately and ineffectively, paying less attention to the notion that the personality traits model was not originally propounded to measure entrepreneurship concept (Robinson et al., 1991).

Other studies have, nevertheless, analysed inclination for entrepreneurship in terms of intentions toward entrepreneurship (Solesvik et al., 2012; Peng et al., 2012; Paço et al., 2011; Linän, Urbano and Guerrero, 2011; Linän and Chen, 2009; Gird and Bagraim, 2008; Autio et al., 2001). Others 
have concentrated on analysing the external environment that can influence entrepreneurship decisions. Factors considered under external environment include macroeconomic climate, political and legal conditions (institutions), national/societal culture, and level of government support (Bridge, O'Neill and Martin, 2009; Stephen, Urbano and Hemmen, 2005; Lüthje and Franke, 2003; Baumol, 1990; North, 1990).

Moreover, advocates of the entrepreneurial capabilities or competencies position suggest that besides students having to acquire specific knowledge in subject disciplines, they must also acquire enterprise capabilities (or skills). These skills include idea generation skills, dedication, decision-making, goal-setting, planning, responsibility, and confidence. Insight, technical competencies, sensitivity to changes, networking and contacts, developing relationships, and project management are other skills (Bridge et al., 2009). Individuals who possess these competencies may feel more able to engage in any entrepreneurial activity and succeed. Meanwhile, each of the four schools (personality, attitude, competence, and external context proponents) argues for the superiority of its proposition almost to the exclusion of the others. Some of these studies, however, have their merits, but each proponent in the debate seems to be vying with one another for dominance with only a little acceptance of the plausibility of the other theses.

In general, theoretical models that strongly support the usefulness of understanding of what influences entrepreneurship argue that starting a business is a planned action (behaviour): intentions precede it. Therefore, engaging in entrepreneurial activities is intentional (Krueger and Brazeal, 1994; Krueger and Carsrud, 1993; Ajzen, 1991; Shapero, 1984; Shapero and Sokol, 1982). For example, Krueger and Carsrud (1993) demonstrate that intentions predict behaviour better than attitudes, beliefs, individual personality traits and personal demographics. They also state that entrepreneurial intentions are well predicted by attitudes such as perceived attractiveness of entrepreneurship, perceived social norms about entrepreneurship and perceived selfefficacy/control of entrepreneurship. According to them, for a successful business venture there must be certain levels of favourable attitudes demonstrated toward business that is in turn mediated by intentions. Ajzen (1991) contends that intentions help in channelling beliefs, motivations and several other external factors into the intent to act.

In the developed countries, researchers have shown empirical studies in which students and sometimes practising entrepreneurs are the subjects for testing the various intention models. For example: Paço et al. (2011) studied Portuguese students; Van Gelderen et al. (2008) studied Netherlands students; Jones et al. (2008) studied Polish students, and Krueger, Reilly and Carsrud 
(2000) studied USA students. They demonstrate that the relevance of attitudes as antecedents of entrepreneurial intentions and the need to change personal attitude is much more desirable than mere subject knowledge. They also believe that HEls should develop competencies connected to entrepreneurship, social skills and cultural alertness.

In the developing countries, empirical studies also suggest that personal attitudes toward entrepreneurship, subjective norms, perceived behavioural control, perceived desirability, perceived feasibility or self-efficacy influence entrepreneurship through intentions. For example: Kadir, Salim and Kamarudin (2012) studied Malaysian students; Ugwu and Ugwu (2012) studied Nigerian students; Wu and Wu (2008) studied Chinese students; and Gird and Bagraim (2008) studied South African students. There are also cross-national studies of the phenomenon. For example lakovleva et al. (2011) studied nine developed and five developing countries; Fitzsimmons and Douglas (2011) studied Australia, China, India and Thailand MBA students. Also, Linän and Chen (2009) studied Spanish/Taiwanese students; Mariano et al. (2012) studied six countries, and Engle et al. (2010) conducted a twelve-country comparison. The evidence in these studies is almost uniformly consistent in demonstrating the significance of attitude constructs and their antecedents in influencing behaviour through intentions.

Only a handful of studies, however, have paid attention to integrating and examining the influence of exogenous or "contextual" factors on entrepreneurial attitudes and intentions. Exogenous components include levels of barriers, government support, and levels of entrepreneurial competencies of students (Peng et al. 2012; Linän and Chen, 2009; Lüthje and Franke, 2003). Also, it is useful to undertake cross-societal comparative studies involving the different ethnic minority groups and contrasting it with the majority ethnic group. lakovleva et al. (2011) advocate this as a way of building an in-depth understanding of entrepreneurial intentions among undergraduates in a country. Most previous research, however, failed to consider this comparison, and research conducted to compare the indigenous undergraduate students of South-south and Southeast Nigeria is scarce.

Moreover, one of the deficiencies in previous research on students' entrepreneurial intentions reviewed is that relatively fewer studies (aside Van Gelderen et al., 2008; Lüthje and Franke, 2003) employed mixed methods strategy. However, although researchers have employed mixed methods strategy for entrepreneurship research in general but specifically in the students' entrepreneurship intentions research, the use of the mixed methods strategy is scant. Mixed methods strategy is combining a quantitative instrument (e.g. a survey questionnaire, secondary data) and a qualitative instrument (e.g. focus groups interview, participant observation). This 
research argues that the latter can provide avenues to gather different perspectives on an issue. The focus groups, for example, can enable the researcher to gain information on the participants' attitudes, beliefs, motivations and perceptions and "why" they think or feel the way they do. It provides a medium for brainstorming and generating ideas, with the participants discussing different angles of the problem and possibly helping to identify holistic solutions (Litosseliti, 2003).

There are relatively fewer empirical studies on the status of entrepreneurial intentions and specifically on the factors that influence students' intentions for setting up businesses in Nigeria. This inadequate empirical study is regrettable because it is the kind of evidence that university administrators and Entrepreneurial Skills Development Programme (ESDP) facilitators in universities in the South-south and Southeast Nigeria require if they are to support evidenceinformed policies for undergraduates' entrepreneurship development effectively.

This research, therefore, attempts to contribute to the knowledge base on academic entrepreneurship development by exploring the factors that encourage or discourage entrepreneurship intents among the indigenous students of South-south and Southeast Nigeria. The research argues that the undergraduates, however, must first intend to become entrepreneurs before they can later realise such desire. According to Krueger et al. (2000), the intention is the best predictor of planned action or behaviour, especially if the action needs some time lags to get it implemented. Although intentions may be unrealised eventually; no one can establish business or engage in entrepreneurial activities in general without first having an intention.

The main idea of this research is that by integrating the different factors proposed by each school of thought and examining the factors within a robust structural model, this thesis hopes to shed better insights into what best influences entrepreneurial intentions. It does this by using the partial least squares structural equation modelling (PLS-SEM) technique. Surprisingly, this modelling is rarely used within the context of a developing country such as Nigeria (the summary of the reviewed empirical literature in Table 4.1 portrays this absence). Moreover, it argues that even if such a model explains entrepreneurial intentions, it is useful simultaneously to include the opinions of the affected (i.e., undergraduates) to bring more insights and a holistic picture. This integration is the contribution of this "sequential explanatory" mixed methods research (that is, the mixing of the survey and focus group interview findings). The researcher argues that this knowledge can help the promoters of Entrepreneurship Skills Development Programmes in universities in the two regions to know what factors weigh the greatest in guiding the undergraduates toward achieving entrepreneurship goals. 
This inquiry, however, delimits itself to examining the "starting point" for the undergraduate students studied (i.e. the perception of their entrepreneurial traits), it does not examine explicitly the ways or means in which capabilities, attitudes, perceived barriers and support evolve through processes of education and experience. To examine these ways or means in which the constructs listed above evolve through processes of education and experience would require a measurement and evaluation study to understand explicitly how the entrepreneurship development course taught in the universities impacted on, for example, the students' capabilities, attitudes or support received toward venture creation. The impact evaluation would have measured and compare the significance or otherwise of the students' pre-and post-education and experience levels on entrepreneurship intentions.

\subsection{Aim and objectives}

This research focuses on assessing the status of entrepreneurial intentions of potential business founders (i.e., the undergraduates). It aims at understanding further whether personality traits, personal attitudes, perceived capabilities, perceived barriers, and perceived support influence students' intentions for setting up businesses. It draws from the understanding that undergraduates are near a career tipping point where they will need to decide whether or not to enter self-employment. The research acknowledges that setting up a new venture is partly an individual decision. Thus, the individual's qualities and attitudes of an entrepreneur (or as in this context the potential entrepreneur) are central to the investigation of entrepreneurship (Littunen, 2000). The other essential aspects, however, are the degree to which the wider external contexts can influence the individuals' entrepreneurship pursuits (Bae et al., 2014; Kadir et al., 2012; Lüthje and Franke, 2003). Therefore, the specific objectives of the study are:

1) To examine the historical contexts of entrepreneurship development in Nigeria (Chapter Two);

2) To examine the literature in the context of entrepreneurship education (Chapter Three);

3) To critically examine the theoretical and empirical literature on entrepreneurial intentions (Chapter Four);

4) To develop a conceptual framework based on the key influencing factors of entrepreneurial intentions identified in the literature (Chapter Four, Section 4.3); 
5) To empirically examine the factors that influence entrepreneurial intentions among indigenous undergraduate students of the South-south and Southeast regions of Nigeria (Section 7.2.1);

6) To empirically examine the extent of similarities or differences in the hypothesised factors that influence entrepreneurial intentions among indigenous undergraduate students of the South-south and Southeast regions of Nigeria (Section 7.2.2); and

7) To explore the issue to know further how students "make meaning", explain or "think differently" about the factors that influence creation of businesses (Section 7.2.3).

\subsection{Research Questions}

Thus, the research would attempt to answer the following central questions:

1) Are the undergraduates' business-founding intentions influenced by their personal attitudes, perceived capabilities, personality traits, perceived barriers and support?

2) Are the influencing factors similar or dissimilar among the groups studied?

3) What do the students think or how do they explain the factors that influence their creation of businesses?

\subsection{Organisation of the study}

The study has eight chapters. Following this general introductory chapter is Chapter Two that takes an overview of the kind of entrepreneurship in Nigeria. It traces a brief history of entrepreneurship and highlights the major strides made in enterprise creation before and after Nigeria's independence in 1960. It highlights the problems faced by entrepreneurs in Nigeria. Moreover, it demonstrates the reasons for the selection of the indigenous undergraduate students of the South-south and Southeast regions of Nigeria for study. Chapter Three takes a look at the contexts of entrepreneurship education and how these shape the quality of entrepreneurs produced by the HEls.

The literature review is carried out in Chapter Four. It first examines the different theoretical underpinnings advanced in the literature in explaining the reasons some individuals (or regions) could be more enterprising than others. It draws from the integrative approach to entrepreneurship as being a more plausible approach for developing a conceptual framework for this study. The integrative approach helps in explaining better the factors that influence the 
similarities or differences in the entrepreneurial intentions between people from the two regions. Secondly, a formal empirical literature review is carried out to examine past researches related to the specific objectives of the study. The Chapter Five considers the research methodology. It examines in detail the design adopted for finding answers to the research questions. It enumerates the procedures used as a research strategy, explains the design of the questionnaire survey instrument and the focus group technique used for data collection.

Chapter Six reports the research findings. It begins with a highlight of the characteristics of the respondents (their demographics). It next examines in some detail the results of the various measures of the entrepreneurial intentions of the respondents among the two regions studied. In Chapter Seven, the research findings will be discussed and related back to the reviewed literature. It pinpoints the extent of agreement or disagreement with past research and finds plausible explanations for any surprises.

In Chapter Eight, the study summarises and concludes. It begins with the summary of the thesis chapters and the major findings and demonstrates the contributions made to knowledge on the determinants of entrepreneurial intentions. It next draws the conclusions before stating the possible limitations of the study. It then summarises the implications of the study and recommends solutions for policy based on the integrative approach to understanding entrepreneurship intentions adopted. It next identifies possible new areas for post-doctoral study. Lastly, it reflects on the doctoral programme journey.

\subsection{Definitions of some key concepts}

1. Entrepreneurship is a phenomenon linked to entrepreneurial activities (Ahmed and Hoffmann, 2012). Blundel and Lockett $(2011$, p.7) add that it "involves a complex pattern of social interactions that extends beyond individual entrepreneurs to incorporate teams, organisations, networks, and institutions."

2. Entrepreneurial activities are enterprising actions of human beings aimed at the creation of value, through engaging in or growing of economic activities (monetary or nonmonetary), by recognising and exploiting new products, methods or markets (Ahmed and Hoffmann, 2012).

3. Entrepreneurs are persons (or owners of businesses) who strive to add value, through the creation or growing of economic activities (monetary or non-monetary), by recognising and exploiting new products, methods or markets (Ahmed and Hoffmann, 2012). 
4. Entrepreneurial intentions are mental perspectives such as the desire, wish and hope that influence individuals' choice of entrepreneurship (Peng et al., 2012).

5. Perceived social norms mean the seeming social pressures on a person to carry out or not a certain behaviour or action (lakovleva et al., 2011).

6. Perceived behavioural control is the individual's control beliefs concerning the behaviour or action in question (lakovleva et al., 2011).

7. Constructs (also called latent variables) measure concepts that are abstract, complex, and cannot be directly observed using (multiple) items. Constructs are represented in path models as circles or ovals (Hair et al., 2014).

8. Measurement theory specifies how the constructs are measured (Hair et al., 2014).

9. Second-order hierarchical component model (also called higher-order models) are higherorder structures (mostly second-order) that contain several layers of constructs and involve a higher level of abstraction (Hair et al., 2014).

10. Continuous variables are variables that can be measured to any level of precision, example, time because there is in principle no limit on how finely it could be measured (Field, 2013).

In the next chapter, the study takes a brief descriptive and historical assessment of the kind and nature of entrepreneurship in Nigeria. It describes what kinds of enterprises the Nigerian entrepreneurs engaged in; looking at both before and after her independence in 1960. It is, therefore, a synoptic snapshot of Nigerian entrepreneurship. It argues for a shift from merely engaging in only the basic primary sectors of economic activities but to further use small-andmedium scale enterprises as well as large-scale businesses to contribute to solving today's global challenges. For example, challenges in areas of the economy, energy, the environment, equity, and education to help improve the standard of living. 


\section{CHAPTER TWO}

\section{THE HISTORICAL CONTEXTS OF ENTREPRENEURSHIP DEVELOPMENT IN NIGERIA AND THE ROLE OF INSTITUTIONS}

\subsection{Introduction}

There is scant work published that shows comprehensive outlooks on entrepreneurship, in general, and specific enterprises created, within Nigeria's six geopolitical regions. This chapter undertakes a brief overview of entrepreneurship development efforts in Nigeria. It defines entrepreneurship development efforts as those implemented to increase entrepreneurship and impacts. The entrepreneurship outputs are created by those who engage in necessity-driven or opportunity-driven or improvement-driven activities (Singer, Amorós and Moska, 2014). The chapter, therefore, attempts to bring an understanding of the entrepreneurship efforts undertaken in Nigeria highlighting certain characteristics of the entrepreneurship. It next examines the contexts of institutional factors such as political (e.g. size of the state) and legal factors (e.g. property rights) and how these can impact the entrepreneurship development quests in the general contexts. It next examines some of the problems the Nigerian entrepreneurs face, although some of these challenges cannot be unique to the Nigerian entrepreneurs. It argues that one of Nigeria's paths to rapid entrepreneurship development may lie in her quick alignment with global best practices and in tackling the weaknesses in those institutions that should support entrepreneurship development. It concludes by highlighting the reasons this study chose the undergraduates of the South-south and Southeast regions as respondents for the research.

\subsection{Some entrepreneurship development efforts in Nigeria: A brief history}

In human history, all the nations of the world have had their early struggles for economic survival. The struggle is irrespective of whether the countries are classified as developed or developing nations. In this regard, Nigeria had her early entrepreneurs and businesspeople who struggled to develop entrepreneurship activities. They did not, however, develop enterprise as much as one would expect. Studies have argued that the reason for the inadequate early large-scale ventures development in Nigeria is connected with the British colonial rule over Nigeria (Anyanwu, 1999). The reason is that the British rule gave more priority to developing workers who were essentially civil servants, clerks, and storekeepers, doing administrative duties for the smooth running of the government. The civil servants were comparatively well-paid. Their earnings provided them value 
for money because the economy was better-managed and non-inflationary. Therefore, the civil servants were living relatively affluently.

In contrast, Anyanwu (1999) noted that the businesspeople were struggling for survival during the period. The environment encouraged little self-employment and the developing of the younger generation in business enterprise development. The impact of the colonial rule in shaping the individual's inclinations toward developing business enterprises is a subject that researchers have not studied adequately.

By 1960, when Nigeria gained her independence from the Great Britain, there was a noticeable gap between the number of people in paid-employment and those in self-employment (Anyanwu, 1999). The Nigerian government realised that she could no longer cope with the huge wage bills of the public and civil servants. However, the government failed to think of adequate and innovative ways of encouraging her citizens to go into entrepreneurship such as: developing the capacity for enterprise and vocational education, science and technology training and development, incentives, and favourable policy environment. Rather, the civilian governments of the early 1960s decided to establish government corporations (otherwise called public corporations) and ministries. The criticism is that these corporations were used as channels by politicians to employ and settle their political cronies or "loyalists" and personal family relatives. These public organisations were poorly managed, lacked adequate controls and carried huge wage bills. By the early 1970s, it was clear that the corporations were financially distressed added to the corporations' inability to render commensurate services. The federal government began to implement some economic policies in an attempt to redirect the economy toward domestic productivity.

The primary target of the policies was to discourage excessive importation and encourage local production of such hitherto imported goods and services. Because public corporations showed signs of failure in late 1977, the government promulgated and implemented the Indigenisation Decree of 1977 to expand the entrepreneurial class in Nigeria. The decree classified all enterprises in Nigeria into the following:

1. Enterprise exclusively reserved for Nigerians

2. Enterprises in which Nigerians must have an interest of 60 per cent and above

3. Enterprises in which Nigerians are to have a minimum of 40 percent interest

Following the decree, most enterprises owned and managed exclusively by foreigners had their ownership interest and management base diluted in favour of Nigerian ownerships. Anyanwu 
(1999), reports that the indigenisation decree marked a major milestone in the growth of entrepreneurship in modern Nigeria. It could be taken as a part of the decolonisation strategy.

As a result of the failure of the public organisations that started from late 1977, the government was no longer willing to bear the huge losses of these corporations. The government began to retrench the workers in those corporations. By 1978, the then Head of State General Olusegun Obasanjo introduced some austerity measures. Following the handing over of his government to a democratically-elected president in 1979, a civilian president, Alhaji Shehu Shagari introduced the Economic and Stabilisation Act of 1982. The economy did not recover; it continued in the doldrums. In 1985, the military took over power and Major General Mohammadu Buhari promulgated the Financial (Miscellaneous Taxation Provision) Decree (Anyanwu, 1999). The military came into power with the promises of revamping the economy, but Major General Mohammadu Buhari's government lasted for only 18 months; there was a coup by General Ibrahim Babangida in 1985.

In 1986, the government of General Ibrahim Babangida, military Head of State (1985-1993), implemented the Structural Adjustment Programme (SAP) based on the International Monetary Fund's economic prescriptions. The adoption of the IMF's SAP was a reversal of the decolonisation strategy of the indigenisation scheme implemented in 1977 and the introduction of a new form of colonisation. The aim of the government's proposed policy was mainly to restructure the economic and productive base of Nigeria and diversify the economic fortune of the country away from the mono-product nature and over-dependence on crude oil exports. However, the SAP policy was not well implemented, so it was abandoned in early 1990. Nevertheless, the SAP policy is alleged to have accorded many Nigerians the opportunity to try their hands at different economic ventures as most of the hitherto imported goods were banned (Anyanwu, 1999). The government claimed to have provided the needed motivations for entrepreneurial development during the SAP period. Anyanwu notes that the motivations were provided under the aegis of the National Directorate of Employment (NDE), which is still functioning as a directorate in the Presidency till date. The programmes provided by NDE included:

1. Youth Employment Vocational Skills Development Programme (YEVSDP)

2. National Open Apprenticeship Scheme (NOAS)

3. Waste to Wealth Scheme (WWS)

4. Disabled Scheme (DS)

5. Small Scale Industries and Graduate Employment Programme

6. Graduate Job Creation Loan Scheme 
7. Mature People's Loan Scheme

8. School Leavers Loan Scheme

9. Graduate Agricultural Loan Schemes

10. School Leavers Agricultural Loan Schemes

11. School on Wheels Scheme

12. Small and Medium Scale Enterprises Loan Scheme

The aims of the programmes (e.g., 1-12) were to encourage the youths and retired workers to develop enterprise and business interests. Government's desire was to create a crop of the more employment-generating population rather than more job seekers. However, successive governments abandoned most of the programmes over the years, but they are believed to have helped considerably in raising some entrepreneurial development consciousness in Nigeria (Ekanem, 2010).

\subsection{The kind and pattern of entrepreneurship activities in Nigeria}

Entrepreneurship activities have developed through a series of three distinct eras: small-scale agriculture, commerce, road transport and those by immigrant groups during the period 19001945. After that, it moved into small-scale manufacturing, importation/exportation of agricultural produce, properties, agro-allied, banking/finance and insurance during the period 1945-1970. Then from 1970 to date, entrepreneurs expanded into oil and gas, airlines transports, large-scale farming, fishing, manufacturing, ICT, and mobile telecommunication subsectors. Others established private educational institutions (secondary and tertiary education), and some overseas investments (Ekanem, 2010; Emmanuel, 2008; Forrest, 2005; Nwachukwu, 1990). The following subsections discuss these selected eras further:

1) The era of subsistence farming and trading (1900-1945)

During the period 1900-1945, people were more into subsistence farming and petty trading, being artisans with limited formal education, as well as undertaking apprenticeship and bicycle parts trading. The Ibos in the South-east Nigeria and the Calabar people in the South-south specialised in the palm produce trade. Moving from a pure agrarian base directly to an industrial base, or from trade to large-scale agriculture, was much more limited. Also during this period, Nigeria's enterprises were more in furniture making, saw milling, baking, printing, building material sale, motor transport, and garment making. 
Historically also, there were some traders with large commercial enterprises employing many thousands of people. For example, Jaja of Opobo and Nana Olomu of Itsekiriland (both in Southsouth region of Nigeria) were early middlemen who attained wealth and influence. They specialised in trade and exports businesses, considered the preserve of the European firms. In fact, Jaja successfully arranged the shipping of his palm oil to a Birmingham firm. There were some Nigerian merchants who owned steamships and used them in the Niger trade. Among them were J. P. L. Davies, Samuel and Josiah Crowther and J. S. Leigh. Therefore, Nigerians were not lacking in entrepreneurship and business pursuits right from the early days as a people although the scale was sole-proprietorship with fewer plans for continuity (Ekanem, 2010).

Also among the important traders during this period were J. N. Cole, J. H. Doherty, Mohammed Shitta-Bey, J. J. Thomas, Z. A. Williams, and R. B. Blaize, reputed to have been the merchant prince of them all. His estimated financial resources were about $£ 150,000$. A good indication of the importance of Nigerian traders was the critical role they played in the Lagos Chamber of Commerce founded in 1888, for example (Forrest, 2005). By 1906, four African merchants, S. A. Coker, J. H. Doherty, D. A. Taylor, and C. A. Oni opened branches at Abeokuta (Ogun State in the Western Region) and Ibadan (Oyo State, Western Region) in 1914. Moreover, J. H. Doherty had ten branches in Zaria, Kano (Northern Nigeria) and Duala in the Cameroons. A merchant such as Samuel Peace (1866-1953) is reported to have launched businesses with partners from Sierra Leone and also became an agent for the Africa and Gold Coast Trading Corporation (Forrest, 2005). In 1897, he went to Calabar (in the South-south) dealing in all imported goods and exporting palm produce, rubber, especially ivory. He moved to Lagos in 1902 with his newly acquired wealth, traded in palm produce and developed extensive property interests. He bought shares in the Gold Coast Mining Companies and in 1907 he opened the first hotel in Lagos. Thomas, a general merchant, began his career in Calabar before moving to Lagos and diversified into corn milling, tanning and a model farm. In 1920, he had 25 branches inland; he had eight Europeans in his employ in the early 1920s (Macmillan, 1968).

There were other entrepreneurs and small-scale enterprises during the period before Nigeria's independence in 1960; some decided to move away from trading, transports, agents to some foreign businesses and tried banking services also. For example, in $1933 \mathrm{Dr}$ Akinola Maja, J. A. Doherty and H. A. Subair established the National Bank of Nigeria Ltd (NBN). There were others, who earlier attempted establishing banks, but the banks failed because of poor management; yet, the NBN Ltd survived. The NBN Bank provided short-term finances for African importers, exporters, produce buyers and traders. Also, the entrepreneurs exploited new opportunities in small-scale industries like confectionery and printing. 
2) The era of small-and-medium-scale manufacturing and more personal/corporate financial services participation (1945-1970)

During this period, Nigeria's advancements into the industrial sector and large-scale manufacturing were patchy and in some areas it was vulnerable to volatile economic conditions, yet entrepreneurs still attempted some small-scale manufacturing (Emmanuel, 2008). Then, business people started making important advances in the scale of operation and basic technology usage. This advancement happened in the food and beverages, garment making, textiles, furniture, printing, vegetable oil production and rubber processing subsectors. Also, people opened new businesses in the carpets, ceramics, cotton ginning, starch, detergents, distilling, industrial gas, pharmaceuticals (including injectable), motor parts, and motor body panels subsector. Others expanded into the steel rolling and fabrication, condensers, windscreens, electric cables, plastics, paper conversion and recycling, packaging, oil and other technical services subsector (including computers and telecommunications). Large indigenous firms existed in many industrial sectors though they did not have a dominant position compared to the foreign stakeholders. For example, in the agro-allied industry, Lebanese and Indian investors had an important stake. In the textiles industry, Indians and Chinese had a stronger presence than Nigerians. Only in Kano state did there appear to be sizable indigenous investments in this sector (Emmanuel, 2008).

During the 1950s, Nigerian private enterprise was still characterised by small-scale, fragmented and regional. The areas where it was present on a significant scale included commerce (e.g. importing, wholesaling, retailing, and the produce trade), real estate, transport, construction, and palm oil. Other areas included rubber processing, saw milling and furniture, tyre retreading, bakeries, printing, and shoe making. There was a very limited presence in banking and insurance (Forrest, 2005).

In what follows, an attempt is made in examining the kinds and nature of entrepreneurship in the post-independence period in Nigeria. The focus in entrepreneurship shifted to areas such as the oil industry, airlines, shipping, large-scale farming, fishing, banking/finance and insurance and overseas investments. These are examined one after another shortly. 
3) The era of indigenous participation in the oil and gas subsector and the modern economy (1970-present)

The major characteristics of this period included the beginning of the new Nigeria and economy after the end of a devastating three-year civil war in 1970. It also witnessed a stronger participation of Nigerian entrepreneurs in the oil and gas subsector and the beginning of the oil boom with its attendant petrodollar earnings for investors. A brief discussion of the key sectors and subsectors that witnessed the participation of Nigerian entrepreneurs during this period is as follows:

\section{(i) Oil Industry}

The early discovery of oil in Nigeria in the late 1950s made room for investments in this sector. Harris' (1967) reports on the oil industry is that during the 1960s, the opportunities created for Nigerian-owned companies were only in areas such as furniture, printing, clearing drilling sites, supplying specialised heavy transport equipment (1962), and welding pipelines (1964). It was only after the civil war in 1970 and also during the 1980s that the key investments by Nigerians in the oil sector resumed. In this field, the civil war severely disrupted and delayed the growth of indigenous capacities. During the 1970s, Nigerians increased their shareholding in oil, service, and subcontracting companies and also set up petroleum transport and distribution companies as licenced independent dealers.

By the end of the 1980s, local companies also started venturing into capital-and-skill-intensive areas of the oil industry. Located in Port Harcourt and Warri (in the South-south), these companies engaged in the construction of flow stations and pipeline regrinding, protection and installation, and mechanical corrosion engineering. Furthermore, they engaged in mud logging, well testing, directional drilling, wireline services, instrumentation, servicing of pumps and compressors, and specialised transport equipment. Indigenous oil-service companies were established (as shown in Table 2.1). Forrest (2005) reports that the first private indigenous oil exploration and production company, the Dubri Oil Company, commenced oil production in 1987. It was owned and promoted by $\operatorname{Dr}$ U. J. Itsueli, a former Managing Director of Philips Petroleum. He acquired part of the assets and absorbed some key personnel from Philips when the company left Nigeria (Forrest, 2005). By the end of 2010, about 20 indigenous oil companies were licenced for oil prospecting leases and some made discoveries of crude oil in commercial quantities. The formation of the Nigerian Association of Indigenous Petroleum Exploration and Production Company (NAIPEC) followed. In a sense, these efforts point to some enterprise endeavours of Nigerians in the oil and gas energy 
subsector. Table 2.1 indicates some of the early efforts made by entrepreneurs in the oil subsector:

Table 2.1: Major indigenous oil service and production companies in Nigeria

\begin{tabular}{|c|c|c|c|c|c|}
\hline & Company & $\begin{array}{l}\text { Start- } \\
\text { up }\end{array}$ & Service activity & $\begin{array}{l}2004 \\
\text { employment }\end{array}$ & Background of founders \\
\hline 1 & Enosco Nigeria Limited & 1972 & $\begin{array}{l}\text { Pipeline maintenance, } \\
\text { construction, anticorrosion }\end{array}$ & 80 & $\begin{array}{l}\text { Founder, Chief Akpan Eno } \\
\text { worked for indigenous } \\
\text { and foreign companies as } \\
\text { a pipeline welder }\end{array}$ \\
\hline 2 & $\begin{array}{l}\text { Arco Petroleum } \\
\text { Engineering }\end{array}$ & 1980 & Supply and servicing equipment & 40 & $\begin{array}{l}\text { Mr Alfred I. Okoigun was a } \\
\text { former staff of Nigeria } \\
\text { National Petroleum } \\
\text { Corporation }\end{array}$ \\
\hline 3 & Negris & 1980 & $\begin{array}{l}\text { Supply, installation and } \\
\text { maintenance of production } \\
\text { equipment and logging }\end{array}$ & 150 & Former Gulf Oil employee \\
\hline 4 & Petro log & 1980 & Mud logging & $\begin{array}{l}80 \\
83 \\
120 \\
60\end{array}$ & $\begin{array}{l}\text { Former Geo-Services } \\
\text { employee }\end{array}$ \\
\hline 5 & Ciscos & 1983 & $\begin{array}{l}\text { Drilling and completion, } \\
\text { cementing and pumping }\end{array}$ & 30 & $\begin{array}{l}\text { Three former } \\
\text { Schlumberger and } \\
\text { Weatherford employees }\end{array}$ \\
\hline 6 & Weitek & 1986 & instrumentation & 75 & $\begin{array}{l}\text { Two former employees of } \\
\text { Flopetrol, Schlumberger } \\
\text { and NNPC }\end{array}$ \\
\hline 7 & Zumax & 1986 & Wireline services & 20 & $\begin{array}{l}\text { Chief Azuka E Uzor and } \\
\text { Chuck Nduka-Eze were } \\
\text { two former Otis } \\
\text { employees }\end{array}$ \\
\hline 8 & $\begin{array}{l}\text { Ada Mac Group: } \\
\text { Adamac Engineering } \\
\text { Adadrill } \\
\text { Strasbourg }\end{array}$ & 1987 & $\begin{array}{l}\text { Supply of technical equipment } \\
\text { well completion } \\
\text { well head }\end{array}$ & $30 \quad * 420$ & $\begin{array}{l}\text { Founder traded in Aba } \\
\text { and USA }\end{array}$ \\
\hline 9 & Benek Engineering & 1987 & $\begin{array}{l}\text { Mechanical corrosion } \\
\text { engineering }\end{array}$ & 20 & $\begin{array}{l}\text { The founder worked for } \\
\text { Shell drilling supervisor. } \\
\text { Ten engineers employed }\end{array}$ \\
\hline 10 & $\begin{array}{l}\text { DrillLog Petro- } \\
\text { Dynamics } \\
\end{array}$ & 1990 & $\begin{array}{l}\text { Direction drilling and bore-holes } \\
\text { survey }\end{array}$ & & $\begin{array}{l}\text { Former MD, Anadrill } \\
\text { Schlumberger (1984-90) }\end{array}$ \\
\hline 11 & IMC & 1992 & Transportation & 30 & $\begin{array}{l}\text { Six vessels on lease to } \\
\text { Shell. Recruited from } \\
\text { former NNSL staff }\end{array}$ \\
\hline 12 & Kogi Oil Services & 1992 & Mud logging & 25 & Part of Dangote Group \\
\hline 13 & Oil Test Services & 1992 & $\begin{array}{l}\text { Well testing, production services, } \\
\text { PVT laboratory, wireline logging }\end{array}$ & $20-5$ & $\begin{array}{l}\text { Four former Schlumberger } \\
\text { employees }\end{array}$ \\
\hline
\end{tabular}

*Group's employment figure

\section{Sources: Forrest (2005); companies' website}

Table 2.1 above shows the major indigenous oil services and production firms and indicates that investments in the subsector began as early as 1972 and showed that Nigerians were also involved in the major segments of the industry. Some engaged in pipeline maintenance, installations and production of equipment and logging while others had businesses in drilling and mechanical 
corrosion engineering services. Employment generation in some of the firms ranged from 20 to 420 workers. It also indicates that most founders had some level of cognate experience working as the staff of foreign oil firms in Nigeria before establishing theirs. Their experiences acted as motivation. The implication of this is that people would more likely go into entrepreneurship in the sectors they got work experience. Currently, there are over 50 major indigenous ${ }^{1}$ oil servicing and production firms in Nigeria mostly located in the South-south region. The current efforts are geared toward the development of local contents in the subsector.

\section{(ii) Airlines}

Private Nigerian airlines made notable advances from the early 1980s. Nigeria Airways, the national carrier, also operated. Most of the companies emerged out of the spot charters and the aircraft spare-parts business. The private airlines competed successfully with the state carrier, Nigeria Airways. Their share of total passenger traffic climbed steadily through the decades. This success was despite the contraction of the domestic economy and the difficulty of generating hard currency to pay for regular maintenance overseas and major inspections. In 1990, the share of domestic traffic was around 75 percent for private airlines, with two operators, Kabo Air and Okada Airways, carrying the bulk of the traffic (Forrest, 2005).

Kabo Air started in 1981 and owned by Alhaji Dankabo. The airline is based in the north in Kano State. The founder was a former staff of Nigeria Airways representing Monrovia and Northern states. Intercontinental Airlines started as a cargo operator mainly working for the Central Bank of Nigeria. It was the only airline operating an international charter with weekly flights to the United Kingdom between 1981 and 1985. Okada Air began in 1983 after four years of spot charters but is now inoperative. Chief Gabriel. O. Igbinedion owned the airline.

Table 2.2 below paints some picture of the level of involvement of Nigerian entrepreneurs in the private airline business in the early years. The last column indicates the founders' backgrounds. It shows a mix of founders, some from northern Nigeria (e.g. Alhaji Mohammadu D. Kabo; Late Aliyu Dasuki; Alhaji Rufai Haruna). Others were indigenous entrepreneurs from the South-south (e.g. Chief Gabriel Igbinedion and ADC co-founder, Augustine Okon). Others came from the Western Nigeria (e.g. Late Chief M. K. O. Abiola and Chief Yemi Akinnagbe). Again, others came from the

\footnotetext{
${ }^{1}$ Available at: http://www.nigeria-oil-gas.com/nigeria__list_of_operators-112-10-2-art.html (Accessed 23 July 2015).
} 
Southeast (e.g. Ike Nwachukwu and Prince Arthur Eze). The number of aircrafts owned ranged from one, by Prince Arthur Eze, to 32 by Chief Gabriel Igbinedion.

Table 2.2: Indigenous Airline Companies*

\begin{tabular}{|l|l|l|l|}
\hline Name & $\begin{array}{l}\text { Start- } \\
\text { up }\end{array}$ & $\begin{array}{l}\text { No. of } \\
\text { planes }\end{array}$ & Founder \\
\hline Kabo Air & 1981 & 16 & Alhaji Mohammadu Dan Kabo former Nigeria Airways staff. \\
\hline Intercontinental Air & 1981 & NA & Chief Victor Vanni. Ceased operations in 1985 \\
\hline Okada Air & 1983 & 32 & $\begin{array}{l}\text { Chief Gabriel Igbinedion. He took over the management of Sierra } \\
\text { Leone National Airline (1993). }\end{array}$ \\
\hline Concord Airlines & 1989 & 8 & $\begin{array}{l}\text { Chief M.K.O. Abiola. Started as RCN Aviation in 1977 within Radio } \\
\text { Communications Nigeria Ltd. Not operational since 1993. }\end{array}$ \\
\hline Hold-Trade Air Services & 1990 & 5 & Late Aliyu Dasuki \\
\hline $\begin{array}{l}\text { Aviation Development } \\
\text { Company Plc (ADC) }\end{array}$ & 1991 & 5 & $\begin{array}{l}\text { Started by four former Nigeria Airways pilots. Flew for the } \\
\text { government of Guinea for three years. Flew West African routes in } \\
\text { 1993. }\end{array}$ \\
\hline Harco Air Services & 1992 & 8 & Alhaji Rufai Haruna \\
\hline Zenith Airlines & 1992 & 2 & Ike Nwachukwu \\
\hline Triax Airlines & 1992 & 1 & Prince Arthur Eze \\
\hline Yvic & 1992 & 2 & Chief Yemi Akinnagbe \\
\hline
\end{tabular}

*Scheduled passenger airlines. This number does not include Cargo and charter companies. Since the advent of private airline operations, some companies have gone into liquidation. They include Barnax Airlines and Oriental Airlines. Oriental Airlines owned by Chief Emmanuel Iwuanyawu was re-launched in 1993.

\section{Sources: Forrest (2005); companies' website}

Table 2.2 above indicates some early indigenous airline companies founded by Nigerian entrepreneurs as far back as 1981. It also indicates the number of aircrafts owned by each outfit as well as the identities of the entrepreneurs who promoted the enterprises. The early 1980-90 period witnessed the participation of Nigerian entrepreneurs in this capital-intensive transport subsector that was previously a preserve of the foreign operators. Again, Nigerian entrepreneurs seemed to show some strong enterprising spirit even in very competitive and huge capitalintensive enterprises in seemingly volatile business environments or sectors.

\section{(iii) Shipping}

During this period, Nigerian entrepreneurs also made notable investments in the shipping business. For example, Henry Stephens Company began in 1969 by chartering vessels for cement and cocoa and acquired a ship in 1969. Alhaji Yinka Folawiyo, the owner of Nigeria Green Lines, was involved in cement trade from Spain (as shown in Table 2.3). The Nigeria Green Lines operated the largest indigenous fleet at the end of the 1970s with six general cargo vessels of 10,000 to 15,000 dead-weight tonnage each, shipping between Nigeria and European ports. 
Between 1985 and 1989, four new shipping businesses were established by indigenous entrepreneurs. With the 1983 UNCTAD Code of Conduct for Liner conferences, more businesses were harnessed by the indigenous shipping companies. The conferences accepted the proposal for two trading countries to share cargoes 40/40, leaving the remaining 20 percent for cross (third) parties. Nigerian shippers have, nevertheless, been seen to lack the facilities to attract sufficient cargoes allotted to them in Europe (Forrest, 2005).

Table 2.3: Major Nigerian indigenous shipping companies

\begin{tabular}{|l|l|l|l|}
\hline Company & $\begin{array}{l}\text { Start- } \\
\text { up }\end{array}$ & Founders & Comment \\
\hline Henry Stephens Shipping & 1969 & $\begin{array}{l}\text { Late Chief Henry } \\
\text { Fajemirokun }\end{array}$ & Three vessels. Now charters only \\
\hline Nigerian Green Lines & 1973 & Alhaji Yinka Folawiyo & $\begin{array}{l}\text { Six vessels by 1979 totalling 87, 800 tonnes } \\
\text { dead weight. One vessel 1990. }\end{array}$ \\
\hline Equatorial Carriers & NA & Sodipo family & $\begin{array}{l}\text { One vessel. Scandia Steamships of India took } \\
\text { 40\% shareholding }\end{array}$ \\
\hline Sea Daintainer Lines & 1978 & $\begin{array}{l}\text { Alhaji Aminu Dantata and } \\
\text { Walford Lines of UK (40\%) }\end{array}$ & Container shipments to Warri ended in 1979. \\
\hline Nigerbras & 1976 & Alhaji Mahmud Waziri & One vessel \\
\hline Africa Ocean Lines & 1985 & $\begin{array}{l}\text { Shehu Yar'adua and M. K. O. } \\
\text { Abiola }\end{array}$ & Two vessels \\
\hline Bulkship (Nig) & 1985 & Alhaji Hassan Adamu & One vessel and Charters \\
\hline Brawal Lines & 1988 & Part of Aeromaritime Group & One vessel \\
\hline $\begin{array}{l}\text { South Atlantic Seafood } \\
\text { Company (SASCO) }\end{array}$ & 1989 & Olu Fashanu & Two passenger ferries and charters \\
\hline
\end{tabular}

NA $=$ Not available

\section{Sources: Forrest (2005); companies' website}

Table 2.3 above indicates the status of early entrepreneurs who ventured into the shipping transport subsector in Nigeria. As far back as 1969, some Nigerian entrepreneurs were involved in chatter and container shipment businesses as well as passenger ferries. Again, the owners' ethnic origins are mixed. The owners of the first three companies and the last one are from the Southwest Nigeria while the rest are from the Northern Nigeria.

\section{(iv) Large-Scale Farming}

Over the years, many indigenous entrepreneurs developed large farms. As early as 1970, there was a class of large-scale landowners in the northern Nigeria, very often title holders in the Emirates, who farmed on a considerable scale. Labaran (1987) reports that in the Kaura Namada area of Sokoto State in the mid-1980s, Alhaji Salabi Liman farmed 1,500 hectares; he had 150 permanent staff and 600 casual staff. In the same area, Alhaji Muazu Gabaki employed 150 permanent staff on his farm. In Bauchi State, Alhaji Ibrahim Mohammed had a farm of 1,500 
hectares (Udubo Green Farms), and Alhaji Ibrahim Ganawa owned farms of 425 hectares at Azare and Ganawa in Bauchi State (Forrest, 2005).

Among the entrepreneurs who went into large-scale farming were: retired military officials, civil servants and businesspeople. The retired military officers included: Lieutenant-General Akinrinade (Niger-Feed and Agricultural Operations); Major-General Shehu Yar'adua (Sambo Farms); and General Olusegun Obasanjo (Obasanjo Farms Ltd). Leading state officials included: Sunday Adewusi (Nefraday Farms); Francis Ellah (Ellah Lakes PIc); Alhaji A. Howeidy (Fertile Acres); Ahmed Joda (Benue Valley Farms and Benue Valley Meat Company); and Bamanga Tukur (Gesedaddo Farms). Businesspeople who invested in large-scale agriculture as part of their diversified enterprises included: Chief Michael Ibru (Cafrad), Sanusi and Aminu Dantata (Anadariya and Asada Farms), Chief Bode Akindele (United Planters Ltd), Chief llodibe (Austin Farms), and Chief Abiola (Abiola Farms Ltd). The Abiola Farms acquired over 17,000 hectares in five different states. A 100 hectare maize farm was developed at Dakka in Adamawa State in 1989. There have also been several numerous smaller examples of investment in farming that are visible in almost every part of the regions in Nigeria (Forrest, 2005).

\section{(v) Fishing}

Most of the fishing businesses in the different regions, especially those whose communities have rivers and seas, are carried out by small and independent fishermen. Their outputs go to servicing the local communities; this makes Nigeria still very much import-dependent for her fish needs (Forrest, 2005). The Ibru Organisation and the Modandola Group were among the early indigenous big operators in the Nigerian fishing industry. Nigeria's fishing industry has been restricted to inshore operations, inland fisheries on the Yauri and Hadejia Rivers in the North and Lake Chad, the largest source of supply of fish. The latter two fisheries gave rise to an extensive North-South trade in smoke-dried fish. Also, there has been substantial investment in shrimping, for export by Express Fisheries, Folawiyo Group and Honeywell Group.

\section{(vi) Banking and Finance}

Nigerian indigenous businesspeople have shown entrepreneurial strides in the area of banking and finance also. It was during the 1970s that the pattern of indigenous participation in banking, insurance and financial services changed (Forrest, 2005). Among the businesspeople who promoted new investments in banking were: Chief Samuel Adedoyin (Industrial Bank), Mike Adenuga (Devcom Merchant Bank that became Equatorial Trust Bank PIc), Chief S. O. Bakare 
(Metropolitan Merchant Bank), Alhaji Aliko Dangote (Liberty Merchant Bank), Alhaji W. I. Folawiyo (Marina International Bank), Olorogun Michael Ibru (Oceanic Bank International), Chief D. U. Ifegwu (Citizens International Bank), Chief G. O. Igbinedion (Crown Merchant Bank), Chief E. C. Iwuanyanwu (ABC Merchant Bank), Otunba M. O. Jolayemi (Victory Merchant Bank), Chief Onwuka Kalu (Fidelity Union Merchant Bank), Mr. Jimi Lawal Alpha Merchant Bank, Chief Dotun Okubanjo (Gulf Bank), Mr. G. O. Onosode (Commercial Bank), Alhaji Isiyaku Rabiu (Grindlays Merchant Bank), Alhaji Bashi Othman Tofa (Century Merchant Bank). All of the merchant banks mentioned had been converted to commercial banks during the universal banking era of the early 1990s, and some merged with other banks and are now leading banks in Nigeria. Two examples are the Oceanic International Bank, which merged with Ecobank PLC and Citizens International Bank merged with four other banks (Fountain Trust Bank Plc, Guardian Express Bank Plc, Omega Bank Plc, Trans International Bank Plc) to become Skye Bank in early 2010.

In the insurance subsector, some indigenous entrepreneurs made investments in insurance companies. In 1988, Amicable Assurance Company established in 1972 by Prince P. A. Adeyemo, became the first insurance company to go public on the Lagos Stock Exchange. In 1989, Chief J. O. Irukwu, the former Managing Director of Unity Life and Fire Insurance (1970-82) and the Nigeria Re-Insurance Corporation (1977-89), set up the African Development Insurance Company. In 1991, the company entered a joint venture with a European Insurance Company, Assiwrozioni General Spa (25 percent). Nigerian private investors also established some reinsurance companies. For example, Mr J. O. Emmanuel, an accountant, launched Universe Re-Insurance in 1985. The company's premium income was 2010 (Universal Insurance, 2010). Forrest (2005) also reports that Continental Reinsurance started in 1987 with a prominent insurance broker from Kano, Alhaji M. H. Koguna as chairperson. However, Nigeria now has sixty-eight private and publicly-quoted insurance companies (National Bureau of Statistics, 2013).

\section{(vii) Overseas Investment}

A further important dimension of indigenous enterprise is the overseas investment. The extent of investment by Nigerian entrepreneurs and enterprises is unrecorded, yet it is accepted that the majority of larger businesses made investments overseas. This investment is seldom an integral part of the corporate strategy of an enterprise based in Nigeria. It is often in the area of real estate. 
A few businesspeople have their base overseas or made their initial investments abroad. Examples include Fanz Organisation (Chief Arthur Nzeribe), Chioke International and Alpha Properties International (Jimi Lawal). Of much more important, historically, for their impacts on the standard of living and enterprises at home has been the existence of Nigerian communities doing business abroad, especially within the West African sub-region. The Hausa trading diaspora is an example; the Yoruba community in Ghana and the Ibo trading community in Cameroon, China, Japan, and Dubai are others. An example that is important for an understanding of the economic revival in Ibo land after the civil war, was the establishment of Ibo trading communities in Cotonou and Lome (Forrest, 2005).

There was also some evidence at the end of the 1980s of Nigerian companies and business people making investments in West Africa. In 1985, Forrest reports that a group of West African entrepreneurs with the active support of the West African Chamber of Commerce set up Ecobank Transnational Incorporated, a holding company based in Lome. The Public Finance Group founded by Chief Paul Erihri in 1982 opened a merchant bank and other financial institutions in the Gambia attracted by the highly liberalised economy. In Ghana, a Nigerian introduced Balkan Airlines to the country; he made a $\$ 4 \mathrm{~m}$ investment in hotels. Another, who made money in second-hand clothing, invested in pineapple production for export. In Gabon, a Nigerian was reported to own the only toilet paper factory in the country (Forrest, 2005).

From the analyses above, it is hard to say which Nigerian region has contributed more or less to the pursuits made in the overall development of entrepreneurship in Nigeria. The entrepreneurs enumerated in the sections have come from different ethnic backgrounds: Yoruba (Southwest), Ibo (Southeast), Hausa/Fulani (North), among other minority groups. Those highlighted here are only a representation as there are numerous old and new businesses founded by different entrepreneurs from the various ethnic nationalities not captured in this study. It would be hard to make distinctive comparisons of differences or similarities in entrepreneurship outcomes without published datasets on the specific entrepreneurship outcomes, which, unfortunately, are unavailable currently for the Nigerian regions.

For example, the GEM $(2014,2015)$ surveys investigated 69 countries and included only six African countries: Angola, Botswana, Burkina Faso, Cameroon, South Africa, and Uganda. It failed to include Nigeria's data. The surveys reported statistics for entrepreneurship perceptions of only 69 countries under three major themes including the following entrepreneurship indicators or dimensions: 
Activity (New Business Ownership Rate, Total early-stage Entrepreneurial Activity (TEA), Total early-stage Entrepreneurial Activity for Female Working Age Population, Total early-stage Entrepreneurial Activity for Male Working Age Population); Aspirations (Growth Expectation early-stage Entrepreneurial Activity: Relative Prevalence, International Orientation early-stage Entrepreneurial Activity, New Product early-stage Entrepreneurial Activity); Attitudes and Perceptions (Entrepreneurial Intention, Entrepreneurship as Desirable Career Choice, Fear of Failure Rate, High Status Successful Entrepreneurship, Know Start-up Entrepreneur Rate, Media Attention for Entrepreneurship, Perceived Capabilities, and Perceived Opportunities).

The study defined and described each of the above dimensions of entrepreneurship in line with the study's adopted methodology and indicated the scores for each of the countries (the details are found in GEM [2014]). The dimensions, however, had no state-by-state or regional bloc comparisons.

The non-availability of the above-specified dataset for Nigeria in the GEM surveys makes it difficult for the present study to use GEM surveys to compare entrepreneurship statistics for the two regions studied. However, the earlier versions of GEM surveys (e.g. 2012) included Nigeria's data but there were not state-by-state breakdown to have enabled the present study undertake regional comparisons. The "World Bank Ease of Doing Business" surveys have data for Nigeria (for all the 36 States and the Federal Capital Territory, Abuja). However, the emphasis is different. Its emphasis is on comparing and ranking "business regulations for domestic firms in 189 economies" (World Bank Ease of Doing Business, 2015). It compares and ranks national economies according to ease of "starting a business", "dealing with construction permits", "registering property", "getting electricity", "resolving insolvency", "enforcing contracts", among others. These indicators would be unable to address the specified needs of this chapter, which sought to examine whether there were significant entrepreneurship differences or similarities between people of the two regions studied. Comparison between the two regions would be possible with some statistics, for example: the total number of venture owners in the regions studied (or states in the regions), rate of creation of firms with employees (compared to one-man businesses), number of high-growth ventures $^{2}$, morbidity rates (i.e. birth minus death rates of firms), number of young, high-growth firms (gazelles), and R \& D institutions (Hoffmann and Vestergaard, 2012; Bridge et al., 2009).

\footnotetext{
2 According to Ăcs et al. (2014, Kindle Locations 443-445), a high-growth firm is a "registered firm (trade registry, employment registry, etc.) that has achieved at least 60 percent employment growth during a
} 
Notwithstanding, even the measures enumerated above by Hoffmann and Vestergaard (2012) and Bridge et al. (2009) cannot adequately account for the quality of businesses founded. For example, quality regarding the level of social impacts, the level of innovativeness, market expansion prospects, growth orientation or prospects, and international outlook. The suggested statistics (by the authors cited above) are what researchers call the output-based entrepreneurship indicators (Ăcs et al., 2014). If these output-based entrepreneurship indicators were available for the two regions studied (or the states that make up the regions), it would have been easier to compare clearly. It would have helped in examining which region has what levels or volumes or spread of each of the statistics published.

Therefore, the present research has resorted to using the participants' (undergraduates) perceptions of similarities or differences in entrepreneurship outcomes between the two regions studied [examined in Chapter Six, Sections 6.5 and 6.7.2; Chapter Seven, Section 7.2.2; and Chapter Eight, Section 8.3(2)]. In future, if the above-listed indicators are available, researchers would be able to conduct a detailed historical data analyses for the South-south and Southeast Nigeria regions using those statistics. Thus, researchers would be able to delineate similarities or differences appropriately. However, the researcher would like to attempt some collaborations with the Global Entrepreneurship Monitor (GEM) or Global Entrepreneurship Development Index (GEDI) publishers to help generate these sets of data for Nigeria (or some of her regions) in the nearest future. Because GEM publisher already has the framework and the methodology used in collecting the data for the six African countries cited earlier, it might be possible to generate the data for Nigeria.

To recap: in this section, the author has sketched some of the advances made by indigenous entrepreneurs in Nigeria's entrepreneurship development quest; the analysis covered the periods 1900-1945, 1945-1970 and 1970-present. It characterised the periods as expanding from the era of subsistence farming and trading during the 1900s to small-scale manufacturing and personal/corporate financial services sector from the period 1945 to 1970 . After that, enterprise efforts expanded to the petroleum industry, aviation, commercial agriculture, aquaculture, manufacturing, mobile technology and telecommunication and private sector education. These sectors opened the opportunities for participation by the indigenous entrepreneurs.

period of two years, with at least 20 percent annual growth each year, and which employed at least 10 people at the beginning of the period (OECD-Eurostat, 2007)." 
However, the business and economic environment that entrepreneurs operate in Nigeria are weak and volatile just as it might be the case for most developing countries, still struggling with the fixing of their institutions to global best practices. The issues of institutional factors would take the attention of the next subsection. The subsection examines the influences of access to property rights and the size of the state as the two key institutional factors that can impact entrepreneurship success the most (Ăcs, Szerb and Autio, 2014).

\subsection{Institutional factors and entrepreneurship development}

There is a growing recognition of the influences of institutional factors (formal and informal) such as the "rule of law", "property rights", "political conditions", "economic reward systems", "culture, values and norms" and "level of economic development" on the economy and entrepreneurship development (Ăcs et al., 2014; Baumol, 1990; North, 1990). Research argues that institutions foster, homogenise, and reinforce individual actions: the nation's institutions create and disseminate different ideas and knowledge, and direct them to resourceful uses (Ăcs, Szerb and Autio, 2013). It is this knowledge that entrepreneurs often "run with" to innovate, create services, or make goods. The present study defines institutions as forms of constraints that people in an entity formulate to control social interaction (Ăcs et al., 2014).

Research links countries' individual institutions and incentive structures with the nature of their entrepreneurship activities (Boettke and Coyne, 2009; Hwang and Powell, 2005). Institutions create the various incentive structures that then determine the entrepreneurship options people make and the entrepreneurship type they choose (Baumol, 1990). In this choice, some entrepreneurship pursuits are productive (e.g. those that support growth) and others can be unproductive (e.g. enterprising use of rent-seeking through using the legal system such as some unwholesome litigations on patent's "infringement" and takeovers). Others also can be destructive as Baumol (1990) ${ }^{3}$ suggests happened in ancient Rome, medieval China, middle ages, and in the $14^{\text {th }}$ century. Thus, the rates and forms of entrepreneurship a country attains are influenced by her contexts such as institutional structures, stage of development, culture, and policy initiatives (Ăcs et al., 2014).

North's (1990) and Baumol's (1990) seminal works showed the theory that links institutional environment and economic and entrepreneurship development. Consequently, entrepreneurs start firms, and the firms tailor their activities and strategies in line with the opportunities and

3 For a classic analyses of how, for example, the ancient Roman reward system on the one hand offered wealth to people in commerce and industry, turned round to offset the benefits by eroding the attendants of their prestige in different circumstances, see Baumol (1990, p.898-909). 
limitations imposed by the formal and informal national institutional frameworks. According to North (1990), the formal institutions comprise of the explicit rules and laws (constitutional laws) that guide the economic incentives in which people and organisations derive benefits. The informal institutions comprise of the invisible social means and norms (i.e. values, acceptable behaviours, and codes of conducts) that impact the ways the formal institutions would function practically.

The inference from North's argument applies to entrepreneurial organisations, which adapt their plans to exploit the opportunities, given the limitations in which the national institutional context provides. Therefore, a more consistently functional business environment would offer more favourable incentives-"rules of the game" as Baumol (1990, p.899) calls it-for her entrepreneurs. Conversely, a weak economic environment would create disincentives for her entrepreneurs. The incentive structures in an economy can "push" different people into either embarking on productive, unproductive or destructive entrepreneurship (Baumol, 1990). Productive entrepreneurship can add to growth in many aspects: it can allow prosperity and wealth by ushering in of innovation and exploitation of opportunities. Non-productive entrepreneurship entails where people use entrepreneurial talents for rent-seeking using government agencies in, for example, created monopolies, preferential tax systems and regulatory exemptions. Destructive entrepreneurship entails acts such as illicit drug businesses and prostitution. Ideally, policymakers make formal rules to enable exchange that can lower transaction costs, which do impact people or groups differently (Ăcs et al., 2014).

Both the formal and informal rules are complements. Often, the informal rules change indirectly and by "accidents, learning, natural selection and most essentially as time passes" (North, 1990, p.88). Moreover, North (1990) emphasises that these two institutions can conflict, given the examples both in history and in the transition economies. Organisations usually adapt their activities and strategies to the opportunities (and limitations) of the formal and informal institutions. Thus, the development of institutions could be influenced intentionally by organisational players, such as entrepreneurs (Ăcs et al., 2014).

\subsubsection{Institutions, incentives and entrepreneurship development}

Entrepreneurship-supporting incentives can encourage economic growth and entrepreneurship development. In reverse, none or inadequate incentives can lead to choices where some entrepreneurs engage in some unproductive entrepreneurial activities. The range of choices 
depends on the existing socioeconomic factors and the incentive structures in the economy (Aidis and Estrin, 2014).

Some institutions that support market-based economic activities tend to strengthen more productive entrepreneurship, and ultimately promote economic growth and development. However, sometimes market-based decisions can lead to widespread distortions, inequalities and misallocations. It is then vital to know not only the individual characteristics of the entrepreneur but also the operational contexts that can help promote productive entrepreneurship and reduce market distortions. These contexts include institutions, incentives, and the level of economic development. The mutually reinforcing connection between incentives and institutions also influences other characteristics such as the quality of governance, access to capital, transparency and what entrepreneurs perceive as the rules of the game (Aidis and Estrin, 2014). Institutions play critical roles in influencing economic behaviour in particular and economic transactions, in general. Thus, institutions could engender both direct and indirect effects on the supply and demand for entrepreneurs.

In sum, when incentives support productive entrepreneurship (i.e. bring an increase in economic growth rate), then such form of entrepreneurship will predominate. Contrariwise, when entrepreneurs see that the benefits of operating an illegal entrepreneurial activity outweigh the costs, some would more likely undertake destructive entrepreneurship, sabotaging economic development (Ăcs et al., 2014; Baumol, 1990). Entrepreneurs evaluate the incentives available in their environment, in each of the different cases, and consider the regulations (i.e. formal rules), and the existing culture, values or norms (or the informal rules). Thus, considering the different incentive structures, entrepreneurs may choose to engage in whether productive, unproductive, or destructive entrepreneurship; though the same entrepreneur does not necessarily engage in all three.

\subsubsection{The key institutions for entrepreneurship: "Property rights" and "the size of the state"}

The rights of the individuals and firms to own properties constitute one of the fundamentals of the modern institutions that feature in market-based economies (Aidis and Estrin, 2014). Legal property rights support the wider aspects of the development of economic property rights. According to Barzel $(1997, p .3)$, economic property rights are the "individual ability, in expected terms, to consume the good (or the service of the asset) directly or to consume it indirectly through exchange." Because entrepreneurs must raise business capital, take risks, and sometimes 
penetrate new markets, and entrepreneurs need to conduct these endeavours with a long-term outlook; therefore, there must be "transaction trust."

This trust can only be engendered if there is a stable environment of property rights and that which also enforces the rights effectively. The current thinking in the institutional research circles shifts emphases from "assignment of rights and certification" to "institutional environmental conditions that make execution of these rights effective, especially exchange and other legal contracts based on property rights" (Aidis and Estrin 2014, p.762). The current emphasis is on how accessible the rights are to the wider populace and not only to the political and ruling class, the elites. Thus, access to property rights by the wider populace can increase the size and performance of the entrepreneurial sector (De Soto, 2001). National systems of formal property rights can engender the basis for financial contracts and a vicious cycle of entrepreneurship, assets creation, and finance. Therefore, property rights and financial access are two keys and mutually reinforcing routes of an effective market-based economic system that encourage entrepreneurship breakthrough (Aidis and Estrin 2014, p.762).

There might be some evidence to stress that the wider context through which incentives, institutions and the stage of economic development could be used to engender high-quality entrepreneurship among undergraduates is relatively weak and need overhauling. For instance, the GEM (2012) report portrayed this claim when it summarised that:

Entrepreneurship in Nigeria is highly constrained by government programmes and regulations. Government policies do not consistently favour new and growing firms; public procurement, in particular, is fraught with corruption, bureaucracy and multiple tax burdens. Support for entrepreneurs is not a top policy priority at national or local government level; also, the political and security situation in Nigeria threatens sustainable economic development.

The GEM report captures the challenges impeding the flourishing of more productive entrepreneurship in Nigeria. For example, corruption, which Nigerian citizens and the Transparency International perceive as very high can impede smooth access to property rights, or raise the costs of obtaining the individuals' rights (it is common knowledge that Nigeria is not among the best countries in corruption ratings). Therefore, a way forward would be for the policymakers to begin to enforce the laws on property rights firmly. They should also seek and align more with global best practices to reduce the various perceived negative actions and inactions that weaken entrepreneurship-supporting institutions in Nigeria. 
Now on the size of government: theoretically, the argument is that an expanding government would be linked with better conditions for entrepreneurship. For instance, when the government increases her spending, it could create avenues for stronger institutions because it would also fund law-enforcement systems, which protect contracts and engender critical infrastructure that could support entrepreneurship (Aidis and Estrin, 2014). In contrast, contracting government spending could weaken the business community. Nevertheless, the above narratives do not exhaust the relationship between entrepreneurship and the size of government. Firstly, larger government spending may crowd out private investments and entrepreneurship. It happens because this expansion often goes hand-in-hand with the government taking more economic resources of the business community such as business capital and human resources. It is often the entrepreneurs who would be more negatively impacted than the established companies as the entrepreneurs' experience, networks, and contacts might be inadequate.

Secondly, greater spending or activities of government may significantly affect state finances, and so this is linked with a greater welfare system. Given this scenario, there are greater chances that both the opportunity cost and the net financial return to entrepreneurship would be affected negatively. Thus, as Aidis and Estrin (2014) puts it: "the higher cost of capital that results from financial crowding out will also affect entrepreneurs while higher marginal tax rates will weaken the incentives for entrepreneurship by reducing the expected gains."

Although the quality of the institutions for the enforcement of property rights and the size of the state are not necessarily distinct; however, countries have to achieve certain scale to support institutions. Weak protection of property rights tends to discourage individuals from venturing into productive entrepreneurship. Therefore, governments in such circumstances should try to limit expenditures that often are misallocated.

In the following subsection, attention is now shifted to identifying the problems faced by entrepreneurs in Nigeria. An adequate understanding of the nature of these problems might help indicate what areas policymakers and other stakeholders must focus attention on most. Often, newcomers might perceive the existing problems as barriers to entry; these can discourage their entrepreneurship intentions if they perceive these problems as insurmountable. 


\subsection{Problems faced by Nigerian entrepreneurs}

Entrepreneurs in Nigeria face some problems that make the entry into business sometimes more challenging to potential entrepreneurs. Nwachukwu (1990) conducted a survey on what Nigerian entrepreneurs themselves perceived as being the most challenging factors to the development of entrepreneurship in Nigeria. His observation, though little seems to change now, was that the problems ranged from management problem to the lack of technology especially for those in the manufacturing and services sectors. Stiff expatriate and domestic competitions for those in retail and services sectors, financial problems, a high degree of business success uncertainty, the indifference of financial houses, and cultural barriers were the other factors. Emmanuel (2008) added infrastructural constraints, poor implementation of government policies, and entrepreneurs' personal problems. Drawing from the two authors cited above, the researcher now briefly discusses these problems in turn.

The majority of entrepreneurs in manufacturing and services sectors identified management problems and inadequate technology as their principal hindrances. Business success connotes the ability to carry out effectively such managerial functions as planning, organising, directing and controlling. Success, therefore, requires that organisations should anticipate change continuously and to search for new combinations of activities that generate synergistic benefits to withstand aggressive competitors (Nwachukwu, 1990).

In Nigeria, most businesses are relatively small in nature, and there is a scarcity of highly qualified nationals that the small and medium scale entrepreneurs can readily engage. Even if they were available, the demand and supply situation precludes the small entrepreneur from becoming a serious competitor for highly skilled workers. Often, this inability of small entrepreneurs to employ qualified managers for their organisations leads to the stagnation of business. Some who are afraid of continued growth either start depositing their profits in the banks or engage in other small enterprises requiring one or two employees. Often, small entrepreneurs who choose to continue to grow to find out rather late that they have neither the time nor the necessary information and facilities to make wise decisions (Nwachukwu, 1990). Regarding technology, Nwachukwu notes that the situation in Nigeria is worse since most of the equipment and their parts come from overseas, and sometimes it takes a couple of months for an imported equipment or part to arrive, and these disrupt productions. For example, during the period of implementing the structural adjustment programme in 1986-1990, many small businesses that depended on imported equipment were frustrated. The reason was that the policy constrained the access to 
foreign exchanges required for the importation of raw materials and machinery. The import controls led to many businesses closing down (Nwachukwu, 1990).

Still on management of the business, Akeredolu-Ale (1977) earlier confirmed that most indigenous entrepreneurs concentrate managerial responsibilities on themselves with little or no delegation of authority. Management involves technical, financial, commercial, human resource, statistical and other skills and hardly does any one individual become the most competent in all of these functions. An entrepreneur who does business with little or no good external managerial help might face serious problems; this is often the case with most Nigerian indigenous businesspeople.

Nigerian entrepreneurs in the retail trade and services often particularly worry about stiff competition from foreign and sometimes better-established domestic firms. As in most enterprises where capitalisation is relatively low, competition is often very high because of the ease of entry. Many Nigerian entrepreneurs are in enterprises where such entry is relatively easy. Instability and comparative financial weakness characterise these enterprises.

Many of the competitors do not adhere to any acceptable code of business ethics. Their competitive strategy is at best irresponsible and chaotic. There are also local monopsony and oligopsony firms (Nwachukwu, 1990). These are mostly expatriate firms that are typically large, financially strong, well-managed, and very aggressive in their customer drive for patronage. They are often highly integrated, being involved in the production of the raw material, in processing, in wholesale distribution, and are very influential in retail trade. They are the firms with the brightest gadgets and the most modern lure that are likely to capture the public fancy. Their competitive strategy, while ethical and by modern standards sound, is nevertheless challenging to their lessequipped, financially weak, and managerially uninitiated competitors. The reason is that the local firms depend on the former not only for the goods the expatriate firms import but also for some financing and advice.

Again, many Nigerian consumers rate as superior imported goods or goods sold in stores owned by expatriate firms. This factor seems to give a relatively higher advantage to foreign competitors. For example, a product bought by a small indigenous trader as wholesale from an expatriate firm (e.g. Unilever) and retailed to consumers is considered inferior to an identical product bought from the same expatriate firm. An improved image of Nigerian entrepreneurs will perhaps be the solution to the misconception.

The high degree of social and political uncertainty is another factor identified as militating against the rise of enterprise ownership in Nigeria. The case of incessant take-over of government by the 
military over the past four decades was inimical to business development. In Nigeria, from 19601999, there were six military take-overs of government aside failed or foiled coup plots. Military influences on government formation portrayed the Nigerian business environment as unstable in the eyes of the international business community. Therefore, investors preferred to take their businesses to other West African countries such as Ghana; or to other African countries such as South Africa, Kenya, Botswana, Ethiopia and Namibia, which they considered politically lessvolatile.

As a corollary of the above, in Nigeria there have been incessant changes in monetary, credit and fiscal policies. In 1985, for example, the National Economic Emergency Power decree was promulgated. In 1986 and 1987, there was the introduction of the Structural Adjustment Programme (SAP) and the Second-tier Foreign Exchange Market (SFEM) respectively. The Nigerian entrepreneurs are yet to recover from the effects of these measures on their business operations. Many people lost their businesses because of stiff and unfavourable exchange rate regimes (Emmanuel, 2008). In recent times, 2000-2014, the exchange rate system has been changed by the civilian governments from the Second-tier Foreign Exchange Market system to Dutch Action System (DAS) and to Wholesale Dutch Auction System. These changes make the costs of doing business very expensive and excessively unpredictable. Also, the long depreciation of the local currency makes machinery, equipment and other inputs imported by entrepreneurs too expensive.

The inability of the financial houses to respond promptly to the demands of small and medium enterprises is another challenging factor. Lack of adequate funds has acted to restrict in many ways many entrepreneurs in Nigeria. Although the country's stock market is developing fast, most entrepreneurs cannot use the stock exchange to raise the needed capital because of the stringent conditions required. Application for bank loans is also not easier since most small entrepreneurs do not know how to present an adequate loan application. Many do not have strong collateral securities or guarantor for the business, often a requirement of the conventional banks. The consequent poor financial base further precludes many entrepreneurs from hiring qualified staff.

Cultural, sociological, attitudinal influences and barriers are also challenges to the rise of entrepreneurs in Nigeria. Nwachukwu (1990) argued that the attitudes and values prevalent in developing countries are sometimes inconsistent with entrepreneurial development. In a society where, for example, people see profit as a "dirty word", this might discourage some entrepreneurs. 
A related factor is that most Nigerian ethnic groups place too much emphasis on family relationships in business. This stance often gives rise to favouritism, corruption, nepotism, limited initiative, and employment being based on sentiments and not on merit (Nwachukwu, 1990). There are also widespread unethical practices by businesspeople. Furthermore, little or no attention is paid to product quality and design improvement by businesses. As a result, many prefer imported products not minding prices.

Social instability leading to trade union actions and strikes, incessant students' unrest and tribal clashes pose challenges to entrepreneurs not used to the political culture of bargaining. Fuel scarcity and constant traffic congestion in cities such as Lagos, Port Harcourt, Aba, and Onitsha are the other challenges. Ethnic clashes, religious fighting, and human rights infringements also negatively affect the development and growth of entrepreneurship in Nigeria and how the international business community perceives Nigeria's business environment (Nwachukwu, 1990).

To recap: the first part of this chapter undertook a brief historical overview of entrepreneurship development phases and the kind of entrepreneurship activities in Nigeria. It showed the modest advances by indigenous entrepreneurs during the periods under review. It, therefore, alleges that historically indigenous Nigerian people from the various ethnic groups and regions demonstrated some successes in entrepreneurial activities. These were in areas such as, but not limited to, smallscale farming, large-scale farming, fishing, shipping, hotel and hospitality, airlines, oil and gas industry, manufacturing, telecommunication, private educational institutions, banking and finance, professional services, entertainment, and overseas investments. This study, therefore, argues that it is left for the present younger generation to move the boundaries now forward and use businesses to solve today's challenges and harness the opportunities of the $21^{\text {st }}$ century. They include the opportunities to provide new businesses in areas such as clean energy, integrated and upgraded agriculture, ICT, medicine and healthcare, water and sanitation. Others are affordable housing, productive education, biotechnology and bioinformatics, digital manufacturing and infinite computing, nanomaterial and nanotechnology, artificial intelligence and robotics (Diamandis and Kotler, 2012). Nigerian entrepreneurs and indeed African need to also contribute to the " $4^{\text {th }}$ industrial revolution" in creating new ventures in the following specific areas: computation, internet of things (sensors and networks), robotics/drones, artificial intelligence, 3D printing, materials science, virtual/augmented reality, and synthetic biology. 
The second part of this study examined the roles of institutions in shaping how a country's formal and informal rules engender the incentive structures, which different entrepreneurs can then exploit for either productive or unproductive, or even destructive entrepreneurship. The importance of these external contextual factors toward the degree a nation, region or an individual succeeds in her entrepreneurship endeavours cannot be overemphasised and those that fail to fix a greater portion of these factors lag behind. It then alleges that Nigeria with her developing-country status, her entrepreneurship-supporting institutions can be understood more in the light of the policies she implements to tackle the constraints militating against the vigorous enforcement of property rights. The enforcements of these rights at the moment seem fragile due to weak institutions and corruption as portrayed by the GEM (2012) summary, although the present study did not conduct an in-depth assessment of access to these rights.

Overall, the first part is that the enterprise analysis and the entrepreneurial efforts highlighted in this chapter showed only the initiatives carried out by established or experienced entrepreneurs. The key idea drawn from this analysis is that the perceptions of these practising entrepreneurs in Nigeria concerning the external environment they operate in are still very much challenging, fragile and weak. It would be useful to examine how the undergraduates also perceive the Nigerian external environment and the support factors toward entrepreneurship activities available. Their perceptions could influence whether more (or less) undergraduates would take to entrepreneurship activities in the immediate future. For this reason, the next chapter focuses on examining the role of entrepreneurship education, which in a way is a part of the external environment, in fostering the quality of future entrepreneurs that universities or higher education institutions produce. 


\section{CHAPTER THREE}

\section{THE CONTEXT OF ENTREPRENEURSHIP EDUCATION}

\subsection{Introduction}

In the last chapter, the study undertook a brief overview of entrepreneurship development efforts in Nigeria to bring a fair understanding of the entrepreneurship efforts undertaken in Nigeria highlighting certain characteristics of the different eras chosen. It also examined the role of institutions in influencing the "rules of the game." It next examined the challenges faced by the Nigerian entrepreneurs as well as the reasons the researcher selected the respondents of this study from the two regions investigated.

The aim of this chapter is, therefore, to examine the literature on entrepreneurship education (EE) and distil some lessons from the global perspectives on the subject which can enrich the experiences of the Nigerian context of EE. It is not an attempt at a complete analysis of the entire global frameworks and approaches on EE; it mainly indicates the dimensions in which the global practices might be different from what obtains in the Nigerian EE context. The analysis would, thus, help pinpoint global knowledge and practice in EE and any possible gaps in Nigeria's context. In part, the analysis attempts to resolve the first research objective about the context of entrepreneurship education. It argues for how the appropriate entrepreneurship education in the universities studied holds part of the missing puzzles in encouraging students toward entrepreneurship. Undoubtedly, there is an increasing belief that getting more entrepreneurship (and in turn more entrepreneurs), whether those whose main goals are monetary or nonmonetary, could more likely help create more jobs in a region or country. How best the stakeholders can achieve this goal of producing more entrepreneurs is often the bigger challenge.

However, the Global Entrepreneurship Monitor (GEM) cites three major bottlenecks to entrepreneurship. They are social and cultural barriers, lack of capital, and lack of entrepreneurship education (Rideout and Gray, 2013; Reynolds et al., 2002). However, the barriers to entrepreneurship also include the degree of institutional factors, government policies and programmes, R \& D transfers, commercial infrastructure, internal market openness, physical infrastructure, legal rights and enforcements, and phase of economic development (Amorós and Bosma, 2014). Thus, countries need to approach the entrepreneurship challenges holistically. 
Amorós and Bosma (2014, p.44) corroborate with GEM studies by noting that "first is the recognition that entrepreneurial activity is shaped by a distinct set of factors (referred to as Entrepreneurial Framework Conditions, EFCs). Such factors include training in entrepreneurship and the availability of start-up financing." The present study argues that focusing research works on identifying the dimensions of these barriers that regions face and the stakeholders concentrating efforts at reducing or eradicating them holds the silver board for realising the muchtouted advantages of entrepreneurship.

Specifically on start-up financing or acquiring capital: the better route is to find a financing model that makes other useful resources available, example through leasing, for potential entrepreneurs and not necessarily only cash. These resources might be equipment, raw materials, office space, competent human capital (e.g. mentors) and helps in gaining market access. Improvements in providing and maintaining of physical and commercial infrastructures are also essential. These additional measures too aside cash would lead to or enhance the exploiting of entrepreneurial opportunities by potential entrepreneurs (Bridge et al., 2009).

This chapter examines some barriers to entrepreneurship education and explains how they (globally) could hinder entrepreneurship efforts. It reflects and draws on global perspectives and uses the understanding to beam the light on how Nigeria tackles these barriers to entrepreneurship education. The research argues that getting it right in entrepreneurship education could have positive round-robin effects on the participants' perception of the other barriers and how to surmount them. The reason is that having the "right" entrepreneurship education could more likely positively influence the knowledge of where or how to source for funds for entrepreneurial activities. Specifically, the right knowledge could contribute to the knowhow of where best potential entrepreneurs can get information and access to sources of financing: equities, debts, government funding, business angels, and IPOs. Relevant financial know-how obtained from the appropriate entrepreneurship education can expose potential entrepreneurs to the right mix of these sources too. Lastly, the appropriate entrepreneurship education could also engender a positive influence in preparing individuals to overcome many of the social and cultural barriers to entrepreneurship encountered within a community (Bridge et al., 2009).

\subsection{Higher Education Institutions (HEIs) and Entrepreneurship Education (EE)}

This subsection examines the role of HEls in fostering entrepreneurship among undergraduates. The analysis is to bring some useful perspectives on the nature of entrepreneurship education that higher education institutions (specifically universities) offer. It then examines the nature of 
entrepreneurship course contents, the pedagogies that universities follow; it moves on to examine who teaches entrepreneurship and in what context. Lastly, it examines what the goal of entrepreneurship education should entail. The analysis would offer a wider view for understanding what factors influence entrepreneurship education and the way forward for the universities studied in the present research.

\subsubsection{The influence of "right" university-based entrepreneurship education in producing more entrepreneurs}

The aim of this subsection is to shed some light on some key barriers to appropriate entrepreneurship education. Then, it uses the results of the analysis as a springboard to proffer a way forward for a vibrant EE for Nigerian universities and policymakers. The nature of EE taught in universities could influence the desired entrepreneurship objectives or outcomes, namely: new venture creation, increased total entrepreneurial activity (TEA) ${ }^{4}$, and growth ventures ${ }^{5}$ (Westhead, Wright and Mcelwee, 2011). This study adopts the definition of entrepreneurship education as, "that education which assists students to develop positive attitudes, innovation and skills for selfreliance rather than depending on the government for employment" (Olorundare and Kayode, 2014, p.160). It should engender a change of the students' orientation and attitude and equip them with the skills and knowledge to help them start and manage a business. It is "a dynamic and social process where individuals, alone or in collaboration, identify opportunities for innovation and act upon these by transferring ideas into practical and targeted activities, whether social, cultural, or economic context" (Onu, 2013, p.41). It attempts to offer students the useful knowledge, skills, and motivation to encourage entrepreneurship success in various settings. Its immediate goal is to develop personal qualities, attitude and formal knowledge and competencies through contents and training (William, 2011).

In a recent meta-analysis study by Rideout and Gray (2013, p.348), they examined 12 empirical studies and evaluated the research methodologies used in those studies. As a part of their

\footnotetext{
4 TEA uses an index that shows for every county the percentage of the adult population who have taken some action toward creating a new business in the past year or who are the owner/managers of an active business less than 42 months old (Bridge et al., 2009). The value comprises of two measures: 1. the nascent start-up rate (those in the process of creating a business). 2 . The new firm rate (those actually running earlystage businesses).

${ }^{5}$ Growth-ventures are small or medium ventures designed for the goal of realising high growth and rapid profit increases. Often, to achieve profit and growth goals, these businesses develop products/services and promotion strategies with a pool of investors providing working capital (Westhead, Wright and Mcelwee, 2011).
} 
conclusions, they redirected future researchers to focus more on answering the "real question." They put the central question as: "what type of entrepreneurship education, delivered by who, within which type of university, is most effective for this type of student, with this kind of goal, and under these sets of circumstances?." Although this question is complex, and there is no readily available single research work aimed at addressing all these issues holistically. However, this subsection attempts to find pieces of research works that addressed bits of this question. In doing this, it, therefore, hopes to offer a guide to resolving the question and proffer solutions to some of the barriers to appropriate entrepreneurship education.

On the education modalities, the traditional practice of entrepreneurship education pedagogy has been principally driven by "business plans and general educational principles about what approaches should work for entrepreneurship education" (Rideout and Gray, 2013, p.332). However, at the universities' level, two overall pedagogical approaches seem to be in use: a small business management model and an entrepreneurial venture education approach. The two approaches differ. The former model attempts to imbibe students with the "know-how" in management. This management know-how includes goal/objective setting skills, leadership skills, planning, organising, and controlling skills, which are tailored to small businesses (Winslow, Solomon and Tarabishy, 1999). The latter model, however, is based more on action-oriented mindset but is also geared toward developing a business plan.

Globally and historically, universities use different types of curriculum and teaching and learning methods in the various types of entrepreneurship education (EE) courses they offer. Research advocates that in developing ideal pedagogical components for EE programmes, institutions should include the following: a focus on attributes, skills and tasks, an aspect of concrete experience gained from participating in live projects, directing contents to particular stage of venture development, and promoting functional integration (Solomon, Duffy and Tarabishy, 2002). Also, in $\mathrm{EE}$, courses such as small business management, small business consulting, and new venture creation have become prominent too. However, the trend started shifting toward more integration of practical applications, namely: internships, special projects, simulations, live cases, capstone courses ${ }^{6}$, and consulting (Solomon, Duffy and Tarabishy, 2002).

\footnotetext{
${ }^{6}$ A capstone course is a course "designed to provide opportunities for students to integrate knowledge from their core and concentration courses, to gain insight into the meanings of professionalism and professional practice, and to reflect on the norms of a discipline or profession"

Available at: https://wiki.umn.edu/pub/CHANCE/.../SyllabusSpring09Addendum.doc (Accessed: 28 May 2015).
} 
Some scholars, however, believe that the trend also moved toward the applied aspects, as opposed to the "ivory tower" notion: some studies still indicated that lectures and case studies are also prominent (Rideout and Gray, 2013). As in the past, entrepreneurship education curriculum still typically includes opportunity identification, finance, business planning, marketing, managing growth (Neck and Greene, 2011).

Also, some authors distinguished high-growth and high-tech entrepreneurship ventures from the ordinary small businesses. Therefore, some scholars advocate distinct course contents for teaching technology entrepreneurship (Ohland et al., 2004; Kingon et al., 2002). They propose some special curricular aspects such as "technology idea generation, new business model identification, intellectual property, team-building, prototyping, networking and strategic partnerships, and venture/angel capitalisation (Rideout and Gray, 2013, p.332). Realising that technology entrepreneurship is peculiar; some universities' entrepreneurship education programmes try to offer new entrepreneurs with socio-political strategies. These strategies include facilitating network access and team-building competencies including leadership, elevator pitch skills and public speaking, and prototyping. All these efforts are geared toward catering to the peculiar needs of technology-entrepreneurial activities.

Therefore, the global entrepreneurship education pedagogy is diverse and diverse. Although some programmes use the relatively traditional small business management style, others use a more recent high-growth venture creation approach. Still, others embrace the traditional lecture and case study approaches. There is also an emerging view to encouraging technology entrepreneurship. Again, some universities pursue different contents and focus of pedagogy ${ }^{7}$. In addition, andragogy ${ }^{8}$ and experiential learning via games, simulation, prototyping, fundraising, mentoring, intellectual property/patents, or even real venture creation, may foster learning outcomes (Neck and Greene, 2011). Thus, there is a need for HEls to view entrepreneurship as a critical goal in the educational system and add this objective to the instruction strategy if they must do things differently to achieve better results.

The next subsection attempts to examine and answer Rideout and Gray's (2013) elements of the central question of entrepreneurship education.

\footnotetext{
7 Pedagogy is the practice and method of teaching and study, and the research of it (Mathieson, 2015).

${ }^{8}$ Andragogy: Initially defined as, "the art and science of helping adults learn, "andragogy has come to be understood as an alternative to pedagogy; a learner-focused approach for people of all ages. Available at: https://web.njit.edu/ ronkowit/teaching/andragogy.htm (Accessed: 28 May 2015).
} 


\section{a) What type of entrepreneurship education?: The course content}

The type of entrepreneurship education (EE) useful for increasing a person's ability to perform entrepreneurship activities would be one that imparts essential knowledge, skills and attitudes related to entrepreneurship competencies (Hoffmann and Vestergaard, 2012). Here, competency is defined as "underlying characteristics of an individual that result in effective or superior performance or both in a job" (Bird, 2002, p.203). Hoffmann and Vestergaard (2012) propose that this knowledge should include the following: ability to discover available opportunities for personal, professional or business activities or both, ability to know the contexts in which people live and work, for example, a wider knowledge of the workings of the economy including the opportunities and challenges that an employer or organisation faces. Also, there must be knowledge of ethical obligations in which an organisation should operate and how they can contribute to the "larger good", for example through fair trade or social enterprise.

The essential skills include project management, effective representation and negotiation, team spirit as well as working as an individual effectively, ability to judge and identify one's strengths and weaknesses. Thus, one must be able to use others to leverage one's weak areas. Also, one must have the ability to assess and take risks appropriately. In particular, project management skills would include the ability to plan effectively, organise, manage, lead and delegate, analyse, communicate with clarity, debrief, evaluate, record and follow up promptly (Hoffmann and Vestergaard, 2012).

Conversely, entrepreneurial attitudes are characterised by initiative, pro-activity, independence and innovativeness in personal, social, and work lives. It includes the drive and determination to meet set objectives, whether in personal goals or goals agreed with others as well as at work. All these are essential ingredients to contribute to the quality of students undertaking entrepreneurship education.

Because entrepreneurship as a course or academic discipline is relatively newer, scholars are yet to agree on a unanimous "programme offerings" or pedagogy (Solomon, 2008, p.100). Therefore, the course content is evolving but is pitched in what research shows are needed, and that which universities can teach for successful venture development (Block and Stumpf, 1992). Earlier in the introductory section of this chapter, it was mentioned that the "old way" of programme content in entrepreneurship was essentially on "business plan." Ronstadt (1990), however, adds that it also involved the exposure to experienced visitors who inspired students through stories and personal advice. The focus here was that the entrepreneurial process was dependent most essentially on 
the "right human traits" and characteristics of the "entrepreneurial personality." Now, attention is shifting and even though still action-oriented, it "builds and relies on some level of personal, technical or industry experience" (Solomon, 2008, p.100). The "new school" incorporates and requires critical thinking (dispassionate evaluation and judgement) and ethical assessment. It believes that to be successful in any entrepreneurship activities; it is not only the human factor an entrepreneur must concentrate on but also venture and environmental conditions. Furthermore, it focuses on entrepreneurship "as a career process composed of multiple new ventures and the essential skills of networking or entrepreneurial know-who" (Solomon, 2008, p.100).

Other researchers (e.g. McMullan, Long and Wilson, 1985) had earlier called for courses to be structured around a series of strategic development challenges, which include: identification of opportunities and analysis of feasibilities, new venture planning, financing and operating, new market development and expansion strategies, and institutionalising innovation. Vesper and McMullen (1988, p.10) state that "real-time entrepreneurial activities include projecting new technological developments, strategic planning, assisting and attracting necessary resources, and arranging for joint ventures." According to Solomon (2008), ideally students should create multiple business plans, practise identification of opportunities, and get extensive exposure to entrepreneurship role models. The prescribed ways in which this interaction with role models can occur comprises having entrepreneurs serve as coaches and mentors (Mitchell and Chesteen, 1995), classroom speakers (Hills, 1988), and interview subjects (Truell, Webster and Davidson, 1988). Thus to allow for an effective entrepreneurial education, students need a sizeable hands-on experience; they need to work with local firms so they can learn to add value to real ventures. This opportunity can help them with some experience to draw upon for their enterprise when they eventually start one (McMullen and Long, 1987).

Also on content, one of the major challenges is for entrepreneurship educators to be able to deliver course contents that can better assist the undergraduates to generate multiple business ideas from their courses of study (Abereijo, 2015). Through this means, undergraduates could increase their chances of identifying multiple opportunities and analyse venture feasibilities as suggested by Solomon (2008). Abereijo $(2013,2015)$ proposes how HEls can better tailor the course contents in teaching and learning in any discipline toward generating multiple venture ideas. His guideline is by no means exhaustive of the other routes HEls can take to generate multiple entrepreneurial ideas, but it can serve as a guideline to build on by individual academics. One of the advantages of this tutor's guideline is that the framework was developed from the Nigerian context rather than picking a learning framework from the USA or advanced Europe. The approach was developed in the context of a premier university in Nigeria (Obafemi Awolowo 
University, Ile-Ife). The present research also drew from this tutor's guideline because it already exists in the entrepreneurial education work in the Nigerian university and illustrates the framework below:

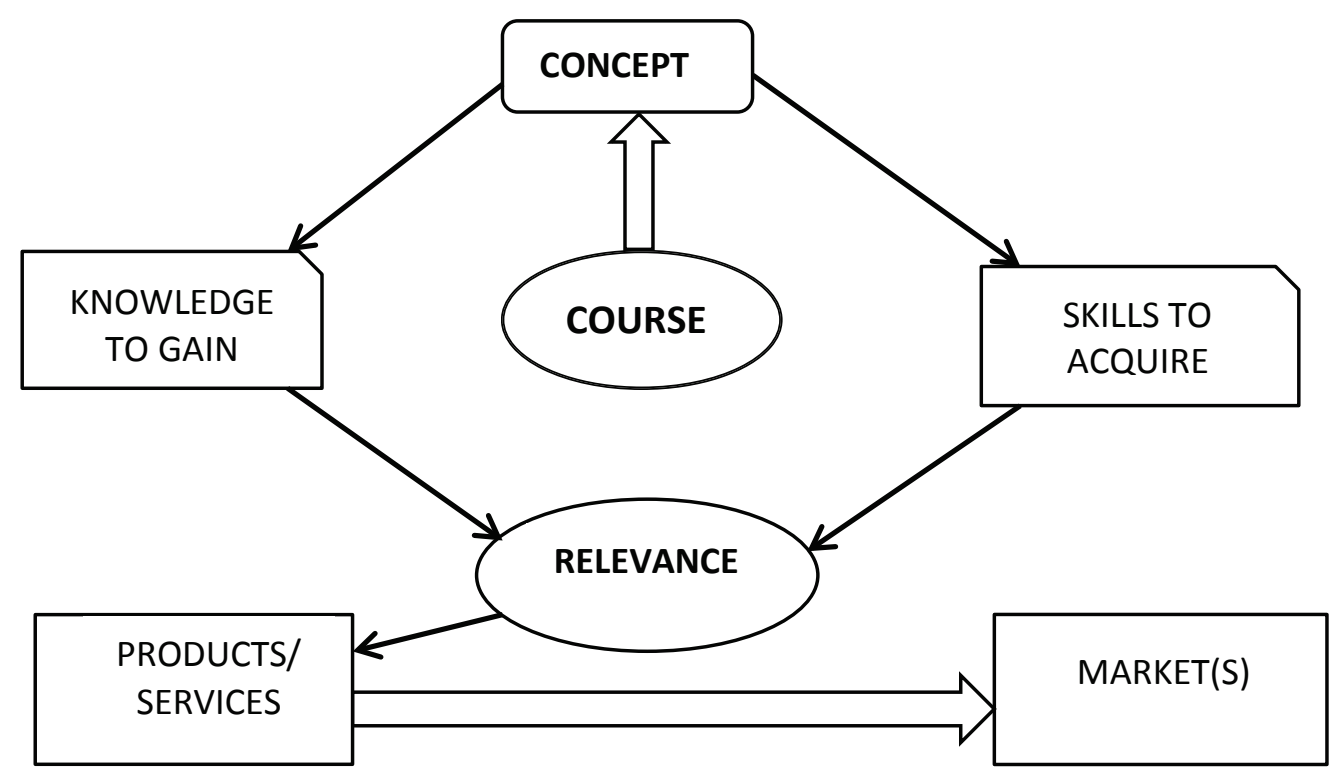

Figure 3.1: Framework for creating business ideas from core courses Source: Abereijo (2015, p.35)

Figure 3.1 is the Abereijo (2015) framework that provides the links between the course concept and the knowledge level the course provides and the skills to acquire, which should be relevant to solving the societies' needs. It meets the needs by offering the routes through which the skills gained provide the encouragement for creating products and services for the different markets. Specifically, the framework offers the "guidelines for teaching that will help students to understand concepts, appreciate the relevance of the knowledge gained to the needs of the society, understand how the knowledge can add value, and generate need-based business ideas" (p.34).

In what follows, this study demonstrates an example of the adapted version of Abereijo's (2013, 2015) approach as a guideline for enhancing how lecturers can teach courses (modules) effectively to generate entrepreneurial or business ideas:

\section{i) Hands-on activities on generating business ideas}

Firstly, some of the under-listed tasks are what lecturers would normally do in teaching any course, example items one to four. However, item five requires that, consistently, the lecturer 
would identify the challenges, gaps or needs in the society in which the knowledge and skills students intend to acquire from the topic or core course can solve. She would then enumerate the products or services students can produce (based on the knowledge and skills) to solve the needs. She would next identify the prospective markets for the proposed products or services. With this approach, students would be more likely able to envision how applicable the seemingly theoretical topics they learned can be amenable to solving practical needs in their society. The procedures for these hands-on activities begin as follows:

- Lecturer decides on a topic of interest and teaches the students

- Lecturer identifies main concepts from the chosen topic

- Lecturer lists key knowledge that students can gain from the topic

- Lecturer lists the skills that students can acquire through the topic if any

- Lecturer Identifies the problem, gap or needs in the society that knowledge/skill acquired can address

- Lecturer lists products/services that one can produce or render from the knowledge/skill from the topic to address the needs

- Lecturer lists the prospective markets for the products/services

ii) Screening business ideas

Secondly, the lecturer moves on to screen the ideas. The overall purpose would be to ascertain whether the business idea generated is an opportunity (i.e. has commercial value). The lecturer would then guide on how to use the basic business tools of S.W.O. T, PEST or PESTLE analysis, whichever combinations are most applicable, to screen the business ideas. These tools give better pictures of what would be possible or not in any available circumstances. The lecturer can then subject each idea to the following tests and evaluations:

- Capabilities required to produce the product or render service

- Locational requirements - whether one can establish the business anywhere

- Legal requirements - whether there are special requirements for setting up and running the business

The location of the product or service within the market that is, whether it is an:

- Existing product/service in an existing market, or

- Existing product/service in a new market, or

- New product/service in an existing market, or

- New product/service in a new market

The availability of the following resources:

- Main raw material (locally or imported)

- Personnel (specialised or non-specialised)

- Technology (locally or imported) 
- Spare parts (locally or imported)

- Maintenance (locally or imported)

- Sources of technical/institutional supports

Abereijo $(2013,2015)$ went a step further to show an example of how the proposed model (guideline) can work in a given course or module. His example is in the industrial research and development subject area, specifically on "Industrial Extension and Management Consulting." However, any subject area can also apply the same principles to generate and screen multiple business ideas in their courses. It begins with picking any course title of interest, then being able to identify the key concepts of the course and pinpoint the relevant knowledge and skills (from teaching and learning the course) which would be useful for solving specific societal needs or challenges. The example is as follows:

\section{Selected course title:}

\section{- Industrial Extension and Management Consulting}

Identified main concepts of the course:

- SMEs development

- SMEs growth and challenges

- Concept of business development services (BDS)

- Business counselling

- Concept of change

Identified relevance:

Acquisition of relevant knowledge and skills (mentoring and counselling) to assist potential and existing SME owners improve the performance of their businesses.

Knowledge and skills students acquired will be needed to bring about:

- Changes in what SME owners know

- Changes in what SME owners can do

- Change in what SME owners think and feel

- Changes in what SME owners do

Problem(s) that the knowledge of and skill from this course can address in the society:

- Unemployment

- Inadequate supply of relevant business information

- Business failure and attendant problems

Values that the knowledge of this course can add:

- Business survival, growth and expansion

Product(s)/Service(s) that students can develop from the course: 
- Business Development services (BDS), such as:

- Coaching, mentoring and counselling,

- Consultancy and training

- Provision of relevant business information

- Business advisory services: technology, export, etc

- Linkages with assistance institutions

- Technology-based BDS:

- Web-based advisory and information services

- Creating business social network

Prospective market:

- Existing and potential entrepreneurs

- Non-governmental agencies involved in SMEs development

- Agencies of government responsible for the SMEs development

- Agencies of multilateral institutions responsible for SMEs development

Abereijo's $(2013,2015)$ proposal attempted to show that it is feasible for lecturers to refocus the course contents so that the contents can become more useful in guiding students see how their learning applies to solving practical problems. Presently, the researcher is unsure how many Nigerian university entrepreneurship development centres follow the above-suggested enterprise programme or similar procedure. What is sure is that University of Calabar, Nigeria, for example, where the researcher taught entrepreneurship development, does not follow this approach. However, it might never be possible to subject all classroom learnings to solving real world problems, although this would be the ideal that all learning should lend itself to application and not to learn for learning's sake (Mathieson, 2015). Some teaching and learning are and would remain at the level of theory and help lay the structures for training the mental faculties of the students to think in wider perspectives. It is the judgement of the experienced lecturers to determine which topics would lend toward practical applications.

ii)

What type of entrepreneurship education: The pedagogy

Aside the challenge of having the "appropriate" course contents, the other challenge of what type of entrepreneurship education that would be beneficial for effective learning is how to design the learning opportunities for undergraduate entrepreneurship. On this, Solomon (2008) suggests that entrepreneurship programmes should emphasise individual activities over groups'. Sexton and Upton (1984) note that programmes should also be comparatively less-structured, and bring problems requiring innovative solutions under circumstances often characterised by ambiguity and risk. The usefulness of this suggested approach is to make students have a feeling of the 
uncertainties often experienced by entrepreneurs in the real business environment (Ronstadt, 1990). Offering undergraduates the chances of "experiencing" entrepreneurship and small business management is a theme of different entrepreneurship education programmes.

Researchers note that the commonest elements in entrepreneurship courses are still business plan writing, case studies, and readings and lectures by guest speakers and faculty (Kent, 1990; Gartner and Vesper, 1994). However, for the typical small business management courses, the most common elements include classroom works, tests and a major project-often a consulting project (Carroll, 1993). Solomon (2008, p.101) aptly captures the underlying structure and activities that HEls often implement in entrepreneurship pedagogy when he said:

Project-based, experiential learning is widespread in entrepreneurial education and takes many forms, such as the development of business plans (Hills, 1988; Vesper and McMullen, 1988; Gartner and Vesper, 1994; Gorman, Hanlon and King, 1997); student business start-ups (Hills, 1988; Truell, Webster and Davidson, 1998); consultation with practicing entrepreneurs (Klatt, 1988; Solomon, Weaver and Fernald, 1994); computer simulations (Brawer, 1997); and behavioural simulations (Stumpf, Dunbar and Mullen, 1991). Other popular activities include interviews with entrepreneurs (Solomon, Weaver and Fernald, 1994); environmental scans (Solomon, Weaver and Fernald, 1994); "live" cases (Gartner and Vesper, 1994); and field trips and the use of video and films (Klatt, 1988). Student entrepreneurship clubs are also widespread (Gartner and Vesper, 1994).

Thus, a university can employ a combination of these teaching activities, depending on her peculiarities, needs and infrastructure. However, focusing intensely on strategy formation and implementation, being flexible and open to feedback and in the proper application of technology to one's advantage are what should be the guide. The pedagogy that an institution selects should be adequately challenging and meet the "creative mindset" or needs of the students.

iii) Entrepreneurship education by whom, within which type of university is most effective for what type of student?

Entrepreneurial pedagogy is changing and moving out of business schools and business faculties to other students (undergraduates and post-graduates) in the universities. It is no longer the exclusive preserve of those in the business schools to "own" the teaching and learning of entrepreneurship. New interdisciplinary programmes now use faculty teams to develop programmes for non-business undergraduates (e.g. for science, arts, engineering, and medicine/allied students). 
Research cautions that HEls should not implement entrepreneurial teaching and learning like any other "taught" courses; it needs to be facilitated (Luczkiw, 2008). Luczkiw notes that for individuals who aspire to discover their potential areas of contribution to the economy and society, they need first to learn about both entrepreneurship and themselves. This first step to discovery needs a facilitator who knows the person and environment within which they interact. This facilitation needs someone who understands how people learn-not a sage on a stage, but a guide on the side. It means the facilitator knows how to engage each learner's distinct talents to connect their creativity with opportunities in the community or locality.

The second step in the delivery (by the facilitator) deals with learning for enterprise (Luczkiw, 2008). It requires a skilled facilitator who demonstrates pedagogical capability together with an able practice of entrepreneurship. It requires that specifically-selected models of enterprise initiated within the locality serve as examples for students to learn from and imitate.

The third step in the facilitation is learning through enterprise (Luczkiw, 2008). This step is the practice of entrepreneurship itself. It needs to be a local environment-based model. This model incorporates the business practices of the community or local environment along with the theory of entrepreneurship, small business management and growth practices.

Consequently, learning about, learning for and learning through enterprise requires a comingtogether of partners, each sharing their distinct expertise to venture start-up and growing firms in their respective local environments. Thus, indigenous undergraduate students can learn entrepreneurship better working in collaboration with entrepreneurs and mentors from their local environment and develop or integrate into the wider business community. So, universities need to decide which approach is best for her.

In an attempt to delineate the approaches to entrepreneurship education in which universities pursue, Hoffmann et al. (2008) distinguish between two approaches. The first approach is the focused entrepreneurship education and the second is the unified approach (also called the university-wide approach). However, this framework was originally developed by Streeter, Jacquett Jr. and Hovis (2002).

In the focused entrepreneurship education approach, universities "delegate" entrepreneurship pursuit exclusively to the business school. Teachers (faculties), students and other staff of the business school all work to satisfy the entrepreneurship education needs of the institution. Harvard University adopts this approach. Her Harvard Business School (HBS) exclusively controls 
the entrepreneurship education of the university for the business school students. In her MBA course, for example, other students in the university may also apply but only a very limited number gets admitted.

In the unified entrepreneurship education approach, there is an opening up for all students outside the business school. In the United States, for example, more universities are embracing the university-wide EE approach. Streeter et al. (2002) examined 38 ranked entrepreneurship programmes in the U.S.; they found that about 75 percent offered university-wide entrepreneurship programmes. Within this unified approach, two different models also exist the magnet and the radiant.

In the magnet model, universities draw students from a broad range of majors. Then, a single academic entity manages and offers the entrepreneurship course and every student of the university attends the course and its activities. The university puts all her resources and skills in that single entity, which then helps facilitate the co-ordination and planning of the entrepreneurship activities. The MIT adopts this approach. Her Sloan School of Management then manages the entrepreneurship programmes.

In the radiant model, each institute, college, school or faculty facilitates the integration and visibility of her entrepreneurship activities. They can then adjust the entrepreneurship activities to the specific structure of their institute, college, school or faculty. The Cornell University, for example, applies this model; they teach EE in the nine schools and colleges (Hoffmann et al., 2008). So, different universities seem to follow the slightly different model for her entrepreneurship programmes.

In Nigeria, for example at the University of Calabar and this goes for many other universities, the universities practise the magnet model of the university-wide approach to entrepreneurship education. Most Nigerian universities have special entrepreneurship centres. Here, a single entity (the Centre for Entrepreneurship Development) facilitates entrepreneurship classes offered to students from all departments. This approach requires relatively the least resource-intensive need to offer a wide range of entrepreneurship classes to all students. However, to develop entrepreneurship competencies specific to the students' degree or specialisation, the radiant model is advantageous in having specialised entrepreneurship faculties (teachers) in the department (Solomon, 2008). Some universities, however, also man entrepreneurship courses specific to their departmental needs. 
Hoffmann et al. (2008, P.160) note that universities could choose to combine "the two modelsthat is, have a centralised administration to manage university-industry ties and to facilitate one or more core entrepreneurship classes, which could be required for all students at the university." Then, each department could offer electives within some specific entrepreneurship subject areas in their subject discipline. Therefore, universities should only adopt models that align with the characteristics and needs of students to help students gain useful entrepreneurial knowledge, skills and attitudes.

iv) What should be the overall goal of entrepreneurship education (EE)?

In general, business schools domicile EE programmes in most universities, and there is a lack of consensus on the exact contents of entrepreneurship curriculum and pedagogies. Because today's business world changes rapidly, business programmes offered in the business schools must be strongly relevant to the needs of the dynamic business environment. However, Solomon (2008) observes that the traditional business programmes seem inadequate in meeting this goal and, therefore, have been criticised. The criticism is that it is often too functional-oriented; thus, neglecting the "cross-functional" complex nature of business problems. It sometimes also kills the creativity and own-thinking that students at both undergraduates and post-graduate levels sometimes wished to acquire or exude (Solomon, 2008). These over-structured aspects of many business school courses-that sometimes fail to present problems that need novel solutions are the other criticisms (Sexton and Upton, 1984).

Solomon (2008) observes that entrepreneurship courses seem to be falling into this trap too. Also, Bird (2002, p.210) describes many core entrepreneurship courses like those that:

Require students to write and present a business plan, and often students (in teams limited to classmates who may not be rationally chosen as partners) choose the business concepts to pursue....Problems are presented and time frames for solving them given. There is often the illusion or reality of right answers.

Another criticism common in entrepreneurship classroom is the "too much theory classes"; that is, "either management theory, adjusted to advise entrepreneurship and small business or entrepreneurship theory explaining the emergence of entrepreneurs and their personal traits" (Solomon, 2008, p.103). This objection is because entrepreneurship educators make entrepreneurship programmes sound like educating "about" entrepreneurship instead of educating "for" entrepreneurship. Solomon (2008), therefore, believes that EE should strongly mirror reality in most of its contents. 
For Garavan and O'Cinneide (1994), the methods best suited to an entrepreneurial learning style are active-applied and active-experimentation including concrete experience, reflective observation and abstract conceptualisation. In lending a voice to what style of entrepreneurial learning university should provide Plaschka and Welsch (1990, p.62) state that:

Educational programmes and systems should be geared toward creativity, multidisciplinary and process-oriented approaches and theory-based practical applications. What are needed are a more proactive, problem-solving and flexible approach rather than the rigid, passive-reactive concept and theory-emphasised functional approach.

Thus, although the theoretical foundations are very relevant in providing the students with the logical structures and superstructure, entrepreneurship educators must strongly balance entrepreneurship theory with practice. For this reason, entrepreneurship educators must explore constantly ways in which what they teach in theory can be used in real-life circumstances. They can tie practical-application, principally, to the core of their curriculum and pedagogies.

\subsection{The "individual" motivating factors to starting one's businesses}

This subsection examines briefly the individual (or personal) motivating factors to business startups as opposed to the contextual factors (the researcher examined the former in Chapter Two). It assesses the literature on what specific motivational factors more likely influence individuals (toward entrepreneurship) and use the results to assess the Nigerian student context. This assessment would help answer in part the fourth research objective on "the factors that influence entrepreneurial intentions among indigenous undergraduate students of the South-south and Southeast regions of Nigeria."

In a recent study, Stephan et al. $(2015$, p.11) differentiated between individual drivers of entrepreneurial motivation and "contextual" drivers. Individual drivers are "factors related to the entrepreneur and his/her business, whilst contextual drivers refer to regional and national characteristics including macroeconomic variables (GDP), formal institutions (such as welfare systems and property rights), and informal institutions/national culture." Thus, assessing the individual drivers, as opposed to regional or national characteristics, becomes important here especially in the context of students' sample whose majority are yet to experience how the national characteristics affect actual businesses (i.e. students are only potential entrepreneurs presently). 
The motivations to start businesses differ vastly across the globe and individuals. For example, the GEM framework contrasts between the traditional necessity-driven motives and opportunitydriven motives (Amorós and Bosma, 2014). Under the necessity-driven motives, rather than going into entrepreneurship as a result of seeing it as an opportunity, people engage in start-ups because the individuals are unable to find better options for work. Under the opportunity-driven motives, however, individuals start businesses as a result of seeing business as offering the opportunities for meeting needs and personal objectives (rather than no other options for work). The GEM study went further to assess the nature of this opportunity. They found that some individuals are "improvement-driven opportunity (IDO) entrepreneurs." The study defined IDO entrepreneurs "as those opportunity-driven entrepreneurs who sought to either earn more money or be more independent, as opposed to maintaining income" (Amorós and Bosma, 2014, p.32).

For example, GEM study showed that entrepreneurs in factor-driven economies (e.g. developing economies) tend to have more entrepreneurs by necessity. However, necessity-driven entrepreneurship further declines as the economy develops more while improvement-driven opportunity motives rise. Also, economic conditions can influence necessity motives. For example, individuals in early development stage economies may found businesses because there are inadequate job supplies and low levels of social security privileges, and the residents are pushed into creating income sources. As economies develop the supply of jobs rises, so fewer people are pushed into entrepreneurship. For instance, the GEM study showed that in 2013 many developing economies showed more than 40 percent of their early-stage entrepreneurs driven by necessity. This was the case of Jamaica, Malawi, Philippines, Poland, Slovakia and Bosnia and Herzegovina, while for Scandinavian economies like Norway and Sweden, or Luxembourg and Switzerland less than 10 percent are motivated by necessity (Amorós and Bosma, 2014).

Earlier, Gilad and Levine (1986) differentiated two major motivations for entrepreneurship as push and pull factors. The pull motivational factor describes people "drawn" to entrepreneurship. The push theory describes when people are "drawn away from something toward entrepreneurship" (Vanevenhoven, 2013, p.466). This form of drawing relates to the necessity-based entrepreneurship as espoused by Stephan et al. (2015) and Reynold et al. (2002) in their earlier Global Entrepreneurship Monitor (GEM) methodology. They described the causes of push entrepreneurship as those occurring where there are relatively limited choices that people face such as in many of the poor-populated countries. Thus, the push factor mirrors the necessitydriven entrepreneurs while the pull factor mirrors the opportunity-driven entrepreneurs. 
Hence, in the present study the researcher would expect that Nigeria being a developing country, many potential entrepreneurs would more likely be motivated by necessity and would engage more in the micro and small enterprises. This is because the opportunities to get employed after graduation are becoming dimmer. However, some undergraduates might still be motivated toward entrepreneurship purely to fill some observed needs or exploit opportunities, earn more money, or prefer to be independent.

Stephan et al. (2015, p.91) moved the debate further from what they termed "the simplistic opportunity and necessity motives analyses." They focused, rather, on the questions about whether necessity-driven businesses tend to survive and succeed. The usual assumption is that necessity-driven businesses will be less successful than those started to exploit an opportunity. Researchers still dispute this position although it might still be true that sometimes necessitydriven businesses tend to lead to low or no-growth businesses. However, it can be argued that individuals (and by inference circumstances) that began as necessity-driven entrepreneurs can give rise to improvement-driven entrepreneurship at a later development stage of the economy when it creates more opportunities. Thus, the initial necessity-entrepreneurship can birth improvements during the processes of the initial business creations that then birth more opportunities-taking entrepreneurs (Stephan et al., 2015).

Some studies have argued that the association of necessity entrepreneurship with low success and entrepreneurship skills might be an oversimplification of the wider contexts. They argue that during recessions and high unemployment contexts, for example, necessity entrepreneurs are more probably going to have collectively higher average levels of skill (Stephan et al., 2015). Others with lower entrepreneurial skills may also start businesses not necessarily out of "necessity", but also "those that are otherwise able but are discriminated against in the workplace such as minority entrepreneurs and female entrepreneurs" (Levie and Hart, 2013, p.101). Also, Block and Sandner (2009) found in their longitudinal study of German entrepreneurs that opportunity and necessity-motivated entrepreneurs stay equally long in self-employment. They showed, however, that after controlling for selection effects, this can be the case. Their argument suggests that opportunity-driven entrepreneurs survive longer as entrepreneurs, not necessarily because of the opportunity in itself but because they start with better human and financial capital compared to necessity entrepreneurs. Again, other, studies show that both skill and motivation may change over the process of starting a business and running it (Cassar 2007). That is, entrepreneurs learn how to run a business and this in turn influences their motivation. So, necessity entrepreneurship may at least for some individuals be a way into successful entrepreneurship. 
Stephan et al. (2015) examined 1,000 respondents of GEM survey, used ten exploratory interviews and further in-depth interviews with 40 entrepreneurs. Although they studied practising entrepreneurs and what motivated them toward entrepreneurship, however, some of the drivers they highlighted might resonate with some potential entrepreneurs in certain places. They analysed the many dimensions of motivations behind U.S. entrepreneurs.

Stephan et al. (2015, p.14) reviewed the "multi-dimensional typologies of entrepreneurial motivation" and used these dimensions for their GEM study of U.S. entrepreneurs. In what follows is a brief highlight of the seven dimensions of entrepreneurship motivation; a full review can be obtained from Stephan and colleagues' work. The commonest dimensions identified are:

- Achievement, challenge and learning: This dimension explains the individuals' desire for personal development using the process of entrepreneurship. Included in this dimension also are aspects such as having meaningful work and responsibility and learning from the challenge of founding/running a business. Also included in this dimension are aspects of craving for self-realisation including the desire for accomplishing one's personal vision.

- Independence and autonomy: This dimension explains the reasons behind people who wish to control their work life including control of one's time and work, decisions, having the flexibility to combine work with personal life.

- Income security and financial success: This dimension captures the role of financial benefits from entrepreneurship.

- Recognition and status: This dimension deals with aspects related to social status as crave for recognition and respect from colleagues, family and the entire community as a result of being an entrepreneur.

- Family and roles: This dimension captures the desire to continue a family tradition and following other role models. It also captures crave for establishing a family legacy as being a motivating factor for embracing entrepreneurship.

- Dissatisfaction: This dimension explains why people take to entrepreneurship as a result of dissatisfaction with the previous work environment. It is similar to the necessity-driven entrepreneurship motive.

- Community and social motivations: These dimensions capture crave for contributing back to one's society as an entrepreneur. People can fulfil this by philanthropy or using the business itself (e.g. social entrepreneurship). It sometimes includes aspects such as caring more about the workers of the organisation and paying greater attention to environmental issues. 
Different studies have examined and found aspects of each of these dimensions as being the motives individuals go into business (e.g. Uddin and Kanti, 2013; Fernández-Serrano and Romero 2012; Friedman et al., 2012; Williams and Williams, 2012; Jayawarna, Rouse and Kitching, 2011; Reynolds and Curtin 2008). Most of the studies drew on data collected by large-scale survey projects in mostly developed countries. Some of these projects include the Global Entrepreneurship Monitor (GEM), Panel Study of Entrepreneurship Dynamics (PSED I and PSED II), EU Flash Barometer (EUFB), and Global Entrepreneurship Development Institute Index (GEDI).

Consequently, studying a developing country such as Nigeria and specifically the student population and examining the motives for their decision to embrace entrepreneurship (using results of the focus group interviews) might add useful dimensions that research may have ignored. The next subsection addresses the aspects of cultural and social factors and their influences on start-up endeavours.

\subsection{Cultural and social barriers to entrepreneurship intentions}

What influences do cultural values and social environment have on entrepreneurship and specifically on start-up intentions? This subsection briefly analyses the relevance of these factors and in doing so, it attempts to broaden understanding of how these can inhibit enterprise in some instances. The understanding would help the researcher later in the analysis and discussion chapters to tie in the participants' perceptions of their attitudes and beliefs toward entrepreneurship with the wider literature on effects of cultural and social conditions on entrepreneurship.

The scholarly literature posits that culture can influence peoples' attitudes to work, consumption, organisation of economic activities, shaping and effectiveness of institutions, social networks, and confidence building within social groups (Bergmann, 2015; Fukuyama, 2001). Although many scholars define culture differently, yet, the essence of culture is the "values, norms, interpretations and modes of behaviour that characterise societies or other social groups" (Fukuyama, 2001, p.31). It portrays people's collective values and beliefs, shared at least in part, with others in the same social environment or those belonging to the same group. It is this collectively-shared reality which people learn consciously or unconsciously that Hofstede (1994, p.5) bring to the fore when he said that culture is "collective programming of the mind which distinguishes the members of one group or category of people from another." This group can be national (which some call it "national culture"); it can also be regional, ethnic, religious, and gender levels (Hofstede, 1994; Shapero, 1984). 
In this analysis, the interest is not to examine strictly the "national culture" which Hofstede (1994) categorises into five. The categories are: "power distance", which is the "extent to which the less powerful members of institutions and organisations within a country expect and accept that power is distributed unequally" (p.98); "uncertainty avoidance", which is the "extent to which the members of a culture feel threatened by uncertain or unknown situations" (p.161); and "individualism/collectivism", which is a society that reflects the extent to which it is the interest of the individual or the interest of the group that prevails. The others are: "masculinity/femininity", which is a "society in which social gender roles are clearly distinct; men focus on material success, women are supposed to be more modest, tender, and concerned with the quality of life" (p.297); and lastly, "long-term orientation", which defines a country in terms of its trade-off between short-term and long-term gratification of needs, in particular, it emphasises virtues such as "perseverance and thrift" (p.359).

The interest of this analysis, however, is to focus on what kind of influences cultural values may have on business start-up intentions. The emphasis here is apparently on "regional" cultural values rather than the "national" culture emphasised by Hofstede's study. Hofstede's analysis of culture, however, did not investigate culture along entrepreneurship lines. Also, the influences of culture play out in various ways. A major way is in influencing attitudes toward entrepreneurship or business-founding. Cultural features can influence attitudes toward entrepreneurship and these attitudes, in turn, influence entrepreneurial activities (Bergmann, 2015). It was Milner (2012a, p.65) who highlighted cultural features as: "risk attitude and fear of failure, perceptions about entrepreneurs and entrepreneurship (i.e. the desire for business ownership), and attitudes toward starting a business and ambitions. Attitudes (to risk) focus on whether people in a community would prefer self-employment, their determination to follow that goal through and their ambition level. Here, perception is about whether people thought confidently about their skills and knowledge to be business owners.

At the individual, regional, and group levels, the relationship between culture, attitudes and startup activities may be dominant (Davidsson and Wiklund, 1997). There exists a direct relationship on the individual level when, on account of cultural features, many individuals show a favourable attitude toward business, and because of such attitude, decide to be entrepreneurs. When that happens, there is a direct relationship between culture and entrepreneurship since it is more likely that only individuals who have positive mindsets can take to self-employment. Bergmann (2015) asserts that it is this line of argument that Kirzner (1985), McClelland (1961) and Schumpeter 
(1934) portrayed when they noted that there was a direct link between attitudes and entrepreneurship.

At the level of society, however, a relationship between culture and entrepreneurial pursuits may also exist. The scholarly literature argues that the prevalent values, beliefs and norms in a social environment that a person lives could influence her likelihood of starting an enterprise (Etzioni, 1987). It then follows that any cultures averse to venture formation may suppress entrepreneurial activities. For instance, that would be true when entrepreneurs (and businesses) connote a poor image within a society or region and the people do not consider this option of livelihood even though they do not harbour any reservations toward entrepreneurs. In such situations, there is a relationship between culture and entrepreneurship not only on the individual level but also on the societal, regional or groups' levels. However, it seems unclear how people's culture can be measured about entrepreneurship but some researchers (e.g. Milner, 2012b) have attempted to measure the dimensions of entrepreneurship culture.

Milner (2012b) acknowledges that culture is difficult to measure but attempted to develop measures for entrepreneurship culture using the OECD framework. Milner (2012b) derived six indicators for measuring the culture of entrepreneurship as attitudes toward risk, role models, perceptions, attitudes, media and the formal sector. As indicated in Table 3.1 below, the OECD study developed indicators to measure each of the dimensions of culture based on an earlier qualitative study conducted. To further assess the specific indicators (i.e. questions) and the OECD methodology used for measuring each of the six cultural factors, one can refer to Milner (2012b, p.112). It measured media as the most important top-down indicator to indicate the culture of entrepreneurship. It used the Google Trends (as a proxy for media-entrepreneurship culture) to measure the number of times the news media and web searches mention the word entrepreneurs and entrepreneurship. For the size of the formal sector, it reflects the culture of businesses in the country and shows whether new businesses created are likely to be formal or informal. The other dimensions such as risk attitude, attitudes, and perceptions are described as were highlighted earlier in this section. Table 3.1 below highlights the six culture dimensions as follows: 
Table 3.1: Culture indicators

\begin{tabular}{|c|c|c|c|c|c|}
\hline \multicolumn{6}{|c|}{ CULTURE } \\
\hline $\begin{array}{c}\text { Attitudes } \\
\text { toward risk }\end{array}$ & Role models & Perceptions & Attitudes & Media & $\begin{array}{l}\text { Formal } \\
\text { sector }\end{array}$ \\
\hline $\begin{array}{l}\% \text { of people } \\
\text { willing to take } \\
\text { risks - } \\
\text { Eurobarometer }\end{array}$ & $\begin{array}{l}\text { \% of population that } \\
\text { know someone who } \\
\text { has started a business } \\
\text { - GEM }\end{array}$ & $\begin{array}{l}\% \text { of people that } \\
\text { see } \\
\text { entrepreneurship } \\
\text { as a good career } \\
\text { choice-GEM }\end{array}$ & $\begin{array}{l}\% \text { of people } \\
\text { aiming to start a } \\
\text { business - } \\
\text { Eurobarometer }\end{array}$ & $\begin{array}{l}\text { Number of times } \\
\text { entrepreneur and } \\
\text { entrepreneurship } \\
\text { is mentioned in } \\
\text { news and in web } \\
\text { searches - } \\
\text { Google trends }\end{array}$ & $\begin{array}{l}\text { Size of the } \\
\text { informal } \\
\text { economy- } \\
\text { World Bank }\end{array}$ \\
\hline $\begin{array}{l}\% \text { of people } \\
\text { willing to take } \\
\text { risks - World } \\
\text { Values Survey1 }\end{array}$ & $\begin{array}{l}\% \text { of population that } \\
\text { have seen stories } \\
\text { about successful } \\
\text { entrepreneurs in the } \\
\text { media-GEM }\end{array}$ & $\begin{array}{l}\% \text { of people that } \\
\text { respect } \\
\text { entrepreneurs - } \\
\text { GEM }\end{array}$ & $\begin{array}{l}\% \text { of people } \\
\text { aiming to start a } \\
\text { business - GEM }\end{array}$ & & \\
\hline \multirow[t]{4}{*}{$\begin{array}{l}\text { \% of people } \\
\text { unwilling to } \\
\text { take risks - } \\
\text { WVS }\end{array}$} & $\begin{array}{l}\text { \% of population } \\
\text { whose close family } \\
\text { have started a } \\
\text { business - } \\
\text { Eurobarometer }\end{array}$ & $\begin{array}{l}\text { Opinion of } \\
\text { entrepreneurs } \\
\text { compared to other } \\
\text { groups - } \\
\text { Eurobarometer }\end{array}$ & $\begin{array}{l}\text { \% of business } \\
\text { owners that aim } \\
\text { for growth - GEM }\end{array}$ & & \\
\hline & & $\begin{array}{l}\text { Opinion of } \\
\text { entrepreneurs } \\
\text { compared to other } \\
\text { groups - Gallup } \\
\text { poll }\end{array}$ & $\begin{array}{l}\text { \% of population } \\
\text { that is determined } \\
- \text { WVS }\end{array}$ & & \\
\hline & & $\begin{array}{l}\text { believe they have } \\
\text { the confidence, } \\
\text { skills and } \\
\text { knowledge to start } \\
\text { a business - GEM }\end{array}$ & $\begin{array}{l}\text { \% of population } \\
\text { that is ambitious - } \\
\text { Eurobarometer ( } 3 \\
\text { indicators) }\end{array}$ & & \\
\hline & & & $\begin{array}{l}\text { \% population that } \\
\text { is passionate } \\
\text { about their work - } \\
\text { WVS }\end{array}$ & & \\
\hline
\end{tabular}

Note: WVS (World Value Survey), GEM (Global Entrepreneurship Monitor)

Source: Milner (2012b, p.111)

On the social factors that can influence entrepreneurship, Milner (2012b) highlights them as follows: family (history of entrepreneurship), wealth status, role models, educational level, media and religion. It noted that children can acquire values and behaviours from their parents and family as they grow up and also from other social institutions in the wider society such as schools, faith-based and non-faith-based affiliations. For example, the Protestant Work (Labour) Ethics 
which research often cites had a major influence on the development of modern capitalism and enterprise because it altered peoples' attitudes toward labour in the Tawney's century, 1540-1640 (Bergmann, 2015). Although religion may be less relevant in many secular cultures today, the debates on cultural features, enterprise-related attitudes and entrepreneurship continues in research circles. For a fuller discourse on the role of some major religions on the development of capitalism and enterprise, refer to Munro (2010), Murray (2010) and Kuran (2010).

In conclusion, to empirically analyse the cultural and social factors in order to measure their influences on the Southeast and South-south undergraduates would have given a clearer picture of the level of barrier or not that these factors have on entrepreneurship choice. However, it is more likely that this line of investigation would have diverted the researcher from the core objectives of the present study. Therefore, if respondents indicate (and narrate) the likelihood of starting their businesses, level of fear of starting, attitudes and perceptions of societal views toward entrepreneurs, these would at least help the researcher understand how culture and social factors influence their start-up intentions. A complete investigation of Milner's (2012b) culture indicators on the undergraduates in the regions studied can be attempted in the future.

\subsection{Raising capital to start entrepreneurial activities}

Raising the required capital for a business is one of the biggest challenges for new or potential entrepreneurs even in the developed countries and more especially in developing countries (Akpan, 2014). Research attests that about one in ten succeeds in getting "angel funding" from individuals desiring to help out and fewer than one in hundred advances to venture capital (Lavinsky, 2012). Failing to raise the sufficient initial funding can lead to the death of the enterprise. When people fail to get the much-desired funding from angel investors, banks or venture capitalists, they can give up, and the business may never see the light of the day. Fraser (2004), however, argues that often poor access to private external finance might be more of lack of adequate information concerning the available sources of funding than the lack of funds itself. Thus, governments at various levels can solve the information gaps with creative enlightenment campaigns through mass media and in the various medium and associations where entrepreneurs affiliate. 
If it sometimes seems this difficult for practising entrepreneurs to raise funds to start their entrepreneurial activities, it might be harder for undergraduates or fresh graduates. One suggestion is that undergraduates or potential entrepreneurs should start businesses that need as little money as possible that allows one to start generating revenues as quick as possible. Also, raising small amounts of money, for instance through credit cards where the facilities are available, is particularly useful and easier (Lavinsky, 2012). First, the new entrepreneur would have some money to reinvest in her business and grow it. Second, investors would be much more likely or confident to fund the enterprise since the new entrepreneur has proven she can execute and that customers will buy what she is creating.

However, ultimately some businesses require some outside funding; therefore, the individuals need some creative approaches to raising the capital for such huge ventures. For example, new entrepreneurs can brainstorm other low-cost business ideas (such as providing consulting) that would serve the same customers as their ultimate business. In doing so, the entrepreneur can gain connections to these customers. Ultimately, these same customers may help fund the venture that the entrepreneur truly wants to build. Thus, by serving them now, the entrepreneur would better understand the customers' wants and needs, which will help the entrepreneur to succeed in her current and ultimate business (Lavinsky, 2012).

Obviously, there are several other factors that may militate against the fostering of entrepreneurship education in different countries and regions. Milner (2012a, p.67) highlighted the two specific challenges of entrepreneurship education common in many countries as: "(1) the challenge of developing high-quality new programmes led by qualified teachers and (2) the lack of commitment by institutions, demonstrated by the lack of formal academic programmes in Universities and schools." These challenges may also apply to Nigerian universities. Also, studies have enumerated other macro and micro level factors that are challenges to entrepreneurship education in Nigerian universities as poor knowledge-based economy and low competitiveness; poor enterprise culture; inadequate supply of high-quality and experienced entrepreneurship teachers; inadequate materials and equipment; unavailability of required funding; non-inclusion of entrepreneurship programme in the general school curricula; poor societal attitudes to technical 
and vocational education development; inadequate facilities and equipment for teaching and learning in practical-related courses; insensitivity of government to enterprise creation and expansion strategy; and poor planning and execution of processes of action (Olorundare and Kayode, 2014). However, even as the government continues to tackle many of the challenges enumerated above through the various relevant agencies it might take some time, though, for the benefactors to feel the agencies' full impact because of policy time-lags.

From the analysis, the key lesson is that in moving forward, Nigerian universities would need to align her entrepreneurship education programmes more with what is obtained in other environments if they are to develop high-quality future entrepreneurs. From the scholarly literature in entrepreneurship education available, the global best practice mostly in the U.S. and advanced European countries is that the goals of undergraduate entrepreneurship programmes are achieved using several methods (Zahra and Welter, 2008). These methods include: one, handson training in creativity techniques; two, lectures and case studies on the various aspects of business; three, training in communication; and four, providing opportunities for networking with entrepreneurs and venture capitalists to gain confidence in dealing with diverse stakeholders. Five, some universities give students the chance to work to develop and refine their business plans in teams: universities usually provide faculty or executive coaching and feedback for these teams. Six, with the help of faculty and entrepreneurs, students typically spend time analysing their teams' decision-making processes and their decision-making styles and develop effective strategies for improvement.

Seven, other universities introduce their students to the process of entrepreneurship and then require them to develop business plans for ventures of their choice. Usually, the students work in collaboration with the faculty advisors or entrepreneurs who help them in refining the business plans. Students also role-play and present their business plans to their colleagues and business people, thus, honing their business presentation skills. Because students have limited experience, most universities in the U.S. for example, often depend on guest speakers for inspiring and motivating students, sharing their experiences, and rendering feedback on the students' projects (Zahra and Welter, 2008).

From the seven methods enumerated above, it is emphasised here that following most of these best practices in teaching and learning of undergraduate entrepreneurship education programmes in Nigerian universities and adapting the practices to the peculiarities of the local environment could help increase more student interest in entrepreneurship. Therefore, drawing from the 
analysis above, the present study would examine the perceptions of the participants studied concerning the methods their universities use in the teaching of entrepreneurship development course. The analysis of their perceptions would enable the researcher compare the extent of satisfaction or dissatisfaction of the participants studied with the global best practices on entrepreneurship education methods. Also, it would help in drawing implications and making specific recommendations to assist in shaping entrepreneurship education practice in Nigeria. For example, recommending some measures to universities and their Enterprise Development Centres for producing enterprising graduates including how lecturers could teach applications-based course contents to generate venture ideas from their core courses.

In the next chapter, the focus shifts to examining of the scholarly literature, both theoretical and empirical, on the underlying factors that influence undergraduates' desire toward entrepreneurial pursuits. The inputs from the literature search on the subject would enable the researcher develop a theoretical framework that would guide the conceptual logic of the rest of the research.

\subsection{Reasons for selecting the undergraduates of Southeast and South-south Nigeria for this study}

Nigeria has three major ethnic groups: Yoruba (Southwest), Ibo (Southeast) and Hausa-Fulani (North-east, west and central) and close to 250 other ethnic minorities (Forrest, 2005). The Southsouth region comprises parts of the ethnic minority groups. The academic reason for selecting the two regions for the study is that this can enable research to establish a cross-societal framework for comparison. That is, comparing the Ibo (Southeast), Efik, Ibibio, Annang, Oron, ljaw, Urhobo, and Bini tribes (South-south) needed for the development of understanding of entrepreneurship development in southern Nigeria. They share common boundaries, inter-marry and share some common religious beliefs and traditions. For this reason, a clear understanding of the underlying issues with respect to the influencing factors would perhaps be essential for the prescription of research-informed policies. This result can help in furthering the development of entrepreneurial capacities of potential entrepreneurs from any deficient region.

Each of the component ethnic groups in Nigeria has certain peculiar behaviours-social, cultural, economic and political. While some identifiable behaviour may be common to some or all of the groups as a result of long years of inter-ethnic co-habitations, associations, exchanges and marriages, certain behaviours have remained unique to each of the groups. In particular, studies recognise that the lbo ethnic group has an aspect of their culture called "self-help and selfenterprise." This has become both an ideology and a mantra amongst the Ibos referred to as "Igba 
Mbo" (Olutayo, 1999). It is a kind of informal and unstructured training program, scheduled for an agreed period of time, which a person undergoes in order to acquire a desirable aspect of entrepreneurship skill (Orugun and Nafiu, 2014). Thus, this socio-economic structure of the Ibo communities may be one of the explanations that make other ethnic groups perceive them as different in entrepreneurial pursuits.

Olutayo $(1999$, p.150) notes that "the Ibos, when compared to the other major ethnic groups in Nigeria, are in the forefront of entrepreneurial activities, especially in the informal sector." They predominantly undertake their entrepreneurial activities outside of the Igbo states. Nworah (2011) also asserts that one of the visible attributes of the Ibos in entrepreneurship is that they have always relied on self-help and self-enterprise in their business endeavours. This perhaps may have been as a result of the victim mentality created by the losses they suffered during the NigeriaBiafra civil war. Olutayo $(1999$, p.164) also adds that "One major and unique trait of the Igbo entrepreneur is the courage, perseverance, and determination with which they carry on in spite of the bad experiences and losses during the Nigerian civil war from 1967 to $1970 . "$

Of the three main ethnic groups in Nigeria, LeVine (1966) earlier argued that the lbos are the most energetic parvenus who have successfully challenged the established order of supremacy which the Yoruba occupied in the elitist professional civil service establishments. Green (1947) observed that the Igbo admire "the man of energy, the go-getter..." and that the qualities stressed in children's upbringing are property, money, honesty, and loyalty to kinsmen (p. 88). The Ibos, he argues, "placed a premium on occupational skill, enterprise and initiative," upon which mobility is dependent. Individuals are motivated to work hard and "cleverly marshal available resources of increasing wealth" so that more people, unlike among the Hausa and Yoruba, he points, have access to wealth, and wealth brings power rather than power bringing wealth. The various studies cited above point to some evidence of the possible differences in entrepreneurial intentions among the groups studied. However, the contribution of the present study is to assess empirically the nature and sources of the perceived differences using an analysis from a qualitative focus group interview method. Also in the final chapter, it would highlight the implications of any perceived differences and suggest policy interventions to shape entrepreneurship education in Nigeria.

While it may be true that the Ibos are very industrious and entrepreneurial, it is equally true for other ethnic groups. Various factors can be used to explain the entrepreneurial ability of individuals rather than which ethnic group they belong. Most important in various analyses in the 
entrepreneurship circles is the requirement to satisfy the basic needs, and the opportunities available for the satisfaction of these needs.

There are fewer entrepreneurship studies that used undergraduate respondents from the Southsouth Nigeria. Halliru (2013) studied the effects of culture on the development of entrepreneurs of the Hausa ethnic group in the Northern Nigeria and compared it with the Ibos in the Southeast. The study acknowledged the role of the system of apprenticeship of the Ibos believed to have helped "masters" recruit and train the younger ones to become future entrepreneurs. In comparison to the Hausas, Halliru found also that the difference was that although the Hausas believe in the importance of having the necessary entrepreneurial qualities to succeed, most Hausas also perceive that "one's destiny as ordained by God will eventually prevail and is, therefore, most fundamental in influencing behaviour" (p.59). However, that the Ibos "believe that an entrepreneur's success is entirely dependent on his personal qualities" (p.59).

For the Yoruba ethnic group of the Southwest, there is a fairly longstanding entrepreneurship research effort made to understand the entrepreneurship backgrounds of the region. For example, Akeredolu-Ale (1977) chronicled a sociological overview of entrepreneurship development among the Yoruba people and their early relationship with other African traders. Also, Lagos in the Southwest had economic incentives as well as its proximity to ports that encouraged entrepreneurship in the past decades. Reports show that four African groups were active contributors to the commercial development of Lagos at the turn of the nineteenth century (Ofonagoro, 1979). These included the Afro-Brazilians, freed slaves from Sierra Leones and their descendants, popularly known as Saros. The others included the white-cap chiefs who were the traditional landowners of Lagos, and the immigrant traders and merchants from Egba, ljebu, Ibadan/Oyo, llesha, and Ondo (in Southwest Nigeria).

Adebayo and Kolawale (2013) studied the historical background of entrepreneurship development in Nigeria with emphasis on the Yoruba ethnic group. They emphasised the roles of the early technical and vocational colleges in the region that engendered entrepreneurship-supporting studies. However, there are fewer studies relating specifically to comparing the entrepreneurship behaviours of undergraduates of the South-south and Southeast regions. The present research is a fair attempt at contributing to filling this research gap.

In what follows in Figure 3.2 is the map of Nigeria, which shows the location and states that make up the South-south and Southeast regions studied. Geographically, Nigeria is located on the Gulf of Guinea in West Africa. Its area of over 923,773 square kilometres is entirely within the tropical 
zone between latitudes $4^{\circ}$ and $14^{\circ} \mathrm{N}$ and longitudes $2^{\circ} 20^{\prime}$ and $14^{\circ} 30^{\prime} \mathrm{E}$. It extends northward from the coastline for over 1,046 kilometres. Its 2006 official population was 140,431,790 (National Bureau of Statistics, 2013). The Southeast comprises of five states: Abia, Anambra, Ebonyi, Enugu, and Imo. The South-south comprises of six states: Akwa Ibom, Bayelsa, Cross River, Delta, Edo, and Rivers. The arrows indicate the geographical positions of the two regions: 


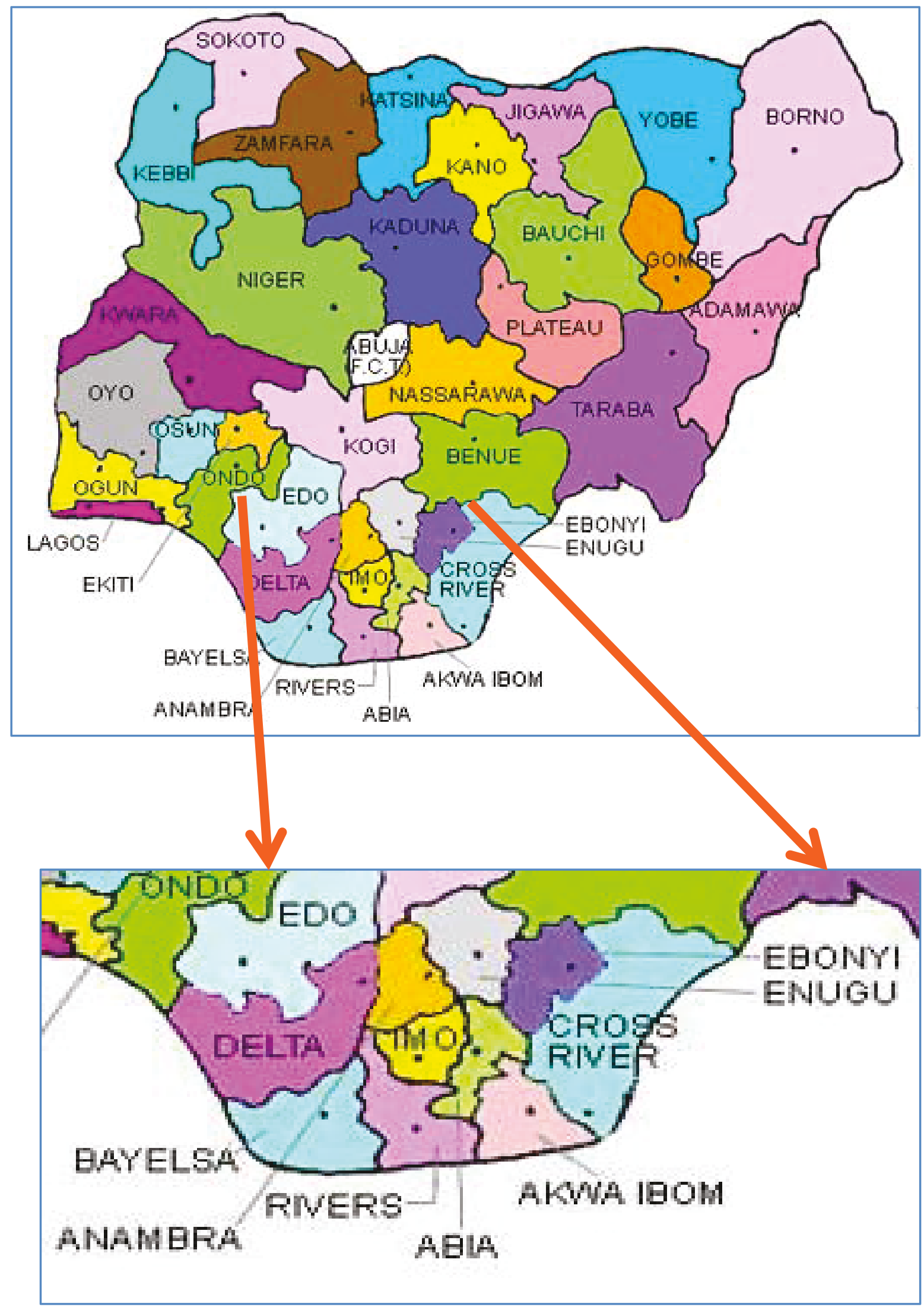

Figure 3.2: Map of Nigeria showing the six South-south and five Southeast states 


\section{CHAPTER FOUR}

\section{REVIEW OF RELATED LITERATURE}

\subsection{Introduction}

The last chapter examined how the role of understanding and using the appropriate entrepreneurship education based on global best practices can enrich the entrepreneurial experiences of the Nigerian undergraduates and thus increase their interest in entrepreneurship. This chapter examines the relevant theories propounded to explain entrepreneurial intentions and their influencing factors. A clear understanding of these theories will assist in formulating a theoretical framework for this research. The related empirical literature on entrepreneurial intentions and its influencing factors will also be critically examined.

\subsection{Theoretical perspectives on entrepreneurial intentions and its influencing factors}

In the entrepreneurial ecosystem, the first stepping-stone is the formation of intentions for enterprise creation as a career option (Gartner et al., 1994). Entrepreneurial intention as used in this study means "mental orientations such as the desire, wish and hope that influence people's choice of entrepreneurship" (Peng et al., 2012, p.96). Scholars have propounded different theories for predicting the factors that influence entrepreneurial intentions They include: Shapero's (1984) theory of the entrepreneurial event; Bird's (1988) model of implementing entrepreneurial ideas; and Robinson's et al. (1991) entrepreneurial attitude orientation model. Others are Ajzen's (1991) theory of planned behaviour; Krueger and Carsrud's (1993) intentional basic model; Krueger and Brazeal's (1994) entrepreneurial potential model. The rest are: Boyd and Vozikis' (1994) intention model; Davidsson's (1995) economic-psychological model; Douglas and Shephard's ( 2002) maximization of expected utility model; and Elfving, Brännback and Carsrud's (2009) contextual model of entrepreneurial intentions. These models are briefly examined below.

\subsubsection{Shapero's (1984) "model of the entrepreneurial event"}

This model posits that intentions act as pre-conditionality for behaviours or actions. Here, the behaviour can be new venture creation, self-employment, or corporate entrepreneurship. These three options are outcomes of entrepreneurial behaviour. Shapero believes that businessfounding intentions require that founders see the career option as a "credible" choice. This "credibility" rests on the awareness that the enterprise is altogether appropriate and realisable. Also, external influences or "push factors" such as retrenchment, unemployment, dissatisfaction 
with present employment, and divorce among other extraneous events can influence people's attitudes toward the feasibility of entrepreneurial options. The illustration of this concept is in Figure 4.1 below:

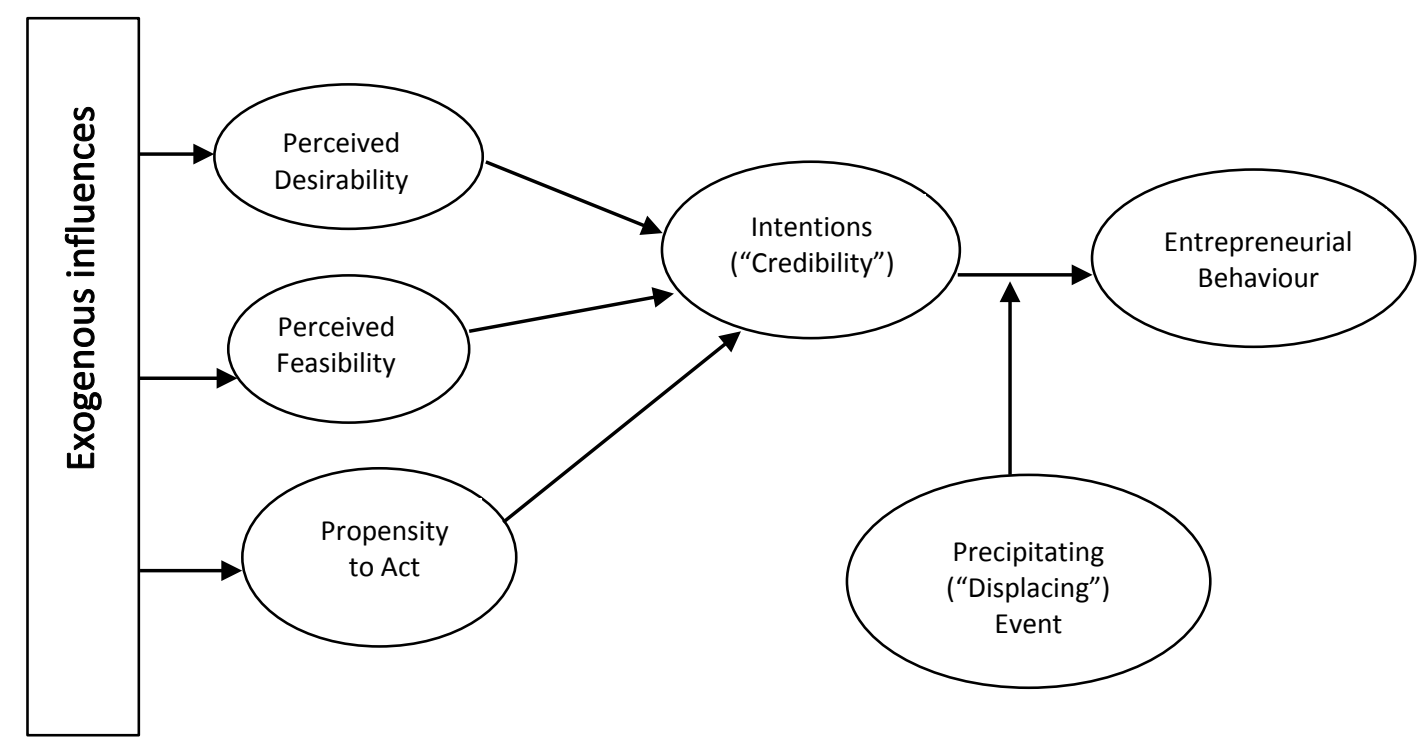

Figure 4.1: Shapero's model of the "entrepreneurial event" Source: Shapero $(1984$, p.29)

From the figure above, the measure of perceived desirability is analogous to Ajzen-Fishbein's (1980) construct of personal attractiveness whereas perceived feasibility is similar to the latter's perceived behavioural control. The "propensity to act" is the attitude of willingness based on personal volition. The external push factors earlier mentioned above correspond to what Shapero calls "displacing" or "precipitating event" that causes the entrepreneurial actions.

Krueger (1993) empirically tested the above model, and results showed that perceived entrepreneurial desirability, entrepreneurial feasibility and "propensity to act" significantly impacted intentions. External factors such as previous experiences in entrepreneurial activity influence the levels of perception of entrepreneurial desirability and entrepreneurial feasibility, which turns round also to impact intentions toward entrepreneurial behaviour.

Shapero's model opened up the theory-based research approach to studying entrepreneurship. His model, nevertheless, has received little empirical testing and application especially for potential entrepreneurs whom "displacing" effect is irrelevant. 


\subsubsection{Bird's (1988) "model of implementing entrepreneurial ideas"}

This model is one of the earliest contemporary attempts at advancing a theory-based research in entrepreneurship studies beyond previous descriptive analyses. Bird's model addresses a psychological base of venture creation that contributes to distinguishing entrepreneurship from strategic management (Bird, 1988).

Bird (1988, p. 422) describes intention as "a state of mind directing a person's attention (and therefore experience and action) toward a specific object (goal) or a path in order to achieve something (means)." Furthermore, Bird assumes that "entrepreneurial intention directs goal setting, commitment, communication, development and growth from the beginning" (p.422). In Bird's model, personal and contextual factors facilitate entrepreneurship intentions. Personal factors include economic, political, cultural, and social components. Also, other factors that impact the intention include thinking in terms of cause and effect, rationality, analytical thinking, initiative, holistic and context-specific thinking. Figure 4.2a below illustrates this concept:

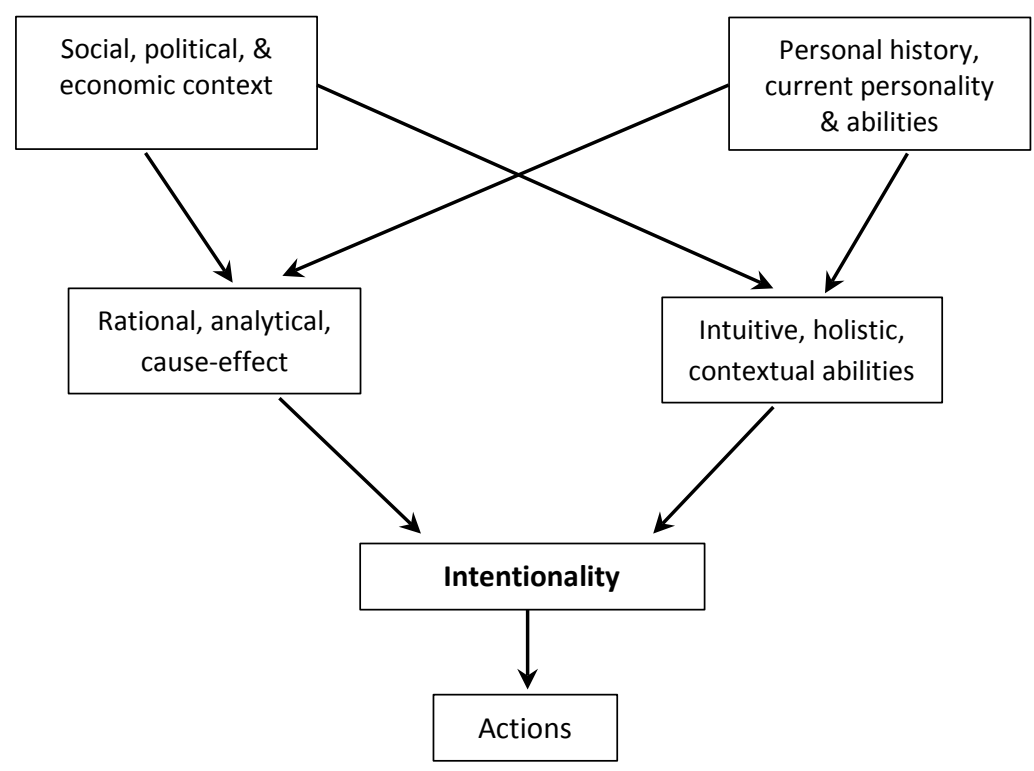

Figure 4.2a: The contexts of intentionality Source: Bird (1988, p.444)

Accordingly, Bird defines the process of entrepreneurial intentions as starting with a person's personal needs, wants, values, beliefs and habits that have their antecedents. Central to intention and behaviour, there are three intra-psychic activities, namely, "creating and maintaining a temporal tension, sustaining strategic focus and developing strategic posture" (Bird, 1988, p.445). 
These intra-psychic activities contribute to the initiation of new ventures or innovating in an existing firm and, in turn, affect an individual's beliefs, values, needs, wants and habits. Figure $4.2 \mathrm{~b}$ below illustrates this model:

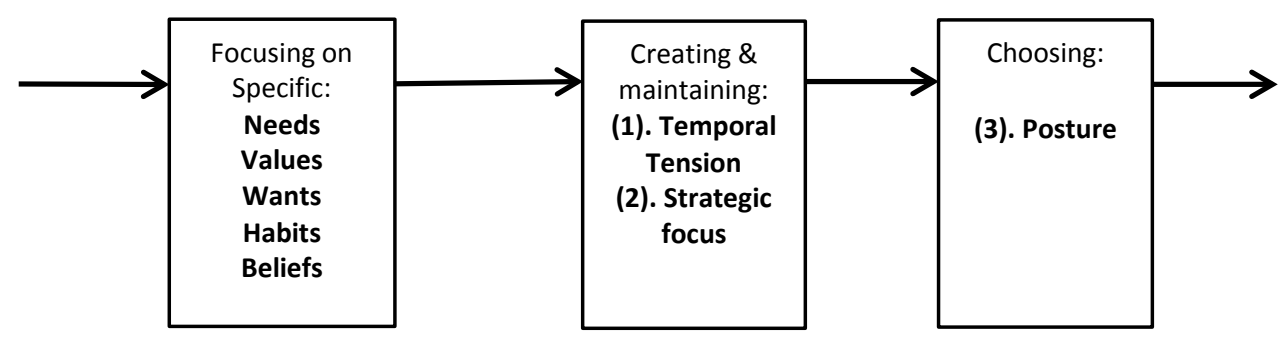

Figure 4.2b: Intention-direction process Source: Bird (1988, p. 445)

In explaining the sustaining of temporal tension, Bird hypothesises that time is an irreversible movement along a straight line. She observes that the "most obvious dimension of temporal tension among entrepreneurs concern connecting the present to the future that is yet to come" (p.445). The meaning is that the farther an entrepreneur envisions and projects into the future; the more uncertainties and immediate tensions there will be as the entrepreneur attempts to bring the future to today's planning. She claims that this is how entrepreneurs act. Knowing that positioning strategically for both the future and the present is essential for success in business, remarkable entrepreneurs "are agile in moving from the present to future and across different future horizons" (p.445).

On sustaining strategic focus, intentions by entrepreneurs are "directed toward goals, which are desired end-states, rather than toward means of conduct, although both ends and means can be intentional" (Bird, 1988, p.447). Using the ideas of Timmons (1978), Bird suggests that the purposes of entrepreneurs include organisational growth and staying afloat economically. Personal acquisition of wealth and organisational, financial health are, however, only means of achieving higher goals for the entrepreneurs, they are not the ultimate goals in themselves. This idea portrays entrepreneurs as being "means-and-end-oriented" for they appear to be opportunistic in the ways they pursue their goals including profit making, breaking even as well as making phenomenal growth in business.

Bird reiterates that to develop business intentions, individuals have to position themselves in line with their values, needs and the larger world. To do this, people need an alignment and 
"attunement." Using the ideas of Harrison (1983), Bird (1988, p.447) conceptualises "alignment is a configuration of parts such that all parts are contributing to a single purpose and direction." The meaning is that people's many inner "voices", wishes and memories must align. Failure to have this sort of mental alignment inhibits focused intentions. She suggests that, for example, having "conflicts in values such as work versus family or control versus growth can slow, stop, and even divert intended actions. Therefore, those who implement new ventures are "more likely to have concepts of career, risk, rewards, work, and family that align with the venture concept" (p.447).

According to Bird, "attunement connotes the readiness to receive and send information, guidance or meaning from diverse sources that demand to be open-mindedness, attentiveness, selfconfidence and the capacity to take mistakes as learning curves. "Attunement" makes people take rational business steps especially when the business environment requires such adjustments. Furthermore, "attunement" requires networking and the external mastermind groups of the entrepreneur. This group includes venture capitalists, accountants, lawyers as well as business advisors who can help entrepreneurs to access significant resources required in new ventures. Drawing from the ideas of Aldrich, Rosen and Woodward (1987), Bird believes the make-up of the network, the activity pattern and the experiences received from networking with these groups are related with how the new business will consequently perform.

Bird's model examines entrepreneurial intentions in line with strategic planning, temporal tensions, and postures. Although it offers some insights into the psychological, creative process of venture development, it is not without some drawbacks. One, her qualitative study of United States entrepreneurs did not include would-be or potential entrepreneurs and so her constructs may not appropriately and effectively apply to a population of potential entrepreneurs. Two, the framework as depicted by Bird does not lend itself to empirical testing and might be one of the reasons that researchers hardly apply the model in students' entrepreneurial intention studies.

\subsubsection{Robinson's et al. (1991) “entrepreneurial attitude orientation model”}

Robinson and his associates summarise the different criticisms levelled against the two longstanding, traditional approaches to studying entrepreneurship (i.e. personality characteristics and demographic variables). They then adopted a tripartite model of attitude to explain entrepreneurial intentions. The model holds that there are three kinds of response to everything: affective, cognitive and conative responses. The cognitive component includes the beliefs and thoughts that a person has about an attitude object, in this case, entrepreneurship. The affective component includes the positive or negative feelings that a person has toward entrepreneurship. 
But the conative component involves the behavioural intents as well as the tendencies to respond in a prescribed manner toward entrepreneurship (Robinson et al., 1991).

Drawing from the ideas of Hornaday and Nunnally (1987) and Hornaday (1987), Robinson and his friends note that the problem with the psychological/traits approaches in predicting entrepreneurship propensities are many. Firstly, that the research methodologies usually applied to this approach were not originally developed for evaluating entrepreneurial intentions. But the approach was developed in psychology and researchers only apply it to entrepreneurship, sometimes inappropriately and often ineffectively. In all cases, it is commented "they carried with them the theoretical and meta-theoretical assumptions of the theory from which they came" (Robinson et al., 1991, p.14). Secondly, there is the problem of convergent validity. The meaning is that various instruments being used by different authors to measure the same concept do not correlate adequately (e.g. Paulhus, 1983; Yamauchi and Doi, 1977).

Thirdly, the traditional personality models are said to be rigid compared to the most interactive models in human behaviour that emphasise that theoretical models should both impact as well as be impacted by interaction with the environment. In contrast, the traditional personality model suggests that people form traits in their earliest years. That it remains essentially stable after that which might sometimes be incorrect (Faulconer and Williams, 1985; Gergen, 1985; Manicas and Secord, 1983). The proposition of the "interactionists" is that in the overall, entrepreneurship includes people working in a socially-connected setting (Robinson et al., 1991).

Robinson et al. (1991) also criticise the traditional demographic approach of using personal demographics to determine profiles of the entrepreneur's personality. There is an objection to the position that family characteristics, marital status, sex, race, birth order, age, socioeconomic status, role models, prior work experience, and work practices can singularly predict entrepreneurship. Firstly, following the criticisms by Rychlak, (1981), Robinson et al. (1991) argue that linking behaviour to demographic characteristics such as race, sex, or birth order puts too much emphasis on experiences that one has other than the actual conclusions one draws from one's experiences. Robinson and friends state that it is people's actual reactions to particular situations that influence entrepreneurial behaviours other than just some sets of demographics.

Secondly, it is deemed as inappropriate to "use demographic characteristics as surrogates for personality characteristics, imputing personality traits based on demographics" (Robinson et al., 1991, p.16). Furthermore, they criticise "it is not the demographic characteristics themselves that affect entrepreneurship so much as it is stable personality characteristics or traits developed by 
someone having those demographic characteristics" (p.16). Thirdly, the method is incapable of predicting people who are likely to become or not become entrepreneurs. This might be the case where research that used those background characteristics yield conflicting results in predicting entrepreneurship (e.g. Okhomina, 2010; Athayde, 2009; Krasniqi, 2009; Siyanbola et al., 2009; Taormina and Lao, 2007; Gurol and Atsan, 2006; Louw, et al., 2003). The reason is that demographics is deemed to be static in nature and so are weak in explaining the dynamics in a multifaceted phenomenon such as entrepreneurship. Therefore, demographic information can only depend on the prevalence of other basic characteristics such as attitudes that directly impact entrepreneurship (lakovlena, Kolvereid and Stephan, 2011; Ajzen, 1991).

Having criticised the traditional approaches to predicting entrepreneurship, Robinson and his colleagues proposed the entrepreneurial attitude orientation (EAO) model. The concepts of their model use four-attitude sub-scales that consist of three components: affect, cognition, and conation. The four-attitude subscales comprise of business achievement, which refers to the tangible and measurable results from a new business and another growth record of business. Another is business innovation, which relates to recognising and performing business functions in the novel and distinctive manner. The others include "perceived personal control of business outcomes", which concerns the person's foresight for controlling and influencing business decisions. The last one is "perceived self-esteem in business", which pertains to the "selfconfidence and perceived competency of an individual" in connection with the business activities (Robinson et al., 1991, p.19).

Using students, entrepreneurs, and non-entrepreneurs they developed and validated an entrepreneurial attitude orientation model in line with the four attitude subscales. They concluded that three out of the four subscales significantly impacted the discriminant function (i.e. innovation, personal control and self-esteem). The major criticism of the EAO model is that it failed to show clearly the holistic interactions of the dynamism involved in the entrepreneurial formation process. Also, researchers who conduct empirical studies on student intentions to business startups rarely use or apply the EAO framework. Therefore, it may offer a limited application for studying the direct and indirect influences that affect students' business-founding intentions.

\subsubsection{Ajzen's (1991) "theory of planned behaviour" (TPB)}

The common belief is that Ajzen's version of the theory of planned behaviour (TPB) predicts entrepreneurial intentions most reliably (Mariano et al., 2012; Engle et al., 2010; Autio et al., 2001; Krueger, Reilly and Carsrud, 2000). The apparent superiority of the TPB is premised on its logical 
and applicable theoretical framework. The TPB allows one to identify and predict entrepreneurial intention by considering both the social and personal factors (lakovleva et al., 2011). Also, it is held that the TPB predicts many other behaviours aside entrepreneurship. For example, behaviours such as the practical application in health care (e.g. losing weight and quitting smoking), and marketing campaign (e.g. using coupon). Another is in road traffic safety (e.g. using of the seat belt) as reported in the meta-analysis by Armitage and Conner (2001).

The main tenet of the TPB is that intentions are influenced by three primary antecedents or forerunners, namely: personal attitude toward outcomes of the targeted behaviour (PATB), perceived subjective norms (PSNs) and perceived behavioural control (PBC). The actual behaviour is eventually influenced by intentions. Conversely, perceived behavioural control can influence actual behaviour. In the same way, perceived behavioural control is related to the subjective norm. It follows, therefore, that the antecedents of intentions might interconnect with one another resulting in direct and indirect interaction effects (Ajzen, 1991). Figure 4.3a below presents the original form of the model:

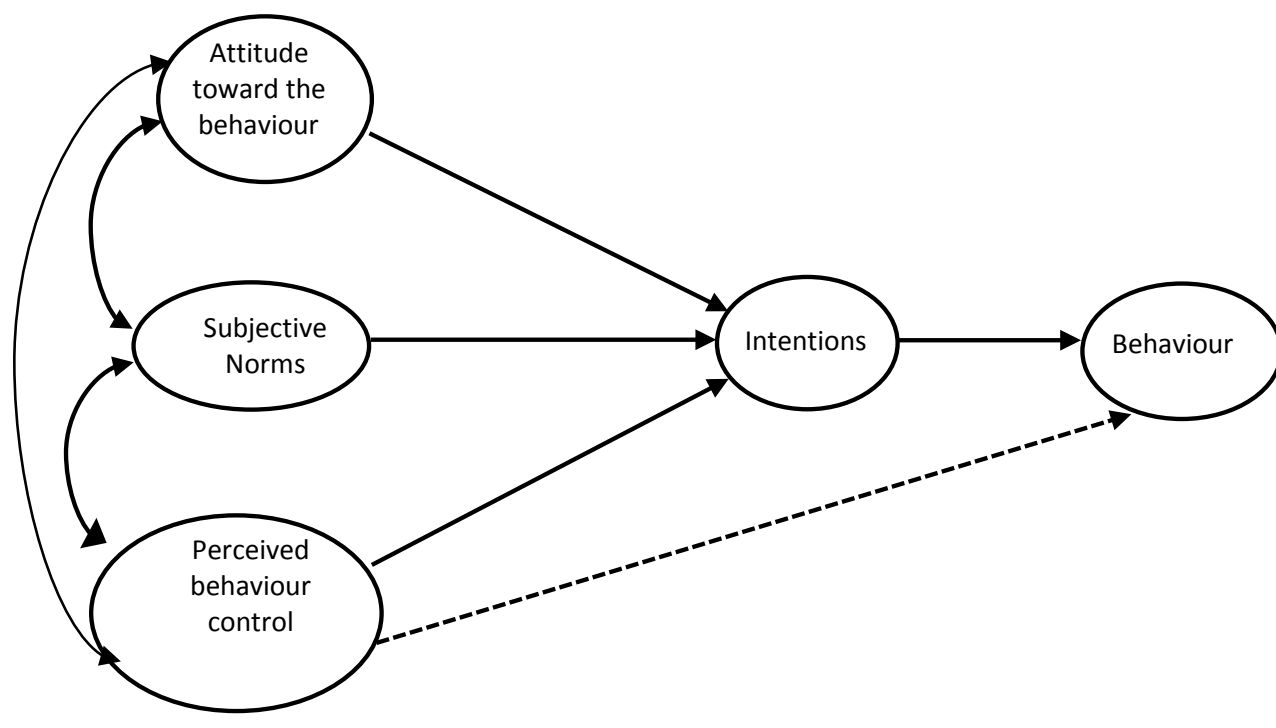

Figure 4.3a: Ajzen's theory of planned behaviour Source: Ajzen (1991, p.182)

Personal attitude toward start-up means the extent to which a person favours or disfavours the evaluation of the behaviour being considered, in this case, taking up an entrepreneurial career (Ajzen, 1991, 2001). Ajzen believes that when a person's behavioural beliefs are assessed, and 
linking the behaviour to several outcomes and attributes, the result is a pointer to a person's attitudes. In other words, attitudes toward start-up comprise both affective considerations (e.g. I like to be an entrepreneur; it is attractive). It also comprises evaluative considerations (e.g. it is advantageous to be an entrepreneur) as expounded in Linän and Chen (2009).

Perceived subjective norms capture how a person perceives the surrounding social pressure to perform an action or not (Ajzen, 1991). Specifically, it connotes how an individual perceives the way his "powerful others" will admire her decision to enter entrepreneurship, or do otherwise (Linän and Chen, 2009; Ajzen, 2001). Ajzen and Fishbein (1980) see subjective norms from two perspectives: "normative beliefs" and the "motivation to conform to these beliefs." The former concerns how likely an individual perceives the way her "significant others" or groups will welcome or reject a given behavioural action. These groups set the norms to which citizens should behave. The latter connotes the extent of willingness to comply with the group's norms; in other words, to conform and not to offend the significant others. Therefore, these pressures can act as a boost or impediment to the development of a person's career as an entrepreneur.

The third forerunner of entrepreneurial intentions, the perceived behavioural control, measures how an individual perceives the ease of starting a business (Linän and Chen, 2009; Ajzen, 1991). This concept is the opposite of Bandura's (1997) self-efficacy and Shapero and Sokol's (1982) perceived feasibility. The three concepts (i.e. perceived behavioural control, self-efficacy and perceived feasibility) all point to the sense of being able to start up an enterprising activity. Ajzen (2002), nevertheless, differentiates perceived behavioural control from self-efficacy. The former includes both the feeling of being capable of starting up a business venture or enterprise, as well as the perception concerning controllability of the behaviour. This thinking informs the superiority and use of Ajzen's version of behavioural control.

In later studies by Ajzen, the original model was slightly modified to indicate explicitly the factors that influence the predictive power of the theory. Ajzen (2005) demonstrates that attitude toward the behaviour is influenced by behavioural beliefs (BB), subjective norms by normative beliefs (NB), and perceived behavioural control by control beliefs (CB). It is these three beliefs (i.e. BB, NB and $\mathrm{CB}$ ) that are then directly impacted by different background factors. The background factors as outlined by Ajzen (2005, p.135) include "personal (e.g. general attitudes, personality traits, values, emotions and intelligence); social (e.g. age, gender, race, ethnicity, education and religion); and information (e.g. experience, knowledge and media exposure)." The behavioural or motivational, normative and control beliefs are the guidelines that have informed the 
questionnaire items used in measuring attitudes in the present study. Ajzen's modified model is as illustrated in Figure 4.3b below:

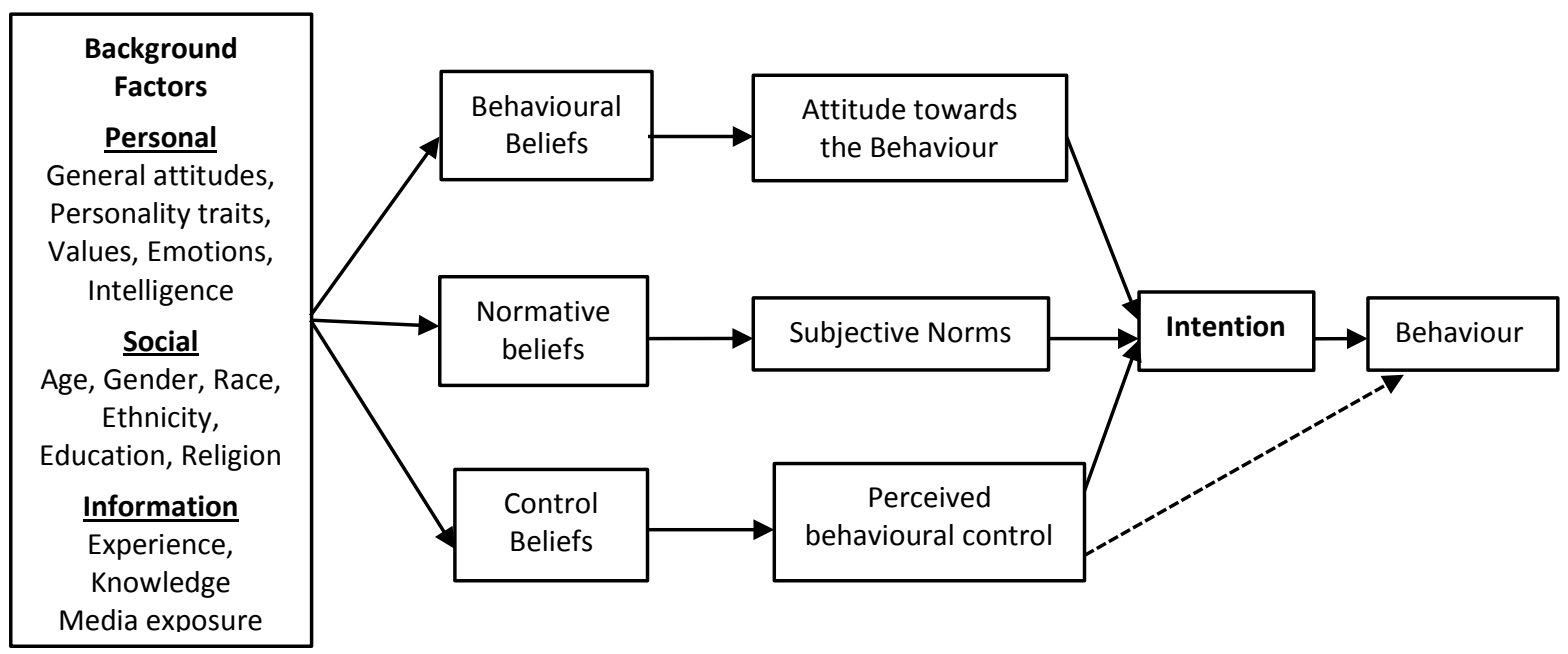

Figure 4.3b: Factors that influence the predictive power of Ajzen's theory of planned behaviour Source: Ajzen (2005, p.135)

Therefore, researchers can test Ajzen's three motivational antecedents of entrepreneurial intentions empirically, thus making application to entrepreneurial intentions possible (Ajzen, 1991, 2002).

\subsubsection{Krueger and Carsrud's (1993) “intentional basic model”}

Drawing from the theory of planned behaviour by Ajzen, the "intentional basic model" specifies the channels through which exogenous factors can influence entrepreneurial behaviour. The model suggests, "exogenous influences usually affect intentions and behaviour indirectly through attitude changes, not directly" (Krueger and Carsrud, 1993, p.316). Figure 4.4 depicts the model:

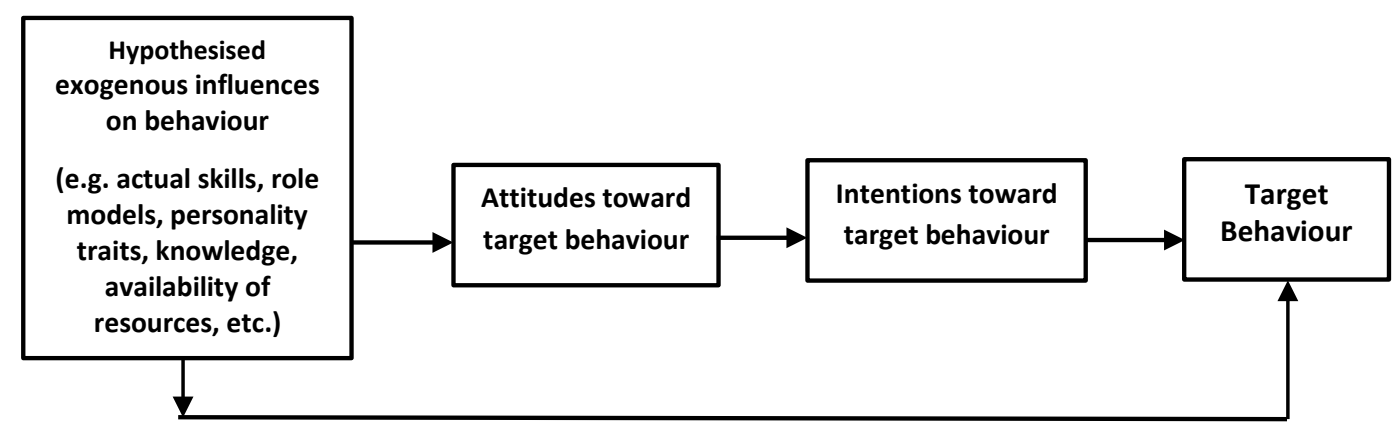

Figure 4.4: The basic intentions-based process model Source: Krueger and Carsrud (1993, p.317) 
From Figure 4.4 above, the authors suggest that only intentions directly affect the behaviour, whereas attitudes affect intentions. The exogenous factors impact either attitudes or moderate (catalyse) the intentions-behaviour link. In other word, they either enable or hinder the actualisation of business-founding intentions. From Krueger and Carsrud (1993, p.317), they believe that intentions are person-and-context-specific. But the "exogenous factors are typically either person variables (e.g. personality traits and demographics) or situation variables (e.g. economic climate and financial support)." Thus, they conclude that it is not surprising that the exogenous factors usually influence entrepreneurial behaviour indirectly, and research finds that exogenous influences only weakly affect entrepreneurial activity. Therefore, they believe that the intentions-based approaches present testable and theory-driven models of the channels through which exogenous factors affect attitudes, intentions, and behaviour.

The strength of Krueger and Carsrud's model is its simplicity, but its main weakness is that it fails to capture fully the complex nature of the various attitude factors that connect the entrepreneurial intention-behaviour outcome. Thus, it may not yield an improved percentage of explanation of the attitude-intention prediction in an empirical test.

\subsubsection{Krueger and Brazeal's (1994) “entrepreneurial potential” model}

Krueger and Brazeal drew from Shapero's (1984) ideas on "entrepreneurial event" for this model. They posit, "before there can be entrepreneurship there must be the potential for entrepreneurship whether in a community seeking to develop or in a large organisation seeking to innovate" (Krueger and Brazeal, 1994, p.91). They also believe that this entrepreneurial potential requires potential entrepreneurs who should take initiatives when an opportunity (i.e. "potential") comes up. According to Shapero (1984), the entrepreneurial event demands that there should be a readiness to take the chances that show up, plus events that trigger that decision. Krueger and Brazeal advocate that potential entrepreneurs do not require "only salient intentions toward starting a business; their potential is latent and is causally and temporally prior to intentions" (Krueger and Brazeal, 1994, p.91) to find and inspire many would-be entrepreneurs. However, the theory of entrepreneurial potential offers a recipe for encouraging the creation of entrepreneurial potential.

The entrepreneurial potential model argues that the attitudes and beliefs of would-be business founders are influenced by their thoughts aside objective criteria such as psychological traits, demographic characteristics, and static conditions. The model adopts three critical constructs related to Ajzen's "theory of planned behaviour" (TPB) and Shapero's "model of entrepreneurial event" to explain entrepreneurship potential. These constructs are a propensity to act, perceived 
feasibility, and perceived desirability. Here perceived feasibility (in the SEE model) is similar to perceived behavioural control in Ajzen's TPB (and both are equivalent to perceived self-efficacy). The remaining two attitude dimensions in the TPB become embedded in SEE's perceived desirability as illustrated in Figure 4.5 below:

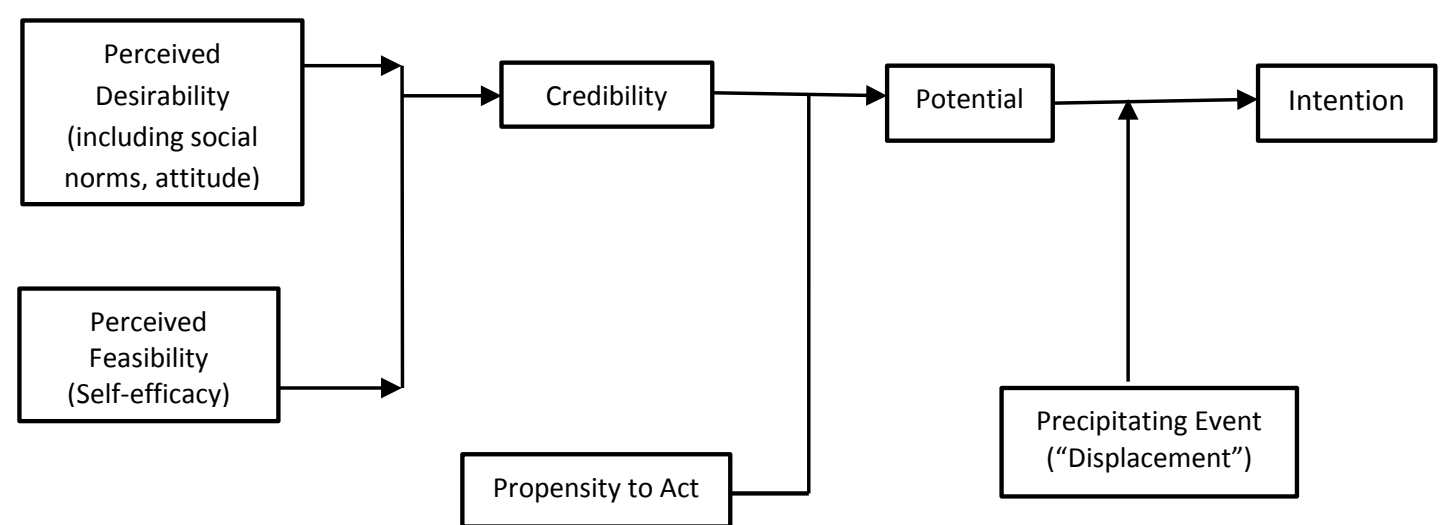

Figure 4.5 Model of entrepreneurial potential (simplified) Source: Krueger and Brazeal (1994, p.95)

For a group, organisation, or community to possess some potential for entrepreneurial activity, they must have an increasing number of persons who see themselves as would-be business owners (Krueger and Brazeal, 1994). The model examines entrepreneurial potential in the following settings: enterprise development and corporate ventures. By examining concepts around each element within the model, however, the authors pinpoint some characteristic attitudes and beliefs characterising potential business founders. Similar to Shapero's model, the Krueger and Brazeal's model assumes that "inertia guides human actions until something displaces or disrupts that inertia" (Krueger and Brazeal, 1994, p.96). The displacing factor may be negative events in a person's life (e.g. retrenchment or divorce), or it can be a positive event (e.g. inheritance). Drawing from the ideas of Katz (1992), Krueger and Brazeal (1994) believe that displacement triggers changes in behaviour as people look for the best prospects obtainable from available alternatives.

The selection of the subsequent behaviour is based upon the relative "credibility" of alternative behaviours (i.e. to the decision maker) with some "propensity to act" (failure to have this may result in inaction). For there to be "credibility", the behaviour has to be equally desirable and realistic. Therefore, the entrepreneurial event requires that the potential to found a business ("credibility and propensity to act") must first be present before the displacement (together with the "propensity to act" following the displacement). Similar to the theory of planned behaviour, 
other influences work via a person's "perceptions of desirability and feasibility" and through "propensity to act." Therefore, these variables do not influence intentions or behaviour individually. It implies that for individuals to go into entrepreneurship, their attitudes must first be influenced toward having the intentions then to the behaviour or action (Krueger and Brazeal, 1994).

Krueger and Brazeal acknowledged that entrepreneurship lies more in people's culture, and societal context, and is interlinked within a people's economic, social, and psychological networks, thus suggesting a need for a holistic framework. However, their model did not explicitly capture these complexities.

\subsubsection{Boyd and Vozikis' (1994) intention model}

Boyd and Vozikis built on Bird's model. To them intention is "based on the way in which people perceive their social and physical environment as well as the way in which they anticipate the future outcomes of their behaviour" (Boyd and Vozikis, 1994, p.69). To develop entrepreneurship intentions however, the authors believe people's preferences, attitudinal dispositions, beliefs, hopes, and actual circumstances often influence them. Moreover, the quality of these perceptions has something to do with one's past unique experiences. Based on these experiences and the amount of information acquired, people can then make sense of their personal situation and context. Thus, this model suggests that "rational and intuitive thinking" influence people's behavioural intentions as well as enterprise.

Boyd and Vozikis's model incorporated self-efficacy as their central contribution. Self-efficacy indicates the confidence that people have in their ability to perform an action (Bandura, 1977). The authors believe that it is an "outcome of these cognitive thought processes and the development influenced by mastery experiences, observational learning, social persuasion and perceptions of physiological well-being that have been derived from the personal and contextual variables" (Boyd and Vozikis, 1994, p.69). The self-efficacy and personal attitudinal disposition toward failure or achievement eventually influence the development of business-founding intentions. Thus, higher self-efficacy serves as a central condition of moving from intention to action. Figure 4.7 below illustrates Boyd and Vozikis' model: 


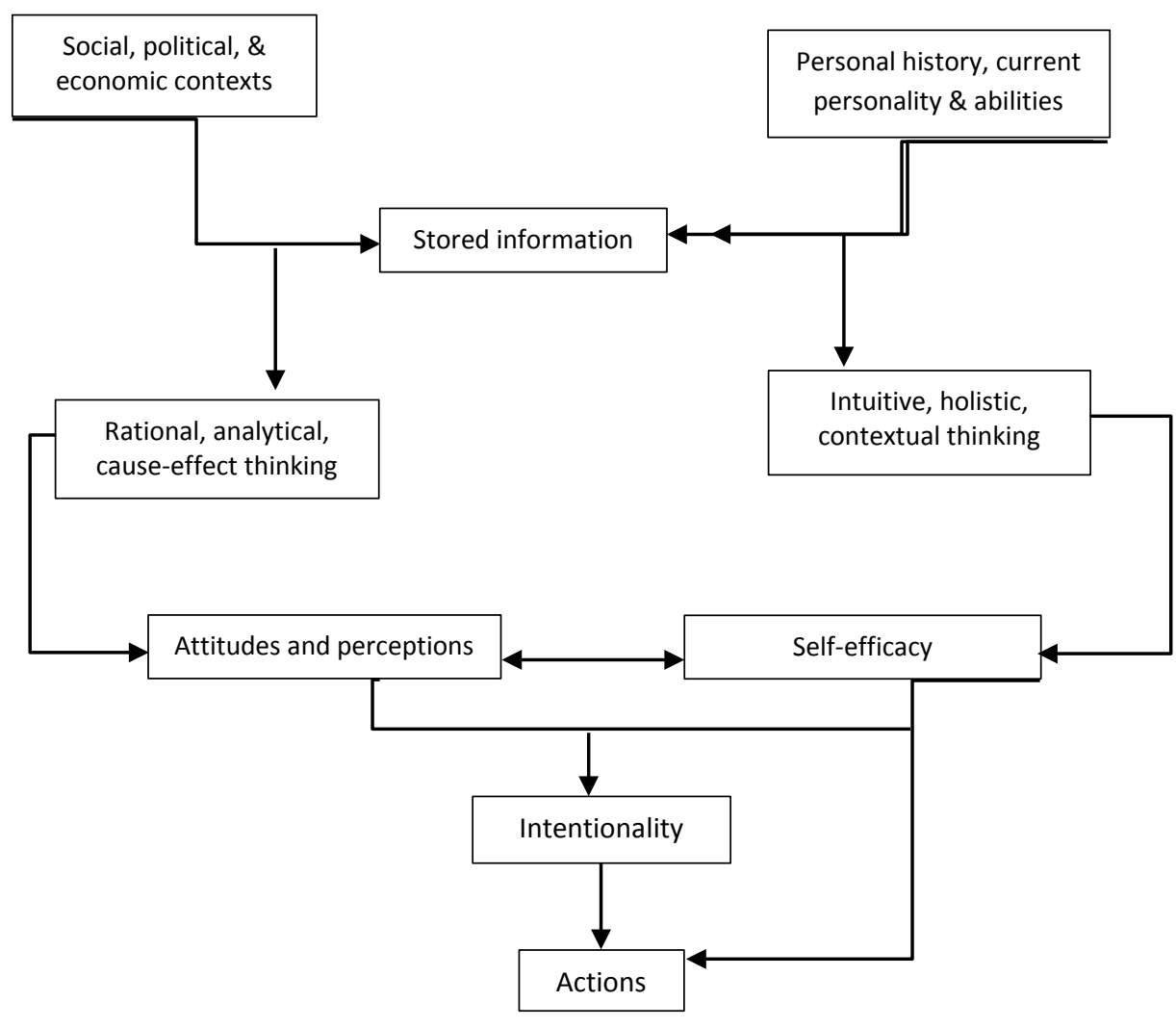

Figure 4.6: Intention model of Boyd and Vozikis Source: Boyd and Vozikis (1994, p.69)

\subsubsection{Davidsson's (1995) “economic-psychological model” of entrepreneurial intentions}

Davidsson's model is the integration of economic and psychological dimensions at the conceptual level, but the author also empirically tested the concepts to support his propositions. He theorised that entrepreneurial intentions are primarily influenced by a person's conviction, which is in turn influenced by general and domain attitudes, as well as personal background measures. The "situation" factor, however, acts as a mediator for both the conviction component and intentions. Figure 4.6 below illustrates the model: 


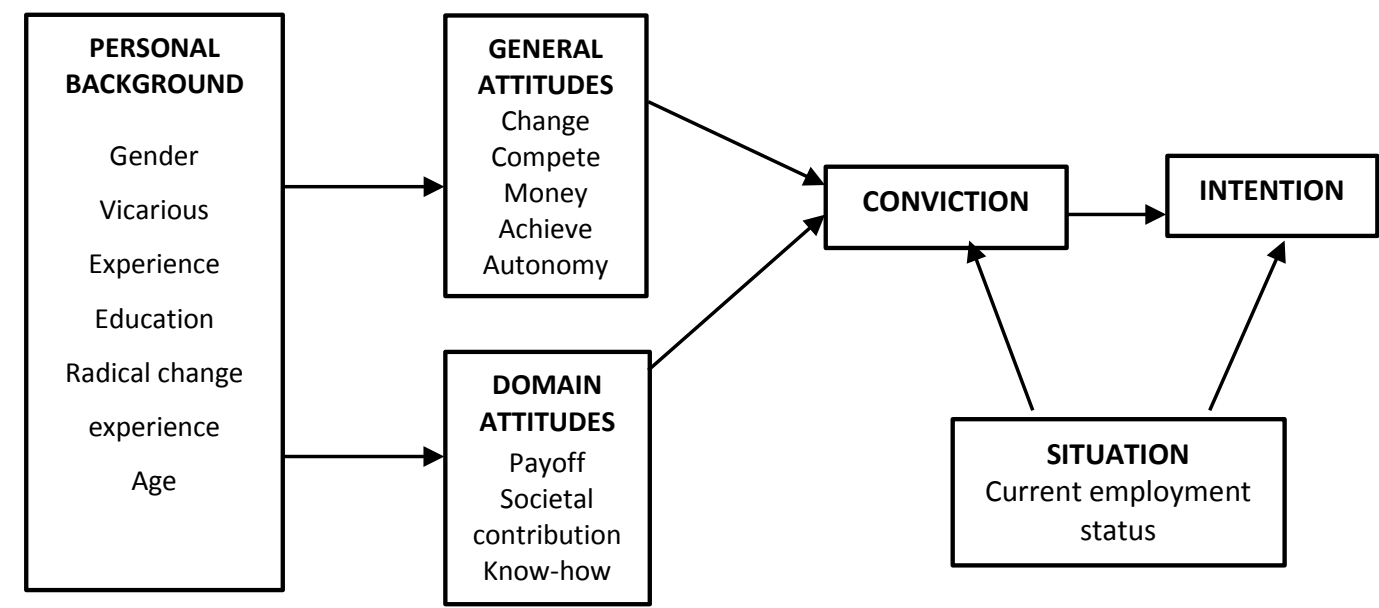

Figure 4.7: An economic-psychological model of determinants of entrepreneurial intentions Source: Davidsson (1995, p.5)

The model propounds that an individual's conviction that a particular career is the appropriate one for her is the paramount influencing factor of entrepreneurial intentions (Davidsson, 1995). This conviction implies whether the individual feels that running her own business would be a suitable alternative for herself, given her competencies, skills and life situation. Such feelings, according to the author should be "more closely related to actual behaviour than mere know-how beliefs" (Davidsson, 1995, p.8). Although this concept of conviction might be compared to "perceived selfefficacy" in others' theories (e.g. Krueger and Brazeal, 1994; Shapero, 1984), Davidsson submits that the way he applied the concept in his model includes not only questions of "I would manage (and like) running my own business" types but also questions insinuating that such an option would be helpful in enhancing the individual's living standard.

Davidsson's situational factor (i.e. current employment status) is analogous to the "displacement" factors advanced by other theorists (e.g. Krueger and Brazeal, 1994; Shapero, 1984). The current employment situation is assumed to influence intentions (given that firm formation is taken as a planned action). It also influences conviction (given that the responses to some of the questions in the conviction index are likely to be susceptible to the respondents' present situations).

Davidsson also differentiated between his "general" and "domain" attitudes. Here his questions for general attitudes do not dwell on entrepreneurship or small firms whereas the questions used for domain attitudes are specific to entrepreneurship. From his analyses, general attitudes suggest that there is still some room for trait-like psychological interpretations. General attitudes in 
connection to change orientation, competitiveness, achievement and autonomy contribute to making individuals more convinced that having their businesses is a desirable option.

On the domain attitudes side, expected payoff entails an individual's belief as regard the workload, risk, and returns expected from the business. Also, the societal contribution is an influencing factor. This contribution reflects how a potential entrepreneur views the way society places practising entrepreneurs. Thus, drawing from the ideas of McGrath et al. (1992), Scheinberg and MacMillan (1988), Davidsson concludes that if one perceives that entrepreneurs are held in high esteem by the society, one might be more convinced to become a business owner.

These two attitude measures, payoff and societal contribution, are more directly related to an individual's beliefs concerning what pertains to business creators and firms' managers in general. It is, nonetheless, the last domain attitude variable; that is perceived know-how, directly related to oneself. Know-how measures whether an individual would know all that she needs to do should she arrived at a good business concept and wanted to implement it. The influences of personal background factors (e.g. educational achievement and vicarious experience) are likely moderated by variables such as perceived know-how (Davidsson, 1995; Shaver and Scott, 1991). Thus, both general and domain attitudes mediate the impact of personal background and gender; remote experience also directly impacts entrepreneurial intentions (Davidsson, 1995).

Although Davidsson's model has introduced a novelty in adding the competitiveness dimension, the model still has some drawbacks. About his adopted methodology, the reliance on multiple regression techniques to determine both direct and indirect effects of the explanatory variables on intentions is neither feasible nor statistically plausible. It is the structural equation model that best handles these effects. It has the major advantage of assessing simultaneously the measurement model (i.e. the questions or items in each construct) and the structural model (i.e. the different latent constructs in the model). Structural equation models also report the levels of biases originating from each source in the entire framework.

\subsubsection{Douglas and Shepherd's (2002) "maximisation of expected utility" model}

Models and theories examined so far are prominently within the subject areas of psychology and sociology, yet economists also attempted to offer explanations for why people decide to become entrepreneurs. The study includes works such as Baumol (1990), Campbell (1992), Douglas and Shepherd (2000, 2002). The works of Douglas and Shepherd (2002) were a major integration of these expected utility maximisation approaches. Their model is examined herein. 
Previous empirical works in economics on entrepreneurial intentions concentrated largely on the analysis of macroeconomic and demographic factors that affect entrepreneurship. It was, however, Baumol (1990) who propounded that people's choice of becoming entrepreneurs will be enhanced if they think the utility they will derive from the wealth, influence and power from owning their enterprise can be maximized. Moreover, this choice is dependent on the structure of the reward system and the predominant "rules of the game that control the payoff to entrepreneurship" (Baumol, 1990, p.894). It was Campbell (1992) who examined people's attitudes to risk-taking and expected economic values of the subjective costs-benefits position for entrepreneurship. But Eisenhauer (1995) advances that wishing to be an entrepreneur relies on the "expected utility" to be gained from the "working conditions" weighted between the options existing in paid employment and self-employment.

In Douglas and Shepherd (2000), they link people's income potentials to their attitudinal disposition and capabilities. They examine attitudes toward particular work settings including risk; efforts needed and freedom in taking decisions. Therefore, their theory of entrepreneurial intention is based on a "utility maximisation model of human behaviour" (Douglas and Shepherd, 2002).

The theory of utility maximisation of human behaviour argues that individual's attitude to making income, individuality, risk-taking, and workload influence career choices. Although these factors are not necessary or sufficient conditions in themselves, the greater these positive attitudes, the higher the intentions toward business formation, ceteris paribus (Douglas and Shepherd, 2002). The theory offers economists' viewpoint on entrepreneurship as a reaction to utility-maximization.

On attitudes to work effort, Douglas and Shepherd (2002) define work effort as how much physical and mental energy one is prepared to offer in a task. The rough calculation is to multiply hours of work by the intensity of working. Drawing from the ideas of MacDonald (1984), Douglas and Shepherd suggested, based on the agency theory, that people differ in their levels of aversion to work effort. The expectation is that people who are more tolerant to work effort will be more likely self-employed. The reason is that they expect a greater utility gain from income that they might generate. It turned out, though, that Douglas and Shepherd's empirical test of the theory repudiated that work effort creates greater utility as a result of expected additional income. On this, Douglas and Shepherd (2002, p.88) suggest, "perhaps people generally expect the level of work required to be commensurate with income or do not believe that 'low work effort' would be tolerated by any employer (or possible in self-employment)." 
On attitudes toward risk, the authors posit that an individual with greater risk-tolerance derives comparatively little additional disutility from additional risk-bearing. They argue that more risktolerant people choose self-employment because the larger chunk of the business profit is expected to go to the entrepreneur. Greater risk-tolerance is captured in the diminishing absolute marginal rate of substitution of income for risk. This concept is analogous to a flatter indifference curve contrasting with an individual who is more risk-averse (Douglas and Shepherd, 2002). Douglas and Shepherd supported this assertion with their empirical findings.

On the attitude of independence, it is hypothesised that people in self-employment typically enjoy higher independence (Douglas and Shepherd, 2002; Katz, 1994; Bird, 1989). Individuals who dislike independence will dislike self-employment except the "utility gains" from the expected marginal revenue is greater than the marginal disutility of risk, work, and independence (Douglas and Shepherd, 2002). The authors, therefore, suggest that the greater the utility (satisfaction) from independence; the higher an individual's entrepreneurial intentions. Again, they supported their theoretical framework with empirical investigations.

Douglas and Shepherd's model attempts to analyse entrepreneurship using the economic approach. It relaxes the strict rationality assumption often followed by many economic theories and adopts an attitude-based model to assess prospective entrepreneurs' decision/assessment policies. The model is, however, somewhat limited. Firstly, it does not reflect explicitly the complexities of social behaviour that require a contextual and holistic assessment. Secondly, the use of regression technique of statistical analysis retains the same limitations that surround other studies earlier pointed out. Therefore, this calls for a model that can capture the measurement and structural components of any adopted framework simultaneously.

\subsubsection{Elfving, Brännback and Carsrud's (2009) contextual model of entrepreneurial Intentions}

Elfving et al. (2009) add a challenge to the entrepreneurial intentions debate. Their model advocates the inclusion of the roles of specific goals and motivations on intentions. They also challenge the linear nature of the relationship as often implied in previous models and argue for a reciprocal causation model of intentions. Furthermore, they question the rationale of the basic structure of previous models.

The contextual model draws from Carsrud's et al. (2007) study and suggests that entrepreneurial intentions can be better comprehended only in the analytical framework that integrates 
motivations, goals and evaluation of the opportunity. Elfving et al. (2009) observe that previous theoretical works (e.g. Krueger, 1993, 2000; Krueger and Brazeal, 1994; Krueger and Carsrud, 1993) failed to incorporate the three factors mentioned. Thus, they suggest that the previous models had limited application of their frameworks. Elfving and her associates borrow from the elements of the models cited above as well as a qualitative study by Elfving (2008) to present a contextual model of entrepreneurial intentions. Figure 4.8 below illustrates their model:

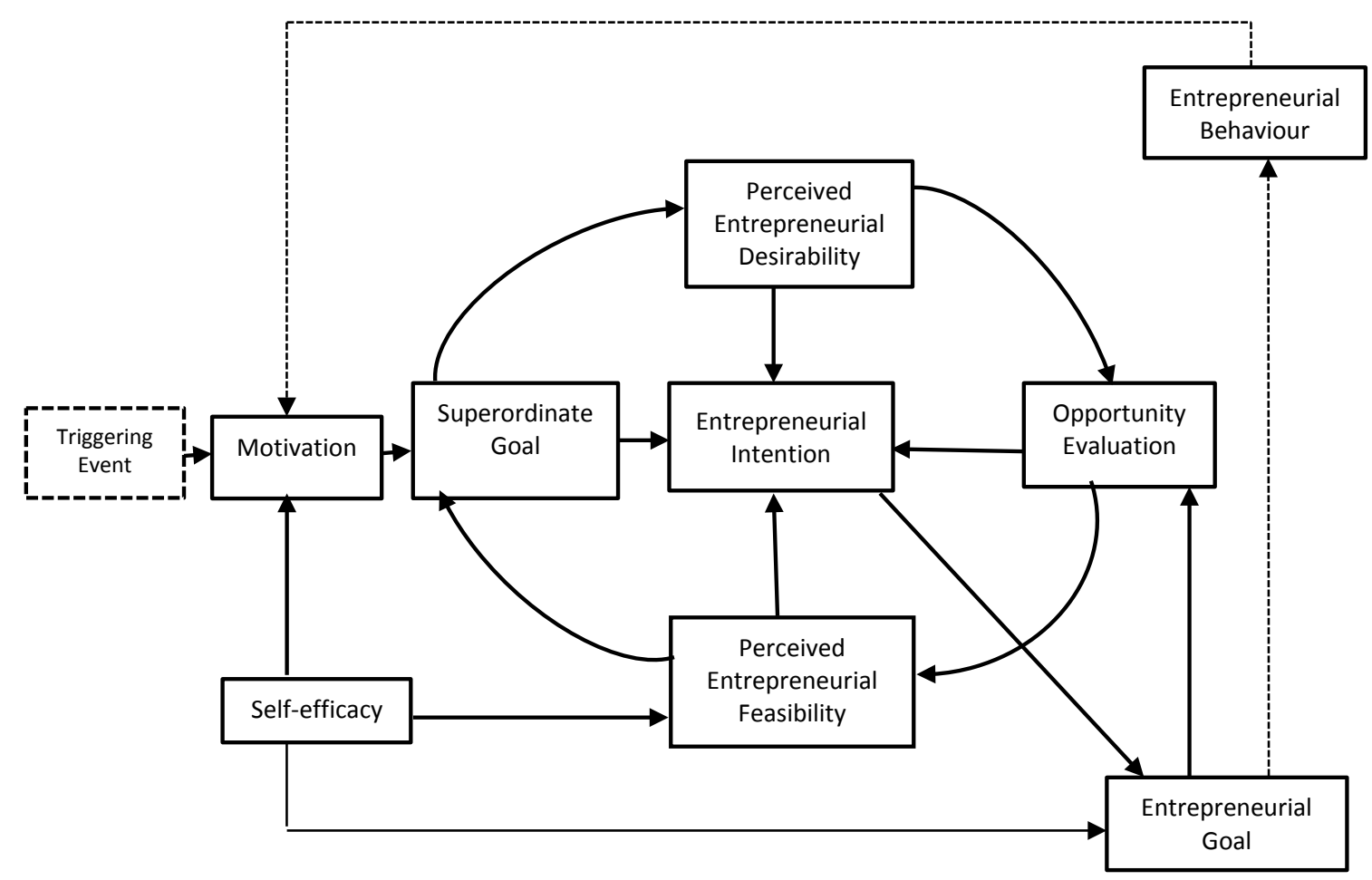

Figure 4.8: The context-specific entrepreneurial intention model Source: Elfving et al. (2009, p.29)

The context-specific model posits that the entrepreneurial intention development process is structured as represented by the variables in Figure 4.8 above. Here entrepreneurial intentions affect entrepreneurial behaviour; however, "entrepreneurial goals" mediates that process, which in itself can be categorised into either superordinate or subordinate entrepreneurial goals. Entrepreneurial goals in turn can be either "focal goals or subordinate goals" (Elfving et al., 2009, p.30). They posit that, however, for an action to eventually be carried out based on the initially formulated goals; other non-volitional variables will have to come into play. It is also possible that a person with an initial intention to carry out an action can fail to take such planned action. Some other things might prevent someone from pursuing her initial plan. 
According to the model, firstly, entrepreneurial intentions originate from "superordinate goals, perceived desirability, perceived feasibility and evaluation of the opportunity" (p.30). These variables surround the entrepreneurial intentions. They affect one another in a multi-directional dimension. Earlier study by Elfving (2008) suggests that both perceptions of "entrepreneurial feasibility and desirability" are impacted by superordinate goals. Thus, for an individual who wants to go into entrepreneurship to mainly be independent, the "entrepreneurial feasibility and desirability" must be examined as it relates to the amount or quality of independence that entrepreneurship will give.

Secondly, the superordinate goal in turn influences opportunity evaluation. Elfving (2008) shows that "motivation and superordinate goals" influence the types of potentials that entrepreneurs identify. Other studies have also suggested that "entrepreneurial desirability and feasibility" in turn influence each other (Carsrud et al., 2007; Brännback et al., 2006). Therefore, perhaps feasibility and desirability mostly go hand-in-hand: as entrepreneurial feasibility increases, it also increases the entrepreneurial desirability and vice versa (Elfving et al., 2009).

The importance of opportunity evaluation in the present model also captures the likelihood of a potential entrepreneur to be optimistic and employ biases that are self-serving that make her not to see herself as taking risks. The results in Elfving's (2008) study indicated that perceived feasibility and desirability influence general attitudes toward business-founding. By adding "superordinate goals and opportunity evaluation", entrepreneurial behaviour becomes linked to contexts. Thus, this enables individuals to assess their attitudes to executing definite entrepreneurship activities (Elfving et al., 2009).

Thirdly, the context-specific model suggests that if people see entrepreneurship as being feasible and desirable, then they are most suited to develop business intentions. It means that they hold a favourable attitude, and also see it being agreeable with their overall life goals as well as see an opportunity to implement business activities. The authors believe that the capacity to predict attitudes in relation to a specific entrepreneurial activity, as opposed to just general attitudes, separates their model as more rigorous than the earliest entrepreneurial intentions models (e.g. Krueger and Brazeal, 1994; Krueger and Carsrud, 1993).

This model also implies that motivation and self-efficacy hardly directly influence the nurturing of business-founding intentions; their indirect influences contribute to the rigour of the framework. For example, motivation influences the type of superordinate goals an individual determines to achieve. These goals are mostly determined based on what people perceive as most motivating to 
them. As motivation influences people's set goals; self-efficacy influences what they perceive they can do. Thus, self-efficacy impacts both superordinate and entrepreneurial goals, which in turn influences motivation largely through commitment. As self-efficacy becomes higher, it improves a person's commitment; thereby makes her more motivated to carry on (Elfving et al., 2009).

The authors believe "reality consists of many different processes and different structures where one event causes another" (Elfving et al., 2009, p.31). Thus, their model depicts that businessfounding intentions can lead to entrepreneurial goals, which invariably results in entrepreneurial behaviour. The emergence of the behaviour drives changes in motivation. The changes can, in turn, act as "triggering events" that lead to new business-founding intentions.

Elfving's et al. (2009) model attempts to bridge self-efficacy, goals, motivations and intentions building from the widely empirically tested frameworks of previous studies (e.g. Krueger, 2000; Krueger and Brazeal, 1994; Krueger and Carsrud, 1993). The observation, though, is that their context-specific model (in its original form) has not been widely subjected to empirical testing to confirm the usefulness of the proposed framework. Thus, this may pose a challenge for incorporating all these variables into a single model of intention and behaviour.

This research examined the various attempts by different scholars at finding theoretical explanations for the concept of entrepreneurial intentions. Specifically, it examined the factors that influence people's entrepreneurial intentions. Therefore, it is fair to conclude that there is no single unified theoretical perspective to capture all the complexities involved in human behaviour such as entrepreneurship. Therefore, by integrating the best strands of one or more models and considering the peculiarities that might be prevalent in different social, economic and cultural environments such as in developing economies will be a laudable attempt.

In the section that follows, this study proposes an integrated framework, which considers some of these peculiarities.

\subsection{Conceptual framework on the factors that influence entrepreneurial intentions}

In this sub-section, the researcher, first, defines the key constructs in the conceptual framework. The working definitions would help in clarifying how this study would understand the constructs in the framework adopted and to aid the assessment of content validity. Based on the insights from the various studies reviewed and the researcher's understanding of the concepts used, this study defines the constructs in the proposed conceptual framework as follows: 
1) Entrepreneurial intention is the mental perspective such as the desire, wish and hope that influence an individual's choice of entrepreneurship. It is the desire to act (Peng et al., 2012).

2) Personal attitude means the extent to which a person favours or disfavours the evaluation of the behaviour or action considered, in this case, undertaking an entrepreneurship career.

3) Perceived social norms mean the seeming social pressures on a person to carry out or not to carry out a certain behaviour or action (lakovleva et al., 2011).

4) Perceived behavioural control is the individual's perceived aptitude to achieve the target behaviour. It measures how an individual sees the ease or difficulty of starting an entrepreneurial activity (lakovleva et al., 2011).

5) Risk-propensity is the ability to have the psychological make-up and resources to cope with any failure (Bridge et al., 2009).

6) Locus of control describes an individual's perception of whether achieving outcomes or goals, was under their own control, or subject to external factors (Blundel and Lockett, 2011).

7) Achievement orientation describes the tendencies of individuals who prefer to strive to realise targets that are challenging but not beyond their abilities (Westhead et al., 2011).

8) Innovation orientation describes the tendencies of individuals who bring new ideas that work to meet pressing unmet needs and improve peoples' lives by creating new products or services, markets, systems, opportunities, processes, methods, institutions, or social change (Blundel and Lockett, 2011)

9) Personality traits are loosely defined in terms of the regularities in action, feeling and thoughts that are characteristic of the individual; some studies assume that the prsonality of individuals explain their actions (Westhead et al., 2011).

10) Capabilities are defined as relating to "enterprise competencies" which include personal qualities set alongside skills and individual orientations that predispose an individual toward venture creation (Bridge et al., 2009).

11) Perceived barriers are some negative factors in peoples' external environment that they think could discourage or stop them from deciding to start entrepreneurship activities.

12) Perceived support is defined as a combination of positive factors in the external environment that people think play some roles in the development or nurturing of entrepreneurship or entrepreneurial activities (Okhomina, 2010). 
The previous sections analysed the different theories propounded to explain entrepreneurial intentions and its antecedent factors. Ajzen's theory of planned behaviour provides a widelyapplicable foundation for developing an integrated conceptual model for this research. This follows previous studies (e.g. Peng et al., 2012; Moriano et al., 2012; Solesvik et al., 2012; Lińän, Urbano and Guerrero, 2011; lakovleva et al., 2011). The integrated conceptual model of entrepreneurial intentions is an attempt to bring together personal/psychological, behavioural, motivational, and social, environmental/contextual, institutional variables to explain the phenomenon. The proposed integrated conceptual model conceptualises that an individual's entrepreneurial intention is directly and positively influenced by attitude variables: "personal attitude", "subjective norms", and "perceived behavioural control." The model considers these three attitude measures and entrepreneurial intentions as being endogenous. Endogenous means that the variables are determined or influenced by the model or system. Put differently, they can influence one another in an interactive feedback manner, and they are multi-directional.

It is, nevertheless, noted that the attitude variables are, in turn, indirectly influenced by the individual's personality traits, as well as one's capability or competence levels. The contextual factors such as perceived barriers and supports act as exogenous factors. Their determination is outside the control of the individual. The present study hypothesises that perceived barriers can influence intentions negatively while perceived supports influence intentions positively or negatively.

Firstly, for an individual to take an "action", it is hypothesised that intentions are central for such behaviour to occur (Ajzen, 1991). Intentions show the desire to act. Where behaviour (such as setting up a business) demands that there be an opportunity and intentions to act; then measuring intentions becomes the suitable unit of analysis (Krueger and Carsrud, 2000). Thus, intentions involve both goals (ends) as well as strategies (means). A person first identifies the goals before making plans (probably at a later date) on how to achieve the goals (Ajzen, 1991, 2002).

It means that an individual can first resolve to create a business venture before choosing a line of business to set up (Brockhaus, 1987). It, therefore, requires a set of purposeful and thoughtful decisions (Bird, 1988; Shapero and Sokol, 1982). Secondly, intentions direct this decision process that can be either formal or informal. A person does not necessarily have to write a formal business plan to develop the intention of setting up a business or prove that intention. Ajzen's (1991) theory of planned behaviour, therefore, specifies three distinct antecedents of intentions as depicted in the framework below as personal attitude, subjective norms, and perceived behavioural control: 


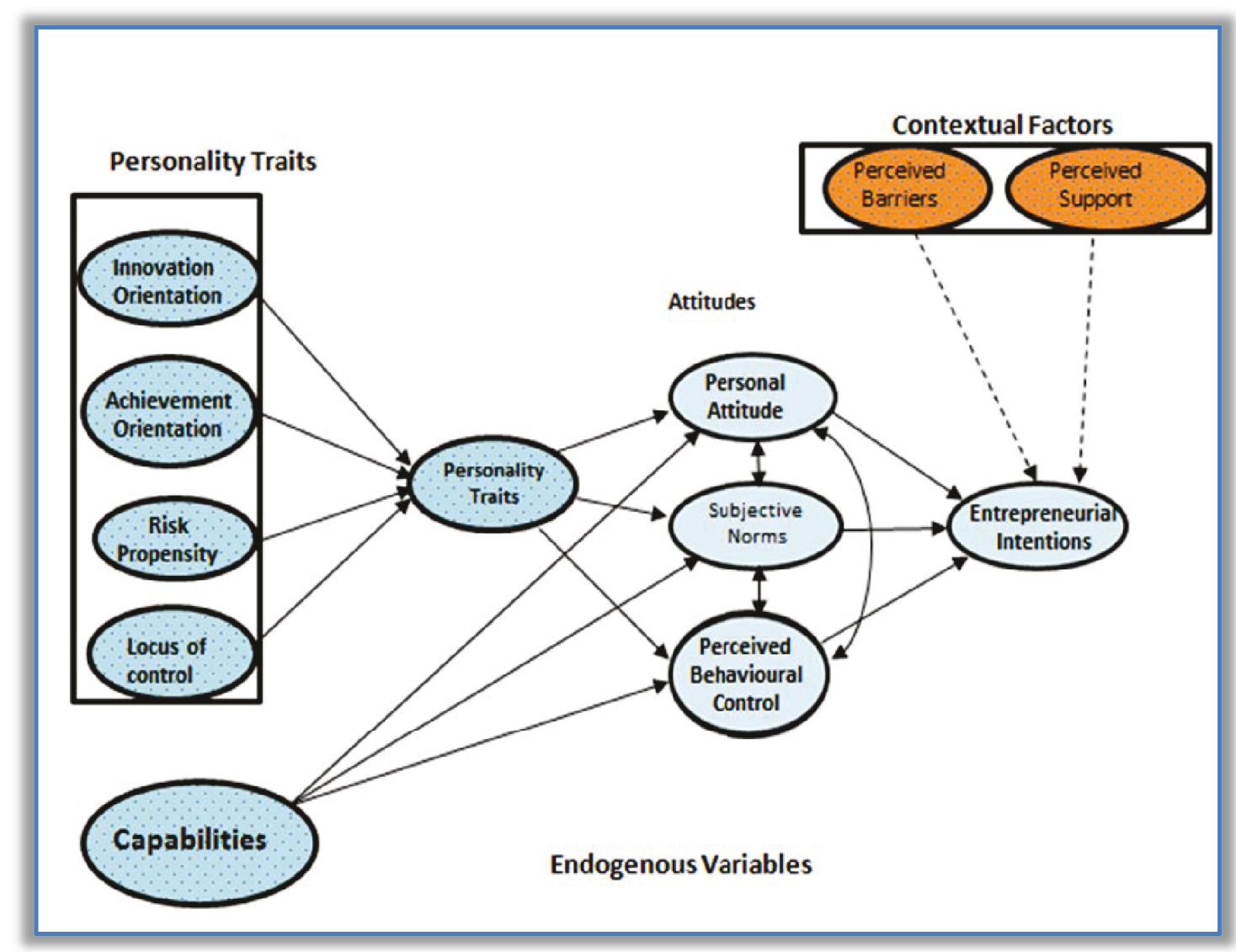

Figure 4.9: Conceptual framework on the factors that influence entrepreneurial intentions

Sources: Adapted from Peng et al. (2012, p.97); Bridge et al. (2009, p.82); Lüthje and Franke (2003, p.139); Caird (1992); Ajzen (1991, p.182)

Ajzen's concept of personal attitude comprises two components. Firstly, affective considerations (e.g. I like to be an entrepreneur; it is an attractive career); secondly, evaluative considerations (e.g. it is advantageous to be an entrepreneur). Accordingly, these attitudes are influenced by the sum of available beliefs connecting an action to many outcomes and further characteristics. Moreover, the power of "each belief is weighted by the assessment of the outcome" (Ajzen, 1991, p.183). Hence, two different persons might strongly believe that setting up a business involves many challenges. One person may, nonetheless, see the challenges in a positive perspective that must be overcome for one to succeed. Whereas the other person might perceive them as inhibiting and insurmountable (Moriano et al., 2012). Therefore, these dual processes involved in the formulation of attitudes enable one to explain the reason individuals holding dissimilar beliefs may demonstrate same attitudes and vice versa.

According to Ajzen's model, the concept of perceived subjective norms captures what "significant" people in a person's life think concerning accomplishing certain behaviour. Behaviours such as 
whether a person's family members, friends, mentors, and role model expect the individual to aspire to become an entrepreneur. If an individual is strongly motivated to comply with what these groups want her to become, and not an entrepreneur, the assumption is that she is low in internal locus of control. Thus, she has a weak orientation toward taking action (Lińän and Chen, 2009; Ajzen, 1991, 2001). It is advocated that research must find who among these groups has the most vital social influences on the potential entrepreneur (Krueger et al. 2000). This normative belief and the motivation to conform to the beliefs pressure one to encourage or dampen the development of a person's career as an entrepreneur.

The last predictive component in Ajzen's model of intention is the "perceived behavioural control." It is similar to self-efficacy emphasised by Bandura (1997) and perceived feasibility by Shapero and Sokol (1982). The concepts as described by Ajzen, Bandura, Shapero and Sokol all point to the sense of being able to start an entrepreneurial activity. But Ajzen (2002) differentiates between "perceived behavioural control" (PBC) and "self-efficacy." Ajzen conceptualises that PBC comprises both the feeling of being capable of starting an entrepreneurial activity (self-efficiency) as well as the perception of one's ability to control the activity.

The "personality" of the creator of the new venture is hypothesised to influence, though indirectly, the intentions of setting up a business. It does so by first influencing the attitudes of the potential entrepreneur. The criticisms that personality traits cannot effectively explain the intention of starting a business (Robinson et al., 1991; Gartner, 1985) become justified if the relationship is conceptualised as a direct one.

Thus, the present study conceptualises that compared with other people, individuals who will more likely become entrepreneurs will largely demonstrate some peculiar personality traits. The traits are the need for achievement, innovativeness, propensity to accept some level of risk and a strong individual locus of control. These variables influence entrepreneurial intentions through their effects on the attitudes of the individual (Peng et al., 2012; Lüthje and Franke, 2003; Shaver, 1995).

Entrepreneurial capabilities or competencies of an individual play a dominant role in the early stage (and probably all stages of business) of business start-up (Garzón, 2010). McClelland (1961) demonstrates that the entrepreneurial capabilities or skills shown in the individual's childhood days can predict the intention of setting up a business. Researchers have examined the influence of entrepreneurial competencies on intentions for setting up a business (Mitra, 2012; SchmittRodermund, 2004; Man and Lau, 2000; Chen, Greene and Crick, 1998; Bird, 1995; Caird, 1992). 
Man and Lau (2000) highlight the following areas of competencies that individuals must integrate as their abilities if they want to succeed in entrepreneurial activities. They are opportunity recognition, strategy, commitment, relationship, conceptualisation of ideas and organisation. Students' entrepreneurial competencies also must include skills in leadership, communication, high-level curiosity, passion for finding solutions to needs in the society, and cooperative capabilities. These are affected by personality traits, quality of training and retraining acquired (Schmitt-Rodermund, 2004).

Caird (1992) explores a model of four aspects of entrepreneurial capabilities that specifically relates to the field of expertise: knowledge, performance, skill and psychological variables. Caird's model incorporates factors that are either trait, cognitive or behavioural in nature. She argues that essential knowledge and skill is context-specific; the underlying trait factors may be more generic. She distinguished between everyday features of competency and the critical features in separating very enterprising people from the only adequately enterprising ones. The former can cope with complex changing circumstances whereas the latter may retreat. Moreover, different levels of competency are required in different jobs and business ventures. Figure 4.10 below shows Caird's model of entrepreneurial competency:

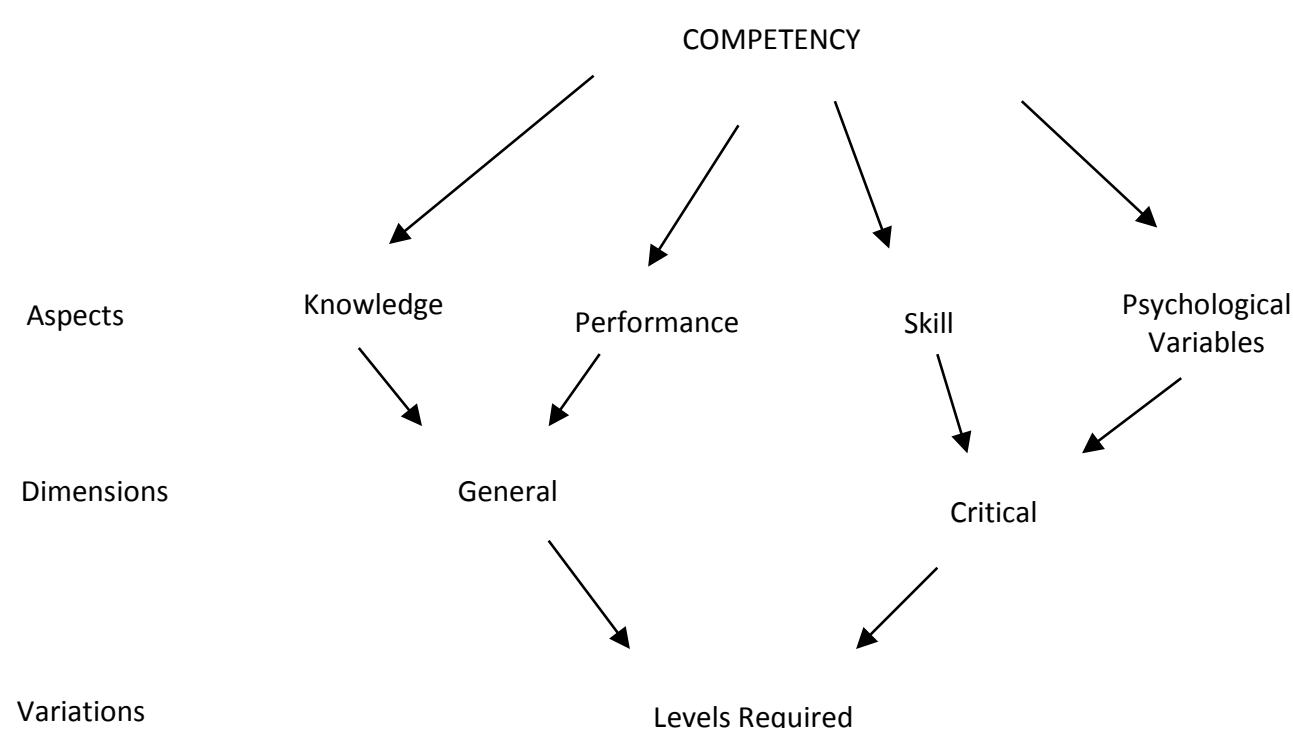

Outputs

Behavioural/Performance Indicators

Figure 4.10: Framework for identifying enterprise competency

Source: Caird (1992, p.16) 
Caird enumerated some possible enterprise competencies. They, however, overlap with entrepreneurial trait variables and include personal qualities set alongside skills and individual orientations. Caird listed these competencies as "dedication, decision making, goal setting, planning, responsibility, creativity, confidence, innovation, risk taking, insight, technical competencies, sensitivity to changes, networking and contacts, developing relationships, and project management" (p.16). Although Caird's work is known for helping to illustrate the concepts, nevertheless, she had noted a lack of adequate knowledge of the meaning of competency. She believed that the concept of competency "runs the risk of meaning everything and nothing" (Caird, 1992, p.16).

The concept seems not definitive as there might not be a competency that belongs to all entrepreneurs exclusively. Thus, cases may exist where non-entrepreneurs might have more business competencies than do some individuals who evidently are entrepreneurs. Caird's (1992) list of entrepreneurial competencies is more general than the domain-specific concepts such as perceived behavioural control or social norms. The emphasis, though, is that if people could be convinced of their self-efficacy regarding key entrepreneurial competencies, this will trigger their motivation to becoming business founders (Bridge, O’Neill and Martin 2009).

The contextual factors are the peculiar background factors that include contextual barriers and institutional environmental supports toward business start-up (Lüthje and Franke, 2003). Developing countries including Nigeria face many context-specific barriers to business start-up (as previously enumerated in Section 2.3) and the manner in which an individual perceives these barriers might influence whether entrepreneurial intentions will be formed or not. Lüthje and Franke argue that irrespective of a person's attitude toward founding business or company if the person mostly perceives the barriers as being intractable the person will be most unlikely desire to become an entrepreneur.

This framework, therefore, suggests a direct influence of perceptions of barriers and support on intentions. It conceptualises that the peculiar environment prevalent in the region is assumed to be the missing link for better understanding of attitudes toward setting up of businesses and intentions toward entrepreneurship. Perception of favourable conditions (trigger effects, to borrow a phrase by Elfving et al., 2009) might encourage students to develop intentions toward entrepreneurship, irrespective of their bad attitude. Conversely, notwithstanding the positive attitude and mentality students might have toward business-founding, if they perceive that the negative environmental factors are insurmountable, they are most unlikely to start any business (Lüthje and Franke, 2003). Moreover, even when people might have no strong support structures 
and role models from home, a productive-thinking support climate at university level can at least encourage students' intentions for setting up businesses (Bergmann, Hundt and Sternberg, 2013).

In sum, the framework that emerged from the conceptual dimensions presented in this chapter is that entrepreneurship intention is a complex phenomenon. It consists of a web of relationships that are both interrelated and interdependent (see Figure 4.9). The proposed model centres on twelve constructs (latent) as factors that influence students' business start-up intentions. They are innovation and achievement orientations, risk-taking propensity, internal locus of control, personality traits, personal attitude, perceived behavioural control, subjective norms, perceived capabilities, perceived barriers, and supportive environments. While each variable contributes to the interaction and the web, it is when all twelve variables interconnect that the full complexity of entrepreneurial intentions can be appreciated, understood and explained. Therefore, the variables should influence whether undergraduates choose in a positive or negative manner regarding entrepreneurial intentions.

\subsubsection{Justification of the conceptual framework and hypothesis formulation}

Ravitch and Riggan (2016, p.xii) note that "Reality is always more complex than any theory can completely capture, and you need to construct a conceptual framework that takes account of this complexity and avoids gross oversimplifications of the things you are studying, as best as you can." Thus, scholars mostly adjudge as better those inquiries that combine complementary theories that account for the various aspects of the research subject investigated (Greene, 2007). According to Greene, this dialectical stance for researching recognises that different philosophical, theoretical, and methodological approaches have different strengths and limitations. That it is often most productive to attempt to engage these different approaches with one another, in ways that provide generative insights and a deeper understanding than any single theory or approach can offer. The conceptual framework provided in the present study highlighted the main things to study (e.g., perception of capability, attitudes, context and traits) the key factors, variables or constructs (endogenous and exogenous) and the presumed relationships among them.

The reason for adopting Ajzen's theory of planned behaviour (TPB) as the foundational theory is because it is an established theory. Also, most researchers use it in explaining the links between future behaviour and today's intentions, and previous studies cited earlier in the empirical literature review section applied the theory to investigate student intentions toward entrepreneurship. Previous studies that used this theory received consistent empirical support 
(Van Gelderen et al., 2008). Researchers have also devoted a great deal of work to testing, advancing and criticising the TPB in many other academic disciplines.

Concerning the additional constructs such as personality traits (innovation orientation, achievement orientation, risk-propensity and locus of control) and capabilities, they do in fact enrich the researcher's understanding of entrepreneurship intentions. The assumption, however, is that the effects of these variables are mediated by the influence of the components of the TPB (i.e., personal attitude, subjective norms and perceived behavioural control) on entrepreneurship intentions variable. They have no direct effects on entrepreneurship intentions; it is the contextual variables and the components of the TPB that have direct effects on the entrepreneurship intentions variable. Based on the reviews in Section 4.3 made concerning the different variables of the model, the study formulates the following null hypotheses, which would be evaluated in the results section. The study highlighted the decisions (i.e., to reject or not to reject) concerning each of these hypotheses in Section 6.6, page 190:

H1: There is no significant relationship between students' level of perceived barriers and entrepreneurial intentions.

H2: There is no significant relationship between students' level of perceived support and entrepreneurial intentions.

H3: There is no significant relationship between students' level of personal attitude and entrepreneurial intentions.

H4: There is no significant relationship between students' level of subjective norms and entrepreneurial intentions.

H5: There is no significant relationship between students' level of perceived behavioural control and entrepreneurial intentions.

In the next subsection, a review of related empirical literature follows. The aim is to identify the gaps in previous studies on intentions toward setting up businesses and the factors that influence such intentions and highlight the need for the present study. 


\subsection{Review of related empirical literature on factors that influence entrepreneurial intentions}

Having examined the integrated conceptual framework that guides this study, this section considers the various empirical studies relevant to this study and takes a thematic review of the concepts applied in this study. It considers both from the empirical and methodological perspectives.

\subsection{1 "Personal attitudes" (PA), "subjective norms" (SN), "perceived behavioural control" (PBC) and entrepreneurial intentions}

Many recent studies have tested the applicability or otherwise of Ajzen's three antecedents of entrepreneurial intentions to predict entrepreneurial behaviour. Studies detected support for the concepts in the model for one or more of the variables (Solesvik et al., 2012; Peng et al.2012; lakovleva et al., 2011; Lińän et al., 2011; Engle et al., 2010; Lińän and Chen, 2009; Gird and Bagraim, 2008). Earlier empirical tests of the theory also exist (Autio et al., 2001; Krueger et al. 2000; Tkachev and Kolvereid, 1999; Kolvereid, 1996). Also found in the empirical literature are studies that tested the applicability or otherwise of Shapero's model of the entrepreneurial event (e.g. Solesvik et al., 2012; Fitzsimmons and Douglas, 2011; Krueger, 1993, 2000).

Both the Ajzen (1991) theory of planned behaviour, Shapero and Sokol (1982) and Shapero (1984) theory of entrepreneurial event have formed the pivot through which other theory-based models have been developed about entrepreneurial intentions. Furthermore, a handful of studies focused on incorporating some elements of these seminal works to build an integrative conceptual model of entrepreneurial intentions (e.g. Solesvik et al., 2012; Moriano et al., 2012; Peng et al., 2012; Fitzsimmons and Douglas, 2011; Pruett et al., 2009; Lüthje and Franke, 2003). The table below is a summary of selected empirical studies. Most studies use Ajzen's theory of planned behaviour, instead of Shapero's entrepreneurial event theory. Results showed some stability with the use of Ajzen's theory (Lińän et al., 2011). 
Table 4.1: Summary of selected studies on entrepreneurial intentions among students showing percentage of variance explained and significant factors

\begin{tabular}{|c|c|c|c|c|c|c|c|c|}
\hline Researcher(s) & $\begin{array}{l}\text { Country } \\
\text { Researched }\end{array}$ & Background & $\begin{array}{l}\text { Statistical } \\
\text { Tools used }\end{array}$ & $\begin{array}{l}\text { Explained } \\
\text { "Total } \\
\text { Variation of the } \\
\text { dependent } \\
\text { variable" } \\
\text { by Shapero's } \\
\text { EET model }\end{array}$ & $\begin{array}{l}\text { Explained } \\
\text { "Total } \\
\text { Variation of the } \\
\text { dependent } \\
\text { variable" } \\
\text { by Ajzen's } \\
\text { TPB model }\end{array}$ & $\begin{array}{l}\text { Explained } \\
\text { "Total } \\
\text { Variation } \\
\text { of the } \\
\text { dependent } \\
\text { variable" } \\
\text { by ICF }\end{array}$ & $\begin{array}{l}\text { Significant factors that } \\
\text { influence } \\
\text { entrepreneurial } \\
\text { intentions in the model } \\
\text { (Insignificant factors in } \\
\text { EET and TPB as may be } \\
\text { applicable) }\end{array}$ & Remarks in respect of ICF \\
\hline Krueger (1993) & USA & $\begin{array}{l}126 \text { university } \\
\text { students from } \\
\text { business faculty }\end{array}$ & $\begin{array}{l}\text { Factor } \\
\text { analysis }\end{array}$ & $54 \%$ & - & - & $\begin{array}{l}\text { "Perceived feasibility", } \\
\text { "perceived desirability" } \\
\text { and "propensity to act." }\end{array}$ & \\
\hline Kolvereid (1996) & Norway & $\begin{array}{l}128 \text { university } \\
\text { undergraduates } \\
\text { from business } \\
\text { faculty }\end{array}$ & $\begin{array}{l}\text { Structural } \\
\text { equation } \\
\text { modelling } \\
\text { (SEM) }\end{array}$ & - & $45 \%$ & - & $\begin{array}{l}\text { "Personal attitude", } \\
\text { "subjective norms", } \\
\text { "perceived behavioural } \\
\text { control", experience in } \\
\text { self-employment and } \\
\text { gender }\end{array}$ & \\
\hline $\begin{array}{l}\text { Tkachev and } \\
\text { Kolvereid (1999) }\end{array}$ & Russia & $\begin{array}{l}512 \text { university } \\
\text { students in } \\
\text { different } \\
\text { faculties }\end{array}$ & $\begin{array}{l}\text { Ordinary } \\
\text { least squares } \\
\text { (OLS)- } \\
\text { multiple } \\
\text { regression }\end{array}$ & - & $45 \%$ & - & $\begin{array}{l}\text { "Personal attitude", } \\
\text { "subjective norms" and } \\
\text { "perceived behavioural } \\
\text { control." }\end{array}$ & \\
\hline $\begin{array}{l}\text { Krueger, Reilly } \\
\text { and Carsrud } \\
\text { (2000) }\end{array}$ & USA & $\begin{array}{l}97 \text { university } \\
\text { students in } \\
\text { business } \\
\text { disciplines }\end{array}$ & $\begin{array}{l}\text { Ordinary } \\
\text { least squares } \\
\text { (OLS)- } \\
\text { multiple } \\
\text { regression }\end{array}$ & $41 \%$ & $35 \%$ & - & $\begin{array}{l}\text { "Propensity to act", } \\
\text { "perceived feasibility", } \\
\text { "perceived desirability", } \\
\text { and "attitude toward the } \\
\text { behaviour." } \\
\text { (Subjective norms) }\end{array}$ & \\
\hline $\begin{array}{l}\text { Armitage and } \\
\text { Conner (2001) }\end{array}$ & & $\begin{array}{l}\text { Took meta- } \\
\text { analyses on TPB } \\
\text { (161 articles) }\end{array}$ & & & - & & $\begin{array}{l}\text { "Personal attitude", } \\
\text { "subjective norms" and } \\
\text { "perceived behavioural } \\
\text { control." }\end{array}$ & \\
\hline
\end{tabular}




\begin{tabular}{|c|c|c|c|c|c|c|c|c|}
\hline Researcher(s) & $\begin{array}{l}\text { Country } \\
\text { Researched }\end{array}$ & Background & $\begin{array}{l}\text { Statistical } \\
\text { Tools used }\end{array}$ & $\begin{array}{l}\text { Explained } \\
\text { "Total } \\
\text { Variation of the } \\
\text { dependent } \\
\text { variable" } \\
\text { by Shapero's } \\
\text { EET model }\end{array}$ & $\begin{array}{l}\text { Explained } \\
\text { "Total } \\
\text { Variation of the } \\
\text { dependent } \\
\text { variable" } \\
\text { by Ajzen's } \\
\text { TPB model }\end{array}$ & $\begin{array}{l}\text { Explained } \\
\text { "Total } \\
\text { Variation } \\
\text { of the } \\
\text { dependent } \\
\text { variable" } \\
\text { by ICF }\end{array}$ & $\begin{array}{l}\text { Significant factors that } \\
\text { influence } \\
\text { entrepreneurial } \\
\text { intentions in the model } \\
\text { (Insignificant factors in } \\
\text { EET and TPB as may be } \\
\text { applicable) }\end{array}$ & Remarks in respect of ICF \\
\hline $\begin{array}{l}\text { Autio et al. } \\
\text { (2001) }\end{array}$ & 4 countries & $\begin{array}{l}3542 \text { university } \\
\text { undergraduate/ } \\
\text { graduate } \\
\text { students: } \\
\text { Finland }=796 \\
\text { Sweden=400 } \\
\text { Colorado } \\
\text { (USA) }=635 \\
\text { Stanford } \\
\text { (USA) }=1614 \\
\text { London Business } \\
\text { School (UK)=97 }\end{array}$ & $\begin{array}{l}\text { Ordinary } \\
\text { least squares } \\
\text { (OLS)- } \\
\text { multiple } \\
\text { regression }\end{array}$ & - & $\begin{array}{c}\text { Combined } \\
\text { data }=36 \% \\
\\
\text { Finland }=30 \% \\
\text { Sweden }=21 \% \\
\text { Colorado } \\
\text { (USA) }=24 \% \\
\text { Stanford } \\
\text { (USA) }=35 \% \\
\text { London Business } \\
\text { School (UK) }=15 \%\end{array}$ & - & $\begin{array}{l}\text { Attitude toward the } \\
\text { behaviour and perceived } \\
\text { behavioural control } \\
\text { (subjective norms) }\end{array}$ & $\begin{array}{l}\text { "Perceived behavioural control" was the most } \\
\text { important influencing factor of entrepreneurial } \\
\text { intentions followed by personal attitudes. } \\
\text { Situational and demographic measures such as } \\
\text { the experience of having worked in an SME, } \\
\text { employment status and expected changes in } \\
\text { employment were either weak or insignificant. }\end{array}$ \\
\hline $\begin{array}{l}\text { Lüthje and } \\
\text { Franke (2003) }\end{array}$ & USA & $\begin{array}{l}512 \text { MIT School } \\
\text { of Engineering } \\
\text { students }\end{array}$ & $\begin{array}{l}\text { Structural } \\
\text { equation } \\
\text { modelling } \\
\text { (SEM) }\end{array}$ & - & - & $91 \%$ & $\begin{array}{l}\text { Composite index measure } \\
\text { of attitude toward } \\
\text { entrepreneurship }\end{array}$ & $\begin{array}{l}\text { Personality traits showed an indirect influence } \\
\text { on intentions. Perceived barriers and perceived } \\
\text { support factors directly influenced intentions. }\end{array}$ \\
\hline $\begin{array}{l}\text { Gird and } \\
\text { Bagraim (2008) }\end{array}$ & South Africa & $\begin{array}{l}247 \text { Finalists in } \\
\text { Commerce at } \\
\text { two universities } \\
\text { in Western } \\
\text { Cape: } \\
\text { University if } \\
\text { Cape Town=168 } \\
\text { University of } \\
\text { Western } \\
\text { Cape=79 }\end{array}$ & $\begin{array}{l}\text { Ordinary } \\
\text { least squares } \\
\text { (OLS)- } \\
\text { multiple } \\
\text { regression } \\
\text { and } \\
\text { Hierarchical } \\
\text { regression }\end{array}$ & - & $28 \%$ & $\begin{array}{l}2 \% \text { (with } \\
\text { situational } \\
\text { variables) } \\
6 \% \text { (with } \\
\text { previous } \\
\text { exposure to } \\
\text { enterprise } \\
\text { activity) }\end{array}$ & $\begin{array}{l}\text { "Attitude toward the } \\
\text { behaviour", "subjective } \\
\text { norms" and "perceived } \\
\text { behavioural control." }\end{array}$ & $\begin{array}{l}\text { Among all the other variables added to explain } \\
\text { entrepreneurial intentions, only previous } \\
\text { exposure to entrepreneurial activity was } \\
\text { significant in the hierarchical regressions. Self- } \\
\text { employed parent, self-employed close family } \\
\text { relative, race and age failed the test of } \\
\text { significance }\end{array}$ \\
\hline $\begin{array}{l}\text { Liñan and Chen } \\
\text { (2009) }\end{array}$ & $\begin{array}{l}\text { Taiwan and } \\
\text { Spain }\end{array}$ & $\begin{array}{l}567 \text { students: } \\
\text { Engineering and }\end{array}$ & $\begin{array}{l}\text { Structural } \\
\text { equation }\end{array}$ & - & $\begin{array}{l}\text { Taiwan }=58 \% \\
\text { Spain }=58 \%\end{array}$ & $56 \%$ & $\begin{array}{l}\text { "Attitude toward the } \\
\text { behaviour", "subjective }\end{array}$ & $\begin{array}{l}\text { Gender influenced "attitude toward the } \\
\text { behaviour" and" perceived behavioural }\end{array}$ \\
\hline
\end{tabular}




\begin{tabular}{|c|c|c|c|c|c|c|c|c|}
\hline Researcher(s) & $\begin{array}{l}\text { Country } \\
\text { Researched }\end{array}$ & Background & $\begin{array}{l}\text { Statistical } \\
\text { Tools used }\end{array}$ & $\begin{array}{l}\text { Explained } \\
\text { "Total } \\
\text { Variation of the } \\
\text { dependent } \\
\text { variable" } \\
\text { by Shapero's } \\
\text { EET model }\end{array}$ & $\begin{array}{l}\text { Explained } \\
\text { "Total } \\
\text { Variation of the } \\
\text { dependent } \\
\text { variable" } \\
\text { by Ajzen's } \\
\text { TPB model } \\
\end{array}$ & $\begin{array}{l}\text { Explained } \\
\text { "Total } \\
\text { Variation } \\
\text { of the } \\
\text { dependent } \\
\text { variable" } \\
\text { by ICF }\end{array}$ & $\begin{array}{l}\text { Significant factors that } \\
\text { influence } \\
\text { entrepreneurial } \\
\text { intentions in the model } \\
\text { (Insignificant factors in } \\
\text { EET and TPB as may be } \\
\text { applicable) }\end{array}$ & Remarks in respect of ICF \\
\hline & & $\begin{array}{l}\text { business } \\
\text { students in } \\
\text { Taiwan=180 } \\
\text { Economics and } \\
\text { business } \\
\text { students in } \\
\text { Spain=387 }\end{array}$ & $\begin{array}{l}\text { modelling } \\
\text { (SEM) }\end{array}$ & & & & $\begin{array}{l}\text { norms" and "perceived } \\
\text { behavioural control." } \\
\text { (Age) }\end{array}$ & $\begin{array}{l}\text { control"; role model influenced attitude } \\
\text { toward the behaviour; self-employment } \\
\text { experience influenced subjective norms; work } \\
\text { experience influenced perceived behavioural } \\
\text { control. "Subjective norms" interacted with } \\
\text { "attitudes toward the behaviour" and } \\
\text { "perceived behavioural control" and not } \\
\text { directly with entrepreneurial intentions. } \\
\text { Age was insignificant. }\end{array}$ \\
\hline $\begin{array}{l}\text { Pruett et al. } \\
\text { (2009) }\end{array}$ & $\begin{array}{l}\text { Spain, USA } \\
\text { and China }\end{array}$ & $\begin{array}{l}1056 \text { university } \\
\text { undergraduates: } \\
\text { Spain }=603 \\
\text { USA }=317 \\
\text { China }=136\end{array}$ & $\begin{array}{l}\text { Ordinary } \\
\text { least squares } \\
\text { (OLS)- } \\
\text { multiple } \\
\text { regression }\end{array}$ & - & - & $28 \%$ & & $\begin{array}{l}\text { Used individual's position in the family, wish } \\
\text { for independence, perceived support from } \\
\text { close family, crave for creativity, history of } \\
\text { entrepreneurship in the family and } \\
\text { participant's country of origin. }\end{array}$ \\
\hline $\begin{array}{l}\text { Engle et al. } \\
\text { (2010) }\end{array}$ & 12 countries & $\begin{array}{l}1748 \text { university } \\
\text { students in } \\
\text { business } \\
\text { disciplines: } \\
\text { Bangladesh } \\
=1440 \\
\text { Russia }=228 \\
\text { USA }=218 \\
\text { Germany }=192 \\
\text { China }=185 \\
\end{array}$ & $\begin{array}{l}\text { Ordinary } \\
\text { least squares } \\
\text { (OLS)- } \\
\text { multiple } \\
\text { regression }\end{array}$ & - & $\begin{array}{l}\text { Varying from } 9 \% \text { in } \\
\text { Egypt to } 42 \% \text { in the } \\
\text { USA and Spain }\end{array}$ & - & $\begin{array}{l}\text { "Subjective norms" in all } \\
\text { the } 12 \text { countries; } \\
\text { "perceived behavioural } \\
\text { control" in } 7 \text { countries- } \\
\text { Spain, France, Egypt, } \\
\text { Germany, Bangladesh, } \\
\text { Russia, Finland. Attitude } \\
\text { toward the behaviour in } 6 \\
\text { countries-Ghana, USA, } \\
\text { China, Russia, Sweden and }\end{array}$ & \\
\hline
\end{tabular}




\begin{tabular}{|c|c|c|c|c|c|c|c|c|}
\hline Researcher(s) & $\begin{array}{l}\text { Country } \\
\text { Researched }\end{array}$ & Background & $\begin{array}{l}\text { Statistical } \\
\text { Tools used }\end{array}$ & $\begin{array}{l}\text { Explained } \\
\text { "Total } \\
\text { Variation of the } \\
\text { dependent } \\
\text { variable" } \\
\text { by Shapero's } \\
\text { EET model }\end{array}$ & $\begin{array}{l}\text { Explained } \\
\text { "Total } \\
\text { Variation of the } \\
\text { dependent } \\
\text { variable" } \\
\text { by Ajzen's } \\
\text { TPB model }\end{array}$ & $\begin{array}{l}\text { Explained } \\
\text { "Total } \\
\text { Variation } \\
\text { of the } \\
\text { dependent } \\
\text { variable" } \\
\text { by ICF }\end{array}$ & $\begin{array}{l}\text { Significant factors that } \\
\text { influence } \\
\text { entrepreneurial } \\
\text { intentions in the model } \\
\text { (Insignificant factors in } \\
\text { EET and TPB as may be } \\
\text { applicable) }\end{array}$ & Remarks in respect of ICF \\
\hline & & $\begin{array}{l}\text { France }=164 \\
\text { Spain }=139 \\
\text { Egypt }=136 \\
\text { Costa Rica }=98 \\
\text { Finland }=86 \\
\text { Ghana }=88 \\
\text { Sweden }=70\end{array}$ & & & & & Finland & \\
\hline $\begin{array}{l}\text { Liñan, Urbano } \\
\text { and Guerrero } \\
\text { (2011) }\end{array}$ & Spain & $\begin{array}{l}549 \text { Business } \\
\text { Administration } \\
\text { and Economics } \\
\text { finalists from } \\
\text { two Spanish } \\
\text { regional } \\
\text { universities: } \\
\text { Universitat } \\
\text { Autonoma de } \\
\text { Barcelona } \\
\text { (UAB), } \\
\text { Catolonia=300 } \\
\text { Universidad de } \\
\text { Sevilla (USE), } \\
\text { Andalusia }=249\end{array}$ & $\begin{array}{l}\text { Structural } \\
\text { equation } \\
\text { modelling } \\
\text { (SEM) }\end{array}$ & - & $\begin{array}{l}\text { UAB }=52.6 \% \\
\text { USE }=56.3 \%\end{array}$ & $\begin{array}{c}\text { Joint } \\
\text { sample: } \\
53.5 \%\end{array}$ & $\begin{array}{l}\text { "Attitude toward the } \\
\text { behaviour" and "perceived } \\
\text { behavioural control." } \\
\text { (Subjective norms) }\end{array}$ & $\begin{array}{l}\text { Subjective norms and "valuation of } \\
\text { entrepreneurship in the closer environment" } \\
\text { were significant in the joint model. } \\
\text { Self-employment experience was insignificant } \\
\text { in both samples. } \\
\text { Gender, role model, age, immigrant and labour } \\
\text { experience were significant in the overall } \\
\text { model. }\end{array}$ \\
\hline
\end{tabular}




\begin{tabular}{|c|c|c|c|c|c|c|c|c|}
\hline Researcher(s) & $\begin{array}{l}\text { Country } \\
\text { Researched }\end{array}$ & Background & $\begin{array}{l}\text { Statistical } \\
\text { Tools used }\end{array}$ & $\begin{array}{l}\text { Explained } \\
\text { "Total } \\
\text { Variation of the } \\
\text { dependent } \\
\text { variable" } \\
\text { by Shapero's } \\
\text { EET model }\end{array}$ & $\begin{array}{l}\text { Explained } \\
\text { "Total } \\
\text { Variation of the } \\
\text { dependent } \\
\text { variable" } \\
\text { by Ajzen's } \\
\text { TPB model }\end{array}$ & $\begin{array}{l}\text { Explained } \\
\text { "Total } \\
\text { Variation } \\
\text { of the } \\
\text { dependent } \\
\text { variable" } \\
\text { by ICF }\end{array}$ & $\begin{array}{l}\text { Significant factors that } \\
\text { influence } \\
\text { entrepreneurial } \\
\text { intentions in the model } \\
\text { (Insignificant factors in } \\
\text { EET and TPB as may be } \\
\text { applicable) }\end{array}$ & Remarks in respect of ICF \\
\hline $\begin{array}{l}\text { Fitzsimmons and } \\
\text { Douglas (2011) }\end{array}$ & $\begin{array}{l}\text { China, India, } \\
\text { Thailand } \\
\text { and } \\
\text { Australia }\end{array}$ & $\begin{array}{l}414 \text { students in } \\
\text { MBA class: } \\
\text { China }=39 \\
\text { India }=204\end{array}$ & $\begin{array}{l}\text { Hierarchical } \\
\text { regression }\end{array}$ & $23 \%$ & - & $7 \%$ & $\begin{array}{l}\text { "Perceived feasibility" and } \\
\text { "perceived desirability." } \\
\text { ("propensity to act") }\end{array}$ & $\begin{array}{l}\text { Interaction effects between "perceived } \\
\text { feasibility and desirability were negative." } \\
\text { Participants revealing low levels of perceived } \\
\text { desirability were less probable to reveal } \\
\text { business-founding intentions if they as well- } \\
\text { revealed high levels of perceived feasibility. } \\
\text { Participants revealing high levels of perceived } \\
\text { desirability yet with low levels of feasibility } \\
\text { were less likely to reveal business-founding } \\
\text { intentions. Participants who had previous } \\
\text { experience in own businesses were more } \\
\text { expected to reveal business-founding } \\
\text { intentions whereas those with higher levels of } \\
\text { education and previous experience at work } \\
\text { were expected to reveal business-founding } \\
\text { intentions. }\end{array}$ \\
\hline $\begin{array}{l}\text { lakovleva, } \\
\text { Kolvereid and } \\
\text { Stephan (2011) }\end{array}$ & $\begin{array}{l}5 \\
\text { developing } \\
\text { and } 8 \\
\text { developed } \\
\text { countries }\end{array}$ & $\begin{array}{l}2225 \text { Bachelor's } \\
\text { and Master's } \\
\text { degree students } \\
\text { from business } \\
\text { and other } \\
\text { disciplines: } \\
\text { Brazil=234 } \\
\text { Mexico }=90 \\
\text { Romania }=115 \\
\text { Russia }=235 \\
\text { Ukraine }=193 \\
\text { Australia }=75 \\
\text { Canada }=96 \\
\text { Czech Rep. }=103 \\
\text { France }=419 \\
\text { Germany=136 }\end{array}$ & $\begin{array}{l}\text { Structural } \\
\text { equation } \\
\text { modelling } \\
\text { (SEM) }\end{array}$ & - & $\begin{array}{l}62 \% \text { for developing } \\
\text { countries } \\
\begin{array}{l}59 \% \text { for developed } \\
\text { countries }\end{array} \\
\begin{array}{c}65 \% \text { for merged } \\
\text { data }\end{array}\end{array}$ & - & $\begin{array}{l}\text { "Attitude toward the } \\
\text { behaviour", "subjective } \\
\text { norms" and "perceived } \\
\text { behavioural control." } \\
\text { (Age) }\end{array}$ & \\
\hline
\end{tabular}




\begin{tabular}{|c|c|c|c|c|c|c|c|c|}
\hline Researcher(s) & $\begin{array}{l}\text { Country } \\
\text { Researched }\end{array}$ & Background & $\begin{array}{l}\text { Statistical } \\
\text { Tools used }\end{array}$ & $\begin{array}{l}\text { Explained } \\
\text { "Total } \\
\text { Variation of the } \\
\text { dependent } \\
\text { variable" } \\
\text { by Shapero's } \\
\text { EET model }\end{array}$ & $\begin{array}{l}\text { Explained } \\
\text { "Total } \\
\text { Variation of the } \\
\text { dependent } \\
\text { variable" } \\
\text { by Ajzen's } \\
\text { TPB model }\end{array}$ & $\begin{array}{l}\text { Explained } \\
\text { "Total } \\
\text { Variation } \\
\text { of the } \\
\text { dependent } \\
\text { variable" } \\
\text { by ICF }\end{array}$ & $\begin{array}{l}\text { Significant factors that } \\
\text { influence } \\
\text { entrepreneurial } \\
\text { intentions in the model } \\
\text { (Insignificant factors in } \\
\text { EET and TPB as may be } \\
\text { applicable) }\end{array}$ & Remarks in respect of ICF \\
\hline & & $\begin{array}{l}\text { Norway=112 } \\
\text { Spain=296 } \\
\text { Netherlands= } \\
121\end{array}$ & & & & & & \\
\hline $\begin{array}{l}\text { Paço et al. } \\
\text { (2011) }\end{array}$ & Portugal & $\begin{array}{l}74 \\
14 \text {-and-15-year } \\
\text { old secondary } \\
\text { students }\end{array}$ & $\begin{array}{l}\text { Structural } \\
\text { equation } \\
\text { modelling } \\
\text { (SEM) }\end{array}$ & - & $57.1 \%$ & - & $\begin{array}{l}\text { Personal attitudes and } \\
\text { perceived behavioural } \\
\text { control } \\
\text { (Subjective norms) }\end{array}$ & \\
\hline $\begin{array}{l}\text { Peng et al. } \\
\text { (2012) }\end{array}$ & China & $\begin{array}{l}2010 \text { final-year } \\
\text { students from } \\
\text { nine universities } \\
\text { in Xi'an }\end{array}$ & $\begin{array}{l}\text { Structural } \\
\text { equation } \\
\text { modelling } \\
\text { (SEM) }\end{array}$ & - & - & $\begin{array}{l}\text { Not } \\
\text { reported }\end{array}$ & $\begin{array}{l}\text { Subjective norms, } \\
\text { entrepreneurial attitudes, } \\
\text { entrepreneurial self- } \\
\text { efficacy and } \\
\text { entrepreneurial resistance } \\
\text { (-). }\end{array}$ & $\begin{array}{l}\text { Previous entrepreneurial experience was } \\
\text { significant on subjective norms and } \\
\text { entrepreneurial self-efficacy; competence and } \\
\text { individual control were significant on } \\
\text { subjective norms, entrepreneurial attitudes } \\
\text { and entrepreneurial self-efficacy. Risk- } \\
\text { propensity was significant on subjective norms. } \\
\text { (Gender, innovation orientation, achievement } \\
\text { orientation, entrepreneurial parents, relatives } \\
\text { and friends were insignificant. }\end{array}$ \\
\hline $\begin{array}{l}\text { Mariano et al. } \\
\text { (2012) }\end{array}$ & 6 countries & $\begin{array}{l}1070 \text { Bachelor's } \\
\text { and Master's } \\
\text { degree } \\
\text { students: } \\
\text { Germany=217 } \\
\text { Master's } \\
\text { India }=86 \\
\text { Iran=114 }\end{array}$ & $\begin{array}{l}\text { Structural } \\
\text { equation } \\
\text { modelling } \\
\text { (SEM) }\end{array}$ & - & $\begin{array}{c}\text { Germany }=19 \% \\
\text { India }=59 \% \\
\text { Iran }=38 \% \\
\text { Poland }=41 \% \\
\text { Spain }=39 \% \\
\text { Netherlands }=58 \%\end{array}$ & $\begin{array}{c}38 \% \\
\text { Overall data }\end{array}$ & $\begin{array}{l}\text { Attitudes toward the } \\
\text { behaviour, subjective } \\
\text { norms, and } \\
\text { entrepreneurial self- } \\
\text { efficacy }\end{array}$ & $\begin{array}{l}\text { Gender, age, major (course) and employment } \\
\text { status were insignificant. No stronger effects of } \\
\text { subjective norms were observed in } \\
\text { collectivistic countries- Spain, India, Poland and } \\
\text { Iran- than in individualistic countries such as } \\
\text { Netherlands and Germany as was hypothesised } \\
\text { by the authors. But the variable "subjective } \\
\text { norms" was only closely related with business- }\end{array}$ \\
\hline
\end{tabular}




\begin{tabular}{|c|c|c|c|c|c|c|c|c|}
\hline Researcher(s) & $\begin{array}{l}\text { Country } \\
\text { Researched }\end{array}$ & Background & $\begin{array}{l}\text { Statistical } \\
\text { Tools used }\end{array}$ & $\begin{array}{l}\text { Explained } \\
\text { "Total } \\
\text { Variation of the } \\
\text { dependent } \\
\text { variable" } \\
\text { by Shapero's } \\
\text { EET model }\end{array}$ & $\begin{array}{l}\text { Explained } \\
\text { "Total } \\
\text { Variation of the } \\
\text { dependent } \\
\text { variable" } \\
\text { by Ajzen's } \\
\text { TPB model }\end{array}$ & $\begin{array}{l}\text { Explained } \\
\text { "Total } \\
\text { Variation } \\
\text { of the } \\
\text { dependent } \\
\text { variable" } \\
\text { by ICF } \\
\end{array}$ & $\begin{array}{l}\text { Significant factors that } \\
\text { influence } \\
\text { entrepreneurial } \\
\text { intentions in the model } \\
\text { (Insignificant factors in } \\
\text { EET and TPB as may be } \\
\text { applicable) }\end{array}$ & Remarks in respect of ICF \\
\hline & & $\begin{array}{l}\text { Poland }=291 \\
\text { Spain }=227 \\
\text { Netherlands }=13\end{array}$ & & & & & & founding intentions in India and Netherlands. \\
\hline $\begin{array}{l}\text { Solesvik et al. } \\
\text { (2012) }\end{array}$ & Ukraine & $\begin{array}{l}192 \text { students of } \\
\text { Economics and } \\
\text { Business across } \\
\text { three } \\
\text { universities }\end{array}$ & $\begin{array}{l}\text { Structural } \\
\text { equation } \\
\text { modelling } \\
\text { (SEM) }\end{array}$ & $40 \%$ & $55 \%$ & $60 \%$ & $\begin{array}{l}\text { "Perceived desirability", } \\
\text { "perceived feasibility", } \\
\text { "attitude toward the } \\
\text { behaviour", "perceived } \\
\text { behavioural control" and } \\
\text { entrepreneurial parents. } \\
\text { (propensity to act, and } \\
\text { subjective norms) }\end{array}$ & $\begin{array}{l}\text { Age, desirability and feasibility were } \\
\text { insignificant in the integrated conceptual } \\
\text { framework (ICF). }\end{array}$ \\
\hline $\begin{array}{l}\text { Van Gelderen et } \\
\text { al. (2008) }\end{array}$ & Netherlands & $\begin{array}{l}1225 \text { Business } \\
\text { Administration } \\
\text { students }\end{array}$ & $\begin{array}{l}\text { Multiple and } \\
\text { logistic } \\
\text { Regression } \\
\text { analyses }\end{array}$ & - & $28 \%$ & - & $\begin{array}{l}\text { "Subjective norms", } \\
\text { "entrepreneurial } \\
\text { alertness", importance } \\
\text { attached to financial } \\
\text { security." }\end{array}$ & $\begin{array}{l}\text { They first conducted a qualitative study but } \\
\text { only for operationalising the components of } \\
\text { the theory of planned behaviour. }\end{array}$ \\
\hline Present research & $\begin{array}{l}\text { South-south } \\
\text { and } \\
\text { Southeast } \\
\text { Nigeria }\end{array}$ & $\begin{array}{l}1,129 \text { final-year } \\
\text { indigenous } \\
\text { undergraduate } \\
\text { students }\end{array}$ & $\begin{array}{l}\text { Partial least } \\
\text { squares } \\
\text { Structural } \\
\text { equation } \\
\text { modelling } \\
\text { (PLS-SEM); } \\
\text { Focus group } \\
\text { interviews, } \\
\text { using } \\
\text { thematic }\end{array}$ & - & - & $44.3 \%$ & $\begin{array}{l}\text { "Personal attitude", } \\
\text { "Perceived behavioural } \\
\text { control" ("subjective } \\
\text { norms") }\end{array}$ & $\begin{array}{l}\text { "Perceived barriers" was significant on } \\
\text { intentions; "Perceived support" was } \\
\text { insignificant on intentions. "Personality traits" } \\
\text { index was insignificant on "subjective norms", } \\
\text { among other findings. The results from the } \\
\text { focus group discussions further suggest that } \\
\text { the factors that the undergraduates perceive } \\
\text { as influencing them toward entrepreneurship }\end{array}$ \\
\hline
\end{tabular}




\begin{tabular}{|c|c|c|c|c|c|c|c|c|}
\hline Researcher(s) & $\begin{array}{l}\text { Country } \\
\text { Researched }\end{array}$ & Background & $\begin{array}{l}\text { Statistical } \\
\text { Tools used }\end{array}$ & $\begin{array}{l}\text { Explained } \\
\text { "Total } \\
\text { Variation of the } \\
\text { dependent } \\
\text { variable" } \\
\text { by Shapero's } \\
\text { EET model }\end{array}$ & $\begin{array}{l}\text { Explained } \\
\text { "Total } \\
\text { Variation of the } \\
\text { dependent } \\
\text { variable" } \\
\text { by Ajzen's } \\
\text { TPB model }\end{array}$ & $\begin{array}{l}\text { Explained } \\
\text { "Total } \\
\text { Variation } \\
\text { of the } \\
\text { dependent } \\
\text { variable" } \\
\text { by ICF }\end{array}$ & $\begin{array}{l}\text { Significant factors that } \\
\text { influence } \\
\text { entrepreneurial } \\
\text { intentions in the model } \\
\text { (Insignificant factors in } \\
\text { EET and TPB as may be } \\
\text { applicable) }\end{array}$ & Remarks in respect of ICF \\
\hline & & & analyses & & & & & $\begin{array}{l}\text { can be summarised as: "transformational", } \\
\text { "affective", "personal fulfilment motives", } \\
\text { "personality traits", "push factors", "barrier } \\
\text { factors", "practical-oriented course teaching", } \\
\text { "experienced entrepreneurs as teachers", } \\
\text { "university-industry ties", and "internship } \\
\text { experiences." }\end{array}$ \\
\hline
\end{tabular}

Notes: EET- "entrepreneurial event theory"; TPB- "theory of planned behaviour"; ICF- "integrated conceptual framework."

Source: Adapted from Solesvik et al. (2012, p.443-444). 
The Ajzen's theory of planned behaviour argues that people's decision to found businesses are anchored on three basic motivational factors. They are personal attitudes toward the behaviour (PA), perceived behavioural control (PBC) and subjective or social norms (SN). A person's attitudes toward the behaviour denote how appealing one considers a positive or negative desire concerning being an entrepreneur. Hence, these attitudes become vital in connection with the perception of venture desirability that influences business-founding intentions (Ajzen, 2002; Kolvereid, 1996). While perceived behavioural control depicts an individual's perceived ease or unease in becoming a business founder; its importance in the business-founding intention process rests on its explanatory power. The reason shows that the person will be able to control the entrepreneurial process. Consequently, Bandura (1997) believes that PBC can be affected by distinct processes including personal judgements, role modelling, enactive proficiency and social group.

Different measures have been employed by some authors (e.g. Boyd and Vozikis, 1994) to determine perceived behavioural control. So far, the measures have been supported in empirical works as reported in Table 4.1 above (Solesvik et al., 2012; Lińän et al., 2011; Paço et al., 2011; lakovleva et al., 2011; Lińän and Chen, 2009; Gird and Bagraim, 2008; Tkachev and Kolvereid, 1999). For example, in Lińän's et al. (2011) study of Spanish students, they found in their overall model significant correlations between perceived behavioural control and entrepreneurial intentions $(r=0.288, p<0.05)$. They also found correlations for attitude toward the behaviour and entrepreneurial intentions $(r=0.471, p<0.05)$. In Paço's et al. (2011) study, they found for Portugal students a higher direct effect of personal attitude on entrepreneurial intentions. A value of 0.737 , which was higher than the threshold value of 0.20 ; also 0.195 or 0.20 for perceived behavioural control and entrepreneurial intentions.

In lakovleva's et al. (2011) study of 13 countries, they detected significant correlations between personal attitudes and entrepreneurial intentions $(r=0.691, p<0.01)$ and between perceived behavioural control and entrepreneurial intentions $(r=0.385, p<0.01)$. These results are in line with other authors' works reported in Table 4.1.

The third component of Ajzen's model is subjective or social norms. Ajzen refers to this measure as the likelihood that significant referent people or groups in a person's life endorse of or object to carrying out a given behaviour (i.e. enterprise formation). Empirical results of the relationship between social norms and entrepreneurial intentions differ in many studies. Lińän and Chen's (2009) study suggested that the cause of this difference in empirical results might be the dissimilarities in the measurement of the concept in the various research settings. 
In their study of USA students, Krueger et al. (2000) found no statistically-significant links between social norms and entrepreneurial intentions. Autio's et al. (2001) study of four countries reported similar results. Recent studies also failed to find the concept to be significant. They include Solesvik's et al. (2012) study of 192 Ukrainian students; Paço's et al. (2011) study of 74 Portuguese secondary school students and Linän's et al. (2011) study of 549 Spanish students.

Conversely, Engle et al. (2010) found statistically-significant correlation between social norms and entrepreneurial intentions in all 12 countries studied. In lakovleva's et al. (2011) study of 13 countries, they found significant correlations between social norms and entrepreneurial intentions in the overall model $(r=0.523, p<0.01)$. The significant path coefficient between the two variables was $0.18(p<0.001)$. Linän and Chen (2009) found in the overall model that there was an interaction between SN, PA and PBC. They found about 20 per cent variance "explained" between SN and PA; and 18 per cent between SN and PBC. They, however, detected no direct effect on social norms and entrepreneurial intentions. Table 4.1 above reported empirical studies that found significant interactions between social norms and entrepreneurial intentions (e.g. Moriano et al., 2012; Kolvereid, 1996; Peng et al.2012; Gird and Bagraim, 2008; Tkachev and Kolvereid, 1999).

Consequently, Ajzen (1991) proposes that the comparative significance of the three variables examined above differs across circumstances and behaviours. In some circumstances, this means that all the three factors can independently influence intentions. In other cases, only personal attitudes toward the behaviour might influence intentions. Still, in other situations both social norms and perceived behavioural control or either one of them might influence intentions. So, particular target behaviour would have to be considered in research at a point in time (e.g. setting up of a new venture). Doing this can prevent universal generalisations across circumstances and behaviours. The reason is that there might be notable contrasts existing among national and regional cultures, ethnic groups, organisations and persons.

\subsubsection{Personality traits and entrepreneurial intentions}

Traits approach to studying entrepreneurship is perhaps the most widely used approach in studying entrepreneurship propensity of budding entrepreneurs (Paco et al., 2011). The approach is also referred to as psychological or personality approach. Other researchers (e.g. Krueger 2000; Muller and Thomas, 2000) use the integrative approach, which incorporates the cognitive factors (thoughts and beliefs) into a conceptual model for investigation. Krueger et al. (2000) advocate that intentions are the best predictors of planned future behaviour. Nevertheless, some scholars 
even after having employed intention models to explain entrepreneurial potentials still recommended the consideration of traits constructs. The reason is for the improvement of the predictive power of their models (Paco et al., 2011).

The usual criticism often levelled against the traits approach is its one-sided position on what it takes to be a successful entrepreneur-that is, the "personality" of the entrepreneur. Therefore, an integrated multidimensional approach incorporating contextual factors, attitudes or motivational factors that perhaps can serve as mediators for personality traits in influencing intentions has been advocated (Paco et al., 2011; Bridge et al., 2009; Hancock and Fitzsimons, 2004; Frese, 2000; Ajzen, 1991).

Empirical studies that examined the various personality trait factors that influence the entrepreneurial tendency of individuals abound in the literature (Okhomina, 2010; Athayde, 2009; Krasniqi, 2009; Siyanbola et al., 2012; Taormina and Lao, 2007; Gurol and Atsan, 2006; Louw et al., 2003). Specifically, Gurol and Atsan (2006, p.31) used the question, "what are you planning to do after graduation" to discriminate between "entrepreneurially-inclined and non-inclined" students in Turkey. They tested the influence of traits and demographic variables on entrepreneurial inclination and applied correlation and t-statistics. They found higher correlations for the higher need for achievement, higher innovativeness orientation, risk-taking propensity, internal locus of control, among the "entrepreneurially-inclined" students as compared to the other students. Nevertheless, the study failed to find significant correlations between self-confidence and tolerance of ambiguity within the two groups.

Taormina and Lao (2007) used descriptive statistics and regression technique on data from three groups of Chinese respondents. They considered achievement striving, social networking (Guanxi) and optimism as constructs for psychological variables. They used "perceived importance of a favourable business environment" scale to measure motivation to start a business (being the dependent variable). They demonstrated that both the personality (or traits) variables and the environmental factors played a role, though unequally. They surmised that personality factors mostly influenced people who are planning to start a business while business environmental factors explained the greater percentage of influence on people who already started a business and were successful. These results are in line with studies such as Okhomina (2010), Krasniqi (2009) and Louw et al. (2003) that all used data from different countries. But their studies employed slightly varying constructs of psychological variables. 
Empirical studies in Nigeria relating to entrepreneurial interest of students include the seminal works by Afolabi et al. (2008) and later by Siyanbola et al. (2009). The study by Siyanbola and colleagues examined the entrepreneurial interest (which they also called entrepreneurial propensity) of 7,560 students sampled from 25 tertiary institutions in Nigeria. Their work used a binary "yes" and "no" approach to measuring entrepreneurial interest of students (as the dependent variable), personal characteristics and demographic factors (as independent variables). They adopted correlation and logistic regression methods. They found that "number of children by father, position among mother's children, father's monthly income and entrepreneurial education" (p.1) were necessary conditions to stimulate entrepreneurial interest.

One of the major departures of the present study from Siyanbola's et al. (2012) work is that it assesses the influences on entrepreneurial intentions from the point of perception of individuals' personality traits, attitudes, capabilities, external support, and barrier factors. It also considered students' direct perspectives using focus group data: the researcher, therefore, assumes this combination is holistic. Siyanbola and colleagues' work only assessed various personal characteristics and demographic factors. Specifically in the aspect of methodology, the present study improves on Siyanbola's et al. (2012) work also by first using a multi-indicator measure (Likert scale) to measure both the dependent and independent variables. This measure allows for better capture of the variability of individuals' responses that serve to reveal the differences between individuals and groups (Caird, 1989). Recent studies advocated this approach (Paco et al., 2011; Bridge et al., 2009).

The current study follows the works of Peng et al. (2012) who using the scale developed by Athayde (2009), examined the usefulness of trait variables in influencing attitudes factors among Xi'an Chinese students (refer to Table 4.1 above). Peng and colleagues used students' personality traits measured from innovation and achievement orientations, risk-taking propensity and individuals' locus of control. These four measures accounted for about 72 per cent of the variance in the respondents' personality traits with a reliability coefficient of the factors spanning from 0.75 to 0.83 . Their results detected that personality traits had significant positive influence on the respondents' social or subjective norms and entrepreneurial self-efficacy (similar to perceived behavioural control in Ajzen' model). Nevertheless, they failed to detect a significant influence of innovation and achievement orientations on personal attitude, self-efficacy and social norms among Chinese undergraduate students. 


\subsubsection{Entrepreneurial capabilities and entrepreneurial intentions}

Recent understanding and consensus among academic researchers and practitioners in the field of entrepreneurship suggest that besides students having to acquire specific knowledge in subject disciplines, they also need to acquire capabilities (otherwise competencies). Trilling and Fadel (2012) suggest competencies in what many acknowledge as $21^{\text {st }}$-century skills. These skills are creativity and innovation, initiative and self-direction, critical thinking, productivity and accountability, problem-solving, adaptability and flexibility. Others are cross-cultural and social skills, collaboration and communication, leadership and responsibility, media, information, and ICT literacies. Competencies in these areas by potential business founders can help them to participate meaningfully in solving both theoretical and more importantly the practical, real-world problems. Solving the "Big E" global problems - the economy, energy, the environment, equity and education can help in improving the quality of life (Trilling and Fadel, 2012, p.157).

Empirical studies attest that an individuals' level of perceived competence plays a key role in business-founding intentions. That is, if people are convinced of their self-efficacy regarding key business competencies, they will more likely be motivated to take to entrepreneurship (Obschonka et al., 2011; Obschonka, Silbereisen and Schmitt-Rodermund, 2010; SchmittRodermund, 2004; Bird, 1995). Bird's study used a model of competency development based on motive/trait, self-concept, social role, and skills for new venture start-up success. She concluded that entrepreneurs do need to learn from distinct and real experiences (as opposed to abstract theories). They need to be active rather than reflective learners. That potential business founders would need exposures to real business problems to learn from and develop competencies rather than the traditional writing, presentations and lectures.

She proposes that competencies are not necessarily "taught" but enhanced through fostering, facilitation and nurturing processes. She also maintains that social intervention needed to change deep level capabilities can be enhanced through enrichment programmes (e.g. Junior Achievers and Head Start in the U.S.). It also needs cultural reforms.

Schmitt-Rodermund's (2004) study of German $10^{\text {th }}$-grade students found association between personality traits, family education, entrepreneurial competencies and intentions. He described entrepreneurial competencies in terms of an individual's leadership skills, tendencies for finding solutions, curiosity, and opportunity recognition. Obschonka et al. (2010) tested the influence of the entrepreneurial personality on early entrepreneurial competencies, mediated by control beliefs, and entrepreneurial intentions of 496 German scientists. They measured entrepreneurial 
competencies in terms of a person's "early inventions", leadership qualities, and early commercial activities performed by the participants. They found support for the notion that entrepreneurship can be encouraged from the early years of an individual: that entrepreneurial personality and early-years entrepreneurial competence were related. Obschonka et al. (2011) also confirmed this finding. But that their respondents were now tested as two separate groups: the first group were those who made progress in the business-founding process while the second group were serial entrepreneurs. Their results supported the notion of the influence of early entrepreneurial competence on serial entrepreneurship.

\subsubsection{Contextual factors and entrepreneurial intentions}

Lüthje and Franke (2003) investigated the influence of context-specific factors on entrepreneurial intentions. Based on their exploratory qualitative interview method and literature review, they created 44 questions that were then administered to 12 students in business and engineering faculties at MIT in the United States. They subjected the responses to a confirmatory factor analysis and detected that the factors that are essential for students' decision to go into entrepreneurial activities can be categorised into "perceived support factors" and "perceived barrier factors." Specifically, they found that MIT engineering students perceived that banks dislike giving loans as venture capital to students. Moreover, that the laws of the state are too limiting toward young business founders, thus, indicating a moderating effect of contextual factors on the attitude and intentions link. This study was a modest attempt at employing students' explanations to knowing the contextual barriers and environmental support factors that students believed influence business-founding decisions. But students in the U.S. might have dissimilar factors as southern Nigeria students. Therefore, a clear knowledge through the qualitative study of the Nigerian students' "stories" concerning what they perceive as barriers and support need investigating. It will help universities' entrepreneurship development programme facilitators in the regions to know what factors or conditions to improve, sustain or expand.

Recent study by Kadir et al. (2012) examined the influence of educational support environment, as a contextual factor, in convincing Malaysian Mara Professional College students to decide for entrepreneurship. They developed their survey instrument around the ideas of HEls supporting students through "pedagogical, syllabus and co-curricular activities" (p. 2167) and administered the survey to 183 students. They detected support among these educational support factors and entrepreneurial intentions. 
Specifically, their regression results showed that the educational support explained about 41 per cent of the variance of the attitudinal factor and 58 per cent of the behavioural factor. Their idea is that the educational environment should provide a purposeful learning to impact students' attitudes, understanding and skills to deal with the intricacies associated with entrepreneurial activities. These activities include opportunity seeking, resource gathering and running the business successfully. They proposed that this can be achieved by providing students an entrepreneurial education that incorporates the experience of mastery, and practical activities. They also proposed training on the development of the high-quality business plan and business simulation or running of actual small/micro businesses.

Also on the nature of pedagogy in entrepreneurial education that students need to be taught, Kuratko $(2005$, p. 583) in using the ideas of Solomon, Duffy and Tarabishy (2002) states that:

A core objective of entrepreneurship education is that it differentiates from typical business education. Business entry is fundamentally a different activity than managing a business (Gartner and Vesper, 1994); entrepreneurial education must address the equivocal nature of business entry (Gartner, Bird and Starr, 1992). To this end, entrepreneurship education must include skill-building courses in negotiation, leadership, new product development, creative thinking, and exposure to technological innovation (McMullan and Long, 1987; Vesper and McMullen, 1988). Other areas identified as important for entrepreneurial education included awareness of entrepreneur career options (Donckels, 1991; Hills, 1988), sources of venture capital (Vesper and McMullen, 1988; Zeithaml and Rice, 1987), idea protection (Vesper and McMullen, 1988), ambiguity tolerance (Ronstadt, 1987), the characteristics that define the entrepreneurial "personality (Hills, 1988; Hood and Young, 1993; Scott and Twomey, 1998), and the challenges associated with each stage of venture development (McMullan and Long, 1987; Plaschka and Welsch, 1990).

To be able to deliver "experiential learning", universities should challenge themselves to develop programmes, re-train lecturers/entrepreneurship facilitators and provide the learning infrastructures to enable the use of entrepreneurship learning tools. Kuratko $(2005$, p.584) summarised these tools as:

Business plans (Gartner and Vesper, 1994; Gorman et al., 1997; Hills, 1988; Preshing, 1991; Vesper and McMullen, 1988); student business start-ups (Hills, 1988; Truell, Webster and Davidson, 1998); consultation with practicing entrepreneurs (Klatt, 1988; Solomon et al., 1994); computer business games and simulations (Brawer, 1997); behavioural simulations (Stumpf et al., 1991); interviews with entrepreneurs, environmental scans (Solomon et al., 2002); "live" cases (Gartner and Vesper, 1994); field trips and the use of video and films (Klatt, 1988). 
Empirical literature also finds a connection between student-centred learning methodology in entrepreneurship and changes in attitudes and intentions toward business-founding (Kuratko, 2005). This centres on "team-oriented learning and learning-by-doing-hands-on events" that provide proficiency experience or repeated performance achievement (Rasmussen and Sørheim, 2006, p.189). The work of Kadir et al. (2012) suggests that success in teaching entrepreneurship require a non-traditional teaching (rather pedagogy) that is linked to action-learning, job-related learning, entrepreneurship training and experiential learning. Thus, there is a greater likelihood for students to wish to become entrepreneurs if they have been equipped with business skills, opportunity recognition skills, detailed business information and pastoral supports from their universities (Galloway and Brown, 2002).

As pointed earlier in Chapter One, the present study investigated as a "starting point" for understanding how the perception of personality traits, attitudes, perception of environmental barriers and support received influences the undergraduates' entrepreneurship intents. It did not extend the investigation to explaining the ways in which these factors change through the students' educational development processes and experiences. However, there is satisfactory theoretical foundation to support a belief that "educational interventions may increase entrepreneurship behaviour and efficacy" (Rideout and Gray, 2013, p.331).

\subsection{Summary of the literature review}

From the empirical literature reviewed, the key idea is that the intention-behavioural models, which previous researchers used in investigating empirical relationships, explained only an average variance of the factors that influence entrepreneurial intentions (see Table 4.1). The result is notwithstanding whether researchers used the seminal works of Shapero's "model of the entrepreneurial event", Ajzen's "theory of planned behaviour", and even the different integrated frameworks as their conceptual model. Previous studies used attitude measures such as "attitude toward the behaviour", "subjective or social norms", "perceived behavioural control or entrepreneurial self-efficacy", "perceived desirability or feasibility." Others used personality traits and other context-related factors to investigate their relationships with the entrepreneurial intentions construct. The present study follows this logic by integrating some of the components (or measures) of the models listed above to form a conceptual model and test the relevance of these components in influencing intentions using data from a developing country, Nigeria.

However, there are no generally-agreed universal factors for explaining intentions for setting up entrepreneurship activities by students that apply to all settings. This study, therefore, argues that 
the factors that explain entrepreneurial intentions in developing countries (and Nigeria in particular) might be different to those in other contexts. There is, thus, a gap in understanding the most important factors in this specific context. Likewise, a useful contribution to the literature is to extend the argument by introducing a qualitative study to know further how potential entrepreneurs in Southern Nigeria make meaning of or interpret what influences their entrepreneurial intentions. Their perceived meaning may contribute to a deeper understanding of how they can be best assisted to become high-quality entrepreneurs in the nearest future. The approach perhaps might lead to uncovering new knowledge on what factors hold the "gold standard" in explaining undergraduates' intentions for engaging in entrepreneurship activities.

There is a need to develop a more holistic understanding of the factors that influence entrepreneurial intentions that include how students "make meaning", interpret or "think differently" concerning founding businesses. The findings might provide new themes for understanding business-founding intentions and within the context of southern Nigeria. There is no research that assessed the status of entrepreneurial intentions among undergraduates of South-south and Southeast Nigeria. Neither have researchers conducted any study on the factors that influence entrepreneurial intentions between the two groups, nor the students' perceptions represented in a comparative study of the two neighbouring regions. This study argues that previous studies that excluded the student's perceptions and explanations to knowing further the factors that influence entrepreneurial intentions undermined the students' angle to the debates.

This lack of a holistic view of the phenomenon is a critical gap in current knowledge about how to encourage business-founding in general and in South-south and Southeast Nigeria in particular. This study is a modest attempt at filling this gap.

In the chapter that follows, the study shifts attention toward examining the research strategies and methodology that will enable the researcher access empirical information for uncovering new knowledge on this issue. 


\section{CHAPTER FIVE}

\section{RESEARCH METHODOLOGY}

\subsection{Introduction}

The previous chapter examined scholarly works on the factors that influence entrepreneurial intentions. It identified Ajzen's "theory of planned behaviour" as the most widely adopted theoretical position in prescribing the constructs that link intentions to behaviour. In the entrepreneurship intentions literature, other researchers have identified other factors that also contribute to developing entrepreneurial intentions. These include personality traits, capabilities or skills level, the perception of support, and perceived barriers. This study attempts to integrate these separate factors and examines how they correlate. It also explores how participants interpret, or perhaps think differently about what influences them. In addressing all these, a systematic and coherent process is needed. This chapter, therefore, examines the means through which first-hand empirical data were gathered to solve the research questions raised in Chapter One. This methodology is informed by the researcher's adopted philosophical position brought into the discourse, the purpose, approach, design, and method.

\subsection{Research methodology}

This study takes research methodology as a "procedural or operational framework" in which the study is conducted (Remenyi, 1998, p.28). It is the description of the entire approach used by the researcher to investigate the problem. It is the skeleton within which every part in the inquiry processes hangs on together to give meaning to facts gathered in research.

Research is guided by some prescribed structure whether the research is in the physical, natural sciences, social or behavioural sciences. It is this structure or framework that allows for the overall assessment of whether the researcher conducted her study within well-defined and explicit theories that underpin the discipline. The explicit nature of the methodology a researcher adopts helps others also to assess the results of the research, nature of claims to knowledge made, and judge the credibility of the research.

Since the methodology entails the above characteristics, the framework usually considers the philosophical worldview or "basic set of beliefs that guide action" (Guba, 1990, p.17). Furthermore, methodology addresses the purpose of research; the approach; design; and methods employed to solve the research questions. All these will contribute to defensible 
conclusions and claims. In this study, the different aspects that make up the research methodology as enumerated above are illustrated in Figure 5.1 below. The diagram illustrates that the philosophical worldview influences what purpose or questions researchers are interested in the investigation. Different authors use different names for "philosophical worldview." For example, Lincoln and Guba (2000) and Merten (1998) call it paradigm and Crotty (1998) calls it epistemology and ontology. But Neuman (2000) calls it "broadly conceived research methodology." The purpose and research questions, conversely, influence the methods, design, and approach to an inquiry (Natasi, Hitchcock and Brown, 2010). Each of these research components will be discussed in detail in the sections that follow.

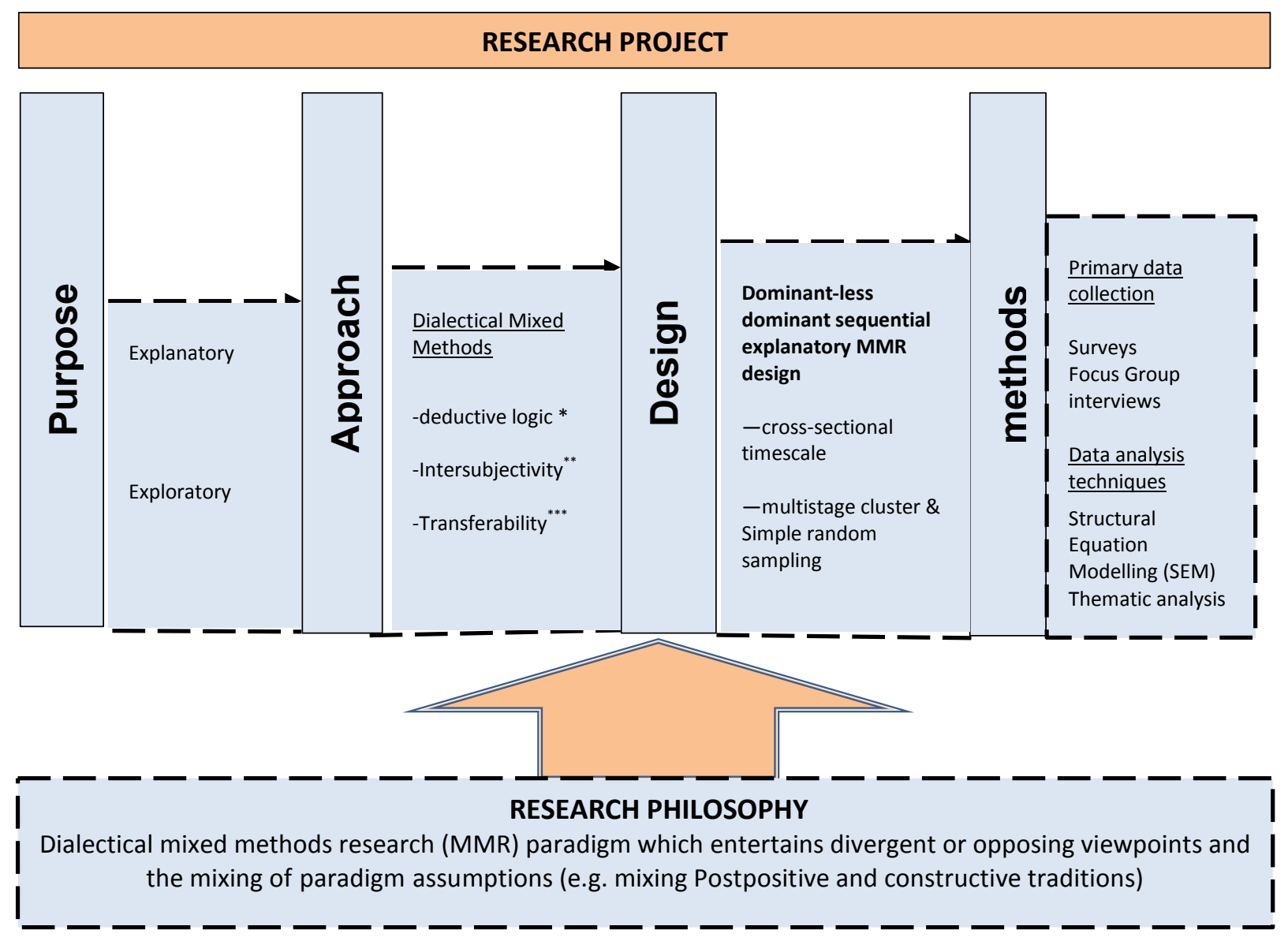

Figure 5.1: Research methodological framework adopted

* Connection between data and theory.

**The researcher's interconnection with the research process

$* * *$ Basis of inference

\section{Source: Author's construction}




\subsubsection{Research philosophy}

Philosophy provides the foundation for research in physical, natural, social, and behavioural sciences. The reason being that most researchers conduct their studies under some underlying assumptions or beliefs about the nature of knowledge they wish to gain from such studies. Such assumptions also direct the research processes and how researcher inquires. Therefore, mixed methods research (MMR) is believed to be guided by philosophical assumptions that researchers, old and new, need to articulate clearly as the foundation for their inquiries. Furthermore, philosophical assumptions or ideas are in the areas of ontology, epistemology, and axiology (to be addressed later in this section). These assumptions then affect the methodology as well as methods for gathering, analysing and interpreting research data (Creswell and Plano Clark, 2011). This study aligns with the "dialectical" philosophical paradigm of MMR (Greene and Caracelli, $1997,2003)$ because of its stance on the plausibility of mixing two different paradigm assumptions in one study.

This research aligns with the dialectical philosophy of research; it herein describes the elements of the paradigm and then attempts to articulate how the elements will influence certain procedures of this study. The section also briefly highlights other philosophical paradigms prominent in MMR. The aim is to demarcate how dialectical paradigm is relevant for this research. It also describes other philosophical paradigms common in MMR.

Scholars believe that pragmatism and dialectics are the two most prominent stances that are used as philosophical paradigms in MMR. Others, however, include realism (critical), feminism, transformative, and participatory inquiries (Biesta, 2010). Pragmatism concentrates on the consequences and implications of research to real-world needs, practical value, and the primary importance of the questions asked. It also concentrates on the most appropriate means for tackling the research questions, context and its conditions rather than philosophical assumptions (Creswell and Plano Clark, 2011). It does not, however, accept mixing of assumptions from different traditions and pays less attention to paradigm or philosophy of research (Greene and Hall, 2010). Thus, this makes the pragmatism paradigm restrictive. Conversely, dialectical paradigm extends and actively accepts "multiple paradigm traditions and mental models together with multiple methods into the same inquiry space and engages them in respectful dialogue one with another throughout the inquiry" (Greene and Hall, 2010, p.124). It seeks more insight than convergence; it generates important understandings and discernments through a combination of different lenses, stances, and perspectives. Thus, it affords a meaningful engagement intended to generate insight and understanding that are of conceptual and practical consequence. 
Realism is the belief that there is a "real world with which we interact, and to which our concepts and theories refer" (Biesta, 2010, p.150). In addition, Philips (1987, p.205) sees philosophic realism as "the view that entities exist independently of being perceived, or independently of our theories about them." Conversely, the feminist approach to MMR focuses on exploring multiple understandings of the nature of social reality as this especially relates to women's affairs and standpoint. It studies across differences in terms of gender, race, class, and so on (Biesta, 2010). The transformative paradigm in MMR focuses on explicit recognition of values and knowledge of self and community. It seeks to address the needs of a specific population and to call for change (Creswell and Clark, 2011; Biesta, 2010).

The participatory inquiry paradigm focuses on political concerns and the need to improve our society and its citizens. Research using this worldview addresses issues such as empowerment, marginalisation, hegemony, patriarchy, and other issues affecting marginalised citizens. In collaboration with the marginalised group, the researcher plans for a social world to be changed and for better, so that individuals will be less marginalised (Creswell and Clark, 2011).

In MMR, many researchers use the pragmatism paradigm. However, pragmatism as mostly anchored in Dewey's theory of knowing posits that knowledge "always concerns the relationship between (our) actions and (their) consequences" (Biesta, 2010, p.110). So it offers philosophical support only for explanatory research but not for exploratory research (Greene and Hall, 2010). Explanatory research aims at identifying causes between events or finding correlations (i.e. intention to explain, which QUAN research mostly handles). But exploratory research aims at identifying intentions of an action and reasons for (social) action (i.e. intention to understand, mostly handled in QUAL research). This inability of pragmatism to adequately offer philosophical supports for both the explanatory and exploratory research (Biesta, 2010), causes a challenge for adopting a pragmatic paradigm. The dialectical paradigm is considered most appropriate in accounting for the type of knowledge that this study aims to generate. The paradigm emphasises the use of multiple worldviews in research (Greene and Caracelli, 1997).

The dialectical thesis assumes that all paradigms have a contribution to make and using multiple paradigms can provide a greater understanding of the phenomenon in question. It can help in explaining the complexities of an increasingly pluralistic world (Teddlie and Tashakkori, 2009; Greene and Caracelli, 2003). "Dialectical" thinking entertains opposing viewpoints and interrelating with the tensions occasioned by others' perspectives (e.g. researchers and the researched); the tensions emanate from dissimilarities in accepting the assumptions of the different paradigms. 
The rationale for aligning with the dialectical paradigm is because of its plausibility in that moving from QUAN to QUAL approach one is moving from positivist (or postpositive) tradition to constructive or interpretive tradition. The question is how can one stay under one paradigm tradition, as prescribed by pragmatism paradigm, without carrying alongside the different paradigm assumptions in the process? The reason being that one is transiting from one tradition to another as it is in this investigation. The dialectical paradigm believes that the researcher can use the assumptions from different traditions. Thus, the dialectical thinking helps in certain procedures in this research such as in the discussion where diverse perspectives and opposing views must not necessarily have to be triangulated or reconciled. But to welcome these as individuals' or groups' unique perspectives (Greene and Caracelli, 2003).

The specific objective of this research is to examine the factors that encourage or discourage undergraduates' business-founding intentions. It is to know whether personal attitudes, perceived capabilities, personality traits, perceived barriers and supports influence their business-founding intentions. Others are to examine similarities/differences among the participants (all these are explanatory in nature). It is also to explore the issue to know further how students "make meaning", interpret or "think differently" of founding businesses (these being exploratory in nature). This study adopts postpositive and social constructive ontology, and an epistemological relativism posture or inter-subjectivity (Teddlie and Tashakkori, 2009). It presupposes that the researcher will "objectively" and statistically assess the respondents based on the numeric data and scores relating to each person as obtained in the surveys. In another instance, the researcher will "subjectively" attempt to understand and interpret the focus groups interview transcripts. Research processes cannot be totally devoid of the researcher's choices, value position or system. More so, since most research involving human is "inter-subjective" connoting the "interpersonal nature of research" (Natasi, Hitchcock and Brown, 2010, p.308). 
Table 5.1: Comparison of elements of dialectical and pragmatic paradigms

\begin{tabular}{|c|c|c|}
\hline $\begin{array}{l}\text { Paradigm } \\
\text { Element }\end{array}$ & Dialectical stance & Pragmatic stance \\
\hline $\begin{array}{l}\text { Ontology } \\
\text { (assumptions, } \\
\text { beliefs, and values } \\
\text { about the nature of } \\
\text { reality of the object } \\
\text { of research) }\end{array}$ & $\begin{array}{l}\text { 1. Accepts mixing of paradigms such that } \\
\text { philosophical assumptions from different } \\
\text { traditions can be respectfully and dialectically } \\
\text { engaged in dialogue toward enhanced, reframed, } \\
\text { or new understanding. } \\
\text { 2. Assumptions, along with context and theory, } \\
\text { essentially guide and direct inquiry decisions. } \\
\text { 3. The inquirer engages in an on-going dialogue } \\
\text { among the various data sets in the study, } \\
\text { repeatedly and critically assessing the merit of } \\
\text { inquiry decisions and results in terms of } \\
\text { generating more comprehensive and insightful } \\
\text { results. It also considers more generative } \\
\text { directions for the study on an on-going basis. } \\
\text { 4. Warranted inferences represent respectful } \\
\text { integrations of diverse lenses on the } \\
\text { phenomenon studied, possibly including jagged } \\
\text { points of dissonance. Warranted inferences } \\
\text { represent more comprehensive and insightful } \\
\text { understandings that could not be attained with } \\
\text { one framework/method only. }\end{array}$ & $\begin{array}{l}\text { 1. It is argued that pragmatism, even in its } \\
\text { various forms, presents a coherent system } \\
\text { of thoughts, so there is no mixing of } \\
\text { assumptions from different traditions. } \\
\text { 2. Assumptions can range from "high" } \\
\text { where transactional assumptions about } \\
\text { human action can essentially guide human } \\
\text { action; can also be "low" where the focus } \\
\text { is reoriented instrumentally to developing } \\
\text { workable solutions to on-going social } \\
\text { problems. } \\
\text { 3. The inquirer engages in on-going } \\
\text { reflection on inquiry decisions and results, } \\
\text { assessing their practical worth and } \\
\text { actionable value. It further engages in on- } \\
\text { going communications with those in the } \\
\text { inquiry context, seeking support for the } \\
\text { practical value of what is being learned. } \\
\text { 4. Warranted inferences represent } \\
\text { actionable knowledge, that is, the } \\
\text { knowledge that can be acted upon, in this } \\
\text { context and others, or knowledge that is } \\
\text { imprectly actionable for improving the } \\
\text { being studied. }\end{array}$ \\
\hline $\begin{array}{l}\text { Epistemology } \\
\text { (relationship } \\
\text { between the } \\
\text { researcher and the } \\
\text { researched) }\end{array}$ & $\begin{array}{l}\text { 1. There is inter-subjectivity where the emphasis } \\
\text { is on the interpersonal nature of research. There } \\
\text { can be a back-and-forth understanding }\end{array}$ & $\begin{array}{l}\text { 1. Either subjectivity or objectivity or both } \\
\text { but since it does not accept mixing of } \\
\text { traditions, there is no engaging on } \\
\text { philosophical underpinning. }\end{array}$ \\
\hline $\begin{array}{l}\text { Axiology } \\
\text { (the role of values in } \\
\text { research) }\end{array}$ & $\begin{array}{l}\text { 1. There is a belief in acceptance of differences; } \\
\text { therefore, researchers can include both biased } \\
\text { and unbiased accounts. }\end{array}$ & $\begin{array}{l}\text { 1. Multiple stances (e.g. researchers can } \\
\text { include both biased and unbiased } \\
\text { perspectives). }\end{array}$ \\
\hline
\end{tabular}

Source: Adapted from Creswell and Plano Clark (2011, p.41-42); Greene and Hall (2010, p.123 and 139) 
In Table 5.1 above, the matrix compares dialectical and pragmatic paradigms and illustrates their common elements in terms of ontology-as assumptions, beliefs and values about what the reality of the object of research is. Next are the elements relating to the epistemology-or relationship between the researcher and those researched. The last element relates to axiology-or the role of value judgement in research (Bryman, 2006; Johnson and Onwuegbuzie, 2004).

Having shown that the dialectical paradigm offers a better and more plausible platform for mixing different philosophical worldviews in one inquiry, attention is now shifted to discussing the postpositive and social constructive worldviews. The next subsection discusses how the paradigms relate well to the elements of this study to offer a holistic understanding of the complex behavioural nature of entrepreneurship.

\subsubsection{Postpositive worldview}

This worldview challenges the traditional stance of absoluteness of "truth" in knowledge. Philip and Burbules (2000), modern positivists, believe that we cannot be too "positive" concerning our claims to knowledge as we understudy behaviours and social actions of man. Thus, any knowledge needs to be "hedged" when it involves human behaviour. Postpositive traditions hold a deterministic philosophy; this holds that there must be possible causes of any outcome. It holds a kind of functional position such as a "fall in prices causes demand for normal goods to increase, other things being equal." Therefore, postpositive tradition mostly looks for and assesses the "causes" that influence outcomes. This view is the kind of ideas in experiments.

They also hold a reductionist view. This view means they take big ideas and reduce them to distinct aspects or sub-ideas for testing (called hypotheses or sometimes use only research questions). Knowledge of this process is based on rigorously observing and measuring the "objective reality" that exists "out there" in the world (Creswell, 2009, p.7). It attempts to measure (numbers) and study the behaviour of persons. Laws and theories rule the world. These laws and theories often require testing (and retesting) and refinement of further knowledge. Therefore for the postpositive, an investigator starts from a theory to collecting data for analysis and to making claims that either agree or disagree with the proposed theory. It uses the scientific method. Sometimes a revision of the theory is made as required, and further testing conducted. Therefore, according to the postpositive views, to conduct a competent inquiry, researchers must strive for objectivity by assessing bias in the methods used and the conclusions reached. This process makes quantitative researchers strive to use standard validity and reliability measures to check biases. 
Having assessed this worldview, the researcher sees its elements as offering certain characteristics relevant for this research. Suffice it to say that it may not be entirely value-free to "objectively" measure human attitudes to a phenomenon such as entrepreneurial intentions, personality traits, and values people hold toward entrepreneurship in society. Nevertheless, with some degree of carefulness put toward measurement design of these concepts, the researcher can still achieve some level of objectivity. Moreover, care was taken to accept only measures that meet pre-set standard validity and reliability criteria. More so, demographics such as gender, ethnicity, state of origin, and course of study can be assessed objectively. The reason being that people can only choose from a category where they belong (e.g. a person's state of origin can only be one state and cannot be a "multiple realities" of states). Therefore, there is no value judgement or bias in categorising respondents according to these demographic characteristics.

\subsubsection{Social constructive worldview}

This worldview is associated with qualitative methodologists while the positivist worldview is associated with quantitative methodologists (Creswell, 2009). Social constructive views assume that individuals search to understand the world they are experiencing. People develop subjective meanings of their experiences concerning particular events, objects, or phenomenon. Since these meanings are diverse, they stretch the researcher to look further into the complexities rather than delimiting meanings to a few positions or opinions. The investigator, therefore, principally depends on the respondents' opinions of the phenomenon under investigation. The questions in the contest are sometimes broad, general and open-ended. Thus stretching the respondents to construct the meaning of a case, this is principally enhanced by discussing and interacting with others. Moreover, the subjective meanings that respondents make of their situations are rooted in their social, cultural, and historical antecedents; focus is on specific contexts that individuals live or work, or both.

In social constructive research, the investigators come with their backgrounds that can influence the interpretations; so they have to decide how their interpretations will be influenced by the culture, history, and experiences of the investigator. Since others hold certain meanings about their worlds, Creswell (2009) notes that the goal of the researcher is then to make sense of these meanings (i.e. researchers interpret). Thus, instead of following an established theory like the postpositive traditions do, social constructive inquirers establish or inductively advance a theory or patterns of meaning (from a particular case to the general themes). 
In this study, respondents were required to make meaning and interpret how and what businessfounding means to them and "construct" what they perceive are the contributing factors to business-founding (whether encouraging or discouraging factors). Students interacting in an open, non-threatening atmosphere, they can offer fresh perspectives on their entrepreneurial intentions or reveal themes that might be worth engaging in for entrepreneurial intentions literature. In Table 5.2 that follows, the researcher summarises and compares the elements of postpositive and constructive worldviews to highlight their implications for research practice. The comparisons are about ontology, epistemology, axiology, the methodological logic of inquiry, and rhetoric.

Table 5.2: Elements of postpositivist and constructivist worldviews and implications for practice

\begin{tabular}{|c|c|c|}
\hline $\begin{array}{l}\text { Worldview } \\
\text { Element }\end{array}$ & Post-positivism & Constructionism \\
\hline $\begin{array}{l}\text { Ontology } \\
\text { (assumptions, beliefs, and values } \\
\text { about the nature of reality of the } \\
\text { object of research) }\end{array}$ & $\begin{array}{l}\text { Singular reality } \\
\text { (e.g. researchers reject or fail to reject } \\
\text { hypotheses) }\end{array}$ & $\begin{array}{l}\text { Multiple realities } \\
\text { (e.g. researchers use some } \\
\text { transcript extracts to demonstrate } \\
\text { dissimilar perspectives) }\end{array}$ \\
\hline $\begin{array}{l}\text { Epistemology } \\
\text { (relationship between the } \\
\text { researcher and the researched) }\end{array}$ & $\begin{array}{l}\text { Distance and impartiality } \\
\text { (e.g. researchers objectively gather } \\
\text { data on instrument) }\end{array}$ & $\begin{array}{l}\text { Closeness } \\
\text { (e.g. researchers arrange visits to } \\
\text { participants sites to gather data) }\end{array}$ \\
\hline $\begin{array}{l}\text { Axiology } \\
\text { (the role of values in research) }\end{array}$ & $\begin{array}{l}\text { Unbiased } \\
\text { (e.g. researchers use validity and } \\
\text { reliability checks to eliminate biases) }\end{array}$ & $\begin{array}{l}\text { Biased } \\
\text { (e.g. researchers vigorously talk } \\
\text { about their biases and } \\
\text { interpretations) }\end{array}$ \\
\hline $\begin{array}{l}\text { Methodological } \\
\text { Logic of inquiry } \\
\text { (What is the logic of inquiry in the } \\
\text { research process?) }\end{array}$ & $\begin{array}{l}\text { Deductive } \\
\text { (e.g. researchers test an a priori } \\
\text { theory) }\end{array}$ & $\begin{array}{l}\text { Inductive } \\
\text { (e.g. researchers begin with } \\
\text { participants' views and build "up" } \\
\text { to patterns, theories, and } \\
\text { generalisations) }\end{array}$ \\
\hline $\begin{array}{l}\text { Rhetoric } \\
\text { (What is the research language?) }\end{array}$ & $\begin{array}{l}\text { Formal style } \\
\text { (e.g. researchers use agreed-on } \\
\text { definitions of variables) }\end{array}$ & $\begin{array}{l}\text { Informal style } \\
\text { (e.g. researchers write in a literary, } \\
\text { informal language style) }\end{array}$ \\
\hline
\end{tabular}

Source: Adapted from Creswell and Plano Clark (2011, p.42).

\subsubsection{Research purpose}

In mixed methods research (MMR) circles, authors categorise the research purpose into several kinds. Newman's et al (2003, p.175) nine categories of research purpose are to: "predict; add to the knowledge base; have a personal, social, institutional, or organisational impact or both; measure change; understand complex phenomenon; test new ideas; generate new ideas; inform constituencies; and examine the past (e.g. from time series data)." Meanwhile, Greene, Caracelli and Graham (1989, p.260), however, had earlier aligned research purposes into five categories. The first is "triangulation" where convergence, intersection, and a confirmation of findings gotten from diverse methods are sought. The second is "complementarity" in which research results from the second method (e.g. QUAL) is used to clarify or improve the explanations of grey areas in the 
first results (e.g. QUAN). The third is "development of the instrument" where primarily survey or interview questions are formed. The fourth is "initiation" that explores fresh perspectives or inconsistencies. The fifth is "expansion" that seeks to offer a more comprehensive and wider scope.

But research purpose fits explanatory, exploratory or descriptive or a combination of these in which researchers can situate their studies (Creswell and Plano Clark, 2011). Explanatory research identifies "causes" (preferably influencing or contributing factors) and seeks for correlation among events. Exploratory research identifies intentions of, and reasons an action is taken; whereas descriptive research illustrates and classifies basic features of the elements under investigation without going beyond what the data provide.

The purpose of the current study was thus primarily explanatory rather than exploratory since most of the research questions seek to measure outcomes and identify contributing or influencing factors of entrepreneurial intentions. However, in terms of the strategy and priority of data analysis and interpretation (Morse, 1991), the data from the exploratory study took relatively closer attention. The reason is that it would provide more in-depth explanations of the quantitative results (Ivankova and Stick, 2007). Therefore, the secondary purpose is to use the results of the exploratory research to know further how undergraduates make meaning, explain, or perhaps think differently toward business-founding. This aspect is exploratory since it seeks for the reasons individuals take some actions. It seeks also to know the complex phenomenon in a holistic way. Most frequently, the primary reason for mixing methods is complementarity. Thus seeking for "elaboration, enhancement, illustration, and clarification of the results from one method with results from another" (Greene, Caracelli and Graham, 1989, p.260).

\subsubsection{Research approach}

This research adopted a mixed methods approach to help in answering the research questions stated in Chapter One. Mixed methods research is a data collection and analysis approach. It is where in one study, the quantitative (numeric scores) and qualitative (texts) data are combined at some selected stages in the research process (Creswell and Plano Clark, 2011). The reasons for choosing this approach was that some of the research questions were more apt to the quantitative investigation. For example, measuring outcomes of entrepreneurial intentions, assessing similarities and differences while the fifth research question needed an exploratory approach. Neither of the approaches could independently and satisfactorily answer the nature of the complex questions surrounding students' entrepreneurial intentions and its contributing factors in 
the context of South-south and Southeast Nigeria. Thus, the two approaches were combined to complement each other. It was also to give a more holistic angle to the research problem (Johnson and Turner, 2003; Tashakkori and Teddlie, 1998; Greene, Caracelli and Graham, 1989).

The reasons for adopting the two-stage approach (mixed methods) was the need to have a complete view of the factors that influence entrepreneurship intentions of the participants studied using different and complementary data sources. This choice aligns with Harrison (2013, p.2156) who notes that "research questions best suited for mixed method inquiry include those in which one data source may be insufficient." The quantitative approach was more apt for addressing questions concerning relationships between the variables hypothesised in the conceptual model, which included "who, where, how many, and how much" types of questions (Harrison, 2013, p.2160) while the qualitative approach was "more apt for answering why and how questions." For example, the research questions one and two stated in Section 1.3 and research objectives five and six stated in Section 7.1 were of this nature, which required quantitative data. The research question three and research objective seven, however, required qualitative data. Therefore, without using the mixed methods inquiry, the researcher would have been unable to meet these objectives or answer the research questions appropriately.

The two-stage approach also helped in reinforcing and expanding the results of the survey since it allowed for more in-depth discussions with the participants. Also, it allowed the researcher to ask follow-up questions. It also provided the opportunity to look for other verbal responses, cues, and reactions; and participants could expand on their understandings.

This study adopted a deductive logic of inquiry; this means building cases from general themes to a particular application (Tashakkori and Teddlie, 1998). This logic is a basic assumption of the postpositive tradition. The study also took an inter-subjective stance on the connection between the researcher and the research process, since it believes that research is interpersonal. The basis of inference is transferable. Being transferable connotes that findings from this study can also be applied to other places that share similar background features as the regions studied.

The phases or sequence adopted (Morse, 1991), priority given (Creswell et al, 2003), and time/stage of mixing (Tashakkori and Teddlie, 1998; Greene, Caracelli and Graham, 1989) are explained in detail in the next section. 


\subsubsection{Research design or strategy (quantitative phase)}

Research strategy is a structure for organising ideas on how to gather, analyse, and interpret data by the researcher (Gorard, 2010). It is the "plans and procedures" used by researchers that comprise the decisions from wide assumptions to specific methods of collecting and analysing research data (Creswell, 2009, p.4). Creswell believes that designs are anchored on the worldview assumptions chosen, guidelines of inquiry (or strategies), and specific methods of data collection, analysis, and interpretation. Therefore, the design is anchored in the nature of the research problem, investigator's experiences, and the beneficiaries of the study.

The design of this study's instruments was such that outcomes on the factors that influence entrepreneurial intentions among undergraduates from the two regions can be derived and predicted from the survey results. Furthermore, the study would enhance understanding of students' perception of the complex nature of what influences them to imbibe entrepreneurial spirit and mindset. It is the researcher's belief that the nature of the problem and the phenomenon of students' entrepreneurial intentions cannot be sufficiently captured with only one method. Thus, this study adopted a mixed methods strategy.

In terms of the sequence, this study adopted a two-phase explanatory sequential mixed method research design (Morse, 1991). In the first phase, quantitative or numeric scores from the survey questionnaire were collected and analysed. From the results, the researcher then identified areas that needed further exploration with the participants to understand and explain the survey findings. In the second phase, a qualitative or textual data from focus group interviews was collected and analysed. The qualitative phase was given priority in this research since it provided more in-depth explanations of the quantitative results. This phase aimed at collecting a wide range of direct first-hand data and diverse opinions on the research questions. The participants were from different academic disciplines and ethnic backgrounds. In addition, the level of analysis was multiple-within-individual and cross-group cases.

On the stage of mixing, the data were mixed at the discussion and analysis stages. At the analysis stage, integration began after the quantitative results were ready; focus groups interview protocol for the quantitative stage was then better articulated. At the discussion stage also qualitative data were employed further to know the reasons some quantitative results may have been significant or insignificant for some identified factors. Also to know why certain descriptive patterns followed the way they did. Following the ideas of Ivankova and Stick $(2007$, p.98) on "phases, procedures, and products", the framework for this study is shown in Figure 5.2 below: 


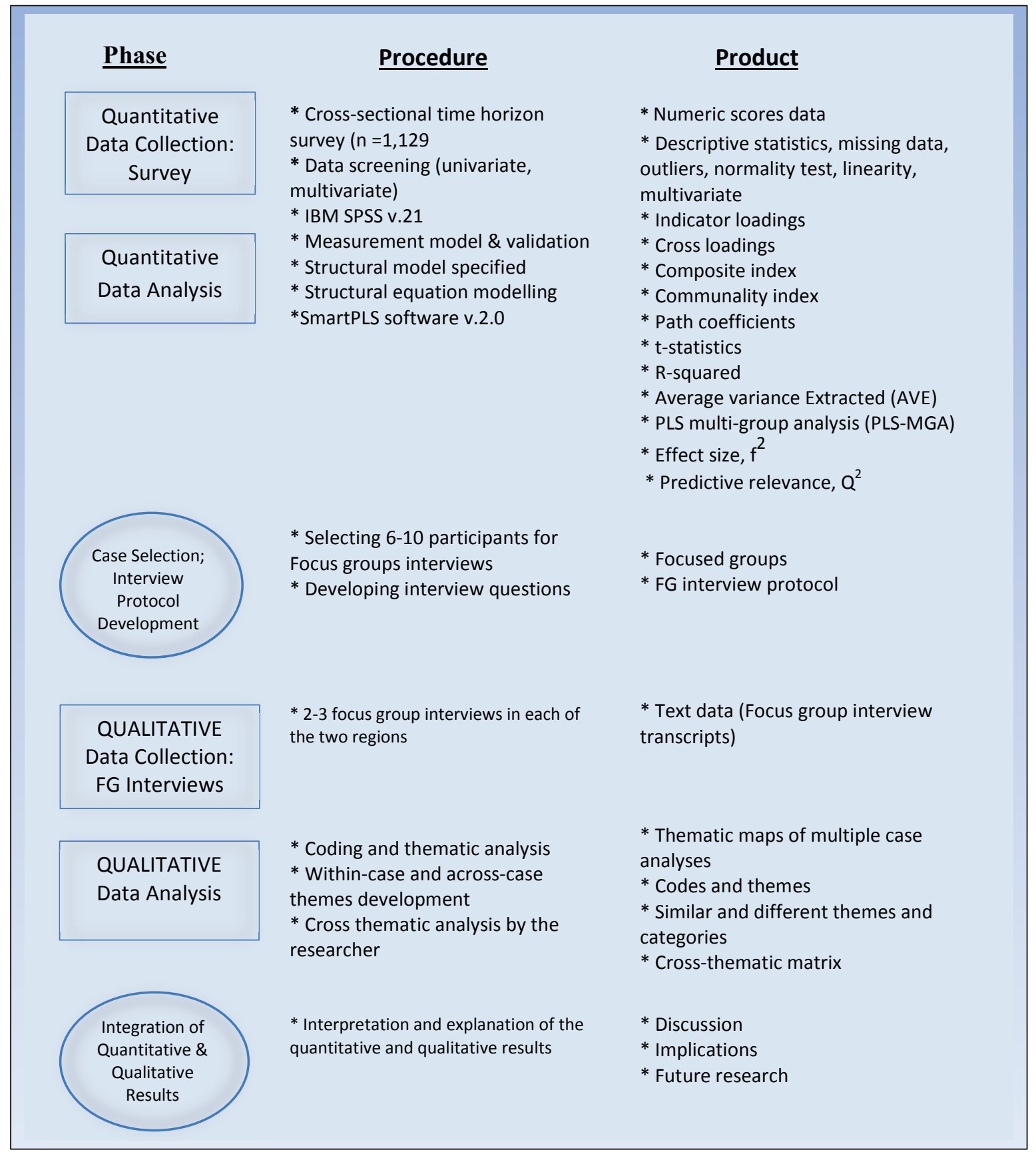

Figure 5.2

Phase, procedure, and product in this explanatory sequential mixed methods

Source: Adapted from Ivankova and Stick (2007, p. 98) 
From the diagram and beginning with the quantitative phase, a cross-section of final-year indigenous undergraduate students of South-south $(n=716)$ and Southeast Nigeria $(n=413)$ were randomly selected using a multistage cluster sampling plan. The researcher administered a survey questionnaire in classrooms in the participants' campuses. The questionnaire measured 12 "predictor" variables suggested by the literature on entrepreneurial intentions.

The survey data were then coded, prepared, and computer-analysed to assess the demographic and descriptive characteristics of the two groups of respondents. Furthermore, an inquiry of the statistically significant factors that distinguished the two groups was implemented. Then all the proposed statistics as highlighted in Figure 5.2 above were conducted, and conclusions about the findings drawn. Based on the findings and conclusions drawn from the quantitative study, the researcher identified the areas (e.g. significant factors, insignificant factors, or surprising results) that needed further investigation in the second phase. This route is the strategy usually followed in an explanatory sequential MMR (Harrison, 2013; Hesse-Biber, 2010; Hodgkin, 2008).

Meanwhile during the survey exercise, participants were requested to indicate interest to explore the results of the survey. Those who volunteered were, therefore, contacted and the researcher arranged the focus group interviews. There were four focus groups (FG), 42 participants. The interviews were tape-recorded and transcribed verbatim by the researcher. The transcripts were then assessed for description and themes within each case, followed by cross-case analysis. This process helped to pinpoint salient themes about the factors that influence entrepreneurial intentions across the entire FG cases. Lastly, results were combined during the discussion and interpretation stages. The quantitative results were discussed first then indicating how a follow-up qualitative result helped to make meaning of the statistical results in more depth. Also, the discussions made references to previous studies.

The rationale for mixing quantitative and qualitative methods is, first, to offset potential weaknesses in using the survey to generate research knowledge. Here "forced responses" to questions about human lives that are behavioural, social, and perceptual in nature have always been limited in scope in capturing the respondents' broader perspectives. Conversely, the qualitative instrument cannot adequately address measurement levels of entrepreneurial intentions dimensions, nor predict outcomes based on observed patterns. Secondly, if unexpected outcomes were found from the survey analysis (e.g. South-south undergraduates being significantly indifferent from their Southeast participants), then the qualitative study could explore the reasons for such results with the FG interviewees (Bryman, 2006). Thirdly, in terms of credibility, mixing quantitative and qualitative can increase the integrity of the findings of the 
study since two methods are believed to be broader in scope. Overall, it is acknowledged that outcomes may turn up as unpredicted because of the strengths of the application of both quantitative and qualitative techniques.

\subsubsection{Research methods}

This study understands research methods broadly as instruments, techniques, and processes for gathering and analysing research data for drawing conclusions. In a narrow sense, it is the instruments for data collection such as experiments, interviews, survey questionnaires, physical measurements, observations, and secondary data collection practices. It is also the tools of analysis such as inferential and descriptive statistical and non-statistical techniques (Sekaran and Bougie, 2013). The method used in this study was a primary data collection method comprising of surveys followed by focus groups interviews. In the next sections, the study describes the other elements considered in the research method.

\subsubsection{Survey participants and procedures}

The survey was administered to final-year students of South-south and Southeast Nigeria origin. It cut across participants from different federal, state, and private universities within the two regions; the researcher drew participants from the various universities' faculties/schools/college, departments, and final-year classes.

The questionnaire contained information for participants requesting those who wished to participate further in a focus groups interview. The purpose was to discuss aspects of the results of the quantitative study with the researcher at a set later date at the participants' university. They were requested to contact the researcher by email for the FG exercise. Those who were willing to participate in the FG interviews and had emailed the researcher were then contacted, and arrangements made for the interviews.

\subsubsection{Study area}

The regions are in the southern Nigeria. The estimated total area for the South-south region is $85,315.25 \mathrm{~km}^{2}$. The 2012 National Population Commission estimated population for the region was $24,568,687$. In the same vein, estimated total area for the Southeast region is $28,982.67 \mathrm{~km}^{2}$ with a total population of approximately 18,932,315 people. The two regions cover a total area of approximately $56,332.58 \mathrm{~km}^{2}$ (i.e. $6.01 \%$ of Nigeria's $937,052.16$ total area). Nigeria lies between

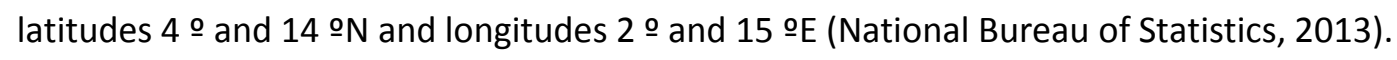


The South-south region is rich in petroleum and gas deposits and situates within the River Niger, which empties into the Atlantic Ocean. The traditional occupation of the residents is farming and fishing. The following states make up the South-south region: Akwa Ibom, Bayelsa, Cross River, Delta, Edo, and Rivers. The region has 17 universities (six federal, seven states, and four private). The Southeast region is below the Benue River down in the east. The traditional occupation of the residents is trading and farming. The following states make up the Southeast region: Abia, Anambra, Ebonyi, Enugu, and Imo. The region has 16 universities (five federal, five states, and six private). A map of Nigeria showing the two regions and the states are as earlier illustrated in Figure 3.2 in Section 3.6.

\subsubsection{Population and sample size}

The target population comprised of all final-year indigenous undergraduate students of Southsouth and Southeast Nigeria. Because Nigeria uses the catchment area system of university admission, the majority of the participants were more likely to be studying at universities within these two regions. It was difficult to have a complete sample frame of the members of the finalyear classes from these regions in all the Nigerian university departments to determine the exact target population size. Therefore, the use of multistage sampling became imminent (universities hardly publish this information and can be difficult to access for all the universities).

The multistage sampling strategy makes possible the linking of the population members to some grouping that researchers can then successfully sample. Fowler (2009) asserts that when there is an inadequate list of individuals in a population and no way to get at the population directly, multistage sampling provides a useful approach.

The researcher, therefore, followed the practice in quantitative studies on students' entrepreneurial intentions involving sampling of this nature. Where researchers apply the structural equation modelling technique, the received advice is to sample a representative size of 300 or above (see Table 4.1 in literature chapter for similar studies). This study randomly selected 1,129 participants from the two regions using the clusters (multistage) of universities within the regions, well more than the minimum requirement.

\subsubsection{Sampling procedure and sampling frame}

This study adopted simple and multistage cluster sampling procedures. The researcher identified the clusters using data based on the number of universities in the two regions, faculties/schools/colleges/institutes within a selected university, and final-year students of the 
selected departments within the faculties. The researcher chose the multistage cluster on the basis of efficiency. This choice was to enable the researcher reach the target population rather than on achieving the traditional sampling criteria strictly. Here, efficiency is the rate at which members of the target population are located among those in the sampling frame (Fowler, 2009).

The researcher adopted a name-on-paper folding and shuffling procedure to determine the universities randomly to include for sampling in the first instance. Then, the researcher conducted further sampling using the same technique at the faculty levels of the selected universities to determine the faculties randomly. Lastly, random sampling at the departmental levels was conducted to identify which departments within the selected faculties would be included. Thus, the final-year students of such selected departments formed the units where the administering of the questionnaire took place. The researcher obtained information on the number of universities, faculties in a university and departments from the various university websites. Universities' information came from the National Universities Commission and university websites. Only indigenous students from the two regions of the study formed the target audience. It took approximately 15 minutes to complete the questionnaire.

In terms of the sampling frame adopted in drawing the study samples, Table 5.3(a) to Table 5.4(c) below highlights the federal, state and private universities in the two regions studied. 
Table 5.3(a): List of the South-south universities

\begin{tabular}{|c|c|c|c|c|}
\hline $\mathrm{S} / \mathrm{N}$ & University Name & State Located & $\begin{array}{l}\text { No. of Faculties/ } \\
\text { Schools/Colleges/ } \\
\text { Institutes }\end{array}$ & $\begin{array}{l}\text { Year } \\
\text { Founded }\end{array}$ \\
\hline & Federal Government Universities & & & \\
\hline 1. & University of Uyo, Uyo. & Akwa Ibom & 12 & 1991 \\
\hline 2. & Federal University, Otuoke & Bayelsa & 10 & 2011 \\
\hline 3. & University of Calabar, Calabar & Cross River & 11 & 1975 \\
\hline 4. & Petroleum Resources University, Effurun & Delta & 2 & 2007 \\
\hline 5. & University of Benin, Benin City & Edo & 13 & 1970 \\
\hline \multirow[t]{3}{*}{6.} & University of Port Harcourt, Port Harcourt & Rivers & 8 & 1975 \\
\hline & & & $\underline{56}$ & \\
\hline & State Government Universities & & & \\
\hline 7. & Akwa Ibom State University, Mkpat Enin & Akwa Ibom & 7 & 2004 \\
\hline 8. & Niger Delta University, Wilberforce Island & Bayelsa & 10 & 2000 \\
\hline 9. & Cross River State University of Technology, Calabar & Cross River & 8 & 2004 \\
\hline 10. & Delta State University, Abraka & Delta & 10 & 1992 \\
\hline $\begin{array}{l}11 . \\
12 . \\
13 .\end{array}$ & $\begin{array}{l}\text { Ambrose Ali University, Ekpoma } \\
\text { Rivers State University of Science and Technology } \\
\text { Ignatius Ajuru University of Education, Rumuolueri }\end{array}$ & $\begin{array}{l}\text { Edo } \\
\text { Rivers } \\
\text { Rivers }\end{array}$ & $\begin{array}{l}10 \\
7 \\
6\end{array}$ & $\begin{array}{l}1980 \\
1979 \\
2009\end{array}$ \\
\hline & & & $\underline{58}$ & \\
\hline & Private Universities & & & \\
\hline 14. & Obong University, Obong Ntak & Akwa Ibom & 2 & 2007 \\
\hline 15. & Western Delta University, Oghara & Delta & 2 & 2007 \\
\hline 16. & Igbinedion University, Okada & Edo & 7 & 1999 \\
\hline \multirow[t]{8}{*}{17.} & Benson Idahosa University, Benin City & Edo & 5 & 2002 \\
\hline & & & $\underline{16} \quad=130$ & \\
\hline & Summary & & & \\
\hline & Universities according to states & Distribution & & \\
\hline & Akwa Ibom $=3$ & 1 Federal, 1 State & 1 Private & \\
\hline & Bayelsa $\quad=2$ & 1 Federal, 1 State & & \\
\hline & Cross River $=2$ & 1 Federal, 1 State & & \\
\hline & Delta & 1 Federal, 1 State & 1 Private & \\
\hline
\end{tabular}

Sources: Adapted from National Universities Commission (2013); respective universities' websites 
Table 5.3(a) indicates that South-south states have 17 universities distributed according to federal, state, and privately-owned universities in the following order: six, seven, and four. The Southsouth comprises of six states, and each state was given a chance of at least one of its universities being selected. Following the paper folding and shuffling process on a state-by-state basis, the researcher selected nine out of the sixteen universities. The following were the included samples. The Table 5.3(b) below indicates that four out of the six federal universities were selected; three out of seven state universities were selected, and two out of four private universities were selected.

Table 5.3(b) Distribution of sampled South-south universities

\begin{tabular}{|c|c|c|c|}
\hline State & Federal University & State University & Private University \\
\hline Akwa Ibom & University of Uyo & Nil & Nil \\
\hline Bayelsa & $\begin{array}{l}\text { Nil (no final-year students: } \\
\text { founded 2011) }\end{array}$ & Niger Delta University & - \\
\hline Cross River & University of Calabar & Cross River University of Technology & - \\
\hline Delta & $\begin{array}{l}\text { Petroleum Resources } \\
\text { University }\end{array}$ & Nil & Western Delta University \\
\hline Edo & University of Benin & $\mathrm{Nil}$ & Igbinedion University \\
\hline Rivers & Nil & $\begin{array}{l}\text { Rivers State University of Science and } \\
\text { Tech. }\end{array}$ & - \\
\hline \multirow[t]{2}{*}{ TOTAL } & 4 & 3 & 2 \\
\hline & & & $\begin{array}{l}\text { = } 9 \text { Universities } \\
\text { selected }\end{array}$ \\
\hline
\end{tabular}

Note: Dash denotes “No private university."

Having included the above South-south universities for this study, the researcher then employed similar sampling procedure, first, to the university faculties, schools, colleges, or institutes, and, second, to the departments. Table 5.3(c) below shows the faculties, schools, colleges, or institutes and departments selected for this study. If for example on average, 15 respondents were willing to assist in the research in each of the 28 departments selected below, the researcher expected to get a total sample of 540 questionnaire responses in South-south Nigeria. Upon screening of the instruments to sort out responses that would likely be unusable, then at least the expected minimum samples would be achieved. 
Table 5.3(c) Distribution of faculties/schools/colleges/institutes and departments: South-south

\begin{tabular}{|c|c|c|c|}
\hline State & Universities & $\begin{array}{l}\text { Faculties/schools/colleges/institutes } \\
\text { [and those selected] }\end{array}$ & Department selected \\
\hline $\begin{array}{l}\text { Akwa } \\
\text { Ibom }\end{array}$ & University of Uyo & $\begin{array}{l}\text { Faculty of Agriculture, Basic Medical Science, } \\
\text { Business Administration, Clinical Science, Education, } \\
\text { Engineering, Environmental Studies, Law, Pharmacy, } \\
\text { Science, and Social Science. } \\
\text { [1. Business Administration; 2. Engineering; 3. Basic } \\
\text { Medical Science; 4. Agriculture] }\end{array}$ & $\begin{array}{l}\text { 1. Management } \\
\text { 2. Electrical/Electronics } \\
\text { 3. Biochemistry } \\
\text { 4. Home Economics }\end{array}$ \\
\hline Bayelsa & Niger Delta University & $\begin{array}{l}\text { Agricultural Technology, Basic Medicine, Clinical } \\
\text { Sciences, Education, Engineering, Law, Management } \\
\text { Science, Pharmacy, Science, and Social } \\
\text { Science.[1.Social Science; 2. Pharmacy; } 3 . \\
\text { Engineering] }\end{array}$ & $\begin{array}{l}\text { 1. Sociology } \\
\text { 2. Pharmaceutical } \\
\text { Microbiology and } \\
\text { Biotechnology } \\
\text { 3. Civil Engineering }\end{array}$ \\
\hline \multirow[t]{2}{*}{$\begin{array}{l}\text { Cross } \\
\text { River }\end{array}$} & 1. University of Calabar & $\begin{array}{l}\text { 1. Agriculture, Allied Medical Sciences, Arts, Basic } \\
\text { Medical Science, Clinical Sciences, Education, Law, } \\
\text { Management Science, Social Sciences, Sciences, and } \\
\text { Institute of Education. } \\
\text { [1. Arts; } 2 \text {. Sciences; } 3 \text {. Clinical Sciences] }\end{array}$ & $\begin{array}{l}\text { 1. Linguistics } \\
\text { 2. Geology } \\
\text { 3. Anatomy }\end{array}$ \\
\hline & $\begin{array}{l}\text { 2. Cross River University of } \\
\text { Technology }\end{array}$ & $\begin{array}{l}\text { 2. Faculty of Engineering, Education, Science, } \\
\text { Environmental Science, Communication Technology, } \\
\text { Management Science, Basic Medical Sciences, } \\
\text { Agriculture and Forestry. } \\
\text { [1. Engineering; 2. Sciences; 3. Communication } \\
\text { Technology] }\end{array}$ & $\begin{array}{l}\text { 1.Mechanical Engineering } \\
\text { 2. Chemical Science } \\
\text { 3. Mass Communication }\end{array}$ \\
\hline \multirow[t]{2}{*}{ Delta } & $\begin{array}{l}\text { 1. Petroleum Resources } \\
\text { University }\end{array}$ & $\begin{array}{l}\text { 1. Science; Technology [1. Technology; } 2 \text {. Science] } \\
\text { 2. Social and Management Sciences, Natural and }\end{array}$ & $\begin{array}{l}\text { 1. Petroleum Engineering } \\
\text { 2. Geo Physics }\end{array}$ \\
\hline & 2. Western Delta University & $\begin{array}{l}\text { Applied Sciences. [1. Social and Management } \\
\text { Sciences; } 2 \text {. Natural and Applied Sciences.] }\end{array}$ & $\begin{array}{l}\text { 1. Hotel and Tourism } \\
\text { 2. Geology and Petroleum } \\
\text { Studies }\end{array}$ \\
\hline \multirow[t]{2}{*}{ Edo } & 1. University of Benin & $\begin{array}{l}\text { 1. Agriculture, Arts, Education, Engineering, Law, Life } \\
\text { Science, Management Science, Pharmacy, Physical } \\
\text { Science, School of Basic Medical Science, School of } \\
\text { Dentistry, School of Medicine, and Social Science } \\
\text { [1.Engineering; } 2 \text {. Education; 3. Social Science; } 3 . \\
\text { Pharmacy] }\end{array}$ & $\begin{array}{l}\text { 1. Computer Engineering } \\
\text { 2. Educational Psychology and } \\
\text { Curriculum Studies } \\
\text { 3. Geography and Regional } \\
\text { Planning. 4. Pharmacology } \\
\text { and Toxicology }\end{array}$ \\
\hline & 2. Igbinedion University & $\begin{array}{l}\text { 2. Arts and Social Sciences; Business and } \\
\text { Management Studies; Engineering; Health Science; } \\
\text { Law; Natural and Applied Sciences; Pharmacy. } \\
\text { [1.Natural and Applied Sciences; } 2 \text {. Business and } \\
\text { Management Studies; 3. Law] }\end{array}$ & $\begin{array}{l}\text { 1. Physics } \\
\text { 2. Economics } \\
\text { 3. Civil Law }\end{array}$ \\
\hline Rivers & $\begin{array}{l}\text { Rivers State University of } \\
\text { Science and Technology }\end{array}$ & $\begin{array}{l}\text { Agriculture, Engineering, Environmental Sciences, } \\
\text { Law, Management Sciences, and Sciences. } \\
\text { [1.Environmental Sciences; 2. Management } \\
\text { Sciences; 3. Agriculture] }\end{array}$ & $\begin{array}{l}\text { 1. Estate Management } \\
\text { 2.Marketing } \\
\text { 3. Animal Science }\end{array}$ \\
\hline TOTAL & & 27 Faculties selected & 27 Departments selected \\
\hline
\end{tabular}

Table 5.4(a) below indicates that the Southeast states have 16 universities distributed according to federal, state, and privately-owned universities in the following order: five, five, and six. The region comprises of five states, and at least one university in each state was selected. The researcher selected no university in Ebonyi State because its federal university (as was allotted herein) does not yet have final-year undergraduates; it was established in 2011. 
Table 5.4(a): List of the Southeast universities

\begin{tabular}{|c|c|c|c|c|}
\hline & University Name & State Located & $\begin{array}{l}\text { No. of Faculties/ } \\
\text { Schools/Colleges/ } \\
\text { Institutes }\end{array}$ & $\begin{array}{l}\text { Year } \\
\text { Founded }\end{array}$ \\
\hline & Federal Government Universities & & & \\
\hline 1. & Michael Opara University of Agric., Umudike & Abia & 9 & 1992 \\
\hline 2. & Nnamdi Azikiwe University, Awka & Anambra & 13 & 1992 \\
\hline 3. & Federal University, Ndufu-Alike Ikwo & Ebonyi & 3 & 2011 \\
\hline 4. & University of Nigeria, Nsukka & Enugu & 13 & 1960 \\
\hline \multirow[t]{3}{*}{5 . } & Federal University of Technology, Owerri & Imo & 6 & 1980 \\
\hline & & & 44 & \\
\hline & State Government Universities & & & \\
\hline 6. & Abia State University, Uturu & Abia & 8 & 1980 \\
\hline 7. & Anambra State University, Uli and Igbariam & Anambra & 10 & 2000 \\
\hline 8. & Ebonyi State University, Abakaliki & Ebonyi & 11 & 2000 \\
\hline 9. & $\begin{array}{l}\text { Enugu State University of Science and Tech., } \\
\text { Enugu }\end{array}$ & Enugu & 9 & 1981 \\
\hline \multirow[t]{3}{*}{10.} & Imo State University, Owerri & Imo & 10 & 1992 \\
\hline & & & 48 & \\
\hline & Private Universities & & & \\
\hline 11. & Gregory University, Uturu & Abia & 7 & 2012 \\
\hline 12. & Madonna University, Okija & Anambra & 11 & 1999 \\
\hline 13. & Paul University, Awka & Anambra & 2 & 2009 \\
\hline 14. & Renaissance University, Enugu & Enugu & 3 & 2005 \\
\hline 15. & $\begin{array}{l}\text { Godfrey Okoye University, Ugwuomu-Nike, } \\
\text { Enugu }\end{array}$ & Enugu & 3 & 2009 \\
\hline \multirow[t]{10}{*}{16.} & Caritas University, Enugu & Enugu & 4 & 2005 \\
\hline & & & $30=122$ & \\
\hline & $\underline{\text { Summary }}$ & & & \\
\hline & $\begin{array}{ll}\text { Universities according to } \\
\text { states }\end{array}$ & Distribution & & \\
\hline & Abia & 1 Federal, 1 State & 1 Private & \\
\hline & Anambra $=4$ & 1 Federal, 1 State & 2 Private & \\
\hline & Ebonyi $=2$ & 1 Federal, 1 State & & \\
\hline & Enugu & 1 Federal, 1 State & 3 Private & \\
\hline & Imo & 1 Federal, 1 State & & \\
\hline & Total & & & \\
\hline
\end{tabular}

Sources: Adapted from National Universities Commission (2013); respective universities' websites 
Following similar sampling procedure, the researcher randomly selected six out of 16 universities on a state-by-state basis. The universities in this region have a somewhat homogenous composition of Ibo indigenes as their undergraduate students in contrast to the South-south counterparts that had many divergent ethnic groups that make up the region. Table 5.4(b) below shows the sampling distribution for the Southeast region. It indicates that two out of five federal universities, two out of five state universities, and two out of six privately-owned universities were selected:

Table 5.4(b) Distribution of sampled Southeast universities

\begin{tabular}{|c|c|c|c|}
\hline State & Federal University & State University & Private University \\
\hline Abia & Nil & Abia State University & Nil (no final-year students: founded 2012) \\
\hline Anambra & Nil & Anambra State University & Madonna University \\
\hline Ebonyi & Nil (no final-year students: founded 2011) & Nil & - \\
\hline Enugu & University of Nigeria & Nil & Caritas University \\
\hline Imo & Federal University of Technology & Nil & $\mathrm{Nil}$ \\
\hline TOTAL & 2 & 2 & $\begin{array}{r}=6 \text { Universities } \\
\text { selected }\end{array}$ \\
\hline
\end{tabular}

Note: Dash denotes “No private university.”

Having included the above Southeast universities for this study, the researcher then employed the same sampling process, first, to the university faculties/schools/colleges/institutes level. Second, to the department level. Table 5.4 (c) below shows the faculties and departments that the researcher selected randomly: 
Table 5.4(c) Distribution of faculties/schools/colleges/institutes and departments: Southeast

\begin{tabular}{|c|c|c|c|}
\hline State & Universities & $\begin{array}{l}\text { Faculties/schools/colleges/institutes } \\
\text { [and those selected] }\end{array}$ & Department selected \\
\hline Abia & Abia State University & $\begin{array}{l}\text { Business Administration, Agriculture, } \\
\text { Education, Biological and Physical } \\
\text { Sciences, Environmental Sciences, Law, } \\
\text { Humanities and Social Sciences, and } \\
\text { Medicine [1. Humanities and Social } \\
\text { Sciences; 2. Biological and Physical } \\
\text { Sciences; 3. Business Administration] }\end{array}$ & $\begin{array}{l}\text { 1. Government and Public } \\
\text { Admiration } \\
\text { 2. Industrial Physics } \\
\text { 3. Management }\end{array}$ \\
\hline \multirow[t]{2}{*}{ Anambra } & 1. Anambra State University & $\begin{array}{l}\text { 1. Agricultural Science, Arts, Basic } \\
\text { Medical Science, Education, Engineering, } \\
\text { Environmental Sciences, Law, Science, } \\
\text { Management Science, Social Science, } \\
\text { and College of Medicine } \\
\text { [1. Science; 2. Arts; 3. Social Science] }\end{array}$ & $\begin{array}{l}\text { 1. Computer Science } \\
\text { 2. Mass Communication } \\
\text { 3. Psychology }\end{array}$ \\
\hline & 2. Madonna University & $\begin{array}{l}\text { Ecclesiastical Studies, Education and } \\
\text { Arts, Engineering and Technology, } \\
\text { Health Sciences, Law, Management and } \\
\text { Social Sciences, Pharmacy, Sciences, } \\
\text { Colleges of Anatomy, Medicine, and } \\
\text { Physiology } \\
\text { [1. Ecclesiastical Studies; } 2 \text {. Engineering } \\
\text { and Technology; 3. Education and Arts] }\end{array}$ & $\begin{array}{l}\text { 1. Religious Studies } \\
\text { 2.Food Science and } \\
\text { Technology } \\
\text { 3. Business Education }\end{array}$ \\
\hline \multirow[t]{2}{*}{ Enugu } & 1. University of Nigeria & $\begin{array}{l}\text { 1. Agriculture, Arts, Biological Sciences, } \\
\text { Business Administration, Dentistry, } \\
\text { Education, Engineering, Environmental } \\
\text { Studies, Health Sciences and } \\
\text { Technology, Law, Medical Sciences, } \\
\text { Pharmaceutical Sciences, and Physical } \\
\text { Sciences. } \\
\text { [1. Business Administration; } 2 . \\
\text { Agriculture; 3. Arts; 4. Law] }\end{array}$ & $\begin{array}{l}\text { 1. Accountancy } \\
\text { 2. Agricultural Economics } \\
\text { 3. English and Literary } \\
\text { Studies } \\
\text { 4. Commercial and } \\
\text { Property Law }\end{array}$ \\
\hline & 2. Caritas University & $\begin{array}{l}\text { 2. Engineering, Environmental Sciences, } \\
\text { Management and Social Sciences, and } \\
\text { Natural Sciences. [1. Natural Sciences; } 2 . \\
\text { Management and Social Sciences] }\end{array}$ & $\begin{array}{l}\text { 1. Physics } \\
\text { 2.Banking and Finance }\end{array}$ \\
\hline Imo & Federal University of Technology & $\begin{array}{l}\text { Agriculture and Agriculture Technology, } \\
\text { Engineering and Engineering } \\
\text { Technology, Environmental Technology, } \\
\text { Health Technology, Management } \\
\text { Technology, and Science. [1. Agriculture } \\
\text { and Agriculture Technology; } 2 \text {. } \\
\text { Management Technology; } 3 \text {. Science]. }\end{array}$ & $\begin{array}{l}\text { 1. Fisheries and } \\
\text { Aquaculture } \\
\text { 2. Transport } \\
\text { 3. Science Lab Technology }\end{array}$ \\
\hline TOTAL & & 18 Faculties selected & $\begin{array}{l}18 \text { Departments } \\
\text { selected }\end{array}$ \\
\hline
\end{tabular}

In the more populated Southeast region, if for example 25 respondents on the average were willing to assist in the research in each of the 18 departments selected above, the researcher could get the needed sample. That is a total sample size of 450 questionnaires from undergraduates from the region. The researcher would then sort the completed questionnaire and screen for responses that would likely be unusable. 


\subsubsection{Survey data collection procedure}

Having determined the university departments selected for this study, the researcher visited the various departments of the universities, one at a time. The researcher obtained written permissions for access from heads of departments or other appropriate authorities. Then during an off-lesson period, the researcher administered the participants' information sheet a day to the survey and invited willing participants to take part in the survey in their next off-lesson period. The survey was self-administered to the students in their classrooms during their off-lesson periods and the completed questionnaires collected. Those who wished to complete the questionnaire later on and return to the researcher were given prepaid stamped self-addressed envelopes for posting of the questionnaires. The author then sorted all the received questionnaires. The data collection procedure continued for other departments and universities until all the sampled schools were visited, and a satisfactory number of surveys administered.

\subsection{Data analysis techniques}

Although this study used a mixed methods research strategy, data analysis techniques were distinct. It was logical, feasible, and systematic to follow different analysis techniques for each research method. Therefore, the analysis was conducted separately for the quantitative and qualitative phases. In the quantitative phase, which used survey questionnaire data, the starting point was to conduct a univariate analysis. This analysis means the displaying; summarising or drawing the conclusion from a single variable or set of variables treated one at a time. A multivariate analysis then followed. This analysis means the examining of relationships between two or more variables. The researcher used the IBM SPSS (version 21) as well as SmartPLS version 2.0 statistical software for the analysis.

In the qualitative phase, focus groups interview transcripts were analysed using "within-case and across-case" thematic analysis techniques. The researcher conducted the analysis manually. The following subsections address details of the analysis techniques in these two phases.

\subsubsection{Analysis techniques and preparation of quantitative data for analysis}

This study implemented two broad statistical techniques, namely: univariate and multivariate. Under the univariate technique, the study analysed the respondents' demographic characteristics and questionnaire responses about the subscales. It also analysed their frequency distributions, means, skewness, kurtosis, medians, range, interquartile range, minimum and maximum values, and standard deviations. On the multivariate side, measurement model validation and structural 
equation modelling were conducted using the SmartPLS software. The aim was to determine the explanatory power, path coefficients and variances extracted, standard residuals of the independent variables and the entire statistics stated in Figure 5.2 previously.

Before data analysis proper, the author screened the data first using the statistical techniques earlier enumerated in Figure 5.2 and as recommended in the MMR data analysis literature (Enders, 2001; Rousseeuw and van Zomeren, 1990). The procedure entailed checking the data for outliers and "out-of-range" values as well as for meeting the normality and homoscedastic assumptions (i.e. constancy of variance). It also entailed the transforming/repairing of data to ensure the study met the assumptions. This approach helped in avoiding the bias of standard errors of the regression coefficients used in assessing the significance of estimates before analysis. Furthermore, the study assessed the data for validity and reliability using the criteria highlighted in the questionnaire design section (5.4).

\subsubsection{The structural equation modelling (SEM) technique}

Structural equation modelling is the simultaneous measurement of relationships involving one or more independent variables and one or more dependent variables. The variables can be measured either as continuous or discrete. Furthermore, the variable can be either factors or latent constructs or "measured variables." "Latent" because the variables are not measured directly, but some set of "good" questions were posed to reflect the construct. Measured variables are indicators or questions. The novelty of SEM over traditional regression is that it allows more flexible assumptions (Garson, 2012).

For example, the partial least squares structural equation modelling technique permits interpretation irrespective of multicollinearity, in many cases. Measurement error is minimised by retaining only the indicators with high outer loadings especially when models use unobserved variables that have multiple indicators. In covariance-based structural equation modelling, however, confirmatory factor analysis (CFA) is used to minimise error of measurement. SEM also provides an interface for modelling visually. There is simultaneous testing of all constructs in the model. It can model "mediating variables rather than be restricted to an additive model as in regression" (Garson, 2012, p.169). It has capacity for modelling error terms, test coefficients through several "between-subjects groups", and compare competing models to determine which one fits better. But the comparison of competing models is only possible in covariance-based structural equation modelling. 
SEM also assesses total effects of each factor that comprise of direct and indirect (e.g. moderating) effects, thus informing how well the conceptual model fits the research data (Ho, 2006). Its overall advantage over other multivariate analysis techniques (e.g. principal component analysis, discriminant analysis, and regression) is in its ability to "test relationships between latent constructs instead of observed constructs." This advantage is one of the reasons for its use in this research. The reason is that SEM "partials the measurement errors out of the observed construct" (Mariano et al., 2012, p.170). This capability enhances the consistency of the model estimates.

Therefore this study adopted the partial least squares structural equation modelling technique, a variance-based technique, for the quantitative data analysis. Its use is because of the advantage over the covariance-based counterpart. It can obtain reliable estimates with less restrictive assumptions and can model both the reflective-and-formative-measured constructs and secondorder constructs in a single model (Hair et al., 2014).

\subsection{Survey questionnaire design}

The researcher developed the questionnaire from various existing scales. It was pilot-tested on 116 participants from the two regions. The primary purpose was to assess the usability of the scale within the present context and to assess whether the participants had difficulties in understanding any aspect of the adapted instrument. Experience from the pilot study suggested that fours scales needed re-testing; also certain words needed some slight revision in section one (i.e. Q1 and Q2).

The main survey instruments generated five sets of 6-point Likert-scale questions that resulted in 12 latent variables used in measuring the "factors that influence entrepreneurial intentions" of the respondents. These latent variables included: "entrepreneurial intentions", "personal attitude", "subjective norms", and "perceived behavioural control." Others are "personality traits", "innovation orientation", "achievement orientation", "risk propensity", "locus of control", "capabilities", "perceived barriers", and "perceived support." Personality traits variable was a second-order hierarchical component.

Table 5.5 below presents the link between these scales/factors, questionnaire statements, and sources of the questions: 
Table 5.5: Questionnaire statements and factors that influence entrepreneurial intentions

\begin{tabular}{|c|c|c|}
\hline Factors & $\begin{array}{l}\text { Questionnaire } \\
\text { items }\end{array}$ & Sources \\
\hline 1. "Entrepreneurial intentions" & Q1. (1-6) & Solesvik et al., (2012) \\
\hline 2. "personal attitude" & Q1. (7-11) & Solesvik et al., (2012) \\
\hline 3. "subjective norms" & Q1. (12-17) & Solesvik et al., (2012) \\
\hline 4. "Perceived behavioural control" & $\begin{array}{l}\text { Q1. (18) and Q1. (19- } \\
\text { 22) }\end{array}$ & $\begin{array}{l}\text { Solesvik et al., (2012) CR }=0.78 \text {; and Lińän, Urbano } \\
\text { and Guerrero (2011) CR }=0.818 \text { respectively }\end{array}$ \\
\hline 5. "Innovation orientation" & Q2. (1-3) & Peng et al. (2012) $\quad C R=0.75-0.83$ \\
\hline 6. "Achievement orientation" & Q2. (4-7) & Peng et al. (2012) \\
\hline 7. "Risk propensity" & Q2. (8 and 9) & Peng et al. (2012) \\
\hline 8. "Locus of control" & Q2. (10-12) & Peng et al. (2012) \\
\hline 9. "Capabilities" & Q3. (1-6) & Peng et al. (2012) $\quad C R=0.82-0.88$ \\
\hline 10. "Perceived barriers" & $\begin{array}{l}\text { Q4. }(2,5 \text { and } 6) \\
\text { Q4. }(1,3 \text {, and } 4)\end{array}$ & $\begin{array}{l}\text { Lüthje and Franke (2003) } \quad C R=0.533 \\
\text { Added from Peng et al. (2012) CR }=0.79\end{array}$ \\
\hline 11. "Perceived support" & Q5. (1-5) & Added from Peng et al. (2012) CR = not indicated \\
\hline
\end{tabular}

${ }^{1}$ CR= Construct Reliability (i.e., using Cronbach alpha)

N/B: A full version of the questionnaire is attached as Appendix 7.

The questions and scales came directly from the literature. Core theories relating to entrepreneurship were combined to indicate a complete view of the phenomenon. They were Ajzen's "theory of planned behaviour" and the personality traits thesis. Others were the propositions relating to contextual influences and capabilities for entrepreneurship. Questions relating to each component of these theories were derived from the literature.

The initial results showed that three of the factors had unacceptable reliability coefficients and were therefore replaced. A repeat pilot study was conducted with 44 respondents; the new results were satisfactory, and the final instrument was consequently administered. Cronbach alpha coefficients ranged from 0.77 to 0.90 . The questionnaire contained five sections of six-point Likerttype questions that resulted in 11 latent variables, excluding "personality traits" which was a second-order construct. These variables were used in measuring the "factors that influence entrepreneurial intentions" of the respondents. These variables included "entrepreneurial intentions" as the dependent variable. The "personal attitude", "subjective norms", "perceived behavioural control" (all four were adopted from Solesvik et al., 2012; Lińän, Urbano and Guerrero, 2011). The "innovation orientation" was adopted from Peng et al. (2012). The "achievement orientation", "risk propensity", "locus of control” were adopted from Caird (2013). The "perceived capabilities" was adopted from Peng et al. (2012). The "perceived barriers", and "perceived support" were adopted from Lüthje and Franke (2003) and Peng et al. (2012).

The original studies established content validity and reliability, but because the items were now used in a different setting, the researcher still conducted reliability tests of the instrument to 
determine consistency. Results from the Fornell-Larcker criterion indicated favourable levels of discriminant validity. Satisfactory results from the average variance extracted (AVE), and the outer loadings indicated convergent validity (Wang, 2008). The results were obtained from IBM SPSS (version 21) and SmartPLS (version 2.0).

\subsubsection{Test for reliability of the questionnaire using the pilot study conducted in Nigeria}

This section discusses how the study assessed the reliability (as a sufficient condition) and validity (as a necessary condition) of the scales. The scales were adopted from previous studies that developed instruments for testing students' entrepreneurial intentions. Although the previous studies validated the instruments, an instrument can be valid but not reliable especially if a researcher adopts them for research in a different context and culture (Field, 2013). Therefore, this study used the Cronbach's test of reliability to assess the consistency of the measures. The author conducted a pilot study in October 2013 in Nigeria with samples from two universities in the regions. Factor analysis was not conducted since the structure of the individual factors already existed from validated scales and the literature in the previous studies. This study did not use items or questions to create variables or "factor structures" or "develop instruments." This study, therefore, depended only on the power of the test of reliability using the Cronbach's alpha test, considered adequate for the purpose (Field, 2013; Cortina, 1993). The following segments present the decision criteria and the associated statistics.

In a reliable scale, "all items should correlate with the total or overall score from the scale" (Field, 2013, p.713). The values of "corrected item-total correlation" were employed to assess individual items in each scale. For an item to qualify for inclusion in the final scale, it must have a value of about 0.3 (Field, 2013, p.714). Items with lesser values may have to be expunged since they do not correlate very well with the scale overall. For the column "Cronbach's alpha if item deleted", it indicates the value for each item in which the overall reliability becomes should such value be deleted from the scale. Thus, if any item has a value higher than the reliability alpha, then it is appropriate to expunge such question so as to improve the scale's reliability. Also, the "Cronbach's alpha if item deleted" tells whether expunging a question or item will improve overall measure of reliability.

In a way to improving scales that have reliability coefficients that are less than 0.7 , if no item has a value in the "Cronbach's alpha if item deleted" column that is more than the existing alpha, then such circumstance indicates a problem. So, it would mean that the entire items in the subscale "cover quite diverse themes and needs a rethink" (Field, 2013, p.714; Bryman and Bell, 2011, 
p.159). With these criteria in mind, the following tables indicate how the Questionnaire on Undergraduate Students' Intentions (QUSI) for setting up businesses was validated:

Table 5.5(a) Reliability test and total-item statistics for scale 1: Entrepreneurial Intentions

\begin{tabular}{|c|c|c|c|c|c|}
\hline \multicolumn{6}{|c|}{ Reliability Statistics } \\
\hline Cronbach's Alpha & $\mathrm{N}$ of Items & & & & \\
\hline \multicolumn{6}{|l|}{.837} \\
\hline \multicolumn{6}{|c|}{ Item-Total Statistics } \\
\hline & & $\begin{array}{l}\text { Scale Mean if } \\
\text { Item Deleted }\end{array}$ & $\begin{array}{l}\text { Scale Variance if } \\
\text { Item Deleted }\end{array}$ & $\begin{array}{c}\text { Corrected Item- } \\
\text { Total } \\
\text { Correlation }\end{array}$ & $\begin{array}{l}\text { Cronbach's } \\
\text { Alpha if Item } \\
\text { Deleted }\end{array}$ \\
\hline (1) I am ready to do anyt & ing to be an entrepreneur & 24.5345 & 26.216 & .553 & .828 \\
\hline (2) My professional goal & to become an entrepreneur & 24.2931 & 26.592 & .719 & .788 \\
\hline (3) I am determined to $\mathrm{Cr}$ & ate a business venture in the future & 23.7241 & 28.845 & .632 & .808 \\
\hline (4) I have serious though & about starting a firm & 23.9138 & 28.236 & .685 & .798 \\
\hline (5) I have got the intentic & to start a firm one day & 23.9397 & 27.170 & .695 & .794 \\
\hline (6) I intend to start a firr & within five years of graduation & 24.4224 & 28.837 & .458 & .843 \\
\hline
\end{tabular}

Source: Fieldwork (2013)

From Table 5.5(a), the Cronbach's alpha value is 0.837 . The reliability test is above the minimum acceptable benchmark of 0.7. The column, "corrected item-total correlation" indicates that all the items (1-6) carried values that are more than the minimum benchmark of 0.30 . No value in the column "Cronbach's alpha if item deleted" was greater than the reliability index, thus, no item needed any deleting, and the scale is reliable.

Table 5.5(b): Reliability test and total-item statistics for scale 2: Personal Attitude

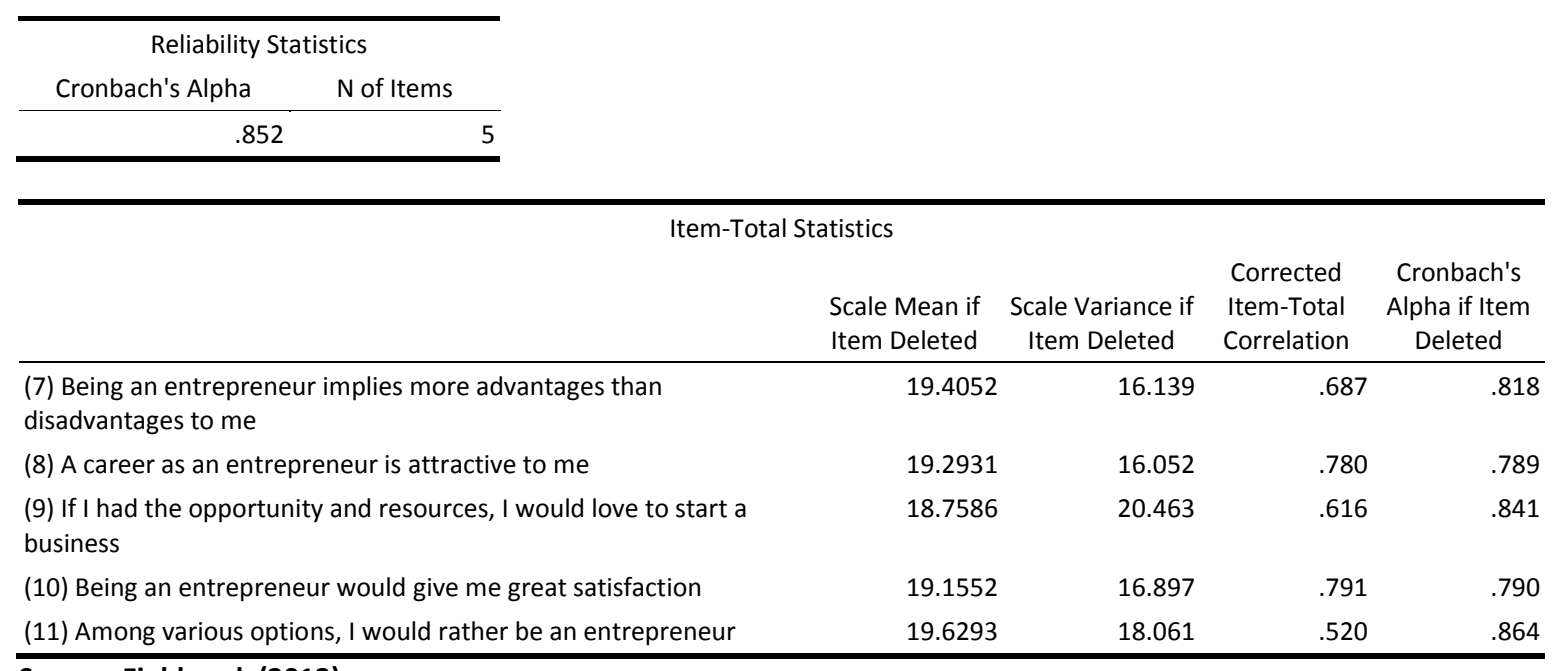

Source: Fieldwork (2013)

From Table 5.5(b), the Cronbach's alpha reported a high value of 0.852 . Both the values in the columns named "corrected item-total correlation" and "Cronbach's alpha if item deleted" are highly satisfactory. Therefore, the scale was considered valid. 
In Table 5.5(c) below, all the six items jointly reported a Cronbach's alpha of 0.898 and values in the other two decision columns are considered adequate. Thus, the scale is internally consistent:

Table 5.5(c): Reliability test and total-item statistics for scale 3: Subjective Norms

\begin{tabular}{rr}
\hline \multicolumn{2}{c}{ Reliability Statistics } \\
\hline Cronbach's Alpha $\quad \mathrm{N}$ of Items \\
.898 & 6 \\
\hline
\end{tabular}

\begin{tabular}{|c|c|c|c|c|}
\hline \multicolumn{5}{|c|}{ Item-Total Statistics } \\
\hline & $\begin{array}{l}\text { Scale Mean } \\
\text { if Item } \\
\text { Deleted }\end{array}$ & $\begin{array}{c}\text { Scale } \\
\text { Variance if } \\
\text { Item } \\
\text { Deleted }\end{array}$ & $\begin{array}{l}\text { Corrected } \\
\text { Item-Total } \\
\text { Correlation }\end{array}$ & $\begin{array}{l}\text { Cronbach's Alpha } \\
\text { if Item Deleted }\end{array}$ \\
\hline $\begin{array}{l}\text { (12) My closest family members think that I should pursue a } \\
\text { career as an entrepreneur }\end{array}$ & 21.1810 & 41.106 & .611 & .897 \\
\hline $\begin{array}{l}\text { (13) I do care about what my closest family members think as } \\
\text { I decide on whether or not to pursue a career as self- } \\
\text { employed }\end{array}$ & 21.1724 & 39.535 & .696 & .884 \\
\hline $\begin{array}{l}\text { (14) My closest friends think that I should pursue a career as } \\
\text { an entrepreneur }\end{array}$ & 21.1034 & 39.346 & .760 & .874 \\
\hline $\begin{array}{l}\text { (15) I do care about what my closest friends think as I decide } \\
\text { on whether or not to pursue a career as self-employed }\end{array}$ & 21.0690 & 37.873 & .740 & .877 \\
\hline $\begin{array}{l}\text { (16) People that are important to me think I should pursue a } \\
\text { career as an entrepreneur }\end{array}$ & 20.9224 & 39.672 & .764 & .874 \\
\hline $\begin{array}{l}\text { (17) I do care about what people important to me think as I } \\
\text { decide on whether or not to pursue a career as self-employed }\end{array}$ & 21.1466 & 39.065 & .781 & .871 \\
\hline
\end{tabular}

Source: Fieldwork (2013)

The scale reported in Table 5.5(d) below indicates a Cronbach's alpha index of 0.819 . The corresponding columns-"corrected item-total correlation" and "Cronbach's alpha if item deleted"-report values that are higher than the benchmark value of 0.7 . Therefore, the scale was considered internally consistent as indicated below:

Table 5.5(d): Reliability test and total-item statistics for scale 4: Perceived behavioural Control

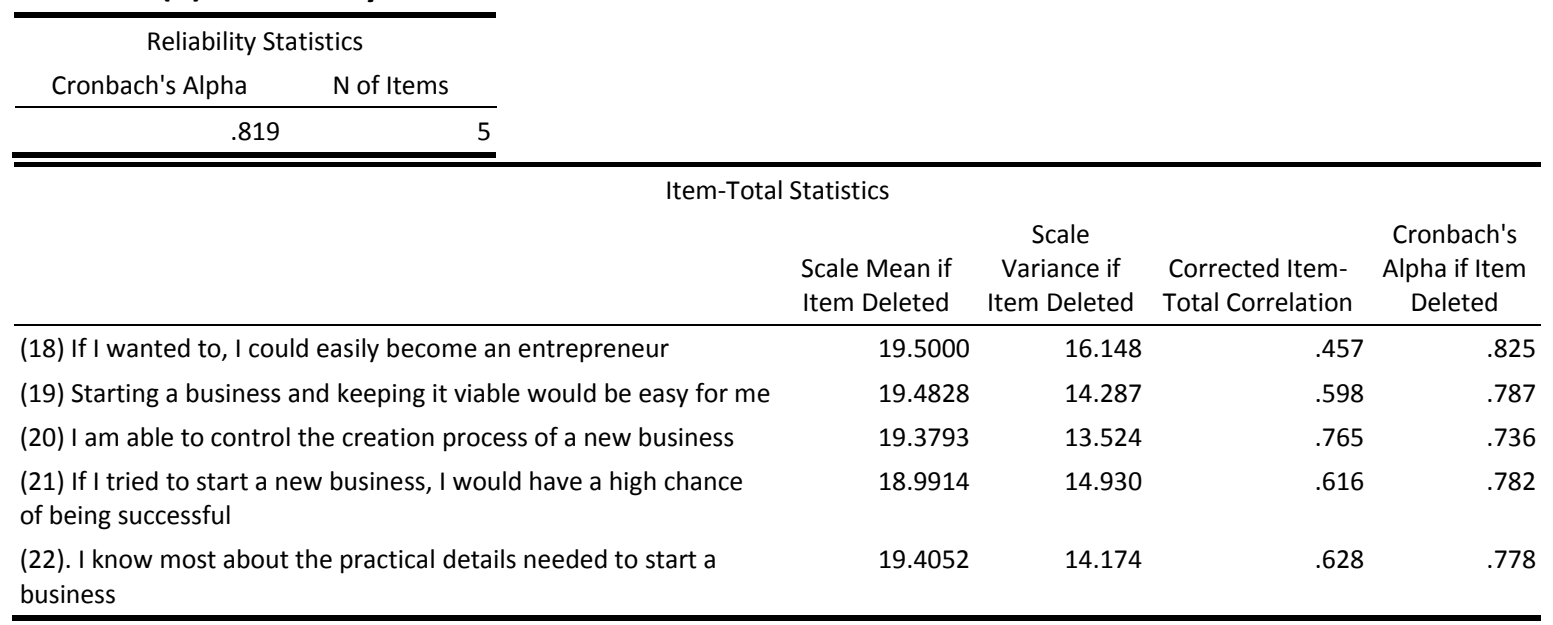

Source: Fieldwork (2013)

In Table 5.5(e) that follows, the scale reported a Cronbach's alpha of 0.783 and values in the column named "correlated item-total correlation" are above the set criterion of 0.3. Values in the 
column "Cronbach alpha if item deleted" also reported adequate indices. It was noted during the computer analysis process that this scale initially failed the reliability test, so an adjusted sample size of 36 was rather used to validate the scale. The reason is that a reliable and consistent response pattern was identified in a subset of 36 respondents within the 116 participants used. Therefore, the insignificance of the reliability test was more of a response pattern than poor items or scale (Ho, 2014):

Table 5.5(e): Reliability test and total-item statistics for scale 5: Innovation Orientation

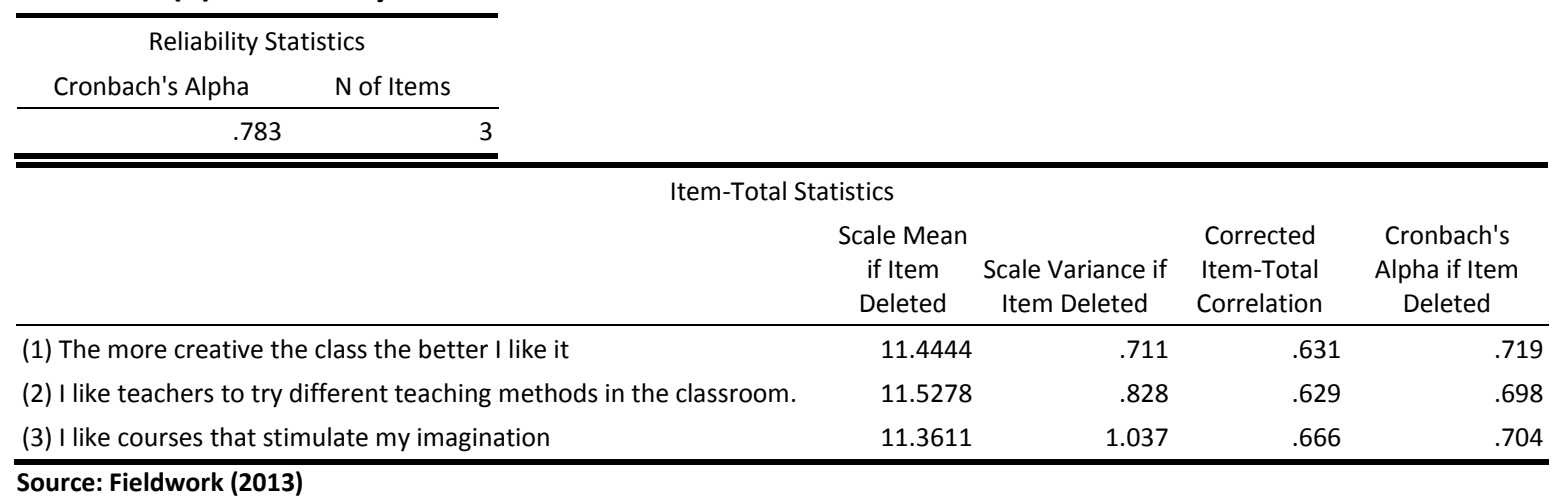

In Table 5.5(f) that follows, the Cronbach's alpha test for internal consistency for "achievement orientation" scale failed reliability test, both with the 116 sample set and the 36 subset samples. The index was 0.527 and below the minimum 0.7 set benchmark. A cursory look at the column "corrected item-total correlation" indicates that the values for items 1 and 2 were less than the 0.3 set criterion. Thus, this suggests a potential problem and the need for deleting, to improve the overall reliability. Nevertheless, the column "Cronbach's alpha if item deleted" reported the values 0.541 and 0.496 respectively. These figures prove incapable of redeeming the poor reliability. Therefore, this scale was pencilled down for modification and a repeat pilot study. An alternative scale is the General Enterprising Tendency (GET2) scale (Caird, 2013). It measures personality traits including "need for achievement", "creativity or innovativeness", "risk-propensity", the "need for autonomy", and "internal locus of control." The test result for achievement orientation is reported below: 
Table 5.5(f): Reliability test and total-item statistics for scale 6: Achievement Orientation

\begin{tabular}{|c|c|c|c|c|c|}
\hline \multicolumn{6}{|c|}{ Reliability Statistics } \\
\hline Cronbach's Alpha & $\mathrm{N}$ of Items & & & & \\
\hline \multicolumn{6}{|l|}{.527} \\
\hline \multicolumn{6}{|c|}{ Item-Total Statistics } \\
\hline & & $\begin{array}{l}\text { Scale Mean if } \\
\text { Item Deleted }\end{array}$ & $\begin{array}{c}\text { Scale } \\
\text { Variance if } \\
\text { Item Deleted }\end{array}$ & $\begin{array}{l}\text { Corrected } \\
\text { Item-Total } \\
\text { Correlation }\end{array}$ & $\begin{array}{l}\text { Cronbach's } \\
\text { Alpha if Item } \\
\text { Deleted }\end{array}$ \\
\hline $\begin{array}{l}\text { (4) I am more willing to } \\
\text { creativity, compared to }\end{array}$ & $\begin{array}{l}\text { dertake a task requiring problem-solving or } \\
\text { ask only requiring me to follow instructions. }\end{array}$ & 14.9167 & 8.593 & .208 & .541 \\
\hline $\begin{array}{l}\text { (5) I am more willing to } \\
\text { to a task to only avoid fa }\end{array}$ & $\begin{array}{l}\text { dertake a task leading to success, compared } \\
\text { re. }\end{array}$ & 14.6111 & 9.273 & .270 & .496 \\
\hline $\begin{array}{l}\text { (6) I am more willing to } \\
\text { responsibility, comparec }\end{array}$ & $\begin{array}{l}\text { e on a task for which I have sole } \\
\text { a task where the responsibility is shared. }\end{array}$ & 15.2222 & 6.463 & .524 & .255 \\
\hline $\begin{array}{l}\text { (7) I am more willing to } \\
\text { one. }\end{array}$ & e more difficult task, rather than an easy & 15.9167 & 6.560 & .304 & .480 \\
\hline
\end{tabular}

Source: Fieldwork (2013)

Table 5.5(g) that follows describes reliability test for risk-propensity scale. Although the test index was high $(\alpha=0.786)$, based on the complete sample $(n=116)$, here the researcher detected some problems with the data iteration process. The problem is indicated by the values in the column "Cronbach's alpha if item deleted." The scale violated reliability assumption of positive average covariance. Therefore, it needed a better scale. Again the GET2 scale provided the new questions for risk-propensity in the re-piloting exercise. Also, since the GET2 scale has up to 12 items measuring risk-taking tendency, the researcher considered it to be better than the present twoitem scale:

Table 5.5(g): Reliability test and total-item statistics for scale 7: Risk-propensity

\begin{tabular}{cr}
\hline \multicolumn{3}{c}{ Reliability Statistics } \\
Cronbach's Alpha & N of Items \\
\hline .786 & 2 \\
\hline
\end{tabular}

\begin{tabular}{|c|c|c|c|c|}
\hline \multicolumn{5}{|c|}{ Item-Total Statistics } \\
\hline & $\begin{array}{l}\text { Scale Mean if } \\
\text { Item Deleted }\end{array}$ & $\begin{array}{c}\text { Scale } \\
\text { Variance if } \\
\text { Item Deleted }\end{array}$ & $\begin{array}{l}\text { Corrected } \\
\text { Item-Total } \\
\text { Correlation }\end{array}$ & $\begin{array}{l}\text { Cronbach's } \\
\text { Alpha if Item } \\
\text { Deleted }\end{array}$ \\
\hline $\begin{array}{l}\text { (8) I am more willing to take on a task with an uncertain outcome, } \\
\text { compared to one with a more predictable result. }\end{array}$ & 4.6207 & 1.646 & .654 &.$^{a}$ \\
\hline $\begin{array}{l}\text { (9) I am more willing to take on a task with risks, compared to a risk-free } \\
\text { task. }\end{array}$ & 4.6121 & 2.222 & .654 & . $^{a}$ \\
\hline \multicolumn{5}{|c|}{$\begin{array}{l}\text { a. The value is negative due to a negative average covariance among items. This violates reliability model assumptions. You may want to } \\
\text { check item coding. }\end{array}$} \\
\hline
\end{tabular}

In Table 5.5(h) that follows, again with the full sample $(n=116)$, the locus of control scale failed the reliability test. Then the subset sample $(n=36)$ was tried. However, the Cronbach's alpha was still below the set benchmark. It had a value of 0.63 . An assessment of the columns "corrected itemtotal correlation" and "Cronbach's alpha if item deleted" identified item 1 as a potential problem. 
The latter column indicated that if item 1 were deleted, the index would become 0.694 . Although this number is approximately 0.7 , a two-item scale might still be a potential problem later also for the measurement theory and structural equation modelling processes. Therefore, this scale was also revised to achieve better internal consistency. Its test result is reported below:

Table 5.5(h): Reliability test and total-item statistics for scale 8: Locus of Control

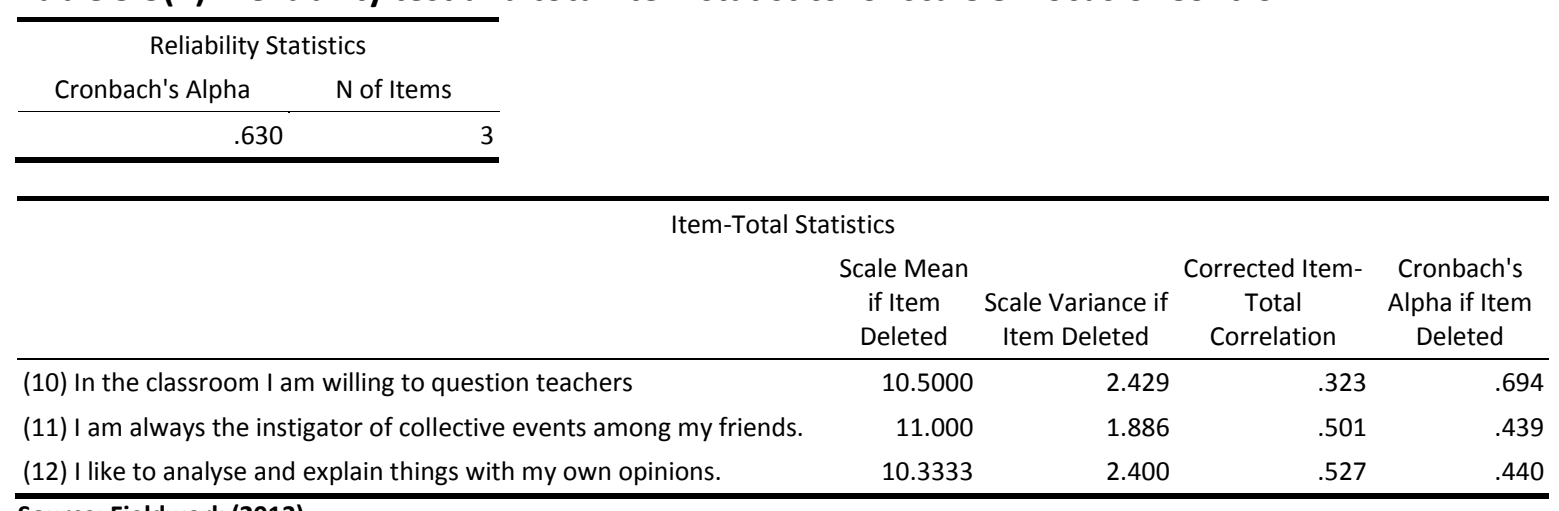

Source: Fieldwork (2013)

In Table 5.5(i) that follows, the scale for "perceived capabilities" reported an adequate Cronbach's alpha $(\alpha=0.861)$. All other decision indices were well within the acceptable limits. Therefore, the scale was accepted as internally consistent. Its result is reported below:

Table 5.5(i): Reliability test and total-item statistics for scale 9: Capabilities

\begin{tabular}{|c|c|c|c|c|c|}
\hline \multicolumn{6}{|c|}{ Reliability Statistics } \\
\hline \multicolumn{6}{|l|}{.861} \\
\hline \multicolumn{6}{|c|}{ Item-Total Statistics } \\
\hline & & $\begin{array}{l}\text { Scale Mean if } \\
\text { Item Deleted }\end{array}$ & $\begin{array}{c}\text { Scale } \\
\text { Variance if } \\
\text { Item } \\
\text { Deleted }\end{array}$ & $\begin{array}{l}\text { Corrected } \\
\text { Item-Total } \\
\text { Correlation }\end{array}$ & $\begin{array}{l}\text { Cronbach's } \\
\text { Alpha if Item } \\
\text { Deleted }\end{array}$ \\
\hline (1) I can discover the op I & rtunity for setting up a business & 24.1826 & 20.361 & .669 & .835 \\
\hline (2) I am able to work eff & tively under pressure or conflict. & 24.8609 & 18.331 & .526 & .883 \\
\hline (3) I am capable of devel & ing a new product or service. & 24.3739 & 19.657 & .693 & .830 \\
\hline $\begin{array}{l}\text { (4) I am able to build up } \\
\text { business effectively. }\end{array}$ & network of contacts needed for setting up a & 24.2348 & 20.936 & .681 & .835 \\
\hline (5) I am capable of orgar & ing key resources needed for setting up a business. & 24.2087 & 21.009 & .727 & .830 \\
\hline (6) I am able to build anc & naintain a team needed for setting up a business. & 24.0522 & 19.962 & .783 & .817 \\
\hline
\end{tabular}

Source: Fieldwork (2013)

In the same vein, Table 5.5(j) presents summaries for the scale "perceived barriers." Its Cronbach's alpha is 0.725 , above the set benchmark of 0.7 , thus indicating that the scale was also internally consistent. The test result is presented below: 
Table 5.5(j): Reliability test and total-item statistics for scale 10: Perceived Barriers

\begin{tabular}{|c|c|c|c|c|c|}
\hline \multicolumn{6}{|c|}{ Reliability Statistics } \\
\hline \multicolumn{6}{|l|}{.725} \\
\hline \multicolumn{6}{|c|}{ Item-Total Statistics } \\
\hline (1) Lack of education in & ting up a business is a hindrance & 28.6000 & 45.716 & .262 & .729 \\
\hline (2) Difficulty in securing & cessary finance is a problem & 28.1304 & 48.167 & .237 & .728 \\
\hline $\begin{array}{l}\text { (6) It is hard to find a bu } \\
\text { before }\end{array}$ & ess idea for a business that hasn't been realised & 29.0783 & 43.160 & .396 & .701 \\
\hline $\begin{array}{l}\text { (7) There are no smooth } \\
\text { business support service }\end{array}$ & $\begin{array}{l}\text { rangements for access to qualified consultants and } \\
\text { or new companies by students }\end{array}$ & 28.6870 & 42.620 & .524 & .678 \\
\hline
\end{tabular}

Lastly, Table 5.5(k) that follows presents summaries for the scale "perceived support." The scale failed the test for reliability $(\alpha=0.531$ ). A further probe revealed that item 1 was a potential problem since its value for "corrected item-total correlation" was less than 0.3 (i.e. 0.032). The deletion of item 1 will raise the index to 0.618 , but this will still be inadequate. Therefore, the scale was modified using items from previously validated scales that had better reliability. The scale was revised in the second pilot study. The test result is reported below:

Table 5.5(k): Reliability test and total-item statistics for scale 11: Perceived Support

\begin{tabular}{|c|c|c|c|c|c|}
\hline \multicolumn{6}{|c|}{ Reliability Statistics } \\
\hline Cronbach's Alpha & $\mathrm{N}$ of Items & & & & \\
\hline \multirow[t]{2}{*}{.531} & 5 & & & & \\
\hline & \multicolumn{5}{|c|}{ Item-Total Statistics } \\
\hline & & $\begin{array}{l}\text { Scale Mean if } \\
\text { Item Deleted }\end{array}$ & $\begin{array}{l}\text { Scale Variance if } \\
\text { Item Deleted }\end{array}$ & $\begin{array}{c}\text { Corrected Item- } \\
\text { Total } \\
\text { Correlation }\end{array}$ & $\begin{array}{l}\text { Cronbach's } \\
\text { Alpha if Item } \\
\text { Deleted }\end{array}$ \\
\hline $\begin{array}{l}\text { (1) The culture in my reg } \\
\text { entrepreneurial activity }\end{array}$ & on is highly favourable toward & 15.4522 & 17.829 & .032 & .618 \\
\hline $\begin{array}{l}\text { (2) The entrepreneur's } r \\
\text { my region }\end{array}$ & e in my country is generally undervalued in & 16.6087 & 12.679 & .470 & .358 \\
\hline $\begin{array}{l}\text { (3) Most people in my re } \\
\text { entrepreneur }\end{array}$ & ion consider it unacceptable to be an & 16.7391 & 12.686 & .400 & .402 \\
\hline $\begin{array}{l}\text { (4) In my region, entrepr } \\
\text { worthwhile, despite the }\end{array}$ & $\begin{array}{l}\text { neurial activity is generally considered to be } \\
\text { sks }\end{array}$ & 15.2783 & 15.676 & .314 & .470 \\
\hline $\begin{array}{l}\text { (5) It is commonly thoug } \\
\text { advantage of others }\end{array}$ & in my region that entrepreneurs take & 15.6783 & 14.097 & .304 & .470 \\
\hline
\end{tabular}

Source: Fieldwork (2013)

Overall, seven out of the 11 scales were adequate on internal consistency given their Cronbach's alpha test of reliability. These included entrepreneurial intentions, personal attitude, and subjective norms, perceived behavioural control, innovation orientation, perceived capabilities, 
and perceived barriers. The other four factors were inadequate; a second pilot study was conducted in January 2014 and the review of the results are in Section 6.2.1. The four factors included: achievement orientation, risk-propensity, the locus of control, and perceived support. In the repeat pilot study, the analysis paid greater attention to these four scales.

\subsubsection{Qualitative focus group interviews: protocol for interview development}

The focused groups' sessions followed a semi-structured interview protocol. The questions in the interview protocol depended more on the expected results of the survey. The purpose of this second phase was to explore further how the students themselves interpret and make sense of or think differently about what factors influence entrepreneurial intentions among them. Openended questions were developed beginning from the opening question (to create familiarity). For example, "tell me who you are and what you most enjoy doing when you are not studying?" There were also introductory questions and transition questions. Next were the key questions and ending questions. For example, "suppose you had one minute to talk with the Vice-Chancellor of your university on the topic, 'how to best prepare students for entrepreneurship', what would you say?", "Is there anything that we should have talked about but didn't?" A full list of the focus group interview questions is attached as Appendix 5.

Although questions were pre-written, the exact nature and order of the core questions were influenced by the statistical test results. The first focus group interview was a sort of the pilot test of the interview questions. The researcher used the experience gathered to determine whether there would be a need to revise the order and structure of the set questions slightly. The researcher also kept interview notes and diary.

\subsubsection{Focused groups interview participants and procedures}

Participants must be indigenous students of the two regions. Nevertheless, the initial plan was that students from South-south region would participate in the focus groups separately in university site within their region while their Southeast counterparts undergo in their universities too. Participants comprised of selected students from those who responded during the survey phase. The emphasis on the composition of the focus group was on students who have a passion for business-founding and entrepreneurship. However, because the analysis of the survey showed that there were no statistically significant differences between participants from the two regions, it was no longer necessary to conduct the interviews separately. The results of "no statistically- 
significant differences" were based on the analysis of the path coefficients of the hypothesised structural model.

Those who had earlier contacted the researcher by email were emailed back a participants' information sheet. The information was to make the participants familiar with the purpose of the interviews and to give their consent. The researcher and participants set a date, time range, and place. The researcher then requested the participants to come over for the exercise on the scheduled date. Follow-up contacts were then directed and personalised to the potential participants to ensure their availability during the set date.

The strategy was to recruit a homogenous group (Fowler, 2009); that is, final-year students who have something in common that might be of interest to this research. They had all undergone the compulsory entrepreneurship classes in their third year "General Studies" course. Final-year undergraduates are also the closest to deciding whether to enter paid employment or becoming business founders after graduation. Sufficient variation in the composition of participants was considered as the guideline to allow for contrasting opinions. Participants cut across different faculties and disciplines. This approach reinforced the philosophical position of the dialectical paradigm which welcomes diversity and conflicting views and engages them respectfully within an inquiry. Thus, the researcher preferred participants from different academic disciplines within the university.

\subsubsection{Qualitative data analysis techniques for the focus groups interview transcripts}

Every interview was audiotaped and transcribed verbatim by the researcher. The analysis was a within-case and across-cases (Creswell and Plano Clark, 2011). The researcher employed a "constant comparison" technique. The researcher looked for similar themes in the transcripts; the identified themes were further examined in-depth within themes (Dovovan et al., 2002). Following the ideas of Yin (2003) and Stake (1995), the researcher adopted a systematic method in the analysis. The steps were as follows: (1). Reading the transcripts perhaps two to three times and creating columns on the transcript pages for memos; (2). Coding the data into segments and labels; (3). Using "inter-coder agreement" ${ }^{\prime 9}$ to verify the correctness of the codes; (4). Forming themes by joining related codes; (5). Linking and interrelating the themes; (6). Presenting thematic maps of "descriptions and themes"; and (7). Conducting "across-case thematic analyses." These steps provided the guideline for this study.

\footnotetext{
${ }^{9}$ This is the extent to which a person agrees over time in the coding of an item (Bryman and Bell, 2011).
} 
The researcher addressed issues of credibility and trustworthiness of results through triangulation of the diverse sources of data. To provide credibility of data, researchers use "member checking, inter-coder agreement, rich and thick descriptions of the interviews, reviewing and resolving disconfirming evidence." They also use supervisory team's assessment process (Creswell and Miller, 2002; Creswell, 1998; Baxter and Eyles, 1997; Miles and Huberman, 1994; Lincoln and Guba, 1985). In the next chapter, the researcher addressed these issues in the results section.

Under credibility, authors must maintain a true and accurate representation of participants' accounts or narratives in the final writing up (Baxter and Eyles, 1997). Lincoln and Guba (1985) assert that "member checking" by the participants in the interviews helps in double-checking whether the researchers' analytical themes, interpretations, and claims align with what the interviewees communicated. In this regard, the researcher arranged and sent soft copies of the group's thematic analysis, interpretations, and conclusions to members of each focus group interview conducted. In checking for accuracy of the researcher's representation of the interviewees' meaning-making, if the interviewees were satisfied with the work done by the researcher, this will be the ideal situation. If participants object, however, the researcher will arrange to meet further the participants to resolve the points of observed misrepresentation.

The essence of this "member checking" is that it can create avenues for the researcher to doublecheck interviewees' intentions for the information they shared earlier, straighten errors of views and misrepresentations. It is also to give/get more information, confirm people's narratives, and render an assessment of the adequacy of the entire exercise. Overall, these can help in resolving conflicting evidence resulting from the researcher's analysis.

Research credibility and trustworthiness in qualitative studies are also enhanced when several respondents are indicating similar position on the matter. This position is what Baxter and Eyles (1997, p.514) term "convergence", a form of triangulation for findings in research. In this study, if it is possible to pinpoint factors where many students identify either as inhibiting or supporting influences on entrepreneurship or indeed for any other variables investigated; these can provide supports for enhancing credibility and trustworthiness of findings. Although the dialectical paradigm welcomes divergent views, however, if several persons agree on a matter, convergence is achieved.

Also on credibility and trustworthiness, this study was supervised by a team of experienced academics who continued to assess the entire piece of work done in the analysis, interpretation, and conclusions sections of the qualitative phase. Thus, making sure that unsubstantiated 
conclusions that threaten the claims to knowledge were avoided. Also, the study had been and will continue to be, presented among peers and the academic research community. This process continued to provide feedbacks, suggestions, reflections, and other readers' experiences in the study area. The author considered the feedback helpful to the entire research process including the qualitative data analysis phase.

Another angle to assessing credibility and trustworthiness is dependability and confirmability (Baxter and Eyles, 1997). Although experiences and accounts presented by respondents must be accurately expressed-this is credibility-another aspect to this is how the researcher becomes an instrument for interpreting people's accounts consistently. This latter aspect is dependability. Conversely, confirmability is to assess the researchers, their interpretations, and the extent to which findings are dependent on the individuals researched. It entails the conditions of the investigation, and not by the "subjective" nature of researchers' interpretations, motivations, interests, and perspectives (Lincoln and Guba, 1985). Lincoln and Guba suggest that credibility and dependability interconnect, and they together constitute how fair the researcher's representation of the respondents' views can be assessed or audited. In this study, therefore, thematic analysis technique provided a dependable and confirmable platform. That is; themes can only emerge as the researcher assesses the interview transcripts and link each theme (given its codes) within the case and across cases. As a result, interpretations, analyses, and claims were always supported with extracts quoted directly from an individual's case or group's consensus in the transcripts. Thus, indicating where and how the author derived ideas, logic, and claims.

\subsection{Integrating quantitative and qualitative findings for interpretation and discussion}

The nature of the phases of this research is interactive or iterative. The reason is that the outcome of one method (QUAN) influenced decisions in the second phase (QUAL). Specifically, this initial interaction helped the researcher in assembling the data collection instrument, the focus group interview protocol (Natasi et al., 2007). The researcher determined the final questions in the focus group interview from the outcomes of the quantitative study. Thus, contributing to the process leading to the confirmation or disconfirmation of the tested theories (e.g. "theory of planned behaviour", personality traits, capabilities, and contextual factors theses). It is to contribute further to an integrated conceptual model of entrepreneurial intentions. Although the researcher planned the design of the focus group interview question, the questions can change over a period depending on the results of the quantitative study. 
The quantitative phase assessed 12 factors hypothesised as influencing the entrepreneurial intentions of undergraduates of South-south and Southeast Nigeria. It tested for structural differences in perceptions of the two groups of participants. The study compared the results of the partial least squares multi-group analysis (PLS-MGA) with the "themes, sub-themes, and categories across cases" (Ivankova and Stick, p.125) derived from the qualitative study. Thus, results from both phases were assessed about their consistency or inconsistency with the reviewed literature on entrepreneurial intentions. A major contribution was to show the advantages of mixing outcomes of both phases and their implications for the entrepreneurial intentions literature. The findings would be integrated and discussed fully in the discussion chapter as most studies do (Harrison, 2013).

\subsection{Research ethics}

Because of involving human participants in this study, therefore, the study considered issues relating to research ethics. First, the application was made to the "University Research Ethics Committee" (UREC), Oxford Brookes University and full approval was granted on $25^{\text {th }}$ September 2013 for the fieldwork to commence. This approval process followed a guideline to ensure that no individual suffers any adverse consequences as a result of this research. In the participant information sheet, in particular, the author made the promise of maintaining confidentiality to participants' responses. Survey answers from each participant were anonymous, and no one could link results to a particular respondent.

Moreover, the author shared no answers given with the participants' university authorities, and participation or non-participation did not affect students' assessment records. These assurances became necessary to make students comfortable with the research undertaken and ensure their assistance. Secondly, participation was voluntary, and approval for access to the students was sought and received from the appropriate university authorities before conducting the study in each school. Lastly, participants could benefit from the study by having access to the final results and findings upon their request to the researcher.

\subsection{Limitations of the methodology}

There were limitations of using cross-sectional time horizon as against longitudinal (panel) design. The reason is that the former studies events or phenomenon at space and point in time whereas the latter covers more by comparing groups in a time series. Thus, it can capture more holistic pattern of an event over a longer period. By undertaking a cross-sectional timescale study, the 
researcher is unable to inquire whether those who indicated high intentions today would realise such dreams within a reasonable time, say three to five years after graduation.

The laborious, time-consuming nature of mixed methods research and the researcher's lack of prior experience in MMR might be a limiting factor compared to if one had conducted several mixed methods research before this study. So, this study is like the first in the researcher's mixed methods research learning curve. Moreover, it might be infeasible to eliminate socially-desirable answers in a survey in the quantitative phase totally. For example, in questions concerning students' perceptions of their entrepreneurial intentions, respondents might have given the impression that they had a high possibility or likelihood of starting their businesses within the next five years. Without a further examination, however, say in a longitudinal study, their responses today can be taken as true claims to knowledge in this study.

Some authors criticise the multistage sampling technique as being a pseudo-probability technique (Fowler, 2009) because researchers mostly employ it when they cannot readily determine complete sample frame for their study. Thus, sampling error-error that results when the same sample is not perfectly representative of the population - cannot be calculated, and some samples might never have been given an individual's equal chance of being selected. The reason is that the researcher clustered samples into groups. This approach is another limiting factor.

\subsection{Summary of the chapter}

This chapter examined in detail the methodology adopted in this research. It adopted a dialectical mixed method research (MMR) paradigm that mixes assumptions of postpositive and social constructive traditions in one study. It is an explanatory/exploratory research with the deductive logic of inquiry; intersubjective epistemology; and transferability as a basis for inference. It adopted a dominant-less dominant sequential explanatory MMR design, which comprised of a cross-sectional timescale, a multistage cluster and a simple random sampling process. It also adopted a primary method of data collection with surveys and focus group interviews, and employed a partial least squares structural equation modelling statistical technique as well as within-case and across-case thematic analysis techniques.

The chapter examined the dialectical MMR paradigm chosen as the central philosophical thinking in this inquiry. The strength of this appraisal is its emphasis and use of multiple worldviews in one research (Greene and Caracelli, 1997). The chapter identified the purpose of the research as being first explanatory, and then exploratory, since most of the research questions sought to measure 
outcomes and identify the contributing or influencing factors of entrepreneurial intentions. The secondary purpose, however, was to use the results of the explanatory research to know further how undergraduates make meaning, interpret, or perhaps think differently of the factors that influence their business-founding intents.

The study adopted a sequential explanatory MMR approach where the first, quantitative phase, measured variables based on survey data and provided results to identify aspects that would need further exploration in the qualitative phase. The study randomly sampled 1,129 participants of South-south and Southeast Nigeria origin; in 15 universities, 12 universities faculties, and across 68 departments.

In October 2013, a pilot study of 116 participants from the region of the study was conducted to test for the reliability of the questionnaire instrument. Results suggested that seven out of the 12 scales used to measure the factors that influence entrepreneurial intentions were reliable with varying levels of the reliability coefficient. But the personality traits factor was a second-order hierarchical construct. The other four variables needed revising and re-testing. The Cronbach's test of reliability was used; however, the general impression in the course of the pilot exercise indicated that some questions needed slight amendment for clarity. The researcher then amended questions on perceived barriers in the final instrument. Overall, statistical results-Cronbach's alpha coefficient, and descriptive statistics-indicated that no serious problems were likely to be encountered in the final exercise if the author sorted out the four problem variables. To improve questionnaire item reliability, for example, the researcher replaced the questions for the variables achievement orientation, risk-propensity, and locus of control with new questions from Caird (2013). The variable perceived support was re-worded for clarity.

In the next chapter, the author presents, analyses, and interprets the quantitative and qualitative results. 


\section{CHAPTER SIX \\ RESEARCH FINDINGS}

\subsection{Introduction}

The previous chapter examined the author's philosophy of research, purpose, approach, design, and method. The philosophy provided the guidelines for gathering empirical data to solve the research problem. Therefore, this chapter reports the findings of the fieldwork ${ }^{10}$. Firstly, it examines the survey data beginning with data screening; it evaluates the path model and examines the estimation results. Secondly, it interprets the quantitative results. Thirdly, it examines the focus group interview transcripts, interprets the results and integrates both the quantitative and qualitative aspects to arrive at a holistic claim.

\subsection{Quantitative data screening}

Having entered all the raw data in the IBM SPSS (version 21) spreadsheet, the researcher checked for accuracy of data entry and completeness. Some errors were detected and consequently corrected.

The researcher used the EXPLORE option in SPSS to check for accuracy of each of the categorical variables (i.e. gender, faculty, state of origin, course of study, faculty, and university). A few out-ofrange numbers were detected and corrected. Here, MINIMUM and MAXIMUM values option and VALID and MISSING CASE options were employed to detect errors. Next, the continuous variables were checked (i.e. EI, PA, SN, PBC, IO, AO, RISK, LOC, PCAPA, and PBARR). The researcher used the ANALYZE and the DESCRIPTIVES options in the SPSS window. These options reported the total sample size, minimum and maximum values, mean, and standard deviation for each of the cases. A few out-of-range values were detected and consequently corrected.

\footnotetext{
${ }^{10}$ Part of the results presented in this analysis section was presented at the George Washington GW Entrepreneurship conference, George Washington University, Washington D.C. on 16-18 October, 2014, titled: "Factors that Influence Entrepreneurial Intentions among Undergraduates of South-south and Southeast Nigeria." See: http://papers.ssrn.com/sol3/papers.cfm?abstract_id=2506268
} 


\subsubsection{Post-pilot study review}

It was shown in the previous chapter that four factors indicated poor reliability coefficient, so the researcher developed new questions. The factors were achievement orientation, risk-propensity, the locus of control (adopted from Caird, 2013). Questions on perceived support in the original questionnaire were rephrased for clarity. A repeat pilot study was then conducted in January 2014. Achievement orientation factor had six questions; risk-propensity had seven questions, locus of control had six questions, and perceived support factor had seven questions. The repeat study used a sample of 40 participants from the study's target population, and Table 6.1 below shows the results of this pilot study:

Table 6.1: Reliability test of achievement orientation (achieve), risk-propensity (risk), locus of control (loc), and perceived support (psupp)

\begin{tabular}{crlcccc}
\hline Variables & AVE & Composite Reliability & R Square & \multicolumn{2}{c}{ Cronbach's } \\
Alpha & \multicolumn{2}{c}{ Communality } & Redundancy \\
\hline EINTEN & 0.6303 & 0.8714 & 0.6397 & 0.8052 & 0.6303 & 0.3071 \\
PA & 0.6055 & 0.8836 & 0.5868 & 0.8334 & 0.6055 & 0.2636 \\
PBC & 0.6862 & 0.8676 & 0.4563 & 0.7719 & 0.6862 & 0.1010 \\
SN & 0.6689 & 0.8580 & 0.2165 & 0.7541 & 0.6689 & 0.0726 \\
ACHIEV & 0.5800 & 0.8037 & & 0.6338 & 0.5800 & \\
CAPA & 0.5805 & 0.8723 & & 0.8262 & 0.5805 & \\
INNOVA & 0.6597 & 0.8529 & & 0.7400 & 0.6597 & \\
LOC & 0.7350 & 0.8912 & & 0.8213 & 0.7350 & \\
PBARR & 0.6131 & 0.7518 & & 0.4199 & 0.6131 & \\
PERSON & 0.3060 & 0.8429 & 0.9868 & 0.8196 & 0.3060 & 0.1317 \\
PSUPP & 0.7075 & 0.8250 & & 0.6501 & 0.7075 & \\
RISK & 0.5280 & 0.7692 & & 0.5689 & 0.5280 & \\
\hline
\end{tabular}

The researcher conducted a quick assessment of the internal consistency reliability of the four scales. The author adopted the most acceptable measure-composite reliability-to assess the scale's reliability (Hair et al., 2014). Its advantage is that it considers the "different outer loadings of the indicator variables" and "overcomes the Cronbach's alpha's limitations in the population" (Hair et al., 2014, p.101). It also makes no assumption of the equality of item loadings.

SmartPLS software (2.0) was employed to calculate this index and Table 6.1 above shows this result. As a guideline, composite reliability figures ranging between 0.60 and 0.70 are adjudged acceptable for exploratory research, whereas figures between 0.70 and 0.90 are adjudged satisfactory (Hair et al., 2014). Based on this decision rule, all four factors were adjudged satisfactory. Specifically, achievement orientation reported a composite reliability value of 0.8037 ; 
the locus of control was 0.7350 ; perceived support was 0.7075 and risk-propensity was 0.7692 . Hence, the author then incorporated the four scales into the original questionnaire.

Furthermore, fresh sampling was conducted, and new departments were added to the initial 48 departments. The researcher conducted a resampling in three Southeast universities-Abia State University, Anambra State University, and the Federal University of Technology Owerri. In these universities, the originally-selected departments were inaccessible as their students were on a three-month industrial attachment scheme outside the universities. In Abia State University, Government and Public Administration Department was replaced with Economics and Marketing departments. In Anambra State University, Mass Communication and Psychology departments were replaced with Industrial Chemistry and Law departments. In the Federal University of Technology Owerri, Fisheries and Aquaculture, and Science Laboratory Technology departments were replaced by a cross-section of students from the under-listed departments. They were: Public Health Technology, Industrial Microbiology, Mechanical Engineering, Biomedical Technology, Agricultural Extension Services, Chemical Engineering, and Computer Science. Others were Food Science Technology, Statistics, Electrical/Electronic Engineering, Information Management Technology, Building Technology, Petroleum Engineering, Soil Science and Technology. Others were Agricultural Engineering, Biotechnology, Project Management Technology, Orthopaedics Technology, Crop Science and Technology, Polymer and Textile Engineering, and Biochemistry. The rest were Maritime Management Technology, Mathematics, Physics, Material and Metallurgical Engineering, Civil Engineering, Industrial Chemistry, Geology, Prosthesis and Orthopaedics Technology, and Geophysics.

\subsubsection{Missing data}

The researcher administered 1,255 questionnaires in 15 universities. Among these, 25 questionnaires had cases of missing data. Most of these cases had a high proportion of the responses missing one or more sections. Some missed two to three entire sections of the questionnaire as well as the personal data section. Two questionnaires were entirely un-useable as the respondents, consistently, ticked more than one answer to a question. Also, 82 respondents were from other regions of Nigeria. Thus, these were non-eligible for the study. Therefore, 27 questionnaires were either a case of missing data or un-useable while 82 were filled by noneligible participants. Then 1146 questionnaires were used for analysis. The collection had a response rate of 93.3 per cent. 
Moreover, a few others had two to three missing data in a particular section. During the data entry sessions, the researcher used Microsoft Excel to calculate the mean values for a particular construct and replaced the missing responses with the approximated mean value (Hair et al., 2014).

\subsubsection{Suspicious response pattern}

During the data entry sessions, the author kept an eye on responses that might contain straight lining answers. The straight lining is where a participant ticks the same option in most of the questions. This pattern was, however, undetected among the responses; therefore the researcher adjudged the database free from this problem.

\subsubsection{Outliers}

The author checked to detect and remove extreme answer to a specific question or extreme answers to all questions. Outliers distort the stability of the estimates and create high mean values. Therefore, their detection and removal create more reliable statistics and estimates.

The author employed the Mahalanobis distance to assess the presence of outliers in the dataset (Tabachnick and Fidell, 2007). The researcher used the dependent variable (i.e. entrepreneurial intentions) as a function of ten other factors in running a multiple regression. The IBM SPSS software calculated the estimates and transferred the Mahalanobis distance values to a column in the original SPSS dataset.

The test of statistical significance of the Mahalanobis distance uses the Chi-square statistic (Ho, 2014). The "criterion for multivariate outliers is Mahalonabis distance at $P<0.001$ " (Tabachnick and Fidell, 2007, p.99). For the ten independent variables in the model (with the degree of freedom $=10$ ), the table value of Chi-square at $P<0.001$ is 29.588 . Thus, any case having a Mahalanobis distance greater than Chi-square equals 29.588; the case is statistically and significantly a multivariate outlier.

Based on this criterion, the results are presented in Table 6.2; 17 cases in the dataset reported Mahalanobis distance greater than 29.588 as shown below: 
Table 6.2: Results of outlier statistics

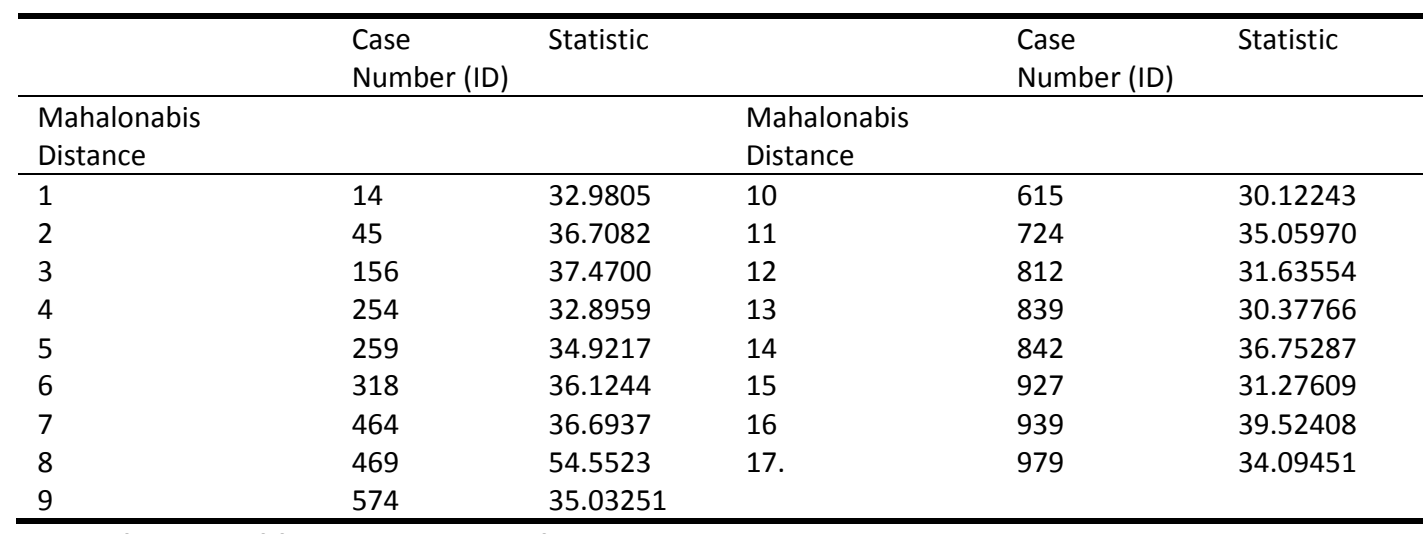

Dependent variable: Entrepreneurial intentions

Independent variables: Personal attitude, subjective norms, perceived behavioural control, innovation orientation, achievement orientation, risk-propensity, locus of control, perceived capabilities, support, and barriers.

From Table 6.2 above, respondents with IDs on serial numbers 1-17 reported statistically significant levels of outliers. The author identified these cases and deleted them from the database; therefore the number of valid responses became 1,129. These 17 cases were further highlighted to show the total scores associated with each of the variables. The computation of the sum up scores used the TRANSFORM> COMPUTE VARIABLE options of the SPSS. Table 6.3(a) and 6(b) below further depict why these cases were outliers:

Table 6.3(a): Aggregated scores of cases identified as outliers and their Mahalonabis

Distance

\begin{tabular}{|c|c|c|c|c|c|c|c|c|c|c|c|c|}
\hline & $\mathrm{El}$ & PA & SN & PBC & 10 & $\mathrm{AO}$ & RISK & LOC & PCAPA & PBARR & PSUPP & MAHA. DIST. \\
\hline 14 & 24 & 9 & 23 & 8 & 31 & 31 & 39 & 31 & 24 & 14 & 20 & 32.98 \\
\hline 45 & 21 & 23 & 22 & 29 & 21 & 13 & 22 & 12 & 10 & 46 & 29 & 36.71 \\
\hline 156 & 22 & 10 & 36 & 7 & 10 & 7 & 17 & 9 & 13 & 33 & 24 & 37.47 \\
\hline 254 & 33 & 25 & 26 & 30 & 26 & 8 & 37 & 25 & 27 & 26 & 35 & 32.90 \\
\hline 259 & 7 & 6 & 32 & 8 & 14 & 8 & 12 & 17 & 12 & 27 & 31 & 34.92 \\
\hline 318 & 13 & 13 & 22 & 15 & 10 & 9 & 35 & 26 & 36 & 27 & 34 & 36.12 \\
\hline 464 & 12 & 6 & 12 & 11 & 7 & 16 & 12 & 11 & 34 & 19 & 33 & 36.69 \\
\hline 469 & 36 & 30 & 25 & 30 & 33 & 32 & 12 & 36 & 23 & 48 & 7 & 54.55 \\
\hline 574 & 33 & 24 & 11 & 17 & 31 & 27 & 7 & 19 & 6 & 23 & 26 & 35.03 \\
\hline 615 & 7 & 6 & 17 & 19 & 36 & 36 & 42 & 36 & 36 & 43 & 32 & 30.12 \\
\hline 724 & 35 & 25 & 14 & 24 & 26 & 13 & 16 & 30 & 33 & 48 & 36 & 35.06 \\
\hline 812 & 28 & 25 & 10 & 25 & 10 & 12 & 22 & 34 & 32 & 16 & 29 & 31.64 \\
\hline 839 & 15 & 10 & 35 & 14 & 12 & 11 & 11 & 10 & 23 & 28 & 24 & 30.38 \\
\hline 842 & 24 & 10 & 6 & 25 & 17 & 31 & 37 & 31 & 16 & 14 & 20 & 36.75 \\
\hline 927 & 10 & 7 & 6 & 13 & 16 & 36 & 24 & 30 & 21 & 40 & 20 & 31.28 \\
\hline 939 & 6 & 5 & 6 & 10 & 8 & 10 & 10 & 8 & 33 & 33 & 23 & 39.52 \\
\hline 979 & 12 & 11 & 7 & 10 & 8 & 9 & 15 & 9 & 30 & 12 & 11 & 34.09 \\
\hline
\end{tabular}


Table 6.3(b): Descriptive Statistics

\begin{tabular}{llll}
\hline & Mean & Std. Deviation & $\mathrm{N}$ \\
\hline EI & 28.65 & 6.587 & 1146 \\
PA & 24.70 & 5.566 & 1146 \\
SN & 20.31 & 7.916 & 1146 \\
PBC & 22.39 & 5.471 & 1146 \\
IO & 26.43 & 5.424 & 1146 \\
AO & 28.76 & 5.185 & 1146 \\
RISK & 31.38 & 6.214 & 1146 \\
LOC & 26.64 & 5.878 & 1146 \\
PCAPA & 27.96 & 5.916 & 1146 \\
PBARR & 30.01 & 7.765 & 1146 \\
PSUPP & 28.73 & 5.739 & 1146 \\
\hline
\end{tabular}

In Table 6.3(a) above, the first column shows the number of the cases with outlying scores; the last column shows the calculated Mahalonabis distance. The in-between columns (2-12) are the summated scores for the factors. A cursory look at some of the scores gives an idea of the reason these cases were outliers. For example, case ID 14. Although it reported an acceptable score (i.e. 24) for the dependent variable $(E I)$, its perceived behavioural control $(P B C=8)$ score and personal attitude $(P A=9)$ score are too low. That is when compared to the average scores of 22.39 and 24.70 respectively. Case ID 14 had a standard deviation of 6.587 (see Table 6.3b above).

Similar scenarios are also noted for ID numbers 45, 259, 318, 464, 574, 615, 839, 842, 927, 939, and 979 . Some of their summated scores also showed too high scores above the average score. A mix of these too low and too high scores for a respondent is the reason for the cases being selected as outliers. The reason is that such inconsistent scores can widely distort other statistics in the estimation processes. Since the 17 cases, out of the 1,146 questionnaires, were adjudged to be outliers and were consequently deleted from the database, the valid cases are now 1,129 respondents. This number was used to calculate the descriptive and other statistics in the ensuing subsections.

\subsubsection{Data distribution}

This section describes the distribution pattern of scores. Data distribution shows the extent to which datasets are skewed or peaked or both; these indicate the level of normality of the scores. The PLS-SEM, however, does not make the strict assumption of normality of research data. Even though this is the case for PLS-SEM, this study however herein tests the extent of normality or departure from normality of each of the factor scores. With skewed data, it is better to use nonparametric descriptive statistics for analysis since it makes no strict normality assumption (Pallant, 2013). It is more acceptable to assesses the median (instead of the mean) and the inter-quartile 
range (i.e. representation of the 25 th and 75 th percentiles of scores). The inter-quartile range serves as the measure of the spread of data from the average score (Pallant, 2013).

\subsubsection{Test of normality}

The study employed the Kolmogorov-Smirnov and the Shapiro-Wilk statistics as tests for normality of data distribution (Ho, 2014). The former is a test used when the sample size is large (i.e. $n>$ 250). The significance level works in reverse; that is if the significant levels of the tests conducted are within $p<0.05$; then the data are non-normal. Thus, for an approximately normal data, the significance levels of the Kolmogorov-Smirnov tests are expected to be higher (than 5 per cent level).

Table 6.4 below reports the Kolmogorov-Smirnov test output from IBM SPSS. It indicates that the dependent variable, entrepreneurial intentions (EI), as well as the other independent variables, reported significance levels that were less than the 5 per cent level. Also, a visual check of the histogram, normal Q-Q plots and box plots for El indicated that scores for IE were non-normally distributed. It had a skewness statistic of -1.090 (SE = 0.073) and a kurtosis of 0.847 (SE = 0.145). Others, except PA construct, had skewness and kurtosis values that approximate zero, thus indicating they were less skewed or peaked. Although skewed data is often the case in large samples, the PLS-SEM test adopted for this study generates stable, reliable results under cases of non-normal data. The reason is that the technique "deemphasises the assumption of normality in data distribution", more so PLS-SEM is a non-parametric test (Hair et al., 2012; Dijkstra, 2010, p.47).

Table 6.4: Kolmogorov-Smirnov test of normality

\begin{tabular}{|c|c|c|c|c|c|c|}
\hline & \multicolumn{3}{|c|}{ Kolmogorov-Smirnov ${ }^{\mathrm{a}}$} & \multicolumn{3}{|c|}{ Shapiro-Wilk } \\
\hline & Statistic & Df & Sig. & Statistic & df & Sig. \\
\hline El & .132 & 1,129 & .000 & .900 & 1,129 & .000 \\
\hline PA & .168 & 1,129 & .000 & .853 & 1,129 & .000 \\
\hline SN & .055 & 1,129 & .000 & .978 & 1,129 & .000 \\
\hline PBC & .103 & 1,129 & .000 & .953 & 1,129 & .000 \\
\hline 10 & .069 & 1,129 & .000 & .979 & 1,129 & .000 \\
\hline AO & .113 & 1,129 & .000 & .940 & 1,129 & .000 \\
\hline RISK & .068 & 1,129 & .000 & .980 & 1,129 & .000 \\
\hline LOC & .077 & 1,129 & .000 & .969 & 1,129 & .000 \\
\hline PCAPA & .091 & 1,129 & .000 & .947 & 1,129 & .000 \\
\hline PBARR & .039 & 1,129 & .000 & .995 & 1,129 & .001 \\
\hline PSUPP & .064 & 1,129 & .000 & .992 & 1,129 & .000 \\
\hline
\end{tabular}

a. Lilliefors Significance Correction 
Descriptive Statistics

\begin{tabular}{|c|c|c|c|c|c|c|}
\hline & \multirow{2}{*}{$\begin{array}{l}\mathrm{N} \\
\text { Statistic }\end{array}$} & \multirow{2}{*}{$\begin{array}{l}\text { Skewness } \\
\text { Statistic }\end{array}$} & \multicolumn{3}{|c|}{ Kurtosis } \\
\hline & & & & Std. Error & Statistic & Std. Error \\
\hline EI & & 1,129 & -1.090 & .073 & .847 & .145 \\
\hline PA & & 1,129 & -1.322 & .073 & 1.366 & .145 \\
\hline SN & & 1,129 & .066 & .073 & -.847 & .145 \\
\hline PBC & & 1,129 & -.624 & .073 & -.166 & .145 \\
\hline 10 & & 1,129 & -.473 & .073 & .148 & .145 \\
\hline $\mathrm{AO}$ & & 1,129 & -.940 & .073 & .972 & .145 \\
\hline RISK & & 1,129 & -.441 & .073 & -.008 & .145 \\
\hline LOC & & 1,129 & -.592 & .073 & .139 & .145 \\
\hline PCAPA & & 1,129 & -.790 & .073 & .483 & .145 \\
\hline PBARR & & 1,129 & .055 & .073 & -.294 & .145 \\
\hline PSUPP & & 1,129 & -.030 & .073 & -.066 & .145 \\
\hline $\begin{array}{l}\text { Valid } \\
\text { (listwise) }\end{array}$ & $\mathrm{N}$ & 1,129 & & & & \\
\hline
\end{tabular}

\subsection{7: Frequency distribution of the respondents and descriptive statistics for the Constructs}

The Statistics table below shows the requested frequency for gender, ethnicity, state of origin, course of study, faculty, and university:

Table 6.5: Frequencies output

Statistics

\begin{tabular}{|c|c|c|c|c|c|c|c|}
\hline & & Gender & Ethnicity & State of origin & Course of study & Faculty & University \\
\hline \multirow{2}{*}{ N } & Valid & 1,129 & 1,129 & 1,129 & 1,129 & 1,129 & 1,129 \\
\hline & Missing & 0 & 0 & 0 & 0 & 0 & 0 \\
\hline
\end{tabular}

Frequency Table

\begin{tabular}{|c|c|c|c|c|c|}
\hline \multicolumn{6}{|c|}{ Gender } \\
\hline & & Frequency & Percent & Valid Percent & Cumulative Percent \\
\hline \multirow{3}{*}{ Valid } & male & 578 & 51.2 & 51.2 & 51.2 \\
\hline & female & 551 & 48.8 & 48.8 & 100.0 \\
\hline & Total & 1,129 & 100.0 & 100.0 & \\
\hline
\end{tabular}

Ethnicity

\begin{tabular}{lllll}
\hline & Frequency & Percent & Valid Percent & Cumulative Percent \\
\hline Igbo (Southeast) & 413 & 36.6 & 36.6 & 36.6 \\
(South-south) & 716 & & & \\
& & 63.4 & 63.4 & \\
Agbor & 6 & & & 37.1 \\
Aniocha & 2 & .5 & .5 & 37.3 \\
Anioma & 4 & .2 & .2 & 37.6 \\
Annang & 46 & .4 & .4 & 41.7 \\
Bekwarra & 18 & 4.1 & 4.1 & 43.3 \\
Bini & 41 & 1.6 & 1.6 & 46.9 \\
Boki & 2 & 3.6 & 3.6 & 47.1 \\
Delta-lgbo & 30 & .2 & .2 & 49.8 \\
Ekperi & 1 & 2.7 & 2.7 & 49.9 \\
Esan & 15 & .1 & .1 & 51.2 \\
Estako & 5 & 1.3 & 1.3 & 51.6 \\
Ibibio & 148 & .4 & .4 & 64.7 \\
Ishan & 4 & 13.1 & 13.1 & 65.1 \\
ljaw & 94 & .4 & .4 & 73.4 \\
Ikwerre & 25 & 8.3 & 8.3 & 75.6 \\
Isoko & 21 & 2.2 & 2.2 & 77.5 \\
Itsekiri & 10 & 1.9 & 1.9 & 78.4 \\
Kalabari & 14 & .9 & .9 & 79.6 \\
Ogba & 3 & 1.2 & 1.2 & 79.9
\end{tabular}




\begin{tabular}{lllll} 
Okpe & 2 & .2 & .2 & 80.1 \\
Okrika & 5 & .4 & .4 & 80.5 \\
Oron & 15 & 1.3 & 1.3 & 81.8 \\
Ukwani & 2 & .2 & .2 & 82.0 \\
Urhobo & 56 & 5.0 & 5.0 & 87.0 \\
Uvwie & 1 & .1 & .1 & 87.1 \\
Efik & 43 & 3.8 & 3.8 & 90.9 \\
Atam & 11 & 1.0 & 1.0 & 91.9 \\
Bakor & 4 & .4 & .4 & 92.2 \\
Ejagham & 18 & 1.6 & 1.6 & 93.8 \\
Ekoi & 20 & 1.8 & 1.8 & 95.6 \\
Ogoni & 16 & 1.4 & 1.4 & 97.0 \\
Qua & 1 & .1 & .1 & 97.1 \\
Yakuur & 15 & 1.3 & 1.3 & 98.4 \\
Ibani & 1 & .1 & .1 & 98.5 \\
Etche & 5 & .4 & .4 & 98.9 \\
Andoni & 2 & .2 & .2 & 99.1 \\
Ekpeye & 4 & .4 & .4 & 99.5 \\
Egbema & 1 & .1 & .1 & 99.6 \\
Abua & 2 & .2 & .2 & 99.7 \\
Elem & 2 & .2 & .2 & 99.9 \\
Total & 1,129 & 100.0 & 100.0 & \\
\hline
\end{tabular}

State of origin

\begin{tabular}{llllll}
\hline & Frequency & Percent & Valid Percent & Cumulative Percent \\
\hline \multirow{6}{*}{ Valid } & Abia & 67 & 5.9 & 5.9 & 5.9 \\
& Anambra & 140 & 12.4 & 12.4 & 18.3 \\
& Enugu & 70 & 6.2 & 6.2 & 24.5 \\
& Imo & 120 & 10.6 & 10.6 & 35.2 \\
& Akwa Ibom & 209 & 18.5 & 18.5 & 53.7 \\
& Bayelsa & 69 & 6.1 & 6.1 & 59.8 \\
& Cross River & 133 & 11.8 & 11.8 & 71.6 \\
& Delta & 131 & 11.6 & 11.6 & 83.2 \\
& Edo & 76 & 6.7 & 6.7 & 89.9 \\
& Rivers & 98 & 8.7 & 8.7 & 98.6 \\
& Ebonyi & 16 & 1.4 & 1.4 & 100.0 \\
\hline
\end{tabular}

Course of study

\begin{tabular}{|c|c|c|c|c|c|}
\hline & & Frequency & Percent & Valid Percent & Cumulative Percent \\
\hline & Accounting & 26 & 2.3 & 2.3 & 2.3 \\
\hline & Agricultural Economics & 23 & 2.0 & 2.0 & 4.3 \\
\hline & Agricultural Engineering & 1 & .1 & .1 & 4.4 \\
\hline & Agricultural Extension Services & 17 & 1.5 & 1.5 & 5.9 \\
\hline & Anatomy & 24 & 2.1 & 2.1 & 8.1 \\
\hline & Animal Science & 7 & .6 & 6 & 8.7 \\
\hline & Biochemistry & 43 & 3.8 & 3.8 & 12.5 \\
\hline & Biomedical Technology & 2 & .2 & .2 & 12.7 \\
\hline & Biotechnology & 1 & .1 & .1 & 12.8 \\
\hline & Building Technology & 3 & .3 & .3 & 13.0 \\
\hline & Business Administration & 101 & 8.9 & 8.9 & 22.0 \\
\hline & Business Education & 14 & 1.2 & 1.2 & 23.2 \\
\hline & Chemical Engineering & 6 & .5 & .5 & 23.7 \\
\hline & Chemical Science & 30 & 2.7 & 2.7 & 26.4 \\
\hline & Civil Engineering & 17 & 1.5 & 1.5 & 27.9 \\
\hline \multirow[t]{15}{*}{ Valid } & Computer Engineering & 42 & 3.7 & 3.7 & 31.6 \\
\hline & Computer Science & 31 & 2.7 & 2.7 & 34.4 \\
\hline & Crop Science and Technology & 1 & .1 & .1 & 34.5 \\
\hline & Economics & 13 & 1.2 & 1.2 & 35.6 \\
\hline & $\begin{array}{l}\text { Educational Psychology and Curriculum } \\
\text { Studies }\end{array}$ & 13 & 1.2 & 1.2 & 36.8 \\
\hline & Electrical/Electronic Engineering & 42 & 3.7 & 3.7 & 40.5 \\
\hline & English and Literary Studies & 4 & .4 & .4 & 40.8 \\
\hline & Environmental Science & 1 & .1 & .1 & 40.9 \\
\hline & Estate Management & 30 & 2.7 & 2.7 & 43.6 \\
\hline & Food Science Technology & 1 & .1 & .1 & 43.7 \\
\hline & Geography and Regional Planning & 6 & .5 & .5 & 44.2 \\
\hline & Geology & 46 & 4.1 & 4.1 & 48.3 \\
\hline & Geology and Petroleum Studies & 1 & .1 & .1 & 48.4 \\
\hline & Geophysics & 1 & .1 & .1 & 48.4 \\
\hline & Government and Public Administration & 3 & .3 & .3 & 48.7 \\
\hline
\end{tabular}




\begin{tabular}{|c|c|c|c|c|}
\hline $\begin{array}{l}\text { Home Economics (Human Ecology, } \\
\text { Dietetics) }\end{array}$ & 26 & 2.3 & 2.3 & 51.0 \\
\hline Hotel and Tourism Management & 4 & .4 & .4 & 51.4 \\
\hline Industrial Chemistry & 17 & 1.5 & 1.5 & 52.9 \\
\hline Industrial Microbiology & 2 & .2 & .2 & 53.1 \\
\hline Industrial Physics & 12 & 1.1 & 1.1 & 54.1 \\
\hline Information Management Technology & 5 & .4 & .4 & 54.6 \\
\hline Law & 99 & 8.8 & 8.8 & 63.3 \\
\hline Linguistics & 30 & 2.7 & 2.7 & 66.0 \\
\hline Management & 72 & 6.4 & 6.4 & 72.4 \\
\hline Marine Engineering & 1 & .1 & .1 & 72.5 \\
\hline Maritime Management Technology & 1 & .1 & .1 & 72.5 \\
\hline Marketing & 39 & 3.5 & 3.5 & 76.0 \\
\hline Mass Communication & 57 & 5.0 & 5.0 & 81.0 \\
\hline Material and Metallurgical Engineering & 3 & .3 & .3 & 81.3 \\
\hline Mathematics & 5 & .4 & .4 & 81.8 \\
\hline Mechanical Engineering & 41 & 3.6 & 3.6 & 85.4 \\
\hline Microbiology & 1 & .1 & .1 & 85.5 \\
\hline Orthopaedics Technology & 1 & .1 & .1 & 85.6 \\
\hline Petroleum Engineering & 19 & 1.7 & 1.7 & 87.2 \\
\hline Pharmacy & 22 & 1.9 & 1.9 & 89.2 \\
\hline Physics & 2 & .2 & .2 & 89.4 \\
\hline Polymer and Textile Engineering & 1 & .1 & .1 & 89.5 \\
\hline Project Management Technology & 2 & .2 & .2 & 89.6 \\
\hline Prosthesis and Orthopaedic Technology & 1 & .1 & .1 & 89.7 \\
\hline Public Health Technology & 2 & .2 & .2 & 89.9 \\
\hline Sociology & 39 & 3.5 & 3.5 & 93.4 \\
\hline Soil Science and Technology & 2 & .2 & .2 & 93.5 \\
\hline Statistics & 1 & .1 & .1 & 93.6 \\
\hline Political Science & 1 & .1 & .1 & 93.7 \\
\hline Medical Lab Science & 1 & .1 & .1 & 93.8 \\
\hline International Studies and Diplomacy & 1 & .1 & .1 & 93.9 \\
\hline Banking and Finance & 26 & 2.3 & 2.3 & 96.2 \\
\hline Nursing & 43 & 3.8 & 3.8 & 100.0 \\
\hline Total & 1,129 & 100.0 & 100.0 & \\
\hline
\end{tabular}

Faculty

\begin{tabular}{llllll}
\hline & Frequency & Percent & Valid Percent & Cumulative Percent \\
\hline \multirow{2}{*}{ Arts/Humanities } & 66 & 5.8 & 5.8 & 5.8 \\
& Pharmacy & 22 & 1.9 & 1.9 & 7.8 \\
& Law & 99 & 8.8 & 8.8 & 16.6 \\
& Education & 30 & 2.7 & 2.7 & 19.2 \\
& Social Sciences & 98 & 8.7 & 8.7 & 27.9 \\
& Environment & 33 & 2.9 & 2.9 & 30.8 \\
& Sciences & 153 & 13.6 & 13.6 & 44.4 \\
& Allied Medical Science & 110 & 9.7 & 9.7 & 54.1 \\
& Engineering & 178 & 15.8 & 15.8 & 69.9 \\
& Management Sciences & 262 & 23.2 & 23.2 & 93.1 \\
& Medicine & 4 & .4 & .4 & 93.4 \\
\hline
\end{tabular}

University

\begin{tabular}{|c|c|c|c|c|c|}
\hline & & Frequency & Percent & Valid Percent & Cumulative Percent \\
\hline & University of Uyo & 144 & 12.8 & 12.8 & 12.8 \\
\hline & Niger Delta University & 83 & 7.4 & 7.4 & 20.1 \\
\hline & University of Calabar & 88 & 7.8 & 7.8 & 27.9 \\
\hline & Cross River University & 120 & 10.6 & 10.6 & 38.5 \\
\hline & Technology & & & & \\
\hline & $\begin{array}{l}\text { Federal University of Petroleum } \\
\text { Resources }\end{array}$ & 33 & 2.9 & 2.9 & 41.5 \\
\hline \multirow[t]{7}{*}{ Valid } & Western Delta University & 23 & 2.0 & 2.0 & 43.5 \\
\hline & University of Benin & 104 & 9.2 & 9.2 & 52.7 \\
\hline & Igbinedion University & 75 & 6.6 & 6.6 & 59.3 \\
\hline & $\begin{array}{l}\text { Rivers State University of Science } \\
\text { and Technology }\end{array}$ & 100 & 8.9 & 8.9 & 68.2 \\
\hline & Abia State University & 27 & 2.4 & 2.4 & 70.6 \\
\hline & Anambra State University & 42 & 3.7 & 3.7 & 74.3 \\
\hline & Madonna University & 63 & 5.6 & 5.6 & 79.9 \\
\hline
\end{tabular}




\begin{tabular}{lllll} 
University of Nigeria & 107 & 9.5 & 9.5 & 89.4 \\
Caritas University & 46 & 4.1 & 4.1 & 93.4 \\
$\begin{array}{l}\text { Federal University of Technology } \\
\text { Owerri }\end{array}$ & 74 & 6.6 & 6.6 & 100.0 \\
Total & 1,129 & 100.0 & 100.0 & \\
\hline
\end{tabular}

The frequency tables highlight the breakdown of the outputs for the six categorical variables listed earlier. Each table shows (1) the frequency of occurrence for each figure received by that variable, (2) the frequency for each value expressed as a percentage of the aggregate sample, (3) the valid percent for each figure, in case there were missing values, (4) the cumulative percent of each succeeding value for that variable. For instance, the frequency table for the gender variable indicates 578 for male and 551 for female. These figures represent 51.2 per cent and 48.8 per cent respectively. The valid percent figures are similar to the percent figures as there were no missing cases in the database. The cumulative percent captures the "percentage of scores falling at or below each score" (Ho, 2014, p.23). Consequently, for the sample of 1,129 participants, the 578 males receive 51.2 per cent of the distribution while the remaining 551 females receive a cumulative percentage of 100 per cent. The frequency tables for ethnicity, state of origin, course of study, faculty, and university variables are interpreted in a similar manner.

Furthermore, the distribution of scores for the 1,129 respondents is further understood viewing from the way Figure 6.1 below presents them:

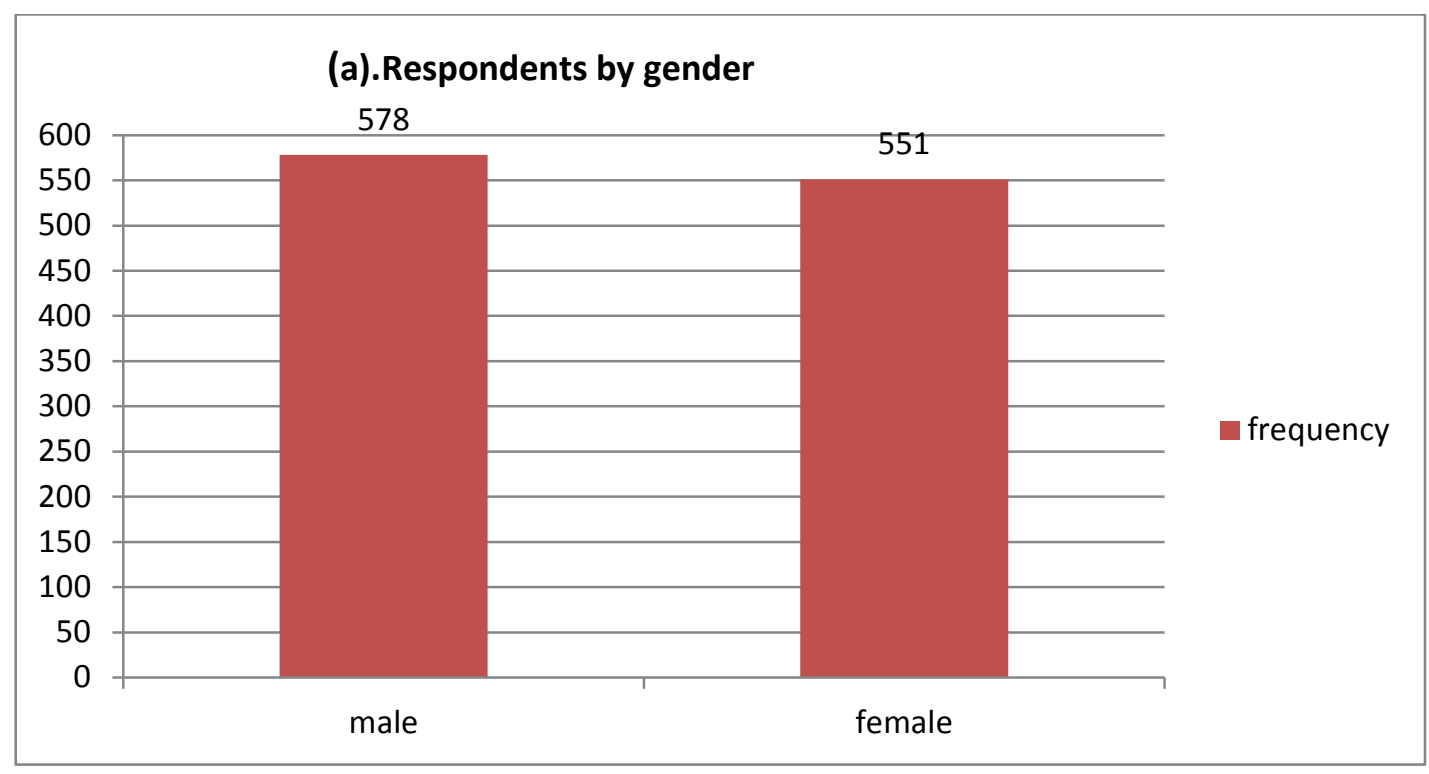



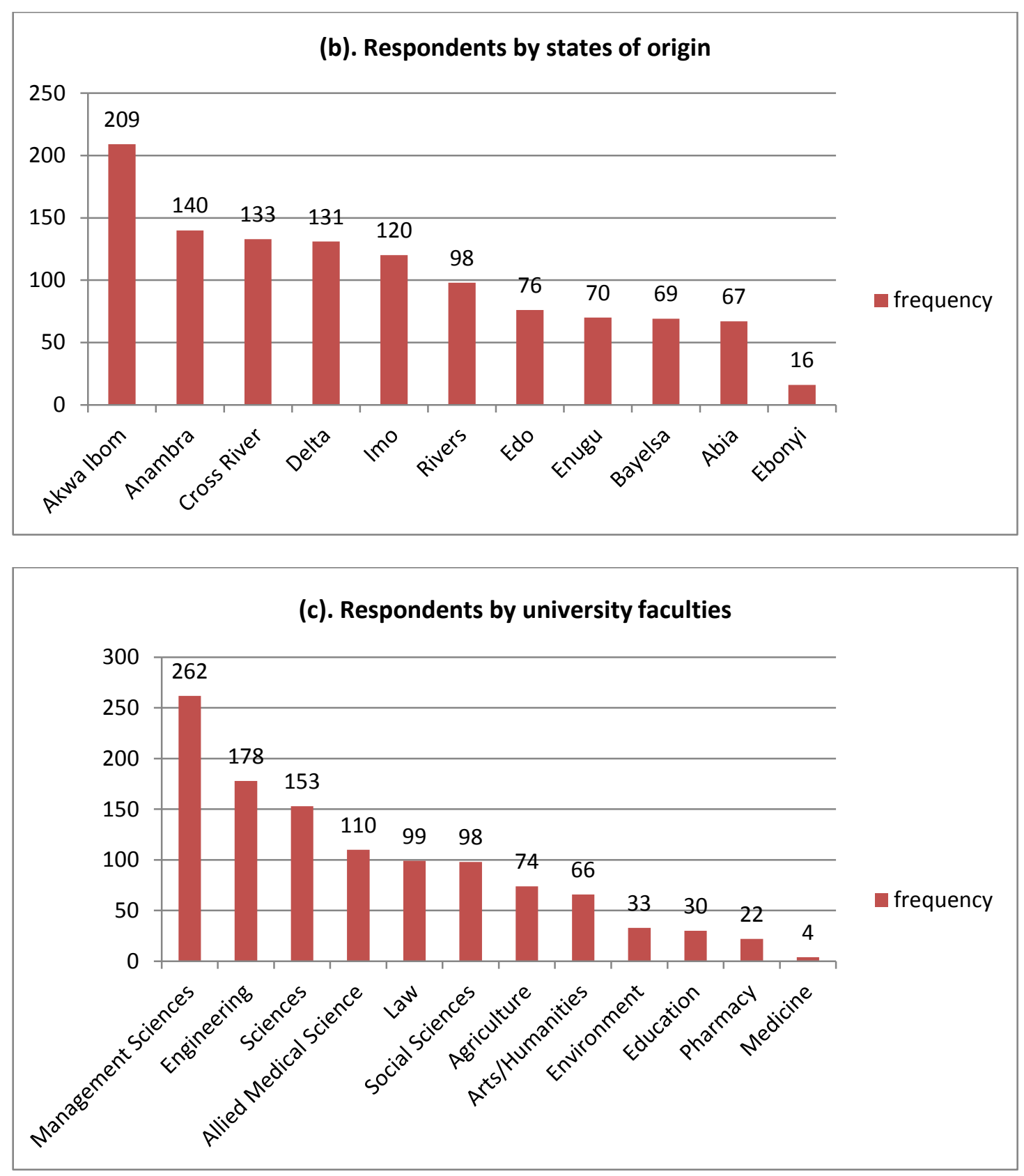

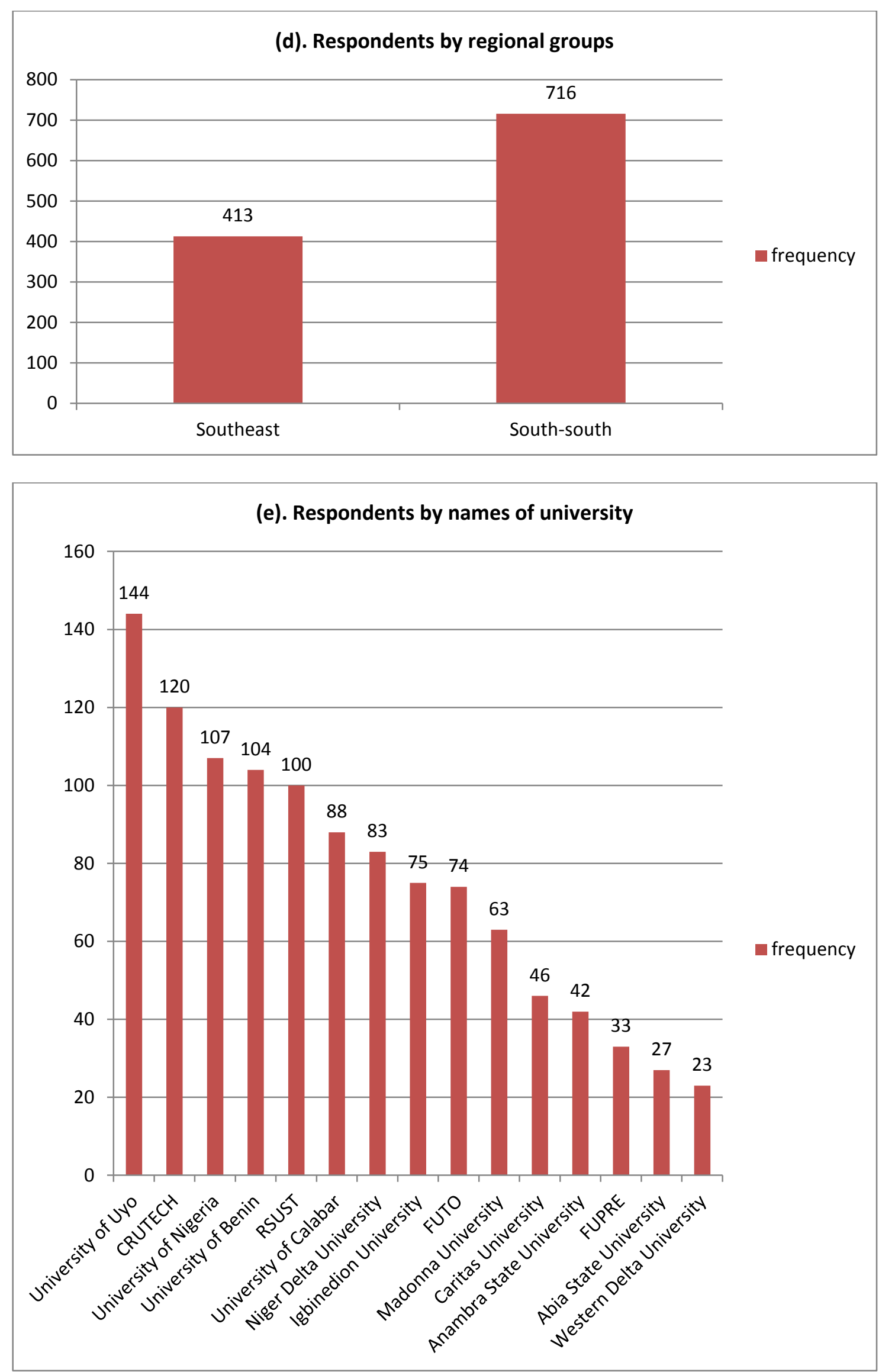

Figure 6.1: Distribution of respondents by size 
The graphs present the distribution of respondents by size ranging from the highest to the lowest scores. The gender variable indicates that male participants were slightly more than female participants by a margin of 1.2 per cent or about 11 participants. Respondents by states of origin indicate that most participants were from Akwa Ibom State (209), followed by Anambra (140), Cross River (98), Delta (131), Imo (120), Rivers (98), Edo (76), Enugu (70), Bayelsa (69), Abia (67), and Ebonyi (16). Participants by university faculties indicate that majority came from Management Sciences (262), followed by Engineering (178), Sciences (153), Allied Medical Sciences (110), Law (99), Social Sciences (98), Agriculture (74), Arts/Humanities (66), Environment (33), Education (30), Pharmacy (22), and Medicine (4).

Participants by region indicate that more South-south respondents partook in the exercise than their Southeast counterparts. The difference was a 13.4 per cent margin or 152 participants. Also, assessment of participants by university indicates that the majority were from the University of Uyo, (144). Next is the Cross River University of Technology (CRUTECH; 120), University of Nigeria (107), University of Benin (104), Rivers State University of Science and Technology (RSUST; 100), and University of Calabar (88). Others are South-south University (83), Igbinedion University (75), Federal University of Technology Owerri (FUTO; 74), Madonna University (63), and Caritas (46). The rest are Anambra State University (42), Federal University of Petroleum Resources (FUPRE; 33), Abia State University (27), and Western Delta University (23).

Lastly, the graph showing "distribution by the course of study" was not presented because of its large size (67 courses). The reason being that it appeared too clumsy; an assessment of the top 25 departments/courses with the highest representation in the study, however, is as follows: Business Administration (101), Law (99), Management (72), Mass Communication (57), Geology (46), and Biochemistry (43). Nursing (43), and Computer Engineering (42) Electrical/Electronic Engineering (42), Mechanical Engineering (41), and Marketing (39). Sociology (39), Computer Science (31), Chemical Science (30), and Estate Management (30), Linguistics (30), and Accounting (26). Followed by Anatomy (24), Agricultural Economics (23), Pharmacy (22), Petroleum Engineering (19), Agricultural Extension Services (17), and Civil Engineering (19).

Overall, it is believed that the survey fairly cut across most of the university faculties, schools, colleges, departments, and courses. 


\subsubsection{Descriptive statistics for each construct}

Because the study measured each construct as an interval scale, and the constructs are continuous variables, their analysis and interpretation are meaningful to undertake. Measures of central tendency-median-as well as the measures of dispersion-range, interquartile range-are herein analysed. Moreover, PLS-SEM makes no assumption about normality. Although there were some levels of skewed data found among the variables, it might be most appropriate to report nonparametric descriptive statistics. The reason is that these are less disturbed by the nature of data distribution, outliers or extreme values (Pallant, 2013). The requested output is as presented below:

Table 6.6: SPSS output of descriptive statistics for each construct

\begin{tabular}{|c|c|c|c|c|c|c|c|c|}
\hline \multirow[t]{2}{*}{ Construct } & \multirow{2}{*}{$\begin{array}{l}\text { No. of } \\
\text { Items }\end{array}$} & \multirow[t]{2}{*}{ Range } & \multirow{2}{*}{$\begin{array}{l}\text { Interquartile } \\
\text { Range (IQR) }\end{array}$} & \multirow[t]{2}{*}{ Minimum } & \multirow[t]{2}{*}{ Maximum } & \multicolumn{3}{|c|}{ Percentiles } \\
\hline & & & & & & 25th & 50th (Median) & $75^{\text {th }}$ \\
\hline EI & 6 & 30 & 8 & 6 & 36 & 26.00 & 30.00 & 34.00 \\
\hline PA & 5 & 25 & 7 & 5 & 30 & 22.00 & 26.00 & 29.00 \\
\hline SN & 6 & 30 & 12 & 6 & 36 & 14.00 & 21.00 & 26.00 \\
\hline PBC & 5 & 25 & 7 & 5 & 30 & 19.00 & 23.00 & 26.00 \\
\hline 10 & 6 & 28 & 7 & 8 & 36 & 23.00 & 27.00 & 30.00 \\
\hline $\mathrm{AO}$ & 6 & 28 & 6 & 8 & 36 & 26.00 & 30.00 & 32.00 \\
\hline RISK & 7 & 33 & 9 & 9 & 42 & 27.50 & 32.00 & 36.00 \\
\hline LOC & 6 & 30 & 8 & 6 & 36 & 23.00 & 27.00 & 31.00 \\
\hline PCAPA & 6 & 30 & 7 & 6 & 36 & 25.00 & 29.00 & 32.00 \\
\hline PBARR & 8 & 40 & 10 & 8 & 48 & 25.00 & 30.00 & 35.00 \\
\hline PSUPP & 7 & 33 & 7 & 9 & 42 & 25.00 & 29.00 & 32.00 \\
\hline
\end{tabular}

The descriptive statistics table reports the median scores for each construct. This score indicates the number in the centre of the distribution. The interquartile range (IQR) indicates the range of scores that make up the middle 50 per cent of the distribution. This figure indicates where half of the sample scores (for each construct) lie between the lower quartile (same as 25 th percentile) and the upper quartile (same as 75 th percentile). Thus indicating that 25 per cent is lower than the lower quartile and 25 per cent is higher than the upper quartile.

Specifically, for entrepreneurial intentions (EI) variable, the median score, Md = 30 (IQR: 26, 34). This result indicates that half of the aggregate scores for entrepreneurial intentions variable ranged between 26 and 34; 25 per cent is smaller than 26, and 25 per cent is higher than 34 . For the personal attitude variable (PA), the median score, $M d=26$ (IQR: 22, 29). This result indicates 
that half of the total scores for personal attitude variable are between 22 and 29; 25 per cent is smaller than 22, and 25 per cent is higher than 29. The interpretation of the median and interquartile range for subjective norms (SN), perceived behavioural control (PBC), innovation orientation (IO), achievement orientation (AO), risk-propensity (RISK), locus of control (LOC), perceived capabilities (PCAPA), perceived barriers (PBARR), and perceived support (PSUPP) follow similar fashion.

Overall, the spread of scores for the constructs is minimal, thus suggesting that their average scores (i.e. median) are a true representation of the distribution used in this study.

\subsection{Path model specification}

After the reporting of the characteristics of the data, the researcher now shifts attention to showing the path models for this study. The researcher's knowledge of partial least squares structural equation modelling (PLS-SEM) drew largely from the work of Hair et al. (2014), except otherwise stated. The researcher constantly communicated with two of the authors (Joe Hair and Marko Sarstedt) and had immensely drawn from their experiences and feedbacks for this analysis.

Path models are diagrams that illustrate, in pictures, the relationships among variables in a structural equation modelling scenario. Circles represent constructs, or variables measured indirectly. Rectangles represent indicators or the questionnaire items. Arrows connect the relationship between constructs and the indicators.

Path models in partial least squares structural equation modelling comprise of two parts: the structural or inner model and the measurement or outer model. The former indicates the relationships among the different constructs whereas the latter indicates the relationships among constructs and indicators. Error terms are also connected to each indicator, and they indicate the "unexpected variance" or possible bias while estimating the path models (Hair et al., 2014, p.12). The next section illustrates these relationships.

\subsubsection{The structural model specification}

The structural model primarily came from the theory that prescribes how variables or concepts are interrelated with one another. In specifying the structural model for this study, the Ajzen's (1991, 2005) theory of planned behaviour, Krueger and Carsrud's (1993, p.317) and Krueger's et al. (2000) "basic intentions-based process model" served as the basis for indicating how intention is the best 
predictor of planned behaviour. The theories enumerate the antecedents of intentions. These antecedents include personal attitude, subjective norms, and perceived behavioural control.

The personality traits approach to entrepreneurship (Paco et al., 2011) forms the conceptual framework that informed the inclusion of personality traits as potential factors that may influence entrepreneurial intent. This study incorporated entrepreneurial traits such as innovation, achievement motivation, risk-taking, and internal locus of control as second-order components. These psychological traits combined to form personality traits index.

Caird's (1992) model of entrepreneurial competencies (capabilities) and Bridge et al. (2009) concept of entrepreneurial capabilities also informed the composition of the structural model. The capabilities school believes that individuals who perceive themselves as being entrepreneurially capable will be more motivated to become business founders. Furthermore, contextual factors are perceived as "contingencies" or "external" factors that can influence entrepreneurship intents. Lüthje and Franke's (2003) concept of "contextual factors" informed the inclusion of perceived barriers and perceived support as contextual factors in this study. These factors helped explain how perceived barriers and perceived institutional supports received toward business-founding can influence entrepreneurship.

Overall, since the understanding of the factors that influence entrepreneurial intentions is a complex phenomenon, attempting to use an unnecessarily simple or single model to analyse only some aspects of this concept might prove inadequate. Specific studies on attitude, personality traits, contextual factors, or competencies are partial. A more justifying route is to develop a model that is holistic, integrative, and near-to-the-real-world enough to capture the different facets of entrepreneurship intents. Perhaps in a structural model that looks at all the different components simultaneously. This approach is an attempt made in this section. Thus, the structural model is presented in Figure 6.2 below: 


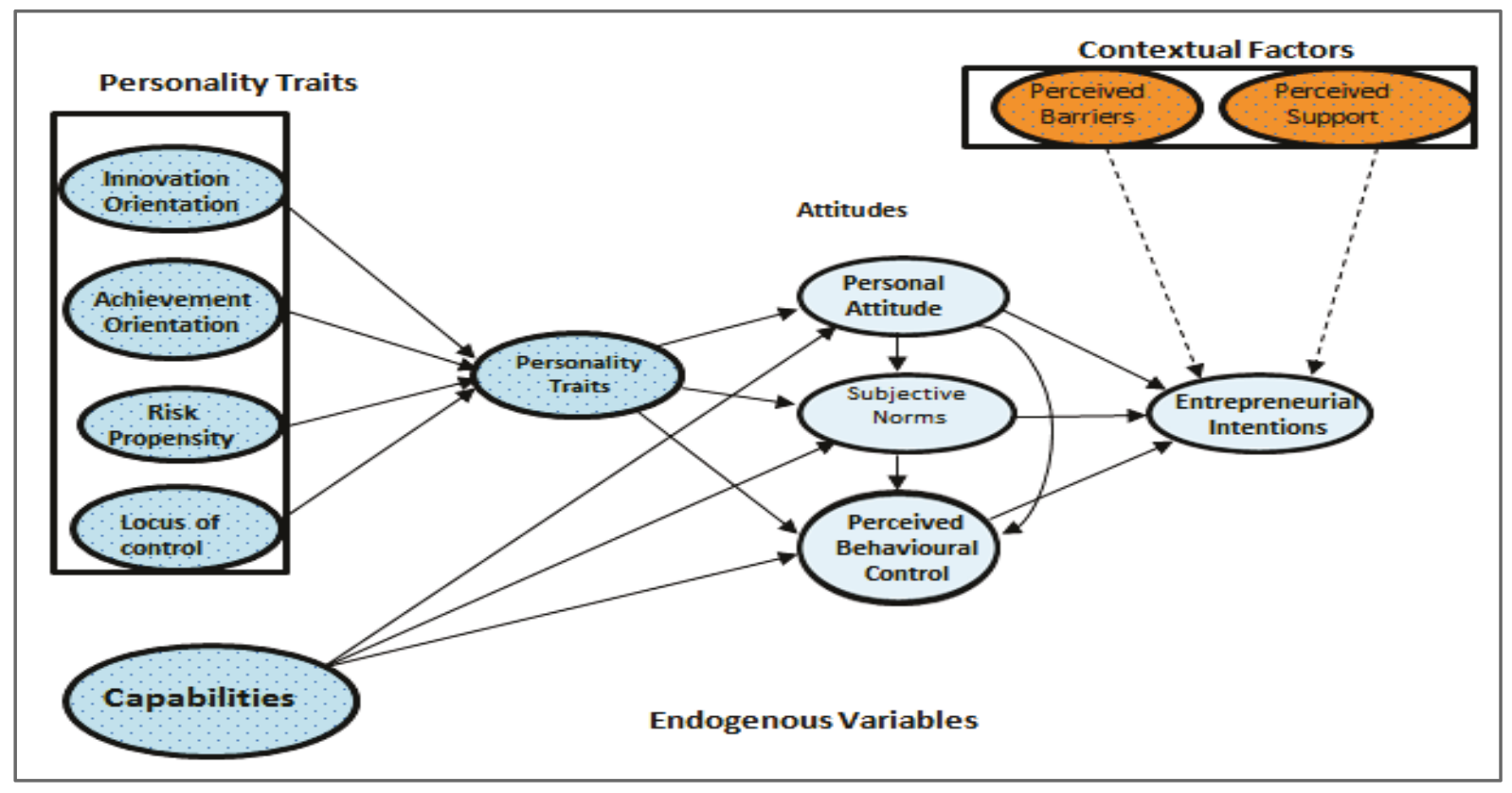

Figure 6.2: Structural model of the factors that influence entrepreneurial intentions

Sources: Adapted from Lüthje and Franke (2003, p.139); Peng et al. (2012, p.97); Ajzen (1991, p.182); Caird (1992); Bridge et al. (2009, p.82)

From Figure 6.2 above, the four psychological traits constituted the index of personality traits that forms a "higher-order component" model. The model is used to capture the indirect influence of personality traits on entrepreneurial intentions. Personality traits influence intentions through the influence of attitudinal factors. Furthermore, the perception of capabilities influences entrepreneurial intentions through its influence on attitude (Wilson, 2010). It is the attitudinal variables-personal attitude, subjective norms, and perceived behavioural control-that directly influence entrepreneurial intentions. The attitudinal factors, in turn, reinforce one another. Lastly, the contextual factors-perceived barriers and perceived support-also directly influence entrepreneurial intentions.

The four personality traits variables, capabilities, and contextual factors act as latent exogenous variables. They only help to explain other variables. They are also independent variables. The personality traits index (as a second-order construct), personal attitude, subjective norms, and perceived behavioural control, and entrepreneurial intentions variables are the endogenous latent variables. They are being explained by other variables and have arrows directed toward them.

The personality traits index, personal attitude, subjective norms, and perceived behavioural control variables, although they are endogenous latent variables in the structural model; they are also independent variables. The reason is that they help to explain the dependent variable (i.e. 
entrepreneurial intentions). In the next session, it reports how the measurement theory informed how to measure each of these constructs.

\subsubsection{Specification of the measurement model}

Measurement model directs the manner to measure each latent variable. Researchers do measure constructs in either a reflective or formative manner. Reflective measures are also called "effect" measures while formative measures are otherwise called "cause or induced" measures (Eberl, 2010, p.462). Specifically, arrows drawn from the indicators (rectangles) to the construct (circle) indicate that the measurement of the construct is reflective. However, arrows drawn from the construct (circle) to the indicators (rectangles) indicate that the measurement of a construct is formative. Thus, the results are assessed differently.

This study measured its constructs reflectively, thus, following the assumption that "the construct causes the measurement. More precisely, it is the co-variation of the indicator variables" but with some level of errors assumed in the measurement (Hair et al., 2014, p.13). Also, the constructs were measured with multiple items. The measurement model is diagrammatically illustrated in Figure 6.3(a) below: 


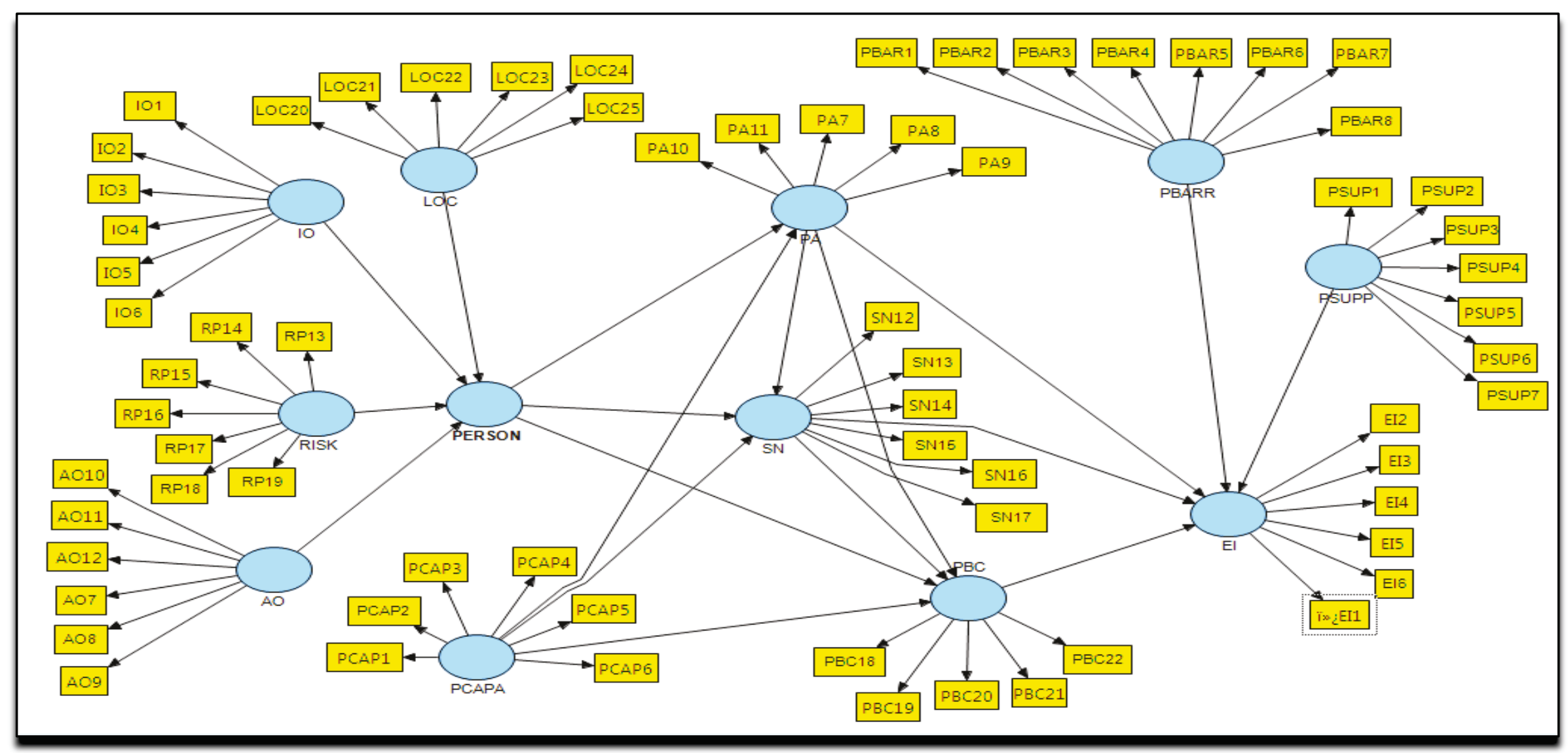

Figure 6.3(a): Measurement model of the factors that influence entrepreneurial intentions (in SmartPLS window) Source: Author's construction on SmartPLS window 
The path model indicates that there are seven exogenous variables in the structural model. These are: innovation orientation (IO), achievement orientation (AO), risk-propensity (RISK), locus of control (LOC), perceived capabilities (PCAPA), perceived barriers (PBARR), and perceived support received (PSUPP). Also, there are five endogenous variables. These are: personality traits index (PERSON), personal attitude (PA), subjective norms (SN), perceived behavioural control (PBC), and entrepreneurial intentions (EI). The researcher measured each of them with multiple items. For example, El was measured with six indicators (i.e. El1 to El6), with a scale numbering from one to six which indicates from "strongly disagree to strongly agree." Participants answered the following questions: "I am ready to do anything to be an entrepreneur", "My professional goal is to become an entrepreneur", and "I am determined to create a business venture in the future." Others were "I have serious thoughts about starting a firm", "I have got intention to start a firm one day", and "I intend to start a firm within five years of graduation." The El construct was then measured, though indirectly, by the participants' answers to these six questions. The remaining ten constructs are explained in like manner.

There are 18 arrows drawn from one variable to another. Arrows represent the path coefficients between the latent variables, and they measure the strength and significance of the relationship between the constructs. For example, arrows from El to the indicators represent the outer loadings of the indicators and measure the reliability of the indicators in explaining the construct, EI. Similar explanations apply to the other arrows between constructs and indicators. The SmartPLS software attaches error terms to each indicator to represent the unexplained factors or variance or the bias likely to occur when measuring a latent construct with indicators. Error terms are only attached to the endogenous variables but not to the exogenous constructs since the latter "only explain other latent variables in the structural model (Hair et al., 2014, p.12).

A representation of the type of higher-order component (HOC) used in measuring the relationship between the psychological factors and the personality traits index is demonstrated in Figure 6.3(b) below: 


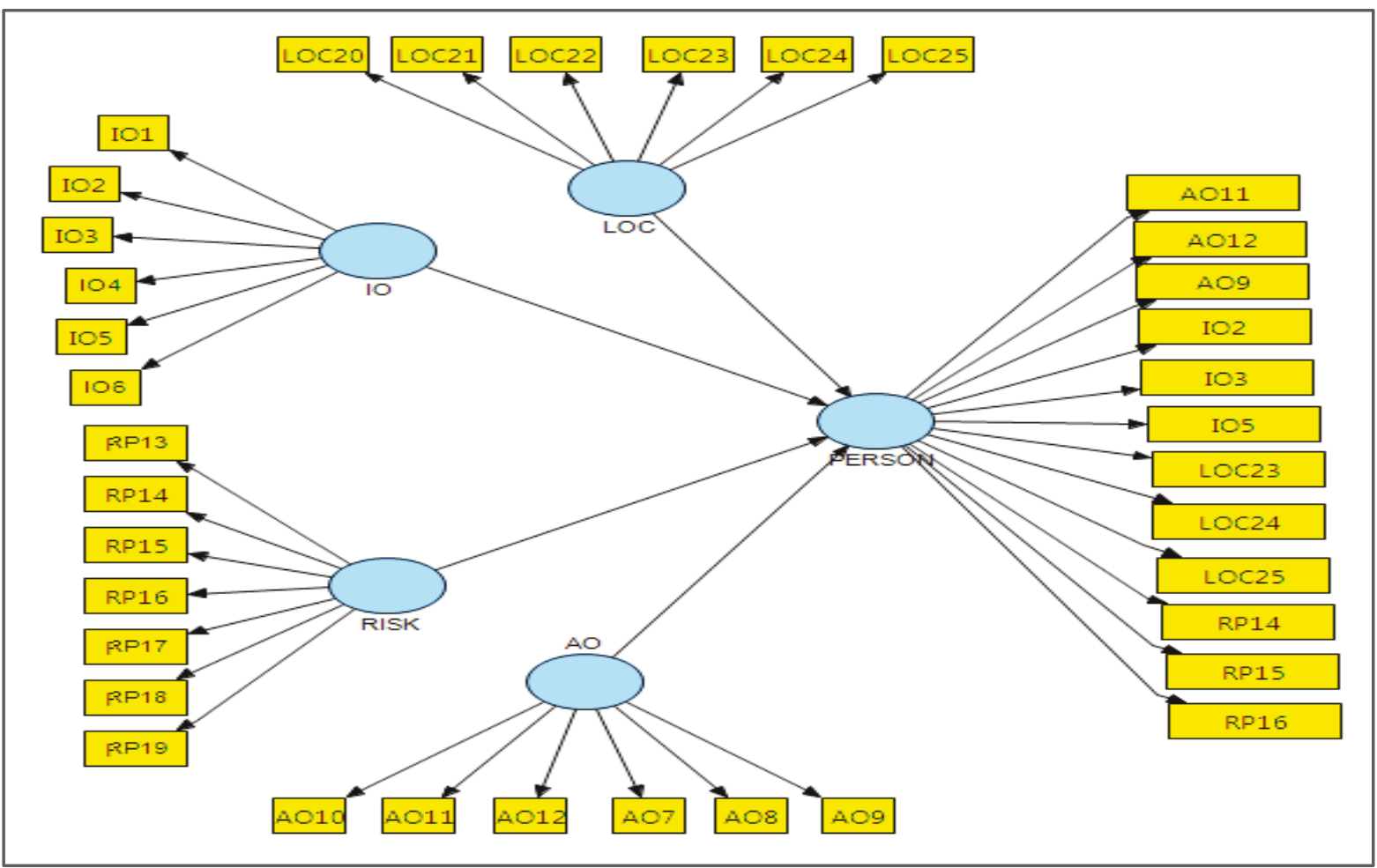

Figure 6.3(b): Reflective-formative type of second-order component model Source: Author's construction on SmartPLS window

Figure 6.3(b) above presents the second-order (higher) components model. The author derived the component when the indicators for the four personality variables (IO, AO, RISK, and LOC) were used to form an index for personality traits. This method is called the "repeated indicator approach" to hierarchical modelling (Wilson, 2010, p.637). SmartPLS calculated the coefficient of multiple determination (R-squared) for the formative construct (i.e. PERSON) using the indicators from the four personality trait variables as independent variables. This capability is one of the laudable advantages of using PLS-SEM. The personality index variable is measured as a formative construct thereby resulting in a reflective-formative type of hierarchical component model (Ringle et al., 2012). The indicators for the formative item carry weights (instead of loadings, for the reflective measures). The size and "significance of the weight indicates the importance of the contribution of the latent variables" on personality traits index (Duarte and Raposa, 2010, p.463).

The researcher first copied the research data into the SmartPLS project pane. The software calculated the parameters after the researcher had accurately drawn the measurement model on the SmartPLS 2.0 window. For this study, the author used the following parameter settings in calculating the results: 
Weighting scheme:

Data metric:

Maximum iterations:

Abort criterion:

Initial weights:
Path weighting scheme

Mean 0 , variance 1

300

$1.0 \mathrm{E}-5$

1.0

Section 6.5 reports the estimated results of the project.

\subsubsection{Meeting the assumptions of partial least squares structural equation modelling (PLS-SEM)}

The variance-based PLS-SEM technique makes lesser number of assumptions compared to the covariance-based structural equation modelling scheme (CB-SEM). It only requires that the researcher samples the respondents randomly. This study used a randomly selected sample of 1,129 participants. The PLS-SEM technique also makes "practically no assumptions about the underlying data (see Cassel, Hackyl and Westlund, 1999)" (Hair et al., 2014, p.15)

In relation to sample size and statistical power, Hair et al. (2014) drawing on the work of Cohen (1992) emphasise that to achieve the 80 per cent conventional level of statistical power, attention must be paid to size of the sample. In calculating this statistical power, the technique also considers the specified level of complexity of the PLS path model. Based on this recommendation, the researcher used the web-based G*Power statistic a priori sample size calculator for SEM to calculate the required sample size. The results from G*Power calculator indicated that with the level of model complexity of this study, the research required 776 samples. This study more than satisfied the sample size requirement as the sample size is 1,129 . Meanwhile, the parameter settings used for the G*Power size calculation that indicated the 776 minimum required sample size is as illustrated below:

Anticipated effect size:

Desired statistical power level:

Number of latent variables:

Number of the indicator variables:

Probability level:

Web-calculated results:

Minimum sample size to detect effect: $\quad 776$

Minimum sample size for model structure: 110

Recommended minimum sample size: $\quad \mathbf{7 7 6}$
0.1 (i.e. small)

0.8 (or $80 \%$ )

12

62

0.05

Source: www.danielsoper.com/statcalc3/calc.aspx $?=89$ (Accessed: 10 October 2013) 


\subsection{PLS-SEM measurement model validation}

In this section, the results for the reflective measures are assessed for internal consistency, item reliability and validities. Validation of the measurement model is a prerequisite for the evaluation of the structural model.

Firstly, the internal consistency reliability of the indicator is evaluated. The composite reliability coefficients are the test statistics used to evaluate items reliability. It is a more reliable index as it makes no assumption of the equality of loadings, like the traditional Cronbach alpha index does (Wilson, 2010). Individual item loading is also considered using the conventional criteria for retaining an indicator. The conventional 0.708 criterion is considered acceptable for retaining an indicator. Some authors believe that even when some items are less than 0.708 (e.g. 0.5 to 0.69 ), one can still retain such items. The reason is that the items might be important in explaining the construct (content validity), or their deletion adds minimal or no improvement in the composite reliability index (Hair et al., 2014).

The result for this test is presented in Table 6.7 that follows. The table highlights the number of questions in the original instrument as well as the number after deletion. The range of indicator loading (after deletion) is on the fourth column. The composite reliability index indicates that all the constructs were internally consistent and reliable. The indices ranged from 0.746 (for innovation orientation) to 0.897 (for perceived support). 
Table 6.7: Results of measurement model constructs and PLS algorithm overview

\begin{tabular}{|c|c|c|c|c|c|c|c|}
\hline Construct & $\begin{array}{l}\text { Original } \\
\text { number of } \\
\text { indicators }\end{array}$ & $\begin{array}{l}\text { Final number of } \\
\text { indicators after } \\
\text { deletion }\end{array}$ & $\begin{array}{l}\text { Range of indicator } \\
\text { loadings }\end{array}$ & R-square & $\begin{array}{l}\text { Composite } \\
\text { index }\end{array}$ & $\begin{array}{l}\text { Cronbach } \\
\text { alpha }\end{array}$ & AVE \\
\hline Entrepreneurial intentions (EI) & 6 & 4 & 0.702 to 0.841 & 0.443 & 0.860 & 0.781 & 0.606 \\
\hline Personal attitude (PA) & 5 & 5 & 0.718 to 0.833 & 0.196 & 0.875 & 0.821 & 0.585 \\
\hline Subjective norms (SN) & 6 & 3 & 0.797 to 0.867 & 0.171 & 0.880 & 0.795 & 0.709 \\
\hline Perceived behavioural control (PBC) & 5 & 3 & 0.793 to 0.870 & 0.360 & 0.860 & 0.756 & 0.673 \\
\hline Locus of control (LOC) & 6 & 3 & 0.735 to 0.857 & & 0.856 & 0.747 & 0.665 \\
\hline Innovation orientation (IO) & 6 & 3 & 0.652 to 0.737 & & 0.746 & 0.489 & 0.496 \\
\hline Risk-propensity (RISK) & 7 & 3 & 0.730 to 0.758 & & 0.784 & 0.588 & 0.548 \\
\hline Achievement orientation (AO) & 6 & 3 & 0.705 to 0.761 & & 0.785 & 0.589 & 0.549 \\
\hline Perceived capabilities (PCAPA) & 6 & 5 & 0.711 to 0.813 & & 0.873 & 0.818 & 0.580 \\
\hline Personality traits index (PERSON) & NA & HOC; 12 & 0.478 to 0.607 & 1.000 & 0.832 & 0.779 & 0.292 \\
\hline Perceived barrier (PBARR) & 8 & 2 & 0.748 to 0.807 & & 0.753 & 0.347 & 0.605 \\
\hline Perceived support (PSUPP) & 7 & 2 & 0.863 to 0.949 & & 0.897 & 0.785 & 0.814 \\
\hline
\end{tabular}

NA= not applicable; $\mathrm{HOC}=$ higher-order component; $\mathrm{AVE}=$ average variance extracted 
Moreover, on convergent validity, what researchers usually consider are the indicators' outer loadings and the average variance extracted (Wilson, 2010). There is confirmation of convergence where a measure co-varies positively with other measures of the similar construct. When an indicator reports a higher outer loading, it is considered that such indicator has more communality captured by the construct in question (Fornell and Larcker, 1981). The average variance extracted, a common measure of convergent validity, is the "grand mean value of the squared loadings of the indicators associated with the construct" (Hair et al., 2014, p.103).

The common norm is to accept constructs within the 0.50 AVE thresholds; this means 50 per cent communality. This figure indicates that, on average, the construct in view explains at least 50 per cent of the biases of its items. The illustration of this validity is as presented in Table 6.8 below:

Table 6.8: PLS algorithm's cross-loadings

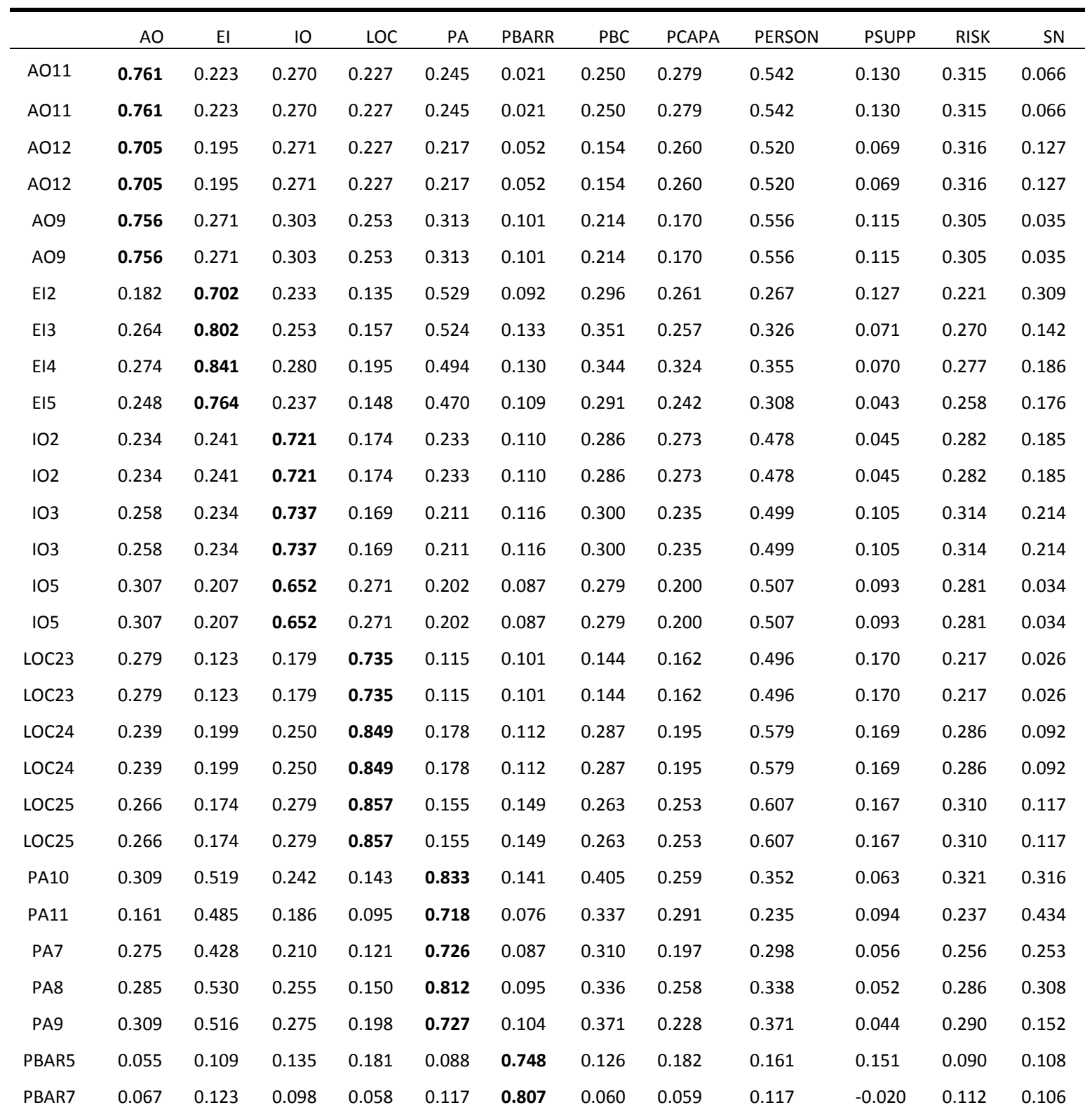




\begin{tabular}{|c|c|c|c|c|c|c|c|c|c|c|c|c|}
\hline PBC19 & 0.185 & 0.289 & 0.294 & 0.246 & 0.351 & 0.088 & 0.795 & 0.331 & 0.331 & 0.149 & 0.228 & 0.303 \\
\hline PBC21 & 0.280 & 0.346 & 0.347 & 0.214 & 0.388 & 0.085 & 0.793 & 0.346 & 0.377 & 0.122 & 0.254 & 0.211 \\
\hline PCAPA1 & 0.252 & 0.303 & 0.260 & 0.185 & 0.278 & 0.157 & 0.333 & 0.711 & 0.356 & 0.167 & 0.330 & 0.184 \\
\hline PCAPA4 & 0.212 & 0.267 & 0.222 & 0.194 & 0.232 & 0.071 & 0.360 & 0.788 & 0.317 & 0.214 & 0.284 & 0.210 \\
\hline PCAPA5 & 0.234 & 0.265 & 0.270 & 0.181 & 0.239 & 0.109 & 0.373 & 0.813 & 0.351 & 0.222 & 0.329 & 0.235 \\
\hline PCAPA6 & 0.267 & 0.219 & 0.240 & 0.200 & 0.211 & 0.130 & 0.366 & 0.757 & 0.362 & 0.224 & 0.338 & 0.191 \\
\hline RP14 & 0.325 & 0.231 & 0.316 & 0.206 & 0.227 & 0.106 & 0.223 & 0.342 & 0.551 & 0.104 & 0.733 & 0.182 \\
\hline RP15 & 0.305 & 0.208 & 0.295 & 0.262 & 0.237 & 0.059 & 0.223 & 0.295 & 0.565 & 0.091 & 0.758 & 0.090 \\
\hline RP15 & 0.305 & 0.208 & 0.295 & 0.262 & 0.237 & 0.059 & 0.223 & 0.295 & 0.565 & 0.091 & 0.758 & 0.090 \\
\hline RP16 & 0.305 & 0.292 & 0.313 & 0.275 & 0.343 & 0.125 & 0.271 & 0.298 & 0.574 & 0.097 & 0.730 & 0.163 \\
\hline RP16 & 0.305 & 0.292 & 0.313 & 0.275 & 0.343 & 0.125 & 0.271 & 0.298 & 0.574 & 0.097 & 0.730 & 0.163 \\
\hline SN12 & 0.029 & 0.192 & 0.153 & 0.075 & 0.293 & 0.116 & 0.252 & 0.223 & 0.128 & 0.087 & 0.113 & 0.797 \\
\hline SN14 & 0.108 & 0.221 & 0.187 & 0.061 & 0.332 & 0.098 & 0.290 & 0.217 & 0.182 & 0.086 & 0.172 & 0.860 \\
\hline
\end{tabular}

Based on the stated criterion, all the reflectively-measured constructs are adjudged to be within the acceptable index. The reason is that the indicator loadings are above the 0.708 thresholds, and are statistically significant. The bootstrapping results confirmed this. The AVE ranged from 0.496 to 0.814 , thus indicating a sharing of a high proportion of variance.

As regard discriminant validity, constructs must be truly unique from others. Therefore, discriminant validity connotes that constructs must be distinct and should explain concepts not captured by other constructs. Authors often assess the discriminant validity using the indicators' cross-loadings as well as the Fornell-Larcker criterion (Wilson, 2010). Researchers consider the first criterion as liberal and require that the outer loadings of each indicator for a given construct must have its values greater than those of the other indicators (of other constructs) under consideration.

The second criterion requires "the square root of the average variance extracted (AVE) of each reflectively-measured construct should be higher than its highest correlation with any other construct (Hair et al., 2014, p.107). Alternatively, the "AVE should exceed the squared correlation with any other construct" (p.105). The reasoning behind this is that a construct shares greater variance with its items compared to what it shares with other constructs. This study adopted the first criterion. 
Table 6.8 below presents the cross-loadings for all the constructs to assess whether discriminant validity criterion was met. From the table, the second column corresponding to the first six rows (in bold fonts) indicates the cross-loadings for achievement orientation variable as $0.761,0.761$, $0.705,0.705,0.756$, and 0.756 . The repeats are for the higher-order component variable, PERSON. The figures are greater than the loadings for all the remaining constructs in columns 3 to 13 (i.e. from EI to SN). Similarly, column 3 indicates the cross-loadings for entrepreneurial intentions (EI) construct (in bold fonts). Its values $0.702,0.802,0.841$, and 0.764 are greater than the figures for the cross-loadings of all the other constructs. The rest of the constructs are explained in a similar fashion. Thus, these cross-loadings suggest that the measured constructs were valid.

The Fornell-Larcker criterion is illustrated in Table 6.9 below. The table presents the PLS algorithm's correlation matrix for the 12 constructs in the non-diagonal pane and the square roots of the AVE in the diagonal pane. The values for the AVE were picked from Table 6.7 in Section 6.5, and the square roots were manually computed and represented in bold fonts along the diagonal pane below:

Table 6.9: Results of Fornell-Larcker criterion of discriminant validity

\begin{tabular}{|c|c|c|c|c|c|c|c|c|c|c|c|c|}
\hline & $\mathrm{AO}$ & $\mathrm{EI}$ & 10 & LOC & PA & PBARR & PBC & PCAPA & PERSON & PSUPP & RISK & SN \\
\hline $\mathrm{AO}$ & 0.741 & & & & & & & & & & & \\
\hline $\mathrm{EI}$ & 0.31 & 0.778 & & & & & & & & & & \\
\hline 10 & 0.38 & 0.32 & 0.704 & & & & & & & & & \\
\hline LOC & 0.32 & 0.20 & 0.29 & 0.815 & & & & & & & & \\
\hline PA & 0.35 & 0.65 & 0.31 & 0.18 & 0.765 & & & & & & & \\
\hline PBARR & 0.08 & 0.15 & 0.15 & 0.15 & 0.13 & 0.778 & & & & & & \\
\hline PBC & 0.28 & 0.41 & 0.41 & 0.29 & 0.46 & 0.12 & 0.820 & & & & & \\
\hline \multirow[t]{2}{*}{ PCAPA } & 0.32 & 0.35 & 0.34 & 0.25 & 0.32 & 0.15 & 0.45 & 0.762 & & & & \\
\hline & & & & & & & & & $\begin{array}{l}\text { Reflective- } \\
\text { Formative }\end{array}$ & & & \\
\hline PERSON & 0.73 & 0.40 & 0.70 & 0.69 & 0.42 & 0.18 & 0.45 & 0.46 & $\mathrm{HOC}$ & & & \\
\hline PSUPP & 0.14 & 0.10 & 0.12 & 0.21 & 0.08 & 0.08 & 0.19 & 0.26 & 0.21 & 0.902 & & \\
\hline RISK & 0.42 & 0.33 & 0.42 & 0.34 & 0.36 & 0.13 & 0.32 & 0.42 & 0.76 & 0.13 & 0.740 & \\
\hline SN & 0.10 & 0.26 & 0.20 & 0.10 & 0.39 & 0.14 & 0.33 & 0.27 & 0.21 & 0.11 & 0.20 & 0.842 \\
\hline
\end{tabular}

A cursory look at the table indicates, for example, that the square root of the AVE for entrepreneurial intentions (EI) variable is 0.778 and is greater than the correlation of the other construct $A O$ (i.e. $0.778>031$, see the third row). In the fourth row, the square root of AVE for innovation orientation (IO) is 0.704 and is greater than the correlation figures of all the other constructs within the column. Similar explanations are applied to explaining the other reflectivelymeasured constructs. Meanwhile, the Fornell-Larcker criterion is inapplicable to other forms of 
measures such as the higher-order component model, for example, the personality traits index (Hair et al., 2014). Therefore, the results indicate that there was discriminant validity among all the constructs.

As the researcher met the basic conditions of validation for the measurement model, the study could then evaluate the structural model. This evaluation is the task implemented in the next sections beginning with the multi-group analysis (MGA).

\subsection{Partial least squares multi-group analysis (PLS-MGA): observed heterogeneity test}

The author first conducted a PLS-MGA to examine whether there were significant differences in the characteristics of the structure of the data among respondents from the two regional groups (see Eberl, 2010).The study used regional and ethnic groupings to divide the dataset into Southsouth and Southeast sub-samples. The author then accessed the path coefficients and standard errors of the entire 18 construct paths in the structural model from the bootstrapping (resampling) procedure. The procedure used 413 cases for Southeast Nigeria, and 716 cases for South-south Nigeria, 5000 samples, and "no sign changes" in the bootstrapping scheme.

The t-statistic test was conducted to determine whether the assumption of equality or nonequality of standard errors held for the two sub-samples. Chin (2010) provides the following formulae for the t-statistic: (1) if there is equality of standard errors observed in the results:

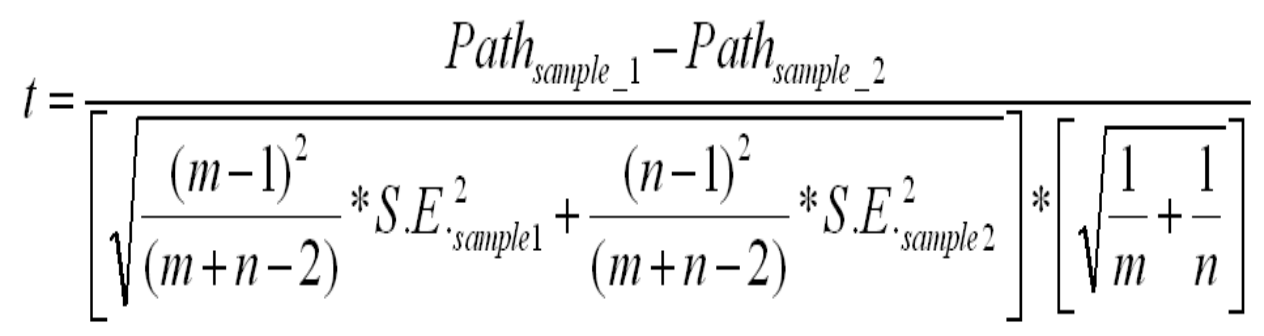

Where:

$$
\begin{array}{ll}
\text { Path sample } 1 / 2 & =\text { original sample estimate for the path coefficient in the two } \\
& \text { subsamples respectively } \\
\mathrm{m} & =\text { number of cases in sample } 1 \text { (i.e. Southeast Nigeria) } \\
\mathrm{n} & =\text { number of cases in sample } 2 \text { (i.e. South-south Nigeria) }
\end{array}
$$


Se sample $1 / 2$

$=$ standard error of the path coefficient in both subsamples respectively (as derived from bootstrapping procedure)

However, if inequality in standard errors is assumed, then:

$$
\mathrm{t}=\frac{\text { Path } \text { sample } 1-\text { Path sample } 2}{\text { Vs.e }^{2} \text {.sample } 1+\text { s.e }^{2} \text {.sample } 2}
$$

The researcher computed the estimates; then conducted the pairwise comparison of the two groups. If more than two significant paths were found, the two groups would then be compared pairwise before interpreting the entire results (Eberl, 2010). Using the above as a guideline, the researcher employed the Excel spread sheet provided by Hair et al. $(2014$, p.253) to compute the estimates for the 18 paths. This spread sheet incorporates the above formulae into a template that is made ready to compute the t-statistics and p-values automatically for any construct path immediately one inserts the standard errors and path coefficients. Table 6.10 below reports the result of the procedure: 
Table 6.10: Results of PLS multi-group analysis

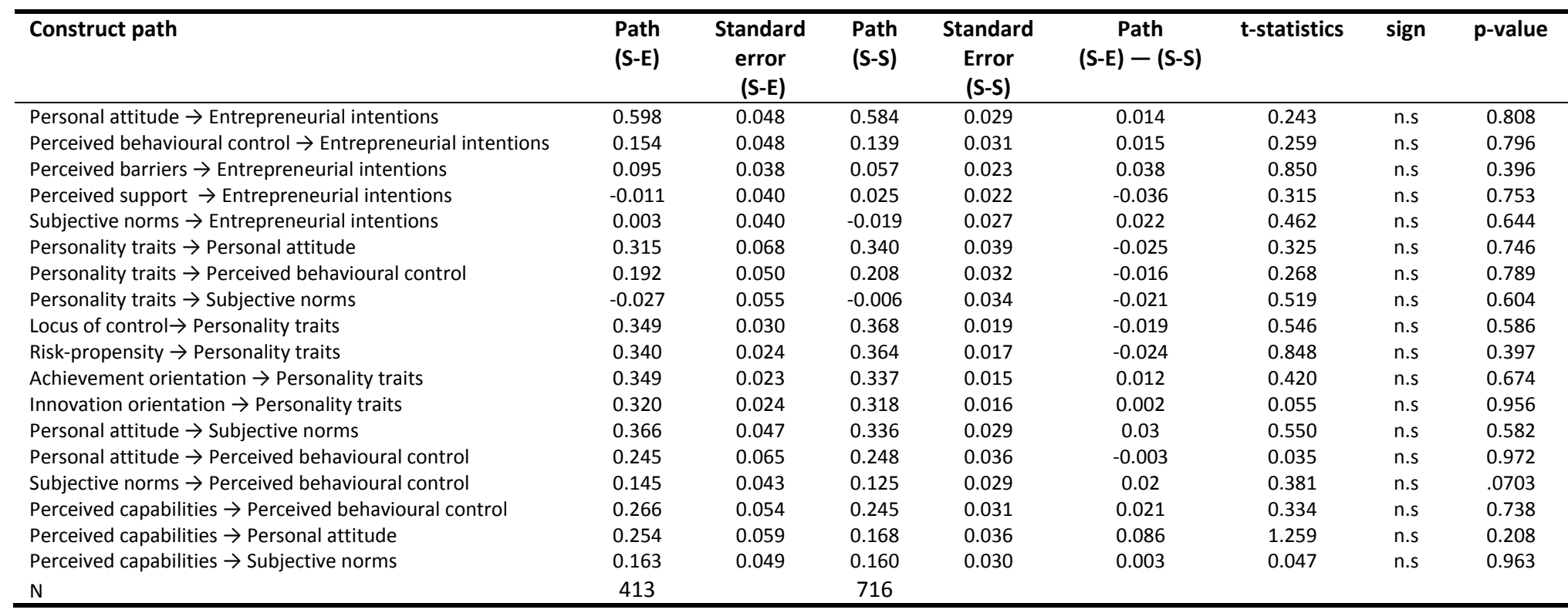

S-E = Southeast regional Group; S-S = South-south regional Group; Path = construct's path coefficient; n.s. = not significant 
From Table 6.10 above and starting with the path from personal attitude to entrepreneurial intentions, the path coefficient is 0.598 for the Southeast region, and the standard error is 0.048 . Similarly, the path coefficient for South-south region is 0.584 with a standard error of 0.029 . The path difference is 0.014 , and the t-statistics is 0.243 . With the $p$-value of 0.808 , this indicated no significant difference in the perception of the participants between the groups. The other structural paths can be interpreted in a similar fashion.

The results indicate that no path coefficient was statistically significant when one compares the perceptions of students of the two ethnic groups concerning the relationships exemplified by the hypothesised model paths. Thus, suggesting that the empirical data did not support or substantiate any assumed structural differences (in the data) on the status of entrepreneurial intentions and the factors that influence entrepreneurial intentions among the undergraduates. Consequently, the researcher then analysed and interpreted the final data and results for the two regions together as one dataset.

\subsection{Structural paths' model estimation results}

The result is first presented in the modelling window (Figure 6.4), and then Table 6.11(b) presents the full results for analysis and interpretations. The SmartPLS software provided the following results. Firstly, the outer loadings and outer weights. Secondly, the path coefficients that relate the path relationships in the structural model. Thirdly, the R-squared figures for the five endogenous constructs, that is: personality traits (PERSON), personal attitude (PA), subjective norms (SN), perceived behavioural control (PBC), and entrepreneurial intentions (EI). The assessment of PLSSEM model follows a two-step process (Hair et al., 2012). The first is to evaluate the measurement model for internal reliability, indicator reliability, and validity. The researcher showed this validation in the last section. The second is to evaluate the structural model. The evaluation is with respect to collinearity, the degree of model's prediction power (R-square), size and significance of path coefficients, predictive relevance $\left(Q^{2}\right)$, and effect sizes $\left(f^{2}\right.$ and $\left.q^{2}\right)$. This section will report these estimates.

The study first evaluated the collinearity problem. This problem occurs where two constructs are too correlated in a structural model. In assessing the presence or absence of this problem, researchers often use the variance inflation factor (VIF) to measure the severity of multicollinearity (Hair, Ringle and Sarstedt, 2011). The criterion is to assume that there is no problem of collinearity if the VIF value of the construct is less than five, or its tolerance level is above 0.20 . Otherwise, such construct should be removed, or transformed into a higher-order component model. 
To estimate the VIF values for the structural model, the researcher accessed the results of the PLS algorithm and the latent variable scores for all the 12 constructs. Then copied them to the SPSS window and ran multiple regression analyses. The regressions provided the collinearity statistics requested. Specifically, two distinct regression analyses were conducted; that is, one for each segment of the structural model. The study used the following equations. Firstly, achievement orientation (AO), innovation orientation (IO), locus of control (LOC), and risk-propensity (RISK) as a function of PERSON. Secondly, PERSON, perceived barrier (PBARR), perceived capability (PCAPA), perceived support (PSUPP), PA, PBC, and SN as a function of El. Table 6.11(a) below reports the requested collinearity diagnostics:

Table 6.11(a): Assessment of collinearity diagnostics

\begin{tabular}{lcclcc}
\hline $\begin{array}{l}\text { First set: } \\
\text { Constructs }\end{array}$ & Tolerance & VIF & $\begin{array}{l}\text { Second set: } \\
\text { Constructs }\end{array}$ & Tolerance & VIF \\
\hline AO & .750 & 1.334 & PERSON & .664 & 1.505 \\
IO & .762 & 1.312 & PA & .674 & 1.484 \\
LOC & .834 & 1.199 & PBARR & .953 & 1.049 \\
RISK & .721 & 1.388 & PBC & .637 & 1.570 \\
& & & PCAPA & .680 & 1.471 \\
& & & PSUPP & .913 & 1.095 \\
& & & SN & .806 & 1.240 \\
\hline
\end{tabular}

Table 6.11(a) reports the tolerance levels and VIF figures of the regression results. An assessment of the result indicates that all the constructs have VIF values below 5 . Thus, multicollinearity problem was a non-issue among the constructs. Figure 6.4 below shows the results for the structural model and its evaluation follows: 


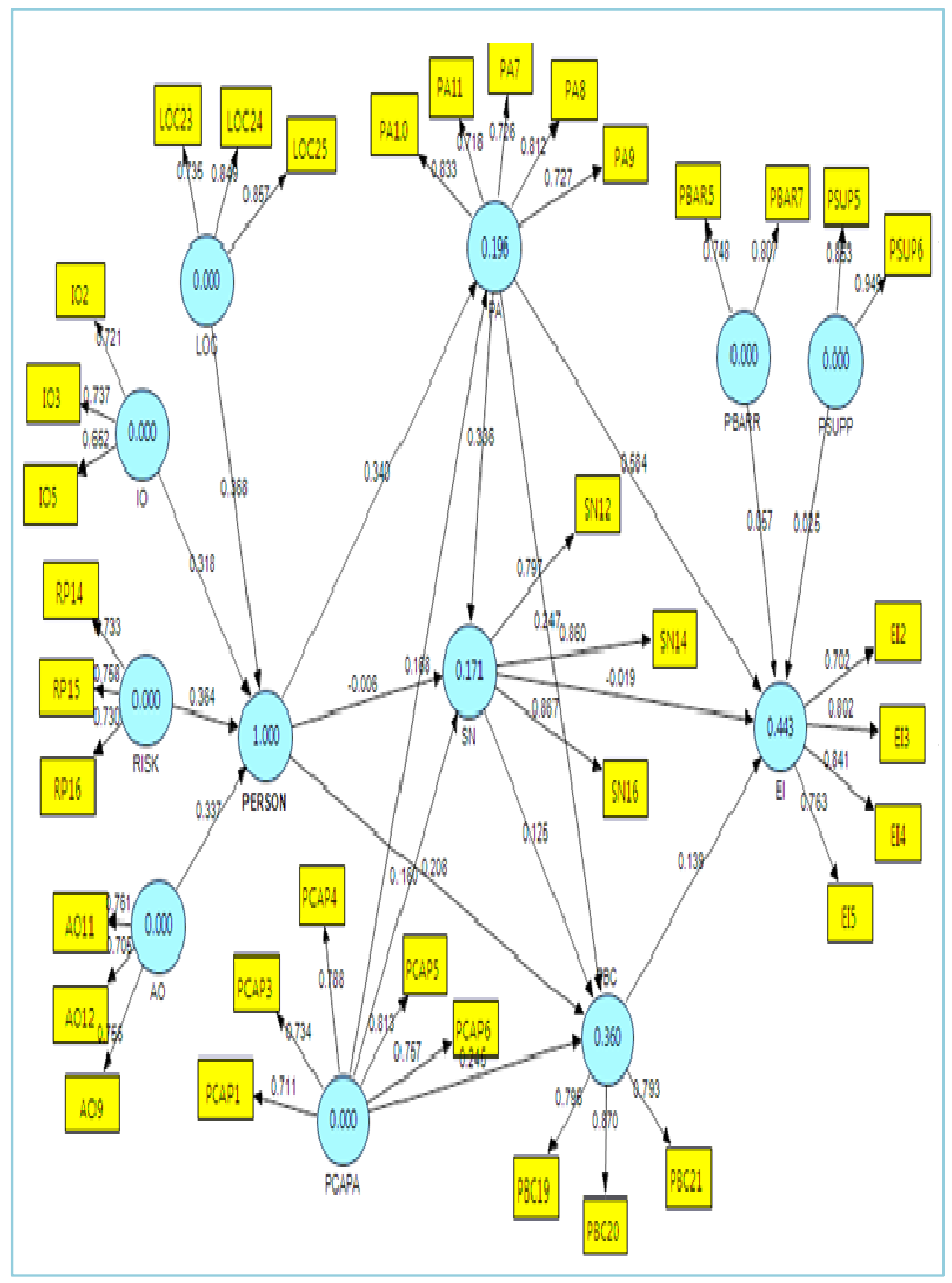

Figure 6.4: Algorithm results in PLS window 
The requested results for the structural model indicated that the personal attitude influenced entrepreneurial intentions the strongest (i.e., 0.584). The results of the bootstrapping scheme (see Table $6.11 \mathrm{~b}$ below) shows the statistical significance of the path coefficient. It indicates a highly significant influence between these two constructs [t $(1117)=20.354, p<0.001$ ] Thus, the assumption of no significant relationship between students' personal attitude and entrepreneurial intentions is rejected. Perceived behavioural control factor was the next strongest influence on entrepreneurial intentions with a coefficient of 0.139 [ $t(1117)=4.468, p<0.001$ ]. Thus, the assumption of no significant relationship between students' perceived behavioural control and entrepreneurial intentions is rejected.

Next was the level of perceived barriers with path coefficient of 0.057 [ $t(1117)=2.42, p<0.05$ ] This relationship was a slightly weaker influence. Thus, the assumption of no significant relationship between students' perception of barriers and entrepreneurial intentions is rejected. The influence of subjective norms on entrepreneurial intentions was negative and insignificant. Thus, the assumption of no significant relationship between students' level of subjective norms and entrepreneurial intentions cannot be rejected. Perceived support was also insignificant though positive. Thus, the assumption of no significant relationship between students' level of perceived support and entrepreneurial intentions cannot be rejected.

Meanwhile, the level of explained variance for the three endogenous variables (PA, SN, and PBC) and the two exogenous variables (PBARR and PSUPP) on entrepreneurial intentions was 44.3 per cent. That is, the $R^{2}$ is equal to 0.443 . This figure is indicated by the estimate in the circle in the PLS window (in Figure 6.4 above). This $\mathrm{R}^{2}$ value suggests a moderate level of model fit.

The influence of personality traits on attitude factor was greatest on personal attitude, followed by perceived behavioural control but negative and insignificant on subjective norms. In the same vein, the components of psychological factors (AO, IO, LOC, and RISK) that formed personality traits received the greatest influences from the internal locus of control (LOC) and risk-propensity (RISK). The next were achievement orientation (AO) and innovative orientation (IO). All four indices were statistically significant at better than the one per cent level. In this order: personal attitude greatly influenced subjective factor with a path coefficient of 0.336 [t $(1117)=11.631, p<$ 0.001]; it influenced perceived behavioural control with a path coefficient of 0.248 [ $\mathrm{t}(1117)=$ 6.860, $\mathrm{p}<0.001$ ]; and subjective norms factor influenced perceived behavioural control factor with a path coefficient of 0.125 [t $(1117)=4.342, p<0.001]$. The level of perceived capabilities influenced more of the perceived behavioural control factor, having a path coefficient of 0.245 [ $t$ 
$(1117)=7.899, p<0.001]$, followed by personal attitude with a path coefficient of 0.168 [t (1117) $=4.616, p<0.001]$. Subjective norms had a path coefficient of $0.16[t(1117)=5.268, p<0.001]$.

From Figure 6.4, in terms of the predictive or explanatory power of the conceptual model, PCAPA, PERSON, SN, and PA jointly explained about 36 per cent of the variation in PBC. This figure indicates a moderate explanatory power of the model. Personality traits and perceived capabilities predicted about 20 per cent of the variation in personal attitude, thus indicating a weak explanation. Also, personality traits, personal attitude and perceived capabilities predicted about 17 per cent of the variation in subjective norms. This figure was also a weak model fit.

Table 6.11(b): Bootstrapping results of PLS path coefficients

\begin{tabular}{|c|c|c|c|c|}
\hline Construct path & Coefficient & $\begin{array}{l}\text { Standard } \\
\text { error }\end{array}$ & t-statistics & Sign \\
\hline Personal attitude $\rightarrow$ Entrepreneurial intentions & 0.584 & 0.029 & 20.354 & $* * *$ \\
\hline Perceived behavioural control $\rightarrow$ Entrepreneurial intentions & 0.139 & 0.031 & 4.468 & $* * *$ \\
\hline Perceived barriers $\rightarrow$ Entrepreneurial intentions & 0.057 & 0.023 & 2.420 & $*$ \\
\hline Perceived support $\rightarrow$ Entrepreneurial intentions & 0.025 & 0.022 & 1.148 & n.s \\
\hline Subjective norms $\rightarrow$ Entrepreneurial intentions & -0.019 & 0.027 & 0.722 & n.s \\
\hline Personality traits $\rightarrow$ Personal attitude & 0.340 & 0.039 & 8.670 & $* * *$ \\
\hline Personality traits $\rightarrow$ Perceived behavioural control & 0.208 & 0.032 & 6.475 & $* * *$ \\
\hline Personality traits $\rightarrow$ Subjective norms & -0.006 & 0.034 & 0.161 & n.s \\
\hline Locus of control $\rightarrow$ Personality traits & 0.368 & 0.019 & 19.592 & $* * *$ \\
\hline Risk-propensity $\rightarrow$ Personality traits & 0.364 & 0.017 & 21.510 & $* * *$ \\
\hline Achievement orientation $\rightarrow$ Personality traits & 0.337 & 0.015 & 22.012 & $* * *$ \\
\hline Innovation orientation $\rightarrow$ Personality traits & 0.318 & 0.016 & 20.506 & $* * *$ \\
\hline Personal attitude $\rightarrow$ Subjective norms & 0.336 & 0.029 & 11.631 & $* * *$ \\
\hline Personal attitude $\rightarrow$ Perceived behavioural control & 0.248 & 0.036 & 6.860 & $* * *$ \\
\hline Subjective norms $\rightarrow$ Perceived behavioural control & 0.125 & 0.029 & 4.342 & $* * *$ \\
\hline Perceived capabilities $\rightarrow$ Perceived behavioural control & 0.245 & 0.031 & 7.899 & $* * *$ \\
\hline Perceived capabilities $\rightarrow$ Personal attitude & 0.168 & 0.036 & 4.616 & $* * *$ \\
\hline Perceived capabilities $\rightarrow$ Subjective norms & 0.160 & 0.030 & 5.268 & $* * *$ \\
\hline
\end{tabular}

*** $\mathrm{P}<0.001 ; * * \mathrm{P}<0.01 ; * \mathrm{P}<0.05$ (based on: $\mathrm{t}_{(1117)}$, two-tailed test; $\mathrm{n} . \mathrm{s}=$ not significant; Bootstrapping scheme (Samples=5000, cases $=1,129$, No sign changes)

Table 6.11(c): Bootstrapping results of total effects of selected paths

\begin{tabular}{lccc}
\hline Construct path & Total effect & t-values & Sign. Level \\
\hline Personal attitude $\rightarrow$ Entrepreneurial intentions & 0.618 & 25.847 & $* * *$ \\
Locus of control $\rightarrow$ Personality traits & 0.368 & 19.539 & $* * *$ \\
Risk-propensity $\rightarrow$ Personality traits & 0.364 & 21.838 & $* * *$ \\
Personality traits $\rightarrow$ Personal attitude & 0.340 & 8.850 & $* * *$ \\
Achievement orientation $\rightarrow$ Personality traits & 0.337 & 22.182 & $* * *$ \\
Innovation orientation $\rightarrow$ Personality traits & 0.318 & 20.243 & $* * *$ \\
Personality traits $\rightarrow$ Perceived behavioural control & 0.306 & 9.419 & $* * *$ \\
Personality traits $\rightarrow$ Entrepreneurial intentions & 0.239 & 8.508 & $* * *$ \\
Perceived behavioural control $\rightarrow$ Entrepreneurial intentions & 0.139 & 4.484 & $* * *$ \\
Perceived capabilities $\rightarrow$ Entrepreneurial intentions & 0.138 & 5.751 & $* * *$ \\
Personality traits $\rightarrow$ Subjective norms & 0.109 & 3.331 & $* * *$ \\
Perceived barriers $\rightarrow$ Entrepreneurial intentions & 0.057 & 2.398 & $* *$ \\
Perceived support $\rightarrow$ Entrepreneurial intentions & 0.025 & 1.153 & n.s \\
Subjective norms $\rightarrow$ Entrepreneurial intentions & -0.002 & 0.077 & n.s \\
\hline
\end{tabular}

${ }^{* * *} \mathrm{P}<0.001 ;{ }^{* *} \mathrm{P}<0.05$ (based on: $\mathrm{t}_{(1117)}$, two-tailed test; $\mathrm{n} . \mathrm{s}=$ not significant; Bootstrapping scheme (Samples $=5000$, cases $=1,129$, No sign changes) 
Table 6.11(c) reports the results for total effects of selected constructs of interest on the target entrepreneurship intentions, attitude, and personality traits. The total effect column lists the size and magnitude of the effect of the factors on entrepreneurial intentions from the highest effect to the lowest effect. The results indicated that total effects were statistically significant at the different levels of significance but only insignificant for perceived support and subjective norms. The greatest effects on entrepreneurial intentions came from personal attitude (0.618), followed by personality traits $(0.239)$, perceived behavioural control $(0.139)$, and perceived barriers $(0.057)$. The total effects of psychological factors on the formation of personality traits were greatest from the locus of control $(0.368)$ and risk-propensity (0.364). The next were achievement orientation (0.334) and innovation orientation (0.318) in this order. Conversely, the total effects of personality traits on attitude constructs were greatest on personal attitude $(0.340)$, followed by perceived behavioural control (0.306), and subjective norms (0.109).

\subsubsection{Assessment of effect size, $\mathrm{f}^{2}$}

The effect size enables one to assess a structural model to determine whether by excluding a certain exogenous variable, this exclusion can affect the model. The effect can be the small, medium, or large on the R-squared value of the endogenous variable (Eberl, 2010). Thus, indicating the size contribution of an exogenous variable on the predictive power of the endogenous variables. The procedure is first to run the PLS algorithm and derive the R-square values of the endogenous variables. Then delete an exogenous variable connected to the particular endogenous variable in which one is interested in assessing for $\mathrm{f}^{2}$ effect size, and rerun the PLS algorithm to derive a new R-square value. The old and new R-square values are then used to calculate the $f^{2}$ effect size of the exogenous variable on the endogenous variable. The formula is:

$$
f^{2}=\frac{R_{\text {included }}^{2}-R_{\text {excluded }}^{2}}{1-R_{\text {included }}^{2}}
$$

Where:

$f^{2}=$ effect size

$\mathrm{R}^{2}$ included $=\mathrm{R}$-square value with the particular exogenous variable

$\mathrm{R}^{2}$ excluded $=\mathrm{R}$-square value without the particular exogenous variable

The researcher implemented the above-described procedures in deriving the $f^{2}$ effect sizes of the construct paths and Tables 6.12 and 6.13 below present the results. 
Table 6.12: Results of $R^{2}$ and $Q^{2}$ values

\begin{tabular}{lccc}
\hline Endogenous latent variables & $\mathrm{R}^{2}$ & $\mathrm{Q}^{2}$ \\
\hline Personality traits & (PERSON) & 1.00 & 0.2901 \\
Entrepreneurial intentions & (EI) & 0.443 & 0.2639 \\
Perceived behavioural control (PBC) & 0.360 & 0.2393 \\
Personal attitude & (PA) & 0.196 & 0.1141 \\
Subjective norms & (SN) & 0.171 & 0.1207 \\
\hline
\end{tabular}

Table 6.13: Summary of results

\begin{tabular}{|c|c|c|c|}
\hline Construct path & $\begin{array}{l}\text { Path } \\
\text { coefficients }\end{array}$ & $\begin{array}{l}f^{2} \\
\text { effect } \\
\text { size }\end{array}$ & $q^{2}$ effect size \\
\hline Personal attitude $\rightarrow$ Entrepreneurial intentions & 0.584 & 0.442 (L) & $0.02(\mathrm{M})$ \\
\hline Perceived behaviour control $\rightarrow$ Entrepreneurial intentions & 0.139 & $0.02(S)$ & $0.01(N)$ \\
\hline Perceived capabilities $\rightarrow$ Entrepreneurial intentions & 0.138 & $0.00(\mathrm{~N})$ & $0.0001(\mathrm{~N})$ \\
\hline Perceived barriers $\rightarrow$ Entrepreneurial intentions & 0.057 & $0.005(\mathrm{~N})$ & $0.003(\mathrm{~N})$ \\
\hline Perceived support $\rightarrow$ Entrepreneurial intentions & 0.025 & $0.002(N)$ & $0.0003(\mathrm{~N})$ \\
\hline Subjective norms $\rightarrow$ Entrepreneurial intentions & -0.019 & $0.00(\mathrm{~N})$ & $-0.0003(\mathrm{~N})$ \\
\hline Locus of control $\rightarrow$ Personality traits & 0.368 & $0.06(S)$ & $0.07(S)$ \\
\hline Risk-propensity $\rightarrow$ Personality traits & 0.364 & $0.06(S)$ & $0.033(S)$ \\
\hline Achievement orientation $\rightarrow$ Personality traits & 0.337 & $0.05(S)$ & $0.033(S)$ \\
\hline Innovation orientation $\rightarrow$ Personality traits & 0.318 & $0.05(S)$ & $0.03(S)$ \\
\hline Perceived capabilities $\rightarrow$ Perceived behavioural control & 0.245 & $0.07(S)$ & $0.04(S)$ \\
\hline Perceived capabilities $\rightarrow$ Personal attitude & 0.168 & $0.03(\mathrm{~S})$ & $0.014(\mathrm{~N})$ \\
\hline Perceived capabilities $\rightarrow$ Subjective norms & 0.160 & $0.02(S)$ & $0.02(S)$ \\
\hline Personality traits $\rightarrow$ Personal attitude & 0.340 & $0.11(S)$ & $0.06(S)$ \\
\hline Personality traits $\rightarrow$ Perceived behavioural control & 0.208 & $0.05(S)$ & $0.03(S)$ \\
\hline Personality traits $\rightarrow$ Subjective norms & -0.006 & $0.00(\mathrm{~N})$ & $0.0001(\mathrm{~N})$ \\
\hline
\end{tabular}

$\mathrm{L}=$ large effect; $\mathrm{N}$ = no effect; $\mathrm{S}$ = small effect; $\mathrm{M}=$ medium effect

Table 6.12 above reports the original or included R-square values of the five endogenous variables while Table 6.13 reports the path coefficients, $\mathrm{f}^{2}$ and $\mathrm{q}^{2}$ effect sizes of the constructs connected to the five endogenous variables. For example, the path from personal attitude to entrepreneurial intentions has an $f^{2}$ effect size of 0.442 . This value was derived by first accessing the R-square value of the model where personal attitude construct was a component: this R-square value was 0.443. Personal attitude construct was then deleted from the structural model and the PLS algorithm re-estimated, and it yielded a new R-square value for entrepreneurial intentions as 0.197. Using these two R-square values and calculating manually with an electronic calculator based on the formula above, the $f^{2}$ effect size of the path from personal attitude to entrepreneurial intentions became 0.442 . Other paths were calculated in a similar manner.

According to Cohen (1988), the value of 0.02 denotes a small effect size; a value of 0.15 denotes a medium effect size, and a value of 0.35 denotes a large effect size. As can be seen, the value of 0.442 denotes that personal attitude construct contributed a larger effect size to the R-square value of entrepreneurial intentions in the structural model. Perceived behavioural control, another attitude factor, contributed only a small effect size $\left(f^{2}=0.02\right)$. The other four constructs to the 
entrepreneurial intentions path had no effect on the R-square value of entrepreneurial intentions. They were subjective norms, SN; perceived capabilities, PCAPA; perceived support, PSUPP; and perceived barrier, PBARR. Most of the other construct paths also had small effects on the R-square values of the target endogenous variables.

\subsubsection{Blindfolding and assessment of predictive relevance, $Q^{2}$}

The study also assessed the $Q^{2}$ values as an additional medium of evaluating the magnitude of the R-square values as a criterion of predictive accuracy. The $Q^{2}$ value assesses the predictive relevance of the model. If a study established a predictive relevance, it means that the data points of items in the reflectively-measured model were correctly predicted (Hair et al., 2014). The authors report that with $Q^{2}$ value greater than zero, the path model of the construct in question is adjudged relevant and well-predicted by an exogenous construct. The $Q^{2}$ value is derived by a blindfolding routine that "omits every nth data point in the endogenous construct indicators and estimates the parameters with the remaining data points" (p.178). In this study, the researcher chose the default omission distance of seven during the PLS blindfolding scheme.

If the $Q^{2}$ value is above zero, this denotes support. Table 6.12 above shows the results of the $Q^{2}$ values from the PLS blindfolding scheme. This study then employed this result in calculating the $\mathrm{q}^{2}$ effect sizes and reports it in Table 6.13.

The $q^{2}$ effect size uses a similar approach as the $f^{2}$ effect size. But it only uses $Q^{2}$ values of the "predictive relevance as inputs (after running the blindfolding procedure)" instead of $R^{2}$ values (Hair et al., 2014, p.196). It computes a blindfolding scheme by omitting one exogenous construct at a time to detect its effect size on the change in $Q^{2}$ values. In the PLS blindfolding procedure, only the construct cross-validated redundancy (CV-R) in the "total" pane is the most needed value. The "1 - SSE/SSO" column indicates the value of the predictive relevance of the requested endogenous latent variable. The SSO is the sum of squared observation and SSE is the sum of squared prediction errors.

To illustrate the computation of the $\mathrm{q}^{2}$ effect size, for instance, and considering the path from personal attitude to entrepreneurial intentions, the $Q^{2}$ value of entrepreneurial intentions in Table 6.12 is 0.2639 . When the researcher deleted the personal attitude construct and rerun the blindfolding routine, the excluded $\mathrm{Q}^{2}$ value became 0.1167 . These two figures were then used to compute the $q^{2}$ effect size; similar to the $f^{2}$ effect size computation described in the last section, 
and the resultant $q^{2}$ effect size was 0.20 . This figure indicates a medium $q^{2}$ effect size. The study used the same procedure in computing the remaining $q^{2}$ effect sizes of the construct paths.

As can be seen, none of the paths to entrepreneurial intentions reported effect size that is within the acceptable threshold values. The paths from psychological factors to personality traits showed small $\mathrm{q}^{2}$ effect sizes. Other paths had a mix of small or no $\mathrm{q}^{2}$ effects as demonstrated in the last six rows in Table 6.13.

In summary, an assessment of the results of the structural model demonstrates that out of the three attitude factors, personal attitude factor had the strongest influence on entrepreneurial intentions. Next was the perceived behavioural control factor. Subjective norms factor was negative and insignificant. Between the two contextual factors, only perceived barriers construct reported a significant influence on entrepreneurial intentions; perceived support was insignificant. The influence of personality traits was greatest on personal attitude factor followed by perceived behavioural control factor but insignificant on subjective norms factor.

On perceived capabilities, however, this factor influences perceived behavioural control factor the most followed by personal attitude and subjective norms factors. In general, the structural model has moderately explained the influences of personality traits, attitude, perceived capabilities, and contextual factors on entrepreneurial intentions. In terms of total effects, the results suggest that the greatest effects on entrepreneurial intentions, in this order, come from personal attitude, personality traits, perceived behavioural control, and perceived barriers factors. The effects of psychological factors on the development of personality traits are most profound from the internal locus of control, risk-propensity, achievement orientation, and innovation orientations, in this order. The effects of personality traits on attitude, however, are most profound on personal attitude, perceived behavioural control, and subjective norms, in this order.

In considering the $\mathrm{f}^{2}$ effect sizes, results indicate that only personal attitude factor had a large effect size on entrepreneurial intentions whereas perceived behavioural control factor had a small effect size. The subjective norms, perceived barriers, perceived support, and perceived capabilities factors reported a no-effect size on entrepreneurial intentions. All the four psychological factors showed small effect sizes on personality traits index. In turn, personality traits index showed a small effect size on two attitude constructs but no effect on subjective norms factor. Perceived capabilities factor reported a small effect size on each of the three attitude factors. 
An assessment of the predictive relevance of the model indicates that all the five endogenous constructs reported above-threshold values for $Q^{2}$, thus demonstrating that the model paths are relevant and well-predicted by the seven exogenous constructs. The $q^{2}$ effect size, related to predictive relevance $Q^{2}$, indicates that only personal attitude factor had a medium effect size on entrepreneurial intentions, the other factors had no $q^{2}$ effects on entrepreneurial intentions. All four psychological factors reported small $q^{2}$ effect sizes on entrepreneurial intentions. Of all the three attitude factors, only personal attitude factor reported a no effect size from perceived capabilities to personal attitude factor. The other two factors reported small effect sizes. In the same vein, the $\mathrm{q}^{2}$ effect size from personality traits to attitude factors indicated small effects on personal attitude and perceived behavioural control but none of subjective norms factor.

Lastly and surprisingly too, results suggest that the levels of entrepreneurial intentions and the factors hypothesised as influencing entrepreneurial intentions among undergraduates from the two regions were statistically similar. This conclusion was based on the results of the PLS multigroup analysis. The study detected no statistically significant differences in the respondents' perceptions concerning the hypothesised relationships.

The study will now focus on the analysis of the qualitative data.

\subsection{Results of the qualitative study}

Four focus groups made up of 42 participants participated in this exercise. The researcher selected two groups each from the University of Calabar, Cross River State and the University of Uyo, Akwa Ibom State. Participants were from the faculties of social sciences, education, sciences, business and management, and arts. The four sessions took place in June 2014 at the resource centres of the two universities.

After verbatim transcription of the groups' interviews, the researcher printed and read the transcripts twice and began to highlight words and phrases that captured the attention. Transcripts of each focus group were copied to an Excel column. Three other columns were created to record the initial codes (or open codes) and the focused codes (or axial codes). The last column recorded the identification (pseudonyms) of the participants linked to the different quotes. The initial codes were given serial numbers, with their identification, according to the focus group questions. This procedure, therefore, helped the researcher to link the research questions to codes and to develop the themes used in writing the narratives below. The tables 
showing the responses of the participants and the codes used in deriving the themes and their identification are attached as Appendix 1.

\subsubsection{Results of qualitative study on the factors that influence entrepreneurial intentions}

One of the research questions posed during each of the four focus group interviews was: why do you think you are different from other students who don't have the assumed entrepreneurial mindset that you have? What is it that makes you think you should become an entrepreneur?

The data presented herein offer some insights into the participants' understanding of the drivers or influencing factors of entrepreneurial intentions. The importance of the groups' responses is that it seems to extend knowledge beyond what the earlier reviewed academic literature posits as the drivers of entrepreneurial intentions among students. The striking aspects of the findings are the different ways the participants expressed what influences them and how they think universities can stimulate entrepreneurship within their courses of study. Ten themes listed below emerged as the perceived influencing factors:

- Transformational Factor or the Desire to see Changes

- Affective Factors

○ Personal Fulfilment Motives

○ "Push" Factors

○ Barrier Factors

- Personality Traits

- Preference for Practical-oriented Teaching Approaches of Courses

- Preference for Experienced Entrepreneurship Teachers

- Preference for University-Industry Links

- Preference for Internships

A diagram summarising the classification of the themes is as follows: 


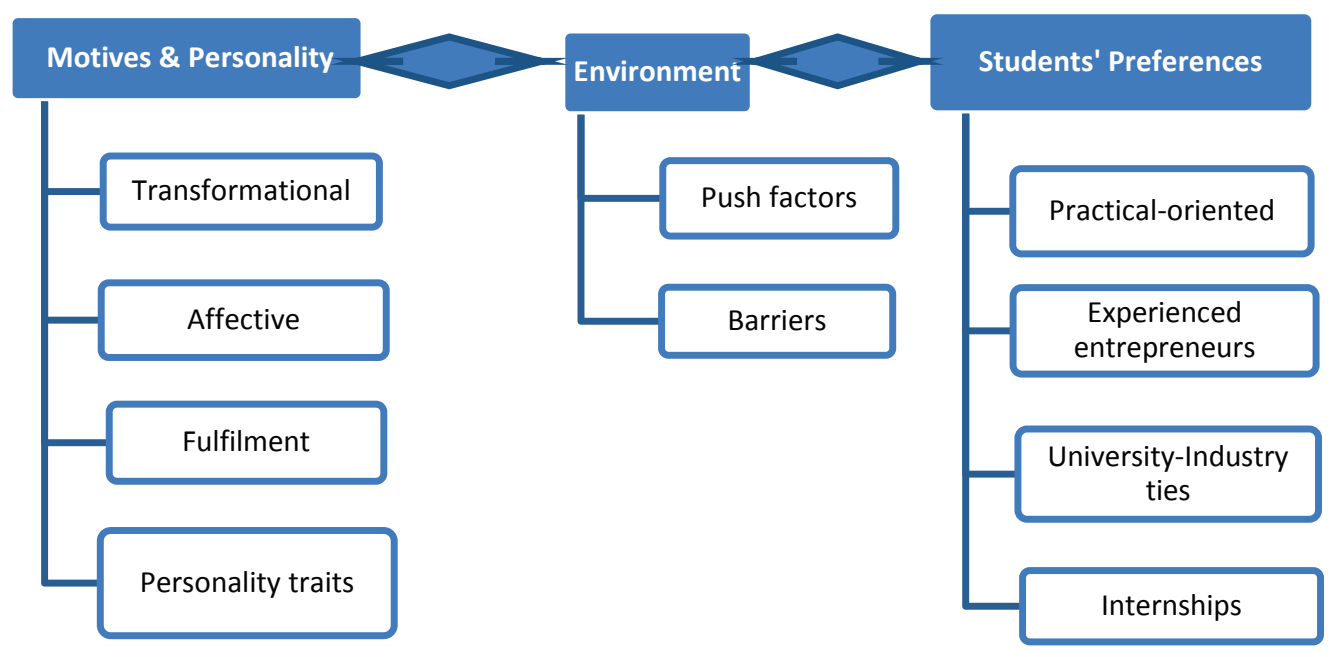

Figure 6.5: Classification of the themes

Figure 6.5 above indicates the three broad categories in which the researcher thinks the ten themes fit. The participants were influenced by personal agendas and their personality traits, the conditions in their environment and their expectations or preferences from their universities. The ten factors or motives were highlighted by the participants as driving their liking of entrepreneurship. Some factors were a discouragement (or barrier) to students' interest in entrepreneurship. Their first motive was the agenda to see massive transformations in the society to engender change in the different sectors of the economy. The second motive was the participants' passion ("affective") or preference for business as opposed to other career paths. The third was the motive to be personally fulfilled in life and this they thought can be better achieved by owning businesses and enterprises. The fourth was the "push factor" caused by the limited paid-employment opportunities in their regions thereby "pushing" them to opt for entrepreneurship. The fifth aspect was the barriers they experienced during their university days which militated against most students deciding for entrepreneurship.

The sixth motive was their personality traits that the participants believed naturally drew them toward entrepreneurship. The seventh was undergraduates' preference for practical-oriented approaches to teaching and learning of their courses. The eighth theme was the undergraduates' preference for experienced entrepreneurs as teachers. The ninth theme was their preference for stronger links between the university and the industry. The tenth theme was the preference for relevant internships in the various disciplines. These expressed preferences were what the students expected from their universities; they expected these to be in place to boost their interest in entrepreneurship. The following is a brief discussion of each of the ten themes: 


\section{1) Transformational agenda or the desire to see changes}

When the researcher asked the participants why they wanted to be entrepreneurs, many of the responses can better be described as being transformational or change agendas. That is, the desire to transform one's community. The desire to be beneficial to one's society was frequently echoed by the groups' participants. This desire aligns with the social entrepreneurship motivation (Renko, 2013). In their study of U.S. new business starters, Dunkelberg et al. (2013) compared entrepreneurs with wealth-motivated goals and those with non-monetary goals (including achievement and independence motivation). They observed that the latter invest more of their own (and their family's) time and money in their firm. Jayawarna's et al. (2011) study of UK entrepreneurs in deprived communities reported somewhat related findings that financiallymotivated entrepreneurs seemed impatient and made high debt investments, yet investing less of their own time. However, Renko (2013) notes that the challenge for beginners going first into social entrepreneurship can be daunting. The reason is that they appear to face particularly difficult legitimacy challenges and may struggle with attracting funding especially in developing countries and also in securing sales.

Participants expressed strong feelings of desiring to see improvements of their economy, to create positive influences, and to create impacts through job creation. These opinions were vividly expressed by the participants in the focus groups:

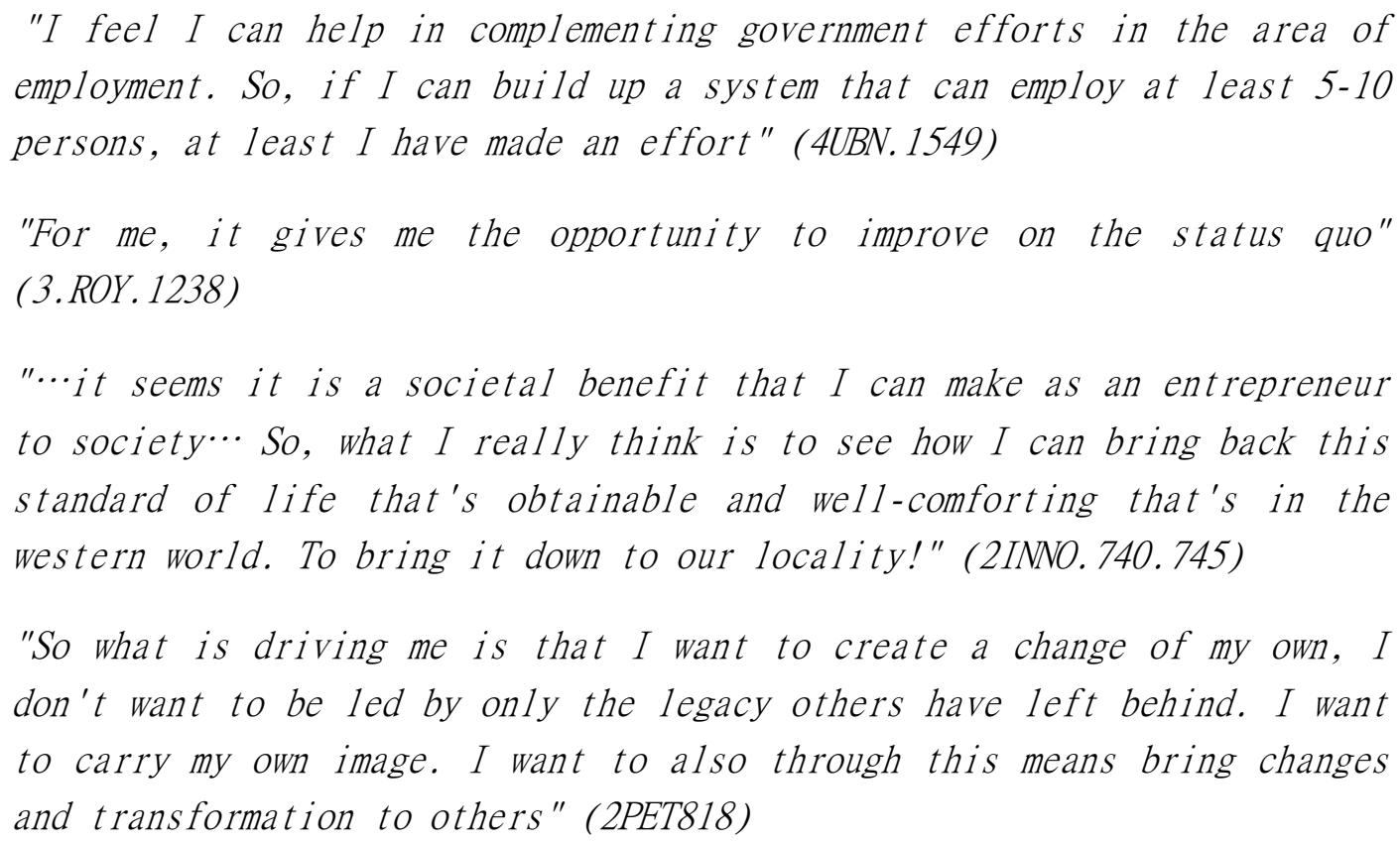

Participants in focus groups two, three, and four expressed similar feelings for seeing the society transformed. The pattern shown by these participants was that of enthusiasm that characterises 
youthfulness. They have a passion for bringing transformation into their society. Their expressions suggest that if there are the appropriate environment and incentives, undergraduates are willing to contribute to the changes needed in their communities. They wish to do this through their future businesses.

Related to the passion for bringing transformation is a passion for raising the quality of decisionmaking processes in their community. In group four, the participants expressed the opinion that the motivation to add to the transformation of the society and improve the quality of decisionmaking was a driving force. One mature participant captured this drive in the following words:

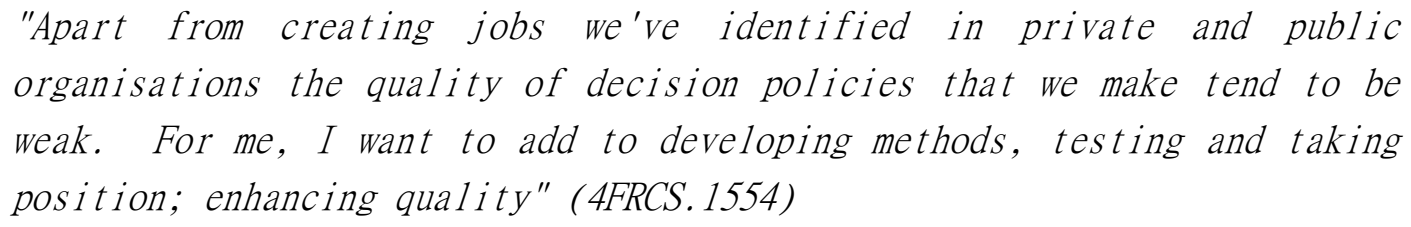

The statement above, therefore, suggests that the undergraduates are willing to make positive differences through business creation.

\section{2) Affective factors}

The affection for and choice of business as a career path to achieving one's independence or autonomy have been captured in the literature (Stephan et al., 2015; Renko, Kroeck and Bullough, 2012; Friedman et al., 2011; Jayawarma et al., 2011; Reynolds and Curtin, 2008). In a metaanalysis of what motivates entrepreneurs, Stephan et al. (2015) for example, found that seeking independence and autonomy were the most important motivations proclaimed in the group of nascent entrepreneurs more likely to create high-impact, growth-oriented businesses. This factor was followed in importance by wealth-creation motive. Reynolds and Curtin (2008) had related findings for the U.S. in the PSED I and II studies. They found that women put slightly less emphasis on achievement, income/wealth and reputation motives but a slightly greater emphasis on a liking for autonomy and flexibility.

Participants in groups two and three perceived they were driven by their love for business since the business could help them achieve the change they want. Many of the participants love autonomy. They believe that having their own business can give them space and freedom to manage ("own") their time and life. They also believe this freedom can offer them the opportunities to explore new things for themselves and the society. Some of the participants were of these views as expressed in the selected quotes below: 
"...it is the love I have for entrepreneurship because I'll have the opportunity to be my boss. I can divide my time to suit me, for my family" (2STEV.800)

"For me, it is the love to do something I like. Change! Not just skill acquisition" (3EMI.1245)

"It's because of my passion for business" (2J0S. 709)

"For me, I have this passion for new things. Innovation" (3BLE. 1221)

These expressions indicate that undergraduates sought to showcase their freedom by being in the career options they love. They believe this can better be achieved by being their bosses.

\section{3) Personal fulfilment motives}

The participants also expressed the motive to be personally fulfilled in life as being the driving force behind their intentions of entrepreneurship. Most people want to be materially rich through the means of profit-making offered by making successes in various businesses. It was Renko et al. (2012) that linked an individual's prior start-up motivation to firm emergence. They noted that this initial motivation energises the potential entrepreneur to make some efforts willingly. They found that financial success (from business profits) motivated people to make efforts. Jayawarma et al. (2011) also corroborated this observation and added that financially-driven entrepreneurs tend to experience "comparatively" high growth eventually.

Some participants believed that job satisfaction can better be achieved by owning their businesses. They believed this could also lead to personal fulfilment in life. Participants stressed that the routine civil service job was detestable and boring. Some expressed a desire to be influential in life and society as their motivating factors. The following selected quotes captured the groups' feelings in this area:

"The phobia for civil service, that's what I call "modern slavery" I'm afraid of that. And the love for doubling profits" (General laughter) [2ROL. 771]

"One has to do with the natural traits in me. I've grown up to understand that every human has $\cdots$ Actually, if I'm dashed 200 naira, I see it as a seed to be sown to make profit. That one is in me" (4KAT.1573)

"... I found that you can never be rich working for someone; until you take a risk and establish your own enterprise. So, I decided to quit my 
job, back then, tried to put together some cash and started business.

Now, I feel relieved" (4SHER.1560)

"Socio-economically, I see an entrepreneur as being more influential, I

don't believe in political power too much; I don't believe in office work

(civil service)" (4KAT.1581)

The drive to have material wealth and influence was a recurring expression of different participants in the focus groups. The conclusion could be that the undergraduates are motivated by a desire for own profits, which they believe could give more personal satisfaction in life.

\section{4) Push factors}

Research sometimes associates necessity entrepreneurship (or "pushed factor" entrepreneurship) with lower entrepreneurial skills or slow-growth (Jayawarna et al., 2011; Block and Sandner, 2009). Sometimes individuals are pushed into certain career paths, not of their volition but by circumstances within their environment (Stephan et al., 2015; Vanevenhoven, 2013; Gilad and Levine, 1986). These kinds of entrepreneurs are the "necessity" entrepreneurs as opposed to the opportunity-induced entrepreneurs. Although going into entrepreneurship because of necessity can lead to less-successful, low-growth or no-growth businesses; however, Stephan et al. (2015) has argued that this might not always be true. There might be instances, for example when an economy grows more, what started as necessity entrepreneurship creates more opportunities for people to exploit thereby resulting in more improvement-induced opportunities.

Also, skills and motivation may change over the process of starting a business and running it (Cassar, 2007). Thus, entrepreneurs can learn how to run a business, and this can turn around and influence the entrepreneur's motivation. Therefore, for some individuals at least necessity entrepreneurship may be a way for venturing into successful entrepreneurship, most especially in the developing countries because of the stage of economic development. However, this is not the best drive toward entrepreneurship; it is most often preferable to choose entrepreneurship because of the drive to exploit created or existing opportunities.

Being pushed into entrepreneurship was suggested in this study. Some participants expressed the notion of being driven into rethinking entrepreneurship because of the lack of lucrative job opportunities. Therefore, some participants were being pushed into entrepreneurship by the prevailing unemployment situation. The following selected expressions portray this situation among the participants: 
"For me ... I'm the black sheep among the goats. I don't see anything especially different about being an entrepreneur. As to my personality I don't see anything spectacular becoming an entrepreneur. Basically, I feel it is lack of job opportunities. Also to maximize profits" (3ADA.1234)

"...So when I got home, I felt bad because I wasn't chosen. I thought of what to do to get a living because the problem of unemployment is so much in Nigeria!"(1HAP.135)

As can be seen, one of the participants saw himself as the black sheep of the group. By this statement, he meant that he disagreed with others who thought there was something special about them that led them to becoming entrepreneurs. Rather, he saw the drive toward entrepreneurship as being necessitated by the inadequate lucrative opportunities in the job market in Nigeria. His other push is profit making. Stephan et al. (2015) note the role of income security and financial success that a successful entrepreneurship could bring. Other participants decided to go into entrepreneurship having been unable to get jobs from their previous job applications.

\section{5) Barrier factors}

Zahra and Welter (2008) show in their European (central, eastern and south-eastern) study how significant cultural, legal, political and institutional forces can constrain entrepreneurship in a country or region. They also indicated how entrepreneurship education can play a positive role in creating momentum for change. Problems range from lack of qualified teachers, to the approach and teaching methods that negate interactive and action-oriented methods, to limiting entrepreneurship education to only HEls, and not considering that entrepreneurship is deeply embedded in national cultures and draws upon the previous experiences of individuals and their societies.

In the present study, the participants in all the groups seem to be expressing some level of discontent toward the manner in which certain factors in their universities have discouraged students from entrepreneurship. KAT saw the problem of inadequate education on entrepreneurship. HAP spoke of the lack of targeted training such as marketing and sales. OFF believed there is over-taxing by the government; PAT believed there is a lack of information, in general, and INI saw the problems of mindset. Other barriers mentioned are the lack of sources of borrower-friendly capital and the fear of starting. Participants felt that their universities should 
have identified, mitigate or adequately address these setbacks if universities want to encourage them toward entrepreneurship. The following selected quotes illustrate this opinion:

"The school, the study I've taken for the last four years now has not prepared me adequately to be an entrepreneur the problem is fundamental .. in fact the entire structure of education of the country from primary to secondary education" (4KAT.1688)

"I don't even know how to start it. So, something like training on that aspect because that's the problem some of us are having; on how to start, to remove the fear from us. Fear of how to start" (1HAP.451)

"I usually hear the complaint about high tax; that it is a problem in Cross River State; it's a problem in the country, that the government is taxing more than necessary" (1OFF.503)

"I'm not disagreeing with HAP; another problem is knowledge of where to get the loan" (1PAT.350)

"If you can solve the problem of the mindset of students here..." (1INI.295)

"For the graduates, some don't have the financial ability" (3HAPP. 126)

"So, I want to say that it's not always easy to be an entrepreneur. It's so hard to start $\cdots$ But my problem now is how to start and where to start this business" (1HAP.116.119)

Therefore, undergraduates see the lack of capital, lack of proper education and targeted training, and over-taxation as a discouragement to students' entry into entrepreneurship. Others believed the lack of good information in general; the problem of wrong mindset about business, and the harsh business environment in their regions are serious barriers toward undergraduates' entrepreneurship career choice and interest.

\section{6) Personality traits}

The individuals' personality traits may have some indirect influences on their business-founding intentions by influencing their attitudes (Ajzen, 2005; Krueger et al., 2000; Krueger and Carsrud, 1993). Although personality traits alone would not lead an individual to successful entrepreneurship, traits must be combined with skills, education, motivation, favourable regional business environment, and other institutional factors (Stephan et al., 2015). It resonated within the groups that participants see themselves as having certain inborn traits that attracted them 
toward business. Some saw themselves as being creative, risk-takers, innovative, independent, and achiever-minded. Research shows that achievement mindset can lead to founding and running businesses as well as high business growth eventually (Jayawarma et al., 2011). The following quotes exemplify the participants' beliefs about traits and entrepreneurship links:

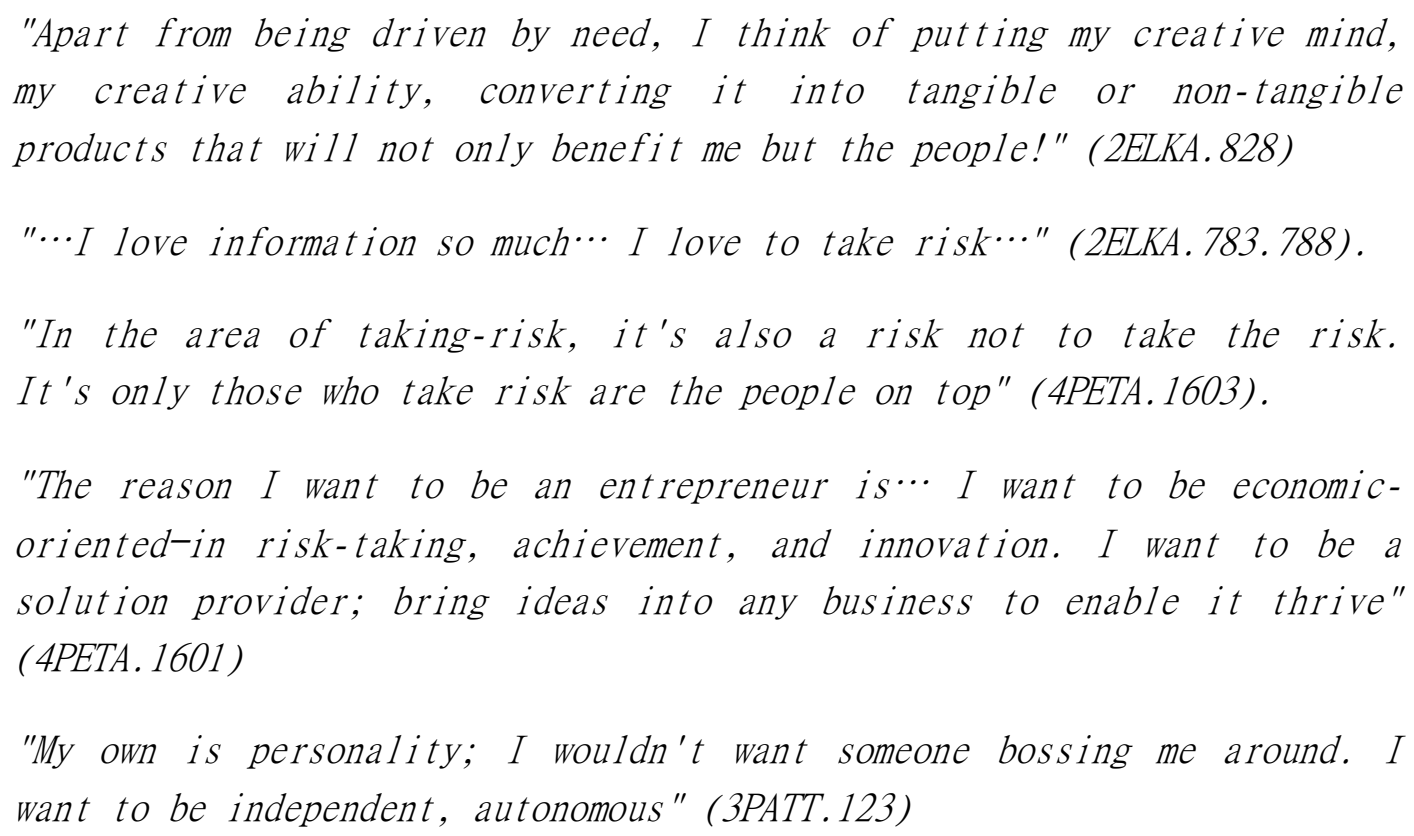

As can be seen, undergraduates believed that their personality characteristics also contributed to their decision of entrepreneurship. Although ADA had earlier refuted this belief this was not the popular feeling among the participants. Undergraduates rather saw themselves as being "pulled" by their creativity, crave to be innovative, risk-taking tendencies, crave for independence and need for achievement.

\section{7) Preference for practical-oriented teaching approaches of courses}

The participants' desire to see their courses have more practical contents was the most enthusiastically expressed theme in the four focus group interviews. By word counts, the participants used the word for between 40-47 times during the four interviews. This count shows the importance the participants attached to universities making conscious efforts to bring practical elements or applications to the courses and disciplines. Zahra and Welter's (2008) study have noted that one of the challenges of academic institutions is her theoretical/abstract knowledge. They suggest that institutions should engage local entrepreneurs as role models and source of feedback learning. In a recent interview, the Vice Chancellor, University of Lagos, Nigeria also acknowledged the role of practical applications when he said: 
Secondly, we should focus on skills acquisition in our programmes. Without skills, people could pass through the universities and still end up without being able to offer any service. You create jobs by deploying the skills and knowledge that you have, and expressing them in the form of a service or product... You go to school to broaden your knowledge, but you must have something that you can translate into practical expression in the form of product or service (Bello, 2015).

For instance, many participants indicated the desire for practical applications of their learning giving the following views:

"I read electrical/electronic engineering. What we've been taught in school most times is theoretical, not practical" (4UBN.1616)

"I think it is the course of teaching only theory without practical that deters students' interest" (3FATT.1279)

"..make the course you're studying more practical; you're going to have more entrepreneurs in the society" (1INI.295)

"There's a centre for entrepreneurship, but they should make it more of practical" (1AUS.382)

"Like we have many practical sessions that after graduation, you don't even need to go and meet anybody to employ you: the mortuary, embalming section, making of slides and models" (IPAT.461)

"Ask me, in this school, next is the centre for entrepreneurial development, I've been in this faculty for the last four years, I've never stepped in there, there are no workshops, no symposium. You only do it in names" (4.KAT.1714)

"... Like they'll come to class, teach you just the theoretical aspect of it, if you're asked to do the practical aspect of it, you can't do it" (1PAT.90)

Participants enumerated how the non-practical nature of their course contents had acted as a disincentive to interest in entrepreneurship. A balance on the issue of theory and practical contents of university programmes, however, is what Bello (2015) captures saying that "tertiary education is founded on theory. Without theory, there will be no practical application. We need theories to guide our reasoning and define the framework of our academic pursuit and teaching. We need theories to guide our reasoning and define the framework of our academic pursuit and teaching." 
It is a common belief in the entrepreneurship circles that all the courses offered in the universities; all have potentials for start-ups, for creating businesses (Duke, 2006). For example, even someone from English and Literary Studies (ELS) can be an editor, help people in learning standard written English like those needed for newspaper publications, or in international English examinations. An ELS graduate can create a business around that area: can be a copywriter, a proof-reader, or can create a business around these fields. So, irrespective of the course, the objective of the entrepreneurship course in Nigeria was to give undergraduates the skills so that they can create something around their subject discipline. But the participants' experiences suggest that the goal of the entrepreneurship course seems underachieved given the following quotes:

"Even that one is just theoretical, no practical applications. Some lecturers come once or twice in a semester; no one will teach you once or twice and expects you to go out there and practice what you're being taught. So, even the course itself is nothing to write home about; it's useless!" (3PATT.1340).

"In tourism management, they're teaching me tour guide, when I go out, I don't even know it just because you were teaching me in the classroom. So, they should be practical about everything than theory" (3HAPP. 1374)

"Like in marketing sometimes I think we are supposed to have like fieldwork, from there you'll learn the practical aspect of what you're doing" (2LAW.860)

"..But this is business faculty where everything centres on business; I think.. we never got any discussions, any practical, any anything from the centre on what we are being taught" (4KAT.1718)

The inference from these group interviews is that there is more to do in the entrepreneurship course in the universities than what is done at the moment if universities desire to see students change their mindsets toward the course. Perhaps, the universities should locate a model that has worked well in other universities and adapt such a successful model for her entrepreneurship development programmes.

\section{8) Preference for experienced entrepreneurship teachers}

To encourage students' interest, students advocated improved quality of teaching and learning of the entrepreneurship development course. A very enthusiastic female participant stressed that if she had the opportunity to sit with the vice chancellor of her university her advice will be " $\cdots V C$ should also send the lecturers teaching this course for an advanced retraining 
so they can be effective" (4KAT.1735). She expressed the need for a restructuring of the course delivery method to accommodate experienced entrepreneurs as teachers or facilitators. The reason is that most of the present teachers of the entrepreneurship course did not have practical business experience and so find it hard to make useful contributions to applicable examples during their lessons.

Zahra and Welter (2008) note for the business schools in European OECD countries the problem of universities making little use of former entrepreneurs in teaching. This tradition is unlike the U.S. business schools, where practitioners and former entrepreneurs are well represented in the classroom. They act as teachers, guest lecturers, or executives in residence who counsel the faculty, students and the administration concerning issues of entrepreneurship curriculum. Increasingly, however, the OECD countries are copying the U.S. model, where more and more entrepreneurs and managers are being recruited to teach entrepreneurship in Europe, where university regulations permit. This trend mirrors a growing recognition of the value of practical experience in teaching entrepreneurship; it also signals a serious shortage of qualified faculty who can teach entrepreneurship in the universities so as to change students' mindsets.

To encourage an entrepreneurial mindset, KAT offered a practical insight that students' talents should be discovered at their budding years. The researcher found that a private university, Afe Babalola University ${ }^{11}$, Ado-Ekiti, Ekiti State, Nigeria is implementing this concept of talent discovery and has a Centre for Talent Discovery on her campus. Other universities can also work out the details of implementing their own talent discovery concept and help add value to students' start-up intentions. When talents fail to be discovered early enough so that students could be properly guided to realise goals, it leads to frustration and career mismatches. This discovery of talents requires teachers with experience. KAT expressed her frustration regarding the failure to discover her talent. She said: "now, the primary school failed me; the secondary school failed me; now, I found myself in the higher institution, I was simply failed as well. I think the universities.. just like he rightly said, the lecturers will only give you what they have; the same structure that produced them" (4KAT.1707)

To enhance the capacity of learning entrepreneurship so that it will help the learners to use it in the real life, the participants believed that their teachers should be persons who have working

${ }^{11}$ Available at: http://abuad.edu.ng/?s=Talent+Discovery+centre. (Accessed: 27 July 2015) 
knowledge and experience in their fields. This was the desire of the participants in groups three and four as follows:

"..'some lecturers have tried, but it's mostly theoretical than practical. To help us know how to solve problem, ideas, discipline, etc. we need something more than from your textbook; we need real life challenges and situations." (3ADA.1388)

"But the major problem is that the school management or lecturers at the initial stage did not inform the student, number one, and those courses you're taking from year 1, 2, 3: given us disjointedly, it's supposed to be something that flows" (4SHER. 1642)

Therefore, experienced and successful entrepreneurship teachers will more likely encourage students in seeing business as one the viable career options.

\section{9) Preference for university-industry links}

To encourage the application of learning to life world cases, the participants in the fourth session were enthusiastic about universities having healthy collaborations with the relevant industry practitioners. They stressed that many businesses and organisations are formed from the links universities have with industry. Some firms are those established by university alumni. Potter (2008) notes how this collaboration would enable universities tap into the resources of alumni networks to help fund and support entrepreneurship programmes, for example, by providing teachers and links to companies for placements and mentorships. Also, vibrant collaborations would facilitate access to common materials and sharing of good practice by favouring networking among universities, industries and teachers and providing support for the inter-institution mobility of entrepreneurship teachers. Therefore designing and maintaining vibrant links with these sources can create ways for current students to apply their knowledge, and they can create their business ideas from such collaborations. The following words express these views:

"Whatever lecturers are giving in the university, it's not the place of the lecturer to relate himself to the industry. The programmes of the university have not been designed such that the lecturers have exposure of what is helping in the industry. They only give you what they know" (4FRCS. 1666)

"We've not gone for any industrial attachment. I have a sister in Chemistry who went for industrial attachment only for two weeks; what 


\section{will you learn from a factory in two weeks? So, I want to say that the entrepreneurship arrangement here is poor" (4KAT.1721)}

Thus, the need for universities to explore how to develop and sustain the links with the practitioners in the various economic sectors can be a motivating factor for developing students' interests in entrepreneurship further. However, university administrators do seem to be very much constrained in this aspect as reported by Bello (2015) who said: "The reality though is that we have been operating under very severe constraints imposed by deficits in infrastructure and this deficit is both in the institutions and the industry. When you talk about practical exposure, you must have the facilities to practise what the theory has provided. That is what has been lacking in some areas."

\section{0) Preference for internships}

Research has long acknowledged the practical experience from the provision of internships for students as one of the short routes to applying theoretical and intellectual knowledge to business formation and growth (Zahra and Welter, 2008). The absence of or the lack of well-coordinated internships or student placements for practical knowledge were perceived as serious barriers to interest in entrepreneurship. The participants stressed the usefulness of universities providing relevant internships in all disciplines. This route is to provide an avenue for gaining practical knowledge of one's field. Participants in focus group two stressed that many companies refuse to employ graduates sometimes because graduates lack practical experiences. Internship can be a means of bridging the experience gap. The following quotes expressed this opinion:

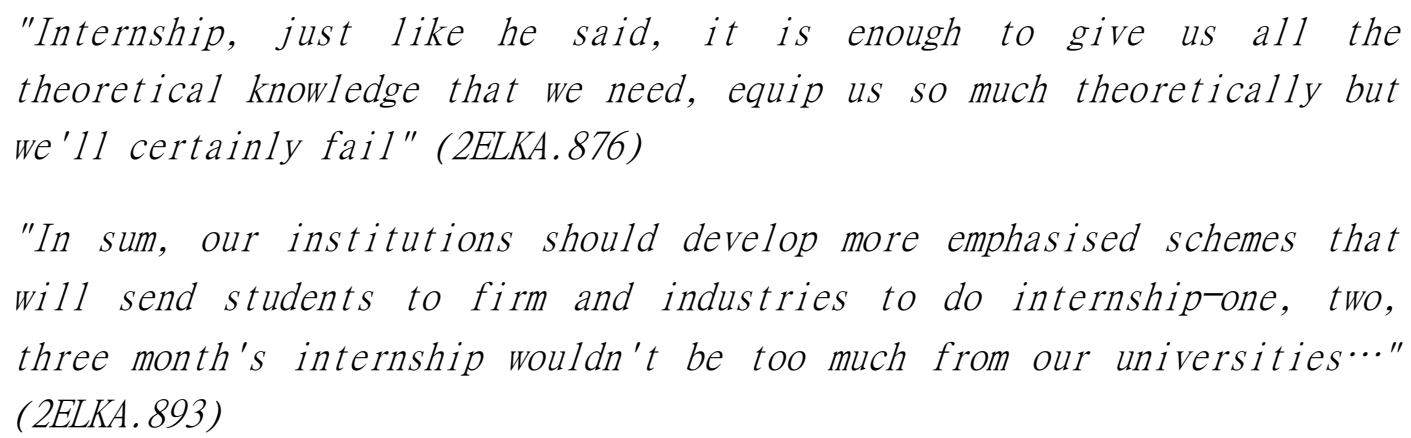

As can be inferred, it follows that if undergraduates have the opportunities to gain experience during internship schemes, more so in the areas relevant to their intended entrepreneurial activity; most could develop interest in further using their gained experiences to create their businesses. There are some cases where discoveries, sometimes in the sciences, technology and ICT sectors, are being made by fresh minds from the universities who were attached to work as interns. Therefore, universities should first provide the opportunities. 


\subsubsection{Results of qualitative study on whether there were regional differences or not}

The other central question was to assess the perception of entrepreneurial differences or similarities between the South-south and Southeast people. The question was to help understand the participants' perspectives and help the research address parts of the fifth and sixth research objectives. The question was: take a look at the people of South-south states. Take a look at how they do business, the way they like or dislike business. Take a look at their attitude and all that, and compare that with people from the Southeast states (Ibos). Look at their behaviour toward business and the experience you've had with them, these two regions, do you think there's anything different or similar about their business attitude? Why do you think so? Two primary themes emerged from the interview results on this subject, namely: differences in culture and differences in the business alertness.

\section{1) Differences in culture}

The participants perceived that the culture of the Southeast people was probably more favourable toward entrepreneurship compared to their South-south counterparts. Milner (2012b) notes that a society with a high percentage of people willing to take risks by not looking for paid (predictable and stable) incomes is a differentiating indicator of good entrepreneurship cultures. It also showed that an ambitious attitude, preference for self-employment, passion about one's work, and crave for success in business to make people recognise one's achievements are all indicators of good entrepreneurial cultures. Good entrepreneurial cultures also depend on access to role models in terms of having close family members such as parents who had started businesses as well as knowing someone who has set up a business or is self-employed over the last three years. From the analysis of the participants' perceptions in preference of the Southeast people, factors that more likely distinguished the two regions included mindsets such as a preference for independence, industry, early childhood introduction to business, communal serial mentorship and apprenticeship, persistence, and who the society upholds as successful. The following verbatim words portrayed these opinions:

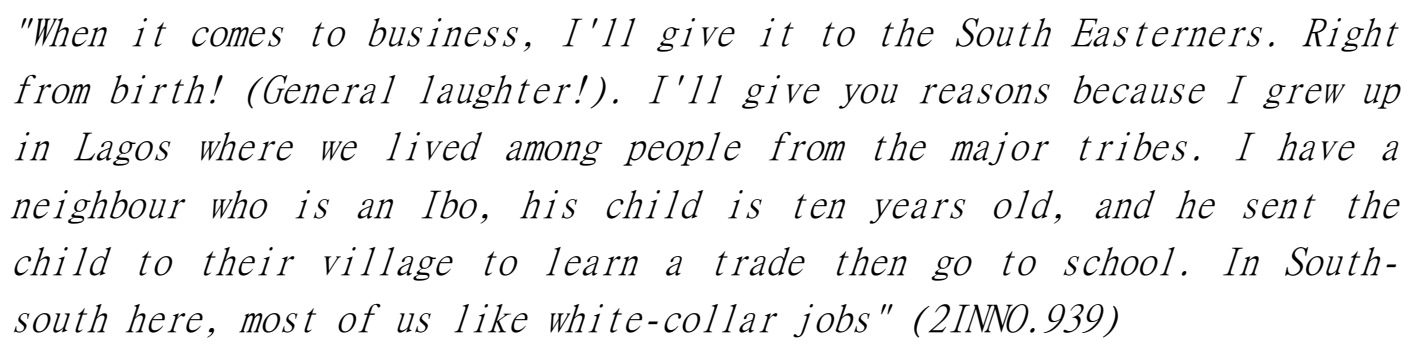


"I think it has to do with culture-the way of life of the people. The Ibos' children grow up to see their parents being businessmen, so some of them will go to become also businessmen because they've been in the family, they learn the trade from them" (2JOE.951)

"...That's why if an Ibo man takes his child to the village, even if he's going to university, the child will still know what is going on in the family shop" (3ROY.1453).

It follows from the above narratives that certain culture and orientations may probably have distinguished the Southeast people from their South-south counterparts. From the above expressions, INNO, JOE, and KAT captured these perceived cultural differences. It might be helpful for one to take a more critical look at the underlying cultural features that influence entrepreneurship exhibited by the Ibo communities in Nigeria (Halliru, 2013).

The Ibo people also seem to imbibe the culture of "community." They take more pride in brotherhood than do most communities; thus more often wanting to help one another in business than it is in many Nigerian communities. This spirit seems to make the practice of serial mentorship and apprenticeship very common among the Southeast people (Halliru, 2013). UBN in focus group four put it this way: "The two are different. The Ibos' method of business is that they always pass through serial mentorship. Someone will be under somebody for many years, learn a trade and graduates; a similar business is handed over to him as a settlement. So, that mentorship is there" (4UBN.1777).

The Ibo people seem to demonstrate being relatively much more ambitious. The pressure for success in their communities makes them want to work harder to achieve success in businesses. They want to produce whatever they can even if it is starting with imitation and inferior quality products. They use this process to learn the trade and to improve the quality. Participants stressed this notion when they said:

"...and I hear culture, I accept their quest and desire for things, and most times money is very high. And the only way they think they can realise this cash they're in need of it, without anybody cheating or playing on them, are to go into business. In the end, I see them realise the goals. This profit motive drives" (2PET.993)

"When we talk about culture, Ibos they generate from their culture... Now, what we lack in the South-south is that knowledge of business!" (2LAW.984). 
The south easterner sees something from, say, America; he'll like to produce such. Imitate it. When they bring it down to the South-south, we'll say it's imitation, "Aba-made" (3HAPP. 1431)

Thus, these traits and many more that the participants stressed seemed to distinguish the people of the two regions. As mentioned earlier, undergraduates from these two regions were perceived to be more likely going to toe a similar fashion.

\title{
2) Differences in business alertness
}

There was a wide acceptance as well as perception by the participants that the Southeast people were comparatively more profit-motivated in most of their endeavours. These people were more likely to focus on meeting the needs of customers better than it would be undertaken by most South-south people. This notion was illustrated by this male participant in focus group four, UBN:

\begin{abstract}
"The attitude of a businessman from the South-south is not "customercentric" or "customer-centred." They treat customers like chaff $\cdots$ If you go to buy something, say a shop, they might expect you to get them the change (balance). Whereas a typical Ibo man, for instance, will go the extra mile making sure the customer is pleased, make you happy, etc. Before you know, you've given him all your money (purchased)" (4UBN.1769).
\end{abstract}

Even though most people consider starting a new enterprise a desirable career option, however, Milner (2012b, p.112) notes that it is a society in which "those successful at starting a new business have a high level of status and respect" that indicates good entrepreneurial culture. A female participant captured Milner's thought on this when she said:

"They have this natural knack for business than us. We here, it is education, academic preference. No matter how you make it in business here, as he rightly said, you may not be respected, except you're sitting down in one ministry or handling one government whatever. Prestige is more in academia and paid work than in business for a typical South-southerner. So, this seriously discourages people; people take business as a second fiddle to just make up, a substitute" (4KAT.1818).

In terms of production, the participants stressed that the Southeast people's love for manufacturing makes them more likely to be proactive in seeing that they fill the peoples' needs. On this matter, JUD said: "They have this love for it. Two, instead of believing they 
have to go and buy this thing where people are in need of, they believe they can produce it" (3JUD.998). Patience and risk-bearing propensity were the other aspects of business consciousness that seem to differentiate the Southeast people from their South-south counterparts. The psychology of individuals who would make it through the uncertainties of business can be inferred from the following comments about the Southeast people as opposed to others:

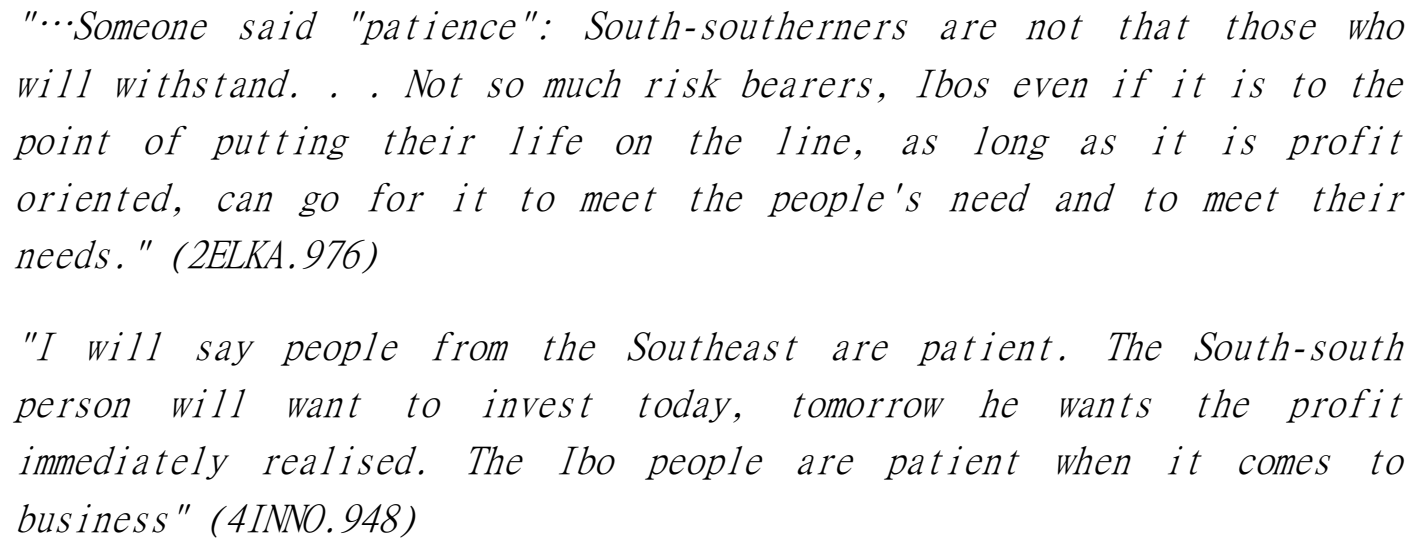

In all, there was a consensus by the groups' participants that whatever they said concerning the perceived differences, will translate to the following conclusions: that the "attitude of what you see out there as exhibited by the Southeast people (non-students) is likely going to be the same attitude that would be exhibited by their Southeast students? And same is likely going to the South-south people and their students?" Therefore, the question of the factors that account for such pattern variation opened up the subject of further inquiry.

\subsection{Integration of findings}

This study will discuss and integrate the findings of the quantitative (numeric scores) and qualitative (texts) phases more in the discussion chapter (Harrison, 2013) that follows as indicated earlier in Section 5.5 and discuss any apparent contradictions. The study examined the factors that influence entrepreneurial intentions of students in two separate regions in Nigeria. It assembled and interpreted both the quantitative and qualitative data collected. Findings from the quantitative study highlighted the statistically significant factors believed to drive entrepreneurial intentions the most among the participants. These included personal attitude toward enterprise, perceived behavioural control over situations, and perceived barriers that are constraints.

The qualitative study found additional factors that were silent in the most literature reviewed. These include: transformational or change factors, personal fulfilment motives, and push factors, preference for practical-oriented teaching approaches, preference for internship experience, 
preference for experienced entrepreneurship lecturers, and preference for university-industry collaborations. The multi-group analysis in the quantitative study indicated no statistically significant differences in the factors assumed as influencing entrepreneurial intentions among participants from the two regions. The qualitative study, however, found that the participants perceived that the Southeast people were different in their culture and consciousness toward entrepreneurship. Specifically, they were perceived to be largely influenced by a preference for independence and autonomy, industry, early childhood invitation to business by the family, and serial mentorship and apprenticeship. Others include persistence and consistency and in who their communities hold as being successful. That is; they see business people as the most successful as opposed to their South-south counterparts who somewhat regard more formal paid job and office holders as successful people.

The creative usefulness of the mixed methods research comes to the fore by these related but dissimilar multi-findings. It combines the research traditions of postpositive and social constructive worldviews to examine a research subject in a manner the author thinks is comparatively holistic. It makes more sense of a seemingly complex and multi-faceted issue.

\subsection{Credibility and trustworthiness of the results}

Electronic copies of the developed themes, interpretations and the conclusions reached by the researcher were sent to the interviewees for verification. After two reminder emails, most interviewees responded. Among those who responded, no one objected to the conclusions presented in the preceding sections as reached by the researcher. Moreover, the final piece of the analysis was read by the researcher's supervisory team and every feedback provided an avenue to improve on the research. The researcher also presented the findings to an entrepreneurship research community at the 5th George Washington Annual Entrepreneurship Conference. This conference held in Washington DC, the USA on 16-18 October 2014. It received favourable feedbacks from researchers. The researcher, therefore, maintains that making this work available to others for verification and feedbacks increased the credibility and trustworthiness of the research.

\subsection{Summary of the chapter}

This chapter reported the quantitative and qualitative results and indicated the main factors that encourage or discourage undergraduates' entrepreneurship intentions. In the qualitative study, personal attitude, perceived behavioural control, and perceived barrier were the most significant 
factors. The qualitative study, the focus group interview results found new themes such as transformational, affective, push and personal fulfilment motives. Also, it indicated that undergraduates would embrace entrepreneurship if courses were more practical-oriented than theory-oriented. Also, if they had appropriate internships introduced into their courses, experienced entrepreneurs taught them and presence of healthy collaborations for relevant industry practices.

The partial least squares multi-group analysis detected no significant differences in the perception of the influencing factors among the two student groups. This finding came from the statistical results of the model paths. Conversely, participants in the focus groups consistently demonstrated that they see the Southeast Nigerian people as exhibiting a peculiar flair for entrepreneurship. The participants offered various explanations to back up this perception. The perceived differences are more or less in the areas of practice of apprenticeship and serial mentorship, preference for independence, and early childhood introduction to business by the family, which could encourage continuity. Participants also perceived that graduates from the two regions may more likely follow this same observed pattern in their entrepreneurial endeavours.

In the next chapter, the author discusses the entire results and relates back to the research objectives. 


\section{CHAPTER SEVEN}

\section{DISCUSSION OF THE FACTORS THAT INFLUENCE ENTREPRENEURIAL INTENTIONS AMONG UNDERGRADUATES OF SOUTH-SOUTH AND SOUTHEAST NIGERIA}

\subsection{Introduction}

In the last chapter, the quantitative study showed that the personal attitude, perceived behavioural control, and perceived barrier constructs were the most important factors that influenced undergraduates' entrepreneurial intentions. The study also reported and interpreted all the other requested tests including the multi-group analysis. In the qualitative study: transformational, affective, barriers, push, personality traits, and personal fulfilment motives were reported as influencing undergraduates' entrepreneurial intentions. Participants in the focus groups also revealed additional factors they perceived would encourage entrepreneurship.

This chapter, therefore, integrates and discusses these findings (quantitative and qualitative) in detail and relates them to the extent of agreement or disagreement with previous studies reviewed in Chapters Two to Four. It relates the findings back to the research objectives earlier stated in Chapter One. The main goal here is to answer the research questions and address the research objectives that needed data for empirical verification. Thus, the next subsections discuss the specific objectives, which were stated as follows:

1) To examine the historical contexts of entrepreneurship development in Nigeria (Chapter Two);

2) To examine the literature in the context of entrepreneurship education (Chapter Three);

3) To critically examine the theoretical and empirical literature on entrepreneurial intentions (Chapter Four);

4) To develop a conceptual framework based on the key influencing factors of entrepreneurial intentions identified in the literature (Chapter Four, Section 4.3);

5) To empirically examine the factors that influence entrepreneurial intentions among indigenous undergraduate students of the South-south and Southeast regions of Nigeria (Section 7.2.1); 
6) To empirically examine the extent of similarities or differences in the hypothesised factors that influence entrepreneurial intentions among indigenous undergraduate students of the South-south and Southeast regions of Nigeria (Section 7.2.2); and

7) To explore the issue to know further how students "make meaning", explain or "think differently" about the factors that influence the creation of businesses (Section 7.2.3).

Objectives one and two, however, were handled in Chapter Two and Chapter Three respectively while objectives three and four were addressed in Chapter Four. Objectives five, six and seven are the subjects of the next discussion.

\subsection{Discussion of the empirically-researched findings}

The primary goal of this mixed methods research was to examine the factors that encourage or discourage entrepreneurial intentions among undergraduates in South-south (the Ibos) and Southeast Nigeria. It found that the personal attitude, perceived behavioural control, perceived barriers, transformational, affective, push, personality traits, and personal fulfilment motives were the most direct influences on the participants' entrepreneurial intentions. The undergraduates' preference for practical-oriented approaches to teaching and learning of their courses rather than simply theories was another identified factor from the interviews. Others factors included: the preference for relevant internship experience; a preference for being taught by entrepreneurship lecturers who have some level of enterprise experience, and healthy ties with industry practitioners.

The quantitative phase which examined the participants' perception of the factors that influence their entrepreneurial intentions also indicated no significant differences among undergraduates from the two regions. This result suggests that the hypothesised factors were the same for the two regions. This finding is intriguing and surprising. One of the possible reasons for finding "no differences" in the factors that influence entrepreneurial intentions between the two groups may be that the new generation may have changed their perceptions concerning what used to be the "old beliefs" about entrepreneurship imbalances between regions of Nigeria. Cultures change; stereotypes change (Mokyr, 2010). However, this study did not prove these alluded changes empirically; more so, the discussants in the focus groups pointed to a different direction.

Based on the participants' responses, the researcher believes that it is possible that the surprising results of the survey analysis may have resulted from sampling effects because the multistage sampling technique used is a pseudo-probability technique that can introduce sampling bias 
(Fowler, 2009). Nevertheless, the researcher's introduction of a qualitative phase to the study helped in complementing and clarifying the survey results. It is noteworthy that the survey only investigated whether the factors hypothesised by this study as encouraging or discouraging entrepreneurship were similar or dissimilar among undergraduates of the two regions. However, the focus group session investigated whether the participants thought the people of the two regions were similar or different in their entrepreneurship pursuits. The two investigations, thus, addressed related but slightly different issues: the former, the undergraduates' evaluation of themselves; the latter, the undergraduates' evaluation of the perception of societal and historical contexts of the people of the two regions.

In the focus groups the participants, however, consistently pointed out that the approaches, attitudes and motivations toward entrepreneurship demonstrated by people of Southeast Nigeria were seemingly different from their South-south counterparts. They also alleged that these observed patterns were more likely to be followed by undergraduates (and therefore graduates) from the region. In the same vein, the entrepreneurship attitudes showed by the South-south people would more likely be followed by their undergraduates too.

The participants enumerated these perceived regional entrepreneurial differences. The explanations offered as the distinguishing characteristics of the Southeast people were that they would more likely prefer to be independent and be their bosses. The love for profit-making and the culture of inviting their children, right from childhood, to experience some level of business were the other reasons offered. Also highlighted were their communities' love for mentorship and apprenticeship, and striving to be consistent in business. The rest were the Ibo's common esteem for people who make successes in the various businesses being regarded as the truly successful, instead of esteeming the paid workers or office holders.

Furthermore, participants in the focus groups indicated that undergraduates would more likely be encouraged toward entrepreneurship if they were provided the preferences stated in Section 7.2. Lastly, the undergraduates expected the governments and universities to solve the students' perceived barriers. In particular, barriers such as inaccessibility to cheap capital, fear of starting, and lack of supports to bounce back when one fails. It was Milner (2012b) who noted the fear of starting a business as one of the culture indicators that would make people wish to take up paid jobs to avoid business risks.

In the quantitative study, there was evidence of support for personality traits as an important, influential factor, but "personality traits factor" influences attitude rather directly, and then intentions indirectly. It influences intentions through the personal attitude and perceived 
behavioural control. The personal attitude toward entrepreneurship, in plain language, relates to the view that an individual deeply loves or would prefer to become an entrepreneur given other career options. The perceived behavioural control connotes that an individual deeply believes she can overcome the difficulties involved in carrying out a task. This study also found support for perceived capabilities as an important, influential factor in the integrated conceptual model of entrepreneurial intentions adopted. The perceived capabilities factor influences attitude through behavioural control, personal attitude and subjective norms variables. Subjective norms connote the extent of influence of other people on an individual to comply with peoples' expectations.

In terms of total effects, the greatest effects on intentions came from the personal attitude, personality traits, behavioural control and perceived barrier variables. The effects of psychological factors in the formation of personality traits were weightier from the locus of control, riskpropensity, need for achievement, and innovativeness variables, in this order. Lastly, the effects of psychological factors on attitude were weightier from the personal attitude, behavioural control and subjective norms variables, in this order too.

Surprisingly, in the quantitative model also, there was no statistical significance found for the subjective norms and perceived support variables on entrepreneurial intentions. The insignificance of the subjective norms factor suggests that the participants cared little or nothing about others' opinions of them deciding to become entrepreneurs. In the same vein, the insignificance of the perceived supports factor suggests that participants never considered the supports received as important enough to encourage them toward entrepreneurship. This insignificance was disappointing.

Taken together, the theoretical model suggests that the explanatory power of the integrated conceptual model of entrepreneurial intentions adopted is moderate. This result followed from the reported joint influences of the personality traits, attitude, perceived capabilities, and contextual factors. Specifically, the joint influence was 44.3 per cent as reported in Figure 6.4. It can be inferred, therefore that other unknown influential factors, not captured by this integrated conceptual model, explained the larger remaining portion of the influences on the undergraduates' entrepreneurial intentions variable. This study argues that the other influential factors as found in the qualitative study, therefore, can be incorporated to improve the conceptual model in future studies. These factors include the transformational, affective, push, and personal fulfilment motives; preference for practical-oriented methods to teaching undergraduate courses as against being simply theories, experience of relevant internship, preference for experienced 
entrepreneurship lecturers, plus healthy university-industry links. However, these factors would need further empirical testing to validate their application in other or similar contexts.

\subsubsection{Discussion of the factors that influence undergraduates' intentions in the two regions}

In this subsection and in the ones that follow, the researcher will engage, more critically and conceptually, on the main influential factors and explain how the factors fit into the big or general picture.

\section{1) Personal attitude and perceived behavioural control}

Theoretically, the significance of the personal attitude and perceived behavioural control variables on the entrepreneurial intentions variable suggests some evidence of the usefulness of attitude studies. It supports the Azjen's theory of planned behaviour, in particular, in understanding the influential factors of entrepreneurial intentions. Only the subjective norms variable was insignificant, but this is common. This result is similar to Solesvik's et al. (2012) findings, which found the subjective norms variable insignificant in their study of 192 Ukrainian Economics and Business students. Similar studies with insignificant subjective norms variable include Paco et al. (2011) and Linän et al. (2011). Autio et al. (2001) also found no significance for the subjective norms in their four-country study of 3,542 students in Finland, Sweden, USA, and UK. On the contrary, studies by Peng et al. (2012), Mariano et al. (2012), and lakovleva et al. (2011) found the subjective norms variable significant on intentions. All the three studies adopted an integrated conceptual model of entrepreneurial intentions too (see Table 4.1 in the literature chapter).

Personal attitude is a person's approach to knowledge of the end product of her action and the extent to which someone favours or disfavours carrying out the action (Ajzen, 1991). The end product in this case is to carry out an entrepreneurial activity, or simply the founding of one's own business. Thus, the stronger the personal attitudes toward entrepreneurship shown by undergraduates, the more businesses might be founded by undergraduates and vice versa. Based on the findings of this study, and the responses to the surveys, it infers strong personal attitudes toward entrepreneurship by undergraduates in the South-south and Southeast Nigerian universities. Most undergraduates strongly believed that being an entrepreneur would be more beneficial to them and choosing a career as an entrepreneur is something they see as attractive. They also strongly believed that if the opportunities and resources are available, they would more 
likely start their businesses. The reason is that they see being an entrepreneur as giving great satisfaction and would rather be one, given other career options.

Perceived behavioural control is a person's belief that she can carry out her plans and that the plans are within her control (Ajzen, 1991). Here the plan would be, but not necessarily, to establish one's business (Baumol, 1990). The more people believe they have control over such plans; the more success they could achieve, other things being equal. Based on the participants' responses, it follows that most undergraduates in the study sample strongly believed that starting a business and making it viable would be easy for them. They also believed that they can control the creation processes of new businesses. They believed they could succeed if they try to start a new business. Although this is different from what a female participant in a focus group said: "So, I want to say that it's not always easy to be an entrepreneur. It's so hard to start $\cdots$ But my problem now is how to start and where to start this business" (1HAP.116.119). Therefore, the survey analysis strongly suggests that the participants feel confident that they can control the business-founding and running processes. However, some participants in the group discussions such as HAP quoted above still recognised some difficulties involved in Nigerian students starting their businesses. The implication is that if undergraduates perceive they cannot overcome their fear of starting, and with no support and help from their universities, then the universities might less likely achieve the goal of producing more high-quality entrepreneurs.

\section{2) Personality traits}

The significance of the variable "personality traits" on two out of the three attitude variables, namely "personal attitude" and "perceived behavioural control" suggests some support for steady personality traits in entrepreneurial intentions studies. Here, having a steady personality means a person places emphasis on cooperating with others within existing circumstances to carry out a task (Lüthje and Franke, 2003). Specifically, the notion in the literature is that personality traits can influence intentions better through its influence on attitude. However, the influence is an indirect one. Simply, a person's personality has some indirect influences on her business-founding intentions. This notion is widely supported by the literature (Ajzen, 1991, 2005,; Lüthje and Franke, 2003; Krueger et al., 2000; Krueger and Carsrud, 1993). However, among the authors cited only Lüthje and Franke adopted an integrated conceptual model. The significance of the personality traits index on both personal attitude and perceived control supports the work of Lüthje and Franke (2003). They found a strong indirect influence of personality traits on the attitude to founding one's own business. 
In the present study, four personality characteristics of the respondents were tested to explain their influences on the undergraduates' perception of their personalities. The four characteristics were innovation, need for achievement, risk-taking tendencies, and test of internal locus of control. On innovation, the findings indicated that the participants saw themselves as having a personality that thinks obsessively about information to come up with new ideas and solutions. This notion is also in line with what participants said in one of the focus groups: "NI love information so much.' I love to take the risk..." (2ELKA.783.788). The participants perceived that other people think of them as always making changes and attempting new ideas. They also liked to associate with people who think in different ways. On the need for achievement, the respondents saw the importance of doing a job well rather than attempting to please people. They believed their time is precious, and people should honour time; they respected deadlines and aimed to complete their tasks. These are good attributes for successful entrepreneurship. These attributes and their analyses came directly from the participants' responses to the questionnaire items posed.

On risk-taking tendencies, the participants believed they like to test boundaries and venture into where few have ventured into before. They believed if they wished to accomplish a goal that had a fifty-fifty chance of realisation, they would rather take the chances. They also strongly indicated that they were willing to invest and borrow to accomplish a goal if the task had a good prospect for money-making. On the level of internal control, the participants strongly believed that personal successes are the result of hard work and a little luck. The participants believed that getting what they want is a just reward for their efforts. They also believed that they get what they desire in life as a result of their hard work. This result shows strong levels of internal locus of control.

Taken together, the participants strongly favoured the above characteristics as reflecting their personalities. However, personality traits are said to be difficult to change quickly to achieve policy goals required since they are relatively stable or pre-determined in a person (Lüthje and Franke, 2003). This difficulty is the reason researchers prefer using various external contextual factors as they are easier to change in achieving policy goals.

\section{3) External Context}

Current and earlier studies show that the way a person perceives the context of her external environment and cultural values can influence her readiness to establish her business (Bae et al., 2014; Kadir et al., 2012; Karimi et al., 2011; Kuratko, 2005; Lüthje and Franke, 2003). Some studies used external environmental factors such as "support factors" that include availability of loans and 
venture capital to assess how they facilitate businesses. Other authors used participants' perceptions relating to how state laws, setting of rules and regulating of businesses facilitate enterprise; these factors come under "barrier factors" (Lüthje and Franke, 2003). Kadir et al. (2012) used factors relating to the general educational support environment to test how this encourages Malaysian students toward founding their businesses. The common belief is that a supportive and entrepreneurship-focused educational environment would engender students' interest in self-employment.

The study by Bae et al. (2014) used the context of entrepreneurial education and two measures of culture to test these relationships with entrepreneurial intentions. Their measures of culture were uncertainty avoidance and society's encouragement of gender equality. So, they believe that in societies that encourage equal opportunities for both men and women, both genders would take up entrepreneurship chances in roughly the same manner. Thus, they suggest a positive relationship between entrepreneurship education, gender equality and entrepreneurship intentions. Also, a society with a culture in which most people try to avoid uncertainties but prefer to keep their norms will result in lower levels of entrepreneurship intent. Their study found that the relationship between the contexts of entrepreneurship education, entrepreneurship intentions was more positive in low gender equality societies. They found same positive relationship for low uncertainty-avoiding societies.

The present study found that students perceived the support they receive from the universities toward the development of entrepreneurial skills and creative ideas as being too limited to significantly influence many students. Rather, they perceived that the state rules and regulations are discouraging the running of businesses. This is what participants agreed in one of the focus groups as a barrier: "I usually hear the complaint about high tax; that it is a problem in Cross River State; it's a problem in the country, that the government is taxing more than necessary" (1OFF.503). The participants believed that there were no smooth provisions made for access to qualified consultants and business support services for students wishing to undertake new ventures. They were pessimistic and narrated that the sources of help and entrepreneurship-related training facilities were inadequate. For example, KAT said: "Now, the primary school failed me; the secondary school failed me; now, I found myself in the higher institution, I was simply failed as well (4KAT.1707). In general, the undergraduates see barriers to existing businesses in their environment as a discouragement to entry into self-employment. 
Lüthje and Franke (2003) found evidence of the influences of "perceived support" and "perceived barriers" in their study of 512 MIT engineering students. But the present study failed to find such evidence for Southern Nigerian students. It only found support for perceived barriers, which the participants saw as hindering undergraduates from their readiness to start businesses. The participants acknowledged no significant supports from their families, university, region, or society toward their readiness for self-employment. The works of Karimi et al. (2011) did not find evidence of a relationship among perceived support, perceived barriers, and entrepreneurial intentions in their study of 347 Iranian students. The present study correlates with the study by Karimi et al. (2011) who found no evidence of a relationship between perceived support and entrepreneurial intentions. The present study, however, differs from the findings of Karimi et al. (2011) who found no evidence of perceived barriers and entrepreneurial intentions: the present study found evidence of this relationship.

It is evident from the analysis of the participants' perception that the general support for entrepreneurship was inadequate. This finding of perceived "lack of support" for entrepreneurship from the Nigeria's external environment has many implications for the country, universities studied, and policymakers in the two regions, given the prominence the external environment plays in national entrepreneurship development. The possible reasons for the students' negative opinion might be because there are inadequate entrepreneurship promotion and education; barriers to entry and exit; and lack of business start-up support. Lack of start-up and seed financing are the other possible reasons, all of which Stevenson and Lundström (2007) recognise are core components that governments and policymakers need to resolve if they wish to enhance entrepreneurship. The authorities, however, need to adopt an integrated framework for addressing these support factors.

In other climes such as advanced European countries, the governments design a group of policies to enhance the perceived value of entrepreneurship in society and more generally, to create more awareness of entrepreneurs and entrepreneurship. For instance, government departments and agencies do engage with high-profile entrepreneurs, using them to publicise and endorse their initiatives. Organisations such as television broadcast stations also play some roles in providing profile-raising programmes, for example, in the United Kingdom, the BBC's Dragon's Den has this intent of raising entrepreneurship awareness (Blundel and Lockett, 2011). The negative perception of the participants regarding government's promotion of entrepreneurship implies that governments of the regions studied need to enhance entrepreneurship profile-raising programmes to change these perceptions. 
Studies acknowledge that countries or regions that pursue policies that make it less timeconsuming and more attractive to pursue an entrepreneurial career stand to attract more individuals toward embracing entrepreneurship (Blundel and Lockett, 2011). The requirement is that the authorities systematically review the impact of their legal, administrative, and regulatory systems on existing SMEs and new ventures, which these policy structures often affect disproportionately. Suffice it to say that in Nigeria, the challenge for the authorities is that most times the policymakers fail to evaluate the potential impacts of new laws and regulations before they introduce them. For example, before the December 2015 foreign exchange restriction policies of the Central Bank of Nigeria, they failed to conduct any prior policy impacts. The implementation caused much distortion to the manufacturing and merchandise sectors that depend so much on the supply of foreign exchange for their business activities. The fallout is that as the potential entrepreneurs continue to witness these kinds of policy somersault and difficulties current entrepreneurs are experiencing, their likelihood of going into an entrepreneurship career could be hampered.

Governments in leading economies also support start-ups by delivering information, advice and specialist support and networking platforms for entrepreneurs and potential entrepreneurs as they move through the start-up cycle. They provide services such as personalised mentoring and training, financial support for incubators (i.e., low-cost office spaces and similar support services), and science parks, and supporting networks that provide an opportunity to interact with other entrepreneurs (Blundel and Lockett, 2011). It seems the lack of such entrepreneurship supports which the participants alluded to in the present study may have contributed to their negative reactions on the "perceived support" variable in the research model. It would, therefore, require concerted efforts by the authorities to fix these and provide an enabling environment to boost undergraduates' interest in entrepreneurship.

Policymakers in leading economies also encourage institutions that provide start-up and seed financing. Because some new and early-stage ventures often experience funding gaps, governments often encourage policies to solve funding needs of potential entrepreneurs. Governments do these through micro-financing, loan guarantees, and specialist "seed capital" funds, which they design to enable technology entrepreneurs to move beyond the prototype stage. They also seek to encourage networks of business angels, venture capitalists, and venture philanthropists, who specialise in finance for social entrepreneurs (Blundel and Lockett, 2011). Like one participant noted during the focus group session "For the graduates, some don't have the financial ability" (3HAPP. 126); an organised network of venture idea financiers, a requirement for encouraging entrepreneurship, is still very much at the low ebb in developing 
economies including Nigeria. The efforts would also require that universities take more proactive steps and collaborate with financiers and link students who have good venture ideas for funding.

\section{4) Capabilities or Competencies}

Cognitive theories highlight the individual decision-making process and the influence of perceived capabilities in the decision to become self-employed. The way in which people interpret their capabilities, or its context, is essential. Although there is no agreement on the meaning of competencies, nevertheless, Caird (1992) has specifically focused on some competencies for enterprise. Others only concentrated on managerial competency. Caird summarises that four aspects of competency exist: knowledge, skill, performance, and psychological factors. These competencies relate especially to one's area of expertise. This research had earlier discussed the nature of entrepreneurial competencies in Sections 4.3 and 4.4 .3 in the literature chapter. This study adopted the questions from Peng's et al. (2012) work, which measured perceived competencies of potential entrepreneurs. The questionnaire included items related to Caird's (1992) four aspects of competency.

The present study examined the influence of individual perceived competence level on entrepreneurial intentions. Given that theory explains competency as a behavioural factor; it would not influence entrepreneurial intentions directly. However, it rather influences intentions indirectly through its influence on the behavioural control, personal attitude, subjective norms, and self-efficacy variables (Bridge et al., 2009). The present study found that the participants' perception of competency was significant on all the aspects of behavioural factors including the behavioural control, subjective norms and personal attitude variables. This result indicates that the undergraduates felt confident about themselves in relation to aspects of competencies including opportunity discovery, idea generation, networking, organising of key resources for setting up business, and team building. The list above followed from their responses to the research survey items administered. The results confirm the works of Obschonka et al. (2010). They found that the more people are self-confident (self-efficacious) concerning key business competencies; the more they would likely be inclined toward enterprise creation.

Although the survey suggests that the participants may have given the impression that they were confident of their personal competence to start their businesses, it is hard to say whether actually this might be the case. The reason for the caveat is that given the number of problems they enumerated earlier concerning their general training and in the entrepreneurship subject area; one could doubt their levels of entrepreneurial capability. For example, PAT in the first focus group 
interview said: "'..if you're asked to do the practical aspect of it, you can't do it" (1PAT.90). This statement is an expression of doubt on the ability to manage the practical aspects of business as the participants had no trainings in practical business formation and management. PAT was not alone in this. UBN in the fourth interview said: "I read electrical/electronic engineering. What we've been taught in school most times is theoretical, not practical" (4UBN.1616). Therefore, the participants' views in the survey regarding enterprise competencies should be interpreted in the light of the realities from the focus group discussions; this might be one of the advantages of using mixed methods for further probing.

Based on these findings, this study, therefore, answers in part, the research question of what factors influence undergraduates toward entrepreneurship. It provides some evidence to argue that entrepreneurial intentions are influenced directly by personal attitude towards entrepreneurship, entry barriers; and the belief and ability to control the founding processes, both of which are supported by one's steady personality and competence levels.

\subsubsection{Discussion of the extent of similarities or differences regarding the factors that influence undergraduates' entrepreneurial intentions in the two regions}

This research also sought to investigate whether there were significant differences in the perceptions of the participants regarding the factors that foster entrepreneurial intentions among students from the two regions. At least two significant differences in the hypothesised relationships would imply that their responses can no longer be analysed together but separately (Hair et al., 2014). The following conceptual relationships were tested to determine the outcome of the proposed differences. The direct relationships were between the following 18 model paths:

1. Personal attitude $\rightarrow$ Entrepreneurial intentions

3. Perceived behavioural control $\rightarrow$ Entrepreneurial intentions

5. Perceived barriers $\rightarrow$ Entrepreneurial intentions

7. Perceived support $\rightarrow$ Entrepreneurial intentions

9. Subjective norms $\rightarrow$ Entrepreneurial intentions

11. Personality traits $\rightarrow$ Personal attitude

13. Personality traits $\rightarrow$ Perceived behavioural control

15. Personality traits $\rightarrow$ Subjective norms

17. Locus of control $\rightarrow$ Personality traits

2. Risk-propensity $\rightarrow$ Personality traits

4. Achievement orientation $\rightarrow$ Personality traits

6. Innovation orientation $\rightarrow$ Personality traits

8. Personal attitude $\rightarrow$ Subjective norms

10. Personal attitude $\rightarrow$ Perceived behavioural control

12. Subjective norms $\rightarrow$ Perceived behavioural control

14. Perceived capabilities $\rightarrow$ Perceived behavioural control

16. Perceived capabilities $\rightarrow$ Personal attitude

18. Perceived capabilities $\rightarrow$ Subjective norms 
Section 6.5 and Table 6.10 in the analysis chapter showed the results of the multi-group analysis. The findings indicated that there was no significant difference in any of the hypothesised relationships. Thus, the overall data were then analysed as one data set.

In all, the value of the collected survey data wholly depends upon how honest respondents are in answering the questionnaires. In general, the advice is that researchers who use surveys accept respondents' answers as true (Shaughnessy, Zechmeister and Zechmeister, 2011). However, the authors cited maintained that "survey researchers" must have "another way of directly observing respondents' behaviour in comparison with their verbal reports to determine what behaviours they really engage in or what attitudes they really uphold" (p.161). In stepping back and critically examining the data collection approaches, the researcher observes that little lies in the hands of the researcher in controlling how most honest responses from the participants could be in a survey exercise. For this reason, the chance of examining a research subject further or differently through the use of a parallel approach might prove useful. That is one of the advantages that the researcher thinks the focus group discussions provided as the author did not perceive the complexity of the issues could be holistically understood only by the survey results.

For this reason, priority was given to the qualitative phase of the study as earlier highlighted in the research design or strategy section in Chapter Five (Section 5.2.6). The focus group discussions afforded the author the opportunities to probe further points that would have been left unresolved or less understood at best if there were no such fora. The author had no cogent reasons to jettison the groups' discourse on the various issues raised, analysed and discussed in Chapter Six, Section 6.7.1. The author perceived that the exercise took place in a non-coercive and non-ethnocentric atmosphere although a research of this nature cannot guarantee the absence of possible preconceptions and stereotypes.

Findings from the focus group interviews showed interesting contrasts with the survey results. Notably, however, the survey did not ask the direct questions such as: "do you think there is a difference or not in entrepreneurial intentions, pursuits or endeavours among people of the two regions?", which the focus group sessions addressed. It did not address whether the participants thought there were any perceptible differences or similarities among the people of the two regions (or their practising entrepreneurs). It only measured the students' perceptions based on the factors hypothesised by the researcher as influencing entrepreneurial intentions and further tested whether these perceptions were different or similar between the two student groups. 
The usefulness of that result (students' perceptions) is that, in future undergraduate entrepreneurship studies that use samples from these regions, there might be no need to treat data or test this proposed model separately. So, data can be integrated. Furthermore, the survey did not ask whether there were differences in the observed patterns in entrepreneurial pursuits between people or entrepreneurs from the two regions. This question was a subject evaluated in the qualitative phase of the research (i.e. in the focus group sessions). The responses of the participants in the focus groups to the above questions were based on the participants' perception of the non-student population of the two regions (i.e. their entrepreneurs and nonentrepreneurs). But the responses to the survey questions were based on students' population: indeed, the students themselves partook in the survey. Thus, there is room to argue that these two investigations are related but not exactly addressing the same issues.

A better way of examining regional differences or similarities, other than asking research participants for their perceptions, however, would have been to use historical or time-series data to show different levels of enterprise indicators or conditions for each of the regions (Ahmed and Hoffmann, 2012). As enumerated earlier in Chapter Two, the indicators would include: total number of business owners in the regions, rate of creation of firms with employees (as opposed to sole-proprietorship), number of high-growth firms, morbidity rates (birth minus death rates of firms), number of young, high-growth firms (gazelles), income levels in the regions, human and financial capital levels, R \& D institutions, business and policy infrastructures, legal and regulatory environment. Although there are some data for Nigeria published on some of these categories by the National Bureau of Statistics and other global media such as GEM, GEDI, PSED, unfortunately, this set of data are unavailable currently at the states or regional levels in Nigeria. However, there are arguments within circles in entrepreneurship economics and geography suggesting the importance of regional variations in differentiating entrepreneurial context. It was Dodd and Hynes (2012, p.742) who said that "it is not new to find differences", and Baumol (1990, p.893) also said "the supply of entrepreneurs varies among societies."

Participants in all the focus groups demonstrated that there seem to be perceived significant differences between how people from the two regions see, conduct, or embrace entrepreneurship. They illustrated their perspectives in terms of differences in culture and overall business orientation among the South-south and Southeast people and that the same pattern may more likely be followed by the undergraduates too. Specifically, the participants highlighted that the Southeast people were somewhat different from their South-south counterparts in the areas of preference for independence and consistency in business pursuits. Other areas are profitorientation, early childhood introduction to business, serial mentorship and apprenticeships, and a 
high regard for successful business people compared to public office holders; their narratives were clearly highlighted in Chapter Six (Section 6.7.2).

These findings are at parallel with other empirical studies that found differences in entrepreneurial inclinations among students from different regions, ethnicity or countries. For example, lakovleva et al. (2011) found in their study of students from five developing and nine developed nations that their hypothesised relationships were significantly different among the respondents. They used components of the Ajzen's theory of planned behaviour too although their overall model was dissimilar to the present study. In the present study, however, it found no significant differences in the hypothesised relationships concerning the factors that foster students' entrepreneurial intentions. Nevertheless, on the issue of regional differences or similarities, there is some evidence to suggest that the respondents perceived the Southeast people to be somewhat different from their South-south counterparts practically. That by implication, their undergraduates (and by inference their graduates too) would more likely follow suit compared to undergraduates of the South-south region.

Therefore, the answer to the research question of the extent of similarities or differences in what fosters entrepreneurship among undergraduates of the two regions is that the Southeast students are not significantly different from their South-south counterparts. This result was based only on the researcher's hypothesised relationships and the analysis of the surveys. However, graduates from the two regions might likely follow the patterns perceived and described by the focus group participants concerning the Southeast and South-south people in terms of culture and alertness to business pursuits.

\subsubsection{Discussion of students' "meaning making", explanation, and thinking on what influences entrepreneurship intents}

The qualitative phase of this research was an attempt to consider what the explanations of the undergraduates are on what encourages or discourages their business-founding intents. There are few studies that have accounted for students' explanations or the meaning making of the factors that influence entrepreneurial intentions (exceptions include Van Gelderen et al., 2008; Lüthje and Franke, 2003). Most studies using integrated conceptual models concentrated only in using one approach to examining the debate. In addition, many quantitative studies generally yielded either unsatisfactory or moderate model fit. For example, in Table 4.1, in ascending order: Fitzsimmons and Douglas (2011) recorded seven percent model fit; Pruett et al. (2009) recorded 28 per cent; Mariano et al. (2012) recorded 38 per cent; Lińän et al. (2011) recorded 53.5 per cent; Lińän and 
Chen (2009) recorded 56 per cent; and Solesvik et al. (2012) recorded 60 per cent. Interestingly, in the present study, incorporating the explanations and perspectives of students into the debate has revealed useful contributions. Their explanations strongly suggest how to now approach undergraduate entrepreneurship development, if universities in the regions wish to get the results they want in producing enterprising graduates.

Firstly, the participants revealed that they have a passion for effecting change and transforming their regions through the various businesses which they could establish. They were enthusiastic about the transformation of their communities using the knowledge gained from their various fields. The strong emotions shown by the participants suggest that the passion for enterprise is present. Their passion is fuelled by their affection for entrepreneurship as this has the potential of making them fulfil their personal life goals too. The goals range from profit-making to being wealthy and influential in the society.

Secondly, although there are many perceived barriers stated as hindering many students from going into self-employment, the participants still believed that they have the personality that drives them to always wanting to be independent, creative, innovative, and desiring to take risk to achieve in life. This desire to control one's destiny is supported in the literature on the psychological traits that predispose people to having an interest in tackling enterprising tasks (Bridge et al., 2009). Personality approaches to entrepreneurship indicate that peoples' personalities explain their actions or behaviours, for example, personalities such as achievement motivation. For instance, when people accomplish an enterprising task, this can give them a strong sense of achievement and affirm their ability to control their lives too. Thus, the motivation to achieve in life as exemplified by the participants is an indication that given the right enabling factors the undergraduates can achieve their life goals through creating their businesses.

Thirdly, the participants enumerated some preferences they would like to see in their teaching and learning experiences to encourage interest in entrepreneurship. They strongly expressed preference for the applications of courses that engender real world experiences. Participants would like to see course contents being taught and learned with the eye of using them. This preference by the participants might be difficult for universities that run only the traditional lecture-type of teaching and learning. The preferences the participants requested may need some radical changes by universities and teachers in drawing up new approaches to course content delivery to include concrete applications. For example, they may require combining discussion sessions, workshops, incentive competitions, problem-based learning, business games and 
simulations with traditional lectures. A new approach might also require some changes in pedagogy, syllabus and curriculum (Mathieson, 2015; Kuratko, 2005).

As a corollary of the above preferences, experienced entrepreneurship teachers are required to handle the entrepreneurship development courses in the universities. The quality of teachers to inspire students' interest in entrepreneurship depends strongly on the practical business experiences of their entrepreneurship teachers. This notion was the opinion of the participants in this study. The challenge for the universities, therefore, is to provide experienced entrepreneurs as teachers. Or at least to facilitate the process where experienced entrepreneurs can work or teach more practical sessions alongside with the regular teachers.

Because the industry practitioners are the ones who implement the practical aspects of most of what universities teach, therefore, developing healthy ties is useful. The ties are useful to the universities as some students can work as interns in those organisations. It is also useful to the practitioners who can benefit from research from the collaborative universities to improve practice. Therefore, continuous healthy collaborations between universities and practitioners are win-win intangible assets.

Preference for student internship experience was also a strong point raised by the participants. Internship can act as a mentorship and apprenticeship factor for students. Because having wideranging experiences in one's field of study might be difficult during undergraduate education, therefore, relevant internships can offer a medium for undergraduates to apply their learning. Undergraduates saw this avenue as something very useful for enhancing their practical knowledge. Therefore, universities would do well to design, creatively, how to introduce relevant internships in most, if not all, courses. The participants believed that well-organised and supervised internship programmes could foster students' interest in entrepreneurship.

Therefore, the answer to the research question of how students explain and make meaning of what influences them to start and run their businesses is that they see their passion for entrepreneurship as a better route to bring the desired changes in their communities. Their view is that entrepreneurship could enable them to earn greater profits, wealth and influence. However, business could enable people to achieve these aspirations either in the monetary, non-monetary or social enterprise spheres. There are many barriers to entrepreneurship in the participants' communities; however, the participants perceived that their personality traits and mindsets would help them overcome most of these barriers. Also, that they could overcome these barriers better if their teaching and learning were more practical-oriented with exposures to implement their 
learning than being more theories. Also, it would be helpful if there were greater ties between their universities and industry practitioners. Lastly, they viewed also that it would be very encouraging for them if they were offered relevant internship experiences and taught by experienced entrepreneurs.

In the next chapter, the study summarises the thesis' chapters and the key empirical findings, states the contributions to knowledge and concludes. It then states the implications of the findings, makes recommendations for policy and offers options for further research as well as reflects on the doctoral journey. 


\section{CHAPTER EIGHT}

\section{SUMMARY, CONCLUSIONS AND RECOMMENDATIONS}

\subsection{Introduction}

Chapter Seven showed how this research met its earlier stated objectives and also answered the central research questions. This final chapter, Chapter Eight, therefore, is devoted to summarising the study, concluding and making recommendations. It begins with a summary of the thesis chapters and the key findings; then states the contributions to knowledge and makes conclusions based on the findings. It next summarises the implications and makes recommendations as well as states the limitations of the research. Some of the limitations and recommendations for further research are the areas the researcher would like to study further during his post-doctoral research. Lastly, the study ends with some reflections on the Ph.D. journey.

\subsection{Thesis chapters' summary}

In the Chapter One of this study, it was outlined that the key objective of this study was to find explanations for what factors foster entrepreneurial intentions among undergraduates of Southsouth and Southeast Nigeria. The study was conducted primarily to find research-based evidence for universities in the two regions on how to encourage entrepreneurship among their undergraduates. It was also to examine empirically the notion that youths from the Southeast are more likely to go into entrepreneurship than their South-south counterparts; this had previously received little empirical verification.

To meet the research objectives, in Chapter Two the thesis started by examining the history of entrepreneurship development efforts in Nigeria and also examined the institutional factors that influence enterprise creation. Taking guidance from the seminal works of Baumol (1990) and North (1990) and recently by Ăcs et al. (2014), it noted that the joint influences of institutional factors such as the "rule of law", "property rights", "political conditions", "economic reward systems", "culture, values and norms" and "level of economic development" can positively or negatively impact a nation's entrepreneurship outcomes. That for Nigeria, the institutions that should foster, homogenise, reinforce individual action, create and disseminate different ideas and knowledge, and direct them to resourceful uses are mostly volatile and weak. Perhaps, getting it right now in the teaching and learning of entrepreneurship can help place the future 
entrepreneurs to position themselves to overcome most of the weaknesses observed through their leadership in businesses.

In Chapter Three, the thesis examined the link between the appropriate kind of entrepreneurship education $(\mathrm{EE})$ and the quality of potential entrepreneurs that universities can produce. The literature from the U.S. and advanced European countries who are leaders in EE indicates a view that universities can achieve their entrepreneurship education goals with several methods (Zahra and Welter, 2008). The methods could be hands-on training in creativity techniques, lectures and case studies in the various aspects of business, communications training, networking opportunities, team business plans, coaching and feedback, among others. The central thesis of the chapter was that universities that apply themselves more toward discovering global best practices in undergraduate entrepreneurship education and adapting their teaching and learning methods to align with the needs of their local environment stand a better chance of encouraging more students toward entrepreneurship.

In Chapter Four, the thesis then examined ten theoretical perspectives as well as the empirical literature on the factors that encourage or discourage entrepreneurship intentions. The theory of planned behavior, TPB (Ajzen, 1991, 2005), psychological traits model (from Peng et al., 2012), competencies thesis (Caird, 1992), and external context measures (Lüthje and Franke, 2003) were selected to derive the conceptual model. A combination of these four theoretical foundations aligned with the concept of an integrated conceptual model (Solesvik et al., 2012; Peng et al., 2012; Krueger et al., 2000) that scholars use in the entrepreneurship circles to study entrepreneurship intentions. The thesis, therefore, is that there are interrelationships among some elements of the attitude construct, personality traits, perceived competence factor, external context factor and entrepreneurship intentions. Incorporating the narratives of the students simultaneously would also foster useful insights into understanding holistically the underlying factors that engender the likelihood of undergraduates becoming entrepreneurs.

In Chapter Five, the focus shifted to the issues of how this research project would meet the research objectives stated earlier. It adopted the mixed methods research (MMR) technique. Firstly, it adopted the "dialectical" philosophical paradigm of MMR as the plausible philosophical position (Greene and Caracelli, 1997, 2003) because of its multi-logical assumption. It assumes that it is plausible to mix two dissimilar paradigm assumptions in one study so far as it is logical in providing the framework for meeting the research questions or objectives or both. In the present study, some of the objectives stated in Chapter One (e.g. objective five) aligned with the philosophical assumptions of the postpositive traditions. This tradition aligns with the quantitative 
research and helps explain the associations or correlations in the relationships among factors. Conversely, some of the objectives (i.e. six and seven) aligned with the social constructive traditions that apply to the qualitative research helping in exploring different angles to the subject and perhaps also helping the researcher to identify possible solutions (Ivankova and Stick, 2007; Litosseliti, 2003).

This study collected data with a questionnaire and focus group interview instruments. For the quantitative study phase, the researcher adopted a multistage cluster and simple random sampling techniques to collect the survey data between December 2013 and June 2014. It collected primary survey data from 1,129 final-year indigenous undergraduate students in nine South-south and six Southeast universities in Nigeria and had four sessions of focus group interviews in two of the universities.

The analysis of the survey data helped highlight factors that influenced entrepreneurial intentions the most (research objective five). It also answered whether the factors were different or similar among the participants of the two regions investigated (research objective six). The qualitative phase adopted focus group interviews to collect data. It held four sessions at two selected universities in the study area. Analysis of the transcripts helped to identify factors that the participants perceived influenced their intentions to start enterprises (research objective five). It also helped address in part what the participants' perceptions were and whether people from the two regions engaged in entrepreneurship in the same or different manner (research objectives six and seven). The analysis of the fieldwork data collected then followed.

In Chapter Six, the researcher analysed the survey data using the partial least squares structural equation modelling technique (PLS-SEM) and the interview transcripts used a thematic analysis technique. The personal attitude construct was the strongest influence on entrepreneurial intentions construct, followed by the perceived behavioural control and the perceived barriers factor. The focus group interview results suggest that the undergraduates perceived the following factors as their primary motivations toward entrepreneurship career option: transformational, affective, push, personal fulfilment motives and personality traits. Moreover, they perceived that practical or application-oriented approach to teaching and learning, relevant internships, experienced entrepreneurship lecturers teaching them, and their universities having strong collaborations with relevant industries would enable them to embrace entrepreneurship in a more positive way. 
In Chapter Seven, the study next discussed the findings of this sequential explanatory mixed methods research. It answered the question of what factors explained entrepreneurial intentions among undergraduates of South-south and Southeast Nigeria and whether those factors were similar or dissimilar for the two regions. It discussed what explanations undergraduates made of the factors that influence their readiness to establish their enterprises. Having analysed the results of the relationships hypothesised and based on the ideas from the integrated conceptual framework adopted, the study argued that the South-south and Southeast undergraduates did not differ significantly in their attitude, outlook, or intents toward entrepreneurship pursuits. Nevertheless, the discussions with the participants in the focus group sessions revealed that in the contexts of the wider society, students perceive that the Southeast people are more likely to engage in entrepreneurship activities compared to their South-south counterparts. In practice, however, it was believed that the indigenous undergraduates students of the two regions might probably follow the same pattern of entrepreneurship behaviour that was highlighted earlier. It contrasted with the view that in the wider society, people of the two regions studied might be motivated by different factors toward entrepreneurship career. It is important to emphasise that individual cases witnessed may fail to apply to the whole Southeast or South-south communities.

This final chapter, Chapter Eight, is devoted to summarising the study, concluding and making recommendations. It provides a summary of the thesis chapters and the key findings; then it highlights the contributions to knowledge in three areas: theory, methodology and practice; and then makes conclusions based on the findings. It then summarises the implications and makes recommendations as well as stating the limitations of the research. Lastly, the study ends with some reflections on the Ph.D. journey.

\subsection{Summary of the major findings}

In this subsection, the study restates the specific research questions asked earlier in Chapter One, and presents the findings that answered each research question as follows: this summary is drawn from the results of both the survey and the focus group responses and their analyses.

1) Are undergraduates' business-founding intentions influenced by their personal attitudes, perceived capabilities, personality traits, perceived barriers and support?

The results of the partial least squares' bootstrapping scheme in Section 6.6, which showed the significance of each explanatory variable in the structural model, indicate that the personal attitude construct had the strongest influence on the undergraduates' entrepreneurial intentions construct. This construct had a coefficient of 0.584 . The second strongest influence came from the 
perceived behavioural control factor with a coefficient of 0.139 . The third strongest influence was from the perceived barriers factor with a coefficient of 0.057 . The influences of the perceived support factor and subjective norms factor were insignificant having coefficients of 0.025 and 0.019 respectively. The perceived capabilities factor and personality traits factor influenced intentions variable indirectly through their separate influences on the attitude factors. However, the personality traits factor was insignificant on the subjective norms factor.

2) Are the influencing factors similar or dissimilar among the study groups?

The results of the partial least squares multi-group analysis reported in Section 6.5 tested the groups' differences based on the various constructs hypothesised about the various relationships in the model. The results indicated that, for example, examining the path between the personal attitude and entrepreneurial intentions variables, the path coefficient for the Southeast respondents was 0.593 with a standard error of 0.048 . For the South-south counterparts, the path coefficient was 0.584 with a standard error of 0.029 . Therefore, their path difference was 0.014 ; this reported the $t$-statistics value of 0.243 . This value indicates a $p$-value of 0.808 , thus suggesting a no significant difference of the path coefficients. All the other 17 path coefficients showed no significant differences of opinion too; meaning that the participants' perceptions about the questions posed were relatively similar irrespective of their ethnic origin.

But on further examination of the issue of similarity or distinctiveness of entrepreneurship intentions and endeavours of the two regional groups, more responses that further illuminated the debate emerged. Participants in the various focus groups raised the following arguments to suggest that they perceived some differences between the Southeast people and their Southsouth counterparts in real business lives. They also perceived that the undergraduates would more likely follow the same observed patterns. Citing some of the selected narratives, the respondents said:

\footnotetext{
"The two are different. The Ibos' method of business is that they always pass through serial mentorship. Someone will be under somebody for many years, learn a trade and graduates; a similar business is handed over to him as a settlement. So, that mentorship is there" (4UBN. 1777)

"When it comes to business, I'll give it to the Southeasterners. Right from birth! (General laughter) $\cdots$ (2INNO.939)

"I think it has to do with culture-the way of life of the people. The Ibos' children grow up to see their parents being businessmen, so some
} 
of them will go to become also businessmen because they've been in the

family, they learn the trade from them" (2JOE.951)

"The attitude of a businessman from the South-south is not "customer-

centric" or "customer-centred." They treat customers like chaff

(4UBN.1769)

"They have this natural knack for business than us $\cdots$ (4KAT.1818)

However, the above perceptions by the participants concerning the behavioural and cultural patterns should be taken with some caution because cultures are not static or fixed. It is historically formed and can undergo changes as it always does even if the changes do not appear very visible in the short term just like Mokyr (2010, p.185) said: "Societies exist with certain institutional structures, and in most cases these structures change but slowly, much like culture." Undoubtedly, there are individuals in the South-south region who might be (or are already) more successful in entrepreneurship than their Southeast counterparts. The focus groups' responses only suggest that taken together people from the Southeast might more probably take to entrepreneurship career than their South-south counterparts. But the researcher asserts that on an individual basis, it is possible to see mixed patterns.

3) What do the students think or how do they explain the factors that influence their creation of businesses?

This question sought to understand how undergraduates explain the factors that influence them toward planning to enter into entrepreneurship. The responses would help, in part, to address the sixth research objective as well as the third research question. The study presented the evidence in the words of the participants about what they thought were the factors that influenced or would influence them toward entrepreneurship career options. Broadly speaking, the undergraduates' explanations can be categorised into motives and personality traits, environmental influences, and students' preferences or expectations from their universities. Following the earlier analysis of the direct quotes from the participants as highlighted in Section 6.7.1, and to avoid unnecessary repetitions, the researcher here summarises the themes of the participants' responses as follows: transformational agenda or the desire to see changes; affective factors; personal fulfilment motives; push factors; barrier factors; personality traits; preference for practical-oriented teaching approaches of courses; preference for experienced entrepreneurship teachers; preference for university-industry links; and preference for targeted internships. These factors, therefore, suggest how the participants explained what influenced or would better influence them toward entrepreneurship career choice. 


\subsection{Contributions to knowledge}

This research contributed to knowledge in three key areas summarised as follows:

1) Theoretical or conceptual contributions

- Enhancement and furtherance of knowledge-by implementing an integrated conceptual model

\section{2) Methodological contributions}

- Application of mixed methods to entrepreneurial intentions studies of a developing country-by introducing students' explanations and meaning making into understanding entrepreneurship intentions and the contributing factors.

3) Practical contributions

- Provision of evidence-informed results of the status of undergraduates' entrepreneurial intentions useful to university administrators and entrepreneurial skills development programmes (ESDP) facilitators in South-south and Southeast Nigeria universities.

Firstly, in terms of contributions to the theory and literature, this research attempted to study in a comprehensive manner the usefulness of the competing models of entrepreneurship. It did this by examining the total effects (i.e. direct and indirect effects) of the elements of the extant theories of influences on entrepreneurship intentions. There have been calls to understand the direct and moderating effects of entrepreneurial intentions (Schlaegel and Koenig, 2013; Mariano et al., 2012; Carsrud and Brännback, 2011). Therefore, based on an integrated conceptual framework of entrepreneurial intentions adopted, this study combined the elements of the theory of planned behaviour, personality traits, competencies, and external context theses. It tested them empirically to examine the predictive soundness of the conceptual models. It extended the knowledge of the influencing factors of entrepreneurship intentions among undergraduates in Southern Nigeria by also applying a qualitative research approach to examine the perspectives of the participants. Only a few studies among those reviewed have taken this route (e.g. Van Gelderen et al., 2008; Lüthje and Franke, 2003). Interestingly, useful themes emerged from the participants' discourse of the factors that foster entrepreneurial intentions among them.

The combined model provided the routes through which each of the influential factors links with the participants' measure of entrepreneurship intentions. The conceptual model provides a holistic angle to examining the participants' perceptions of the influential factors of their 
entrepreneurship intentions. This theoretical approach thus fulfils the quest by Shook, Priem and McGee (2003) for combining the separate models to reduce the "entrepreneurial intention models" that researchers would have to choose from.

In terms of contribution to the literature, the critical review of the ten theoretical models of entrepreneurship inclinations and intentions conducted in Chapter Four, brought together in one piece of work, could offer future researchers an accessible literature on the factors that influence entrepreneurial intentions. This access could be more useful for researchers in Nigeria, whom the researcher knows by experience having worked as a lecturer, have challenges in accessing some world databases. Also, few research works have conceptualised the factors that influence undergraduates' entrepreneurial intentions in the manner proposed by this research (see the literature summary in Table 4.1). The integrated conceptual model adopted had a reasonable model fit. The additional influential factors offered by the findings of the qualitative study added the opportunity for improving the theoretical literature.

Secondly, in terms of contributions to methodology, the creative usefulness of the mixed methods research approach provided an avenue to use data to answer whether there were regional differences or similarities in entrepreneurship pursuits. The analysis of the undergraduates' responses to the survey detected no statistically significant differences in the hypothesised conceptual relationships. This aspect addressed the specific question of whether the researcher's model for the hypothesised relationships concerning the influencing factors were similar or dissimilar between the two regions.

A slightly different route to the question dwelled on: whether the participants thought there were any perceptible differences or similarities among the people. Specifically, the direct question centred on: looking at the behaviour of the people toward business and the experience the participants have had with people in the two regions, did they think there was anything different or similar concerning the peoples' business attitude? And why they thought so? This aspect addressed the participants' "historical observations" and perceptions on the issue. The undergraduates perceived that the Southeast people, and by extension their graduates, were more likely to pursue entrepreneurial endeavours compared to their South-south counterparts. Therefore, the route provided by the mixed methods research approach for alternative or further investigation of preliminary results is one of the methodological contributions of this study.

Thirdly, the application of the variance-based partial least squares structural equation modelling technique to the study of undergraduates' entrepreneurship intentions is not very common 
looking at the literature previously-reviewed. In fact, none of the studies reviewed (in Table 4.1) applied the variance-based partial least squares structural equation modelling (PLS-SEM) technique. One of its advantages is that the technique can model very many variables simultaneously and conveniently in one model and still converges unlike its covariance-based counterpart used by the other studies reviewed (Hair et al., 2014). A study using data from a developing country, such as Nigeria, to study the perceived regional differences or similarities in entrepreneurship intentions, makes it another contribution to methodology literature.

Fourthly, on practical contributions, this study combined students' perception of their personality traits, attitudes, competencies and external context measures, and focus groups interview approach to finding answers to the drivers of entrepreneurial intentions. The study has identified some useful themes that the researcher suggests the universities and entrepreneurship development programme centres in the two regions should look closely in their quests for finding ways to foster students' interest in entrepreneurship.

Furthermore, the study has attempted to fill the knowledge gap of inter-regional understanding of the drivers of entrepreneurship, specifically the drivers of start-up intentions, of final-year undergraduates of the eleven states in the two regions studied. Although the knowledge is limited to undergraduates' start-up intentions, however, universities can follow up and generate data on the proportion of these undergraduates who later started their businesses, grew and sustained them or failed. Doing this, could help further fill the gap in future inter-regional entrepreneurship analysis. The generated data can be adapted to follow the GEM methodology suggested in Section 2.3. These data are currently unavailable for the two regions studied.

\subsection{Conclusions}

This study extends and contributes to the knowledge of academic research on entrepreneurship and enterprise education, and on the applications of Ajzen's $(1991,2005)$ theory of planned behaviour to entrepreneurship. Also, it extends the application of perception of the individuals' personality traits, perceived capabilities and external context propositions in forming an integrated conceptual framework (ICF) to study the factors that influence undergraduates' entrepreneurial intentions. It argued that by combining the elements of the separate theories and models and simultaneously incorporating the narratives of the undergraduates into the debate offered useful insights into understanding further the debate. The study infers that universities that want to promote positive personal attitudes toward business formation by undergraduates and tackling how undergraduates can control the founding processes and removing the perceived 
barriers to entrepreneurship would benefit more. The benefits would outweigh focusing just on psychological factors such as personality traits, which are less directly controllable but are relatively fixed in individuals (Lüthje and Franke, 2003). The perceived barriers, which are broadly the external contextual factors, institutional barriers present as well as nature of entrepreneurship education the university undergraduates engage in can deeply shape the magnitude and quality of the entrepreneurial intents and actualisation of the different regions or individuals.

Are the factors that foster entrepreneurship similar or dissimilar among undergraduates of Southsouth and Southeast Nigeria? This research argues from the analysis of the quantitative data that the South-south and Southeast undergraduates do not differ significantly in their attitude, outlook, or intents toward entrepreneurship. The basis of this claim is from the analysis of the results of the hypothesised relationships explained by the integrated conceptual framework adopted. Nevertheless, participants in the focus group sessions observed that in the wider society there is some evidence that might also lead them to perceive the Southeast people as being more likely to engage in entrepreneurship activities compared to the South-south people. Also, that it appears graduates of the two regions might follow the same pattern the respondents have observed of the entrepreneurship behaviours and motivations.

However, since individuals are motivated differently toward performing an action and personality traits also influence people's attitude, the knowledge of how undergraduates explain the motives behind their intentions toward entrepreneurship is crucial. This research notes that what would boost the undergraduates' choice of becoming entrepreneurs would be when universities begin to focus more on knowing the motives of students' entrepreneurship intentions. Also, on providing the environment that encourages this intent and leveraging on the specific areas the students are enthusiastic about seeing changes. It concludes that undergraduates explain their motivating factors toward entrepreneurship differently.

Although there has been a sizeable literature reviewed which used quantitative data to delineate the factors that purportedly correlate with students' entrepreneurial intentions, few discussions have been on the specific expectations of the students. Also, very few studies focus on students' "stories" and perspectives offered as "actionable solutions." The mixed methods approach, therefore, demonstrates its usefulness in building a fuller picture that challenges the inadequate attention paid to students' perspectives on what encourages them toward entrepreneurship. Thus, this study claims that investigating, identifying and tackling the specific needs of the undergraduates, and providing the appropriate entrepreneurship education with knowledge, skills and positive attitudes, are indispensable parts of the puzzle in understanding holistically the 
influencing factors of entrepreneurship intentions among the undergraduates studied. Therefore, the universities studied should follow these routes identified to fix the missing puzzle.

\subsection{Limitations of the study}

One of the limitations the researcher suspects might have a potential influence on the findings of this work is about the accuracy of responses students gave on each of the constructs. As expressed earlier in the methodology chapter, this study used questionnaire items from previous works mostly conducted in industrialised countries. The researcher could not totally eliminate the chances of the participants in this study misunderstanding some of the questions of the survey. For example, in completing the questionnaire, there were cases where students drew the researcher's attention and requested for explanations of the meaning of some items. However, the researcher was able to clarify any confusing words where students called for attention. But it is uncertain whether participants who were not bold enough to call for attention for clarifications did not assume different meanings to questions asked. For example on the questionnaire item one (Q11) about measures of entrepreneurial intentions, to the question "I am ready to do anything to be an entrepreneur", some participants misunderstood the question. Some thought it meant "anything" including unethical means. It was not until the researcher clarified that, academicallythinking, the phrase excludes unethical means that most students could then decide their options.

The researcher's presence, however, during the questionnaire administration exercise was helpful in clarifying grey areas of the questionnaire items. In the future, it would be useful during the pilot study stage to vividly emphasise that the participants point out words or phrases that have the potential of misinterpretation by students. Item wordings should consider the given contexts in developing countries as non-native speakers. It would also be useful to generate questionnaire items based mostly on the experiences and peculiarities of the same environment or culture in whose participants the researcher would be studying. This route could likely minimise potential misinterpretations.

Another limitation that might have a potential impact on the findings is the somewhat "personal" way of arriving at the codes and themes in conducting the qualitative phase. There were no other members (researchers) to analyse the transcripts simultaneously to arrive at their codes and themes that the researcher could then compare to determine whether the criterion of inter-coder reliability was met. As highlighted in Chapter Five (Section 5.4.3), the inter-coder agreement helps in verifying the correctness of the codes. Because the researcher submitted no extra names as research assistants who would access the transcripts (data) and, thus, assist in the inter-coder 
agreement exercise; the researcher relied only on his judgement in the coding exercise. To allow others to access the raw data at that stage would create ethical concerns, and there was also a time constraint.

However, the researcher paid due attention to the texts and meanings in deriving the codes and themes; having conducted and transcribed the interviews personally. Also, the researcher highlighted in Section 6.7 the mechanism for deriving the codes and the outcome shown in Appendix 1. Also for future studies, the researcher would like to employ the transcript analysis software, ALCESTE for a more systematic and impersonal coding. After having completed the analysis of the focus group transcripts, the researcher recently had contact with some colleagues at the London School of Economics and Political Science who introduced the software in a methodology training session. The ALCESTE systematically and automatically organises any transcript and arrive at "word classes" or themes that most coherently represent the original texts. Its advantage over the other qualitative analysis software such as the present NVivo is that it eliminates the individual researcher's choices and power of choosing codes and themes, which is more likely subject to interpretations and biases.

The researcher is also aware of the problems in which using a multistage sampling technique can influence outcomes where different samples were grouped into clusters as stated earlier in Section 5.7 (limitations of the methodology). Multistage sampling technique is not completely a random sampling technique. Also, the study did not capture in its conceptual model the impacts of the educational processes that the participants undertook and how those influenced their entrepreneurship intentions and behaviours. However, their importance was signalled in the literature reviewed.

\subsection{Summary of implications and recommendations}

In this subsection as well as the next and following from the summary of the findings of this study, the researcher now highlights the implications of these findings. It also recommends actions for universities studied and their entrepreneurship development centres, entrepreneurship teachers, entrepreneurship development theorists and methodologists, and future researchers.

\section{1) Implication 1 and recommendations for entrepreneurial intentions theorists}

Firstly, the motivations of people, and specifically undergraduates, wishing to take the path of selfemployment through creating their entrepreneurial activities seem to be a major influence on the participants of this study. The challenges, in terms of the barriers identified in this study and the 
"push factor" of widespread graduate unemployment, seem to be relevant for explaining the driving factors of entrepreneurial intentions. It was noted in Chapter Three (Subsection 3.3) that individuals who are "pushed" into entrepreneurship may achieve low or no growth in business. However, Stephan et al. (2015) arguing somewhat differently suggests that what starts as a necessity-driven entrepreneurship might result in "opportunity entrepreneurship", along the stages of development of the economy. Also, necessity-driven entrepreneurship reduces when an economy improves, which then gives rise to improvement-driven opportunity motives. For example, during recessions where many people are retrenched, many people might be driven into self-employment or found businesses with their severance entitlements; thus, they are pushed into creating some income sources. However, as the economy recovers job supply rises and fewer people are pushed into entrepreneurship (Amorós and Bosma, 2014). Thus, an initial push factor might indirectly foster opportunities in the longer term.

However, adopting "push factors" as a driver of entrepreneurship has the potential of creating some negative effects (earlier stated in Section 3.3) as well as "displacement effects" (Sections 4.2.1 and 4.2.6), which can reduce rather than increase employment in the longer term. Thus, developing countries whose population more often engage in necessity entrepreneurship, sometimes understood because of their stage of development, should recognise that there are better routes to approaching entrepreneurship. That is, it is most often better to drive entrepreneurship by the critical exploitation and use of opportunities and innovations rather than out of lack of choices (Krueger and Brazeal, 1994; Shapero, 1984).

Secondly, the preferences of the students in terms of what they expect their universities to provide are a relevant variable. Although the literature recognises factors in the external environment and context as a major influence on entrepreneurial intentions (Lüthje and Franke, 2003), however, it paid less attention to undergraduates' motives and preferences. There is no explicit inclusion of these two dimensions in entrepreneurial intentions models. Thus, this research stresses that including these two factors could improve the model fit of the entrepreneurial intentions construct. It hypothesises that the motives behind students' interest in entrepreneurship, as well as their expectations or preferences from their institutions of learning, could directly influence entrepreneurial intentions. Thirdly, for "push factor" the assumption is that because it is the economic conditions or other "displacing" external factors that instigate it, it can affect entrepreneurship intentions directly (Amorós and Bosma, 2014). Including these factors can ultimately also improve the model fit, although their influences could be either positive or negative depending on the dimensions or levels concerned. 
However, the caution on incorporating the "push factor" variable in the revised model is more relevant for the developing economies, which research notes often have a larger population of their entrepreneurs embracing entrepreneurship because of necessities and displacements. However, in the wider context and for the advanced economies, it might be more plausible to use the alternative "opportunity- or innovation-driven factor" as the motivation for entering entrepreneurship.

For these reasons, this study strongly recommends that if researchers would include these three dimensions in future models; it might raise the R-squared value of the entrepreneurial intentions variable of the integrated conceptual framework. Based on the analysis above, Figure 8.1 below offers a revised integrated conceptual framework for future research on students' entrepreneurial intentions and the influencing factors based on the review findings. Firstly, the deletion of the "support factors" included in the original framework was because it was statistically insignificant in the model analysed. The conceptual reasoning behind the framework is same as those offered in Section 4.3 when the researcher derived the original framework. Secondly, the additions to the model are the "push factor", the three motivational influences (based on Stephan et al., 2015; Amorós and Bosma, 2014) and the four preferences or expectations of students conceptualised as also influencing entrepreneurial intentions. Specifically on the four preferences or expectations, the "practical-oriented" factor comes from suggestions by Solomon (2008), Hills (1988), and Vesper and McMullen (1988). The "experienced entrepreneur" factor comes from insights by Solomon (2008), Solomon et al. (1994), and Klatt (1988). The "internships" factor is added from insights by Luczkiw (2008) and Solomon et al. (2002). Their inclusion follows the conceptual logic reflected in the earlier discussions in Chapter Three on the "context of entrepreneurship education." 


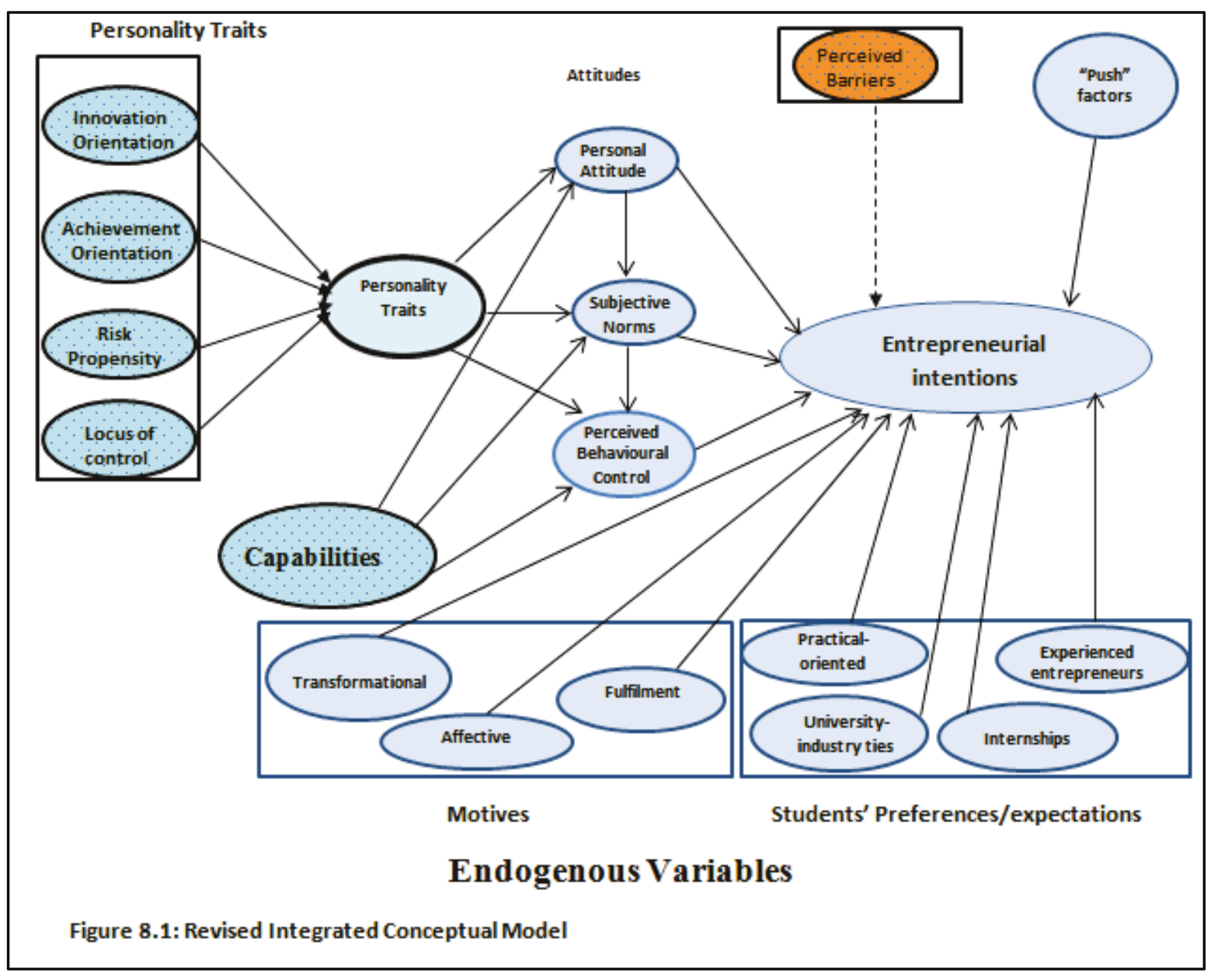

However, this model is yet to be tested with empirical data; it is tentative. So, researchers would have to test it to either confirm or refute its plausibility in other contexts or modify it over time.

\section{2) Implication 2 and recommendations for universities (HEIs)}

Positive personal attitudes toward entrepreneurship discriminate individuals between those who would more likely act entrepreneurially or specifically establish their enterprises and those who would not (Solesvik et al., 2012; Lińän et al., 2011; lakovleva et al., 2011). The survey data and even the transcripts from the focus group interviews indicate that undergraduates in the two regions showed a strong positive attitude toward entrepreneurship. Although in the latter, the evidence based on the participants' perceptions suggests that undergraduates from the Southeast region would more likely go into entrepreneurship than their South-south counterparts. It implies that any adopted mechanism that can influence the attitude, mindset and motivation of individuals could also foster entrepreneurial intents among the undergraduates studied.

As a part of an enterprise education strategy, the study recommends to the universities who want to encourage positive undergraduates' attitudes toward entrepreneurship to invite some successful entrepreneurs regularly to deliver business talks in their universities. They can also 
invite some trade union leaders and non-profit enterprise leaders for these talks too especially individuals who would help encourage the development of more holistic approaches to enterprise creation. They can follow the examples of Stanford University, Singularity University in the USA, and TEDTalks (www.ted.com). For example, Singularity University frequently hosts top entrepreneurs such as Bill Gates (Microsoft founder), Mark Zuckerberg (Facebook founder), and Larry Page (Google co-founder). The talks could motivate students to "dream", "think creative", and "think transformational" toward actions that can solve today's big problems using their ideas and creations. Universities can invite top entrepreneurs from their regions or country. Universities can implement these talks at either faculty or university-wide level. Universities or faculties should identify their core areas such as "how to overcome the fear of starting", "business ideas generation tips", "how entrepreneurs raised capital in practice" as topics or sub-topics for the entrepreneurs (speakers) to handle. The reason is that people need lots of motivation to maintain persistent focus and interest in any pursuit including entrepreneurship (Burchard, 2014). Implementing these recommendations could help achieve this goal faster.

Also, as a part of the enterprise education strategy of the universities, there is value in universities setting up start-up incubators to assist students in testing their various enterprise ideas. Universities can collaborate with one another. Universities whose regions have private or government business incubation centres can also collaborate.

\section{3) Implication 3 and recommendations for entrepreneurship teachers (HE professionals)}

One of the most emphasised concepts during the focus group sessions and perhaps the most worrisome for most students is the non-practical-oriented nature of teaching and learning of most undergraduate courses. The participants enthusiastically expressed their views on this issue: students' belief is that teaching showing practical dimensions of their courses would enhance more students' interest in entrepreneurship. The questions are: "how can university teachers teach more applications than theories?" and "how can lecturers generate and screen business or entrepreneurial ideas from the core courses they teach?" Research shows that lecturers can assume this new role of being entrepreneurial learning facilitators added to their traditional professional roles. Abereijo $(2013,2015)$ illustrated how lecturers can more usefully play this role. They are to teach in such a way that their courses can help students generate multiple entrepreneurial ideas, and the lecturers can screen the ideas.

As highlighted in Chapter Three (Section 3.2.1), if lecturers would think some more through many of their taught courses in the manner suggested by Abereijo's $(2013,2015)$ approach, the outcome 
is that students would more likely have many entrepreneurial ideas and concepts to build on during their study period. In fact, with such ideas many students should be able to team up with other colleagues to start some entrepreneurial activities even during their schooling years or at least build on those ideas after graduation and create businesses.

For lecturers to succeed in this new role, it would imply that teaching a generic entrepreneurship course to all students like universities do in the schools studied would be counter-productive. Lecturers in their fields of expertise are the ones more likely to have the better edge at thinking through deeply in their disciplines to generate the kind of ideas espoused by Abereijo's (2013, 2015) proposal. For this reason, this study recommends that those who would volunteer to teach entrepreneurship courses in their respective departments should at least first receive some retraining to enable them adapt the proposed tutor's approach. University departments or faculties should domicile the teaching of entrepreneurship in their faculties where they can better assist the students achieve their entrepreneurial goals. Nevertheless, willing and interested teachers should undergo some retraining toward teaching entrepreneurship effectively; although this training should be voluntary to respect academic freedom.

4) Implication 4 and recommendations for universities and entrepreneurship teachers (HEIs)

Perceived behavioural control, interpreted in this context as the individual's belief in her ability to control the business-founding processes, can be a challenge if one lacks the practical experience of business formation. A person's judgement, access to role models, social groups or networks, and general proficiency can influence her perceived behavioural control (Ajzen, 2002; Bandura, 1997). Data from the survey analysis suggests that the participants' perceived control beliefs correlated with their entrepreneurial intentions.

This study recommends that to continue encouraging students' perceived control beliefs, HEls should establish mechanisms for identifying students' talents and aspirations early and make concerted efforts at developing at least some of them into businesses. Just as it is a common saying that: "talents should be nurtured and taken to the stage and not to the grave." Universities are in a better place to achieve this. A good example is a case shared by a participant in focus group three. This person pointed how Kwara State University, Nigeria attempts to develop her undergraduates in entrepreneurship. They attach students to a supervisor from year one. Students develop an idea, irrespective of their course; by the end of their 200-levels they write a business plan. By 300-levels, as much as possible, they start a small business (they are encouraged to do so). The university becomes the students' client for the products they are producing. Ideally, a few of some the basic things used in the university environment (i.e. Kwara State University) are 
products from students' start-ups. At graduation, the university expects the students to become independent of the university buying from them as a primary client; at this time, they can then broaden their clientele base. The outcome of this idea is that students can have avenues of developing their entrepreneurial skills on a small scale basis and can then learn whether or not to go large-scale or how to go large-scale.

The Kwara State University's approach is far from perfect; however, schools can adopt their strategies along these lines. Schools can establish feasibly and creative mechanisms to help students exploit and bring their talents and life ambitions to the stage (i.e. market). The overall goal should be to help talented undergraduates focus, discover and develop their future choice of venture early and concentrate energy even during the university days on seeing it started. Universities should better guide undergraduates discover their venture paths early. However, developing the ambitions and talents of undergraduates through entrepreneurship education is not necessarily turning universities into vocational training centres but it is to provide the intellectual tools and skills for potential entrepreneurs to visualise and evaluate opportunities (Zahra and Welter, 2008; Fiet, 2001).

The researcher asserts that universities in the regions studied can do much more in offering concrete platforms that assist students undertake their first enterprises; the platforms offered should also encourage partnerships among students across disciplines. It seems less satisfactory to see most undergraduates, for example in Nigeria, graduating from a four- or five-year university training, and after some months of unfruitful job searches and for some people years, they then begin to think of self-employment. It might be better for undergraduates to seek out the routes to self-employment much earlier during their university study years and then run with their ideas. They should be able to get most of the assistance they require (during those years) to stabilise the business-founding processes and actualise their various entrepreneurial ambitions.

The argument is that many bright enterprise ideas and business formation can be realised during the undergraduate years. This position corroborates with what an entrepreneur, Hermione Way (www.newspepper.com), stated when asked what suggestions to give students in the universities. The response was: "my advice would be to start a business while at university as you will have the resources and talent around you to start, and the risk factor will be much lower at this time than during the rest of your life. I learned more in my first year in business than the entire three years of my degree taught me" (Blundel and Lockett, 2011, p.23). With the right environment and adequate guidance provided, students can start various entrepreneurial activities early in their university days. For example, Facebook's Mark Zuckerberg launched the business with four friends 
from Harvard University's dormitory rooms (Wikipedia, 2015). There are also similar cases in the U.S. and most advanced European nations ((Solomon, 2008; Wilson, 2008).

5) Implication 5 and recommendations for universities and entrepreneurship teachers (HEIs)

The level of capability or competence of people in any place indicates how much knowledge, skills and ability to solve complex problems they have by such people (Trilling and Fadel, 2012). This capability is what distinguishes nations. Entrepreneurial competencies help individuals to use their ideas to create products and services. Industrialised nations have found, among other things, ways of using science and technology capabilities by their citizens and residents; therefore, they produce and generate employment and higher per capita income levels. The non-industrialised nations without these capabilities have lower per capita income (Ogbimi, 2015).

Although the present study did not assess actual entrepreneurial competencies of the participants, it assessed a very useful dimension of competence of potential entrepreneurs. It assessed their "perceived competence" level (Bird, 1995). Results of the survey data analysis suggest that the participants perceived themselves as having competencies in the various dimensions of entrepreneurial dimensions the study assessed. The dimensions included recognising opportunities, generating viable ideas, networking, organising the required key business resources, and building a successful team. But on probing further during the focus group sessions, the analysis (in Section 7.2.1, item 4) suggests that some students might still lack the requisite competencies of founding viable businesses and managing them successfully.

For this reason, this study recommends that, first, universities should assess the entrepreneurial learning capacities of their university properly. They should do this by first defining and assessing its dimensions (i.e. entrepreneurial learning capacities) in collaboration with industry leaders and in "lining up" with what other reputable academic institutions do. They should evaluate the impact of entrepreneurship teaching, learning and knowledge transfers so as to determine the right scale of effort and to identify the most effective forms of action forward. Universities need to become much more flexible if they want to play truly their role in helping young minds figure out what they are passionate about, and acquire the knowledge and skills they need for entrepreneurship activities they want. Thus, the universities should focus on developing "competencies", partly determined by hands-on-experience entrepreneurs and professional associations so that undergraduates master the enterprise-related skills they need. However, there is currently little evaluation evidence available on the entrepreneurship programmes in the universities studied. For example, information on the impact of entrepreneurship teaching on firm start-ups or survival 
rates and the impact of university knowledge transfers on SME productivity and competitiveness would help in better curriculum reviews.

Second, a university should be able to locate entrepreneurial learning models from universities that she considers as having the best-desired qualities of entrepreneurial learning in which she wishes to emulate. Universities must collaborate with other more entrepreneurial HEls. Thus, this means a university should have her "mentor university or universities" in the area of entrepreneurial learning, build on what she can emulate, and so improve on her entrepreneurship development programmes. By this approach, the university can maintain focus and have yardsticks to measure and compare her entrepreneurial learning and impact performances.

\section{6) Implication 6 and recommendations for entrepreneurs (practitioners)}

Research recognises the important roles that practising entrepreneurs can play in complementing the efforts universities make at encouraging entrepreneurship among undergraduates (Luczkiw, 2008; Solomon, 2008). This study found that the participants would find it more useful for experienced entrepreneurs to collaborate with university faculties or specific departments to bridge the perceived gap between practitioners and the academics and by extension practice and theory. In doing this, practitioners should see their collaboration as a contribution to moving developments in entrepreneurship forward and by implication employment, production, economic growth, and industrialisation. Presently, this concerted collaboration happens very much less in the Nigerian university context, from the impressions given by the focus group participants. However, it is possible there might be some collaborations here and there, example at Kwara State University, Illorin ${ }^{12}$, however, the collaborations seem inadequate or haphazard. For example, during the years the researcher taught entrepreneurship development at the University of Calabar, Nigeria (2010-2012), the researcher had no experience of such collaborations at the University of Calabar.

12 Examples of some recent transnational EE intervention projects in Nigeria include: 1). Adesola, S., Bamkole, P. and Beresford, R. 'Enterprise education for employability' under the BIS and British Council Funded PM12 Education Partnership for Africa initiative, 2009 -2011; aimed at promoting and embedding sustainable processes and structures to create an enterprising culture in institutions to impact and contribute towards greater levels of student employability and economic growth in Nigeria; 2). Adesola, S. and Mueller, S. 'Authentic business and responsible entrepreneurship amongst the European and Nigerian students, funded project by Oxford Brookes University, UK and Burgundy Business School, France, 2011 2013. 
Thus, it is recommended that successful entrepreneurs should contribute more by acting as mentors to some promising university entrepreneurs. They can allow undergraduates with brilliant business ideas to undergo internships in the entrepreneur's organisations or recommend them to business friends. The universities could also invite entrepreneurs to be on the curriculum development committees to offer their experiences as inputs for keeping up with current practices.

\section{7) Implication 7 and recommendations for entrepreneurship research methodologists}

Adopting a combination of methods to examine social sciences or behavioural research problems can be the creative and most appropriate research approach in many research situations (Creswell and Plano Clark, 2011). This "heterodox" research approach is particularly useful in cases in which using only one method cannot fully explain the complexities of the issues. Because the researcher considered that the issues of finding what factors explain undergraduates' entrepreneurial intentions is complex, a mixed methods approach enabled the researcher to avoid the pitfall of the "risk of critical misunderstanding." The divergent findings on whether the people of Southeast Nigeria (and by extension their undergraduates) and their South-south counterparts behave differently or not toward entrepreneurship got more insights because of using mixed methods.

The study recommends that complex social and behavioural research problems would need the application of a mixed methods approach for their investigation. For this reason, the outcome of using MMR approach is that the error of the likelihood of researchers arriving at faulty claims to knowledge would reduce. Moreover, a fuller picture from considering the issues from wider perspectives to capture why human participants behave in a certain way, or have certain preferences, or motivated differently could better be achieved by MMR.

\subsection{Recommendations for further research}

The integrated conceptual model proffered in this study creates a guideline for future researchers in the subject area of undergraduate entrepreneurial intentions and the factors that influence such intentions. Future research can adopt this proposed model to test the plausibility of the model. Researchers should adopt the proposed integrated conceptual model and also include the "push" factor, "motives" factors as well as the "students' preferences or expectations" factors. Because this study found these categories as having influences on undergraduates' entrepreneurial intentions, their inclusion and further testing in other cultures could increase knowledge. Researchers need to know how valid and reliable these factors are in other environments or across a wider context such as in other African countries, other developing 
countries or industrialised countries. In fact, researchers should use the revised model presented in Section 8.7 (Item a).

However, researchers should take with caution the suggestion of the plausibility of adopting the three categories or factors as direct influences on entrepreneurial intentions. Before researchers adopt them as a formal component of the model, they should conduct further testing in other contexts. Until researchers do this, these factors can only remain conceptual. More so, to test these new factors, researchers need to raise indicators (or questionnaire items) to measure the dimensions of these factors formally. That is the indicators for the "push", "motives" and "students' preferences" constructs. Here, the "motives" factor includes "transformational", "affective", and "fulfilment" motives. The "students' preferences" factors include "preference for practical-oriented course contents", "preference for experienced entrepreneurs as teachers", "preference for a stronger university-industry ties", and "preference for internships." The suggestion is to conduct a qualitative study and include these factors as direct influences on entrepreneurial intentions and then subject the factors to a formal scale development procedure and exploratory factor analysis (Bryman, 2012).

The researcher notes that one of the salient points of the findings of this research is the participants' enthusiastic call for more practical-oriented course contents as being the most critical factor that could influence their entrepreneurial intentions. For this reason, this research strongly suggests that further studies should unbundle how universities' faculties and departments can drive the processes needed in transforming theoretical and abstract teachings to more practical or applicable contents. For this reason, it suggests as one starting point, the adoption of the modified version of Abereijo's $(2013,2015)$ tutor's guidelines for the hands-on teachings in generating entrepreneurial ideas from core course contents. In Chapter Three (Subsection 3.2.1), the researcher illustrated how this approach could work in a typical course. Retraining university teachers to embrace and master this approach could be a rich area for future research and consultancy, which the researcher would like to explore further. Nevertheless, as stated earlier, this retraining of lecturers must remain voluntary to respect the academic freedom of those who do not want the retraining.

However, because universities exist primarily to develop critical approaches to knowledge as well as research and social or community services (Mathieson, 2015), academics must also contribute to courses that develop critical approaches to business so that the final decision toward setting up businesses, individuals are fully aware of the positive and negative aspects of being involved in entrepreneurship. The reason is that entrepreneurs do not necessarily always act in the best 
interests of the nation but more in their interests. It would, therefore, not be out of place to also suggest for further studies: how to move undergraduates from the entrepreneurial intentions stage to successful business development and growth stage. Research should formalise how undergraduates can work with universities' enterprise development or innovation centres to receive the needed practical guidance in taking ideas from the mind through to the marketplace (Spedding, 2013).

\subsection{Final reflections regarding the doctoral programme experience}

Firstly, looking back at where I began, I can simply say that each stage of the doctoral work introduced me to a different experience but also a challenging task. The preliminary stages seemed the most daunting. The first daunting task was, on arrival in February 2012, how to begin the gathering of relevant literature for intensive reading to improve on the proposal submitted for admission. Using my basic literature search skills, I started by gathering books relating to entrepreneurship among students to know which authors first started the debate. Peer-reviewed journals were the next port of call. I also gathered published magazines and conference proceedings related to entrepreneurship. Because there was so much to read, the need to place a priority on reading what directly related to the proposed research objectives and questions were my first learning experiences. At this stage of reading, the priority was to read and document who wrote what, what was the publication date, and what country did the authors research? What methods did the authors apply, and what were the findings and conclusions? This process helped me in developing the needed initial understanding of the literature and developed the secondary research skills I had from my master's education in Nigeria.

At this stage also, I found that lots of researchers focused on lots of different aspects or perspectives in looking at entrepreneurship among the student population. So, I needed to read what authors wrote in a more critical and analytical manner. Attempting to read with a more critical view was a major research experience for me that I think contributed to increasing my capability to assess secondary sources with a view to taking informed stances. Before, one could accept anything published as the "truth" about an academic issue. But the doctoral research experience of having to read to search for the validity of an argument and its supporting evidence, I am more able to spot shortcomings. Especially the ones associated with authors presenting one side of an issue without thinking of other ways concepts, phenomena, or methods might apply.

Secondly, acquiring experience in primary data collection research data was a very valuable experience for me having to move completely from a background of using only secondary data for 
statistical analysis to using a mix of methods. I experienced first-hand how to design a useful survey instrument as well as undertaking the fieldwork to administer research surveys. It was an experience negotiating access to the 15 universities and 68 departments that took part in the survey as well as organising the focus groups interviews.

Engaging in primary data collection procedures and analysing the data contributed immensely to developing my research skills and would help in my future professional pursuits. Writing up and getting the supervisory team to assess my writing, given their most valuable research and academic experiences to bear on my work, is an indispensable value that added to the doctoral experience. They dealt with issues that arose at every stage of the research milestone and mentored me by suggesting useful strategies for my progression.

Thirdly and lastly, the doctoral journey was very useful for sharpening my time-management skills at the personal and professional levels. To prepare the research chapters needs an extensive reviewing and planning, and these need better organisation of my time; I learned to determine what priorities are and how to attempt to meet them. Initially, I never was very thoughtful about how time-consuming some aspects of the research could be, for example, the comprehensive literature review chapter, so I often slacked. I allowed procrastination and left works till I felt pressured. I often felt overwhelmed when I consider the volume of work to do, so I procrastinate.

However, following my interactions with colleagues, I found a way how some senior doctoral students tackled feelings of being overwhelmed. I found it useful to break every unsurmountablelooking tasks into its constituent parts. Then, I set feasible timelines for completion of each small aspect and start with the first, finish it before moving to the next. This scheme helped me to see my tasks only as a small piece that needed doing, one at a time, rather than the huge overall task. Even though, I am yet to perfect my time-management skills, however, breaking large tasks into manageable pieces and concentrating only on a small unit, one at a time, helped me to progress. This skill would no doubt assist me in future professional and personal career pursuits. 


\section{References}

Abereijo, I. O. (2013). Developing entrepreneurial competencies in university lecturers: Obafemi Awolowo University experience. Paper presented at $1^{\text {st }}$ Africa Entrepreneurship Educators Conference (AEEC), Lagos, Nigeria, 15-17 January. Available at: http://africaeec.org/presentation/day\%203/Developing\%20Entrepreneurial\%20Competences\% 20in\%20University\%20Lecturers\%20(Obafemi\%20Awolowo\%20University\%20Experience)\%20b y\%20Dr\%20lsaac\%20Abereijo.pdf. (Accessed: 20 June 2015).

Abereijo, I. O. (2015). Developing Entrepreneurial Competencies in University Lecturers: Obafemi Awolowo University Experience. KCA Journal of Business Management, 6(1), pp.30-42.

Ăcs, Z. J., Szerb, L. and Autio, E. (2013). The Global Entrepreneurship and Development Index. Cheltenham: Edward Elgar.

Ăcs, Z. J., Szerb, L. and Autio, E. (2014). National Systems of Entrepreneurship. In: Ăcs, Z. J., Szerb, L. and Autio, E. (Ed.) Global Entrepreneurship Development Index. CreateSpace Independent Publishing Platform (Kindle Edition).

Adebayo, O. and Kolawale, J. A. (2013). The Historical Background of Entrepreneurship Development in Nigeria: its Gains, Shortcomings and Needful. Journal of Emerging Trends in Economics and Management Sciences, 4(5), pp.493-500.

Afolabi, O. O., Sanni, M., Egbetokun, A. A., Dada, A.D., Jesuleye, O. A., and Siyanbola, W. O. (2008). Explaining gender effects on entrepreneurial behaviour of students, National Centre for Technology Management (NACETEM) Paper series.

Ahmed, N. and Hoffmann, A. (2012). A Framework for Addressing and Measuring Entrepreneurship. In: Kotzeva, M. and Schmiemann, M. (Ed.) Entrepreneurship determinants: culture and capabilities, Luxembourg: Publications Office of the European Union, pp.18-25.

Aidis, R and Estrin, S. (2014). Institutions, Incentives, and Entrepreneurship. In: Ăcs, Z. J., Szerb, L. and Autio, E. (Ed.) Global Entrepreneurship Development Index. CreateSpace Independent Publishing Platform (Kindle Edition).

Ajzen, I. (1991). A theory of planned behaviour, Organisational Behaviour and Human Decision Processes, 50 (2), pp. 179-211.

Ajzen, I. (2001). Nature and operation of attitudes. Annual Review of Psychology, 52, pp.27-58.

Ajzen, I. (2002). Perceived behavioural control, self-efficacy, locus of control, and the theory of planned behaviour. Journal of Applied Social Psychology, 32(4), pp. 665-683.

Ajzen, I. (2005). Attitudes, Personality and behaviour. New York: Open University Press.

Ajzen, I. and Fishbein, M. (1980). Understanding attitudes and predicting social behaviour. Englewood Cliffs, NJ: Prentice Hall

Akeredolu-Ale, E. O. (1977). The Solutions of Private Indigenous Entrepreneurship in Nigeria: some Under-stressed Factors. In: Industrial Development in Nigeria: patterns, Problems and Prospects, Ibadan: Oxford University Press. 
Akpan, E. (2014). Tackling Factors Inhibiting the Development and Growth of African Diaspora's Enterprises and Entrepreneurship. Available at: http://www.isbe.org.uk/effiongakpan. (Accessed: 23 June 2015).

Aldrich, H., Rosen, B., and Woodward, W. (1987). The impact of social networks on businessfounding and profit: A longitudinal study. Paper presented at the Babson Entrepreneurship Research Conference, Malibu, CA.

Amorós, J. E. and Bosma, N. (2014). Global Entrepreneurship Monitor 2013 Global Report Fifteen Years of Assessing Entrepreneurship Across the Globe. Available at: http://www.babson.edu /Academics/centers/blank-center/globalresearch/gem/Documents/GEM\%202013\%20 Global\%20 Report.pdf (Accessed: 4 June 2015).

Anyanwu, A. (1999). New Perspective of Entrepreneurial Development, Owerri: Klet-Ken Publishers.

Armitage, C. L., and Conner, M. (2001). Efficacy of the Theory of Planned Behaviour: a metaanalytic review. British Journal of Social Psychology, 40(4), pp.471-499.

Athayde, R. (2009). Measuring Enterprise Potential in Young People, Entrepreneurship: Theory \& Practice, 33 (2), pp. 481-500.

Autio, E., Keeley, R. H., Klofsten, M., Parker, G. C. and Hay, M. (2001). Entrepreneurial Intent among Students in Scandinavia and in the USA. Enterprise and Innovation Management Studies, 2(2), pp.145-160.

Bae, T. J., Qian, S., Miao, C. and Fiet, J. O. (2014). The Relationship Between Entrepreneurship Education and Entrepreneurial Intentions: A Meta-Analytic Review. Entrepreneurship: Theory \& Practice, March, pp.217-254.

Bandura, A. (1977). Self-efficacy: Toward a Unifying Theory of Behavioural Change. Psychological Review, 84(2), pp.191-215.

Bandura, A. (1997). Self-efficacy: The exercise of control. New York: Freeman

Barzel, Y. (1997). The economic analysis of property rights. Cambridge, England: Cambridge University Press.

Baumol, W. J. (1990). Entrepreneurship: Productive, Unproductive, and Destructive. Journal of Political Economy, 98 (5), pp.893-921.

Baxter, J. and Eyles, J. (1997). Evaluating Qualitative research in Social Geography: Establishing 'Rigour' in Interview Analysis. Transactions of Institute of British Geographer, 22(4), pp.505-525.

Bello, R. (2015). "Varsities need entrepreneurship training”, Punch Newspaper, 21 June. Available at: http: //www.punchng.com/education/varsities-need-entrepreneurship-training-vc-unilag/ (Accessed: 21 June 2015).

Bergmann, H. (2015). Cultural aspects of entrepreneurship. Available at: http://www.oecd.org/site cfecpr/42202841.pdf (Accessed: 20 June 2015). 
Bergmann, H., Hundt, C. and Sternberg, R. (2013). The Interplay of Individual and Contextual Factors in the Formation of University Start-ups: A Multi-level Analysis of Nascent Entrepreneurs. Available at: http://www.alexandria.unisg.ch/publiktionen/223485 (Accessed: 22 June 2013).

Biesta, G. (2010). Pragmatism and the philosophical foundations of mixed methods research. In: Tashakkori, A. and Teddlie, C. (Ed.) SAGE Handbook of Mixed Methods in Social and Behavioural Research, California: SAGE Publications, Incorporated, pp.95-117.

Bird, B. (1988). Implementing Entrepreneurial Ideas: The Case for Intention. Academy of Management Review, 13(3), pp.442-453.

Bird, B. (1989). Entrepreneurial behaviour. Glenview: Scott, Foresman and Company

Bird, B. (1995). Toward A Theory of Entrepreneurial Competency. In: Katz, J.A. and Brockhaus, R. H. (Ed.). Advances in Entrepreneurship, Firm Emergence, and Growth. Greenwich, CN: JAI Press, pp. 51-72.

Bird, B. J. (2002). Learning entrepreneurship competencies: The self-directed learning approach. International Journal of Entrepreneurship Education, 1(2), pp.203-227.

Block, J. and Sandner, P. (2009). Necessity and opportunity entrepreneurs and their duration in self-employment: evidence from German micro data. Journal of Industry, Competition and Trade, 9(2), pp. 117-137.

Block, Z. and Stumpf, S. A. (1992). Entrepreneurship education research: Experience and challenge. In: Sexton, D. L. and Kasarda, J. D. (Ed.) The state of the art of entrepreneurship, Boston, MA: PWS-Kent Publishing, pp.17-45.

Blundel, R. and Lockett, N. (2011). Exploring entrepreneurship: practice and perspectives. Oxford: Oxford University Press.

Boettke, P. and Coyne, C. (2009). Context matters: Institutions and entrepreneurship. Foundations and Trends in Entrepreneurship, 5(3), pp.135-209.

Boyd, N. G. and Vozikis, G. S. (1994). The Influence of Self-efficacy on the Development of Entrepreneurial Intentions and Actions. Entrepreneurship: Theory \& Practice, 9(1), pp.63-77.

Brännback, M., Carsrud, A., Elfving, J., Kickul, J. and Krueger, N. F. (2006). Why Replicate Entrepreneurial Intentionality Studies? Prospects, perils, and academic reality. Paper presented at SMU Edge Conference, Singapore

Brawer, F. B. (1992). Simulation as a vehicle in entrepreneurship education. ERIC Digest, 97-1, ED, pp.433-468.

Brawer, F. B. (1997). Simulations as a vehicle in entrepreneurship education. ERIC Digest, 97-1, ED 433469.

Bridge, S., O'Neill, K. and Martin, F. (2009). Understanding Enterprise, Entrepreneurship and Small Business. London: Palgrave Macmillan. 
Brockhaus, M. (1987). Entrepreneurial folklore. Journal of Small Business Management, 25, pp.1-6.

Bryman, A. (2012). Social research methods. Oxford: Oxford University Press.

Bryman, A. (2006). Paradigm peace and the implications for quality. International Journal of Social Science Research Methodology, 9(2), pp.111-126.

Bryman, A. and Bell, E. (2011). Business research methods. Oxford: Oxford University Press.

Burchard, B. (2014). The motivation manifesto: 9 declarations to claim your personal power. California: Hay House.

Caird, S. (1989). A Review of Methods of Measuring Enterprise Attributes, Durham University Business School, Occasional Paper Series 8914.

Caird, S. (1992). Problems with Identification of Enterprise Competencies and the Implications for Assessment and Development. Management Education and Development, 23, pp. 6-17.

Caird, S. (2013). General measure of Enterprising Tendency test. Available at: www.get2test.net (Accessed: 7 November 2013).

Campbell, C. A. (1992). A decision theory model for entrepreneurial acts. Entrepreneurship: Theory \& Practice, 17(1), pp.21-29.

Cassar, G. (2007). Money, money, money? A longitudinal investigation of entrepreneur career reasons, growth preferences and achieved growth. Entrepreneurship Regional Development, 19(1), pp.89-107.

Carroll, J. J. (1993). Courses and curriculum design in developing and changing nations: Problems following the U.S. model. Proceedings of the International Council for Small Business, Las Vegas, NV, pp.254-263.

Carsrud, A. and Brännback, M. (2011). Entrepreneurial motivations: what do we still need to know? Journal of Small Business Management, 49 (1), pp. 9-26.

Carsrud, A., Krueger, N., Brännback, M., Kickul, J. and Elfving, J. (2007). The Family Business Pipeline: Where Norms and Modelling Make a Difference. Paper presented at Academy of Management Conference.

Cassel, C., Hackl, P., and Westlund, A. H. (1999). Robustness of partial least squares method for estimating latent variable quality structures. Journal of Applied Statistics, 26(4), pp.435-446.

Chen, N. C., Greene, P. G. and Crick, A. (1998). Does Entrepreneurial Self-efficacy Distinguish Entrepreneurs from Managers? Journal of Business Venturing, 13(4), pp. 295-316.

Chin, W. W. (2010). How to write up and report PLS analyses. In: Vinzi, V. E., Chin, W.W., Henseler, J. \& Wang, H. (Ed.) Handbook of partial least squares: Concepts, methods and applications in marketing and related fields. Berlin: Springer, 655-690.

Cohen, J. (1988). Statistical power analysis for the behavioural sciences. Mahwah, NJ: Lawrence Erlbaum.

Cohen, J. (1992). A power primer. Psychological Bulletin, 112, pp. 155-159. 
Cortina, J.M. (1993). What is coefficient alpha? An examination of theory and applications. Journal of Applied Psychology, 78, pp.98-104.

Creswell, J. W. (1998). Qualitative inquiry and research design: Choosing among five traditions. Thousand Oaks, California: SAGE Publications, Incorporated.

Creswell, J. W. (2009). Research Design Qualitative, Quantitative, and Mixed Methods Approaches. California: SAGE Publications, Incorporated.

Creswell, J. W. and Clark, V. L. P. (2011). Designing and conducting mixed methods research. California: SAGE Publications, Incorporated.

Creswell, J. W. and Miller, D. (2002). Determining validity in qualitative inquiry. Theory and Practice, 39(3), pp.124-130.

Creswell, J. W., Plano Clark, V. L., Gutmann, M. L., and Hanson, W. E. (2003). Advanced Mixed Methods Research Designs. In: Handbook of Mixed Methods in Social and Behavioural Research. Thousand Oaks, California: SAGE Publications, Incorporated, pp.209-239.

Crotty, M. (1998). The foundations of social research: Meaning and perspective in the research process. London: SAGE Publications Incorporated.

Davidsson, P. (1995). Determinants of entrepreneurial intentions. Paper presented at the RENT IX workshop, Piacenza, Italy, November 23-24.

Davidsson, P., and Wiklund, J. (1997). Values, Beliefs and Regional Variations in New Firm Formation Rates. Journal of Economic Psychology, 18(2), pp.179-199.

De Soto, H. (2001). The mystery of capital. London: Black Swan.

Diamandis, P. H. and Kotler, S. (2012). Abundance- The Future is Better Than You Think. New York: The Simon \& Schuster Incorporated.

Dijkstra, T. K. (2010). Latent Variables and Indices: Herman Wold's Basic Design and Partial Least Squares. In: Vinzi, V. E., Chin, W.W., Henseler, J. and Wang, H. (Ed.) Handbook of Partial Least Squares- Concepts, Methods and Applications. Heidelberg: Springer, pp. 23-46.

Dodd, S. D. and Hynes, B. C. (2012). The impact of regional entrepreneurial contexts upon enterprise education. Entrepreneurship and Regional Development, 24(9-10), pp.741-766.

Donckels, R. (1991). Education and entrepreneurship experiences from secondary and university education in Belgium. Journal of Small Business and Entrepreneurship, 9(1), pp. 35-42.

Donovan, J., Mills, N., Smith, M., Brindle, L., Jacoby, A., Peters, T., Frankel, S., Neal, D., and Hamdy, F. (2002). Improving design and conduct of randomised trials by embedding them in qualitative research: ProtecT (Prostate Testing for Cancer and Treatment) study. British Medical Journal, 325, pp.766-769.

Douglas, E. J. and Shepherd, D. A. (2000). Entrepreneurship as a utility-maximizing response. Journal of Business Venturing, 15(3), pp.231-252.

Douglas, E. J. and Shepherd, D. A. (2002). Self-Employment as a Career Choice: Attitudes, Entrepreneurial Intentions, and Utility Maximization. Entrepreneurship: Theory \& Practice, Spring, pp.81-90. 
Duarte, P. A. O. and Raposa, M. L. B. (2010). A PLS Model to Study Brand Preference: An Application to the Mobile Phone Market. In: Vinzi, V. E., Chin, W.W., Henseler, J. and Wang, H. (Ed.) Handbook of Partial Least Squares- Concepts, Methods and Applications. Heidelberg: Springer, pp. 449-485.

Duke, J. E. (2006). Entrepreneurial Strategy for the Economic Development of the Niger Delta Region of Nigeria: a Study of Selected Projects/Organisations in the Region, Ph.D. thesis. University of Calabar, Nigeria.

Dunkelberg, W., Moore, C., Scott, J. and Stull, W. (2013). Do entrepreneurial goals matter? Resource allocation in new owner-managed firms. Journal of Business Venturing, 28(2), pp.225240.

Eberl, M. (2010). An Application of PLS in Multi-Group Analysis: The Need for Differentiated Corporate-Level Marketing in the Mobile Communication Industry. In: Vinzi, V. E., Chin, W.W., Henseler, J. and Wang, H. (Ed.) Handbook of Partial Least Squares- Concepts, Methods and Applications. Heidelberg: Springer, pp. 487-514.

Eisenhauer, J. G. (1995). The entrepreneurial decision: Economic theory and empirical evidence. Entrepreneurship: Theory \& Practice, 19(4), pp.67-79.

Ekanem, N. F. (2010). Management and Entrepreneurship- Two Sides of the Same Coin, Uyo: Abaam Publishing Company.

Elfving, J. (2008). Contextualizing Entrepreneurial Intentions. Abo: Abo Academic Press

Elfving, J., Brännback, M. and Carsrud, A. (2009). Toward A Contextual Model of Entrepreneurial Mind. In: Carsrud, A. L. and Brännback, M. (Ed.) Understanding the Entrepreneurial Mind: Opening the Black Box. International Studies in Entrepreneurship. Heidelberg: Springer, pp. 2333.

Emmanuel, C. L. (2008). Entrepreneurship: A Conceptual Approach, Lagos: Pumark Nigeria Limited.

Enders, C. K. (2001). The impact of non-normality on fill information maximum-likelihood estimation for structural equation models with missing data. Psychological Methods, 6, pp.352370.

Engle, R., Dimitriadi, N., Gavidia, J., Schlaegel, C., Delanoe, S., Alvarado, I., Baume, S., and Wolff, B. (2010). Entrepreneurial intent: a 12-country evaluation of Ajzen's model of planned behaviour. International Behaviour and Research, 16(1), pp. 35-57.

Etzioni, A. (1987). Entrepreneurship, Adaptation and Legitimation: A Macro-behavioural Perspective. Journal of Economic Behaviour and Organization, 8(2), pp.175-189.

Failconer, J. E. and Williams, R. N. (1985). Temporality in human action: An alternative to positivism and historicism. American Psychologist, 40, pp. 1179-1188.

Fayolle, A. and Gailly, B. (2015). The Impact of Entrepreneurship Education on Entrepreneurial Attitudes and Intention: Hysteresis and Persistence. Journal of Small Business Management, 53(1), pp.75-93. 
Fernández-Serrano, J. and Romero, I. (2012). Entrepreneurial quality and regional development: Characterizing SME sectors in low income areas. Papers in Regional Science, 92(3), p.495-513.

Field, A. (2013). Discovering statistics using IBM SPSS statistics. London: SAGE Publications Limited.

Fiet, J. O. (2001). The pedagogical side entrepreneurship theory. Journal of Business Venturing, 16(2), pp.101-117.

Fitzsimmons, J. R. and Douglas, E. J (2011). Interaction between feasibility and desirability in the formation of entrepreneurial intentions, Journal of Business Venturing, 26(4), pp. 431-440.

Forrest, T. (2005). The Makers and Making of Nigerian Private Enterprises, Ibadan: Spectrum Books Limited.

Fowler, F. J., Jr (2009). Survey research methods. California: SAGE Publications, Incorporated.

Fraser, S. (2004). Finance for Small and Medium Sized Enterprises: A Report of the 2004 UK Survey of SME Finance, Warwick University, Coventry, UK.

Frese, M. (2000). Success and failure of microbusiness owners in Africa: a psychological analysis, Westport: Greenwood Publications.

Friedman, B. A., Aziz, N., Keles, I., and Sayfullin, S. (2012). Predictors of Students `Desire to be an Entrepreneur: Kyrgyzstan, Georgia, and the United States. Eurasian Journal of Business and Economics, 5(9), p.129-140.

Fukuyama, F. (2001). Culture and Economic Development: Cultural Concerns. International Encyclopaedia of the Social and Behavioural Sciences. Amsterdam: Elsevier, pp.3130-3134.

Galloway, L. and Brown, W. (2002). Entrepreneurship education at university: a driver in the creation of high growth firms? Education + Training, 44(8/9), pp. 398-405.

Garavan, T. N., and O'Cinneide, B. (1994). Entrepreneurship education and training programmes: A review and evaluation- part 1. Journal of European Industrial Training, 18(8), pp.13-32.

Garson, G. D. (2012). Structural equation modelling. Asheboro, NC: Statistical Publishing Associates.

Gartner, W. B. (1985). A conceptual framework for describing the phenomenon of new venture creation, Academy of Management Review, 10, pp. 696-706.

Gartner, W. B. and Vesper, K. H. (1994). Executive Forum: Experiments in entrepreneurship education: Successes and failures. Journal of Business Venturing, 9(3), pp.179-187.

Gartner, W. B. and Vesper, K. H. (1994). Experiments in entrepreneurship education: Success and failures. Journal of Business Venturing, 9, pp. 179-187.

Gartner, W. B., Bird, B. J., and Starr, J. A. (1992). Acting as if: Differentiating entrepreneurial from organisational behaviour. Entrepreneurship: Theory \& Practice, 16(3), pp. 13-32. 
Gartner, W. B., Shaver, K. G., Gatewood, E. J. and Katz, J. (1994). Finding the entrepreneur in entrepreneurship. Entrepreneurship: Theory \& Practice, 18(3), pp. 5-10.

Garzón, M. D. (2010). A Comparison of Personal Entrepreneurial Competencies between Entrepreneurs and CEOs in Service Sector. Service Business, 4, pp.289-303.

GEM (2012). An abundance of willing and able entrepreneurs encouraged by internal market openness but constrained by government programmes and regulations. Available at: http://www.gemconsortium.org/country-profile/93. (Accessed 4 June 2015).

GEM (2014). Global Entrepreneurship Monitor 2014 Report. Available at: http://knoema.com/fxyrgbf/the-global-entrepreneurship-monitor (Accessed: 29 June 2015).

GEM (2015). Global Entrepreneurship Monitor 2014 Report. Available at: http://knoema.com/fxyrgbf/the-global-entrepreneurship-monitor. (Accessed: 29 June 2015).

Gergen, K. J. (1985). The social constructive movement in modern psychology. American Psychologist, 40, pp. 266-275.

Gilad, B. and Levine, P. (1986). A Behavioural Model of Entrepreneurial Supply. Journal of Small Business Management, 24(4), pp.45-53.

Gird, A. and Bagraim, J. J. (2008). The theory of planned behaviour as predictor of entrepreneurial intent amongst final-year university students. South African Journal of Psychology, 38(4), pp.711-724.

Gorard, S. (2010). Research design, as independent of methods. In: Tashakkori, A. and Teddlie, C. (Ed.) SAGE Handbook of Mixed Methods in Social and Behavioural Research, California: SAGE Publications, Incorporated, pp.237-251.

Gorman, G., Hanlon, D. and King, W. (1997). Some research perspectives on entrepreneurship education, enterprise education, and education for small business management: A ten-year literature review. International Small Business Journal, 15(3), pp.56-77.

Gorman, G., Hanlon, D., and King, W. (1997). Some research perspectives on entrepreneurship education, enterprise education, and education for small business management: A ten-year literature review. International Small Business Journal, 15, pp. 56-77.

Green, M.M. (1947). Ibo Village Affairs. London: Sidwick and Jackson.

Greene, J. C. (2007). Mixed Methods in Social Inquiry (Research Methods for the Social Sciences). San Francisco: Jossey-Bass.

Greene, J. C. and Caracelli, V. J. (2003). Making Paradigmatic Sense of Mixed Methods Practice. In: Handbook of Mixed Methods in Social and Behavioural Research. Thousand Oaks, California: SAGE Publications, Incorporated, pp.91-134.

Greene, J. C. and Caracelli, V. J. (Ed.). (1997). Advances in mixed-methods evaluation: The challenges and benefits of integrating diverse paradigms: New directions for evaluation, 74 . San Francisco: Jossey-Bass. 
Greene, J. C. and Hall, J. N. (2010). Dialectics and Pragmatism: Being of Consequence. In: Tashakkori, A. and Teddlie, C. (Ed.) SAGE Handbook of Mixed Methods in Social and Behavioural Research, California: SAGE Publications, Incorporated, pp.119-143.

Greene, J. C., Caracelli, V. J., and Graham, W. F. (1989). Toward a conceptual framework for mixedmethods evaluation designs. Educational Evaluation and Policy Analysis, 11, pp.255-274.

Guba, E. G. (1990). The alternative paradigm dialog. In: Guba, E. G. (Ed.) The paradigm dialog. Newbury Park, CA: SAGE Publications, Incorporated pp. 17-30.

Gurol, Y. and Atsan, N. (2006). Entrepreneurial characteristics amongst university students: Some insights for entrepreneurial education and training in Turkey, Education + Training, 48 (1), pp.25-38.

Hair, J. F., Black, W. C., Babin, B. J., and Anderson, R. E. (2013). Multivariate data analysis. New Jersey: Pearson Educational Publishers.

Hair, J. F., Hult, G. T. M., Ringle, C. M., and Sardtedt, M. (2014). A primer on partial least squares structural equation modelling (PLS-SEM). Los Angeles: SAGE Publications Inc.

Hair, J. F., Ringle, C. M. and Sarstedt, M. (2011). PLS-SEM: Indeed a silver bullet. Journal of Marketing Theory and Practice, 19, pp. 139-151.

Hair, J. F., Sarstedt, M., Pieper, T. M. and Ringle, C. M. (2012). The Use of Partial Least Squares Modelling in Strategic Management Research: A Review of Past Practices and Recommendations for Future Applications. Long Range Planning, 45, pp. 320-340.

Halliru, M. (2013). The Effect of Culture on the Development of Entrepreneurs among the Hausa Ethnic Group in Northern Nigeria. Journal of Marketing and Management, 4(1), pp.59-73.

Hancock, M. and Fitzsimons, P. (2004). Global Entrepreneurship Monitor 2004, National and Regional Summaries. Kauffman Centre for Entrepreneurial Leadership, Kansas City: Ewing Marion Kauffman Foundation.

Harris, J. R. (1967). Industrial Entrepreneurship in Nigeria. Ph.D. thesis. Northwestern University.

Harrison, R. L. (1983). Strategies for a new age. Human Resource Management, 9, pp. 193-235.

Harrison, R. L. (2013). Using mixed methods designs in the Journal of Business Research. Journal of Business Research, 66, p.2154-2162.

Hesse-Biber, S. N. (2010). Feminist approaches to mixed methods research. In: Tashakkori, A. and Teddlie, C. (Ed.) SAGE Handbook of Mixed Methods in Social and Behavioural Research, California: SAGE Publications, Incorporated, pp.169-192.

Hills, G. E. (1988). Variations in university entrepreneurship education: An empirical study of an evolving field. Journal of Business Venturing, 3, pp. 109-122.

Hills, G. E. (1988). Variations in university entrepreneurship education: An empirical study of an evolving field. Journal of Business Venturing, 3(2), pp.109-122. 
Ho, R. (2006). Handbook of univariate and multivariate data analysis and interpretation with SPSS. Florida: Chapman and Hall/CRC.

Ho, R. (2014). Handbook of univariate and multivariate data analysis with IBM SPSS. Florida: Taylor and Francis Group.

Hodgkin, S. (2008). Telling it all: A story of women's social capital using a mixed methods approach. Journal of Mixed Methods Research, 2, pp.296-316.

Hoffmann, A. and Vestergaard, L. (2012). Measuring Entrepreneurship Education. In: Kotzeva, M. and Schmiemann, M. (Ed.) Entrepreneurship determinants: culture and capabilities. Luxembourg: Publications Office of the European Union, pp.100-108.

Hoffmann, A., Vibholt, N. M., Larsen, M. and Moffett, M. L. (2008). Benchmarking Entrepreneurship Education across US, Canadian and Danish Universities. In: Potter, J. (Ed.) Entrepreneurship and Higher Education. France: OECD, pp.139-164.

Hofstede, G. (1994). Cultures and Organizations: Software of the Mind. Intercultural Cooperation and its Importance for Survival. London: Harper Collins.

Hood, J. N. and Young, J. E. (1993). Entrepreneurship's requisite areas of development: A survey of top executives in successful entrepreneurial firms. Journal of Business Venturing, 8, pp. 115135.

Hornaday, R. H. (1987). Small business managerial types and financial performance: Further evaluation of the Filley and Aldag instrument. Paper presented at the 1987 National Academy of Management meeting, August, New Orleans, LA

Hornaday, R. H. and Nunnally, B. (1987). Problems Facing Black-owned Businesses. Business Forum, fall, pp. 34-37.

Hwang, H. and Powell, W . (2005). Institutions and entrepreneurship. In: S. Alvarez, S., Agarwal, R. and Sorenson, O. (Ed.) Handbook of entrepreneurship research. Boston: Kluwer, pp. 179-210.

lakovleva, T., Kolvereid, L. and Stephan, U. (2011). Entrepreneurial intentions in developing and developed countries. Education + Training, 53(5), pp. 353-370.

Ivankova, N. V. and Stick, S. L (2007). Students' persistence in a Distributed Doctoral Program in Educational Leadership in Higher Education: A mixed methods study. Research in Higher Education, 48(1), pp.93-135.

Jayawarna, D., Rouse, J., and Kitching, J. (2011). Entrepreneur motivations and life course. International Small Business Journal, 31(1), p.34-56.

Johnson, B. and Turner, L. A. (2003). Data Collection Strategies in Mixed Methods Research. In: Handbook of Mixed Methods in Social and Behavioural Research. Thousand Oaks, California: SAGE Publications, Incorporated, pp.297-319.

Johnson, R. B. and Onwuegbuzie, A. J. (2004). Mixed methods research: A research paradigm whose time has come. Educational Researcher, 33(7), pp.14-26. 
Jones, P., Jones, A., Packham, G. and Miller, C. (2008). Student attitudes toward enterprise education in Poland: a positive impact. Education + Training, 50(7), pp.597-614.

Kadir, M. B. A., Salim, M. and Kamarudin, H. (2012). The Relationship between Educational Support and Entrepreneurial Intentions in Malaysian Higher Learning Institution. Procedia-Social and Behavioural Sciences, 69, pp.2164-2173.

Karimi, S., Biemans, H. J. A., Chizari, M., Mulder, M. and Zaefarian, R. (2011). The influence of perceived contextual factors on entrepreneurial intentions among Iranian college students. Available at: http://papers.ssrn.com/sol3/papers.cfm?abstract_id=2152953 (Accessed: 17 December 2014).

Katz, J. A. (1992). A psychosocial cognitive model of employment status choice. Entrepreneurship: Theory \& Practice, 17(1), pp. 29-37.

Kent, C. A. (1990). Entrepreneurship education at the collegiate level: A synopsis and evaluation. In: Kent, C. A. (Ed.) Entrepreneurship Education. New York: Quorum Books.

Kington, A. I., Thomas, R., Markham, S. K., Aima-Smith, L. and Debo, R. (2002). An Integrated Approach to Teaching High Technology Entrepreneurship at the Graduate Level. Proceedings of the 2001 American Society for Engineering Education Annual Conference and Exposition. Albuquerque, NM: American Society for Engineering Education (3554), pp.1-13.

Kirzner, I. M. (1985). Discovery and the Capitalist Process. Chicago: University of Chicago Press.

Klatt, L. A. (1988). A study of small business/entrepreneurial education in colleges and universities. The Journal of Private Enterprise, 4(Fall), pp. 103-108.

Klatt, L. A. (1988). A study of small business/entrepreneurial education in colleges and universities. Journal of Private Enterprise, 4 (Fall), pp.103-108.

Kolvereid, L. (1996). Prediction of employment status choice intentions. Entrepreneurship: Theory \& Practice, 21(1), pp. 47-57.

Krasniqi, B. A. (2009). Personal, household and business environmental determinants of entrepreneurship, Journal of Small Business and Enterprise Development, 16 (1), pp. 146-166.

Krueger, N F., Reilly, M. D., and Carsrud, A. L. (2000). Competing models of entrepreneurial intentions. Journal of Business Venturing, 15(5/6), pp. 411-432.

Krueger, N. F. (1993). The impact of prior entrepreneurial exposure on perceptions of new venture feasibility and desirability. Entrepreneurship: Theory \& Practice, 18(1), pp. 5-21.

Krueger, N. F. (2000). The cognitive infrastructure of opportunity emergence. Entrepreneurship: Theory \& Practice, 24, pp. 5-23.

Krueger, N. F. and Brazeal, D. V. (1994). Entrepreneurship Potential and Potential Entrepreneurs. Entrepreneurship: Theory \& Practice, Spring, pp. 91-104. 
Krueger, N. F. and Carsrud, A. L. (1993). Entrepreneurial intentions: Applying the theory of planned behaviour. Entrepreneurship and Regional Development: An International Journal, 5(4), pp. 315-330.

Kuran, T. (2010). The Scale of Entrepreneurship in Middle Eastern History: Inhibitive Roles of Islamic Institutions. In: Landes, D. S., Mokyr, J. and Baumol, W. J. (Ed.) The invention of enterprise, New Jersey: Princeton University Press, pp.63-87.

Kuratko, D. F. (2005). The emergence of entrepreneurship education: development, trends, and challenges. Entrepreneurship: Theory \& Practice, 29(5), pp. 577-597.

Labaran, A. A. (1987). Land Appropriation and Capitalist Farming in the Sokoto Region: some Preliminary Findings. In: Morimore, M.., Olofin, E. A.., Cline-Ode, R. A., and Abdukadir, A. (Ed.) Perspectives in Land Administration and Development in Northern Nigeria, Kano: Bayero University Department of Geography.

Lavinsky, D. (2012). First-time entrepreneurs' biggest mistake? Lack of capital. Available at: http://www.csmonitor.com/Business/new-economy/2012/1026/First-time-entrepreneursbiggest-mistake-Lack-of-capital. (Accessed: 23 June 2015).

Levie, J. and Hart, M. M. (2013). The contribution of migrants and ethnic minorities to entrepreneurship in the United Kingdom. In: Minniti, M. (Ed.) The Dynamics of Entrepreneurial Activity. Oxford: Oxford University Press, pp. 101-123.

LeVine, R. (1966). Dreams and Deeds: Achievement Motivation in Nigeria. Chicago: The University of Chicago Press.

Lińän, F and Chen, Y. (2009). Development and Cross-Cultural Applications of a Specific Instrument to Measure Entrepreneurial Intentions. Entrepreneurship: Theory \& Practice, 33(3), pp. 593617.

Lińän, F., Urbano, D. and Guerrero, M. (2011). Regional variations in entrepreneurial cognitions: Start-up intentions of university students in Spain. Entrepreneurship and Regional Development, 23 (3/4), pp.187-215.

Lincoln, Y. S. and Guba, E. G. (1985). Naturalistic inquiry. Thousand Oaks, California: SAGE Publications, Incorporated.

Lincoln, Y. S. and Guba, E. G. (2000). Paradigmatic controversies, contradictions, and emerging confluences. In: Lincoln, Y. S. and Guba, E. G. (Ed.) Handbook of qualitative research. Thousand Oaks, California: SAGE Publications, Incorporated, pp.163-188.

Litosseliti, L. (2003). Using focus groups in research. London: Continuum.

Littunen, H. (2000). Entrepreneurship and the characteristics of the entrepreneurial personality. International Journal of Entrepreneurial Behaviour and Research, 6(6), pp.295-309.

Louw, L., Eeden, S. M., Bosch, J. K. and Venter, D. J. L. (2003). Entrepreneurial traits of undergraduate students at selected South African tertiary institutions, International Journal of Entrepreneurial Behaviour and Research, 9(1), pp. 5-26. 
Luczkiw, E. (2008). Entrepreneurship Education in an Age of Chaos, Complexity and Disruptive Change. In: Potter, J. (Ed.) Entrepreneurship and Higher Education. France: OECD, pp.65-93.

Lüthje, C. and Franke, N. (2003). The 'making' of an entrepreneur: testing a model of entrepreneurial intent among engineering students at MIT. $R$ and D Management, 33(2), pp.135-147.

MacDonald, G. (1984). New directions in the economic theory of agency. Canadian Journal of Economics, 17, pp. 415-440.

Macmillan, A. (1968). The Red Book of West Africa, London: Frank Cass.

Man, T. W. Y. and Lau, T. (2000). Entrepreneurial competencies of SME owner/managers in the Hong Kong service sector: A qualitative analysis. Journal of Enterprising Culture, 8(3), pp.235254.

Manicas, P. T. and Second, P. F. (1983). Implications for psychology of the new philosophy of science. American Psychology, pp. 38, 399-413.

Mariano, J. A., Gorgievski, M., Laguna, M., Stephan, U. and Zarafshani, K. (2012). A Cross-Cultural Approach to Understanding Entrepreneurial Intention. Journal of Career Development, 39(2), pp. 162-185.

Mathieson, S. (2015). Student learning. In: Fry, H., Ketterridge, S. and Marshall, S. (Ed.) A Handbook for Teaching and Learning in Higher Education Enhancing Academic Practice. London: Routledge, p.63-79.

McClelland, D. C. (1961). The Achieving Society. New York: Van No Strand.

McGrath, R. G., MacMillan, I. C., Ai-Yang, E. and Tsai, W. (1992). Does Culture Endure, Or is It Malleable? Issues for Entrepreneurial Economic Development. Journal of Business Venturing, 7 , pp. 441-458.

McMullan, W. E. and Long, W.A. (1987). Entrepreneurship education in the nineties. Journal of Business Venturing, 2, pp. 261-275.

McMullen, W. E. and Long, W. A. (1987). Entrepreneurship education in the nineties. Journal of Business Venturing, 3(2), pp.261-275.

McMullen, W. E., Long, W. A. and Wilson, A. (1985). MBA concentration on entrepreneurship. Journal of Small Business and Entrepreneurship, 3(1), pp.18-22.

Merten, D. M. (1998). Research methods in education and psychology: Integrating diversity with quantitative and qualitative approaches. Thousand Oaks, California: SAGE Publications, Incorporated.

Miles, M. B. and Huberman, A. M. (1994). Qualitative data analysis. Newbury Park, CA: SAGE Publications, Incorporated. 
Milner, A. (2012a). Training of Entrepreneurs and Future Challenges for Indicator Construction. In: Kotzeva, M. and Schmiemann, M. (Ed.) Entrepreneurship determinants: culture and capabilities, Luxembourg: Publications Office of the European Union, pp.56-74.

Milner, A. (2012b). Indicator Development: The Culture Determinant. In: Kotzeva, M. and Schmiemann, M. (Ed.) Entrepreneurship determinants: culture and capabilities, Luxembourg: Publications Office of the European Union, pp.110-113.

Mitchell, R. K. and Chesteen, S. A. (1995). Enhancing entrepreneurship expertise: Experiential pedagogy and the new venture expert script. Simulation and Gaming, 26(3), pp.288-306.

Mitra, J. (2012). Entrepreneurship, innovation and regional development. Oxford: Routledge.

Mokyr, J. (2010). Entrepreneurship and the Industrial Revolution in Britain. In: Landes, D. S., Mokyr, J. and Baumol, W. (Ed.) The invention of enterprise. New Jersey: Princeton University Press, pp.183-210.

Morse, J. M. (1991). Approaches to qualitative-quantitative methodological triangulation. Nursing Research, 40, pp.120-123.

Muller, S. L. and Thomas, A.S. (2000). Culture and entrepreneurial potential: A nine-country study of locus of control and innovativeness. Journal of Business Venturing, 16, pp.51-75.

Munro, J. (2010). Tawney's century, 1540-1640: The Roots of Modern Capitalist Entrepreneurship. In: Landes, D. S., Mokyr, J. and Baumol, W. J. (Ed.) The invention of enterprise, New Jersey: Princeton University Press, pp.107-155.

Murray, J. M. (2010). Entrepreneurs and Entrepreneurship in Medieval Europe. In: Landes, D. S., Mokyr, J. and Baumol, W. J. (Ed.) The invention of enterprise, New Jersey: Princeton University Press, pp.88-106.

Natasi, B. K., Hitchcock, J. H. and Brown, L. M. (2010). An Inclusive Framework for Conceptualising Mixed Methods Design Typologies- Moving Toward Fully Integrated Synergistic Research Models. In: Tashakkori, A. and Teddlie, C. (Ed.) SAGE Handbook of Mixed Methods in Social and Behavioural Research. California: SAGE Publications, Incorporated, pp.305-338.

Natasi, B. K., Hitchcock, Sarkar, S., Burkholder, G., Varjas, K. and Jayasena, A. (2007). Mixed methods in intervention research: Theory to adaptation. Journal of Mixed Methods Research, 1(2), pp.164-182.

National Bureau of Statistics (2013). NBS Social Statistics in Nigeria 2012- Part III (Health, Employment, Public, Safety, Population and Vital Registration). Available at: www.nigerianstat.gov.ng (Accessed: 30 October 2013).

National Universities Commission (2013). List of Nigerian universities and years founded. Available at: www.nuc.edu.ng/pages/universities.asp (Accessed: 30 October 2013).

Neck, H. and Greene, P. (2011). Entrepreneurship Education: Known Worlds and New Frontiers. Journal of Small Business Management, 49(1), pp.55-70.

Neuman, W. L. (2000). Social research methods: Qualitative and quantitative approaches. Boston: Allyn and Bacon. 
Newman, I., Ridenour, C., Newman, C., and DeMarco, G. M. P., Jr (2003). A typology of research purposes and its relationship to mixed methods research. In: Handbook of Mixed Methods in Social and Behavioural Research. Thousand Oaks, California: SAGE Publications, Incorporated, pp.167-188.

North, D. (1990). Institutions, institutional change and economic performance. Cambridge, England: Cambridge University Press.

Nwachukwu, C. C. (1990). The Practice of Entrepreneurship in Nigeria, Onitsha; Africana-First Publishers Limited

Obschonka, M., Silbereisen, R. K. and Schmitt-Rodermund, E. (2010). Entrepreneurial intention as developmental outcome. Journal of Vocational Behaviour, 77, pp. 63-72.

Obschonka, M., Silbereisen, R. K., Schmitt-Rodermund, E. and Stuetzer, M. (2011). Nascent entrepreneurship and the developing individual: Early entrepreneurial competence in adolescence and venture creation success during the career. Journal of Vocational Behaviour, 79, pp.121-133.

OECD-Eurostat. (2007). Manual on business demography statistics. Paris: OECD.

Ofonagoro, W. I. (1979). Trade and Imperialism in Southern Nigeria, 1881-1929, New York: Nok Publishers International.

Ogbimi, F. (2015). Lack of knowledge doing more harm than corruption in Nigeria (2). Available at: http://dailyindependentnig.com/2015/01/lack-knowledge-harm-corruption-nigeria-2/ (Accessed: 23 January 2015).

Ohland, M. W., Frillman, S. A., Zhang, G., Brawner, C. E. and Miller, T. K. (2004). The Effect of an Entrepreneurship Programme on GPA and Retention. Journal of Engineering Education, 93(4), pp.293-301.

Okhomina, D.A. (2010). The relationship between personality traits and entrepreneurial behaviour and the moderating role of supporting environment. International Journal of Business and Economic Perspectives, 5(1), pp.139-154.

Olorundare, A. S. and Kayode, D. J. (2014). Entrepreneurship Education in Nigerian Universities: A Tool for National Transformation. Asian Pacific Journal of Educators and Education, 29, pp.155175.

Olutayo, O. A. (1999). The Igbo Entrepreneur in the Political Economy of Nigeria. African Study Monographs, 20 (3), pp.147-174.

Onu, A. J. C. (2013). Stimulating entrepreneurship in educational institutions in Nigeria. European Scientific Journal, 9(25), pp. 38-49.

Onu, A. J. C. (2013). Stimulating Entrepreneurship in Educational Institutions in Nigeria. European Scientific Journal, 9(15), pp.38-49. 
Orugun, J. J. and Nafiu, A. T. (2014). An Exploratory Study of Igbo Entrepreneurial Activity and Business Success in Nigeria as the Panacea for Economic Growth and Development. International Journal of Scientific and Technology Research, 3 (9), pp.158-165.

Paço, A M. F., Ferreira, J. M., Raposo, M., Rodrigues, R. G., and Dinis, A. (2011). Behaviours and entrepreneurial intention: Empirical findings about secondary students, Journal of International Entrepreneurship, 9, pp. 20-38.

Pallant, J. (2013). SPSS survival manual A step by step guide to data analysis using IBM SPSS. Berkshire: Open University Press.

Paulhus, D. (1983). Sphere-specific measures of perceived control. Journal of Personality and Social Psychology, 44, pp. 1253-1265.

Peng, Z., Lu, G. and Kang, H. (2012). Entrepreneurial Intentions and its Influencing Factors: A Survey of the University Students in Xi'an China. Creative Education, 3 (Supplement), pp. 95100.

Philip, D. C. and Burbules, N. C. (2000). Postpositivism and evaluation research. Lanham, NY: Rowman and Littlefield.

Philips, D. C. (1987). Philosophy, science, and social inquiry: Contemporary methodological controversies in social science and related fields of research. Oxford, UK: Pergamon Press.

Plaschka, G. R. and Welsch, H. P. (1990). Emerging structures in entrepreneurship education: Curricula designs and strategies. Entrepreneurship: Theory \& Practice, 14(3), pp.55-71.

Plaschka, W. A. and Welsch, H. P. (1990). Emerging structures in entrepreneurship education: Curricula designs and strategies. Entrepreneurship: Theory \& Practice, 14(3), pp. 55-71.

Potter, J. (2008). Entrepreneurship and Higher Education: Future Policy Directions. In: Potter, J. (Ed.) Entrepreneurship and Higher Education. France: OECD, pp.313-335.

Preshing, W. A. (1991). Education by projects. Journal of Small Business and Entrepreneurship, 9(1), pp. 55-59.

Pruett, M., Shinnar, R., Toney, B., Llopis, F., and Fox, J. (2009). Explaining entrepreneurial intentions of university students: a cross-cultural study. International Journal of Entrepreneurial Behaviour and Research, 15(6), pp. 571-594.

Rasmussen, E. and Sørheim, R. (2006). Action based entrepreneurship education. Technovation, 26, pp. 185-194.

Ravitch, S. M. and Riggan, J. M. (2016). Reason and Rigor: How Conceptual Frameworks Guide Research. Sage Publications Incorporated (Kindle Edition).

Remenyi, D., Williams, B., Money, A. and Swartz, E. (1998). Doing Research in Business and Management- An Introduction to Process and Method. London: SAGE Publications Incorporated.

Renko, M. (2013). Early Challenges of Nascent Social Entrepreneurs. Entrepreneurship: Theory \& Practice, 37(5), pp.1045-1069. 
Renko, M., Kroeck, K.G. and Bullough, A. (2012). Expectancy theory and nascent entrepreneurship. Small Business Economics, 39(3), pp.667-684.

Reynolds, P. D., Camp, S. M., Bygrave, W. D., Autio, E. and Hay, M. (2002). Global Entrepreneurship Monitor GEM 2001 Summary Report. London Business School and Babson College.

Reynolds, P.D. and Curtin, R.T. (2008). Business Creation in the United States: Panel Study of Entrepreneurial Dynamics II Initial Assessment. Foundations and Trends in Entrepreneurship, 4(3), pp.155-307.

Rideout, E. C. and Gray, O. G. (2013). Does Entrepreneurship Education Really Work? A Review and Methodological Critique of the Empirical Literature on the Effects of University-Based Entrepreneurship Education. Journal of Small Business Management, 51(3), pp.329-351.

Ringle, C. M., Sarstedt, M., and Straub, D.W. (2012). A critical look at the use of PLS-SEM in MIS Quarterly. MIS Quarterly, 36, pp.3-14.

Robinson, P. B., Stimpson, D. V., Huefner, J. C. and Hunt, H. K. (1991). An Attitude Approach to the Prediction of Entrepreneurship. Entrepreneurship: Theory \& Practice, Summer, pp. 13-31.

Ronstadt, R. (1987). The educated entrepreneurs: A new era of entrepreneurial education in beginning. American Journal of Small Business, 11(4), pp. 37-53.

Ronstadt, R. (1990). The educated entrepreneur: A new era of entrepreneurial education evolves. In: Kent, C. A. (Ed.) Entrepreneurship Education. New York: Quorum Books, pp.69-88.

Rousseeuw, P. J. and van Zomeren, B. C. (1990). Unmasking multivariate outliers and leverage points. Journal of the American Statistical Association, 85, pp.633-639.

Rychlak, J. F. (1981). Introduction to personality and psychotherapy: A theory-construction approach. Boston: Houghton Mifflin

Sarasvathy, S. D. and Venkataraman, S. (2011). Entrepreneurship as Method: Open Questions for an Entrepreneurial Future. Entrepreneurship: Theory \& Practice, 35(1), pp. 113-135.

Scheinberg, S. and MacMillan, I. C. (1988). An 11 Country Study of Motivations to Start a Business. Frontiers of Entrepreneurship Research. Wellesley, MA: Babson College

Schlaegel, C. and Koenig, M. (2013). Determinants of Entrepreneurial Intent: A Meta-Analytic Test and Integration of Competing Models. Entrepreneurship: Theory \& Practice, (March), pp.291332.

Schmitt-Rodermund, E. (2004). Pathways to Successful Entrepreneurship: Parenting, Personality, Early Entrepreneurial Competence, and Interests. Journal of Vocational Behaviour, 65(3), pp. 498-518.

Schumpeter, J. A. (1934). The Theory of Economic Development: An Inquiry into Profits, Capital, Credit, Interest, and the Business Cycle. Trans. Redvers Opie. Cambridge: Harvard University Press. 
Scott, M. G. and Twomey, D. F. (1998). The long-term supply of entrepreneurs: Student's career aspirations in relation to entrepreneurship. Journal of Small Business Management, 26(4), pp. 5-13.

Sekaran, U. and Bougie, R. (2013). Research methods for business a skill-building approach. Sussex: John Wiley and Sons Limited.

Sexton, D. L. and Upton, N. E. (1988). Entrepreneurship education: Suggestions for increasing effectiveness. Journal of Small Business Management, 22(4), pp.18-25.

Shapero, A. (1984). The entrepreneurial event. In: Kent, C. A. (Ed.) The environment for entrepreneurship. Lexington, MA: C. D. Health, pp. 21-40.

Shapero, A., and Sokol, L. (1982). Social dimensions of entrepreneurship. In: Kent, C. A., Sexton, D. L. and Vesper, K. H. (Ed.) Encyclopaedia of entrepreneurship. Englewood Cliffs, NJ: Prentice Hall, pp.72-90.

Shaughnessy, J., Zechmeister, E. and Jeanne, Z. (2011). Research methods in psychology. New York: McGraw-Hill.

Shaver, K. G. (1995). The Entrepreneurial Personality Myth. Business and Economic Review, 41 (3), pp.20-23.

Shaver, K. G. and Scott, L. R. (1991). Person, Process, Choice: The Psychology of New Venture Creation. Entrepreneurship: Theory \& Practice, Winter, pp. 23-45.

Shea, P. (1975). The Development of an Export-oriented Dyed Cloth Industry in Kano Emirate in the Nineteenth Century. Ph.D. thesis. University of Wisconsin.

Shook, M. E., Priem, R. L. and McGee, J. E. (2003). Venture creation and the enterprising individual: A review and synthesis. Journal of Management, 29 (3), pp. 379-399.

Singer, S., Amorós, J. E. and Moska, D. (2014). Global Entrepreneurship Monitor 2014 Report. Available at: http://www.babson.edu/Academics/centers/blank-center/globalresearch/gem/Documents/GEM\%202014\%20Global\%20Report.pdf. (Accessed: 19 July 2015).

Siyanbola, W. O., Afolabi, O. O., Jesuleye, O. A., Egbetokun, A. A., Dada, A. D., Aderemi, H. O., Sanni, M. and Razak, M. (2012). Determinants of entrepreneurial propensity of Nigerian undergraduates: an empirical assessment. International Journal of Business Environment, 5 (1), pp. 1-29.

Solesvik, M. Z., Westhead, P., Kolvereid, L. and Matlay, H. (2012). Student intentions to become self-employed: the Ukrainian context. Journal of Small Business and Enterprise Development, 19(3), pp.441-460.

Solomon, G. (2008). Entrepreneurship Education in the United States. In: Potter, J. (Ed.) Entrepreneurship and Higher Education. France: OECD, pp.95-118. 
Solomon, G. T., Duffy, S. and Tarabishy, A. (2002). The state of entrepreneurship education in the United States: A nationwide survey and analysis. International Journal of Entrepreneurship Education, 1(1), pp. 65-86.

Solomon, G. T., Weaver, K. M. and Fernald, L. W. (1994). Pedagogical Methods of Teaching Entrepreneurship: An Historical Perspective. Gaming and Simulation, 25(3), pp.67-79.

Solomon, G. T., Weaver, K. M. and Fernald, L. W., Jr (1994). Pedagogical methods of teaching entrepreneurship: A historical perspective. Simulation and Gaming, 25(3), pp. 338-353.

Spedding, K. H. (2013). The really practical guide to starting up your own business. Bloomington: AuthorHouse.

Stake, K. S. (1995). The art of case study research. Thousand Oaks, California: SAGE Publications, Incorporated.

Stephan, U., Hart, M., Mickiewicz, T. and Drews, C. (2015). Understanding motivations for entrepreneurship. Available at: https://www.gov.uk/government/uploads/system/uploads /attachmentdata/file/408432/bis-15-132-understanding-motivations-for-entrepreneurship.pdf (Accessed: 5 June 2015).

Stephen, F. H., Urbano, D. and Hemmen, S. V. (2005). The impact of institutions on entrepreneurial activity. Managerial and Decision Economics, 26(7), pp.413-419.

Stevenson, L. and Lundström, A. (2007). Dressing the emperor: the fabric of entrepreneurship policy. In: Audretsch, D. B., Grilo, I. and Thurik, A. R. (Ed.) Handbook of Research on Entrepreneurship Policy, Cheltenham: Edward Elgar Publishing Incorporated, pp.94-129.

Streeter, D. H., Jaquette Jr, J. P. and Hovis, K. (2002). University-wide entrepreneurship education: Alternative models and current trends. Working paper, Department of Applied Economics and Management, Cornell University, USA.

Stumpf, S. S., Dunbar, L. and Mullen, T. P. (1991). Simulations in entrepreneurship education: oxymoron or untapped opportunity? Frontiers of Entrepreneurship Research, 11, pp. 681-694.

Stumpf, S., Dunber, L. and Mullen, T. P. (1991). Simulations in entrepreneurship education: Oxymoron or untapped opportunity? In: Bygrave, W. D. (Ed.) Frontiers of Entrepreneurship Research, Babson College, Wellesley, MA, pp.681-694.

Tabachnick, B. G.and Fidell, L. S. (2007). Using multivariate statistics. Boston: Pearson International Inc.

Taormina, R. J., and Lao, S. K. (2007). Measuring Chinese entrepreneurial motivation: Personality and environmental influences, International Journal of Entrepreneurial Behaviour and Research, 13(4), pp. 200-221.

Tashakkori, A. and Teddlie, C. (1998). Mixed methodology: Combining qualitative and quantitative approaches, Applied Social Research Methods, No. 46. Thousand Oaks, California: SAGE Publications, Incorporated. 
Teddlie, C. and Tashakkori, A. (2009). Foundations of Mixed Methods Research: Integrating Quantitative and Qualitative Approaches in the Social and Behavioural Sciences. California: SAGE Publications, Incorporated.

Timmons, J. A. (1978). Characteristics and role of demands of entrepreneurship. American Journal of Small Business, 3(1), pp. 5-17.

Tkachev, A. and Kolvereid, L. (1999). Self-employment intentions among Russian students. Entrepreneurship and Regional Development, 11(3), pp. 269-280.

Trilling, B. and Fadel, C. (2012). $21^{\text {st }}$ Century Skills: Learning for Life in Our Times. San Francisco CA: Jossey-Bass.

Truell, A. D., Webster, L. and Davidson, C. (1988). Fostering entrepreneurial spirit: Integrating the business community into the classroom. Business Education Forum, 53(2), pp.28-40.

Truell, A. D., Webster, L. and Davidson, C. (1998). Fostering entrepreneurial spirit: Integrating the business community into the classroom. Business Education Forum, 53(2). pp. 28-40.

Uddin, R. and Kanti, T. (2013). Motivation, Success Factors and Challenges of Entrepreneurs in Khulna City of Bangladesh, 5(16), p.148-157.

Ugwu, F. O. and Ugwu, C. (2012). New Venture Creation: Ethnicity, Family Background and Gender as Determinants of Entrepreneurial Intent in a Poor Economy. Interdisciplinary Journal of Contemporary Research in Business, 4(4), pp.338-357.

Universal Insurance PLC Annual Accounts (2010). Available at: http://www.securities.com/Public /company-profile/NG/Universal_Insurance_Plc_en_2361691.html (Accessed: 6 November 2012).

Van Gelderen, M and Masurel, E. (2012). Entrepreneurship in Context. New York: Routledge.

Van Gelderen, M. V., Brand, M., Van Praag, M., Bodewes, W., Poutsma, E. and Gils, A. V. (2008). Explaining entrepreneurial intentions by means of the theory of planned behaviour. Career Development International, 13(6), pp.538-559.

Vanevenhoven, J. (2013). Advances and Challenges in Entrepreneurship Education. Journal of Small Business Management, 51(3), pp.45466-470.

Vesper, K. H. and McMullen, W. E (1988). Entrepreneurship: Today courses, tomorrow degrees? Entrepreneurship: Theory \& Practice, 13(1), pp. 7-13.

Vesper, K. H. and McMullen, W. E. (1988). Entrepreneurship: Today courses, tomorrow degrees. Entrepreneurship: Theory \& Practice, 13(1), pp.7-13.

Wang, C. L. (2008). Entrepreneurial Orientation, Learning Orientation, and Firm Performance. Entrepreneurship: Theory \& Practice, 32(4), pp.635-657.

Westhead, P., Wright, M. and Mcelwee, G. (2011). Entrepreneurship Perspectives and cases. Harlow, England: Pearson Education Limited. 
Wikipedia (2015). Mark Zuckerberg. Available at: https://en.wikipedia.org/wiki/Mark_Zuckerberg (Accessed: 7 July 2015).

William, E. (2011). The global entrepreneur: how to create maximum personal wealth in the new global economic era. Bloomington: iUniverse.

Williams, N. and Williams, C. C. (2012). Evaluating the socio-spatial contingency of entrepreneurial motivations: A case study of English deprived urban neighbourhoods. Entrepreneurship and Regional Development, 24(7-8), pp.661-684.

Wilson, K. (2008). Entrepreneurship Education in Europe. In: Potter, J. (Ed.) Entrepreneurship and Higher Education. France: OECD, pp.119-138.

Wilson, B. (2010). Using PLS to Investigate Interaction Effects Between Higher Order Branding Constructs. In: Vinzi, V. E., Chin, W.W., Henseler, J. and Wang, H. (Ed.) Handbook of Partial Least Squares- Concepts, Methods and Applications. Heidelberg: Springer, pp. 621-652.

Winslow, E. K., Solomon, G. T. and Tarabishy, A. (1999). Empirical Investigation into Entrepreneurship Education in the United States: Some Results of the 1997 National Survey of Entrepreneurship Education. Paper presented at the 1999 USASBE Conference.

World Bank Ease of Doing Business (2015). Doing Business- Measuring Business Regulations. Available at: http://www.doingbusiness.org/data/exploreeconomies/nigeria\#tenforcing-contracts. (Accessed: 29 June 2015).

$\mathrm{Wu}, \mathrm{S}$. and $\mathrm{Wu}, \mathrm{L}$. (2008). The impact of higher education of entrepreneurial intentions of university students in China. Journal of Small Business and Enterprise Development, 15(4), pp. 752-774.

Yamaichi, H. and Doi, K. (1977). Factorial study of achievement related motives. Psychological Reports, 41, pp. 795-801.

Yin, R. (2003). Case study research: Design and methods. Thousand Oaks, California: SAGE Publications, Incorporated.

Zahra, S. and Welter, F. (2008). Entrepreneurship Education for Central, Eastern and South-eastern Europe. In: Potter, J. (Ed.) Entrepreneurship and Higher Education. France: OECD, pp.165-192. 
Appendix 1

\section{Focus Groups Transcript}

\section{DRIVERS OF ENTREPRENEURIAL INTENTIONS}

\begin{tabular}{|c|c|c|c|}
\hline Questions and Responses & Initial coding & Focused coding & Quote Identification \\
\hline \multicolumn{4}{|l|}{ Focus Group 2} \\
\hline $\begin{array}{l}\text { Question: Why you think the way you think? We're thinking all of us will be entrepreneurs as you } \\
\text { indicated, why do you think so? What has influenced you, what drives you? } \\
\text { 32. "It's because of my passion" }\end{array}$ & $\begin{array}{l}\text {-passion for } \\
\text { entrepreneurship }\end{array}$ & Affective motive & 2JOS.709 \\
\hline $\begin{array}{l}\text { 33. "As someone who wants to be on his own- someone with idea because being on your own may give } \\
\text { you more profits." }\end{array}$ & -profit motives & $\begin{array}{l}\text { Personal fulfilment } \\
\text { motive }\end{array}$ & 2NEL.712 \\
\hline $\begin{array}{l}\text { 34. "...it seems it is societal benefit which I can make as an entrepreneur to society... So, what I really } \\
\text { think is to see how I can bring back this standard of life that's obtainable and well-comforting that's in } \\
\text { the western world. To bring it down to our locality!" }\end{array}$ & $\begin{array}{l}\text {-desire to better the } \\
\text { society }\end{array}$ & Transformational motive & 2INNO740.745 \\
\hline $\begin{array}{l}\text { 35. "I think being an entrepreneur, you have to be creative... instead of me buying it from the stores, why } \\
\text { don't I take my time go learn it and make money for myself." }\end{array}$ & - creative mindedness & Personality trait & 2JUD.748.750 \\
\hline $\begin{array}{l}\text { 36. "Example just like someone selling crayfish in the market, this person is selling, you're selling as well, } \\
\text { what you do at least is to promote that product, add value, increase the quality. You can decide to grind } \\
\text { it, seal it, and label it. Adding quality will generate more customers, it's satisfaction of customers, } \\
\text { bringing higher quality." }\end{array}$ & $\begin{array}{l}\text {-quality of product and } \\
\text { services }\end{array}$ & & 2LAW.758 \\
\hline $\begin{array}{l}\text { 37. "I think being a government employee at the end of the month they pay you } 20,000 \text { naira is not } \\
\text { enough for me." }\end{array}$ & -desire to earn more & Personality trait & 2LAW.767 \\
\hline $\begin{array}{l}\text { 38. "The phobia for civil service, that's what I call "modern slavery" I'm afraid of that. And the love for } \\
\text { doubling profits" (General laughter). }\end{array}$ & -to make more profits & $\begin{array}{l}\text { Personal fulfilment } \\
\text { motive }\end{array}$ & 2ROL.771 \\
\hline $\begin{array}{l}\text { 39. "I see myself, I'm a very creative person and I love to see innovations. That's the reason I'm here. I } \\
\text { love information so much... I love to take risk....But it is better to take risk that's not solution-bound and }\end{array}$ & $\begin{array}{l}\text {-creative personality } \\
\text {-risk taker }\end{array}$ & $\begin{array}{l}\text { Personality trait } \\
\text { Personality trait }\end{array}$ & 2ELKA.783.788 \\
\hline
\end{tabular}




\begin{tabular}{|c|c|c|c|}
\hline \multirow{2}{*}{$\begin{array}{l}\text { Questions and Responses } \\
\text { be branded "the man that failed trying to solve a problem" than to be branded the man that was lazy, } \\
\text { living. I identify problem." }\end{array}$} & Initial coding & Focused coding & Quote Identification \\
\hline & & & \\
\hline $\begin{array}{l}\text { 40. "...it is the love I have for entrepreneurships because I'll have the opportunity to be my own boss. I } \\
\text { can divide my time to suit me, for my family." }\end{array}$ & $\begin{array}{l}\text {-affection toward } \\
\text { entrepreneurship } \\
\text {-being own boss }\end{array}$ & $\begin{array}{l}\text { Affective motive } \\
\text { Personality trait }\end{array}$ & 2STEV.800 \\
\hline $\begin{array}{l}\text { 41. "What will possibly drive me to becoming successful entrepreneur is if you look at the world's } \\
\text { system, it's moved by people we'll classify as world changers... A life that is void of vision is not worth } \\
\text { living in this present world." }\end{array}$ & $\begin{array}{l}\text {-To be impactful } \\
\text {-visionary achiever }\end{array}$ & $\begin{array}{l}\text { Transformational motive } \\
\text { Personality trait }\end{array}$ & 2PET.811.815 \\
\hline $\begin{array}{l}\text { 42. "So what is driving me is that I want to create change of my own, I don't want to be led by only the } \\
\text { legacy others have left behind. I want to carry my own image. I want to also through that means bring } \\
\text { changes and transformation to others." }\end{array}$ & $\begin{array}{l}\text {-change agent, legacy, } \\
\text { transformation }\end{array}$ & Transformational motive & 2PET818 \\
\hline $\begin{array}{l}\text { 43. "Apart from being driven by needs, I think of putting my creative mind, my creative ability, } \\
\text { converting it into tangible or non-tangible products that will not only benefit me but the people!" }\end{array}$ & $\begin{array}{l}\text {-Urge to be productive- } \\
\text { achiever }\end{array}$ & Personality trait & 2ELKA.828 \\
\hline $\begin{array}{l}\text { Focus Group } 3 \\
\text { Question: Let's dig a little into what makes somebody, you, an enterprising graduate, to think the } \\
\text { way we here are thinking, i.e. thinking entrepreneurially. What is it that makes you think you should } \\
\text { become an entrepreneur? (The driving force) }\end{array}$ & & & \\
\hline 66. "For me, I have this passion for new things. Innovation." & -passion for innovation & Personality trait & 3BLE.1221 \\
\hline 67. "passion" & -passion for business & Affective motive & 3GIFF.1222 \\
\hline $\begin{array}{l}\text { 68. "For me there are three things that encourage, right from when I was growing up: exposure, } \\
\text { experience, and satisfaction." }\end{array}$ & $\begin{array}{l}\text {-early exposure, } \\
\text { experience, and } \\
\text { satisfaction }\end{array}$ & $\begin{array}{l}\text { Personal fulfilment } \\
\text { motive }\end{array}$ & 3FATT.1223 \\
\hline $\begin{array}{l}\text { 69. "For me it's freedom. I want to work on projects that I like, not just on what my boss or head thinks. } \\
\text { To be independent." }\end{array}$ & -need independence & Personality trait & 3ROY.1225 \\
\hline 70. "To be innovative" & -innovativeness & Personality trait & 3РATT.1227 \\
\hline 71. "I don't like people bossing me around" & -Need independence & Personality trait & 3HAPP.1228 \\
\hline 72. "Basically, I feel it is lack of job opportunities. Also to maximize profits." & $\begin{array}{l}\text {-lack of employment } \\
\text { opportunities }\end{array}$ & Push factor & 3ADA.1234 \\
\hline $\begin{array}{l}\text { 73. "My own is personality, I wouldn't want someone bossing me around. I want to be independent, } \\
\text { autonomous." }\end{array}$ & $\begin{array}{l}\text {-own boss and } \\
\text { independence }\end{array}$ & Personality trait & 3PATT.123 \\
\hline 74. "For me, it gives me the opportunity to improve on the status quo." & -Desire to see & Transformational motive & 3.ROY.1238 \\
\hline
\end{tabular}




\begin{tabular}{|c|c|c|c|}
\hline Questions and Responses & Initial coding & Focused coding & Quote Identification \\
\hline & improvements & & \\
\hline 75. "To be innovative; moving away from the conventional." & -innovativeness & Personality trait & 3PETT.1239 \\
\hline $\begin{array}{l}\text { 76. "For me, the driving force is satisfaction. What some people go to school to learn to design, I want to } \\
\text { show people it's there in me already." }\end{array}$ & -to achieve success & Personality trait & 3UDU.1240 \\
\hline 77. "What influences me mostly is 'how to fill the gap'. Meet people, make relationship." & $\begin{array}{l}\text {-To contribute and create } \\
\text { relationships }\end{array}$ & Transformational motive & 3MAR.1243 \\
\hline 78. "For me, it is the love to do something I like. Change. Not just skill acquisition" & -a liking for business & Affective motive & 3EMI.1245 \\
\hline 79. “...You end up living from hand to month. I don't want to end up with such life." & - be achiever & Personality trait & 3PATT.1249 \\
\hline $\begin{array}{l}\text { Focus Group } 4 \\
\text { Question: I want to move into the core question. Why do we think we are different from other } \\
\text { students who don't have this kind of mind-set that you have, i.e. desire to go into entrepreneurship? } \\
\text { Why do you think you should be an entrepreneur? } \\
\text { 111. "I feel I can help in complementing government efforts in the area of employment. So, if I can build } \\
\text { up a system that can employ at least 5-10 persons, at least I have made an effort." }\end{array}$ & -To be job creator & Transformational motive & 4UBN.1549 \\
\hline $\begin{array}{l}\text { 112. "Apart from creating jobs we've identified in private and public organizations the quality of decision } \\
\text { policies that we make tend to be weak. For me, I want to add to developing methods, testing and } \\
\text { actually taking position; enhancing quality." }\end{array}$ & $\begin{array}{l}\text {-To create job enhancing } \\
\text { quality }\end{array}$ & Transformational motive & 4FRCS.1554 \\
\hline $\begin{array}{l}\text { 113. "... I found that you can never be rich working for someone; until you take a risk and establish your } \\
\text { own enterprise. So, I decided to quit my job, back then, tried to put together some cash and started } \\
\text { business. Now, I feel relieved." }\end{array}$ & -To be richly successful & Personality trait & 4SHER.1560 \\
\hline $\begin{array}{l}\text { 114. "One has to do with the natural traits in me. I've grown up to understand that every human has... } \\
\text { Actually, if I'm dashed } 200 \text { naira, I see it as a seed to be sown to make profit. That one is in me." } \\
\text { 115. "Socio-economically, I see an entrepreneur as being more influential, I don't believe in political } \\
\text { power too much; I don't believe in office work (civil service)." }\end{array}$ & $\begin{array}{l}\text {-natural trait for profit } \\
\text { making }\end{array}$ & Personality trait & 4KAT.1573 \\
\hline $\begin{array}{l}\text { 116. "So, socio-economically, I want to believe on entrepreneur fares better in terms of cash. I also } \\
\text { believe that, eh the person can manage his time; go to where you want to go to; be where you want to }\end{array}$ & -To be influential & Transformational motive & 4КАТ.1581 \\
\hline $\begin{array}{l}\text { 117. "In the first place, how satisfactory will the government work be? It's not exciting, at the moment. } \\
\text { Civil service is not exciting at all. You just walk in there; you're in an office for three months, you don't } \\
\text { really see what brings out something in you. I feel that my capability will be under-utilised working for } \\
\text { government at this level; may be if you get to the point of big appointments in government and you're }\end{array}$ & -To have job satisfaction & $\begin{array}{l}\text { Personal fulfilment } \\
\text { motive }\end{array}$ & 4КАТ.1593 \\
\hline
\end{tabular}




\section{Questions and Responses}

trying to fix things for government, that's fine but now I don't have that longing to work for government."

118. "The reason I want to be an entrepreneur is... I want to be economic-oriented-in risk-taking, achievement, and innovation. I want to be a solution provider; bring ideas into any business to enable it thrive."

119. "In the area of taking-risk, it's also a risk not to take risk. It's only those who take risk are the people on top."

120. "In the area of achievement, when I establish a business; I want to always be at the top, be successful at my business and strategies, to be the best among many."

\begin{tabular}{|l|l|l|l|}
\hline & Initial coding & Focused coding & Quote Identification \\
\hline it & -be an innovator & Personality trait & \\
\hline be & -be a risk-taker & Personality trait & 4PETA.1601 \\
-be achiever & Personality trait & 4PETA.1603 \\
\hline
\end{tabular}

\section{ENTREPRENEURSHIP DEVELOPMENT COURSE and PREPAREDNESS TOWARD ENTREPRENEURSHIP}

\begin{tabular}{|c|c|c|c|}
\hline Questions and Responses & Initial coding & Focused coding & Quote Identification \\
\hline \multicolumn{4}{|l|}{$\begin{array}{l}\text { Question: Apart from these problems mentioned, what impression do you have about entrepreneurship } \\
\text { development as a subject in terms of its robustness, in terms of its effectiveness in preparing you to } \\
\text { understand what you'll need to do if someone were to give you money and say start up a business? }\end{array}$} \\
\hline $\begin{array}{l}\text { 22. "They just came to class and taught us, they didn't ... we just memorise the book and write the } \\
\text { exam." }\end{array}$ & $\begin{array}{l}\text { only theory just } \\
\text { cramming to pass exams }\end{array}$ & Practical orientation & 1PAT.405 \\
\hline $\begin{array}{l}\text { 23. "We never had any training on entrepreneurship. Like myself, as at that time, we were given the } \\
\text { form, I filled in Agriculture, but I've never gotten any training since then." }\end{array}$ & $\begin{array}{l}\text {-school failed to conduct } \\
\text { training }\end{array}$ & Practical orientation & $10 F F .412$ \\
\hline $\begin{array}{l}\text { 24. "Yes, we've not had any training. Except for when we were in final-year, they invited us to the } \\
\text { Entrepreneurship Centre, where the Director brought some people to talk to us about } \\
\text { entrepreneurship." }\end{array}$ & $\begin{array}{l}\text {-only a talk by guest } \\
\text { speaker }\end{array}$ & Practical orientation & 1PAT.417 \\
\hline 25. "Yes, for an entire semester. It was just of cramming the book and writing the exams." & $\begin{array}{l}\text {-dysfunctional } \\
\text { Entrepreneurship class }\end{array}$ & Practical orientation & 1PAT.424 \\
\hline $\begin{array}{l}\text { 26. "Before now, the one that has to do with practical sessions... as it stands; we told them if we add it } \\
\text { to our credit load, it will affect so many people." }\end{array}$ & -overloaded course work & Practical orientation & 1HAP.428 \\
\hline $\begin{array}{l}\text { Question: Keep the entrepreneurship course in one hand and also look at your course that you've } \\
\text { undergone from year } 1,2,3,4 \text {, in totality how much do you think that has prepared you in developing } \\
\text { the competence, capabilities, and skills to make success in entrepreneurship when you graduate? Do } \\
\text { you think you've been adequately developed given the four-year study and the entrepreneurships } \\
\text { course? } \\
\text { 44. "The problem I'm seeing, we're having as students of marketing and entrepreneurship course in this }\end{array}$ & & & \\
\hline
\end{tabular}




\begin{tabular}{|c|c|c|c|}
\hline $\begin{array}{l}\text { institution is all about the practical aspect. Example, a lecturer will be giving us all the necessary } \\
\text { materials, the textbooks, you can be studying, reading them but someone studying these things and } \\
\text { someone who has been reading and having the practical aspect of it can never be the same... Like in } \\
\text { marketing sometimes I think we are supposed to have like fieldwork, from there you'll learn the practical } \\
\text { aspect of what you're doing." }\end{array}$ & $\begin{array}{l}\text {-absence of practical } \\
\text { orientation }\end{array}$ & Practical orientation & 2LAW.852.860 \\
\hline $\begin{array}{l}\text { 45. "I've seen one problem with the Nigerian education. I've be careful to generalise it because I know if } \\
\text { it is happening in Unical, Uniuyo, and Lagos, then it is happening everywhere in Nigeria. Internship, just } \\
\text { like he said, it is not enough to give us all the theoretical knowledge that we need, equip us so much } \\
\text { theoretically but we'll certainly fail" } \\
\text { 46. "It's not about teaching theory of entrepreneurship added to all the theories we know or give us one } \\
\text { or two practical sessions which might not even be relevant." } \\
\text { 47. "In sum, our institutions should develop more emphasised schemes that will send students to firm } \\
\text { and industries to do internship-one, two, three months internship wouldn't be too much from our } \\
\text { universities, though they may have to collaborate with those industries. I'm emphasising internship." }\end{array}$ & $\begin{array}{l}\text {-absence of practical } \\
\text { orientation } \\
\text {-advocacy for internships }\end{array}$ & $\begin{array}{l}\text { Practical orientation } \\
\text { internship }\end{array}$ & $\begin{array}{l}\text { 2ELKA.890 } \\
\text { 2ELKA.893 }\end{array}$ \\
\hline Questions and Responses & Initial coding & Focused coding & Quote Identification \\
\hline $\begin{array}{l}\text { 48. "The university education so far has equipped us very well, but what I'll look at in the } \\
\text { entrepreneurship concept of a think is that it is introduced at a stage where the future has already gone." } \\
\text { 49. "Another typical example is the football sector. We Africans tend not to make an inch in the ongoing } \\
\text { world cup because our players, at the age of } 25 \text { that's when someone begins to develop football skills. } \\
\text { Whereas the Brazilians, Argentines, they have football academies where people (early) who choose } \\
\text { football start from childhood, so the stage at which entrepreneurships is introduced to us is late." }\end{array}$ & $\begin{array}{l}\text {-late introduction of } \\
\text { entrepreneurship } \\
\text {-late introduction of } \\
\text { entrepreneurship }\end{array}$ & & 2INNO.898 \\
\hline $\begin{array}{l}\text { Question: Let's look at the university and her entrepreneurship development course; do you think } \\
\text { there's something that is stopping other students from thinking entrepreneurially, the way you think? } \\
\text { What problems do you see, what's hindering entrepreneurship among university students? Or is it } \\
\text { that everything is going well, everyone is an entrepreneur? } \\
\text { 80. "For the graduates, some don't have the financial ability." } \\
\text { 81. "Time is a constraint for undergraduates who want to be doing business and joggling with lectures." }\end{array}$ & $\begin{array}{l}\text {-lack of financial capital } \\
\text {-Time constraints }\end{array}$ & Barrier & $\begin{array}{l}\text { 3HAPP.1267 } \\
\text { 3HAPP.1268 }\end{array}$ \\
\hline 82. "I believe the major reason is risk. Most people will want to be secured in job, government job." & -fear of taking risk & Personality trait & 3ANTH.1270 \\
\hline $\begin{array}{l}\text { 83. "...Imagine just coming to class talking about entrepreneurship, only theory, and no practical aspect. I } \\
\text { think it is the course of teaching only theory without practical that deters students' interest." }\end{array}$ & -teaching only theories & Practical orientation & 3FATT.1278 \\
\hline 84. "...some are still scared of taking risk. They only want to take the certificate and some get the loans & -Fear of risk & Personality trait & 3MAR.1287 \\
\hline
\end{tabular}




\begin{tabular}{|c|c|c|c|}
\hline and divert it for greedy purposes." & -crave for certificate & & \\
\hline $\begin{array}{l}\text { 85. "The problem starts early from primary school. Parents and teachers advise you to read certain } \\
\text { course to become doctor, lawyer, accountant etc. To them being in business is nothing, except these } \\
\text { professions. It's this base that's affecting some people. Some were already misinformed during their } \\
\text { secondary school level, so when they come here, it's hard for them." }\end{array}$ & $\begin{array}{l}\text {-wrong course } \\
\text { preferences }\end{array}$ & & 3PETT.1290 \\
\hline $\begin{array}{l}\text { 86. "To me it's laziness. I think most graduates are lazy. Like we engage in this Entrepreneurship Action } \\
\text { Us, ENACTUS), most students would think it's a waste of time." }\end{array}$ & -narrow mindedness & & 3GIFF.1296 \\
\hline 87. "Environmentally, fear of things... Mind-set is a challenge." & -fear of taking risk & Personality trait & 3ROY.1299 \\
\hline $\begin{array}{l}\text { 88. "It is source of capital, adequate specific training on entrepreneurship received, and how to identify } \\
\text { what to do; some people don't know this..." }\end{array}$ & $\begin{array}{l}\text {-lack of financial capital, } \\
\text { lack training }\end{array}$ & Barrier & 3ABA.1303 \\
\hline $\begin{array}{l}\text { 89. "For me, l'll think it's the uncertainty about starting a business. In Nigeria, the kind of business } \\
\text { environment we have is a bit harsh; coupled with our graduates' lack of financial knowledge." } \\
\text { 90. ..."And they don't want to hear anything about you starting up a business because they feel it will } \\
\text { take a long time before they get return from you on their capital. So, people find it easier to get any kind } \\
\text { of job to sort out their lives." }\end{array}$ & $\begin{array}{l}\text {-undue parental } \\
\text { expectation }\end{array}$ & $\begin{array}{l}\text { Locus of control } \\
\text { (Personality trait) }\end{array}$ & 3KEV.1309 \\
\hline $\begin{array}{l}\text { 91. "I think some have to do with our mind set. For example, someone graduating, he's offered say a } \\
\text { 'lesser job', but he'll say I can't take such a small job. But my take is that, "take it, start something, start } \\
\text { somewhere." }\end{array}$ & $\begin{array}{l}\text {-unwillingness to start } \\
\text { small }\end{array}$ & barrier & 3EMI.1319 \\
\hline Questions and Responses & Initial coding & Focused coding & Quote Identification \\
\hline $\begin{array}{l}\text { 92. "It is lack of commitment to start something on your own, most times. I know two brothers; one in } \\
\text { addition to his Geology studies learnt an extra trade but was sort of ridiculed by his other brother as not } \\
\text { being befitting job for a graduate. But today, the story is different between the graduates." }\end{array}$ & $\begin{array}{l}\text {-lack of zeal and } \\
\text { commitment to start }\end{array}$ & barrier & 3GAB.1323 \\
\hline $\begin{array}{l}\text { 93. "I think one thing that has hindered entrepreneurship among undergraduates is where we find } \\
\text { ourselves, our location." }\end{array}$ & & Barrier & \\
\hline $\begin{array}{l}\text { 94. "People don't believe they can start up something that will move the market... not patronizing local } \\
\text { products." }\end{array}$ & -self disbelief & & 3UDU.1331 \\
\hline $\begin{array}{l}\text { 95. "Even that one is just theoretical, no practical applications. Some lecturers come once or twice in a } \\
\text { semester; no one will teach you once or twice and expects you to go out there and practice what you're } \\
\text { being taught. So, even the course itself is nothing to write home about, it's useless." }\end{array}$ & $\begin{array}{l}\text {-lack of practicality of } \\
\text { courses }\end{array}$ & Practical orientation & 3PATT.1340 \\
\hline $\begin{array}{l}\text { 96. "In year two marketing, right now I can't go forward in entrepreneurship, year one, year two, nothing } \\
\text { to write home about." }\end{array}$ & $\begin{array}{l}\text {-dysfunctional courses } \\
\text { toward enterprise }\end{array}$ & barrier & 3ADA.1349 \\
\hline $\begin{array}{l}\text { 97. "I think philosophy of education in Nigeria doesn't encourage entrepreneurship because like it has } \\
\text { been said earlier, from year one, you're told read, get a good grade so you can get a good job. They won't } \\
\text { tell you how you can be innovative, create your own ... be your own employer. But we only encourage } \\
\text { good grade to work in good companies, good government corporations." }\end{array}$ & $\begin{array}{l}\text {-philosophy of education } \\
\text { emphasises no } \\
\text { innovativeness in } \\
\text { business venturing }\end{array}$ & barrier & 3PATT.1359 \\
\hline
\end{tabular}




\begin{tabular}{|c|c|c|c|}
\hline $\begin{array}{l}\text { 98. "In some departments like radiography, I see students being attached for practical training ... but in } \\
\text { marketing, right from year } 1,2,3 \text {, they'll only teach. I've never seen a university who is producing say } \\
\text { pure water asking her marketing students to develop a marketing strategy for them... go sell this for us. } \\
\text { It's not just about sitting in the classroom. In tourism management, they're teaching me tour guide, when } \\
\text { I go out I don't even know it just because you were teaching me in classroom." }\end{array}$ & $\begin{array}{l}\text {-lack of practical } \\
\text { application of content }\end{array}$ & Practical orientation & 3HAPP.1370 \\
\hline $\begin{array}{l}\text { 99. "I remember our tour to Kwara State University for a programme. Students are attached to a } \\
\text { supervisor from year one. You have to develop an idea, irrespective of your course, by } 200 \text { levels you're } \\
\text { almost writing a business plan to start up something. By } 300 \text { levels you're started. Finally, the university } \\
\text { is your client in whatever you're producing. Everything, virtually, what we used while we were there } \\
\text { were products from students' start-ups. At graduation, they expect you to be independent of the } \\
\text { university buying from you as primary client. You can broaden your clientele base." }\end{array}$ & -no adopted prototype & Practical orientation & 3EFFG.1378 \\
\hline $\begin{array}{l}\text { 100. "Even if we have issues on entrepreneurship development course we from marketing department, } \\
\text { some lecturers have tried but it's mostly theoretical than practical. To help us know how to solve } \\
\text { problem ideas, discipline etc. we need something more than from your textbook; we need real life } \\
\text { challenges and situations." }\end{array}$ & $\begin{array}{l}\text {-lack of real life } \\
\text { challenges }\end{array}$ & Practical orientation & 3ADA.1387 \\
\hline $\begin{array}{l}\text { 101. "We need industrial attachment as indicated in the handbook; seminars fieldwork, presentations, } \\
\text { etc., they should be implemented." }\end{array}$ & $\begin{array}{l}\text {-failure of } \\
\text { implementation }\end{array}$ & & 3MAR.1392 \\
\hline Questions and Responses & Initial coding & Focused coding & Quote Identification \\
\hline \multicolumn{4}{|l|}{$\begin{array}{l}\text { Question: Let us look at the course you've undertaken; take a picture of all that you've done from year } \\
1-4, \text { take a look at how the courses are structured and taught, how can you say it has prepared you } \\
\text { toward getting the skills, the confidence that you'll need as an entrepreneur out there? Take a look at } \\
\text { the totality of your course structure and how you've been taught. Can you say it has prepared you } \\
\text { adequately enough or not to face all the things you're going to face as would-be entrepreneur? }\end{array}$} \\
\hline $\begin{array}{l}\text { 121. "I read electrical/electronic engineering. What we've been taught in school most times is } \\
\text { theoretical, not practical. Therefore, having studied this course, made a second class upper, I may not be } \\
\text { able to handle a contract that says, "Come and fix this electrically as second class upper graduate." That } \\
\text { shows you that the background received to preparing us to become entrepreneurs is inadequate." } \\
\text { 122. "So, what we are in school for naturally, for every student, is get a good grade. You can be a } \\
\text { nonentity but if you can cram, cram, get a good grade. If possible, get a } 2^{1} \text {. The background in } \\
\text { Electrical/Electronic Engineering toward entrepreneurship is not solid." }\end{array}$ & $\begin{array}{l}\text {-only theory no practical } \\
\text {-no solid practical } \\
\text { background }\end{array}$ & $\begin{array}{l}\text { Practical orientation } \\
\text { Practical orientation }\end{array}$ & 4UBN.1625 \\
\hline $\begin{array}{l}\text { 123." The way the courses are being structured, starting from " } 100 \text { level" till final-year, I believe that has } \\
\text { prepared me for the challenge ahead. The reason is that starting from } 100 \text { to } 200 \text { levels; I've been } \\
\text { equipped with the theoretical aspects. In the } 300 \text { level we've been equipped with the principles, and our } \\
\text { final-year, we've been equipped with the applications." }\end{array}$ & -the courses prepare well & & 4PETA.1635 \\
\hline
\end{tabular}


124. "But the major problem is that the school management or lecturers at the initial stage did not inform the student, number one, and those courses you're taking from year 1, 2, 3: given us disjointedly, it's supposed to be something that flows. Example is that if you have this one, this is the upshot. But the students just come in like that; cram it on paper... without the in-depth knowledge of it."

125. "...our institutions, the way they were designed tend to be far away from the industry. Whatever lecturers are giving in the university, it's not the place of the lecturer to relate himself with the industry The programmes of the university have not been designed such that the lecturers have exposure of what is helping in the industry. They only give you what they know. And one level of knowledge cannot be enough for everything, that's the truth."

126. "The problem comes from the institution, the society, and the students themselves."

\section{Questions and Responses}

127. "My answer to the question asked is considerably "No." The school, the study I've taken for the last four years now has not prepared me adequately to be an entrepreneur... And when I was growing up, it was not properly identified by my parent and coached to know the kind of training in school they shou send me for. If my parent failed in this, I expected that in my primary and secondary school, the schools should have given me adequate guidance and counselling for me to be able to see where I'm gifted and push me, advise me properly to follow that line. So that when I go through that education, it will only quicken or sharpen that which is natural about me. Now, the primary school failed me; the secondary school failed me; now, I found myself in the higher institution, I was simply failed as well. I think the universities... just like he rightly said, the lecturers will only give you what they have; the same structure that produced them."

\begin{tabular}{|c|c|c|}
\hline $\begin{array}{l}\text {-beginning courses } \\
\text { disjointed }\end{array}$ & & 4SHER.1648 \\
\hline $\begin{array}{l}\text {-university disconnects } \\
\text { from industry }\end{array}$ & University-industry ties & 4FRCS.1665 \\
\hline $\begin{array}{l}\text {-institution, society, and } \\
\text { students }\end{array}$ & & 4FRCS.1685 \\
\hline Initial coding & Focused coding & Quote Identification \\
\hline $\begin{array}{l}\text {-failure to identify } \\
\text { talents/gifts }\end{array}$ & Barrier & 4KAT.1687.1700 \\
\hline
\end{tabular}

\section{ADVICE TO THE VICE CHANCELLOR ON ENTREPRENEURSHIP DEVELOPMENT}

Question: So, if you had a choice, if you were to sit in front of the Vice Chancellor and you're to advise him on what is to be done in order to prepare you to become an entrepreneur, what will you say?

27. ".... before the Youth Service, you should be able to make us undergo a kind of training, if he actually loves the outgoing students, he should organize training coordinated by the GSS Department on Entrepreneurial Studies."

28. "The VC should establish a practical centre, just like my colleague said where we'll be practicalising our studies. He should also release money to the centres to see that we achieve what we wanted."

29. "...since we have a course called entrepreneurship, it should be expanded and make it more practical than the theory aspect. And that some other courses that are more of practical, like we are from

Anatomy department, our course is more of practical and theory; more funds should be put into the

\begin{tabular}{|l|l|l|}
\hline $\begin{array}{l}\text {-proper training after } \\
\text { degree exams }\end{array}$ & Practical orientation & 1 PFF.439 \\
\hline $\begin{array}{l}\text {-practical centre for } \\
\text { business basics }\end{array}$ & Practical orientation & 1HAP.446 \\
\hline $\begin{array}{l}\text {-localise training not just } \\
\text { generically }\end{array}$ & & 1PAT.456 \\
\hline
\end{tabular}




\begin{tabular}{|c|c|c|c|}
\hline department to enable the students do their practical sessions." & & & \\
\hline 30. "My colleagues have rightly put it; first of all, you need to have the idea of what you want to do." & $\begin{array}{l}\text {-teach business } \\
\text { generation ideas }\end{array}$ & Practical orientation & 1AUS.474 \\
\hline $\begin{array}{l}\text { 31. "In year one, a form should be issued; you fill it, what you want to do! What do you like doing best at } \\
\text { your leisure time...As one is graduating therefore, you'll come out with a certificate and a skill (trade)"? }\end{array}$ & $\begin{array}{l}\text {-start idea identification } \\
\text { earlier }\end{array}$ & Practical orientation & $1 \mathrm{INI} .476$ \\
\hline $\begin{array}{l}\text { Question: Let's say if you are to have an audience with the VC of your university and you're free to say } \\
\text { anything point blank on what he can do to make most students to begin to think entrepreneurial the } \\
\text { way you think, the way your mentality is, what will you say? } \\
61 . \text { "I'll tell the VC that the already structured entrepreneurial programmes should be improved." }\end{array}$ & $\begin{array}{l}\text {-Improve structure of } \\
\text { Course }\end{array}$ & & 2LAW.1009 \\
\hline $\begin{array}{l}\text { 62. "The VC should develop the study of entrepreneurships in all angle of study in this university. By } \\
\text { giving free interest loans to student who may like to go into their business." }\end{array}$ & -Loans to students & barrier & $2 J O E .1011$ \\
\hline $\begin{array}{l}\text { 63. "...in Covenant, Madonna and other universities, you find students being sent out to study during } \\
\text { vacation, outside the university environment.... I'll still insist on internship. It's not the only way that } \\
\text { you're not just developing theoretical students who can talk everywhere but cannot put to practice } \\
\text { what they say verbally." }\end{array}$ & -internship to all & internship & 2ELKA.1025.1019 \\
\hline Questions and Responses & Initial coding & Focused coding & $\begin{array}{l}\text { Quote } \\
\text { Identification }\end{array}$ \\
\hline $\begin{array}{l}\text { 64. "I'll tell him he should make entrepreneurship more practical, separate entrepreneurship from any } \\
\text { other course where a lecturer can just come in and teach in class and read from his book or jotter. It } \\
\text { should be more practical, it shouldn't be always in the class." }\end{array}$ & $\begin{array}{l}\text {-practical } \\
\text { entrepreneurship }\end{array}$ & Practical orientation & 2PET.1023 \\
\hline 65. "I'll tell him to let entrepreneurship be handled by experienced entrepreneurs." & $\begin{array}{l}\text {-experienced } \\
\text { entrepreneurs to teach }\end{array}$ & $\begin{array}{l}\text { experienced entrepreneur } \\
\text { as teacher }\end{array}$ & 2INNO.027 \\
\hline $\begin{array}{l}\text { Question: Looking at the entrepreneurship development course in your university, you are now seated } \\
\text { with the VC of your University, say in a meeting where you're free to bear your mind on, how the VC } \\
\text { can enhance the course in your University", what would you say to the VC? } \\
\text { 128. "I'Il tell her please intensify and re-structure the entrepreneurial development course." Intensify in } \\
\text { the sense that practical approach should be introduced to the study of entrepreneurship." } \\
\text { 129. "She should also send the lecturers teaching this course for an advanced retraining so they can be } \\
\text { effective." }\end{array}$ & $\begin{array}{l}\text {-practical side of } \\
\text { entrepreneurship } \\
\text {-retrain entrepreneurship } \\
\text { lecturers }\end{array}$ & $\begin{array}{l}\text { experienced entrepreneur } \\
\text { as teacher }\end{array}$ & $\begin{array}{l}\text { 4KAT.1733 } \\
\text { 4KAT.1735 }\end{array}$ \\
\hline $\begin{array}{l}\text { 130. "...She should relook at the design of the university and make it to be business-like. In the sense } \\
\text { that you have centre for entrepreneurial studies, they've not undertaken any feasibility studies for any } \\
\text { companies, as much as I'm aware." }\end{array}$ & $\begin{array}{l}\text {-make the university } \\
\text { entrepreneurial }\end{array}$ & University-industry ties & 4FRCS.1739 \\
\hline $\begin{array}{l}\text { 131. "That creativity should be encouraged, supported, and propagated. Creativity is in the sense that } \\
\text { you give people room to come out of the box and create things extra-ordinary." }\end{array}$ & $\begin{array}{l}\text {-teach and encourage } \\
\text { creativity }\end{array}$ & Practical orientation & 4UBN.1747 \\
\hline
\end{tabular}




\begin{tabular}{|l|l|l|}
\hline 132. "And the school helps the person finance the project, put it to fruition." & -University finance start- \\
ups
\end{tabular}

\section{THE SOUTHEAST AND SOUTH-SOUTH PEOPLE'S ENTREPRENEURIAL ATTITUDE AND BEHAVIOUR}

\begin{tabular}{|c|c|c|c|}
\hline Questions and Responses & Initial coding & Focused coding & $\begin{array}{l}\text { Quote } \\
\text { Identification }\end{array}$ \\
\hline $\begin{array}{l}\text { Question: let's look at those from the South-south states, you know these state and the tribes there. } \\
\text { Do you think that these people have the same liking for business? Do they like business the same } \\
\text { among them. Or it's different? Do they do business the same way like the people from the Southeast, } \\
\text { the Igbos? Reflect on, recall your business experience with people from these two ethnicities and then } \\
\text { tell us what you think. } \\
\text { 50. "When it comes to business, I'll give it to the South easterner. Right from birth... (General laughter). } \\
\text { I'll give you reasons, because I grew up in Lagos where we live among people from the major tribes. I } \\
\text { have a neighbour who is an Igbo, his child is } 10 \text { years old, and he sent the child to their village to learn a } \\
\text { trade then go to school. In South-south here, most of us like white-collar jobs." }\end{array}$ & $\begin{array}{l}\text {-SE early childhood } \\
\text { introduction to enterprise } \\
\text { advantage }\end{array}$ & Culture & 2INNO.939 \\
\hline $\begin{array}{l}\text { 51. "The South easterners believe that instead of staying idle at house they like to come up with } \\
\text { something that will help them be on their own." }\end{array}$ & $\begin{array}{l}\text {-SE industry orientation } \\
\text { advantage }\end{array}$ & Business-oriented & 2JUD.946 \\
\hline $\begin{array}{l}\text { 52. "I will say people from the Southeast are patient. The South-south person will want to invest today, } \\
\text { tomorrow he wants the profit immediately realised. The Igbo people are patient when it comes to } \\
\text { business." }\end{array}$ & -SE persistence & culture & 2INNO.948 \\
\hline $\begin{array}{l}\text { 53. "I think it has to do with culture-the way of life of the people. The Igbos children grow up to see their } \\
\text { parents being businessmen, so some of them will go to become also businessmen because they've been } \\
\text { in the family they learn the trade from them." }\end{array}$ & $\begin{array}{l}\text {-SE business parents } \\
\text { advantage }\end{array}$ & Early introduction & 2JOE.951 \\
\hline $\begin{array}{l}\text { 54. "So far as, Igbo they like being bosses of their own. They don't like depending on people. That's why } \\
\text { they're independent." }\end{array}$ & $\begin{array}{l}\text {-SE prefer independence } \\
\text { and own boss }\end{array}$ & culture & 2STEV.961 \\
\hline $\begin{array}{l}\text { 55. "The Igbos, I see them to be more profit-oriented than product-oriented." } \\
\text { 56. "I'Il say that the South-southerners prefer to, although identify the problem, like to get to know the }\end{array}$ & $\begin{array}{l}\text {-SE more profit- } \\
\text { motivated }\end{array}$ & Business-oriented & 2ELKA.967 \\
\hline
\end{tabular}




\begin{tabular}{|c|c|c|c|}
\hline $\begin{array}{l}\text { processes involved and count the risk, is it worth the risk, is it worth venturing into? And where it is not, } \\
\text { they opt out immediately. Someone said "patience"; South-southerners are not that those who will } \\
\text { withstand ... not so much risk bearers, Igbo are even... if it is to the point of putting their life on the line, } \\
\text { as long as it is profit oriented, can go for it to meet the people's need and to meet their own needs." }\end{array}$ & $\begin{array}{l}\text {-SE more profit- } \\
\text { motivated }\end{array}$ & Business-oriented & \\
\hline \multicolumn{4}{|l|}{$\begin{array}{l}\text { Question: A very short but important question. Do we all know where the South-south is-6 states? } \\
\text { Now from your knowledge of these areas how do you think people take to self-employment and } \\
\text { entrepreneurship? Do people from this area - ljaws, Efiks, Oron, Bini, and lbibio-entrepreneurship? } \\
\text { Do they have the same attitude to entrepreneurship compared to the others within the region? }\end{array}$} \\
\hline $\begin{array}{l}\text { A unanimous 'No' answer chorused! } \\
\text { 102. "Within the South-south, attitudes are different also in business approach." }\end{array}$ & $\begin{array}{l}\text {-locational differences } \\
\text { exist }\end{array}$ & Culture & 3HAPP.1400 \\
\hline $\begin{array}{l}\text { 103. "Because of locational differences, I think within the South-south itself, what an ljaw man would like } \\
\text { to venture into is not what an Akwa Ibom man will like to venture into. ljaw man might like fishing, Akwa } \\
\text { Ibom man driving or other business." }\end{array}$ & $\begin{array}{l}\text {-intra-regional differences } \\
\text { exist }\end{array}$ & & 3ADA.1401 \\
\hline Questions and Responses & Initial coding & Focused coding & $\begin{array}{l}\text { Quote } \\
\text { Identification }\end{array}$ \\
\hline \multicolumn{4}{|l|}{$\begin{array}{l}\text { Question: So, there's disparity in attitude between different people in Southeast (Igbos) How do you } \\
\text { compare the entrepreneurial attitude of the Igbos with the South-south? }\end{array}$} \\
\hline $\begin{array}{l}\text { 104. "According to my belief, I feel the Igbo people are quite business-oriented. They start from the } \\
\text { grassroots. They make sure they get people from the family into the business. They get someone either } \\
\text { from the village. I feel they have the same manner, likewise sense of entrepreneurship." }\end{array}$ & $\begin{array}{l}\text {-SE inculcate business } \\
\text { sense from early } \\
\text { childhood }\end{array}$ & $\begin{array}{l}\text { Early childhood business- } \\
\text { oriented }\end{array}$ & 3ADA.1408 \\
\hline \multicolumn{4}{|l|}{$\begin{array}{l}\text { Question: The last issue is: take a look at the people of South-south states-Akwa lbom, Cross River, } \\
\text { Rivers, Bayelsa, Edo and Delta. Take a look at how they do business, the way they like or dislike } \\
\text { business. Their attitude and all that, and compare that with people from the Southeast states-Abia, } \\
\text { Imo, Enugu, Anambra and Ebonyi (the Igbos). Look at their behaviour toward business and the } \\
\text { experience you've had with them, these two regions, do you think there's anything different or similar } \\
\text { about their business attitude? Why do you think so? }\end{array}$} \\
\hline $\begin{array}{l}\text { 135. "The attitude of a businessman from the South-south is not "customer-centric" or "customer- } \\
\text { centred." They treat customers like chaff... if you go to buy something, say a shop, they might expect } \\
\text { you to get them the change (balance). Whereas a typical Igbo man, for instance, will go the extra mile } \\
\text { making sure the customer is pleased, make you happy, etc. Before you know, you've given him all your } \\
\text { money (purchased)." } \\
\text { 136. "The two are different. The Igbos method of business is that they always pass through serial } \\
\text { mentorship. Someone will be under somebody for many years, learn the trade, and graduates; a similar }\end{array}$ & $\begin{array}{l}\text {-SE adopt serial } \\
\text { mentorship }\end{array}$ & Business-oriented & 4UBN.1769 \\
\hline
\end{tabular}




\begin{tabular}{|c|c|c|c|}
\hline business is handed over to him as settlement. So, that mentorship is there." & & & \\
\hline \multicolumn{4}{|l|}{$\begin{array}{l}\text { Question: Let's say that whatever you're saying that is applicable to the Southeast people that you see } \\
\text { outside, the same might be the case for graduates who are indigenes of Southeast, and vice-versa for } \\
\text { South-south? Okay? Would that be correct? }\end{array}$} \\
\hline \multicolumn{4}{|l|}{ All answered "YES"!!! } \\
\hline $\begin{array}{l}\text { 137. "In the Southeast, the level of exposure, even at tender age from five years, a young man sees } \\
\text { people doing business as most successful. In the core South-south (e.g. Akwa lbom), the people rated } \\
\text { successful are the key-office and position holders." }\end{array}$ & $\begin{array}{l}\text {-SE don't see } \\
\text { businessmen as truly } \\
\text { successful }\end{array}$ & Culture & 4FRCN.1798 \\
\hline $\begin{array}{l}\text { 138. "I'll start by saying that in comparison, I think I'll vote Southeast. Their culture, their natural } \\
\text { instinct, and from my personal interaction with them are my reasons. Their knack for business is } \\
\text { shown. They have the consistency toward business... You'll see an Igbo man have a provision shop and } \\
\text { sells it for } 30 \text { years; that single one, he can own like } 10 \text { across the city but he's still maintaining that one } \\
\text { old shop. Hardly will you see them today here; next tomorrow there. Because one thing in business is } \\
\text { there must be consistency." }\end{array}$ & $\begin{array}{l}\text {-SE consistency culture } \\
\text { encourage enterprise }\end{array}$ & Culture & 4KAT.1811 \\
\hline $\begin{array}{l}\text { 139. "They have the mentorship factor." } \\
\text { 140. "They have this natural knack for business than us. We here, it is education, academic } \\
\text { preference. No matter how you make it in business here, as he rightly said, you may not be respected, } \\
\text { except you're sitting down in one ministry, or handling one government whatever. Prestige is more in } \\
\text { academia and paid work than in business for a typical South-southerner. So, this seriously discourages } \\
\text { people; people take business as a second fiddle to just make up, a substitute." }\end{array}$ & $\begin{array}{l}\text {-SE mentorship factor } \\
\text {-less respect for } \\
\text { successful businessmen }\end{array}$ & $\begin{array}{l}\text { Serial mentorship } \\
\text { Culture }\end{array}$ & $\begin{array}{l}\text { 4KAT.1813 } \\
\text { 4КАT.1818 }\end{array}$ \\
\hline 141. “The South-south seems less business-oriented compared to their Southeast counterpart.” & $\begin{array}{l}\text {-SS less business- } \\
\text { oriented }\end{array}$ & Business-oriented & 4SHER.1826 \\
\hline
\end{tabular}

\section{REASONS FOR THE OBSERVED DIFFERENCES}

Question: So what do you think makes them that way? From guts feeling... or anyone from Igbo, or have you heard anything on this?

57. "The motives, there's a difference between the way the Southeast operate in business. They are so dedicated to business more than the South-southerners involved in business."

58. "....and I hear culture, I accept their quest and desire for things, and most times money is very high. And the only way they think they can realize this cash they're in need of it, without anybody cheating or playing on them, are go into business. At the end I see them realise the goals. This profit motive drives."

59. "They have this love for it."

60. "Two, instead of believing they have to go and buy this thing where people are in need of, they

believe they can produce it. Because most of the things we use today are made by the Igbos. So, instead,

\begin{tabular}{|l|l|l|}
\hline $\begin{array}{l}\text {-SE and SS business } \\
\text { motives different }\end{array}$ & Culture & 2PET.990 \\
$\begin{array}{l}\text {-SE believe business is } \\
\text { better route to big } \\
\text { wealth achievement }\end{array}$ & Business-oriented & 2PET.993 \\
\hline $\begin{array}{l}\text {-SE deep affection for } \\
\text { business }\end{array}$ & Business-oriented & 2JUD.998 \\
2JUD.999
\end{tabular}




\begin{tabular}{|c|c|c|c|}
\hline they try to satisfy those needs.." & -SE self-belief & & \\
\hline \multicolumn{4}{|l|}{$\begin{array}{l}\text { Question: So, whatever you say here, will translate to this: attitude of what you see out there is likely } \\
\text { to be same with attitude of i.e. the Southeast student will likely be the same attitude of Southeast } \\
\text { people out there? And same is likely to go for the South-south students? } \\
\text { A larger "Yes" response was heard but only one dissenting voice. }\end{array}$} \\
\hline $\begin{array}{l}\text { 105. "I think the Southeast people are more perceptive to the problems. Through business, they do } \\
\text { something to meet that need. People in the South-south see the problems, but they don't take it } \\
\text { personal, so they don't go forward to change this." }\end{array}$ & $\begin{array}{l}\text {-SE more perceptive to } \\
\text { business problems }\end{array}$ & & 3РATT.1419 \\
\hline \multicolumn{4}{|l|}{$\begin{array}{l}\text { Question: Ok do we agree with this? } \\
\text { A "Yes" response was echoed. } \\
\text { Question: Okay if you said so, why is this so? }\end{array}$} \\
\hline $\begin{array}{l}\text { 106. "I think they are active. Everyone around you is in business. People you see around you are active in } \\
\text { business. They see problems. As you see all that, you'll learn from that and might respond to business } \\
\text { career. In the South-south, on the average, there's more sluggishness, even among our sellers. If you } \\
\text { grow up around these people who are not into active business, it might affect you." }\end{array}$ & $\begin{array}{l}\text {-more SE numbers of } \\
\text { community in business }\end{array}$ & culture & 3ROY.1425 \\
\hline $\begin{array}{l}\text { 107. "The south easterner sees something from, say, America; he'll like to produce such. Imitate it. When } \\
\text { they bring it down to the South-south, we'll say it's imitation, "Aba-made." }\end{array}$ & $\begin{array}{l}\text {-SE like to imitate foreign } \\
\text { products }\end{array}$ & Business-oriented & 3HAPP.1431 \\
\hline $\begin{array}{l}\text { 108. "The Southeast people employ their brothers for a number of years, then 'establish' or 'settle' the } \\
\text { persons. But here in the South-south it's not like that. They want you to pay money. Even when you pay } \\
\text { for the training, irrespective of whether you're serious or not at the enterprise, most times it's not of } \\
\text { concern to the South-southerner." }\end{array}$ & $\begin{array}{l}\text {-SE practice } \\
\text { apprenticeship and } \\
\text { cooperatives }\end{array}$ & $\begin{array}{l}\text { Apprenticeship and } \\
\text { mentorship }\end{array}$ & 3MAR.1435 \\
\hline $\begin{array}{l}\text { 109. "The South-south people just want job security, government work. But in the Southeast, they don't } \\
\text { really believe in government job. They want to be innovative." }\end{array}$ & $\begin{array}{l}\text {-most SE people don't } \\
\text { believe in government } \\
\text { job }\end{array}$ & Business-oriented & 3PATT.1440 \\
\hline \multicolumn{4}{|l|}{$\begin{array}{l}\text { Question: So we've agreed that the entrepreneurial drive of people of the Southeast are radically } \\
\text { different from the South-south people? }\end{array}$} \\
\hline \multicolumn{4}{|l|}{ A unanimous "YES" response was heard!!! } \\
\hline \multicolumn{4}{|l|}{$\begin{array}{l}\text { And from what l've heard it's a cultural thing, wanting to know what's inside this in order to create } \\
\text { yours too. That's something to do with culture. There's people who accept things the way they are and } \\
\text { use them. }\end{array}$} \\
\hline $\begin{array}{l}\text { 110. "I was speaking to an Igbo person, why this situation in the Southeast. His response to me was that } \\
\text { they were like every other region before the civil war in } 1967 \text {, but after the war there was hunger and } \\
\text { starvation that led them into becoming who they are today and that the same spirit kept on till today. }\end{array}$ & $\begin{array}{l}\text {-the game-changer was } \\
\text { the civil war experience }\end{array}$ & Culture & 3ROY.1449 \\
\hline
\end{tabular}


And that drive is still there. That's why if an Igbo man takes his child to the village, even if he's going to university, the child will still know what is going on in the family shop."

\section{EASE OF STARTING BUSINESS AND SOLUTIONS}

\begin{tabular}{|c|c|c|c|}
\hline Questions and Responses & Initial coding & Focused coding & $\begin{array}{l}\text { Quote } \\
\text { Identification }\end{array}$ \\
\hline $\begin{array}{l}\text { Focus Group } 1 \\
\text { Question: "How easy is it for a graduate in Nigeria to start a business?" } \\
\text { 1. "I think it is not easy. In Nigerian context, to be an entrepreneur you need creativity. If you look at a } \\
\text { young child, young children have good entrepreneurial skills; he has things he can build with his hands. } \\
\text { But go to Nigeria educational system, all they teach you is theory-Physics, Chemistry, Biology and the rest } \\
\text { of them. The real creativity of the child is destroyed." }\end{array}$ & $\begin{array}{l}\text {-Not easy, too } \\
\text { theoretically-based } \\
\text { teaching }\end{array}$ & Practical orientation & $1 \mathrm{INI} .67$ \\
\hline $\begin{array}{l}\text { 2. "It's not easy. For instance, I just graduated, I acquire no skill and to start your own business you need } \\
\text { the skills... in university in Nigeria, you will find yourself doing, often, things not relevant to your field." }\end{array}$ & $\begin{array}{l}\text { - cannot locate any } \\
\text { acquired practical skills } \\
\text {-too many irrelevant non- } \\
\text { core courses }\end{array}$ & Barrier & 1PAT.78.83 \\
\hline 3. "Outside the technical knowhow, we also have the financial aspect" & $\begin{array}{l}\text {-difficulty both technical } \\
\text { and financial }\end{array}$ & Barrier & 1AUS.96 \\
\hline $\begin{array}{l}\text { 4. "So, I want to say that it's not always easy to be an entrepreneur. It's so hard to start... But my } \\
\text { problem now is how to start and where to start this business." }\end{array}$ & $\begin{array}{l}\text { - fear of starting; location } \\
\text { and marketing }\end{array}$ & Barrier & 1HAP.116.119 \\
\hline $\begin{array}{l}\text { 5. "In trying to borrow money from a place, they'll tell you, you must have a business before certain } \\
\text { amount of money is given to you. You don't have business as a fresh graduate, how will you do?" }\end{array}$ & $\begin{array}{l}\text {-channels of borrowing } \\
\text { discriminatory }\end{array}$ & Barrier & $10 F F .133$ \\
\hline $\begin{array}{l}\text { Question: "What do you think can be done?" what do you think is the solution, in your perspective? } \\
\text { 6. "If government knows that some students have a particular idea of something to do, they should loan } \\
\text { them money." }\end{array}$ & $\begin{array}{l}\text {-government loan to } \\
\text { those with sound } \\
\text { business ideas }\end{array}$ & Barrier & 1OFF.154 \\
\hline $\begin{array}{l}\text { 7. "I'll say determination is one of the major factors... So you can get help from anywhere even if } \\
\text { government did not loan money to you." }\end{array}$ & $\begin{array}{l}\text {-greater determination to } \\
\text { succeed even without } \\
\text { government loans }\end{array}$ & & 1HAP.159.165 \\
\hline $\begin{array}{l}\text { 8. "So, I think that is to increase the Corp members' stipend during their service year, so that they can use } \\
\text { some to take care of themselves and save some for their businesses." }\end{array}$ & $\begin{array}{l}\text {-NYSC allowance should } \\
\text { be increased }\end{array}$ & & 1PAT.179 \\
\hline $\begin{array}{l}\text { 9. "Most of the youths, these days, they don't know how to manage their time. They don't use their time } \\
\text { well. If you ask me, on long vacation periods, right from secondary school, some people have long }\end{array}$ & $\begin{array}{l}\text {-learn better time } \\
\text { management of long- }\end{array}$ & & 1AUS.189 \\
\hline
\end{tabular}


vacation periods all these periods can be used also to learn different things outside of your study."

10. It's quite true because in Nigeria, these days, if you are going for any employment they'll ask you for job experience... So, I think doing other things outside your field will help you; showing that you are busy and engaging."

11. "I'Il like to say the extent of this problem is a mind-set thing; because if you instil the right mind-set in people, they can change the society... Schools should be more practical than theoretical. They school we went to... there are bulks of things to do in Anatomy, but it's been all theoretical. Things like production of slides, in Anatomy, how many times were they taught to us? So they were not taught. So, this university is all about theory...theory."

12. "Money is a problem. You can't generalize for every situation... Some people need capital to purchase goods or some equipment to start up what they've learned. It's not in all cases you'll say money is not a problem."

13. "First of all, you have to think of a business, how to go about it then you use money to do it... carry out the business."

14. "People are just sitting down there because of government."

15. "Because of the mind-set we have about university. Your father is saying "finish, l'll fix you up in somewhere." How will you be an entrepreneur? It's mind-set."

16. "If you can solve the problem of the mind-set of students here, make the course you're studying more practical, you're going to have more entrepreneurs in the society."

\section{7. "It's actually the mind-set, I will accept that."}

18. "Most times, if you depend on government loans, you might fall into problems. You can start with the little you have... First of all think of business, know what you want to do, the little you have start with it. And before you know it, you can even generate funds from people around you."

19. "Right now, government has loan for those who need the loan, but some persons don't know where to get the loan. I notice when I wrote my final exam, I discovered that government were giving out loans to some students who want to start certain businesses."

20. "Still on this Government Issue, the government is not the problem. A lot of youths in Nigeria don't know what they need in life."

21. "A place should be set up, called a place for entrepreneurship, bring in some skilled individuals and students will go there and learn from them, stop teaching theory. Set up a place in the university; this is sewing, you're from medicine, okay, go to sewing, you can stir up the interest of a child in sewing and he can set up fashion designing firm."

\begin{tabular}{|c|c|c|}
\hline vacation & & \\
\hline $\begin{array}{l}\text {-multi-skills show you are } \\
\text { engaging }\end{array}$ & & 1РАТ.213.216 \\
\hline $\begin{array}{l}\text {-students' mind-set must } \\
\text { change } \\
\text {-university should be } \\
\text { practical-oriented }\end{array}$ & $\begin{array}{l}\text { Barrier } \\
\text { Practical orientation }\end{array}$ & $\begin{array}{l}1 \mathrm{INI} .233 \\
1 \mathrm{INI} .239\end{array}$ \\
\hline $\begin{array}{l}\text {-provide capital for non- } \\
\text { services start-ups }\end{array}$ & Barrier & 1AUS.268.270 \\
\hline $\begin{array}{l}\text {-conceive a business idea } \\
\text { first }\end{array}$ & & 1HAP.276 \\
\hline $\begin{array}{l}\text {-change mind-set of } \\
\text { overdependence on } \\
\text { government } \\
\text {-change mind-set of } \\
\text { wrong notion on grades } \\
\text {-courses more practical- } \\
\text { oriented }\end{array}$ & Practical orientation & $\begin{array}{l}\text { 1INI.286 } \\
\text { 1INI.287 } \\
1 \text { INI.295 }\end{array}$ \\
\hline -change the mind-set & & 1OFF.298 \\
\hline $\begin{array}{l}\text {-start first with your } \\
\text { small capital }\end{array}$ & & $\begin{array}{l}\text { 1HAP.323 } \\
\text { 1HAP.339 }\end{array}$ \\
\hline $\begin{array}{l}\text {-seek information on loan } \\
\text { sources }\end{array}$ & & 1PAT.352 \\
\hline -set life goals & & $1 \mathrm{INI} .361$ \\
\hline $\begin{array}{l}\text {-experienced } \\
\text { entrepreneurs } \\
\text { participation }\end{array}$ & $\begin{array}{l}\text { Experienced entrepreneurs as } \\
\text { teachers }\end{array}$ & 1INI.366 \\
\hline
\end{tabular}




\begin{tabular}{|c|c|c|c|}
\hline \multicolumn{4}{|l|}{$\begin{array}{l}\text { Question: Apart from these problems mentioned, what impression do you have about entrepreneurship } \\
\text { development as a subject in terms of its robustness, in terms of its effectiveness in preparing you to } \\
\text { understand what you'll need to do if someone were to give you money and say start up a business? }\end{array}$} \\
\hline $\begin{array}{l}\text { 22. "They just came to class and taught us, they didn't ... we just memorise the book } \\
\text { and write the exam." }\end{array}$ & $\begin{array}{l}\text { only theory just } \\
\text { cramming to pass exams }\end{array}$ & Practical orientation & 1PAT.405 \\
\hline $\begin{array}{l}\text { 23. "We never had any training on entrepreneurship. Like myself, as at that time, we were given the } \\
\text { form, I filled in Agriculture, but l've never gotten any training since then." }\end{array}$ & $\begin{array}{l}\text {-school failed to conduct } \\
\text { training }\end{array}$ & Practical orientation & 1OFF.412 \\
\hline $\begin{array}{l}\text { 24. "Yes, we've not had any training. Except for when we were in final-year, they invited us to the } \\
\text { Entrepreneurship Centre, where the Director brought some people to talk to us about entrepreneurship." }\end{array}$ & $\begin{array}{l}\text {-only a talk by guest } \\
\text { speaker }\end{array}$ & Practical orientation & 1PAT.417 \\
\hline 25. "Yes, for an entire semester. It was just of cramming the book and writing the exams." & $\begin{array}{l}\text {-dysfunctional } \\
\text { Entrepreneurship class }\end{array}$ & Practical orientation & 1PAT.424 \\
\hline $\begin{array}{l}\text { 26. "Before now, the one that has to do with practical sessions... as it stands; we told them if we add it to } \\
\text { our credit load, it will affect so many people." }\end{array}$ & -overloaded course work & barrier & 1HAP.428 \\
\hline \multicolumn{4}{|l|}{$\begin{array}{l}\text { Question: So, if you had a choice, if you were to sit in front of the Vice Chancellor and you're to advise } \\
\text { him on what is to be done in order to prepare you to become an entrepreneur, what will you say? }\end{array}$} \\
\hline $\begin{array}{l}\text { 27. "...before the Youth Service, you should be able to make us undergo a kind of training, if he actually } \\
\text { loves the outgoing students, he should organize training coordinated by the GSS Department on } \\
\text { Entrepreneurial Studies." }\end{array}$ & $\begin{array}{l}\text {-proper training after } \\
\text { degree exams }\end{array}$ & & 10FF.439 \\
\hline $\begin{array}{l}\text { 28. "The VC should establish a practical centre, just like my colleague said where we'll be practicalising } \\
\text { our studies. He should also release money to the centres to see that we achieve what we wanted." }\end{array}$ & $\begin{array}{l}\text {-practical centre for } \\
\text { business basics }\end{array}$ & Practical orientation & 1HAP.446 \\
\hline $\begin{array}{l}\text { 29. "...since we have a course called entrepreneurship, it should be expanded and make it more practical } \\
\text { than the theory aspect. And that some other courses that are more of practical, like we are from } \\
\text { Anatomy department, our course is more of practical and theory; more funds should be put into the } \\
\text { department to enable the students do their practical sessions." }\end{array}$ & $\begin{array}{l}\text {-localise training not just } \\
\text { generically }\end{array}$ & barrier & 1PAT.456 \\
\hline 30. "My colleagues have rightly put it; first of all, you need to have the idea of what you want to do." & $\begin{array}{l}\text {-teach business } \\
\text { generation ideas }\end{array}$ & Practical orientation & 1AUS.474 \\
\hline $\begin{array}{l}\text { 31. "In year one, a form should be issued; you fill it, what you want to do! What do you like doing best at } \\
\text { your leisure time...As one is graduating therefore, you'll come out with a certificate and a skill (trade)"? }\end{array}$ & $\begin{array}{l}\text {-start idea identification } \\
\text { earlier }\end{array}$ & Practical orientation & $1 \mathrm{INI} .476$ \\
\hline
\end{tabular}




\section{Appendix 2}

\section{Sample- access letter request}

\section{BROOKER UNIVERSITY}

The DVC (Academics)

Anambra State University, Uli

Nigeria

Dear Sir,

\section{Request for Access to Your Final-Year Students for Academic Research Data}

I am a PhD candidate at Oxford Brookes University, Oxford, United Kingdom. I am writing to ask for your permission and support to access final-year undergraduate students of selected departments in your university/faculty to participate in my research survey. Further details of the research are as stated herein:

\section{Nature of the research}

My doctoral thesis examines students' intentions for setting up businesses and explores the factors that influence such desire. It is believed that intention is the best predictor of behaviour or the eventual action. This study measures and compares status of intentions and its influencing factors among indigenous students of South-south and Southeast Nigeria. It is hoped that the findings can provide evidence for putting forward policy proposals to university administrators for implementation to encourage the creative intentions of students and to enhance students' capabilities for setting up businesses; thus improving the employability prospects of future undergraduates from the regions.

\section{Nature of participation needed}

The first aspect of the study will comprise the administration of survey questionnaire by the researcher to final-year students from different departments of your university and who are from the South-south or Southeast regions. The researcher randomly selected the departments whose final-year students will be participating in this survey based on information on number of departments obtained from your university website. The survey takes not more than 15 minutes to complete. The survey will be mostly completed in class during the students' free period. The second part of the study will commence after analyses of the survey data have been concluded. It will employ focus group interviews comprising of six to eight students who would have accepted to volunteer for participation when the survey was carried out. The interview will take 90 minutes. In order to conduct the focus group interviews, I would also request for the use of a quiet private space at the departments.

\section{Potential impact on the participants}

All data will be de-identified and confidential and there will be minimal adverse impact on the participants during the data collection process.

\section{Benefits}

Students that take part in the study will be provided a summary of the findings which can give them insight into the level of intentions for setting up businesses existing among students from the two regions. For example, which factors play significant influences in entrepreneurial intentions- attitudes, capabilities, perception of difficulties or influence of societal values about entrepreneurs?

If you are willing to permit access or if you have any questions or would like further details on my research, please contact me on the email below.

Thank you for taking the time to read this letter.

Yours faithfully

Ita John

Phd Researcher- Oxford Brookes University

Email: 11124400@brookes.ac.uk

Tel.: +44XXXXXXXXXX 


\title{
Appendix 3:
}

\section{Participant information sheet- Focus groups interview}

\section{OXFORD BROOKES UNIVERSITY}

\author{
Research Topic: "Factors that Influence Entrepreneurial Intentions among \\ Undergraduates of South-south and Southeast Nigeria"
}

\section{Participant Information Sheet-Focus Group Interviews}

You are being invited to participate in a research being carried out as part of my research at Oxford Brookes University, Oxford, UK. Before you decide whether or not to participate, it is vital for you to understand the reasons the research is being undertaken and what it will involve. Please take time to read the following information carefully.

\section{What is the purpose of the study?}

This research focuses on understanding what influences students' intentions for setting up businesses. It is believed that intention is the best predictor of action, which in the case of entrepreneurship is the setting up of business. The study examines what factors influence students to desire to go into self-employment or any other entrepreneurial activity; are the factors personal/individual traits, personal attitude, perceived capabilities, environment or socioeconomic factors? What factors might be inhibiting them from embracing self-employment?

Six focus group interviews will be conducted: three in each of the two regions selected for this study. It is believed that the interviews will provide medium to gather a number of different perspectives on the issue, in the students' own interpretation. Also to enable one to gain information on the students' views, attitudes, beliefs, perceptions, and "why" they think or feel the way they do about starting their own business. This session will provide a medium for brainstorming and generating ideas, with the students discussing different angles of the problem and possibly helping to identify solutions.

\section{Why have I been invited to participate?}

This is because the research is targeted at the indigenous students of South-south and Southeast Nigeria and you come from one of these regions. In addition, your class was randomly selected to participate in the research.

\section{Do I have to take part?}

It is entirely up to you to decide whether or not to participate in the interview. If you decide to take part you will be given the participant information sheet and consent form; however, you are free to discontinue at any time without giving any explanation.

\section{How will the focus groups interview operate?}

You will be invited to attend the focus group interview at a time and venue in your university. You will be asked series of questions related to your intentions or other students' intentions for setting up business. The session will take about ninety minutes. If you agree the session will be audiorecorded and thereafter transcribed. I will provide a copy of the transcript to you within 30 days of the interview on which you may comment if you wish to do so. 
You will be asked about your attitude toward setting up a business, perceived capabilities and skills, perceived difficulties and how you feel the society sees entrepreneurial activities and entrepreneurs. All your responses will be anonymous and treated confidentially in accordance with Oxford Brookes University's Academic Integrity Policy. This includes that the data generated during this study must be kept securely in paper or electronic form for upward of ten years after the completion of this research. Thereafter all the data will be destroyed.

\section{What are the possible benefits of taking part?}

There are no direct benefits for participating; however, by taking part in the session you will be supporting the researcher in generating evidence-based findings on the factors that influence undergraduates to wish to set up their own businesses. Findings can also provide evidence for putting forward policy proposals to university administrators for implementation to encourage the creative intentions of students and to enhance students' capabilities for setting up businesses; thus improving the employment prospects of future undergraduates from the regions.

\section{What will happen to the results of the research?}

The results of the study may be used also as data for journal publications and conference proceedings. You may request for a summary of the findings of this research from the researcher.

\section{Who is organising and funding the research?}

The research is carried out by Ita JOHN and is being directed and supervised by Prof Pritam Singh and $\mathrm{Dr}$ Sola Adesola respectively. The research has the approval of the University Research Ethics Committee (UREC), Oxford Brookes University.

\section{Contacts for further information}

In the case of any concerns or queries regarding any aspect of the research, please do contact Ita JOHN by email: 11124400@brookes.ac.uk. If you have any concerns regarding the manner in which the research has been conducted, feel free to contact my supervisors (details below) or the Chair of the University Research Ethics Committee by email: ethics@brookes.ac.uk.

Prof Pritam Singh, Department of Accounting, Finance and Economics: psingh@brookes.ac.uk Dr Sola Adesola, Department of Business and Management: sadesola@brookes.ac.uk

I appreciate you for taking time to read this information sheet and considering taking part in the exercise.

Date: . $.22^{\text {nd }}$ June 2013 


\section{Full title of Project:}

Factors that influence entrepreneurial intentions among undergraduates of Southsouth and Southeast Nigeria

Name, position and contact address of the Researcher:

\section{Ita JOHN}

Researcher

Oxford Brookes University Business School

Rm9, 10CC College Road,

Wheatley Campus,

Oxford, United Kingdom

OX33 1 HX

Email.11124400@brookes.ac.uk

I confirm that I have read and understand the information sheet for the above study and have had the opportunity to ask questions.

I understand that my participation is voluntary and that I am free to withdraw at any time, without giving reason.

I understand that the focus group will be audio recorded

\section{Please initial box}
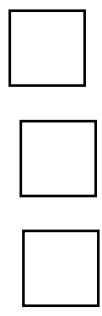

I understand that my data gathered in this study may be stored (after it has been anonymised) in a specialist data centre and may be used for future research.

Please tick box

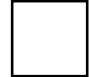




\section{Appendix 5:}

Focus Groups Interview Questions (protocol)

\section{Research Topic: Factors that influence entrepreneurial intentions among undergraduates of South-south and Southeast Nigeria}

\section{Opening Question}

1. Tell us who you are and what you most enjoy doing when you are not studying?

\section{Introductory Questions}

2. What do you think about "becoming an entrepreneur" or "starting your own business"? Is it something you like or dislike?

- What influenced you to think/feel that way? Is it because you feel competent to undertake the task, or love it, or like taking risk, or want to be an achiever, innovator, can control complex situations, etc.? Tell us more!

\section{$\underline{\text { Key Questions }}$}

3. What do you think are the hindrances to students choosing self-employment as a career option? (i.e. the problems)

4. What can be done to encourage entrepreneurship among Nigerian students? (i.e. the solutions)

5. Do you think your university training plus the Entrepreneurship Development Course have equipped you enough for entrepreneurship career option? (If not, what is wrong in the courses?)

6. Do you think that the people of Southeast and South-south ethnicities like selfemployment, business, or entrepreneurship in the same manner?

-Or are they different?

\section{Ending questions}

7. Suppose you had one minute to talk with the Vice-Chancellor of your university on "how to best prepare students for entrepreneurship career." What would you say?

8. Is there anything that we should have talked about but didn't? 


\section{Appendix 6:}

\section{Participant Information Sheet: Self-administered Survey Questionnaire}

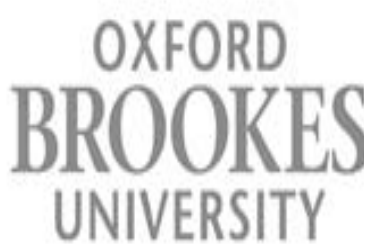

\section{Full title of Project: Factors that influence entrepreneurial intentions among undergraduates of South-south and Southeast Nigeria}

You are being invited to participate in a research study that is being carried out as part of my doctoral study at Oxford Brookes University, Oxford, UK. Before you decide whether or not to participate, it is vital for you to understand the reason the research is being undertaken and what it will involve. Please take time to read the following information carefully.

\section{What is the purpose of the study?}

This research focuses on understanding students' intentions for setting up businesses. It is believed that intention is the best predictor of behaviour or action which in the case of entrepreneurship is assumed to be primarily the setting up of business. The study examines what factors influence students to desire to go into self-employment or any other entrepreneurial activity; are the factors personal/individual traits, social environment or socioeconomic factors? Which factors might be inhibiting them from embracing selfemployment? The survey will be administered to final-year Nigerian undergraduate students of South-south and Southeast origin. About 700 participants are expected to take part in the survey.

Why have I been invited to participate?

This is because the research is targeted at the indigenous students of South-south and Southeast regions of Nigeria and if you come from either of these regions, you are eligible to participate.

\section{Do I have to take part?}

It is entirely up to you to decide whether or not to participate. If you decide to take part you will be free to participate; however, you are free to discontinue at any time without giving any explanation, and none of these actions will have any effects on your assessment grades or programme of studies at your university. You are reassured that the data you provide will not be shared with your university. You will also be requested to contact the researcher via email given below if you would like to participate in further discussions of the topic of this research in a focus group interview to further understand the results of the survey and bring in students' voice into the discourse at a later date to be scheduled here in your university with the researcher.

\section{What is required?}

The questionnaire should take about 15 minutes to complete. You are asked about your attitudes toward setting up a business, perceived capabilities and skills, perceived difficulties and how you feel the society you live in sees entrepreneurial activities and entrepreneurs. All your responses will be de-identified and treated confidentially in accordance with Oxford Brookes University's Academic Integrity Policy. This includes that the data generated during this study must be kept securely in paper form or electronically for ten years after the completion of this research. Thereafter all the data will be destroyed. In addition, if you are interested in the focus groups phase please contact the researcher below who will provide further details of what this involves.

\section{What are the possible benefits of taking part?}

There are no direct benefits for participating. However, by taking part in the survey you will be supporting the researcher in generating evidence-based outcomes on the factors that influence undergraduates from the two regions to form intentions for setting up businesses. Findings can also provide evidence for putting forward policy proposals to university administrators for implementation to encourage the creative 
intentions of students and to enhance students' capabilities for setting up businesses; thus improving the employability prospects of future undergraduates from the regions.

\section{What will happen to the results of the research?}

The results of the study will form part of a thesis for the award of a doctorate degree at Oxford Brookes University and may be used also as data for journal publications and conference proceedings. You may request for a summary of the findings of this research from the researcher.

Who is organising and funding the research?

The research is carried out by Ita JOHN and is being supervised by Dr Pritam Singh, Dr Sola Adesola and Bruce Mitchell. The research has the approval of University Research Ethics Committee, Oxford Brookes University.

\section{Contacts for further information}

In the case of any concerns or queries regarding any aspect of the research, please do contact Ita JOHN by email: 11124400@brookes.ac.uk. Tel.: +44XXXXXXXXXX. If you have any concerns regarding the manner in which the research has been conducted, feel free to contact my supervisors (details below) or the Chair of the University Research Ethics Committee by email: ethics@brookes.ac.uk.

Dr Pritam Singh, Reader, Department of Accounting, Finance and Economics: psingh@brookes.ac.uk Tel.: $+44(0) X X X X X X X X X X$

Dr Sola Adesola, Senior Lecturer, Department of Business and Management: sadesola@brookes.ac.uk Tel.: $+44(0)$ XXXXXXXXXX

Bruce Mitchell, Senior Lecturer, Department of Business and Management: bmitchell@brookes.ac.uk

I appreciate you for taking time to read this information sheet and considering taking part in the survey. Date: 


\section{Appendix 7 \\ Survey questionnaire}

Dear Participant,

\section{OXFORD BROOKE UNIVERSITY}

I am a researcher at Oxford Brookes University Business School, Oxford, United Kingom; I am requesiting for your kind assistance in supplying information for my research.This questionnaire is designed to understand intentions for setting up businesses among Nigerian undergraduates to further understand whether this intention is influenced by "attitude", "personality traits", "perceived capabilities/skills", "perceived barriers", or "supports received." The overall objective is to put forward policy proposals aimed at encouraging students' creative intentions and to enhance capabilities for setting up businesses, thus improving students' employability prospects. It takes about 15 minutes to complete the questionnaire. Your participation in this research is absolutely voluntary and is greatly appreciated. You have the right to discontinue partaking in this survey at any time if you wish to do so without giving any explanation.

Please be assured that the questionnaire is anonymous and all the data and information collected are confidential and used only for the purpose of the study and therefore individuals' details will not be published. You will be identified by numbers only; your name will never be linked to any of your answers. Do feel free to supply your most honest answers to the questions so as to enhance the credibility of the final report.

In the case of any question about the survey, you may contact me using the contact details provided herein. I deeply appreciate you for your time and contribution.

Yours sincerely

\section{Ita JOHN}

Research in Economics and International Business (REI)

Department of Accounting, Finance and Economics

Faculty of Business

Oxford Brookes University

Email: 11124400@brookes.ac.uk

Tel: +44XXXXXXXXXX 


\section{Questionnaire on Undergraduate Students' Intentions (QUSI) for Setting up Businesses}

Instructions: The questionnaire is completed in two ways: by filling the blanks and ticking the boxes. Please enter relevant information or tick(V) the applicable boxes $(\square)$. Please answer all the questions to ensure the usefulness of each questionnaire. There are no right or wrong answers but an expression of your perspectives.

\section{Section 1:}

Q1. Instruction: The following are statements associated with the intentions for setting-up of a business. Please state your degree of agreement by ticking $(V)$ the relevant box. Score "1" means that you "strongly disagree" and "6" means you "strongly agree."

\begin{tabular}{|c|c|c|c|c|c|c|}
\hline \multirow{3}{*}{\begin{tabular}{|l} 
Statement \\
(1) I am ready to do anything to be an entrepreneur
\end{tabular}} & \multicolumn{6}{|c|}{ Level of Agreement } \\
\hline & \multirow{2}{*}{$\begin{array}{c}\text { Strongly } \\
\text { Disagree } \\
1 \square\end{array}$} & \multicolumn{4}{|c|}{ 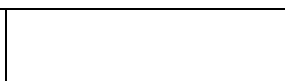 } & \multirow{2}{*}{$\begin{array}{c}\begin{array}{c}\text { Strongly } \\
\text { Agree }\end{array} \\
6 \square\end{array}$} \\
\hline & & $2 \square$ & $3 \square$ & $4 \square$ & $5 \square$ & \\
\hline (2) My professional goal is to become an entrepreneur & $1 \square$ & $2 \square$ & $3 \square$ & $4 \square$ & $5 \square$ & $6 \square$ \\
\hline (3) I am determined to create a business venture in the future & $1 \square$ & $2 \square$ & $3 \square$ & $4 \square$ & $5 \square$ & $6 \square$ \\
\hline (4) I have serious thoughts about starting a firm & $1 \square$ & $2 \square$ & $3 \square$ & $4 \square$ & $5 \square$ & $6 \square$ \\
\hline (5) I have got the intention to start a firm one day & $1 \square$ & $2 \square$ & $3 \square$ & $4 \square$ & $5 \square$ & $6 \square$ \\
\hline (6) I intend to start a firm within five years of graduation & $1 \square$ & $2 \square$ & $3 \square$ & $4 \square$ & $5 \square$ & $6 \square$ \\
\hline $\begin{array}{l}\text { (7) Being an entrepreneur implies more advantages than } \\
\text { disadvantages to me }\end{array}$ & $1 \square$ & $2 \square$ & $3 \square$ & $4 \square$ & $5 \square$ & $6 \square$ \\
\hline (8) A career as an entrepreneur is attractive to me & $1 \square$ & $2 \square$ & $3 \square$ & $4 \square$ & $5 \square$ & $6 \square$ \\
\hline $\begin{array}{l}\text { (9) If I had the opportunity and resources, I would love to start a } \\
\text { business }\end{array}$ & $1 \square$ & $2 \square$ & $3 \square$ & $4 \square$ & $5 \square$ & $6 \square$ \\
\hline (10) Being an entrepreneur would give me great satisfaction & $1 \square$ & $2 \square$ & $3 \square$ & $4 \square$ & $5 \square$ & $6 \square$ \\
\hline (11) Among various options, I would rather be an entrepreneur & $1 \square$ & $2 \square$ & $3 \square$ & $4 \square$ & $5 \square$ & $6 \square$ \\
\hline $\begin{array}{l}\text { (12) My closest family members think that I should pursue a } \\
\text { career as an entrepreneur }\end{array}$ & $1 \square$ & $2 \square$ & $3 \square$ & $4 \square$ & $5 \square$ & $6 \square$ \\
\hline $\begin{array}{l}\text { (13) I do care about what my closest family members think as I } \\
\text { decide on whether or not to pursue a career as self-employed }\end{array}$ & $1 \square$ & $2 \square$ & $3 \square$ & $4 \square$ & $5 \square$ & $6 \square$ \\
\hline $\begin{array}{l}\text { (14) My closest friends think that I should pursue a career as an } \\
\text { entrepreneur }\end{array}$ & $1 \square$ & $2 \square$ & $3 \square$ & $4 \square$ & $5 \square$ & $6 \square$ \\
\hline $\begin{array}{l}\text { (15) I do care about what my closest friends think as I decide on } \\
\text { whether or not to pursue a career as self-employed }\end{array}$ & $1 \square$ & $2 \square$ & $3 \square$ & $4 \square$ & $5 \square$ & $6 \square$ \\
\hline $\begin{array}{l}\text { (16) People that are important to me think I should pursue a } \\
\text { career as an entrepreneur }\end{array}$ & $1 \square$ & $2 \square$ & $3 \square$ & $4 \square$ & $5 \square$ & $6 \square$ \\
\hline \begin{tabular}{|l|} 
(17) I do care about what people important to me think as I \\
decide on whether or not to pursue a career as self-employed
\end{tabular} & $1 \square$ & $2 \square$ & $3 \square$ & $4 \square$ & $5 \square$ & $6 \square$ \\
\hline (18) If I wanted to, I could easily become an entrepreneur & $1 \square$ & $2 \square$ & $3 \square$ & $4 \square$ & $5 \square$ & $6 \square$ \\
\hline $\begin{array}{l}\text { (19) Starting a business and keeping it viable would be easy for } \\
\text { me }\end{array}$ & $1 \square$ & $2 \square$ & $3 \square$ & $4 \square$ & $5 \square$ & $6 \square$ \\
\hline (20) I am able to control the creation process of a new business & $1 \square$ & $2 \square$ & $3 \square$ & $4 \square$ & $5 \square$ & $6 \square$ \\
\hline $\begin{array}{l}\text { (21) If I tried to start a new business, I would have a high chance } \\
\text { of being successful }\end{array}$ & $1 \square$ & $2 \square$ & $3 \square$ & $4 \square$ & $5 \square$ & $6 \square$ \\
\hline $\begin{array}{l}\text { (22). I know most about the practical details needed to start a } \\
\text { business }\end{array}$ & $1 \square$ & $2 \square$ & $3 \square$ & $4 \square$ & $5 \square$ & $6 \square$ \\
\hline
\end{tabular}

(23) How likely do you consider it that within five years of graduation you will be running your own business? per cent (choose from $0-100 \%$ )

\section{Individual/Psychological Factors}

Q2. Instruction: The following are personal statements. Please choose the answer which you think is closest to your situation and tick $(V)$ the relevant box below. Score "1" means that you "strongly disagree" and "6" means you "strongly agree." 


\begin{tabular}{|c|c|c|c|c|c|c|}
\hline \multirow[b]{2}{*}{ Statement } & \multicolumn{6}{|c|}{ Level of Agreement } \\
\hline & $\begin{array}{l}\text { Strongly } \\
\text { Disagree }\end{array}$ & & & & & $\begin{array}{c}\text { Strongly } \\
\text { Agree }\end{array}$ \\
\hline 1) Sometimes people find my ideas unusual & $1 \square$ & $2 \square$ & $3 \square$ & $4 \square$ & $5 \square$ & $6 \square$ \\
\hline $\begin{array}{l}\text { 2) Sometimes I think about information almost obsessively until I } \\
\text { come up with new ideas and solutions }\end{array}$ & $1 \square$ & $2 \square$ & $3 \square$ & $4 \square$ & $5 \square$ & $6 \square$ \\
\hline $\begin{array}{l}\text { 3) Other people think I'm always making changes and trying out } \\
\text { new ideas }\end{array}$ & $1 \square$ & $2 \square$ & $3 \square$ & $4 \square$ & $5 \square$ & $6 \square$ \\
\hline $\begin{array}{l}\text { 4) I prefer to be quite good at several things than very good at one } \\
\text { thing }\end{array}$ & $1 \square$ & $2 \square$ & $3 \square$ & $4 \square$ & $5 \square$ & $6 \square$ \\
\hline $\begin{array}{l}\text { 5) I like to spend time with people who have different ways of } \\
\text { thinking }\end{array}$ & $1 \square$ & $2 \square$ & $3 \square$ & $4 \square$ & $5 \square$ & $6 \square$ \\
\hline 6) Sometimes I have so many ideas that I feel pressurised & $1 \square$ & $2 \square$ & $3 \square$ & $4 \square$ & $5 \square$ & $6 \square$ \\
\hline 7) I find it difficult to switch off from work completely & $1 \square$ & $2 \square$ & $3 \square$ & $4 \square$ & $5 \square$ & $6 \square$ \\
\hline $\begin{array}{l}\text { 8) I like challenges that stretch my abilities and get bored with } \\
\text { things I can do quite easily }\end{array}$ & $1 \square$ & $2 \square$ & $3 \square$ & $4 \square$ & $5 \square$ & $6 \square$ \\
\hline 9) It is more important to do a job well than to try to please people & $1 \square$ & $2 \square$ & $3 \square$ & $4 \square$ & $5 \square$ & $6 \square$ \\
\hline 10) I get annoyed if people are not on time for meetings & $1 \square$ & $2 \square$ & $3 \square$ & $4 \square$ & $5 \square$ & $6 \square$ \\
\hline $\begin{array}{l}\text { 11) When I'm faced with a challenge I think more about the results } \\
\text { of succeeding than the effects of failing }\end{array}$ & $1 \square$ & $2 \square$ & $3 \square$ & $4 \square$ & $5 \square$ & $6 \square$ \\
\hline $\begin{array}{l}\text { 12) I get up early, stay late or skip meals if I have a deadline for } \\
\text { some work that needs to be done }\end{array}$ & $1 \square$ & $2 \square$ & $3 \square$ & $4 \square$ & $5 \square$ & $6 \square$ \\
\hline $\begin{array}{l}\text { (13) I am more willing to take on a task with an uncertain outcome, } \\
\text { compared to one with a more predictable result. }\end{array}$ & $1 \square$ & $2 \square$ & $3 \square$ & $4 \square$ & $5 \square$ & $6 \square$ \\
\hline $\begin{array}{l}\text { 14). I like to test boundaries and get into areas where few have } \\
\text { worked before }\end{array}$ & $1 \square$ & $2 \square$ & $3 \square$ & $4 \square$ & $5 \square$ & $6 \square$ \\
\hline $\begin{array}{l}\text { 15). If I wanted to achieve something and the chances of success } \\
\text { were } 50 / 50, \text { I would take the risk }\end{array}$ & $1 \square$ & $2 \square$ & $3 \square$ & $4 \square$ & $5 \square$ & $6 \square$ \\
\hline $\begin{array}{l}\text { 16). If I had a good idea for making some money, I would be willing } \\
\text { to invest time and borrow to enable me to do it. }\end{array}$ & $1 \square$ & $2 \square$ & $3 \square$ & $4 \square$ & $5 \square$ & $6 \square$ \\
\hline $\begin{array}{l}\text { 17). Before making an important decision I prefer to weigh up the } \\
\text { pros and cons fairly quickly rather than spending a long time } \\
\text { thinking about it. }\end{array}$ & $1 \square$ & $2 \square$ & $3 \square$ & 4D & $5 \square$ & $6 \square$ \\
\hline $\begin{array}{l}\text { 18). I would rather take an opportunity that might lead to even } \\
\text { better things than have an experience that I am sure to enjoy }\end{array}$ & $1 \square$ & $2 \square$ & $3 \square$ & 4D & $5 \square$ & $6 \square$ \\
\hline $\begin{array}{l}\text { 19). I like to start interesting projects even if there is no } \\
\text { guaranteed payback for the money or time I have to put in }\end{array}$ & $1 \square$ & $2 \square$ & $3 \square$ & $4 \square$ & $5 \square$ & $6 \square$ \\
\hline $\begin{array}{l}\text { 20) Capable people who fail to become successful have not usually } \\
\text { taken chances when they have occurred }\end{array}$ & $1 \square$ & $2 \square$ & $3 \square$ & $4 \square$ & $5 \square$ & $6 \square$ \\
\hline 21) When I make plans I nearly always achieve them & $1 \square$ & $2 \square$ & $3 \square$ & $4 \square$ & $5 \square$ & $6 \square$ \\
\hline 22) People generally get what they deserve & $1 \square$ & $2 \square$ & $3 \square$ & $4 \square$ & $5 \square$ & $6 \square$ \\
\hline $\begin{array}{l}\text { 23) Being successful is a result of working hard, luck has little to do } \\
\text { with it }\end{array}$ & $1 \square$ & $2 \square$ & $3 \square$ & $4 \square$ & $5 \square$ & $6 \square$ \\
\hline 24) For me, getting what I want is a just reward for my efforts & $1 \square$ & $2 \square$ & $3 \square$ & $4 \square$ & $5 \square$ & $6 \square$ \\
\hline $\begin{array}{l}\text { 25) I get what I want from life because I work hard to make it } \\
\text { happen }\end{array}$ & $1 \square$ & $2 \square$ & $3 \square$ & $4 \square$ & $5 \square$ & $6 \square$ \\
\hline
\end{tabular}

Q3. Instruction: Please evaluate the following capabilities or skills and tick (V) the relavant box which is applicable to you. Score " 1 " means that you "Describes me very pooly" and "6" means you "Describes me very well."

\begin{tabular}{|l|c|c|c|c|c|c|}
\hline \multicolumn{1}{|c|}{ Statement } & \multicolumn{4}{c|}{ Level of Description } \\
\cline { 2 - 7 } & & $\begin{array}{c}\text { Describes } \\
\text { me very } \\
\text { pooly }\end{array}$ & \multicolumn{4}{|c|}{$\begin{array}{c}\text { Describes me } \\
\text { very well }\end{array}$} \\
\hline (1) I can discover the opportunity for setting up a business & $1 \square$ & $2 \square$ & $3 \square$ & $4 \square$ & $5 \square$ & $6 \square$ \\
\hline (2) I am able to work effectively under pressure or conflict. & $1 \square$ & $2 \square$ & $3 \square$ & $4 \square$ & $5 \square$ & $6 \square$ \\
\hline
\end{tabular}




\begin{tabular}{|l|c|c|c|c|c|c|}
\hline (3) I am capable of developing a new product or service. & $1 \square$ & $2 \square$ & $3 \square$ & $4 \square$ & $5 \square$ & $6 \square$ \\
\hline $\begin{array}{l}\text { (4) I am able to build up a network of contacts needed for setting } \\
\text { up a business effectively. }\end{array}$ & $1 \square$ & $2 \square$ & $3 \square$ & $4 \square$ & $5 \square$ & $6 \square$ \\
\hline $\begin{array}{l}\text { (5) I am capable of organising key resources needed for setting up } \\
\text { a business. }\end{array}$ & $1 \square$ & $2 \square$ & $3 \square$ & $4 \square$ & $5 \square$ & $6 \square$ \\
\hline $\begin{array}{l}\text { (6) I am able to build and maintain a team needed for setting up a } \\
\text { business. }\end{array}$ & $1 \square$ & $2 \square$ & $3 \square$ & $4 \square$ & $5 \square$ & $6 \square$ \\
\hline
\end{tabular}

Q4. Instruction: Please indicate the main difficulties in your opinion facing undergraduates from undertaking self-employment. Tick ( $V$ ) the relvant box. Score "1" means that you "strongly disagree" and " 6 " means you "strongly agree."

\begin{tabular}{|c|c|c|c|c|c|c|}
\hline \multirow{3}{*}{\begin{tabular}{|l} 
Statement \\
(1) Lack of education in setting up a business is a hindrance
\end{tabular}} & \multicolumn{6}{|c|}{ Level of Agreement } \\
\hline & \multirow{2}{*}{$\begin{array}{c}\text { Strongly } \\
\text { Disagree } \\
1 \square\end{array}$} & \multirow[b]{2}{*}{$2 \square$} & \multirow[b]{2}{*}{$3 \square$} & \multirow[b]{2}{*}{$4 \square$} & \multirow[b]{2}{*}{$5 \square$} & \multirow{2}{*}{$\begin{array}{c}\begin{array}{c}\text { Strongly } \\
\text { Agree }\end{array} \\
6 \square\end{array}$} \\
\hline & & & & & & \\
\hline (2) Difficulty in securing necessary finance is a problem & $1 \square$ & $2 \square$ & $3 \square$ & $4 \square$ & $5 \square$ & $6 \square$ \\
\hline (3) Lack of business skills stops me & $1 \square$ & $2 \square$ & $3 \square$ & $4 \square$ & $5 \square$ & $6 \square$ \\
\hline (4) Lack of support from family hinders me & $1 \square$ & $2 \square$ & $3 \square$ & $4 \square$ & $5 \square$ & $6 \square$ \\
\hline $\begin{array}{l}\text { (5) State laws (rules and regulations) are adverse to running a } \\
\text { company }\end{array}$ & $1 \square$ & $2 \square$ & $3 \square$ & $4 \square$ & $5 \square$ & $6 \square$ \\
\hline $\begin{array}{l}\text { (6) It is hard to find a business idea for a business that hasn't been } \\
\text { realised before }\end{array}$ & $1 \square$ & $2 \square$ & $3 \square$ & $4 \square$ & $5 \square$ & $6 \square$ \\
\hline $\begin{array}{l}\text { (7) There are no smooth arrangements for access to qualified } \\
\text { consultants and business support services for new companies by } \\
\text { students }\end{array}$ & $1 \square$ & $2 \square$ & $3 \square$ & $4 \square$ & $5 \square$ & $6 \square$ \\
\hline $\begin{array}{l}\text { (8) The lack of creative atmoshere in my university does not inspire } \\
\text { someone to develop ideas for new businesses }\end{array}$ & $1 \square$ & $2 \square$ & $3 \square$ & $4 \square$ & $5 \square$ & $6 \square$ \\
\hline
\end{tabular}

Q5. Instruction: Please indicate your level of egreement with the following sentences about the values society puts on entrepreneurship. Tick $(V)$ the relvant box. Score " 1 " means that you "strongly disagree" and " 6 " means you "strongly agree."

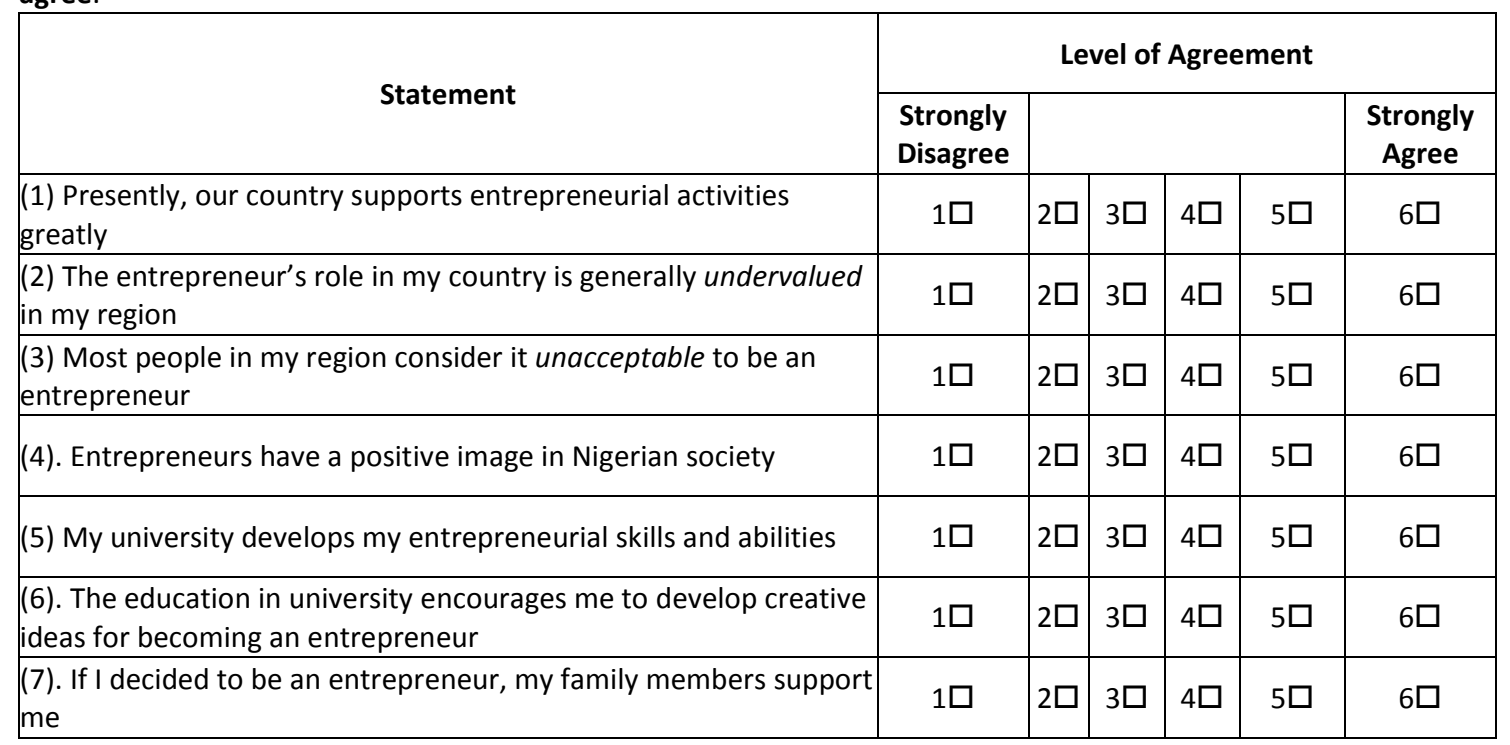




\section{Section 2: About You}

Instruction: Please read the questions carefully and tick $(v)$ the relvant box that you feel is the correct answer and/or key in the answer in the space provided. Try to answeer all the questions.

Q6. Gender: $\quad 1 \square$ Male $2 \square$ Female

Q7. Ethnicity: $1 \square$ Igbo $2 \square$ Ethnic minority, Specify:

Q8. State of origin:

Q9. Your course of study:

Q10. Category of your subjects: $1 \square$ Arts/Humanities

2DPharmacy $3 \square$ Law 4DEducation

$5 \square$ Social Sciences $\quad 6 \square$ Environment $7 \square$ Sciences $\quad 8 \square$ Allied Medical Science

9DEngineering 10 $\square$ Management sciences $11 \square$ Medicine

$12 \square$ Agriculture

Q11. Your university is.

If you will be interested in further discussing the subject of "factors that influence undergraduates' entrepreneurial intentions" in a group interview to further understand the results of the survey and bring in students' voice into the discourse at a later date to be scheduled here in your university with the researcher, do kindly contact me at your convenient time later using my email address provided in the participant information sheet (i.e.: 11124400@brookes.ac.uk)

THANK YOU FOR YOUR PARTICIPATION AND PLEASE SHOULD YOU DECIDE TO TAKE HOME THE QUESTIONNAIRE TO COMPLETE IT, DO REQUEST FOR A SELF-ADDRESSED ENVELOP FROM ME AND RETURN TO:

FACULTY OF BUSINESS, OXFORD BROOKES UNIVERSITY

WHEATLEY CAMPUS, OX33 1HX, OXFORD, UK. 